University of Louisville

ThinkIR: The University of Louisville's Institutional Repository

Electronic Theses and Dissertations

8-2015

\title{
Phosphinimine zinc complexes and neutral phosphinimines for ring opening polymerization of lactides.
}

\author{
Rajesh Thapa \\ University of Louisville
}

Follow this and additional works at: https://ir.library.louisville.edu/etd

Part of the Chemistry Commons

\section{Recommended Citation}

Thapa, Rajesh, "Phosphinimine zinc complexes and neutral phosphinimines for ring opening polymerization of lactides." (2015). Electronic Theses and Dissertations. Paper 2243.

https://doi.org/10.18297/etd/2243

This Doctoral Dissertation is brought to you for free and open access by ThinkIR: The University of Louisville's Institutional Repository. It has been accepted for inclusion in Electronic Theses and Dissertations by an authorized administrator of ThinkIR: The University of Louisville's Institutional Repository. This title appears here courtesy of the author, who has retained all other copyrights. For more information, please contact thinkir@louisville.edu. 


\title{
PHOSPHINIMINE ZINC COMPLEXES AND NEUTRAL PHOSPHINIMINES FOR RING OPENING POLYMERIZATION OF LACTIDES
}

\author{
By \\ Rajesh Thapa \\ B. S. Tribhuvan University, Kathmandu, Nepal \\ M.S. Miami University, Oxford, Ohio
}

\begin{abstract}
A Dissertation
Submitted to the Faculty of the

College of Arts and Science of the University of Louisville In Partial Fulfillment of the requirements for the Degree of
\end{abstract}

Doctor of Philosophy in Chemistry

Department of Chemistry

University of Louisville

Louisville, Kentucky

August 2015 



\title{
PHOSPHINIMINE ZINC COMPLEXES AND NEUTRAL PHOSPHINIMINES FOR RING OPENING POLYMERIZATION OF LACTIDES
}

\author{
By \\ Rajesh Thapa \\ A Dissertation Approved on \\ July 24, 2015 \\ By the Following Dissertation Committee:
}

Dr. Christopher T. Burns

Dissertation Director

Dr. Michael H. Nantz

Dr. Mark E. Noble

Dr. Eric Berson 


\section{DEDICATION}

This dissertation is dedicated to my respected father 'Shyam Dip Thapa', Mother 'Kamala Thapa', my spouse Bamita Thapa, daughter Ashmita Thapa, and son Utsav Thapa. 


\section{ACKNOWLEDGEMENTS}

It would not have been possible to write this thesis without the help and support of the kind people around me, to only some of whom it is possible to give particular name here. Foremost, I would like to express my sincere gratitude to my supervisor Dr. Christopher T. Burns, for his patience, motivation, enthusiasm and immense support. His continuous support and guidance throughout helped me in all times of research and writing of the thesis.

I would like to thank the faculty members at University of Louisville Dr. Machael H. Nantz and Dr. Mark Noble of Department of Chemistry and Dr. Eric Berson of the

Chemical Engineering Department, Speed School for their precious participation, time and serving in my ORP, research seminar and Ph.D. thesis defense committee. I would also like to thank Dr. Neal Stolowich who has been very helpful in running NMR experiments especially for VT NMR for zinc complexes characterization. I am grateful to Dr. Mark S. Mashuta for x-ray crystallographic structures.

I want to pay special thanks to University of Louisville for TA funding and Departmental fellowship that helped for completion of the research and my doctorate degree.

Last but not the least; I would like to thank all my friends and family members for their immense support, enduring love and encouragement till the final completion of the thesis 


\title{
ABSTRACT
}

\section{PHOSPHINIMINE ZINC COMPLEXES AND NEUTRAL PHOSPHINIMINES FOR RING OPENING POLYMERIZATION OF LACTIDES}

\author{
Rajesh Thapa
}

July 24, 2015

Achiral arenesulfonates ligands having a $(\mathrm{NNN})$ or $(\mathrm{NNO})$ side arm have been developed (Chapter 2) and their respective zinc ethyl complexes, NNNZnEt 3.2 and NNOZnEt 3.3, have been synthesized and characterized using spectroscopic methods (Chapter 3). NNNZnEt as well as NNOZnEt complexes are stable under nitrogen atmosphere. In the NNOZnEt $\mathbf{3 . 3}$ complex the protons associated with the pendant (dimethylamino)ethyl arm are broad indicating that a fluxional process is operative, most likely dissociation of the (dimethylamino)ethyl arm at $25{ }^{\circ} \mathrm{C}$ in $\mathrm{CD}_{2} \mathrm{Cl}_{2}$. The fluxional behavior present in the ${ }^{1} \mathrm{H}$ NMR spectrum of $\mathbf{3 . 2}$ could be arrested by cooling the $\mathrm{CD}_{2} \mathrm{Cl}_{2}$ solution to $-60{ }^{\circ} \mathrm{C}$. In Chapter 3, the reactivity of $\mathbf{3 . 2}$ and $\mathbf{3 . 3}$ with alcohols was explored in detail. NNOZnEt was found to be unstable in the presence of alcohols. The NNNZnEt complex does not show any reactivity with weak acids $(\mathrm{p} K \mathrm{a}=16)$, such as ethanol, anthrylmethanol or anthrylethanol. Strong acids $(\mathrm{pKa}=8-10)$ like phenols protonate the 
zinc ethyl bond to produce zinc phenoxide complexes with release of ethane. The rate of the reaction is directly proportional to the acid strength $(\mathrm{pKa})$ of the alcohols. The NNNZnEt complex as well as its corresponding phenoxides show dynamic behavior at 25 ${ }^{\circ} \mathrm{C}$. The dimethylaminoethyl arms in these complexes are hemilable as indicated by ${ }^{1} \mathrm{H}$, ${ }^{13} \mathrm{C},{ }^{31} \mathrm{P}$ and variable temperature $\mathrm{NMR}$, i.e., the dynamic behavior of these complexes was demonstrated. The detail structure of the NNNZnEt was elucidated by examining the single X-crystal structure of analogous air stable NNNZnMe complex. Zinc phenoxides 3.10-3.12 were isolated in good yield by reaction of NNNZnEt complex and one equivalent of the corresponding solid phenols in $\mathrm{CH}_{2} \mathrm{Cl}_{2}$ under $\mathrm{N}_{2}$. Zinc phenoxides 3.103.12 were characterized by ${ }^{1} \mathrm{H},{ }^{13} \mathrm{C}$, and ${ }^{31} \mathrm{P}$ and multi-dimensional NMR. Fluxional behavior was observed at $25^{\circ} \mathrm{C}$ for the pendant (dimethylamino)ethyl arm in complexes 3.10-3.12 as also seen in zinc alkyl complexes 3.7 and 3.13. The dynamic behavior due to association and disassociation of the (dimethylamino) ethyl arm in complexes 3.103.12 could be halted by cooling the $\mathrm{CD}_{2} \mathrm{Cl}_{2}$ solutions to $-40{ }^{\circ} \mathrm{C}$. Complexes $\mathbf{3 . 1 0 - 3 . 1 2}$ were stable in dry $\mathrm{CD}_{2} \mathrm{Cl}_{2}$ for several days at $25^{\circ} \mathrm{C}$ and 12 hours at $45^{\circ} \mathrm{C}$. The catalytic activity of zinc phenols with lactide were tested on NMR scale reactions. The discrete zinc phenoxide as well as in situ generated zinc phenoxides $\mathbf{3 . 1 0 - 3 . 1 2}$ show low catalytic activity with dl-lactide. The low reactivity of zinc phenoxides with dl-lactide is probably due to the low electrophilicity of the zinc center.

In the second part of this dissertation (Chapter 4), a series of tolyl/phenylethyl phosphinimines 4.1-4.8 were synthesized by Staudinger reaction between azide and various phosphines. These phosphinimines were characterized using ${ }^{1} \mathrm{H},{ }^{13} \mathrm{C},{ }^{31} \mathrm{P} \mathrm{NMR}$. In general, the phosphininimine only ring substituted with an electron donating group, such as methoxy or dimethylanino, enhances the basicity of the phosphinimines. The 
correlation between the basicity of the phosphinimines and the downfield shift of the alcohol hydroxyl group when activated by phosphinimine was studied. The catalytic activity of these phosphinimines towards ring opening polymerization of lactide is correlated by alcohol hydroxyl proton shift when interacted with an alcohol (1:1) in nonhydrogen bonding solvent $\mathrm{CDCl}_{3}$ at $25^{\circ} \mathrm{C}$ under $\mathrm{N}_{2}$ atmosphere. The phosphinimines $\mathbf{4 . 5}$ to 4.14 were tested for ROP of lactides and their correlation with the basicity estimated with alcohol activation was shown. These phosphinimines represent highly active catalysts for ROP under $\mathrm{N}_{2}$ at ambient temperature. The phosphinimine 4.7 reacts with lactide monomer even in absence of alcohol initiation with reasonable reaction rate. Phosphinimines initiate the ROP of lactide even in the absence of initiating alcohol. However, the addition of alcohol enhances the rate of the reaction. We anticipate that the ease of handling of these catalysts, combined with their high reactivity on the ROP of lactide will make them useful to the synthetic community. 


\section{TABLE OF CONTENTS}

$\begin{array}{lr}\text { DEDICATION } & \text { iii } \\ \text { ACKNOWLEDGEMENTS } & \text { iv } \\ \text { LIST OF FIGURES } & \text { xi } \\ \text { LIST OF TABLES } & \text { xiii } \\ \text { LIST OF SCHEMES } & \text { xiv }\end{array}$

CHAPTER 1. Ring opening polymerization (ROP) of lactides

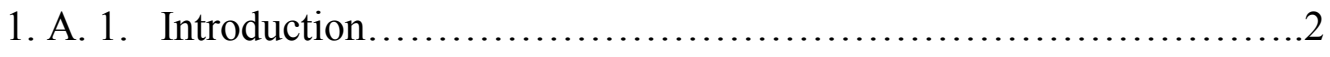

1. A. 2. Biodegradable polymer: polylactide (PLA) ......................

1. A. 3. Synthesis of polylactide................................... 5

1. A. 4. Ring opening polymerization ..............................6

1. A. 5. ROP mechanism ........................................6

1. A. 6. Industrial catalyst for preparation of PLA........................ 9

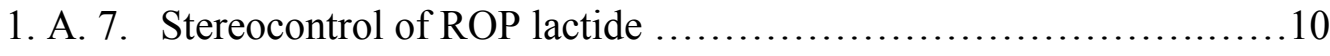

1. B. Metal based initiators for the ROP of lactides.............................13

1. B. 1. Single site homogenous catalysts........................... 13

I. B. 2. Zinc based catalyst........................................... 14

1. B. 3. Aluminium based catalyst.................................20

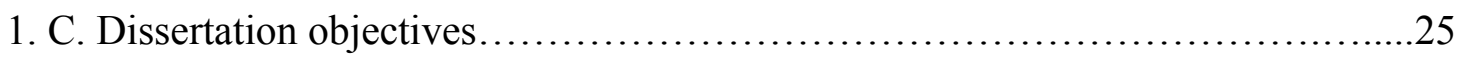

CHAPTER 2. Synthesis of phosphinimine ligands

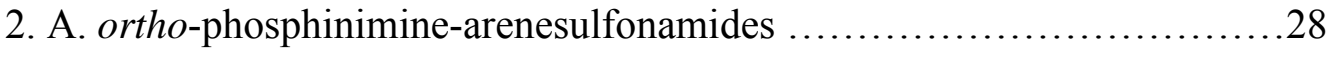

2. A.1. Ligand and catalyst design.........................................28

2. B. Synthesis of ortho-phosphinimine-arenesulfonamides...............31

2. B.1. Introduction............................................ 31

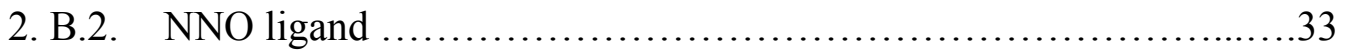




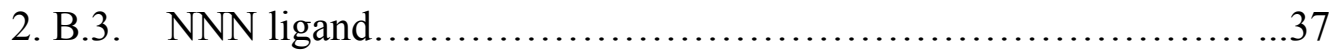

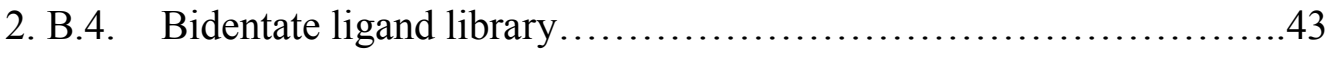

2. B.5. Conclusion................................................... 44

CHAPTER 3. Synthesis and reactivity of LZnEt complexes

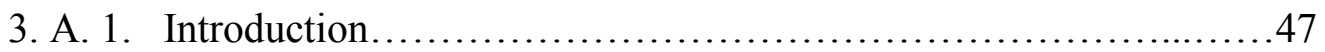

3. A. 2. Synthesis and characterization of [NNO]ZnEt complex …...........49

3. A. 3. Synthesis and of characterization $[N N N] Z n E t$ complex..............50

3. A. 4. Reactivity of $[\mathrm{NNO}] Z n E t$ with alcohols ........................52

3. A. 5. Reactivity of $[N N N] Z n E t$ with alcohols..............................59

3. A. 6. Reactivity with lactide .......................................60

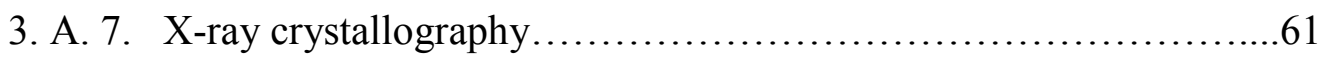

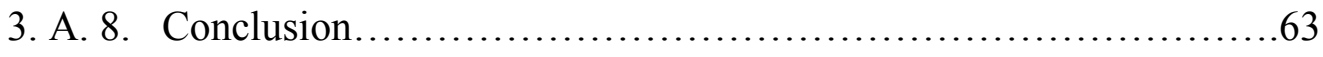

CHAPTER 4. Neutral phosphinimine bases for ROP of lactide

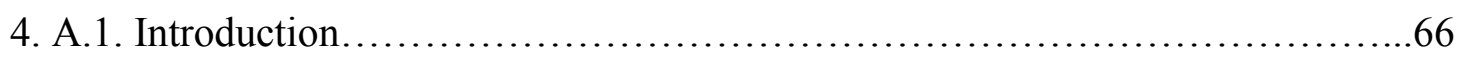

4. A. 2. Synthesis of neutral phosphinimines bases ..................................71

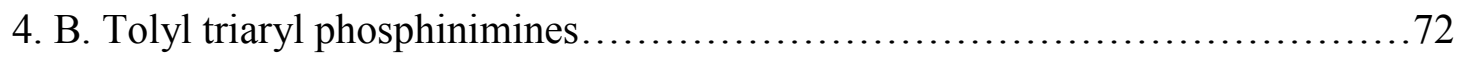

4. B. 1. Synthesis of tolyl triaryl phosphinimines........................ 72

4. B. 2. Alcohol activation by tolyl-phosphinimines........................75

4. B. 3. Polymerization of lactide by tolyl-phosphinimines..................79

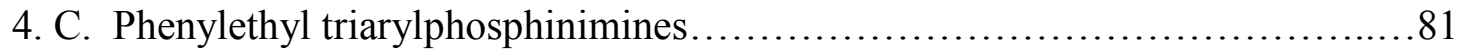

4. C. 1. Synthesis of phenylethyl triarylphosphinimines....................81

4. C. 2. Alcohol Activation by phenylethyl -phosphinimines..................82

4. C. 3. Polymerization of lactide by phenylethyl -phosphinimines............84

4. C. 4. Order of reactivity of phenethyl phosphinimines towards ROP of L-LA ........................................................

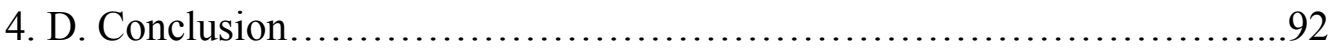


REFERENCES........................................................94

EXPERIMENTAL SECTION................................................. 102

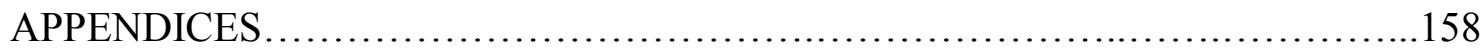

CURRICULUM VITAE .....................................................263 


\section{LIST OF FIGURES}

FIGURE

PAGE

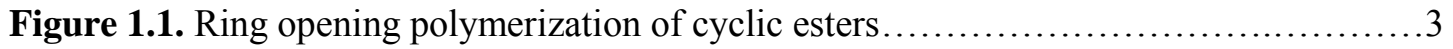

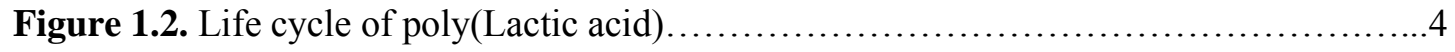

Figure 1.3. Coordination-insertion mechanism of ROP of lactide $\ldots \ldots \ldots \ldots \ldots \ldots \ldots \ldots \ldots \ldots$

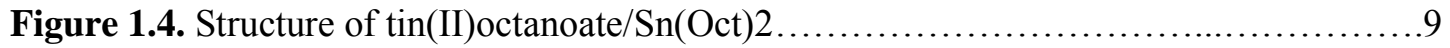

Figure 1.5. Structure of true initiator $\mathrm{Sn}(\mathrm{Oct})$ formed in presence of alcohol............... 9

Figure 1.6. Transesterification reactions......................................... 10

Figure 1.7. Stereoisomers of lactide............................................... 11

Figure 1.8. Typical PLA microstructure from meso- lactide..............................11

Figure 1.9. Schematic diagrams showing chemical shifts (in ppm) of tetrad for PLA.........12

Figure 1.10. $\beta$-diiminato) zinc(II) isoprooxide (1.3) and

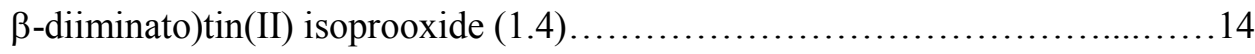

Figure 1.11. Dinuclear zinc complex supported by NNO-tridentate

Schiff base ligand framework....................................... 17

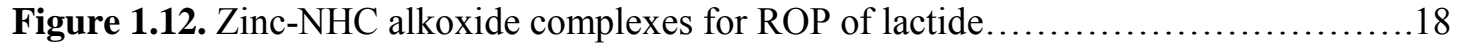

Figure 1.13. Zinc-NHC alkoxide complexes for ROP of lactide......................... 19

Figure 1.14. Lewis acid and Lewis base dual Catalyst for ROP of lactide..................19

Figure 1.15. Zinc NHC-based (1.13) $\mathrm{CNN}$ and (1.14) CNP

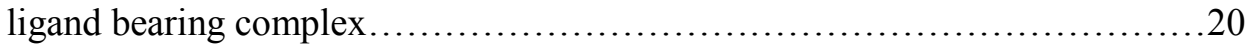

Figure 1.16. Al-metal catalyst with sterically hindered ${ }^{\mathrm{t}} \mathrm{Bu}$ group........................20

Figure 1.17. Enantiopure $(R, R)$ Al-base catalyst with the Jacobsen ligand.................21

Figure 1.18. Aliminum methyl complexes supported by tetradentate aminophenoxide ligand............................................... 21

Figure 1.19. Tetradentate iminophenolato (aluminum) complexes.........................22

Figure 1.20. Al-complexes bearing chiral bidentate anilido-oxzolinate ligands...............24 
Figure 2.1. metal complexes supported by various ligands..........................29

Figure 2.2. ortho-phosphinimine-arenesulfonamide ligand design....................... 30

Figure 2.3. Tridentate ortho-phosphinimine-benzenesulfonamide ligated zinc complex..........31

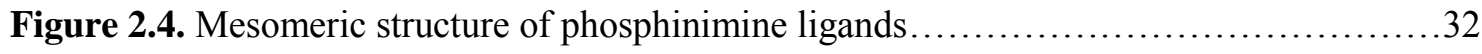

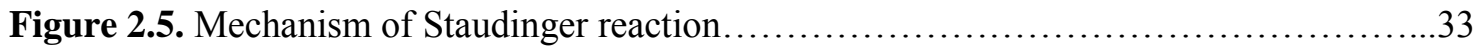

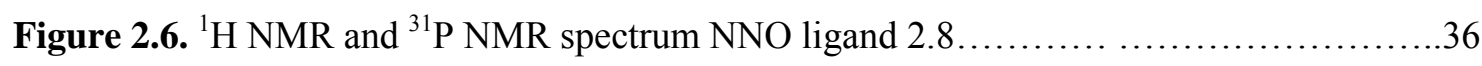

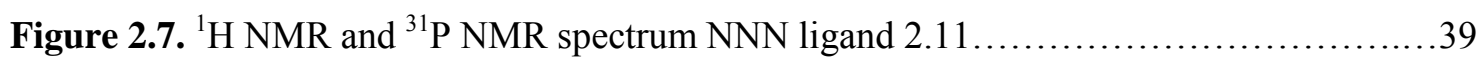

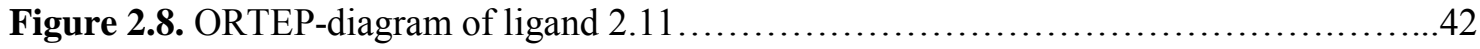

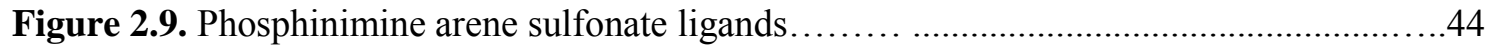

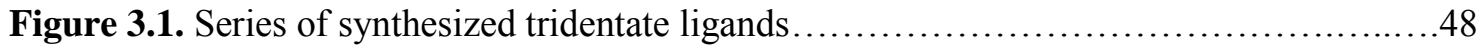

Figure 3.2. ${ }^{1} \mathrm{H}$ NMR of the complex 3.7 showing fluxional behavior.....................51

Figure 3.3. ${ }^{1} \mathrm{H}$ NMR spectrum of $(\mathrm{NNN}) \mathrm{ZnEt} 3.7$ in $\mathrm{CD}_{2} \mathrm{Cl}_{2}$ with variable temperature........52

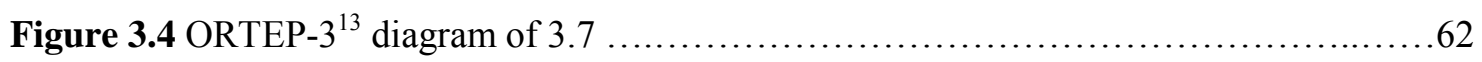

Figure 4.1. Nitrogen bases used as organocatalyst for ROP ...........................68

Figure 4.2. Mesomeric structure of phosphinimine ligands........................... 72

Figure 4.3. Series of tolyl phosphinimine bases.................................... 74

Figure 4.4. Activation of alcohol with base via hydrogen bonding............................75

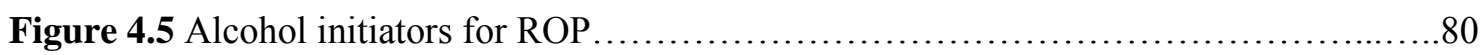

Figure 4.6. Phenylethyl Phosphinimine 4.8-4.11 .................................... 82

Figure 4.7. ${ }^{1} \mathrm{H}$ NMR of activation of phosphinimine with alcohols...........................84

Figure 4.8. ${ }^{1} \mathrm{H}$ NMR showing polylactide (PLA) formation at $5 \mathrm{~min}$ and $25 \mathrm{~min} \ldots \ldots \ldots \ldots . . . .86$

Figure 4.9. Chemical structure of phosphinimine bases............................ 90 


\section{LIST OF TABLES}

TABLE

PAGE

Table 2.1. Tolman cone angles of phosphines.......................................... 32

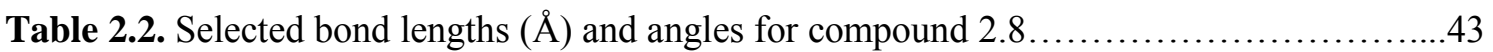

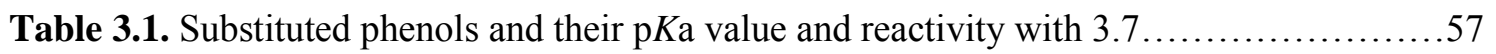

Table 3.2. Substituted phenols and their $\mathrm{p} k$ a value and reactivity with $3.7 \ldots \ldots \ldots \ldots \ldots \ldots \ldots 6 . \ldots \ldots$

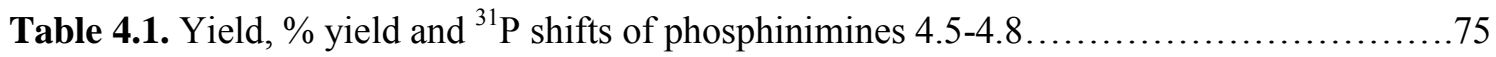

Table 4.2. Activation of alcohol with base via hydrogen bonding.......................... 76

Table 4.3. Alcohol $\mathrm{H}$ shift (in blue) by H-hydrogen bonding activation......................78

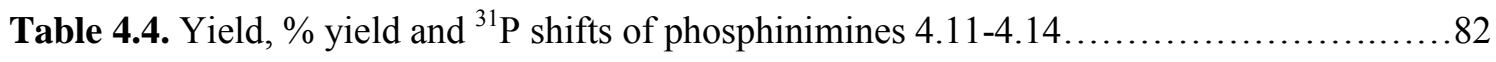

Table 4.5. Alcohol $\mathrm{H}$ shift (in blue) by H-hydrogen bonding activation....................... 83

Table 4.6. Phosphinimine 4.9 activity toward ROP of lactide............................ 85

Table 4.7. Phosphinimine PDDP (4.10) activity toward ROP of lactide..................................87

Table 4.8. Phosphinimine PPDP (4.11) acitivity toward ROP of lactide....................89

Table 4.9. Phosphinimine PTTP (4.12) acitivity toward ROP of lactide....................90

Table 4.10. Order of reactivity of various phosphinimines............................ 91 


\section{LIST OF SCHEMES}

SCHEME

PAGE

Scheme 1.1. Polymerization of lactic acid and ROP of lactide $\ldots \ldots \ldots \ldots \ldots \ldots \ldots \ldots \ldots \ldots \ldots$

Scheme 1.2. Activated Monomer Mechanism.......................................... 8

Scheme 1.3. Synthesis of zinc complexes with $\beta$-diiminate ligand framework..................15

Scheme 1.4. Effect of $N$-substituents in $\beta$-dikitiminate zinc complex..................... 16

Scheme 1.5. Synthesis of isotactic poly(R)-lactic acid..................................22

Scheme 1.6. Synthesis of stereoblock isotactic poly(R)-lactic acid $\ldots \ldots \ldots \ldots \ldots \ldots \ldots \ldots \ldots . .22$

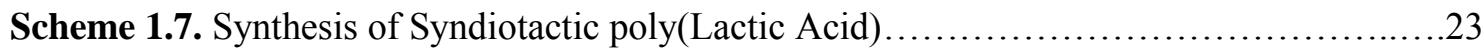

Scheme 1.8. Synthesis of heterotactic poly(lactic acid) .................................. 24

Scheme 1.9. Polymer exchange mechanism for the synthesis of heterotactic PLA...............24

Scheme 2.1. Retrosynthetic plan for synthetic strategies for target ligand ..................33

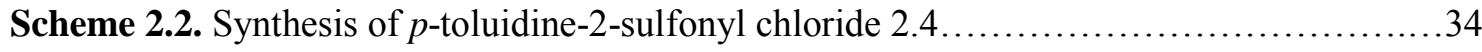

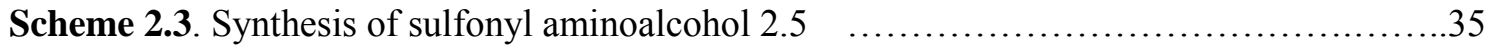

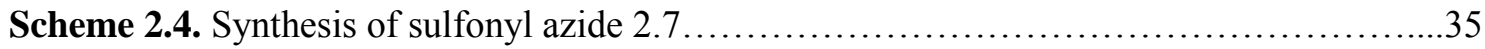

Scheme 2.5. Synthesis of 2-phosphinimine-5-methylbenzene sulfonamides $2.8 \ldots \ldots \ldots \ldots \ldots . \ldots 36$

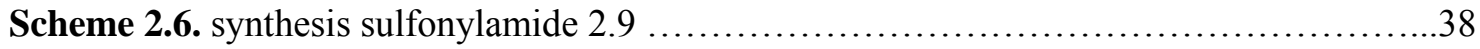

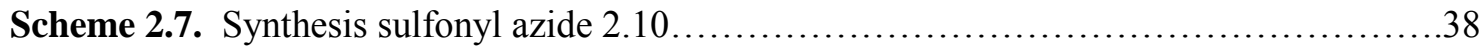

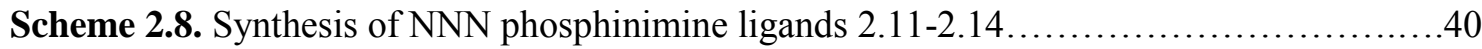

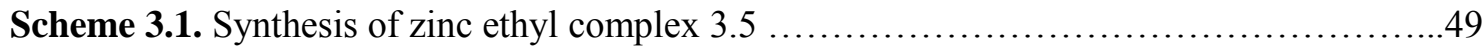

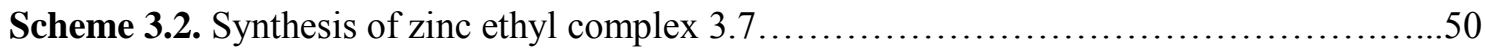

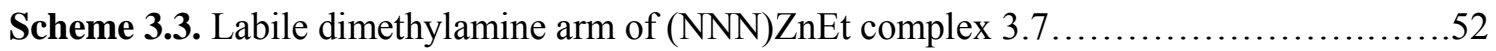

Scheme 3.4. Reaction between (NNO)ZnEt complex and $p$-cyanophenol.....................53

Scheme 3.5. Reaction between (NNO)ZnEt complex and 9-anthrylmethanol...................54

Scheme 3.6. Reaction of $(\mathrm{NNN}) \mathrm{ZnEt}$ complex and anthyrl alcohol........................54

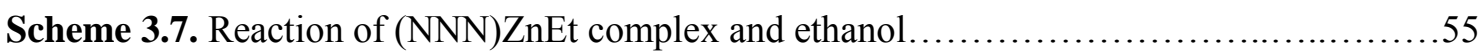

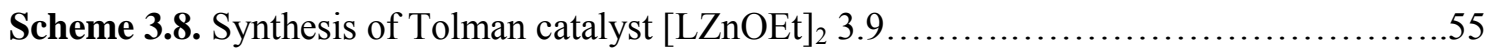


Scheme 3.9. Reaction of 3.7 with phenols........................................... 56

Scheme 3.10. Mechanism for the reaction of ethyl zinc complexes and acids/alcohols..........58

Scheme 3.11. Reaction of Tolman catalyst 3.14 with pyridine...........................59

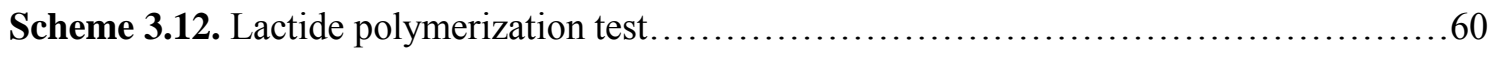

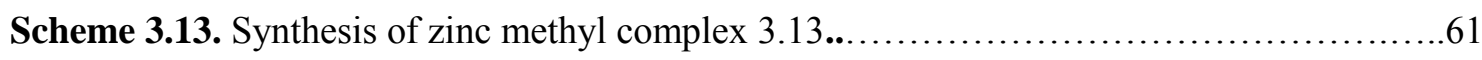

Scheme 4.1. Nucleophilic activation mechanism by DMAP............................66

Scheme 4.2. Alcohol activation mechanism by DMAP ..................................67

Scheme 4.3. TBD-catalysed ROP of LA by the H-bonding mechanism....................69

Scheme 4.4. Nucleophilic activation mechanism ..................................... 70

Scheme 4.5. Chain end activation mechanism ........................................ 70

Scheme 4.6. Bifunctional activation using H-bonding ................................... 71

Scheme 4.7. Synthesis of electron rich phosphines.................................... 73

Scheme 4.8. Synthesis of tolyl phosphinimines4.5-4.8 by the Staundinger reaction..............74

Scheme 4.9. Activation of 2-(9-anthryl)ethanol by phosphinimines........................77

Scheme 4.10. Synthesis of protonated phosphinimine................................... 78

Scheme 4.11. Synthesis of Phosphinimine by Staundinger reaction......................... 81

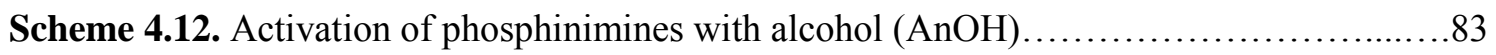

Scheme 4.13. Phosphinimines 4.9 catalyzed ROP of lactide............................... 85

Scheme 4.14. Phosphinimines PDDP catalyzed ROP of lactide............................ 86

Scheme 4.15. Proposed Nucleophilic activation mechanism..............................87

Scheme 4.16. Proposed H-bond activation mechanism...................................88

Scheme 4.17. Phosphinimines PDDP catalyzed ROP of lactide............................... 88

Scheme 4.18. Phosphinimines PTPP catalyzed ROP of lactide .......................... 89

Scheme 4.19. Electrophilic activation by thiourea and H-bonding activation by base...........91

Scheme 4.20. Phosphinimines PTTP catalyzed ROP of lactide...........................92 


\section{CHAPTER 1}

\section{RING OPENING POLYMERIZATION OF LACTIDE}

1. A. Ring opening polymerization (ROP) of lactides

1. A. 1. Introduction

1. A. 2. Biodegradable polymer: polylactide (PLA)

1. A. 3. Synthesis of polylactide

1. A. 4. Ring opening polymerization

1. A. 5. ROP mechanism

1. A. 6. Industrial catalyst for preparation of PLA

1. A. 7. Stereocontrol of ROP lactide

1. B. Metal Based Initiators for the ROP of lactides

1. B. 1. Single site homogenous catalysts

I. B. 3. Zinc based catalyst

1. B. 4. Aluminum based catalyst

1. C. Dissertation objectives 


\section{A.1. Introduction}

A great majority of the synthetic plastics, such as polyethylene, polypropylene, polystyrene, or polyvinyl chloride, are commonly used today. These polymeric materials are derived from petroleum resources. The utilization of fossil fuels such as oil and gas in the manufacture of plastics engender concern over the long-term availability of the required feedstock. Furthermore most of these materials are not readily degradable or recyclable. ${ }^{1}$ They often end their life cycle in landfill sites or being burned generating harmful gaseous emissions.

With all these issues, there has been a drive to discover and commercialize polymeric materials that are both derived from annually renewable resources and are readily degradable without emitting harmful gases to the environment. ${ }^{2}$ One of the best alternatives for this problem discovered in the last two decades is poly(lactic acid) or poly(lactide) (PLA). PLA can be derived either directly by polycondensation of lactic acid or by ring opening polymerization (ROP) of lactide (cyclic dimmer of lactic acid). PLAs are derived from 100\% renewable resources, such as corn and sugar beets, and are highly biocompatible and readily degradable. Therefore PLA offers great promise in range of commodity application. ${ }^{3}$

The ring opening polymerization is initiated by metal complexes, organic compounds, or enzymes, with/without alcohol, to yield high molecular weight PLA in excellent conversion and purity. Metal complexes are desirable because they give rise to controlled polymerization and well defined high molecular weight $\left(\mathrm{M}_{\mathrm{n}}\right)$, narrow polymerdispersity index (PDI). The commonly used initiators are metal alkoxide or amide coordination compounds. ${ }^{4}$ These compounds are useful due to their tolerance, selectivity, rate and minimal side reactions. ${ }^{5}$ 
The metal catalyzed ring opening polymerization (ROP) of cyclic esters such as lactide and caprolactone is an efficient way to produce a biodegradable and recyclable polymeric material. The commercial production of polymers such as polylactide (PLA) for various applications such as packaging, biomedicine, drug delivery etc. relies on this important catalytic transformation. ${ }^{6}$ Various metal alkoxide complexes exhibit varying degrees of effectiveness for stereoselectivity and polymerizationg rates for ring opening polymerization of these cyclic esters. Ligand sterics as well as electronics have been shown to influence the catalytic activity in several metal catalysis systems. ${ }^{7}$

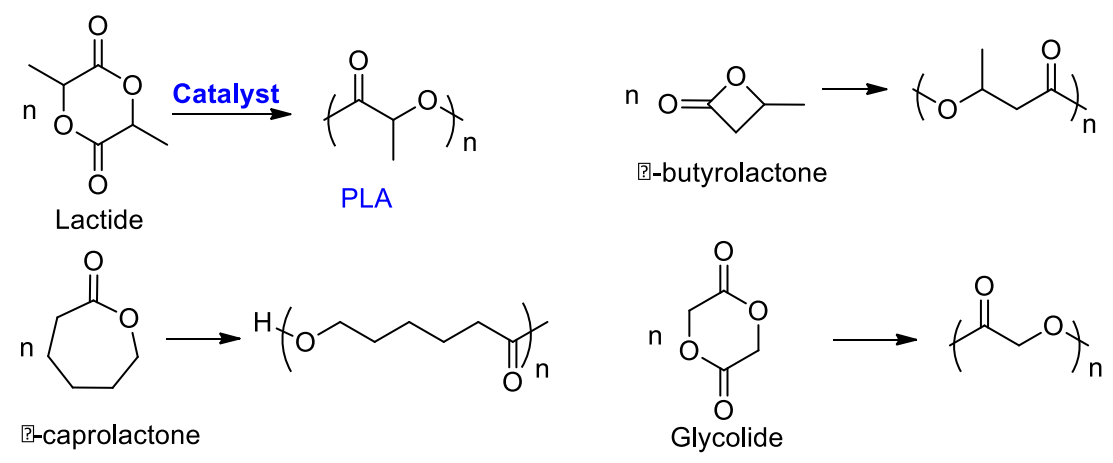

Figure 1.1. Ring opening polymerization of cyclic esters

\section{A.2. Biodegradable polymer: polylactide (PLA)}

Polylactide (PLA) is an aliphatic polyester composed of lactide (LA) repeat units. It is a clear, colorless polymer that can be readily formed as thin films or fibers. The selfcondensation of lactic acid to yield solid material was reported back in the sixteenth century. ${ }^{8}$ However, the polymer was realized only when Carruthers et al. reported the ring opening polymerization of lactide in $1932 .{ }^{9}$ The advantages and applications for degradable PLA were only recognized and medical products such as sutures, stents and fibers were developed in 1970s. PLA is now being manufactured on a large scale (300 million pounds) annually in Nebraska, USA by Natureworks LLC, and on a smaller scale 
by several enterprises in the EU and Japan. In 2003, Natureworks LLC has built the world's largest lactic acid manufacturing facility to feed their polymer plant. ${ }^{6}$ Due to the growing ecological awareness, sustainable development leads to an increasing demand for biodegradable plastics based on renewable raw materials. ${ }^{10}$ PLA has attracted much attention because it is bio-degradable; it hydrolyzes easily to produce lactic acid. Lactic acid can be easily metabolized both in vivo and in the environment. PLA is also proposed as a sustainable alternative to polyolefins because the raw material, lactic acid to make the lactide is produced by fermentation of glucose, which is obtained renewable resources such as corn, sugar beets and agricultural waste. ${ }^{11}$

Polyesters such as poly( $\varepsilon$-caprolactone) (PCL), polylactide (PLA) and their copolymers have attracted a great deal of attention over last decade because of their reduced environmental impact compared to polyolefins, and increasing applications in the biomedical and pharmaceutical fields. ${ }^{3}$

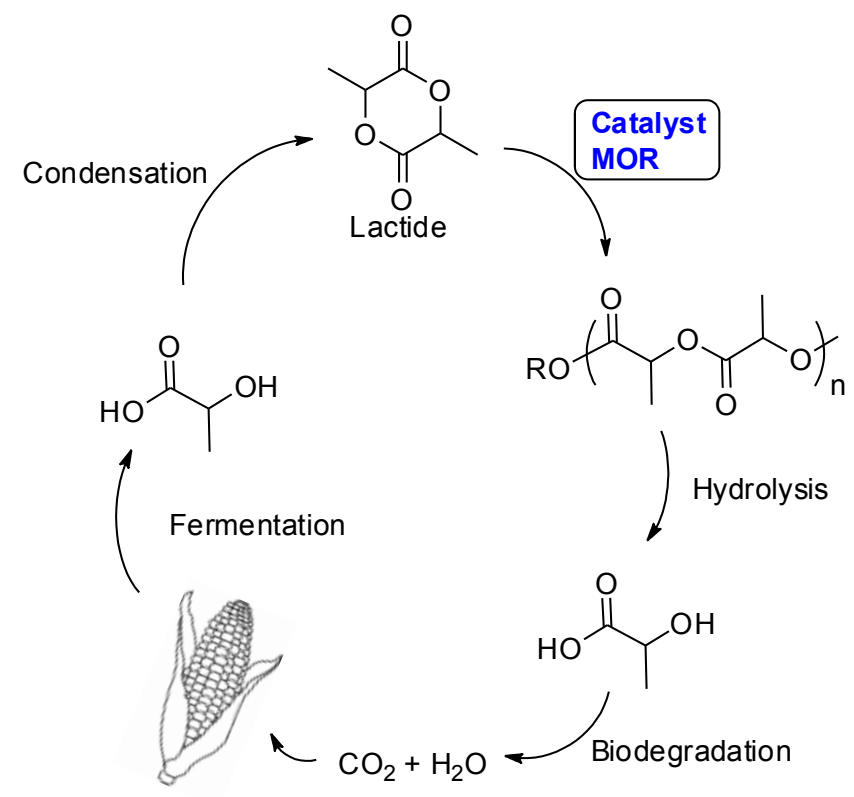

Figure 1.2. Life cycle of Poly(Lactic Acid) 
PLA has applications in the biomedical industry for making sutures and biodegradable screws as well as drug delivery and biodegradable packing materials. PLA has suitable properties that make it environmentally friendly and a sustainable alternative to traditional petrochemical-based plastics, mainly in packaging, coating and fiber applications. $^{12}$ The polylactide can be either recycled or readily composted after use, and therefore its $\mathrm{CO}_{2}$ emission is neutral. Among the several polyesters studied to date, PLAs have proven to be the most attractive and useful class of biodegradable polyesters. ${ }^{4}$

\section{A.3. Synthesis of polylactide}

The synthesis of polylactide can be carried out by either simple condensation of lactic acid or the ring opening polymerization (ROP) of lactide, a cyclic ester (cyclic dimer of lactic acid) (Scheme 1.1). The simple condensation process utilizes azeotropic dehydration process. However, it is difficult to produce high molecular weight polymer by simple condensation process. The direct condensation route is an equilibrium reaction and traces amounts of water are difficult to remove in the late stage of polymerization generally limit the high molecular weight polymer. Therefore, lactide polymerization is

more commonly prepared with the ring opening polymerization using a metal catalyst. ${ }^{2 a}$ ROP enables a greater degree control over the molecular parameters of the polymer.

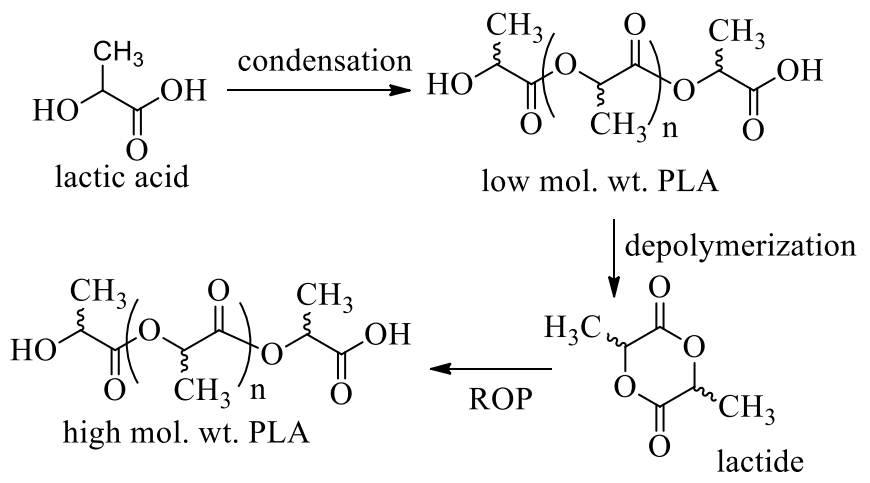

Scheme 1.1. Polymerization of lactic acid and ROP of lactide 


\section{A.4. Ring opening polymerization}

PLA synthesis and the various methods of preparation have been extensively investigated. ${ }^{6}$ The ring opening polymerization is important because this method produces a high molecular weight and stereocontrolled polymer. The ring opening polymerization is initiated by metal complexes, organic compounds, or enzymes, with/without alcohol, to yield high molecular weight PLA in excellent conversion and purity. Ring opening polymerization of lactide promoted by organometallic compounds via a coordination-insertion mechanism represents the most efficient and versatile method to prepare PLA with controlled microstructural properties such as molecular weight, polydispersity and stereoregularity. ${ }^{13}$ Metal complexes are desirable because they give rise to controlled polymerization and well defined high molecular weight $\left(\mathrm{M}_{\mathrm{n}}\right)$, narrow polymer dispersity index (PDI). The commonly used initiators are metal alkoxide or amide coordination compounds. ${ }^{4}$ These compounds are useful due to their tolerance, selectivity, rate and minimal side reactions. ${ }^{5}$

\section{A.5. ROP mechanism}

Several mechanisms have been proposed for the ROP of lactide such as anionic, coordination insertion and a monomer activated mechanism. ROP of the lactide in the presence of metal complexes is believed to occur via coordination-insertion mechanism. The coordination-insertion mechanism is wide accepted and supported experimentally (by end group analysis) and theoretically. ${ }^{3}$ The coordination-insertion process is considered as the most efficient method for the well-controlled synthesis of polyesters with regard to composition, molecular weight and microstructure. ${ }^{3-4,}$ 13-14 The 
coordination insertion mechanism of lactide polymerization involves four steps (Figure 1.3). The coordination of the lactide monomer to the Lewis-acidic metal center, followed by a nucleophilic attack of the alkoxide on the acyl carbon atom and insertion of lactide into the metal-alkoxide species with retention of configuration. ${ }^{15}$ A new metal alkoxide species is formed, which is capable of further insertion reaction. Continuous insertions of lactide monomers produce a polyester chain. Finally termination of the polymerization reaction by hydrolysis of the active propagation chain is performed before isolation of the PLA material.

Different types of mechanism are possible depending upon the nature of the catalyst such as anionic, monomer activated as well as coordination insertion mechanism. In all cases, stereocontrol can be realized by two different mechanisms, chain-end control and enantiomorphic site-control. In the chain-end control mechanism, the stereochemistry of the most recently inserted monomer influences the stereochemistry of

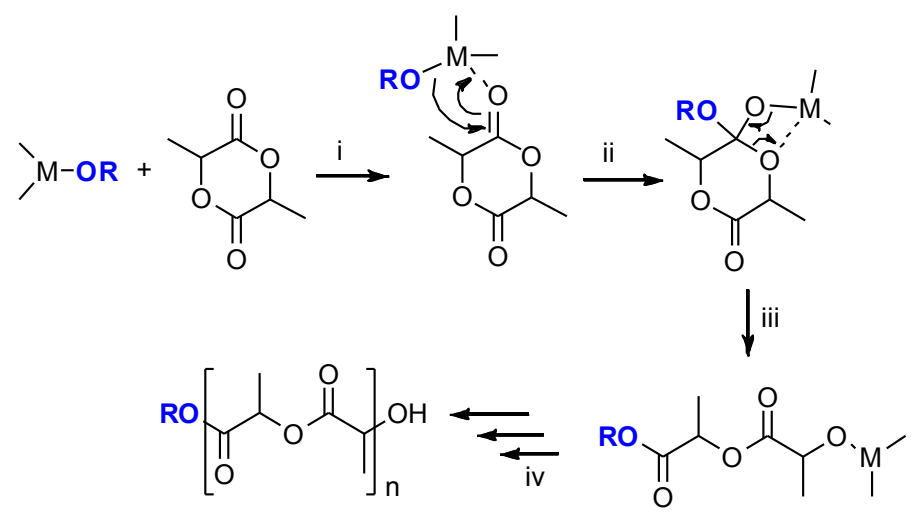

Figure 1.3. Coordination-insertion mechanism of ROP of lactide

the subsequent insertion. This type of control is observed in systems having a sterically bulky ligand around the metal. Sterically bulky ligand around the metal center enforces sterochemical control in the polymerization of rac-LA via chain-end control mechanism. 
Bulky ligand should increase the influence of the stereogenic center of the last inserted monomer that will again determine whether $(R, R)$ - or $(S, S)$-lactide is enchained. ${ }^{16}$ There are two stereochemistries possible. If a chain end of $R$ stereochemistry selects $(R, R)$ lactide, then isotactic PLA forms. If this chain end selects $(S, S)$-lactide (racemic enchainment), the heterotactic PLA forms. ${ }^{17}$ The enantiomorphic site control mechanism relies on the chirality of the ancillary ligand, and hence the catalyst itself is the source of stereochemical selectivity due to steric interaction between the incoming monomer and the catalyst framework. In enantiomorphic site control, the stereocontrol may arise from a complicated interplay between two mechanisms. ${ }^{18}$

With an organocatalytic and cationic initiating catalyst system, the activated monomer mechanism is believed to occur. In this mechanism, a nucleophile substrate activates the lactide monomer toward attack by an alcohol initiator, as shown in Scheme 1.2.). According to activated monomer mechanism, first the monomer is activated by either a Bronsted acid, a nucleophile or an H-bond donor. The alcohol then reacts with the activated lactide to form a ring-opened adduct in the initiation process. The chain end of the polylactide thus bears the ester from the initiating alcohol while the other chain end is a secondary alcohol that serves as the alcohol for propagation of the chain.

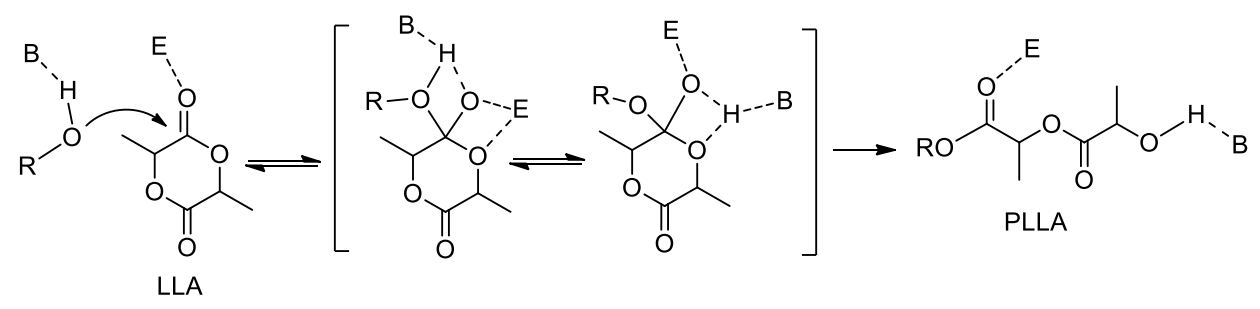

Scheme 1.2. Activated Monomer Mechanism 


\section{A.6. Industrial catalyst for preparation of PLA}

The most widely used catalyst for the industrial preparation of PLA is tin(II)bis(2ethylhexanoate, usually referred as tin(II)octanoate, $\mathrm{Sn}(\mathrm{Oct})_{2}$, is commercially available, easy to handle and soluble in common organic solvents as well as in melt monomers.

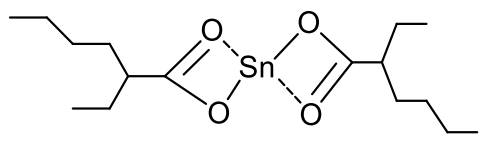

Figure 1.4. Structure of tin(II)octanoate/Sn(Oct $)_{2}$

It is a highly active catalyst in the presence of co-initiators or protic reagents such as alcohols at elevated temperatures (typically under melt conditions) and allows for the preparation of high molecular-weight polymer. ${ }^{19}$ Tin (II) alkoxide, which is generated by the reaction of tin(II)octanoate and protic reagents such as alcohols or even impurities such as lactic acid present in the monomer, is the active species that initiates the ROP of lactides. $^{19 \mathrm{~b}}$

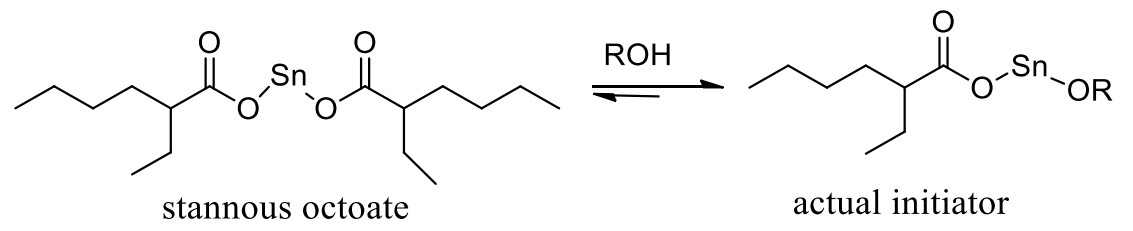

Figure 1.5. Structure of true initiator $\mathrm{Sn}(\mathrm{Oct})_{2}$ formed in presence of alcohol

Tin(II)octanoate polymerizes lactide via a coordination-insertion mechanism. The drawbacks of tin catalyst are (i) polymerization mediated by $\operatorname{Sn}(\mathrm{Oct})_{2}$ is reported to undergo both inter- and intra-molecular transesterification side reactions throughout polymerization process that decrease the level of control and increases the polydispersities $(\sim 2)$. (ii) It is practically impossible to entirely remove the tin 
compounds from the polyesters. This is of concern in biomedical applications for these polyesters because the organometallic tin compounds are characterized by high toxicity.

The common side reaction of ROP is transesterification. Transesterification causes scrambling of polymer chain. There are two types of transesterification reaction that can occur during ROP: (1.1) intermolecular that can increase in the range of chain length. (1.2) intramolecular transesterification leading to cyclic oligomer

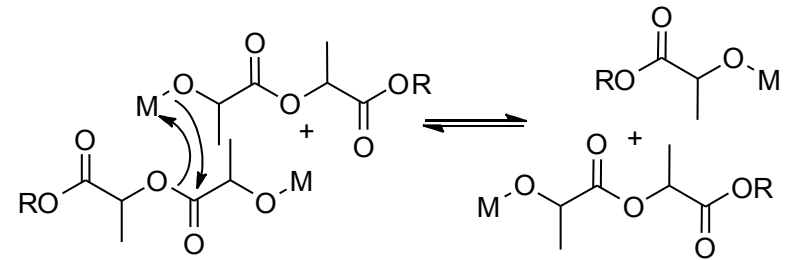

1.1. Intermolecular Transesterification

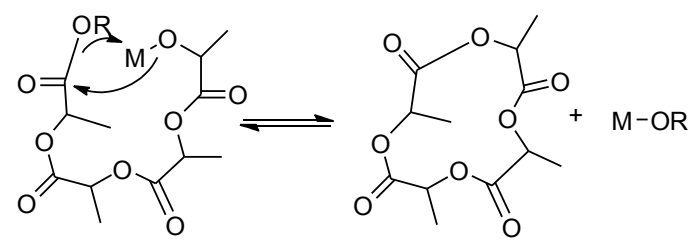

1.2. Intramolecular Transesterification

Figure 1.6. Transesterification reactions

The degree of transesterification can be determined by gel-permeation chromatography, (GPC), MALDI and NMR. The increase of molecular weight distribution (PDI) is the indication of transesterification reaction. In MALDI mass spectrometry chains of odd number of lactic acid repeat units. Analysis of the tetrad level of polymer chain of rac-lactide in ${ }^{1} \mathrm{H}$ NMR and ${ }^{13} \mathrm{C}$ NMR also indicates transesterification reaction.

\section{A.7. Stereocontrol ROP of lactide}

Stereocontrol is an important feature because the polymer's tacticity influences its properties, e.g. isotactic PLA is crystalline while atactic PLA is amorphous. Lactide possesses two stereocenters and therefore three distinct diasteromers. They are single enantiomer, racemic and meso lactide. They are denoted as D-LA or L-LA, rac-LA and 
meso-LA (Figure 1.8.). The four common type of PLA tacticities observed are isotactic, syndiotactic, heterotactic, and atactic. The PLA tacticity depends on the initiator as well as lactide type. ${ }^{5}$
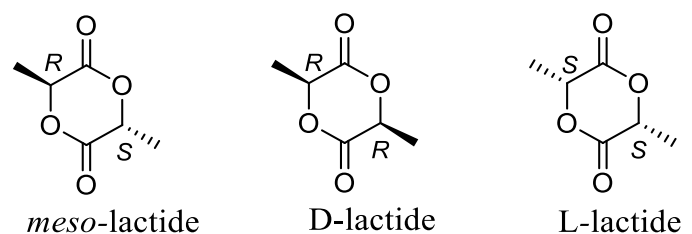

Figure 1.7. Stereoisomers of lactide

The application of ROP technique enables control over the order of insertion of monomer into the polymer chain based on their stereochemistry. Polylactide can exhibit different microstructures depending both on the monomer involved and on the course of the polymerization reaction (Figure 1.9.). ${ }^{14}$

(a)
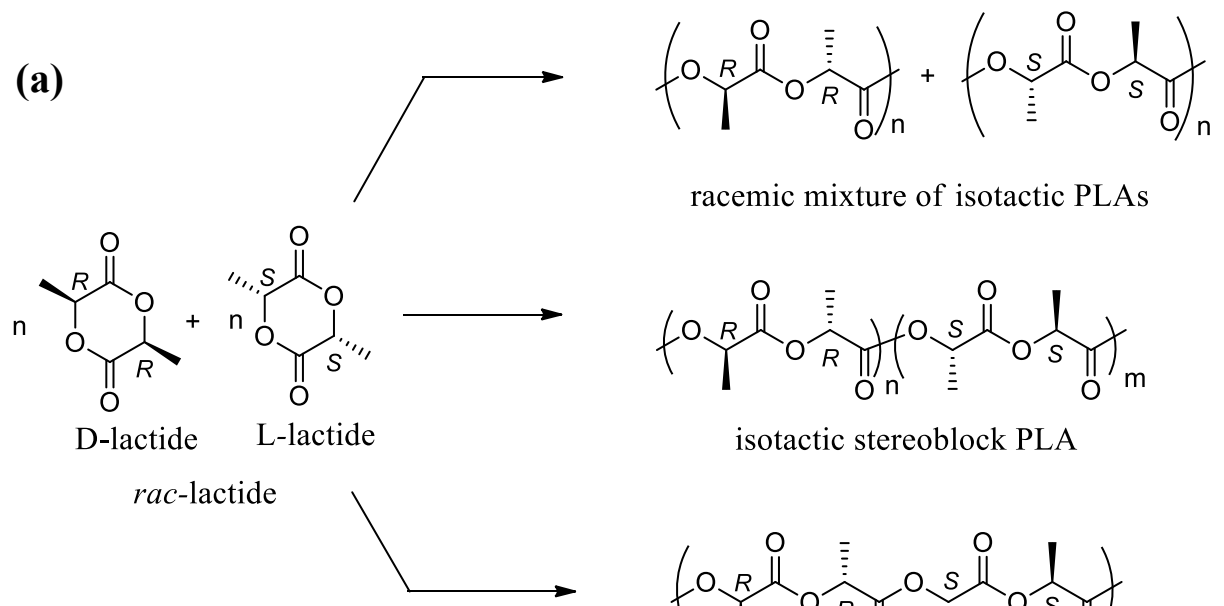

isotactic stereoblock PLA

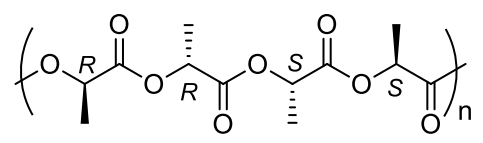

hererotactic PLA

(b)

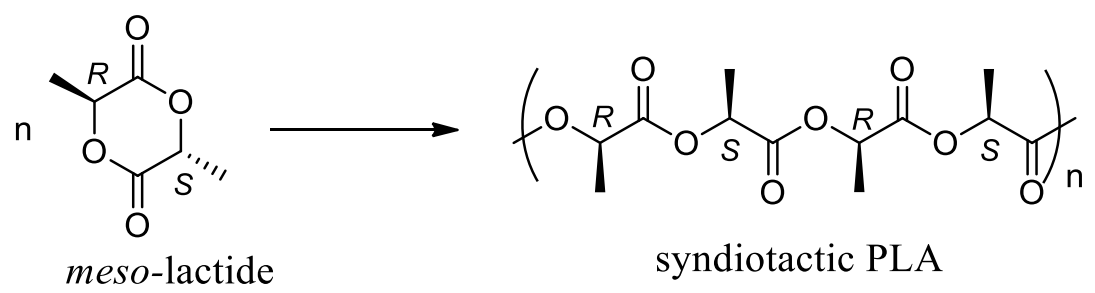


Figure 1.8. (a) Typical PLA microstructure from rac- lactide (b) Typical PLA microstructure from meso- lactide

ROP of the enantiopure monomer results in an isotactic polymer in which all of the stereocenters are aligned along the same side of the polymer chain. Stereocontrolled ROP of meso-lactide can produce either syndiotactic PLA (alternating $S$ and $R$ stereocenters i.e. -SRSRSR-) or heterotactic PLA in which the stereocenters double alternate i.e. -SSRRSS-. ROP of rac-lactide can give heterotactic. ${ }^{4}$
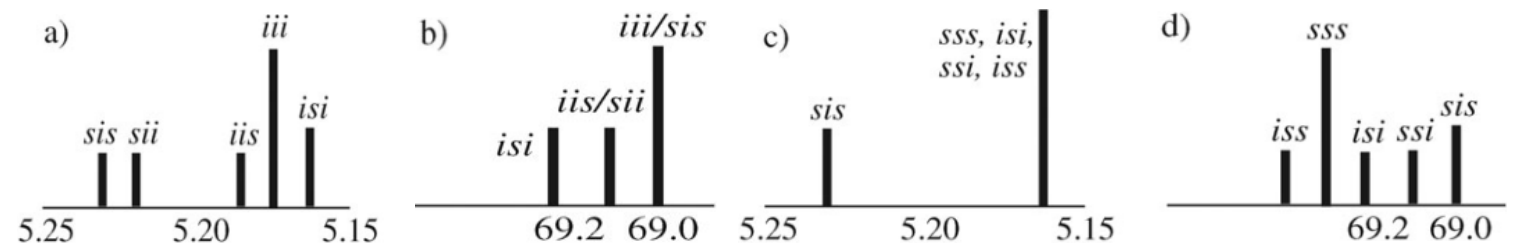

Figure 1.9. Schematic diagrams showing chemical shifts (in ppm) of tetrad for PLA in (a) Homonuclear decoupled ${ }^{1} \mathrm{H}$ NMR of PLA from rac-lactide; (b) ${ }^{13} \mathrm{C}$ NM of PLA from rac-lactide; (c) homonuclear decoupled ${ }^{1} \mathrm{H}$ NMR of PLA from meso-lactide; (d) ${ }^{13} \mathrm{C}$ NMR of meso-lactide.

The tacticity of the polymer at tetrad level can be determined from ${ }^{13} \mathrm{C} \mathrm{NMR}$ and homonuclear decoupled ${ }^{1} \mathrm{H}$ NMR analysis. In order to decouple the effect of splitting between the methyl and methine protons, homonuclear decoupling of the methyl signal is carried out resulting in the singlet resonance in the methine region ( $\delta=5.15-5.25 \mathrm{ppm})$.

The dregree of stereoregularity in lactide ROP is expressed as the probability of racemic or meso enchainment i.e. probability of forming a new racemic (syndiotactic) or meso (isotactic) diad, $P r$ and $P m$, respectively. $P r$ and $P m$ can be directly calculated from the homonuclear decoupled ${ }^{1} \mathrm{H}$ NMR spectra. 


\section{B. Metal based initiators for the ROP of lactides}

\section{B.1. Single-site homogeneous catalysts}

Single-site homogeneous catalysts are usually represented as $L_{n} M R, L_{n}$ is ancillary ligand that can be modified according to the need bound to the catalytically active metal center (M), and a possible initiating group or polymer chain-end (R). The advantages of the homogeneous catalysts are that they allow for the modifications of ligand electronics and sterics, labile metal centers and initiating groups that help control microstructure of polymer as well as possible to study catalysis. Stereochemistry is one of the most important factors determining the physical and mechanical properties of a polymeric material. Due to their stereoregularity, isotactic and syndiotactic polymers are typically crystalline, an important feature for many applications. Design and application of single site catalysis is one of the most promising methodologies for the synthesis of stereoregular polymer. $^{20}$

Several well defined metal catalysts have been developed based on $\operatorname{tin}^{1}$, $\operatorname{zinc}^{21}$,

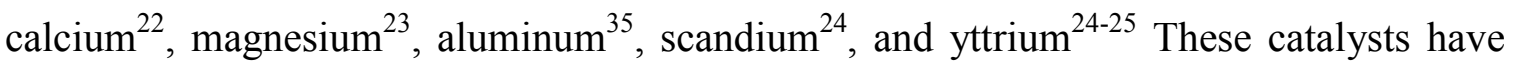
been successfully used in the ROP of lactide. However, PLA is still more expensive than petrochemical based plastics. For the production of a large volume of PLA, the development of new polymerization catalysts is required. Most large scale commercial processes are based on the use of tin compounds as initiators. The toxicity associated with tin compounds limits their use for biomedical applications. Therefore there are several exclusive studies going on concerning the development of active catalyst with well-defined structures for the ROP of lactide using biologically benign metals such as aluminum, magnesium, calcium and zinc. ${ }^{26}$ 
The important features required for lactide polymerization catalysts are high activity, ability to controllably produce high molecular weight, low polydispersity polymer and stereochemical control. Beside these features, low toxicity, low cost, minimal color and odor are also desirable features. ${ }^{13}$ Development of new single site catalyst for the ring opening polymerization is growing rapidly. A number of single site homogenous catalyst systems with many of these features have been reported.

\section{B.2. Zinc metal based catalyst}

( $\beta$-Diiminato)metal complexes have been shown to provide powerful catalysts for the stereospecific ROP of lactide. The Coates research group reported that $\beta$ (diketiminato)zinc isopropoxide complex, $\mathbf{1 . 3}$ (Figure 1.10) produced highly heterospecific ROP of rac-lactide $(P r=0.94)$ at ambient temperature with high yield of polymerization activity i.e., 20 minutes, $\mathrm{DP}=200 .{ }^{16}$ ( $\beta$-Diiminato)tin(II) isoprooxide $\mathbf{1 . 4}$ (Figure 1.11) and dimethylamide complexes were first examples of stereoregular ROP of lactide by tin complex reported. These complexes were shown to be highly active catalysts for the polymerization of lactide that produce stereocontrolled PLA where heterotactic bias is reported $(\mathrm{Pr}=0.77){ }^{1,27}$

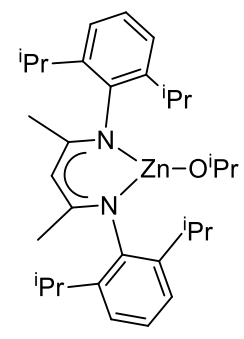

1.3

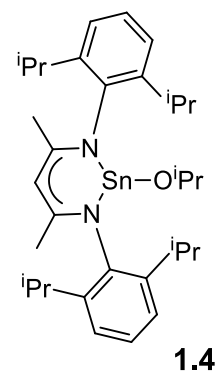

1.4

Figure 1.10. $\beta$-diiminato)zinc(II) isoprooxide (1.3), $\beta$-diiminato)tin(II) isoprooxide (1.4) 
A series of zinc(II) and magnesium alkoxides based on a $\beta$-diiminate ligand framework has been synthesized by Coates et al. Three isostructural zinc alkoxides $\left.\left.\left.[(\mathrm{BDI})-\mathbf{1}) \mathrm{ZnO}^{\mathrm{i}} \mathrm{Pr}\right]_{2}, \quad[(\mathrm{BDI})-\mathbf{2}) \mathrm{ZnO}^{\mathrm{i}} \mathrm{Pr}\right]_{2}, \quad[(\mathrm{BDI})-\mathbf{3}) \mathrm{ZnO}^{\mathrm{i}} \mathrm{Pr}\right]_{2}$ were synthesized by the treatment of the zinc amides with stoichiometric 2-proponol in toluene (Scheme 1.3). All of these three zinc alkoxide retain their dimeric structures in solution. $\left[(\mathrm{BDI}-1) \mathrm{ZnO}{ }^{\mathrm{i}} \mathrm{Pr}\right]_{2}$ $[(\mathrm{BDI}-1)=2-((2,6-$ diisopropylphenyl)amido)-4-((2,6-diisopropylphenyl) $\quad$-imino)-2pentene] shows the highest activity and stereoselectivity of the zinc complexes studied for the polymerization of $\mathrm{rac}$ - and meso-lactide to poly(lactic acid).

[(BDI-1) $\left.\mathrm{ZnO}^{\mathrm{i}} \mathrm{Pr}\right]_{2}$ polymerized $(S, S)$-lactide to isotactic PLA without observable epimerizaiton, rac-lactide to heterotactic PLA $(P r=0.94)$ at $0{ }^{\circ} \mathrm{C}$, and meso-lactide to syndiotactic PLA $\left(\operatorname{Pr}=0.76\right.$ at $\left.0{ }^{\circ} \mathrm{C}\right)$. microstructural study of polymer formed and the kinetic data indicate that the substituents on the $\beta$-diiminate ligands significantly influence the catalytic activity and the ability of zinc complexes to control the stereoche-

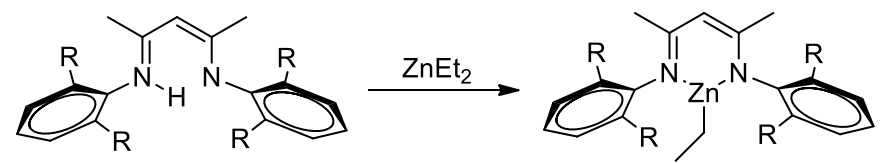

$(\mathrm{BDI}-1) \mathrm{H}\left(\mathrm{R}={ }^{\mathrm{i}} \mathrm{Pr}\right)$

$(\mathrm{BDI}-2) \mathrm{H}(\mathrm{R}=\mathrm{Et})$

$(\mathrm{BDI}-3) \mathrm{H}\left(\mathrm{R}={ }^{\mathrm{n}} \mathrm{Pr}\right)$

(BDI-1)ZnEt

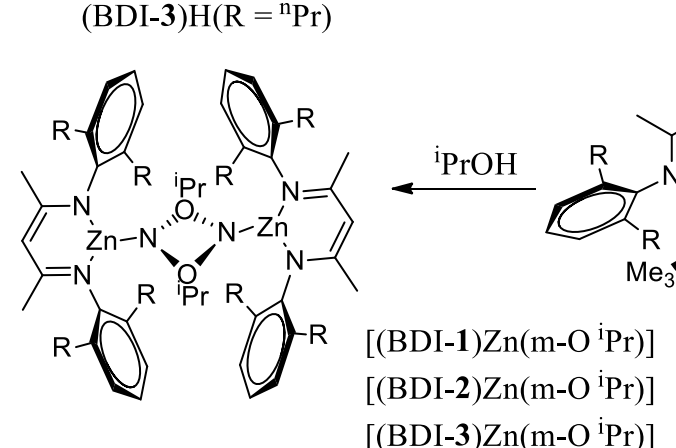

.

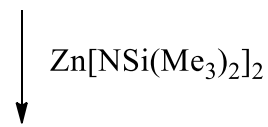

Scheme 1.3. Synthesis of zinc complexes with $\beta$-diiminate ligand framework istry of monomer enchainment. similar stereochemical control was not observed with the magnesium analogues. Tuning of steric bulk of the ligand, as well as the initiating group 
of the complex is very important. Minor changes in ligand greatly influence the polymerization activity. Ligand sterics have been shown to influence the catalytic activity in several systems. ${ }^{28}$

Chen research group synthesized a series of zinc complexes ligated by symmetrical and unsymmetrical $\beta$-diketiminate ligands and studied their reactivity for ring opening polymerization of lactide. ${ }^{7 \mathrm{~b}}$ They have explored specifically steric and electronic effects of these ligands on the polymerization of lactide. The rate of polymerization dependence on the $\mathrm{N}$-aryl substituents with the order as alkyl group/alkoxy group $>$ halide group $>$ nitro group was reported. The substituents in the phenyl ring of the $\beta$-dikitiminate ligand of the zinc complexes alter the catalytic activity of the complexes.
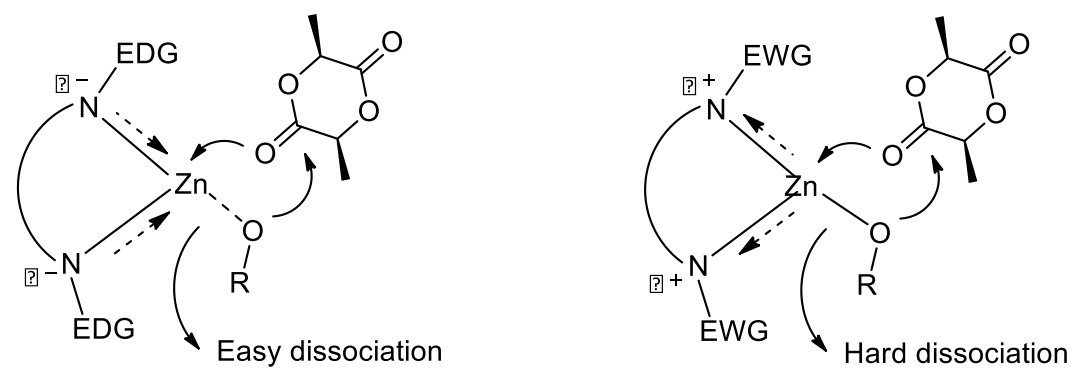

Scheme 1.4. Effect of $N$-substituents in $\beta$-dikitiminate zinc complex

They have found that electron-donating substituent on the phenyl rings at the ortho-position decrease the electrophilicity of the zinc center as well as bond strength between zinc and alkoxide $\left(\mathrm{RO}^{-}\right)$and are favorable for the polymerization (increases the catalytic activity) whereas the electron withdrawing group shows the adverse effect. This effect changes the rate of polymerization. ${ }^{7 \mathrm{a}}$

Series of dinuclear zinc complexes supported by a NNO-tridentate Schiff base ligand framework by Lin et al. ${ }^{29}$ The stability and catalytic properties of organozinc 
complexes can be easily tuned by using different types of ligands. The reactivity of the dinuclear zinc complexes supported by NNO-tridentate Schiff base ligands were dramatically affected by both the electronic and steric properties of the substituents at the ortho and para position. Tridentate base ligand (NNO) with hindered substituents have been shown to give high levels of stereocontrol with zinc and calcium. All these complexes give heterotactic PLA from rac-LA.

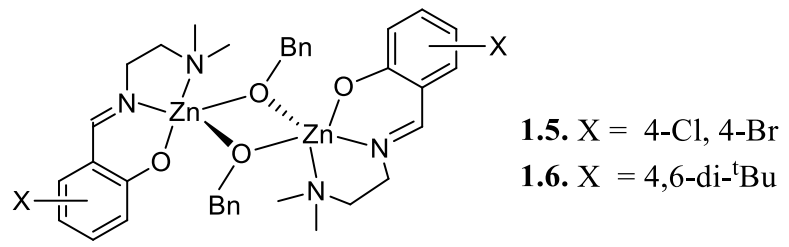

Figure 1.11. Dinuclear zinc complex supported by NNO-tridentate Schiff base ligand.

The zinc complexes (Figure 1.12) give highly heterotactic PLA from the polymerization of rac-lactide $(\mathrm{Pr}=0.91)$. Reduction of steric hindrance shows the reduction in heterospecificity $(\operatorname{Pr}=0.59-0.65)$. Both dimeric and monomeric species are present in the solution as indicated by ${ }^{1} \mathrm{H}$ NMR studies. NNO-tridentate Schiff base zinc alkoxides are reported as an excellent initiators for controlled polymerization of L-LA. They have reported that all complexes are efficient initiator towards ROP of lactide. The para substituted phenyl ring with electron withdrawing group such as $\mathrm{Cl}$ or $\mathrm{Br}$ atom $\mathbf{1 . 5}$ decreases the reactivity. This phenomenon is attributed to the more electronegative behavior of the substituent on the ligand strengthing the zinc alkoxide bond, and this slows the reaction rate. The sterically hindered substituent such as tert-butyl group $\mathbf{1 . 6}$ also decreases the reaction rate dramatically. This may be due to sterically hindered ligand resists the approaching of a monomer toward zinc center. ${ }^{30}$ The imine carbon of the NNO-tridentate Schiff-base ligand intensely affects their activity towards the controlled polymerization of L-LA. ${ }^{31}$ 


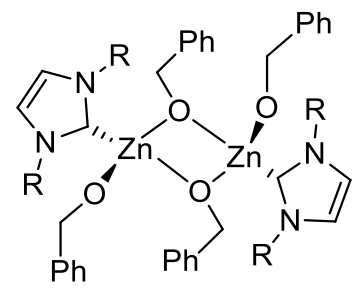

1.7. $\mathrm{R}=2,4,6-\mathrm{Me}_{3} \mathrm{C}_{6} \mathrm{H}_{2}$<smiles></smiles>

1.8. $\mathrm{R}=2,4,6-\mathrm{Me}_{3} \mathrm{C}_{6} \mathrm{H}_{2}, \mathrm{R}_{1}=\mathrm{H}$

1.9. $\mathrm{R}=2,4,6-\mathrm{Me}_{3} \mathrm{C}_{6} \mathrm{H}_{2}, \mathrm{R}_{1}=\mathrm{Ph}$

1.10. $\mathrm{R}=\mathrm{CH}(\mathrm{Me}) \mathrm{Ph}, \mathrm{R}_{1}=\mathrm{Ph}$

Figure 1.12. Zinc-NHC alkoxide complexes for ROP of lactide

These complexes gave heterotactic-biased PLA with a Pr value of 0.60 at room temperature in rac-LA polymerization. Absence of free carbene participation in the lactide polymerization was shown by separate reaction with carbene catalyst $\mathbf{1 . 8}$ in the presence of benzyl alcohol as initiator in rac-LA polymerization. The tacticity of the resulting polymers obtained by using the zinc complex 1.7 compared to using the free carbene found different. Free carbene $\mathbf{1 . 8}$ produced isotactic enriched PLA from rac-LA at $-20^{\circ} \mathrm{C}$ and carbene 1.9 produced highly isotactic PLA material with a $P m$ value up to 0.90 from rac-LA at $-70{ }^{\circ} \mathrm{C} .{ }^{32}$

Recently, new Zn-N-heterocyclic carbene (NHC) alkoxide complexes $\mathbf{1 . 1 1}$ and 1.12 that mediated the ROP of lactide in presence of an alcohol in an effective and controlled manner to produce chain length-controlled polylactide (PLA) was reported. Furthermore, computational analysis of the ROP of lactide initiated by complex $\mathbf{1 . 7}$ revealed that the operating coordination-insertion mechanism was assisted by the second zinc center. ${ }^{33}$ 


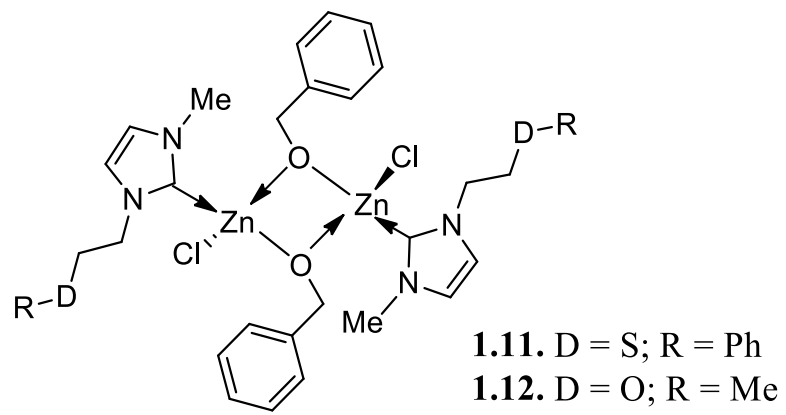

Figure 1.13. Zinc-NHC alkoxide complexes for ROP of lactide

Carpenter and coworkers have used a dual catalytic system combining an original cationic zinc complex (Lewis acidic metal, monomer activator) with a tertiary amine (Lewis base, initiating/propagating alcohol) for the first time towards efficient and controlled ROP of lactides. They have shown the possibility to combine the organic and organometallic approaches in ROP catalysis. ${ }^{34}$

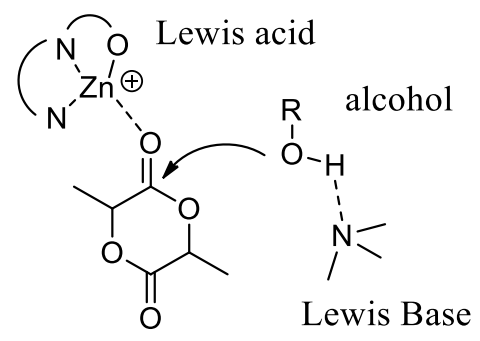

Figure 1.14. Lewis acid and Lewis base dual Catalyst for ROP of lactide

Wang et al. prepared series of zinc complexes bearing NHC-based $\mathrm{C}, \mathrm{N}, \mathrm{N}-$ or C,N,P-tridentate ligands and investigated their activity towards the ROP of rac-lactide in presence of alcohol at room temperature. Few of these complexes are active towards the ROP of rac-lactide in presence of alcohol at room temperature. ${ }^{26 a}$ 


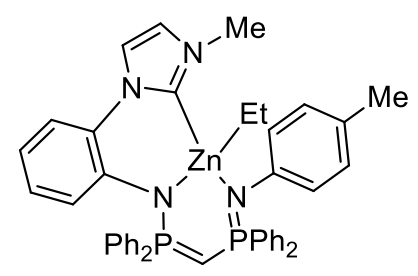

1.13

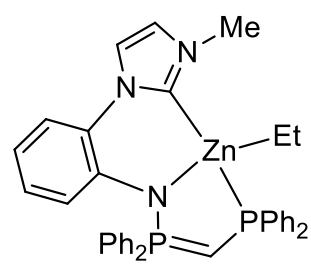

1.14

Figure 1.15. Zinc NHC-based (1.13) CNN and (1.14) CNP ligand bearing complex

\section{B.3. Aluminum metal based catalyst}

Several achiral Schiff base aluminium alkyls were shown to be efficient stereoselective catalysts for lactide polymerization in presence of an alcohol as initiator. ${ }^{35}$ Nomura et al. $^{36}$ reported the synthesis of stereoregular heterotactic $(P r=0.81)$ PLA by achiral aluminium metal catalyst complex with sterically hindered (bulky tert-butyl groups at the ortho and para position of the phenol group ligand (Figure 1.17). These achiral catalysts are postulated to exert stereocontrol via a chain end control mechanism.

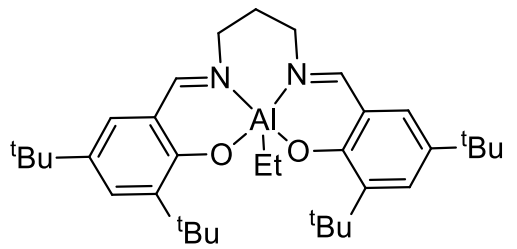

Figure 1.16. Al-metal catalyst with sterically hindered ${ }^{t} \mathrm{Bu}$ group

Feijen and coworkers reported ${ }^{37}$ that enantiopure $(\beta$-diiminato)tin(II) isoprooxide with the Jacobsen ligand (Figure 1.17) showed a preference of 20:1 for ROP of d-lactide ending up with $P m=0.93$ at $85 \%$ conversion. However, only a small initial monomer/ initiator ratio of 62 was used in this reaction. 


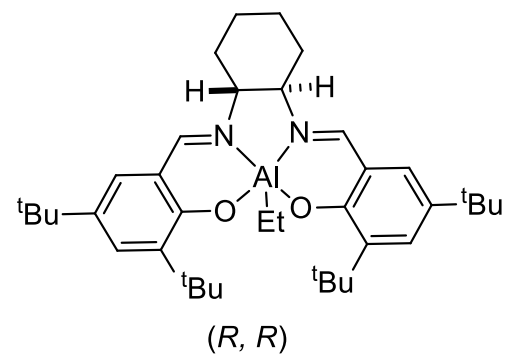

Figure 1.17. Enantiopure $(R, R)$ Al-base catalyst with the Jacobsen ligand

Gibson et $\mathrm{al}^{38}$ reported that the rate and stereochemistry of polymerization of $\mathrm{rac}$ lactide is highly dependent upon the steric properties of the phenoxy substituents with the aluminum initiators bearing tetradentate phenoxy-amine ligands. ${ }^{39}$ They have prepared series of aluminium methyl complexes supported by tetradentate aminophenoxide ligands (Figure 1.18).

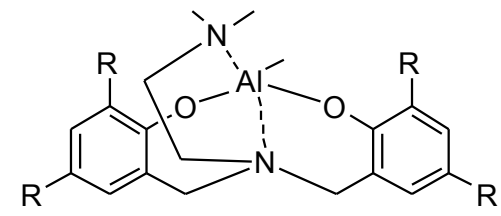
1.15. $\mathrm{R}=\mathrm{Me}$
1.16. $\mathrm{R}=\mathrm{Cl}$
1.17. $\mathrm{R}={ }^{\mathrm{i}} \mathrm{Pr}$
1.18. $\mathrm{R}={ }^{\mathrm{t}} \mathrm{Bu}$

Figure 1.18. Al methyl complexes supported by tetradentate aminophenoxide ligand It was found that the catalytic behavior of these complexes is highly dependent on the substituents at the ortho and para positions of the phenol group. Complexes $\mathbf{1 . 1 5}$ and 1.17 with methyl and isopropyl groups at the ortho and para positions of the phenol group provided isotactic-biased PLA $(P \mathrm{~m}=0.73$ and 0.65$)$. Complex 1.16 with chlorine substituents at the ortho and para positions of the phenol group only gave an atactic material form rac-LA. Complex $\mathbf{1 . 1 8}$ with tert-butyl group at the ortho and para positions of the phenol group give a slight heterotactic polymerization of $r a c$-LA $(\mathrm{Pr}=$ $0.57) .^{39}$ 


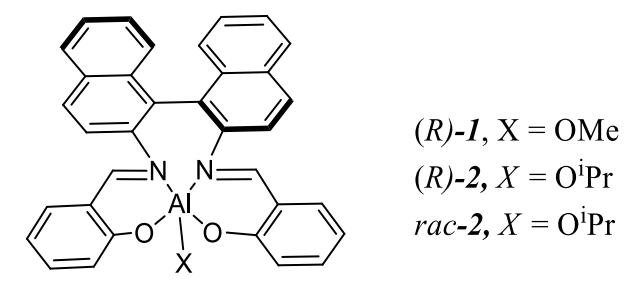

Figure 1.19. Tetradentate iminophenolato(aluminum) complexes

Spassky et al. reported that in a rac-LA polymerization carried out at $70{ }^{\circ} \mathrm{C}$ initiated by the enantiopure Schiff base aluminium methoxide $(R)-\mathbf{1}$, the polymerization rate of $(R, R)$-LA was faster than that of $(S, S)$-LA. They reported that the kinetic resolution of rac-lactide with the methoxide $(R)-\mathbf{1}$ catalyst is highly selective and it preferentially polymerized $(R, R)$-lactide over the $(S, S)$-enantiomer with a relative rate ratio of 20 . The

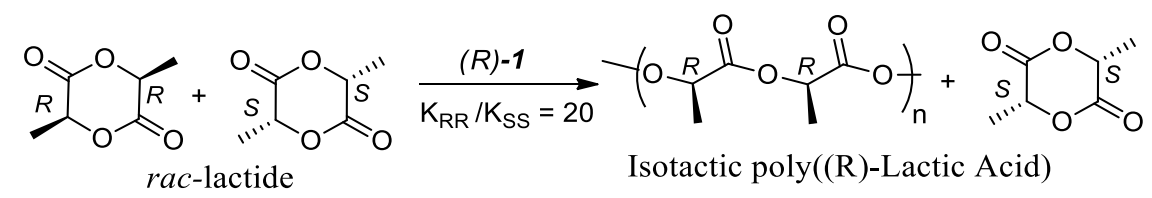

Scheme 1.5. Synthesis of isotactic poly(R)-lactic acid molecular weight of the resultant polymer was controlled by the monomer/catalyst ratio, and MWD was narrow. Isotactic poly $[(R)$-lactic acid was predominantly obtained when the polymerization of $r a c$-lactide was carried out to less than a $50 \%$ conversion. After about $60 \%$ conversion, only $(S, S)$-lactide remained and the reaction slowly approached $100 \%$ conversion because of the kinetic preference of the $R, R$-enantiomer. ${ }^{35,40}$

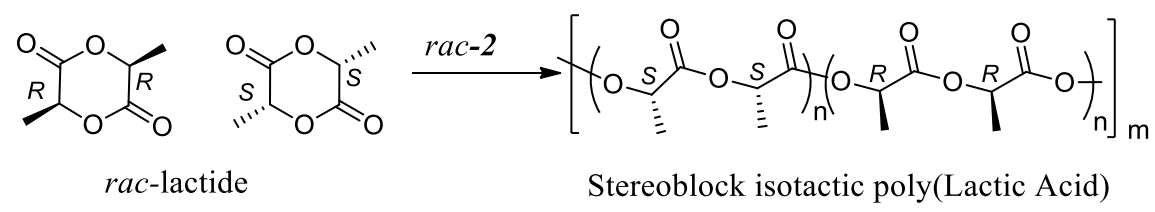

Scheme 1.6. Synthesis of stereoblock isotactic poly(R)-lactic acid 
In 1999, Coates et al. reported that the polymerization of rac-lactide with a racemic aluminium alkoxide ( $\mathrm{rac}-2)$ catalyst produced an isotactic stereoblock PLA that contains both poly $(S)$-segments and poly $(R)$-segments in the main chain. The higher $T_{m}$ of the polymer than that of the enantiomerically pure polymer indicates the cocrystallization of the enantiomeric blocks of the polymer. The polymer exchange pathway mechanism was proposed where living chain ends switch between metal centers to produce diastereomeric active species. ${ }^{35,41}$

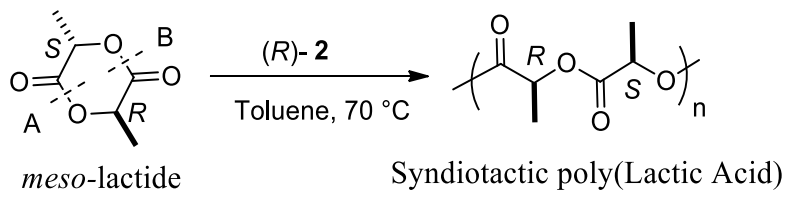

Scheme 1.7. Synthesis of Syndiotactic poly(Lactic Acid)

Coates et al. reported that the enantiomerically pure aluminium complex $(R)-\mathbf{2}$ affords syndiotactic PLA from meso-LA via an enantiomorphic site control mechanism. The polymerization of meso-LA proceeds to $94 \%$ conversion at $70{ }^{\circ} \mathrm{C}$ in toluene for 40 hours, the syndiotacticity of the resulting PLA is 0.96 . The large rrr tetrad peak in the methane resonance of the homonuclear decoupled ${ }^{1} \mathrm{H}$ NMR spectrum is evidence for a highly syndiotactic polymer. This is further confirmed by the ${ }^{13} \mathrm{C}$ NMR in $\mathrm{CDCl}_{3}$. Due to the high degree of syndiotacticity, the PLA produced by meso-LA polymerization using $(R)-2$ is crystalline, annealing at $95{ }^{\circ} \mathrm{C}$ for 60 minutes; this polymer exhibits a glass temperature $(\mathrm{Tg})$ at $34{ }^{\circ} \mathrm{C}$ and a $\mathrm{Tm}$ as high as $152{ }^{\circ} \mathrm{C}$. The proposed mechanism of lactide ring opening is cleavage of an oxygen-acyl bond by metal alkoxide. Since mesoLA has two enantiotopic O-acyl bonds (A, B), a chiral metal alkoxide will exhibit a kinetic preference at one of the sites, producing the syndiotactic polymer. ${ }^{40,42}$ 


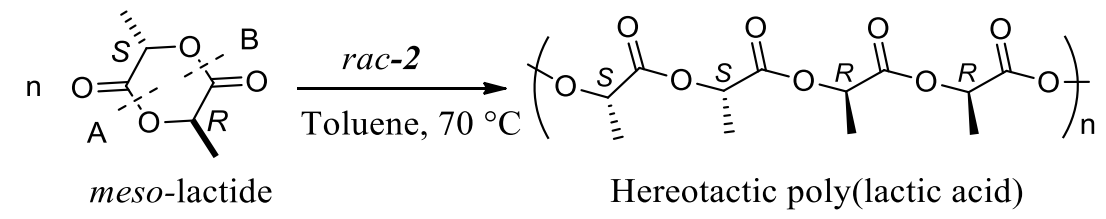

Scheme 1.8. Synthesis of heterotactic poly(lactic acid)

Coates et al. also reported the ROP of meso-lactide using rac-2. The polymerization reached $98 \%$ after $40 \mathrm{~h}$ at $70{ }^{\circ} \mathrm{C}$. Although the resulting polymer has a heterotacticity of 0.80 , it is amorphous and only exhibits a $\operatorname{Tg}$ at $43.2^{\circ} \mathrm{C}$.

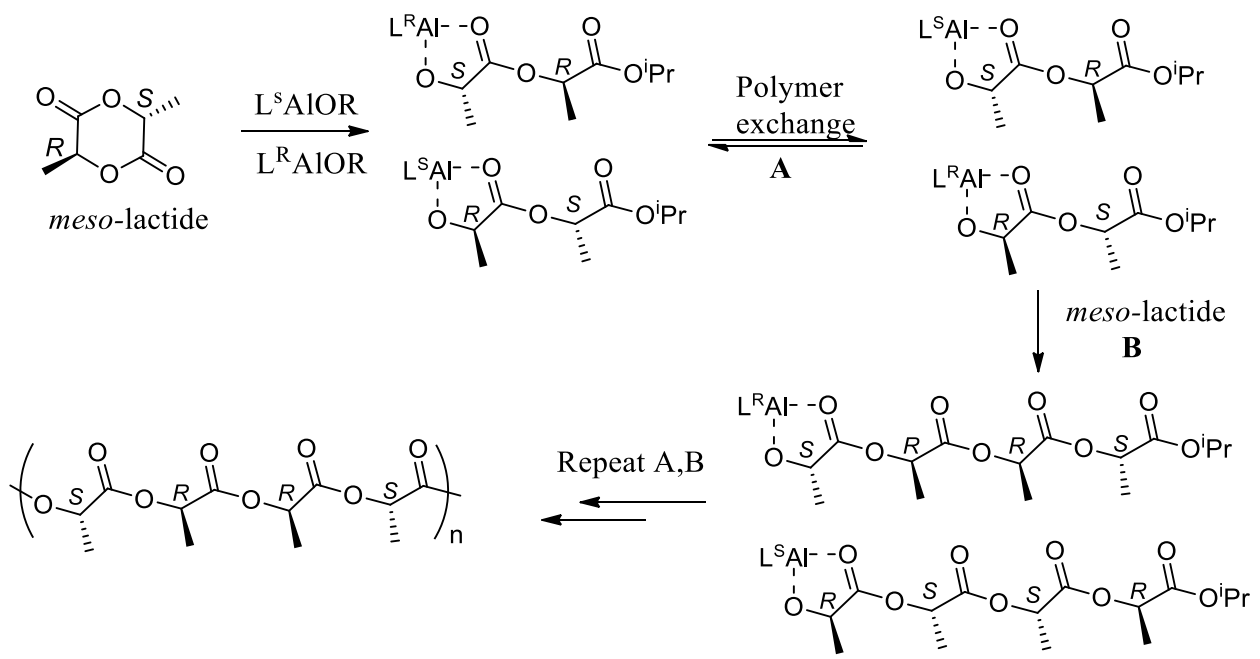

Scheme 1.9. Polymer exchange mechanism for the synthesis of heterotactic PLA

A polymer exchange mechanism was proposed by Coates et al. to explain the formation of the heterotactic structure from meso-LA from $r a c-2$.

Recently, Du and coworkers have prepared series of aluminum complexes bearing chiral bidentate anilido-oxzolinate ligands and showed their catalytic activity towards ROP of rac-lactide in presence of benzylic alcohol cocatalyst.

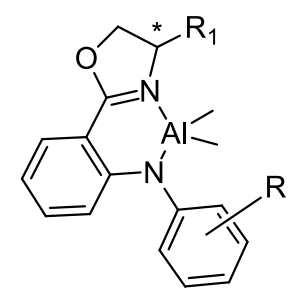

Figure 1.20. Al-complexes bearing chiral bidentate anilido-oxzolinate ligands 
They have reported the microstructure resulting from polylactides ranged from slightly isotactic to moderately heterotatic depending upon different substituent group present in the ligand. The reactivity and selectivity related to the steric and electronic factors of substituents on several specific positions of the ligand motif. ${ }^{43}$

Cano et al. have prepared a series of lithium, sodium and potassium complexes

with phenoxo-imine ligand. ${ }^{44}$ Some to these complexes molecular structure in solid state have been determined by X-ray diffraction. Some of these complexes are reported to be highly active in presence of benzyl alcohol towards ROP of rac-lactide, achieving $100 \%$ conversion in less than 1 minute. Hetero-rich-PLA that was modified by the metal atom and the ligand substituents were reported.

\section{C. Dissertation objective}

The catalytic activity of transition metal catalysts can be controlled by applying proper steric and electronic features around the metal center. In the phosphine sulfonate (PSO) ligands developed by Drent et al., ${ }^{45}$ the tertiary phosphine framework provides tunable electronics and steric properties. Triaryl phosphines act as $\sigma$ donors. Various substituents on the phosphorus aryl group provide a steric effect around the metal center. Phosphinimines are $\mathrm{sp}^{2}$ nitrogen-based donor ligands. The strong donor ability of phosphinimine is due to the highly polarized $\mathrm{P}=\mathrm{N}$ double bond. The steric and electronic properties of phosphinimines are easily adjusted by placing different substituents on the phosphorus atom. To enhance the donor capability and electronic and steric properties, we have designed and synthesized a series of air stable phosphinimine-sulfonate ligands. ${ }^{46}$ Our group has recently reported the synthesis of the palladium complexes and 
investigated their thermal behavior and ethylene reactivity. ${ }^{47}$ In this thesis work, we will discuss the synthesis, characterization and reactivity of tridentate phosphinimine arene sulfonate ligands. In chapter 2, we will discuss the synthesis and characterizations of series of tridentate phosphinimine arene sulfonate ligands. We will also add the synthesis and characterization of several of bidentate phosphinimine arene sulfonate ligands. Synthesis, characterization and reactivity of the zinc complexes with alcohols will be discussed in chapter 3 . The catalytic activity of zinc ethyl complex and zinc alkoxide complexes towards ring opening polymerization of lactide will be also explored in chapter 3. Neutral phosphinimines are strong nucleophilic bases and are potent organocatalysts for ROP of cyclic esters (Chapter 4). A series of neutral phosphinimines were synthesis and the evaluated for their basic property was done to studying the alcohol proton shift observed in the ${ }^{1} \mathrm{H}$ NMR when reacted with alcohol in $\mathrm{CDCl}_{3}$ under $\mathrm{N}_{2}$. These phosphinimines were screened for ROP of lactide. 


\section{CHAPTER 2}

\section{SYNTHESIS OF PHOSPHINIMINE LIGANDS}

2. A. ortho-phosphinimine-arenesulfonamides

2. A.1. Ligand and catalyst design

2. B. Synthesis of ortho-phosphinimine-arenesulfonamides

2. B.1. Introduction

2. B.1. NNO ligand

2. B.3. Bidentate ligand library

2. B.4. Conclusion 


\section{A. ortho-phosphinimine-arenesulfonamides}

\section{A.1. Ligand and catalyst design}

There are several excellent metal catalysts that have been reported in the literature for ring opening of polymerization of lactides. The metals in these metal catalysts are protected by various ligands, such as iminophenolato, $\beta$-diketiminate, aminophenolate etc. ${ }^{3,13}$ The electronic and sterics of the ligand can be controlled by incorporating various groups into the ligand framework. In 1996, Spassky research group reported aluminum metal complex supported my enantiopure Schiff base with salen BINAP chiral ligands. ${ }^{35}$ The enantiopure aluminum complex with bulky chiral backbone was reported for selective ROP of D-lactide from DL-lactide. Coates et al. reported achiral zinc complex incorporating achiral $\beta$-diketiminate ligand for highly heterospecific ROP of raclactide. ${ }^{16}$ The most widely used catalyst for the industrial preparation of PLA is tin(II)bis(2-ethylhexanoate), usually referred as tin(II)octanoate $\left(\mathrm{Sn}(\mathrm{Oct})_{2}\right)$. Tin(II)octanoate is commercially available, easy to handle and soluble in common organic solvents as well as in melt monomers. ${ }^{19}$ Aminophenolate ligand with zinc metal was reported highly active catalyst for the ROP of lactide till date (Figure 2.1). ${ }^{21 \mathrm{~b}}$ The Lewis acidic metal center, chirality of the ligand and introduction of bulky substituents are crucial for the stereocontrol in PLA chain produced from ROP of lactide.

We would like to design single site tridentate ligands that provide appropriate steric as well as electronic effect around the metal center. The sterics around the metal center provides the desired stereocontrol to the growing polymer chain by chain end control mechanism. The Lewis acidic metal center is important for the polymer chain initiation by the coordination insertion mechanism. 


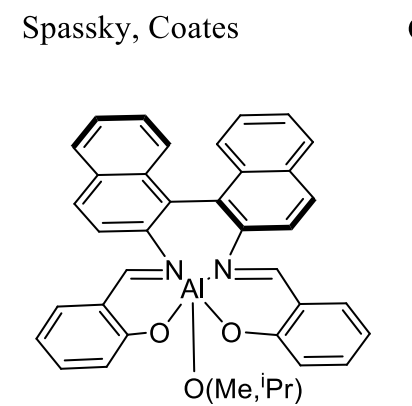

Iminophenolato Al complexes
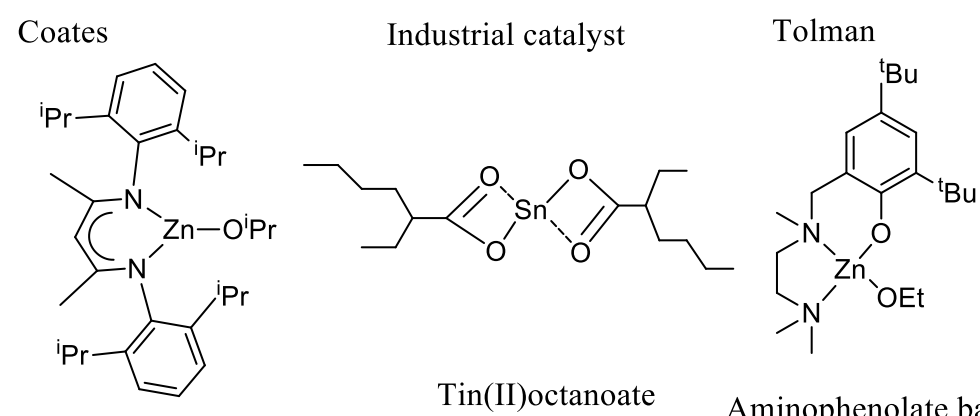

Aminophenolate based zinc complex

Figure 2.1. metal complexes supported by various ligands

Hence, designing the ligand that can provide suitable electronic effect to the metal center is crucial. We would like to incorporate phosphinimine group in our ligand system because the electronic and the sterics of phosphinimine can be manipulated with ease. The coordination chemistry of neutral phosphinimines, both as monodentate as well as bidentate act as good electron donor ligands toward transition metals and are able to form strong metal-nitrogen bonds. This ability is due to the fact that the delocalization about the phosphinimine PN moiety produces compounds with enhanced basicity and nucleophilicity. The excellent donor properties of neutral phosphinimine ligands was illustrated by the synthesis of tungsten tetracarbonyl complexes containing benzene bridged bidentate phosphinimine-imine ligands. ${ }^{48}$ The low Vco values indicate that a phosphinimine is a strong $\sigma$-donor and a poor $\pi$-accepter ligand versus comparable tetracarbonyl (0) complexes that contain benzene bridged bidentate iminophosphine ligands. ${ }^{23}$

Neutral phosphinimines are strong $\sigma$-donor ligands that will coordinate to transition metals via nitrogen and provide steric shielding by exocyclic phosphinimine substituents. The sterics and electronics of the phosphinimines ligands can be manipulated easily by incorporating various substituents in phosphine. The 
phosphinimines steric bulk lies exocyclic to the chelate ring that coordinate to transition metals via nitrogen. The steric bulk is slightly removed from the metal center. This confers a second coordination sphere environment that contains steric bulk and is slightly removed from the metal center The first coordination sphere is thus more open. A few examples exist where an exocyclic phosphinimine group has been incorporated into a mixed donor ligand system for use in the synthesis of late transition metal complexes. ${ }^{30 \text {, }}$ $48-49$

We sought to synthesize bidentate and tridentate phosphinimine-arenesulfonate ligands. We have successfully synthesized anionic non-symmetric strong/weak $\sigma$-donor ortho-phosphinimine-arenesulfonate ligand and isolated corresponding neutral $\mathrm{Pd}(\mathrm{II})$ methyl pyridine complex (Figure 2.3). ${ }^{46}$ As discussed previously, Metal alkoxides are reported, a highly active catalysts till date. Zinc is the best metal candidate for the catalyst, we design. Zinc has very important properties best fit for metal catalyst such as it is biocompatible and non-toxic. Zinc is also cheap and readily available. Our ligand design model is zinc ethyl and zinc alkoxide incorporated with tridentate NNN and NNO donor ortho-phosphinimine-arenesulfonate ligand (Figure 2.2).

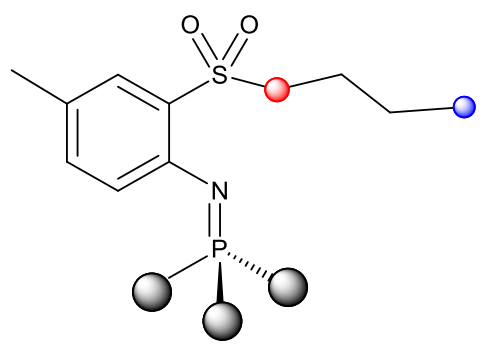

Figure 2.2. ortho-phosphinimine-arenesulfonamide ligand design 


\section{B. Synthesis of ortho-phosphinimine-arenesulfonamides}

\section{B.1. Introduction}

We sought to synthesize a non-symmetric N,N,O and N,N,N-tridentate ligand which incorporated a phosphinimine, sulfonamide and a dialkyl amine for the formation of neutral zinc alkyl and alkoxide complexes and explore their reactivity with lactide. The methyl group in the benzene ring in the commercially available starting material facilitates solubility in the organic solvents and provides excellent spectroscopic handle, with singlet signal appearing at $\delta=\sim 2 \mathrm{ppm}$ in ${ }^{1} \mathrm{H}$ NMR.

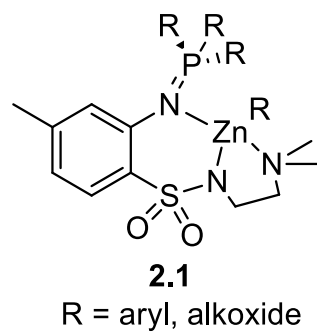

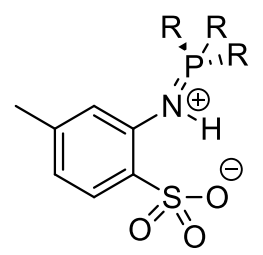

2.2 $\mathrm{R}=$ aryl, alkyl<smiles>[R]P([R])N1c2cc(C)ccc2S(=O)(=O)O[R]1([Y9])[3H]</smiles>

2.3

Figure 2.3. Tridentate ortho-phosphinimine-benzenesulfonamide ligated zinc complex, ortho phosphiniminium-arenesulfonates, and corresponding palladium methylpyridine complexes

We have reported an efficient and modular synthesis of air stable ligand precursors 2-phosphisphiniminium-5-methylbenzenesulfonate zwitterions 2.2. ${ }^{15}$ We have successfully deprotonated zwitterions $\mathbf{2 . 2}$ to form anionic non-symmetric strong/weak $\sigma$ donor ortho-phosphinimine-arenesulfonate ligand and isolate corresponding neutral Pd(II) methyl pyridine complex (Figure 2.3). The thermal stability of the neutral palladium complexes and their reactivity with ethylene was explored. ${ }^{47}$ These ligands are good electron donors towards transition metals and are able to form strong metal-nitrogen 
bonds. This ability is due to the delocalization about the phosphinimine PN moiety (Scheme 2.3) that enhances the basicity and the nucleophilicity.

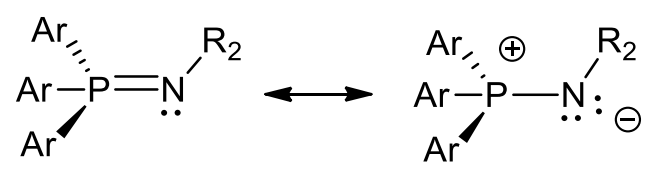

Figure 2.4. Mesomeric structure of phosphinimine ligands

These excellent donor properties of neutral phosphinimine ligand were elucidated by the synthesis of tungsten complexes containing benzene bridged bidentate phosphinimine imine ligands. The low $v_{\mathrm{co}}$ values reported for these ligands are indicative of phosphinimine as a strong $\sigma$-donor and a poor $\pi$-acceptor. ${ }^{48}$ When neutral phosphinimines coordinate to transition metals via nitrogen the steric bulk is slightly removed from the metal center. This confers second coordination sphere environment that contains steric bulk to protect a metal while leaving the first coordination sphere more open. The steric bulk of phosphines can be quantitatively described using Tolman cone angles. The lager the cone angle, the more hindered the steric bulk of the phosphine moiety. Steric hinderance is a limit of Staudinger reaction. However, all of the ligands with $\mathrm{PPh}_{3}\left(145^{\circ}\right)$ worked well in our synthetic method. Tolman cone angle of few phosphines are listed in Table 2.1. ${ }^{50}$

\begin{tabular}{|c|c|}
\hline Phosphine & Tolman angle ( $)$ \\
\hline $\mathrm{PPh}_{3}$ & $145^{\circ}$ \\
\hline $\mathrm{MePPh}_{2}$ & $136^{\circ}$ \\
\hline $\mathrm{Me}_{2} \mathrm{PPh}$ & $122^{\circ}$ \\
\hline $\mathrm{Me}_{3} \mathrm{P}$ & $118^{\circ}$ \\
\hline
\end{tabular}

Table 2.1. Tolman cone angles of phosphines 


\section{B.2. Synthesis of neutral NNO ligand = 2-phosphinimine-5-(methylbenzene- methyl-aminosulfonyl)ethanolate}

The neutral NNO ligand can be prepared with commercially available $p$-toluidine-

2- sulfonic acid. The retrosynthetic plan of NNO ligand synthesis is as shown in scheme 2.1.

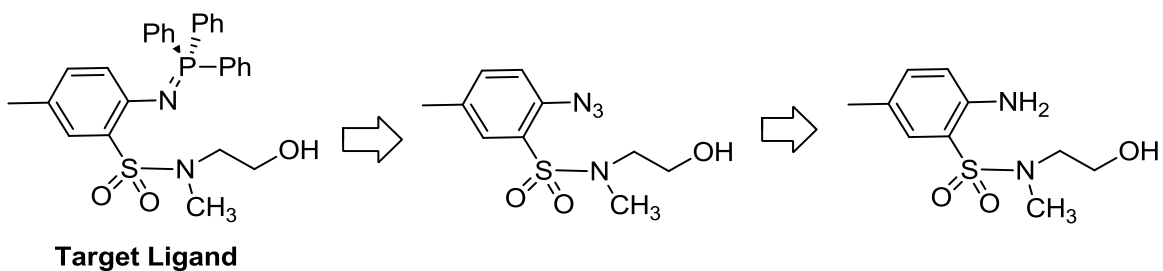

$$
\begin{aligned}
& \Rightarrow \overbrace{\mathrm{NH}_{3}}^{\mathrm{A}_{\mathrm{S}}^{\prime \prime}-\mathrm{O}^{\ominus}} \\
& p \text {-toluidine-2- sulfonic acid } \\
& \text { (Commercially available) }
\end{aligned}
$$

Scheme 2.1. Retrosynthetic plan for synthetic strategies for target ligand

The $-\mathrm{N}=\mathrm{PPh}_{3}$ moiety in the target compound can be obtained from azide precursor reacting with triphenylphosphine via Staudinger reaction. The azide precursor can be obtained from simple azidation reaction of aromatic amine. N-methylaminoethanol moiety can be easily obtained from amidation of sulfonic acid group as shown in scheme 2.1.

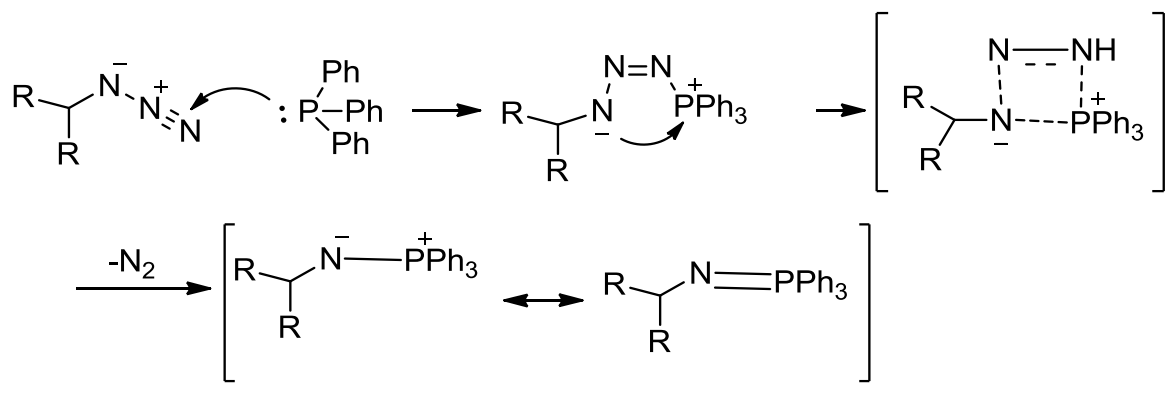

Figure 2.5. Mechanism of Staudinger reaction 
The Staudinger reaction is utilized to incorporate the phosphine moiety for the synthesis of the ligands. We anticipate the steric and electronics of phosphine moiety will provide necessary effect for the ring opening polymerization of lactide. In the Staudinger reaction the phosphine reacts with the azide to generate a phosphazide, which loses $\mathrm{N}_{2}$ to form phosphinimine. Loss of nitrogen is observed with lots of effervescence.

Aqueous work up leads to the amine product. Since our interest is to incorporate phosphinimine motif ligand framework, hydrolysis step is avoided, instead the reaction is done in dry condition to minimize the formation of the side product phosphine oxide. This reaction is easy to handle as the only byproduct is nitrogen gas which is pumped down in schlenk line. The mechanism of the Staudinger is as shown in Figure 2.5.

The synthesis of the ligand started with commercially available $p$-toluidine-2sulfonic acid. $p$-toluidine-2-sulfonic acid $\mathbf{2 . 4}$ was converted to $p$-toluidine-2-sulfonyl chloride $\mathbf{2 . 5}$ by using the synthetic protocol described in the literature. The chlorination reaction in literature reaction protocol is modified in its reaction time and workup to obtained desired product 2.5 with $80 \%$ yield, 4.5 gm scale (Scheme 8$)^{46}$.

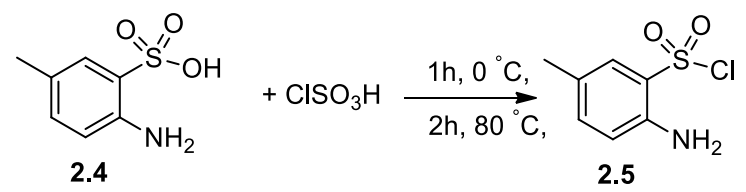

Scheme 2.2. Synthesis of $p$-toluidine-2-sulfonyl chloride $\mathbf{2 . 5}$

Commercially obtained 2-amino-5-methylbenzenesulfonic acid was reacted with neat $\mathrm{ClSO}_{3} \mathrm{H}$ to produce 2-amino-5-methylbenzenesulfonyl chloride $\mathbf{2 . 5} .{ }^{46}$ Sulfonyl chloride 1 was reacted with 1 equivalent of $\mathrm{N}$-methylaminoethanol in the presence of 1.1 equivalent of 1,4-diazabicyclo[2.2.2] octane (DABCO), as proton scavenger in methylene 
chloride solvent at room temperature to yield 2-amino-N-(2-(hydroxy)ethyl)-5methylbenzene sulfonamide $\mathbf{2 . 6}$ in $88 \%$ yield (Scheme 2.3 ). ${ }^{51}$

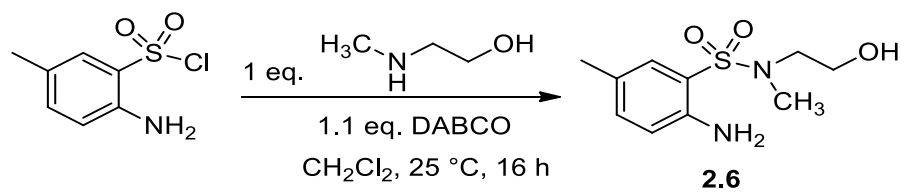

Scheme 2.3. Synthesis of sulfonyl aminoalcohol $\mathbf{2 . 5}$

The amino group in the aromatic ring was converted to azide by azidation reaction. The classical Blackburn's method in which $\mathrm{NaN}_{3}$ solution added into the filtration of the diazonium bisulfate salt $\left(\mathrm{N}_{2}-{ }^{+} \mathrm{HSO}_{4}\right)$ has high risk of forming of highly volatile and toxic hydrazoic acid $\left(\mathrm{HN}_{3}\right) .{ }^{52}$ The unreacted $\mathrm{H}_{2} \mathrm{SO}_{4}$ in the diazonium salt can react with $\mathrm{NaN}_{3}$ since $\mathrm{NaN}_{3}$ solution will be added in the flask with diazonium salt in the classical method. To prevent formation of health hazard hydrozoic acid, after the formation of diazonium salt, $\mathrm{HNO}_{2}$ was quenched with urea and started the azidation reaction in the fresh flask. First, the amine functional group was converted into the diazonium salt using sodium nitrite and acid $\mathrm{HBF}_{4}$ at $0-5{ }^{\circ} \mathrm{C}$. Diazonium salt was treated with thiourea, stirred for 15 minutes and charcoal was treated, stirred for 10 minutes and filtered which was then transferred to fresh flask. In second step, diazonium salt was treated with sodium azide in water at $0{ }^{\circ} \mathrm{C}$ and allowed to warm to $25{ }^{\circ} \mathrm{C}$, stirred altogether for 12 hours. Azide was extracted with diethyl ether (Scheme 2.7). Azide 2.7 is a white solid obtained $5.3 \mathrm{~g}, 88 \%$ yield.

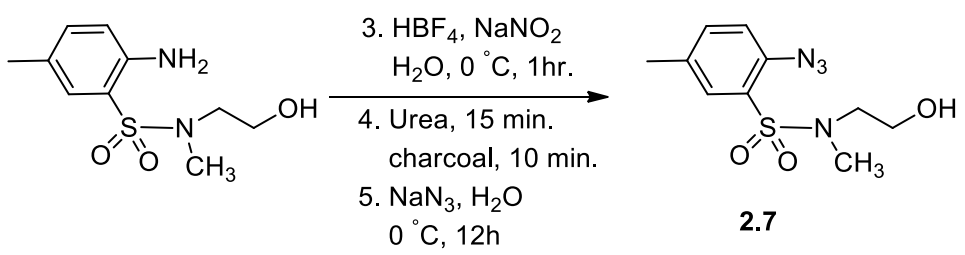

Scheme 2.4. Synthesis of sulfonamide azide $\mathbf{2 . 7}$ 
The triphenylphosphine substituted 2-phosphinimine-5-methylbenzene sulfonamides $\mathbf{2 . 8}$ ligands were synthesized using Staudinger reaction between azides 2.7 and triphenyl phosphines $\left(\mathrm{PPh}_{3}\right)$ (Scheme 2.5). The addition of triphenylphosphine solution in toluene was added to the toluene solution of azides 2.7. Rapid evolution of nitrogen was observed from the clear yellow solution and a white suspension was obtained after $12 \mathrm{~h}$ at $25^{\circ} \mathrm{C}$.

The phosphinimine ligand $\mathbf{2 . 8}$ was isolated as a white solid in $66 \%$ yield by simple filtration in air. Phosphinimine ligand 2.8 was characterized by ${ }^{1} \mathrm{H},{ }^{13} \mathrm{C}$ and ${ }^{31} \mathrm{P}$ $\mathrm{NMR}$ in $\mathrm{CDCl}_{3}$. The resonance of $-\mathrm{OH}$ proton appeared as a broad singlet at $4.41 \mathrm{ppm}$ (Figure 2.3). The two sets of triplet methylene resonance peaks for $-\mathrm{NCH}_{2}$ and -

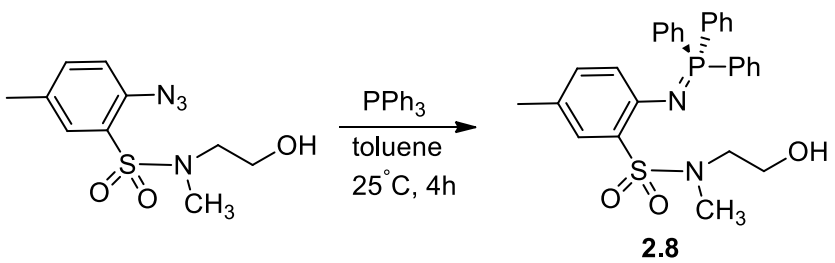

Scheme 2.5. Synthesis of 2-phosphinimine-5-methylbenzene sulfonamides 2.8

$\mathrm{CH}_{2} \mathrm{OH}$ appeared at $3.42 \mathrm{ppm}$ and $3.24 \mathrm{ppm}$ in $\mathrm{CDCl}_{3}$. The methyl group on the nitrogen
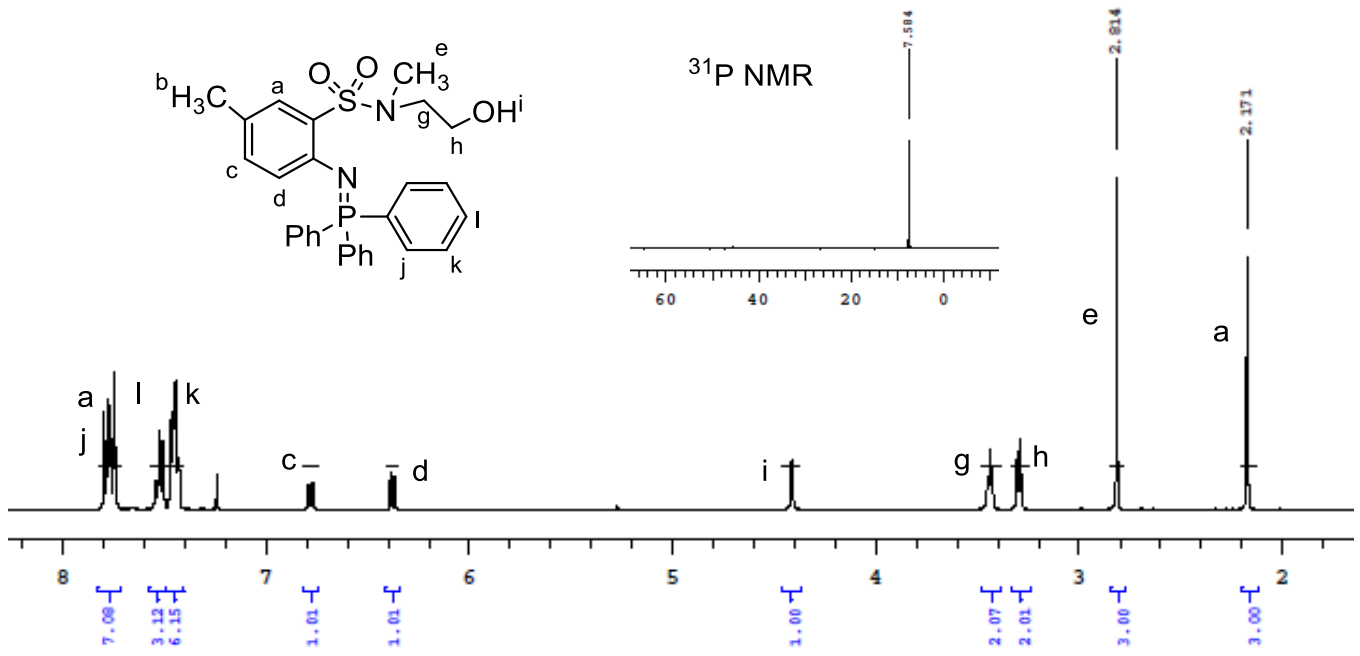

Figure 2.6. ${ }^{1} \mathrm{H}$ NMR and ${ }^{31} \mathrm{P}$ NMR spectrum NNO ligand 2.8 
appeared at $2.80 \mathrm{ppm}$ and the aromatic methyl group appeared at $2.19 \mathrm{ppm}$. The ${ }^{31} \mathrm{P}$ NMR chemical shift of the isolated ligand 2.8 is $7.58 \mathrm{ppm}$ in $\mathrm{CDCl}_{3}$.

Thus observed ${ }^{31} \mathrm{P}$ NMR chemical shift for phosphinimine ligand $(\delta=8.5 \mathrm{ppm})$ is consistent with the values for aryl phosphinimines observed in the literature and not phosphinimiiums $(\delta=35-25 \mathrm{ppm})$ in $\mathrm{CDCl}_{3}{ }^{46,53}$ Staudinger reaction is sensitive to water; presence of water leads to the decomposition of the phosphinimine to corresponding amine and triphenylphosphine oxide. The triphenylphosphine oxide $\left(\mathrm{O}=\mathrm{PPh}_{3}\right)$ appears at ${ }^{31} \mathrm{P} \mathrm{NMR}$ at $28 \mathrm{ppm}$ in $\mathrm{CDCl}_{3}$. The byproduct $\mathrm{O}=\mathrm{PPh}_{3}$ can be washed away with appropriate solvents.

\section{B.3. Synthesis and characterization of neutral NNN ligand $\{N N N\}=2-$ phosphinimine-5-(methylbenzene-methyl-aminosulfonyl) N, N-dimethyl ethanamate}

The neutral NNN ligand can be prepared with commercially available $p$-toluidine2- sulfonic acid. The synthetic route for the synthesis of NNN ligand is similar to NNO ligand as shown in scheme $\mathbf{2 . 6 - 2 . 8}$. The only difference is the amide arm which is incorporated by the reaction of $\mathrm{N}, \mathrm{N}$-dimethylethylenediamine and starting paratoluidine-2-sulfonic acid. The series of (dimethylamino)ethyl-ortho-phosphiniminebenzenesulfonamide ligands 2.11-2.14 were synthesized in good yields by a four-step sequence. Commercially obtained 2-amino-5-methylbenzenesulfonic acid was reacted with neat $\mathrm{ClSO}_{3} \mathrm{H}$ to produce 2-amino-5-methylbenzenesulfonyl chloride $2.5 .{ }^{46}$ Sulfonyl chloride 2.5 was reacted with N,N-dimethylethylenediamine in the presence of 1,4- 
diazabicyclo[2.2.2]octane (DABCO) to yield 2-amino-N-(2-(dimethylamino)ethyl)-5methylbenzene sulfonamide $\mathbf{2 . 9}$ in $91 \%$ yield. ${ }^{51}$

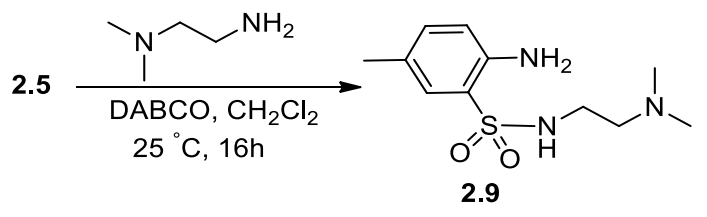

Scheme 2.6. Synthesis of sulfonylamide $\mathbf{2 . 9}$

2-Azido sulfonamide $\mathbf{2 . 1 0}$ was synthesized via diazotization of the corresponding amine 2.9 followed by reaction with sodium azide in water and isolated as red solid in $64 \%$ yield (Scheme 2.7).

Azidation is a two-step process. First, the amine functional group is converted into the diazonium salt using sodium nitrite and acid $\mathrm{HBF}_{4}$ at $0-5{ }^{\circ} \mathrm{C}$, which is then converted to azide by stirring 2 hours with sodium azide in water at $25{ }^{\circ} \mathrm{C}$. Diazonium salt $\left(2.9-\mathrm{N}_{2}-\mathrm{BF}_{4}^{-}\right)$was treated with thiourea, stirred for 15 minutes and charcoal was treated, stirred for 10 minutes and filtered. Then second step azidation reaction was done with sodium azide (Scheme 2.7).

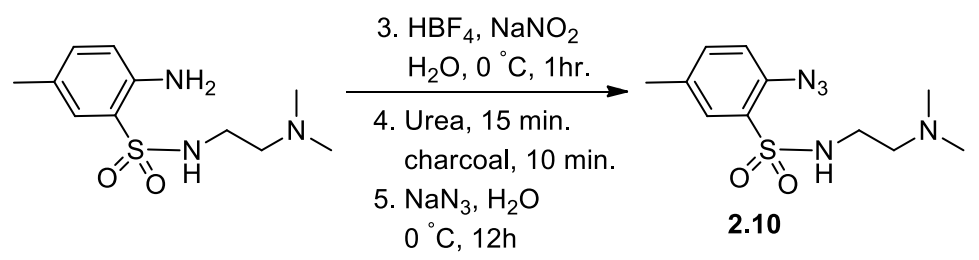

Scheme 2.7. Synthesis sulfonamide azide $\mathbf{2 . 1 0}$

Thus obtained azide is precursor of the Staudinger reaction. The Staudinger reaction converts azide functional group to the phosphinimine functional group. Azide should be free of water $\left(\sim 1.5 \mathrm{ppm}\right.$ in $\left.\mathrm{CDCl}_{3}\right)$ because presence of water decomposes phosphinimine to corresponding phosphine oxide. The reaction of the azide with the 
corresponding phosphines in the suitable organic solvent such as toluene at $25{ }^{\circ} \mathrm{C}$ gives corresponding phosphinimines $\mathbf{( 2 . 1 1 - 2 . 1 4 )}$. When the triphenylphosphine was added to a toluene solution azide $\mathbf{2 . 1 0}$ rapid nitrogen evolution was observed and a white suspension was obtained after only a few hours. The phosphinimine product $\mathbf{2 . 1 1}$ was isolated as a white solid in $87 \%$ yield by simple filtration in the air and rinsed with diethyl ether to remove any excess $\mathrm{PPh}_{3}$. Phosphinimine 2.11 was characterized by ${ }^{1} \mathrm{H},{ }^{13} \mathrm{C}$, and ${ }^{31} \mathrm{P}$ NMR in $\mathrm{CDCl}_{3}$. The remaining triphenyl phosphine and trace of byproduct i.e.; phosphine oxide can be washed away by appropriate solvents.
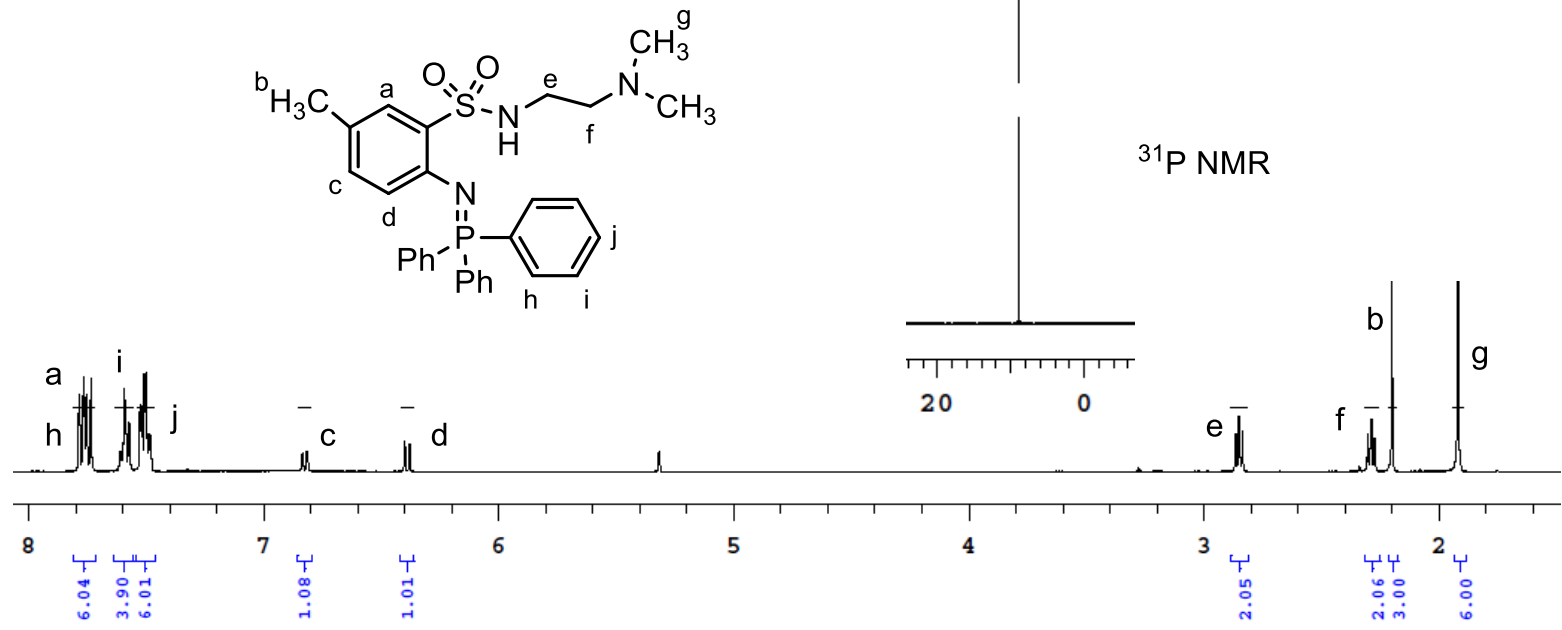

Figure 2.7. ${ }^{1} \mathrm{H}$ NMR and ${ }^{31} \mathrm{P}$ NMR spectrum NNN ligand $\mathbf{2 . 1 1}$

The ${ }^{31} \mathrm{P}$ NMR spectroscopy shows single sharp singlet at $8.92 \mathrm{ppm}$ in $\mathrm{CD}_{2} \mathrm{Cl}_{2}$ (Figure 2.4) which is comparable with NNO ligand 2.8 which is observed at $7.56 \mathrm{ppm}$ in $\mathrm{CDCl}_{3}$. The triplet $-\mathrm{NH}$ proton resonance observed at $6.96 \mathrm{ppm}(J=6 \mathrm{~Hz})$ in $\mathrm{CD}_{2} \mathrm{Cl}_{2}$. The two sets of triplet methylene resonance peaks represent $-\mathrm{CH}_{2} \mathrm{~N}\left(\mathrm{CH}_{3}\right)_{2}$ and $\mathrm{CH}_{2} \mathrm{CH}_{2} \mathrm{~N}\left(\mathrm{CH}_{3}\right)_{2}$ at $2.58 \mathrm{ppm}$ and $2.30 \mathrm{ppm}$ in $\mathrm{CD}_{2} \mathrm{Cl}_{2}$, respectively. The methyl group 
in the aromatic ring and the two methyl groups attached to $\mathrm{N}$ i.e.; $-\mathrm{N}\left(\mathrm{CH}_{3}\right)_{2}$ appeared as singlets at $2.20 \mathrm{ppm}$ and $1.90 \mathrm{ppm}$ in $\mathrm{CD}_{2} \mathrm{Cl}_{2}$ (Figure 2.4).

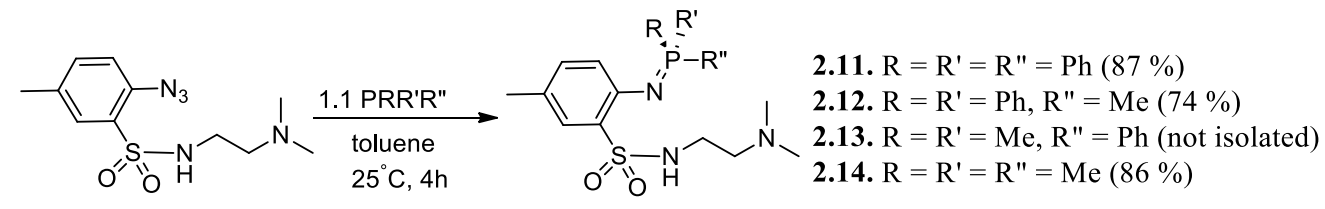

Scheme 2.8. Synthesis of NNN phosphinimine ligands 2.11-2.14

Phosphinimine Ligand 2.12 was obtained by the reaction of azide $\mathbf{2 . 1 0}$ solution in toluene and $\mathrm{PPh}_{2} \mathrm{Me}$ (liquid). When the methyldiphenylphosphine was added to a toluene solution of azide $\mathbf{2 . 1 0}$ rapid nitrogen evolution was observed. The ligand $\mathbf{2 . 1 2}$ was isolated as an off-white solid in $74 \%$ yield by simple filtration in the air and rinsed with diethyl ether to remove any unreacted $\mathrm{PMePh}_{2}$. Off white solid phosphinimine ligand 2.12 was fully characterized on the basis of ${ }^{1} \mathrm{H},{ }^{13} \mathrm{C}$ and ${ }^{31} \mathrm{P}$ NMR spectroscopy in $\mathrm{CD}_{2} \mathrm{Cl}_{2}$. The ${ }^{31} \mathrm{P} \mathrm{NMR}$ spectroscopy shows single sharp singlet at $8.4 \mathrm{ppm}$ in $\mathrm{CD}_{2} \mathrm{Cl}_{2}$ (entry, 2.12, Figure 2.8) which is comparable with ligand $\mathbf{2 . 1 1}$ which is observed at 8.92 ppm in $\mathrm{CDCl}_{3}$. The broad peak of -NH proton resonance observed at $7.1 \mathrm{ppm}$ in $\mathrm{CD}_{2} \mathrm{Cl}_{2}$. The ${ }^{1} \mathrm{H}$ NMR signal of the 9 proton resonance of the three methyl group attached to the phosphorus is appeared as doublet at $1.69 \mathrm{ppm}(J=13.2 \mathrm{~Hz})$ in $\mathrm{CD}_{2} \mathrm{Cl}_{2}$ due to the coupling with phosphorus nuclei.

Phosphinimine Ligand 2.13 synthesis started mixing azide solutions in toluene and $\mathrm{PPhMe}_{2}$ and stirred. When the dimethylphenylphosphine was added to a toluene solution of azide 2.10, rapid nitrogen evolution was observed. Aliquot of the reaction mixture was pumped down in $\mathrm{J}-\mathrm{Y}$ tube and $\mathrm{CD}_{2} \mathrm{Cl}_{2}$ was added via schlenk line. The ${ }^{31} \mathrm{P}$ NMR clearly shows the presence of product resonance at $32 \mathrm{ppm}$ and $6 \%$ phosphine 
oxide peak was observed. The ligand $\mathbf{2 . 1 3}$ was obtained as a brown glue after evaporation of solvent.

Addition of diethyl ether turns it into yellowish brown glue. The attempt of protonating glue 2.13 with $[\mathrm{HPy}]\left[\mathrm{BF}_{4}\right]$ shows protonated species in the $\mathrm{H}$ NMR. Brownish powder of Protonated phosphinimine ligand $\mathbf{2 . 1 3}$ was isolated using toluene and ether solvent mixture. The Brownish powder contains the mixture of protonated ligand (50\%), starting amine and phosphine oxide. Hence, clean product of $\mathbf{2 . 1 3}$ was not isolated.

Ligand 2.14 was obtained by the reaction of azide 2.10 and $\mathrm{PMe}_{3}$ with the same reaction protocol. When the trimethyl phosphine was added to a toluene solution of azide 2.10, rapid nitrogen evolution was observed. The ligand $\mathbf{2 . 1 4}$ was isolated as an off-white solid in $86 \%$ yield by simple filtration in the air and rinsed with diethyl ether to remove any unreacted $\mathrm{PMe}_{3}$. Ligand $\mathbf{2 . 1 4}$ was fully characterized on the basis of ${ }^{1} \mathrm{H},{ }^{13} \mathrm{C}$ and ${ }^{31} \mathrm{P}$ NMR spectroscopy in $\mathrm{CD}_{2} \mathrm{Cl}_{2}$. The ${ }^{31} \mathrm{P}$ NMR spectroscopy shows single sharp singlet at $12.31 \mathrm{ppm}$ in $\mathrm{CD}_{2} \mathrm{Cl}_{2}$ (entry 2.14, Figure 2.7) which is comparable with ligand $\mathbf{2 . 1 1}$ which is observed at $8.92 \mathrm{ppm}$ in $\mathrm{CDCl}_{3}$. The broad peak of $-\mathrm{NH}$ proton resonance observed at $7.1 \mathrm{ppm}$ in $\mathrm{CD}_{2} \mathrm{Cl}_{2}$. The ${ }^{1} \mathrm{H}$ NMR signal of the three methyl group attached to the phosphorus is splitted due to coupling with phosphorus nuclei appeared as doublet at $1.69 \mathrm{ppm}(J=13.2 \mathrm{~Hz})$ in $\mathrm{CD}_{2} \mathrm{Cl}_{2}$. 


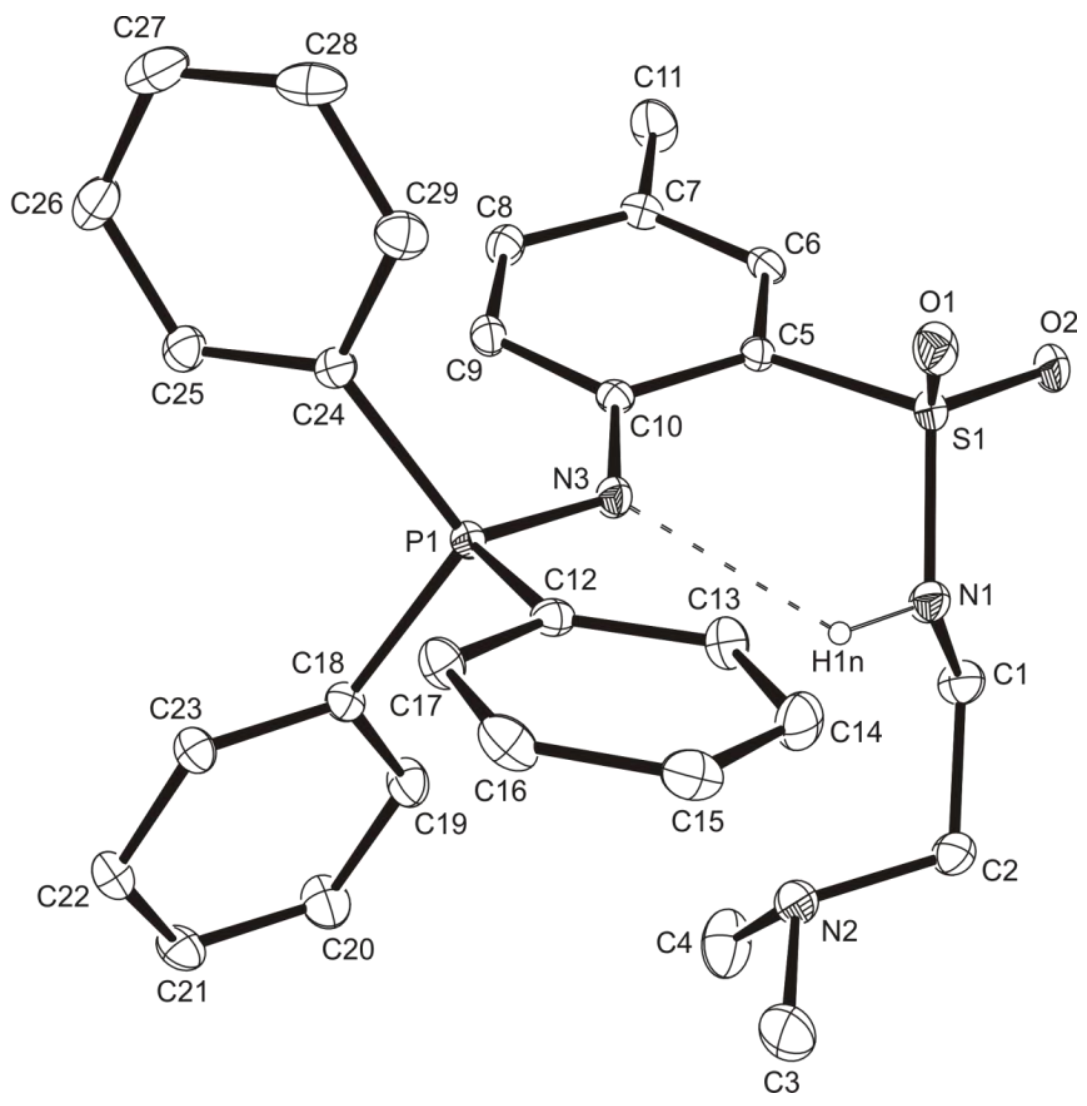

Figure 2.8. ORTEP- $3^{54}$ diagram of $\mathbf{2 . 1 1}$ showing $50 \%$ ellipsoids. H atoms are omitted for clarity.

To confirm the structure of phosphinimine ligand 2.11, a crystal suitable for X-ray crystallography was obtained by slow diffusion of hexanes into a $\mathrm{CH}_{2} \mathrm{Cl}_{2}$ solution of $\mathbf{2 . 1 1}$ at $25{ }^{\circ} \mathrm{C}$. An ORTEP diagram of the corresponding structure is shown in Figure 2.8 and selected bond lengths and angles are listed in Table 2.2.

The structure of $\mathbf{2 . 1 1}$ shows the presence of the exocyclic phosphinimine as well as the sulfonamide -NH- groups. The $\mathrm{P}(1)-\mathrm{N}(3)$ bond distance $[1.5786(13) \AA]$ suggests a high degree of double bond character much like the P-N double bond found in the free phosphinimines $\mathrm{Ph}_{3} \mathrm{P}=\mathrm{NPh}[1.603(3) \AA]$ and 4-(2,6-i $\left.\left.\mathrm{Pr}_{2} \mathrm{C}_{6} \mathrm{H}_{3}\right) \mathrm{NPPh}_{2}\right) \mathrm{C}_{12} \mathrm{H}_{7} \mathrm{O}$ [1.559(2) $\AA]$. 


\begin{tabular}{|l|c|}
\hline & $\mathbf{2 . 8}$ \\
\hline $\mathrm{P}(1)-\mathrm{N}(3)$ & $1.5786(13)$ \\
\hline $\mathrm{C} 10(1)-\mathrm{N}(3)$ & $1.3815(19)$ \\
\hline $\mathrm{C}(5)-\mathrm{S}(1)$ & $1.7586(15)$ \\
\hline $\mathrm{S}(1)-\mathrm{N}(1)$ & $1.6337(14)$ \\
\hline $\mathrm{S}(1)-\mathrm{O}(1)$ & $1.4316(12)$ \\
\hline $\mathrm{S}(1)-\mathrm{O}(2)$ & $1.4366(11)$ \\
\hline $\mathrm{C}(9)-\mathrm{C}(10)-\mathrm{N}(3)-\mathrm{P}(1)$ & $14.1(2)$ \\
\hline
\end{tabular}

Table 2.2. Selected bong lengths $(\AA)$ and angles for compound $\mathbf{2 . 8}$

The $\mathrm{P}(1)-\mathrm{N}(3)$ bond distance in $\mathbf{2 . 1 1}$ is significantly shorter than that found in the protonated phosphinimines $\quad\left[\mathrm{Ph}_{3} \mathrm{PN}(\mathrm{H}) \mathrm{Ph}\right]\left[\mathrm{Cl}_{2} \mathrm{Pd}_{\left(\mathrm{C}_{8} \mathrm{H}_{11}\right)}\right] \quad[1.624(3) \quad \AA] \quad$ and $\left[\mathrm{Ph}_{3} \mathrm{PN}(\mathrm{H}) \mathrm{Ph}\right]\left[\mathrm{BF}_{4}\right][1.635(4) \AA]$ which both display a high degree of P-N single bond character. In addition, the triphenylphosphine group on the nitrogen atom of the phosphinimine is situated below the arene ring plane of the 5-methylbenzenesulfonamide fragment with a $\mathrm{C}(9)-\mathrm{C}(10)-\mathrm{N}(3)-\mathrm{P}(1)$ torsion angle of $14.1(2)^{\circ}$.

\section{B.4. Bidentate ligand library}

We have synthesized a series of N,N bidentate phosphinimine arenesulfonamide ligands 3.5-3.7 in moderate yield with $2.5 \mathrm{~g}$ scale. These ligands were synthesized in a four step reaction sequence with the commercially available starting material $p$-toluidine-2sulfonic acid 2.4 These phosphiminimines ligands were characterized by ${ }^{1} \mathrm{H},{ }^{13} \mathrm{C}$, and Phosphiminimine compound 2.8 was characterized by ${ }^{1} \mathrm{H},{ }^{13} \mathrm{C}$ and ${ }^{31} \mathrm{P}$ NMR in $\mathrm{CDCl}_{3}$. The single peak in the ${ }^{31} \mathrm{P}$ NMR shows the single component in the product in $\mathrm{CDCl}_{3}$. 
Phosphinimine 3.7 was protonated using $\left[\mathrm{HPy}_{3} \mathrm{BF}_{4}\right]$ and protonated phosphinimine tetrafluoroborate salt was islated as stable compound. These compounds are potential candidates for metal complex syntheses. These N,N bidentate phosphinimine arenesulfonamide ligands and their corresponding metal complexes are anticipated to show different properties and activity compared to tridentate metal complexes. Phosphinimine arene sulfonamide ligands $\mathbf{2 . 1 6}$ and $\mathbf{2 . 1 8}$ were also characterized by X-ray structures.

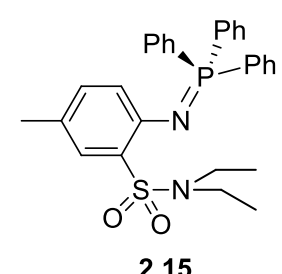

$65 \%, 2.35 \mathrm{~g}$

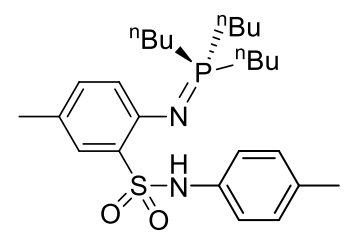

2.18

$65 \%, 2.35 \mathrm{~g}$

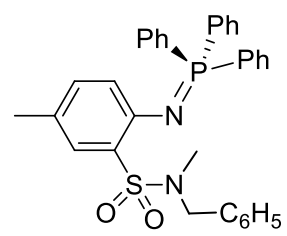

2.16

$58 \%, 2.2 \mathrm{~g}$

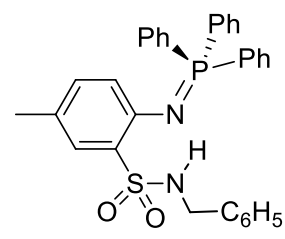

2.19

$63 \%, 2.6 \mathrm{~g}$

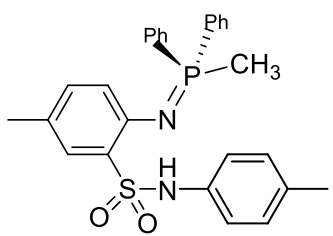

2.17

$73 \%, 1.7 \mathrm{~g}$

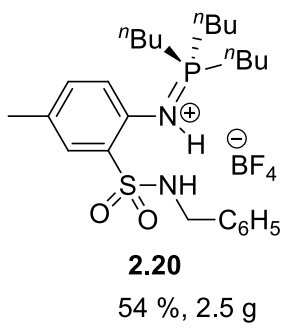

Figure 2.9. Phosphinimine arene sulfonamide ligands

\section{B.4. Conclusion}

The series of tridentate dimethylaminoethyl-ortho-phosphiniminebenzene sulfonamide ligands were synthesized in good yield by a three step reaction sequence. Phosphinimes are stronger donors than phosphines due to potential delocalization of the $\mathrm{P}=\mathrm{N}$ double bond. The modular nature of phosphinimine synthesis allows for the creation of a diverse ligand library where steric and electronic properties can be manipulated with ease. ${ }^{46}$ The steric properties of phosphinimine are quantified by Tolman 
angle $\left(\theta^{\circ}\right)$. The triphenylphospine has cone angle of $145^{\circ}$ and the trimethylphosphine has cone angle of $118^{\circ}$. The proper steric and electronic around the metal center controls rate of reaction, tacticity and molecular weight polymer chain obtained by ring opening polymerization of lactide. ${ }^{28}$ The tridentate phosphinimine ligands $2.8,3.1,3.2$ to 3.4 are synthesized by 3 step reaction protocol. All of these phosphinimine ligands are characterized by ${ }^{1} \mathrm{H}$ NMR, ${ }^{13} \mathrm{C}$ NMR, and ${ }^{31} \mathrm{P}$ NMR in $\mathrm{CD}_{2} \mathrm{Cl}_{2}$ at $25{ }^{\circ} \mathrm{C}$. Phosphinimine ligand 2.8 has $\mathrm{N}, \mathrm{N}, \mathrm{O}$ atoms to coordinate to the metal center, and other three phosphinimines 3.1, 3.2 and 3.4 have $\mathrm{N}, \mathrm{N}, \mathrm{N}$ coordinating atoms. We have also synthesized a series of N,N bidentate phosphinimine arenesulfonamide ligands starting from commercially available $p$-toluidine-2-sulfonic acid $\mathbf{2 . 4}$ (Figure 2.9). These N,N bidentate phosphinimine arenesulfonamide ligands and their corresponding metal complexes are anticipated to show different properties and activity compared to tridentate metal complexes. 


\section{CHAPTER 3}

\section{SYNTHESIS AND REACTIVITY OF LZnEt COMPLEXES}

3. A. Synthesis and Reactivity of LZnEt Complexes

3. A. 1. Introduction

3. A. 2. Synthesis and characterization of [NNO]ZnEt complex

3. A. 3. Synthesis and of characterization $[\mathrm{NNN}] Z n E t$ complex

3. A. 4. Reactivity of $[\mathrm{NNO}] \mathrm{ZnEt}$ with alcohols

3. A. 5. Reactivity of $[\mathrm{NNN}] \mathrm{ZnEt}$ with alcohols

3. A. 6. Reactivity with lactide

3. A. 7. X-ray crystallography

3. A. 8. Conclusion 


\section{A.1. Introduction}

Single-site homogeneous catalysts are usually represented as $L_{n} M R, L_{n}$ is ancillary ligand that can be modified according to the need bound to the catalytically active metal center (M), and a possible initiating group or polymer chain-end (R). The advantages of the homogeneous catalysts are that they allow for the modifications of ligand electronics and sterics, labile metal centers and initiating groups that help control microstructure of polymer as well as possible to study catalysis. The ring opening polymerization (ROP) of cyclic esters such as lactide and caprolactone is an efficient way to produce a biodegradable and recyclable polymeric material. The ROP is initiated by metal complexes, organic compounds, or enzymes, with/without alcohol, to yield high molecular weight PLA in excellent conversion and purity. Metal complexes are desirable because they give rise to controlled polymerization and well defined high molecular weight $\left(\mathrm{M}_{\mathrm{n}}\right)$, narrow polymerdispersity index (PDI). The commonly used initiators are metal alkoxide or amide coordination compounds. ${ }^{4}$ These compounds are useful due to their tolerance, selectivity, rate and minimal side reactions. ${ }^{5}$

Development of new single site catalyst for the ring opening polymerization of cyclic esters such as lactide is growing rapidly. A number of single site homogenous catalyst systems with many of these features have been reported..$^{13}$ The important features required for lactide polymerization catalysts are high activity, ability to controllably produce high molecular weight, low polydispersity polymer and stereochemical control. Beside these features, low toxicity, low cost, minimal color and odor are also desirable features. $^{13}$ 
Stereochemistry is one of the most important factors determining the physical properties of a polymeric material. Due to their stereoregularity, isotactic and syndiotactic polymers are typically crystalline, an important feature for many applications. Design and application of single site catalysis is one of the most promising methodologies for the synthesis of stereoregular polymer. ${ }^{20}$ Zinc based catalysts have been extensively employed and among the highly active metal-based catalysts used to date for the controlled polymerization of lactide. ${ }^{5}$

The series of phosphinimine NNN ligands and NNO ligand were synthesized in moderate to high yields (Chapter 2). The various substituents in the phosphinimine phosphorus provide easy manipulation of steric and electronic in the phosphinimine arene-sulfonamide ligands and metal complex. The Tolman cone angle provides the steric measurement of the steric around the phosphinimine ligand. The Tolman cone angle of $\mathrm{PPh}_{3}, \mathrm{PPh}_{2} \mathrm{Me}, \mathrm{PMe}_{3}$ are $145^{\circ}, 165^{\circ}$ and $118^{\circ}$ respectively. The steric and electronic around the metal center is very important for catalysis towards the ring opening polymerization of lactide that controls rate of polymerization, high molecular weight polymer chain, and stereoseleletivity. ${ }^{4}$

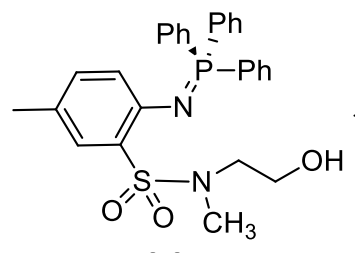

2.8

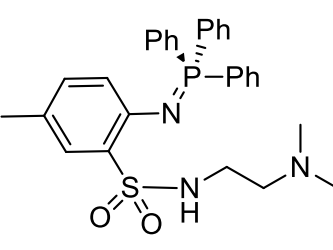

2.11

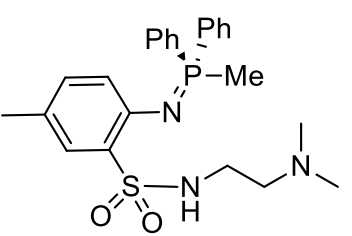

2.12

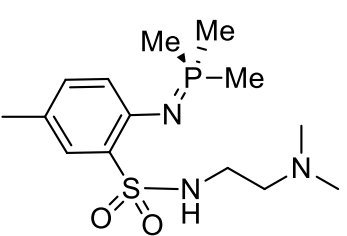

2.14

Figure 3.1. Series of synthesized tridentate ligands 


\section{A.2. Synthesis of NNOZnEt complexes $\{\mathrm{NNO}=2$-phosphinimine-5- (methylbenzene-methylaminosulfonyl)ethanolate\}}

Diethyl zinc solution in toluene was added to the solution of ligand $\mathbf{2 . 8}$ in toluene at $-35{ }^{\circ} \mathrm{C}$ and allowed to warm to room temperature. ${ }^{21 b}$ The mixture was further stirred for 12 hours at room temperature to obtained, well-defined NNO ligated zinc ethyl complex 3.5 via protonation of one ethyl group in diethyl zinc to give ethane and the neutral zinc complex 3.5 with $80 \%$ yield, $0.4 \mathrm{~g}$ scale (Scheme 3.5).

Compound 3.5 was fully characterized by interpretation of ${ }^{1} \mathrm{H},{ }^{13} \mathrm{C}$ and ${ }^{31} \mathrm{P}$ NMR spectra and multi-dimensional spectra. The incorporation of ethyl group with zinc in the complex is depicted by the downfield shift of $-\mathrm{CH}_{2}$ (quartet) and $-\mathrm{CH}_{3}$ (triplet) groups of diethyl zinc from $0.02 \mathrm{ppm}$ and $1.05 \mathrm{ppm}$ to $0.25 \mathrm{ppm}$ and $1.10 \mathrm{ppm}$ in neutral zinc complex.

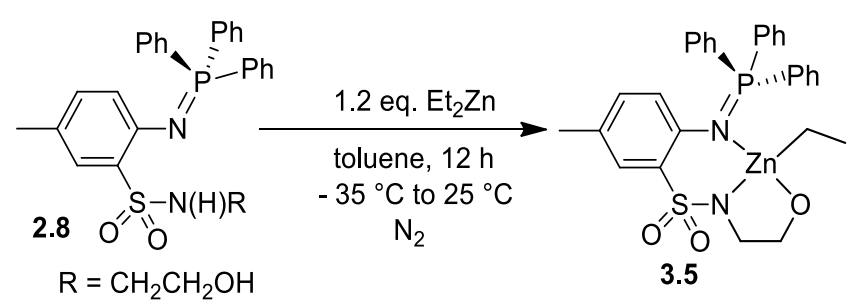

Scheme 3.1. Synthesis of zinc ethyl complex $\mathbf{3 . 5}$

The single ${ }^{31} \mathrm{P}$ NMR peak shift upfield as ligand show up at $7.56 \mathrm{ppm}$ and the diethylzinc complex 3.5 appeared at $3.06 \mathrm{ppm}$. The ${ }^{31} \mathrm{P}$ NMR chemical shift shows single peak for discrete zinc ethyl complex 3.5. The two dimensional NMR spectroscopy (NOESY) of complex 3.5 indicates that the sulfonamide methyl group and the zinc ethyl group are oriented in the same direction while the phosphinimine triphenylphosphine 
substituent is pointed away from the zinc center and on the opposite side compared to the sulfonamide methyl group. We are not able to grow crystals of complex $\mathbf{3 . 5}$ for $\mathrm{x}$-ray crystallography to establish its solid state structure.

\section{A.3. Synthesis of neutral NNNZnEt complexes; $\{N N N=2$-phosphinimine-5- (methylbenzenemethylaminosulfonyl)ethanamate\}}

(NNN)ZnEt Complex 3.7 is synthesized. NNN ligated zinc ethyl complex synthesized via protonation of one ethyl group in diethylzinc to give ethane and the neutral zinc complex 3.7 with $92 \%$ yield, $1 \mathrm{~g}$ scale (Scheme 3.2).

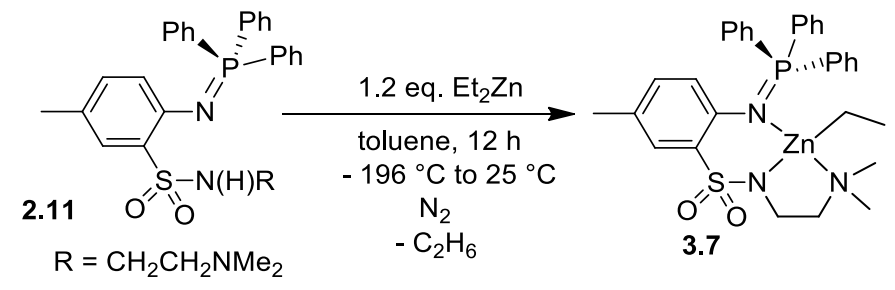

Scheme 3.2. Synthesis of zinc ethyl complex 3.7

The incorporation of ethyl group with zinc in the complex is depicted by the downfield shift of $-\mathrm{CH}_{2}$ (quartet) and $-\mathrm{CH}_{3}$ (triplet) groups of diethyl zinc from $0.02 \mathrm{ppm}$ and $1.05 \mathrm{ppm}$ to $-0.88 \mathrm{ppm}$ and $0.69 \mathrm{ppm}$ in neutral zinc complex.. The single ${ }^{31} \mathrm{P}$ NMR peak at $26.43 \mathrm{ppm}$ (ligand appear at $8.8 \mathrm{ppm}$ ) in $\mathrm{CD}_{2} \mathrm{Cl}_{2}$ is indicative of tight phosphinimine binding to the zinc center. The broad peak at 2 ppm that accounts for 8 proton resonance in ${ }^{1} \mathrm{H}$ NMR is indicative of the fluxional behavior of the dimethylamino arm of the complex 3.7 (Figure 3.2). 


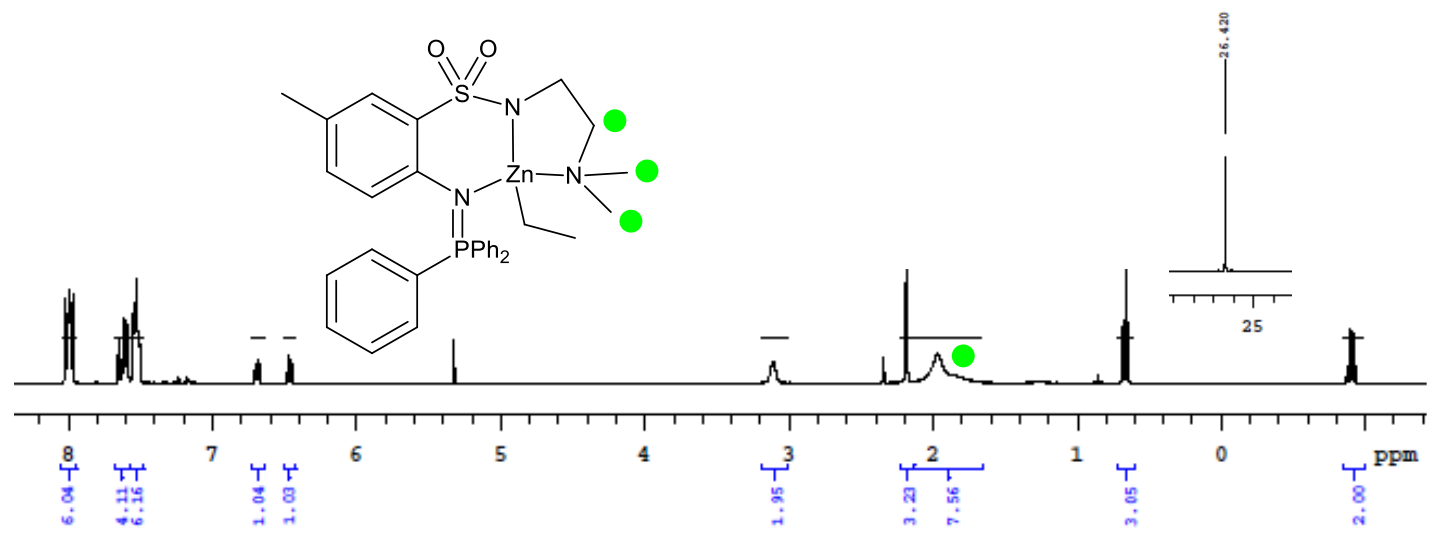

Figure 3.2. ${ }^{1} \mathrm{H}$ NMR of the complex 3.7 showing fluxional behavior

Fluxional behavior of two methyl groups attached with nitrogen and the adjacent methylene group observed at $25{ }^{\circ} \mathrm{C}{ }^{1} \mathrm{H}$ NMR. The dynamic behavior of these nuclei concerned are exchanging at a rate faster than the NMR timescale. We slow down the exchange by cooling the sample up to $-60^{\circ} \mathrm{C}$.

Variable Temperature ${ }^{1} \mathrm{H}$ NMR has been studied for complex 3.7 using an temperature arrays, $45,35,25,20,15,0,10,-10,-20,-30,-40,-50,-60,-70,-80,{ }^{\circ} \mathrm{C}$. The low temperature ${ }^{1} \mathrm{H}$ NMR spectrum shows that coalescence occurs at $-60{ }^{\circ} \mathrm{C} .{ }^{1} \mathrm{H}$ NMR at $-60{ }^{\circ} \mathrm{C}$ separated the two methyl groups attached with nitrogen and the adjacent methylene group peaks to see the static spectrum in which peaks are clear and distinct. The two methylene protons attached to zinc become distinct diastereotopic at $-60{ }^{\circ} \mathrm{C}$. The two methyl groups attached to the nitrogen are inequivalent showing two separate peaks at $-60^{\circ} \mathrm{C}$ but broad signal is observed at $25{ }^{\circ} \mathrm{C}$, which sharpens to single peak at $45{ }^{\circ} \mathrm{C}$ (blue region Figure). The two methylene protons attached to zinc show clear triplet at 25 ${ }^{\circ} \mathrm{C}$ which turn into two clear diastereotopic proton peaks at $-60{ }^{\circ} \mathrm{C}$ (red region Figure). 


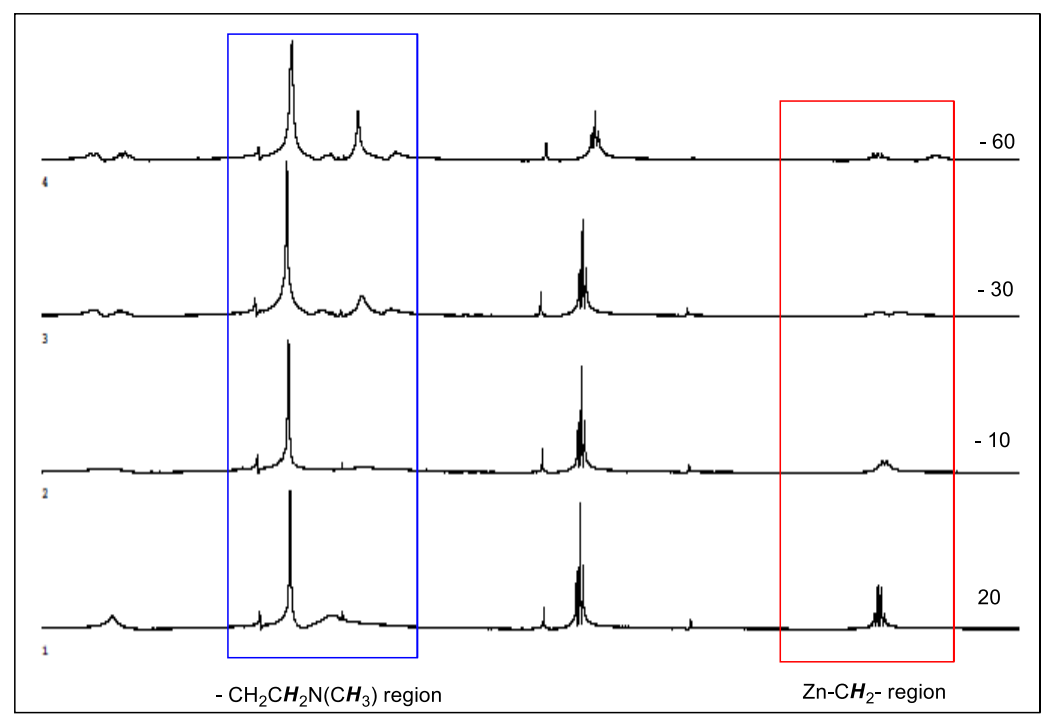

Figure 3.3. ${ }^{1} \mathrm{H}$ NMR spectrum of 3.7 in $\mathrm{CD}_{2} \mathrm{Cl}_{2}$ with variable temperature

This variable temperature ${ }^{1} \mathrm{H}$ NMR experiment observation and the fluxional behavior of two methyl groups attached with nitrogen at $25{ }^{\circ} \mathrm{C}$ indicative of the $\mathrm{Zn}$ $\mathrm{N}\left(\mathrm{CH}_{3}\right)_{2}$ bond of (NNN)ZnEt Complex 3.7 coming on and off at $25^{\circ} \mathrm{C}$ (Scheme 3.3). In other words, the (NNN)ZnEt 3.7 has hemi-labile diethyl amine arm as shown in scheme 3.3 .

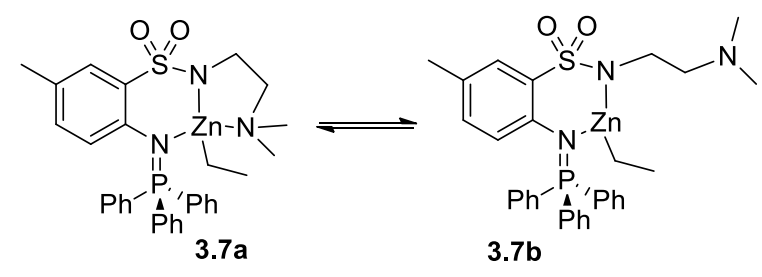

Scheme 3.3. Labile dimethylamine arm of (NNN)ZnEt complex 3.7

\section{A.4. Reactivity of (NNO)ZnEt complex with alcohols}

The most common initiators for ROP are metal alkoxide or amide coordination compounds. The metal alkoxide in some cases is formed in situ by reaction of metal precursor complex with the appropriate alcohol-referred to as an initiating system. The ROP is initiated by metal complexes with alcohol generating metal alkoxide in situ or 
discrete metal alkoxide complexes, to yield high molecular weight PLA in excellent conversion and purity. We ran test reactions of neutral ethyl zinc complex with alcohols in small scale in the J. Young tube to study its reactivity with various alcohols.

\section{(i) With $p$-cyanophenol}

The reaction of the neutral (NNO)ZnEt complex 3.7 with $p$-cyanophenol ( $p$ ka ca. 9) was carried in J-Young tube under moisture and air free condition. Reaction with $p$ cyanophenol showed that $38 \%$ decomposition to the ligand based on ${ }^{31} \mathrm{P}(\delta=7.56 \mathrm{ppm}$ in $\mathrm{CD}_{2} \mathrm{Cl}_{2}$ ) and shows multiple peaks at $\delta=28.8 \mathrm{ppm}$ in 10 minutes. Both unreacted starting materials were observed in the ${ }^{1} \mathrm{H}$ NMR. Aromatic region of ${ }^{1} \mathrm{H}$ NMR is broadened and not interpretable. (NNO)ZnEt complex is not stable with $p$-cyanophenol. (NNO)ZnEt complex (5 mol. \%) does not show any catalytic activity towards ring opening polymerization of $\mathrm{rac}$-lactide.

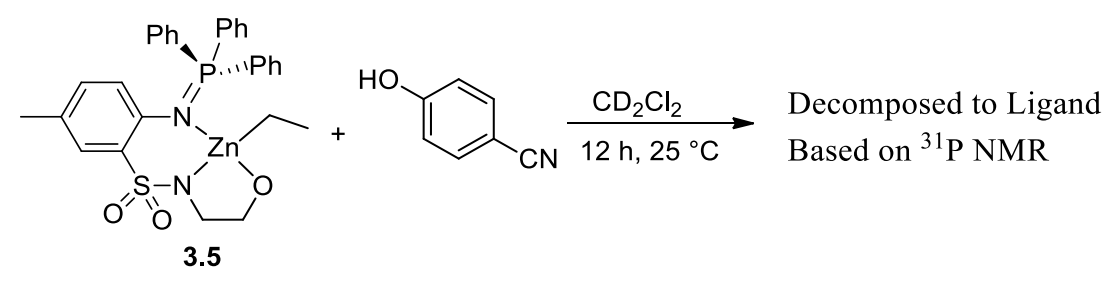

Scheme 3.4. Reaction between (NNO)ZnEt complex and $p$-cyanophenol

\section{(ii) With 9-anthrymethanol}

The reaction of the neutral (NNO)ZnEt complex 3.7 with 9-anthrylmethanol ( $p \mathrm{ka}$ $=15)$ showed that $76 \%$ of the complex decomposed to the ligand based on ${ }^{31} \mathrm{P}(\delta=7.56$ ppm) and shows multiple peaks at $\delta=28.8$ in $\mathrm{CD}_{2} \mathrm{Cl}_{2}$ ppm at $25^{\circ} \mathrm{C}$. 


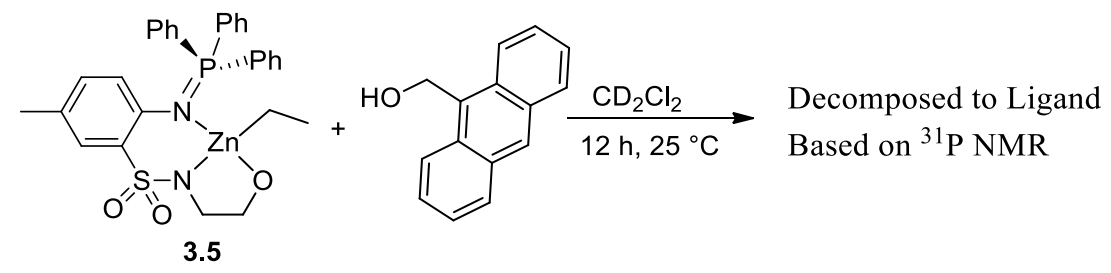

Scheme 3.5. Reaction between (NNO)ZnEt complex and 9-anthrylmethanol

Complete decomposition of the (NNO)ZnEt complex was observed after 32 hours. No further change was observed after two weeks at $25{ }^{\circ} \mathrm{C}$. (NNO)ZnEt complex ( $\left.5 \mathrm{~mol} \%\right)$ does not show any catalytic activity towards ring opening polymerization of dl-lactide.

\section{A.5. Reaction of with (NNN)ZnEt complex with alcohols:}

\section{(i) With Anthrylmethanol \& Anthrylethanol}

(NNN)ZnEt complex with anthrylmethanol does not show any reaction. With anthrylethanol, small amount of ligand present in solution (8\%) and unreacted starting material 3.7 (92\%) after 24 hours was determined by ${ }^{31} \mathrm{P}$ NMR spectroscopy (Scheme 3).

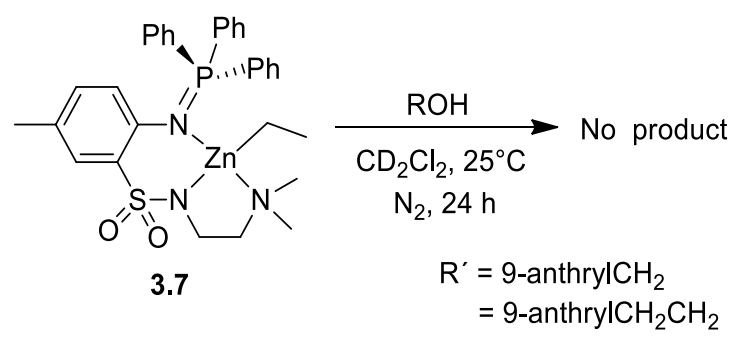

Scheme 3.6. Reaction of (NNN)ZnEt complex and anthyrl alcohol

\section{(ii) With Ethanol}

Reaction of 3.7 with 1.5 equivalents of ethanol in $\mathrm{CD}_{2} \mathrm{Cl}_{2}$ at $25{ }^{\circ} \mathrm{C}$ was also very slow and after 24 hours the solution contained unreacted starting material $3.7(87 \%)$ as well as decomposed ligand (13\%) as shown in Scheme 3.7. 


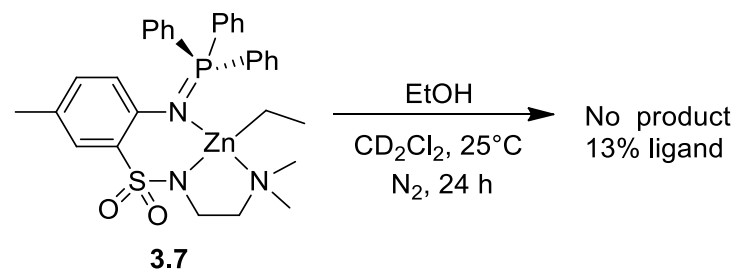

Scheme 3.7. Reaction of (NNN)ZnEt complex and ethanol

Tolman and coworkers demonstrated that the (diaminophenoxy)ZnEt 3.8 complex reacted with ethanol at $25^{\circ} \mathrm{C}$ to form (diaminophenoxy)ZnOEt 3.9 in 24 hours. The zinc ethoxide product could be isolated as a dimer in good yield. ${ }^{21 \mathrm{~b}}$ The inertness of the zinc ethyl bond in $\mathbf{3 . 7}$ towards protonation with these three alcohols can't simply be attributed to the steric bulk of the triphenylphosphinimine group inhibiting the protonolysis reaction.

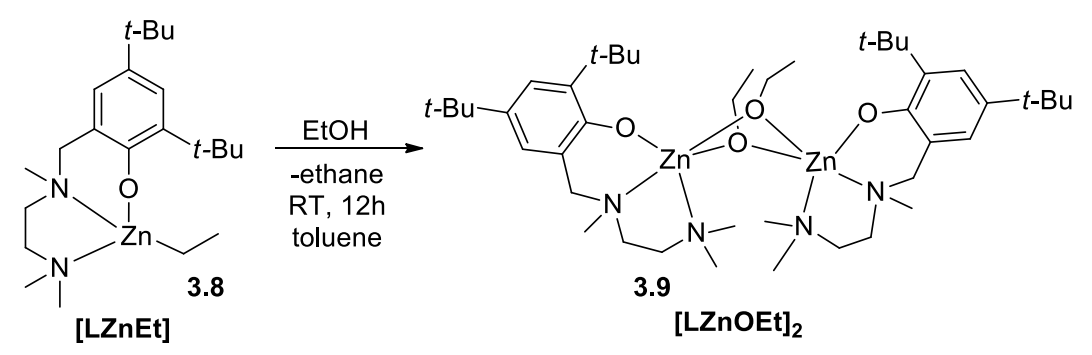

Scheme 3.8. Synthesis of Tolman catalyst $[\mathrm{LZnOEt}]_{2} \mathbf{3 . 9}$

It would be expected that ethanol, being smaller than either 9-anthrylalcohol, would show greater reactivity that was observed. It is clear that the acidity of the alcohol plays an important role in the observed reactivity with zinc ethyl complex 3.7. Alkyl alcohols have high $\mathrm{p} K_{\mathrm{a}}$ values $(\sim 30$ in DMSO) are not prone to ready proton dissociation in organic solvents such as methylene chloride. ${ }^{55}$ Aromatic alcohols (phenols) are more acidic ( $\mathrm{p} K_{\mathrm{a}} \sim 18$ in DMSO) and would be expected to promote the desired protonolysis of the zinc ethyl bond in 3.7. ${ }^{21 a}$ 


\section{(iii) With phenols}

The reaction of zinc ethyl complex 3.7 with solid aromatic alcohols was initially explored on a small scale and monitored by ${ }^{1} \mathrm{H}$ and ${ }^{31} \mathrm{P}$ NMR. The reaction of the neutral $(\mathrm{NNN}) Z n E t 3.7$ complex with $p$-cyanophenol $(\mathrm{pKa} \sim 9)$ was carried in J-Young tube under moisture and air free condition. Reaction of $\mathbf{3 . 7}$ with one equiv. of 4-cyanophenol at $25{ }^{\circ} \mathrm{C}$ in $\mathrm{CD}_{2} \mathrm{Cl}_{2}$ for 10 minutes leads to the formation of ethane and $\left[\kappa^{3}-2-\right.$ $\left.\left(\left(\mathrm{C}_{6} \mathrm{H}_{5}\right)_{3} \mathrm{P}=\mathrm{N}\right)-5-\mathrm{CH}_{3} \mathrm{C}_{6} \mathrm{H}_{3} \mathrm{SO}_{2} \mathrm{NH}\left(\mathrm{CH}_{2}\right)_{2} \mathrm{~N}\left(\mathrm{CH}_{3}\right)_{2}\right] \mathrm{Zn}\left(4-\mathrm{OC}_{6} \mathrm{H}_{4} \mathrm{CN}\right) 3.10$ in quantitative yield (Scheme 3.9). The ${ }^{31} \mathrm{P}$ NMR shift upfield from 26.4 to $28.8 \mathrm{ppm}$ in phenoxy zinc complex, 3.10 at $25^{\circ} \mathrm{C}$ in 10 minutes. The aromatic ${ }^{1} \mathrm{H}$ NMR resonance of the cyanophenol shifted and appeared as broad signal at $25^{\circ} \mathrm{C}$. However, the phenoxy zinc complex shows fluxional behavior as in the case of its starting (NNN)ZnEt complex.

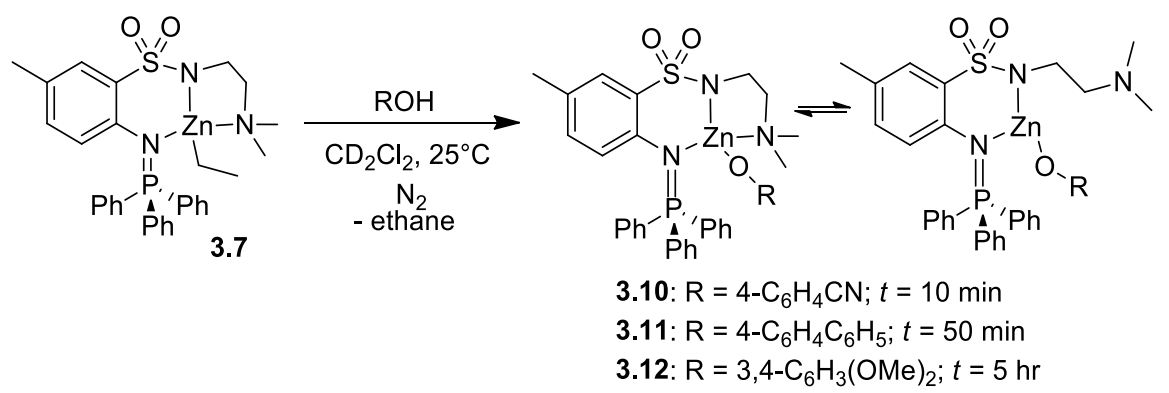

Scheme 3.9. Reaction of 3.7 with phenols

The low temperature ${ }^{1} \mathrm{H}$ NMR resonance of the phenoxy zinc complex show that the two amine methyl group $-\mathrm{N}\left(\mathrm{CH}_{3}\right)_{2}$ are inequivalent and appeared at $\mathbf{2 . 1 5}$ and $\mathbf{1 . 8 6}$ ppm. The two aromatic proton of the phenoxy group bind to zinc center appeared at 7.17 $(J=8 \mathrm{~Hz})$ ppm and $6.32(J=8 \mathrm{~Hz}) \mathrm{ppm}$. The two ethylene proton $-\mathrm{CH}_{2} \mathrm{~N}_{\left(\mathrm{CH}_{3}\right)_{2}}$ resonance are inequivalent at $-40{ }^{\circ} \mathrm{C}$. The structure is fully characterized on the basis of ${ }^{31} \mathrm{P}$ NMR, low temperature ${ }^{1} \mathrm{H}$ NMR and 2D NMR. 


\begin{tabular}{|c|c|c|}
\hline $\mathrm{pKa}=8$ & $\mathrm{pKa}=9.96$ & \\
\hline & \\
\hline
\end{tabular}

Table 3.1. Substituted phenols and their $\mathrm{pKa}$ value and reactivity with $\mathbf{3 . 7}$

When 3.7 was reacted with the less acidic 4-hydroxybiphenyl in $\mathrm{CD}_{2} \mathrm{Cl}_{2}$ at $25{ }^{\circ} \mathrm{C}$ the reaction proceeded at a slower pace but complete consumption of $\mathbf{3 . 7}$ was observed after 50 minutes to form $\left[\kappa^{3}-2-\left(\left(\mathrm{C}_{6} \mathrm{H}_{5}\right)_{3} \mathrm{P}=\mathrm{N}\right)-5-\mathrm{CH}_{3} \mathrm{C}_{6} \mathrm{H}_{3} \mathrm{SO}_{2} \mathrm{NH}\left(\mathrm{CH}_{2}\right)_{2} \mathrm{~N}\left(\mathrm{CH}_{3}\right)_{2}\right] \mathrm{Zn}(4-$ $\left.\mathrm{OC}_{6} \mathrm{H}_{4} \mathrm{C}_{6} \mathrm{H}_{5}\right) 3.11$ and ethane (Scheme 3.9). Finally, when 3,4-dimethoxyphenol was reacted with 3.7 in $\mathrm{CD}_{2} \mathrm{Cl}_{2}$ after 10 minutes only $33 \%$ consumption of $\mathbf{3 . 7}$ had occurred and it took 5 hours for all of complex 3.7 to be consumed to form $\left[\kappa^{3}-2-\left(\left(\mathrm{C}_{6} \mathrm{H}_{5}\right)_{3} \mathrm{P}=\mathrm{N}\right)-5-\right.$ $\left.\mathrm{CH}_{3} \mathrm{C}_{6} \mathrm{H}_{3} \mathrm{SO}_{2} \mathrm{NH}\left(\mathrm{CH}_{2}\right)_{2} \mathrm{~N}\left(\mathrm{CH}_{3}\right)_{2}\right] \mathrm{Zn}\left(3,4-\mathrm{OC}_{6} \mathrm{H}_{3}(\mathrm{OMe})_{2}\right) 3.12$ as illustrated in Scheme 3.9 .

Zinc aryloxides 3.10-3.12 can be isolated in good yield by reaction of 3.7 with one equivalent of the corresponding solid phenols in $\mathrm{CH}_{2} \mathrm{Cl}_{2}$ under $\mathrm{N}_{2}$. Zinc aryloxides 3.10-3.12 were characterized by ${ }^{1} \mathrm{H},{ }^{13} \mathrm{C}$, and ${ }^{31} \mathrm{P}$ and multi-dimensional NMR. The ${ }^{31} \mathrm{P}$ NMR $\left(25^{\circ} \mathrm{C}, \mathrm{CD}_{2} \mathrm{Cl}_{2}\right)$ chemical shifts for the triphenyl phosphinimine substituent in 3.10-3.12 appear as a singlet at $\delta=28.6 \mathrm{ppm}$ for 3.10 and $\delta=28.5 \mathrm{ppm}$ for 3.11-3.12. Fluxional behavior was observed at $25^{\circ} \mathrm{C}$ for the pendant (dimethylamino)ethyl arm in complexes 3.10-3.12 as seen in zinc ethyl complex 3.7. The dynamic behavior due to association and disassociation of the (dimethylamino)ethyl arm in complexes 3.10-3.12 could be halted by cooling the $\mathrm{CD}_{2} \mathrm{Cl}_{2}$ solutions to $-40{ }^{\circ} \mathrm{C}$. Complexes 3.10-3.12 were stable in dry $\mathrm{CD}_{2} \mathrm{Cl}_{2}$ for several days at $25^{\circ} \mathrm{C}$ and 12 hours at $45^{\circ} \mathrm{C}$. 
The Mehrkhodavandi research group synthesized a chiral version of the Hillmyer and Tolman complex i.e.; (NNO)ZnEt and studied its reactivity with alcohols. Their catalyst is found to be unreactive towards stoichiometric amounts of methanol, ethanol, isopropanol and water in various organic solvents. However, phenol $(\mathrm{pKa}=10)$ and $\mathrm{HCl}$ reported to react to give phenoxide complex $(\mathrm{NNO}) \mathrm{ZnOPh}$ and $(\mathrm{NNO}) \mathrm{ZnCl}$. This result concludes that only strongly acidic alcohols and acids are able to protonate zinc ethyl to give free ethane.

The reaction between 4-coordinate ethyl zinc complex and alcohols may have two different possible mechanisms depending on the nature of the substrates (Scheme 3.11). The reactivity of the zinc ethyl complex with alcohols depends on the $\mathrm{p} K \mathrm{a}$ of the alcohols. Phenol and $\mathrm{HCl}$, (stronger acid) can dissociate easily forming $\mathrm{H}^{+}$and proceed via a direct protonation of the zinc ethyl bond. In the case of less acidic alcohols such as methanol, ethanol, isopropanol, first the alcohol must coordinate at the metal center and leading to decrease in the $\mathrm{pKa}$ of coordinated species then dissociation of the terminal amine arm.

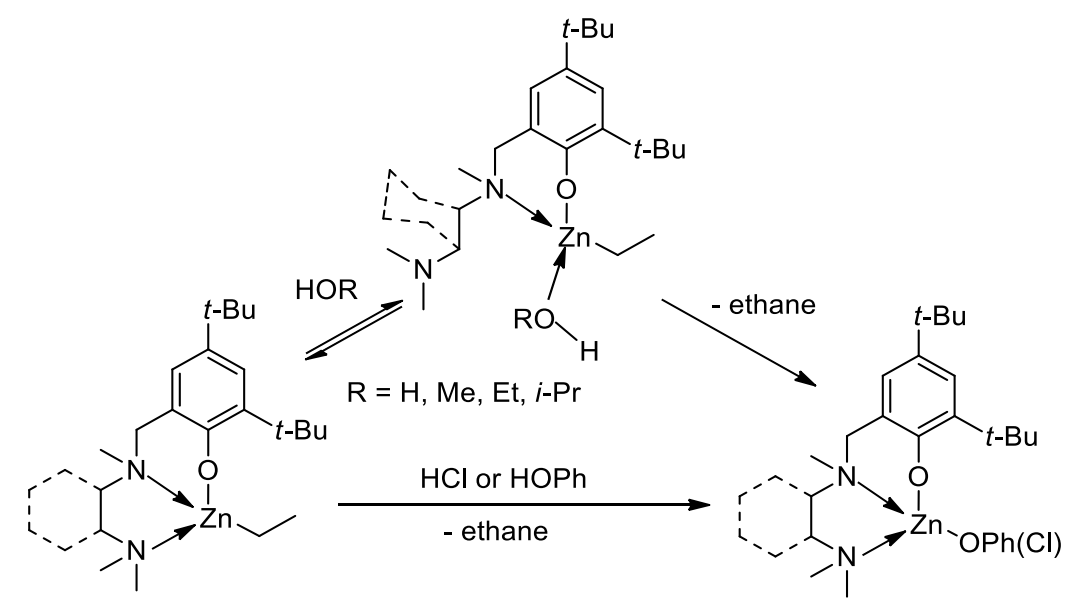

Scheme 3.10. Mechanism for the reaction of ethyl zinc complexes and acids/alcohols 
The dissociation of the terminal amine arm of the chelating ligand must occur so the alcohol can bind to zinc.
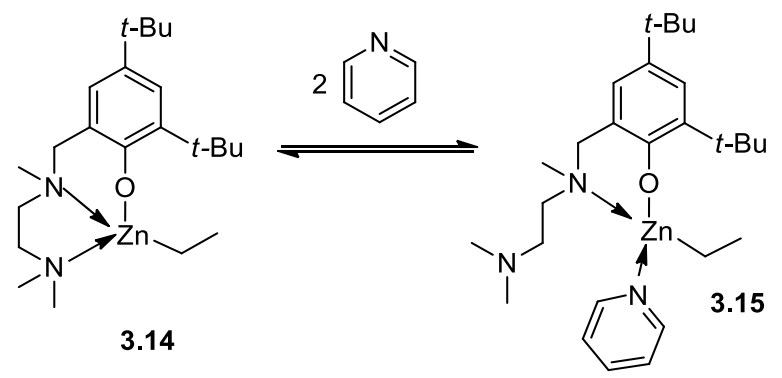

Scheme 3.11. Reaction of Tolman catalyst 3.14 with pyridine

The possible equilibrium between the ethyl zinc complex $L_{n} \mathrm{ZnEt}(\mathbf{3 . 1 4 - 3 . 1 5})$ and pyridine in situ is shown in Scheme 3.12. Two distinct methyl peaks of the dimethylated amine are observed in absence of pyridine. This is due to the asymmetry of the two methyl groups of amine in the ethyl zinc complex (3.14). ${ }^{21 a}$ When pyridine was added to the ethyl zinc complex 3.14, the equilibration of the two signals occurred showing a broad single resonance in ${ }^{1} \mathrm{H}$ NMR spectra. The equilibration is due to the dissociation of the dimethyl amine in presence of pyridine. This investigation concluded that the dimethyl amine dissociates before the coordination of other coordinating species in this four coordinate ethyl zinc complex system. ${ }^{21 a}$

The chiral zinc ethyl complex analogue of highly active Tolman catalyst synthesized by Mehrkhodavandi research group is not reactive toward alcohols such as ethanol in direct contrast to Tolman catalyst, which reacted readily to form corresponding zinc ethoxide. The reactivity of chiral catalyst toward alcohols is explained by lack of dissociation of the diamine ethyl arm of the ancillary ligand, that coordination and deprotonation of alcohols with high $\mathrm{pKa}$ values. In case of complex 3.7, the dimethyl 
amine arm is hemi labile but still we do not see reactivity with weakly acidic alcohols such as ethanol.

\section{A.6. Reactivity with L-lactide}

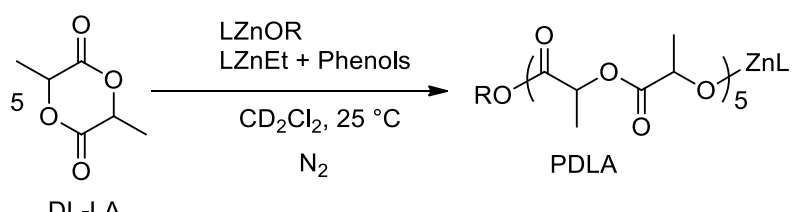

Scheme 3.12. Lactide polymerization test

The catalytic activity of zinc phenols with lactide was tested in NMR scale reactions.

The discrete zinc phenoxides as well as situ generated zinc phenoxides 3.10-3.12 reveal low catalytic activity toward ROP of dl-lactide.

\begin{tabular}{|c|c|c|}
\hline $\mathrm{pKa}=8$ & $\mathrm{pKa}=9.96$ & $\mathrm{pKa}=10.6$ \\
\hline $\mathrm{LZnOR}_{1}(3.10)$ & $\mathrm{LZnOR}_{2}(3.11)$ & $\mathrm{LZnOR}_{3}(3.12)$ \\
\hline$t=96 \mathrm{hr} ., \mathrm{No}$ Polymer & $t=24 \mathrm{hr} ., 24 \%$ Polymer & $t=48 \mathrm{hr} ., 12 \%$ Polymer \\
\hline
\end{tabular}

Table 3.2. Substituted phenols, their $\mathrm{pKa}$ values and reactivity with 3.7

Complex 3.10 show no catalytic activity toward dl-lactide monomer up to 24 hours in $\mathrm{CD}_{2} \mathrm{Cl}_{2}$ at $25{ }^{\circ} \mathrm{C}$ under $\mathrm{N}_{2}$ atmosphere. Complex 3.11 and 3.12 show slow activity toward lactide monomer with $24 \%$ and $12 \%$ conversion to polylactic acid (PLA) in 24 hours in $\mathrm{CD}_{2} \mathrm{Cl}_{2}$ at $25^{\circ} \mathrm{C}$ under $\mathrm{N}_{2}$ atmosphere. The conversion rate is calculated directly from the integration of methine proton resonance of monomer vs polymer appeared in ${ }^{1} \mathrm{H}$ NMR. The low reactivity of the zinc phenoxide is attributing to the low 
electrophilicity of the zinc center showing the carbon attached to the zinc resonance downfield -0.6 ppm (In Tolman catalyst $4 \mathrm{ppm}$ ). The zinc ethyl bond is not strong base to react with weak acid such as ethanol but strong enough to react with strong acidic phenols to give zinc phenoxide complexes 3.10-3.12. The zinc center of the zinc phenoxide 3.7 is not Lewis acidic enough to coordinate strongly to activate lactide monomer which is the basis of coordination insertion mechanism.

\section{A. 7. Synthesis of stable (NNN)ZnMe Complexes for x-ray crystallography}

Roesky research group reported the synthesis of a new organozinc based catalyst, $N$-isopropyl-2-(isopropylamino)troponiminate zinc methyl for the hydroamination reaction. This complex is distinguished by functional group tolerance, good activity in the catalytic conversion of non-activated C-C multiple bonds and a relatively high stability towards moisture and air.

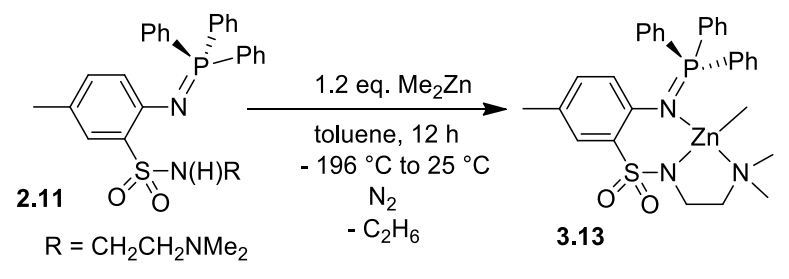

Scheme 3.13. Synthesis of zinc methyl complex $\mathbf{3 . 1 3}$

To obtained good x-ray crystallography data, we synthesized more stable NNNZnMe complex (scheme 3.14). We tentatively propose that the structure of NNNZnEt complex, for which no X-ray crystal structure could be obtained, is analogous to that of NNNZnMe complex. NNNZnMe complex was obtained by the reaction of ligand 2.11 reacting with dimethyl zinc in toluene at -196 C under nitrogen. Complex 3.6 
was obtained white solid in high yield with $78 \%$ yield in $0.5 \mathrm{~g}$ scale. The details of X-ray crystallography of the complex $\mathbf{3 . 6}$ are as follows.

Crystals suitable for X-ray crystallography were obtained by slow diffusion of hexanes into a chlorobenzene solution of $\mathbf{3 . 7}$ and the structure was determined by X-ray diffraction. An ORTEP diagram of the corresponding structure is shown in Figure 3.3 and selected bond lengths and angles are listed in Table 2.2 (Chapter 2). The X-ray

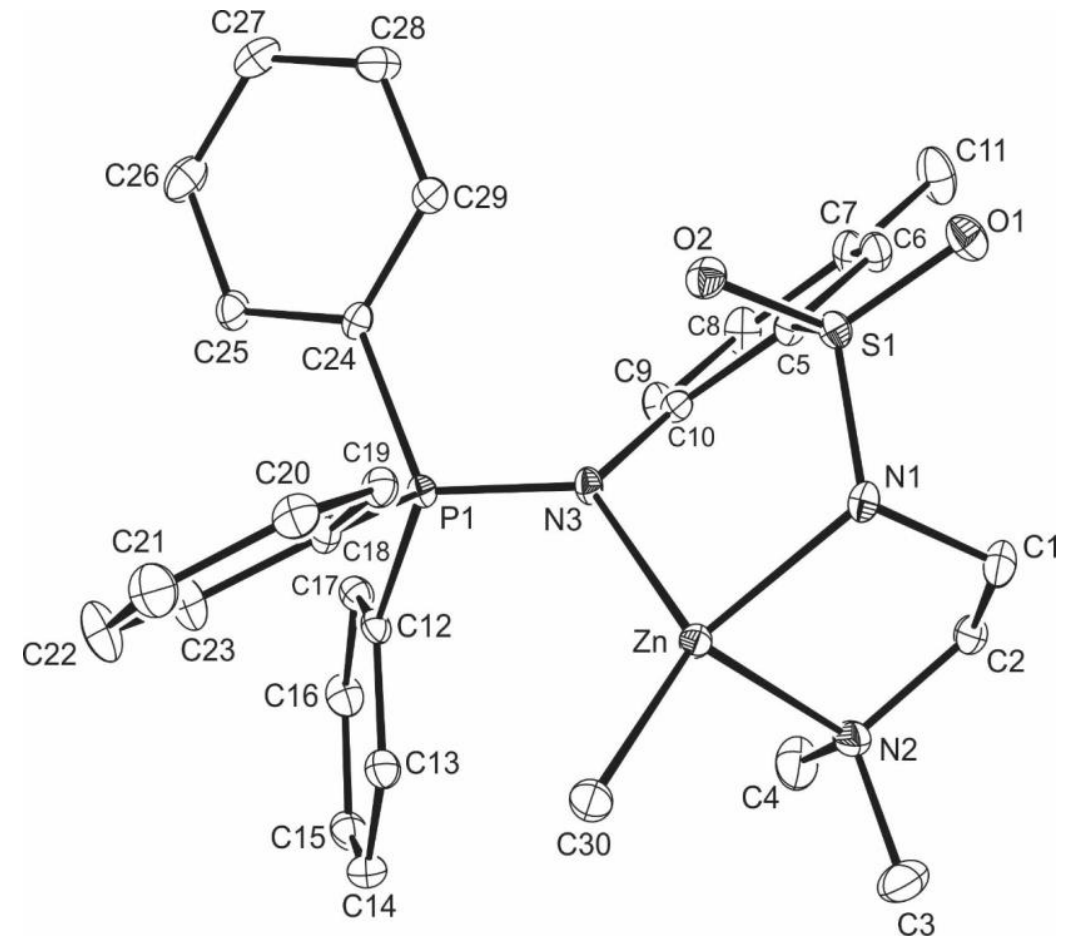

Figure 3.4 ORTEP- $3^{54}$ diagram of $\mathbf{3 . 7}$ showing $50 \%$ ellipsoids. $\mathrm{H}$ atoms are omitted for clarity

structure shows that $\mathbf{3 . 7}$ is monomeric, with the four-coordinate $\mathrm{Zn}(\mathrm{II})$ ion adopting a distorted tetrahedral geometry. The differences between the angles $\mathrm{C}(30)-\mathrm{Zn}(1)-\mathrm{N}(3)$ $\left(123.13(10)^{\circ}\right)$ and $\mathrm{N}(1)-\mathrm{Zn}(1)-\mathrm{N}(2)\left(84.49(9)^{\circ}\right)$ are illustrative of the distortion from an ideal tetrahedral geometry. The $\mathrm{Zn}(1)-\mathrm{C}(30)$ distance of $1.983(3) \AA$ is longer than observed for $\mathrm{Zn}(\mathrm{II})$-alkyl bonds in complexes that contain bidentate $\mathrm{N}^{\wedge} \mathrm{N}$ ligands such as BDI or 9-N-alkylamino-1-N'-alkyliminophenalene [1.941(3)-1.966(3) $\AA$ ]. It is similar in 
length to $\mathrm{Zn}(\mathrm{II})$-alkyl bonds in complexes that contain tridentate ligands such as tris(pyrazolyl)borate and diaminophenoxy [1.981(8)-1.997(4) $\AA]$. Ligand $\mathbf{2 . 1 1}$ coordinates to the zinc ion in a tridentate fashion. In complex 3.7, the pendant (dimethylamino)ethyl- arm coordinates to the zinc ion with a $\mathrm{Zn}(1)-\mathrm{N}(2)$ distance of 2.187(2) Å which is shorter than observed for two $\beta$-diketiminato Zn(II) ethyl complexes that contain a coordinating (dimethylamino)ethyl- arm [2.457(3) and 2.482(2) $\AA] .{ }^{56}$

The exocyclic phosphinimine $\mathrm{P}(1)-\mathrm{N}(3)$ bond distance $[1.607(2) \AA]$ is slightly longer than the same P-N bond found in ligand $\mathbf{2 . 1 1}$ but still has a high degree of double bond character. It is very similar in distance to the exocyclic phosphinimine P-N bond found in $\left[\kappa^{2}-2-\left(\mathrm{Ph}_{3} \mathrm{P}=\mathrm{N}\right)-5-\mathrm{MeC}_{6} \mathrm{H}_{3} \mathrm{SO}_{3}\right] \mathrm{PdMe}\left(4-{ }^{t} \mathrm{BuPy}\right)[1.608(2) \AA]$ which contains a high degree of double bond character. ${ }^{47}$

\section{A. 7. Conclusion}

In summary, we have synthesized and characterized neutral zinc ethyl complexes supported by novel phosphinimines amidosulfonyl NNO and NNN tridentate ligands having $-\mathrm{SO}_{2} \mathrm{NCH}_{3} \mathrm{C}_{2} \mathrm{H}_{5} \mathrm{O}$ - and $-\mathrm{SO}_{2} \mathrm{NCH}_{3} \mathrm{C}_{2} \mathrm{H}_{4} \mathrm{~N}\left(\mathrm{CH}_{3}\right)_{3}$ groups and a phosphinimine motif. The structures of neutral zinc complex are characterized with the help of NMR, and single $\mathrm{x}$-ray crystallography. The low temperature NMR revealed that amine arm of NNNZnEt complex is coming on and off. Phosphinimines are $\mathrm{sp}^{2}$ nitrogen donor with polar $\mathrm{P}=\mathrm{N}$ double bonds. The ligand steric influences the catalytic activity. In phosphinimines amido sulfonyl ligands, sterics and electronics can be altered and tuned easily through application of various groups on the phosphorus atom. The incorporation of these ligands with zinc metal produces neutral zinc ethyl complexes. The reactivities 
of zinc ethyl complexes with several alcohols are established. Lower $\mathrm{pKa}$ alcohols (strongly acidic proton) such as $p$-cyanophenol are able to protonate the zinc ethyl bond to produce ethane. However, higher $\mathrm{p} K \mathrm{a}$ alcohols are not able to protonate the zinc ethyl bond to produce ethane. Zinc phenoxide complex was synthesized by the reaction between zinc ethyl complex and p-cyanophenol. The zinc phenoxide complexes are inert and are not able to polymerize lactide. The NNN zinc complex polymerizes L-lactide but very slowly. The chiral version of Toman catalyst synthesized by Mehrkhodavandi research group is not reactive to ethanol because the dimethyl amine arm of NNOZnEt complex is not labile. In NNNZnEt complex 3.7 the amine arm is labile shown by the fluxional behavior. The dynamic behavior is observed because there is association and disassociation of the (dimethylamino)ethyl arm in complex 3.7. However the NNNZnEt complex 3.7 does not react with ethanol (high $\mathrm{pKa}$ ) to give zinc ethoxide because the metal center is not electrophilic enough to react with weaker bases. The low electrophilicity of zinc alkyls complexes is identified by downfield shift of carbon directly attached to the zinc compared to highly active Tolman catalyst. In the Tolman catalyst precursor (NNOZnEt) the carbon bonded to zinc resonates at $4 \mathrm{ppm}$ where as in the catalysts 3.10-3.12 the carbon bonded to zinc resonates at $-0.57 \mathrm{ppm}$ for $\mathrm{NNN}\left(\mathrm{PPh}_{3}\right) \mathrm{ZnEt}$ and $0.89 \mathrm{ppm}$ for $\mathrm{NNN}\left(\mathrm{PMe}_{3}\right) \mathrm{ZnEt}$. This clearly shows that the zinc center in the catalysts 3.10-3.12 is weakly electrophilic. Future work will involve further modification of ligands to improve the Lewis acidity of metal center. 


\section{CHAPTER 4}

\section{NEUTRAL PHOSPHINIMINE BASES FOR ROP OF LACTIDE}

4. A.1. Introduction

4. A. 2. Synthesis of Neutral phosphinimines bases

4. B. Tolyl triaryl phosphinimines

4. B. 1. Synthesis of Tolyl triaryl phosphinimines

4. B. 2. Alcohol Activation by tolyl-phosphinimines

4. B. 3. Polymerization of lactide by tolyl-phosphinimines

4. C. Phenylethyl triarylphosphinimines

4. C. 1. Synthesis of Phenylethyl triarylphosphinimines

4. C. 2. Alcohol Activation by Phenylethyl -phosphinimines

4. C. 3. Polymerization of lactide by Phenylethyl-phosphinimines

4. C. 4. Order of reactivity of phenethyl phosphinimines towards ROP of L-LA

4. D. Conclusion 


\section{A.1. Introduction}

Aliphatic polyesters are an important class of polymers having excellent material properties, and have several applications such as packaging, microelectronics and drug delivery. ${ }^{1}$ Common synthetic ways to aliphatic polyesters utilize transition metal complexes to effect the ring opening polymerization (ROP) of cyclic esters. ${ }^{2}$ Although organometallic catalysts provide effective synthetic route to synthesis of aliphatic polyesters, this method has limited application in microelectronics and resorbable biomedical areas due to the toxic heavy metal residue trapped within the polymer materials. ${ }^{3}$ The first organocatalytic approach to the ROP of lactide using strongly basic tertiary amines i.e., 4-(dimethylamino)pyridine (DMAP, Figure 4.1) was reported by Hendrick et al. in 2001. ${ }^{4}$ This strategy used a nucleophile such as an alcohol that initiated the polymerization of lactide in the presence of the DMAP. ${ }^{5}$ They showed mild and highly selective polymerization conditions produced polylactides with predictable molecular weight and narrow polydistersities. DMAP catalyzed ROP of lactide was originally proposed to react via nucleophilic monomer activation mechanism (Scheme 4.1). ${ }^{4}$

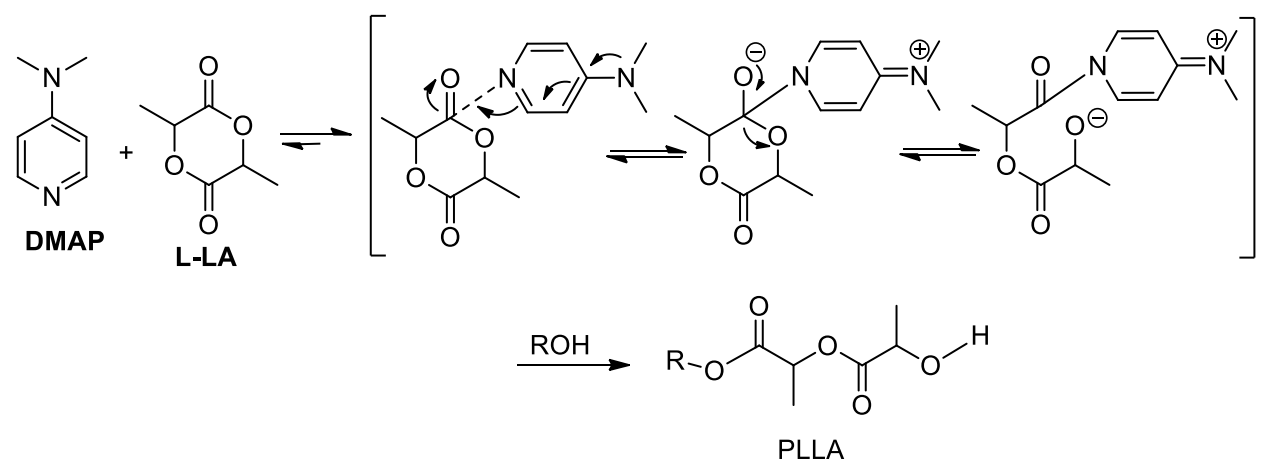

Scheme 4.1. Nucleophilic activation mechanism by DMAP 
In the nucleophilic activation mechanism, the nucleophile (DMAP) attacks the monomer (lactide) to generate a reactive chain end containing an alkoxide intermediates. The alkoxide is protonated by the initiating alcohol and and resulting alkoxide acylates the carbonyl group which releases the nucleophile leading to the formation of a ringopened alcohol that can propagate by repeated attack on the activated monomer. ${ }^{4}$

However, computational studies suggest that an alcohol activation mechanism may be effective in the DMAP catalyzed ROP of lactide (Scheme 4.2). In the alcohol activation mechanism, the initiator or chain end is activated by deprotonation to generate an alkoxide. Attack of the alkoxide at the carbonyl carbon on the monomer is followed by acyl-oxygen bond cleavage. This forms an ester end group and an active alcoholate species which reacts with the monomer for further propagation. ${ }^{6}$

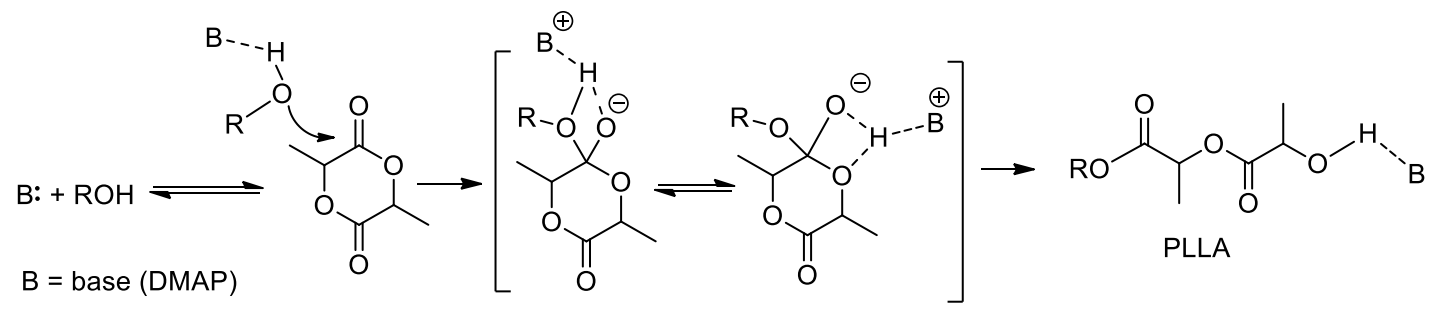

Scheme 4.2. Alcohol activation mechanism by DMAP

The catalytic activity of a number of phosphines towards ring opening polymerization of lactide in the presence of an alcohol was reported. ${ }^{7}$ Alkyl substituted phosphines are more active than the corresponding aryl containing phosphines towards ROP of lactide. They were shown to be effective ROP catalyst that generates narrowly dispersed polylactides with predictable molecular weights. These phosphine catalysts were investigated in bulk at $135^{\circ} \mathrm{C}$ and $180^{\circ} \mathrm{C}$ and in solution in various solvents such as THF, toluene and $\mathrm{CH}_{2} \mathrm{Cl}_{2}$ with benzyl alcohol as the initiator. The high phosphine 
concentration (more than 1 equivalent) and high temperature leads to broader molecular weight distribution, which indicates the presence of adverse transesterification reactions during the polymerization. Compared to DMAP, phosphine catalyzed ROP in solution was observed to be slower and less selective.

The guanidine and amidine, N-methyl 1,5,7-triazabicyclododecene (MTBD) and diazabicycloundecene (DBU) shown in Figure 4.1, were shown effective for the polymerization of LA producing polymer up to $\mathrm{DP}=500$ with narrow polymerdispersity index (PDI) in less than 1 hour. ${ }^{8}$ In these cases an alcohol-activated mechanism was proposed for the ROP of lactide. In such a mechanism, the "nucleophilic" catalyst activates the initiating alcohol but remains inert towards the ring opening of the monomer.

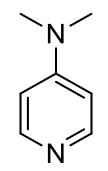

DMAP

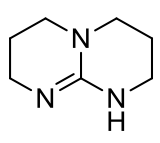

TBD

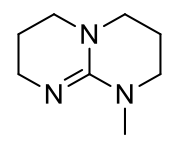

MTBD

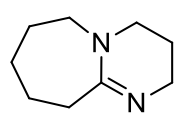

DBU

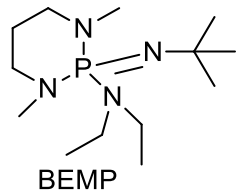

BEMP

Figure 4.1. Nitrogen bases used as organocatalyst for ROP

The importance of hydrogen bonding in the organocatalytic ring opening reactions of Llactide was investigated. ${ }^{9}$ The mechanism based on hydrogen bonding by the catalyst was shown to be more favorable than the mechanism based on acetyl transfer (nucleophilic activation mechanism). In case of the guanidine TBD (Figure 4.1), the hydrogen attached to the amine nitrogen activates the carbonyl group of L-lactide through hydrogen bonding and the imine nitrogen activates the alcohol by attracting the hydrogen atom of the alcohol's hydroxyl group through a lone pair interaction (Scheme 4.3). ${ }^{10}$ In case of MTBD, the hydrogen attached to the amine nitrogen is absent due to methyl substitution. ${ }^{9}$ 
The rate of ROP of L-lactide mediated by MTBD is more than 90 times slower versus the reaction run with $\mathrm{TBD} .{ }^{11}$ This result shows that lack of a hydrogen bonding motif in the catalyst slows the reaction rate immensely.

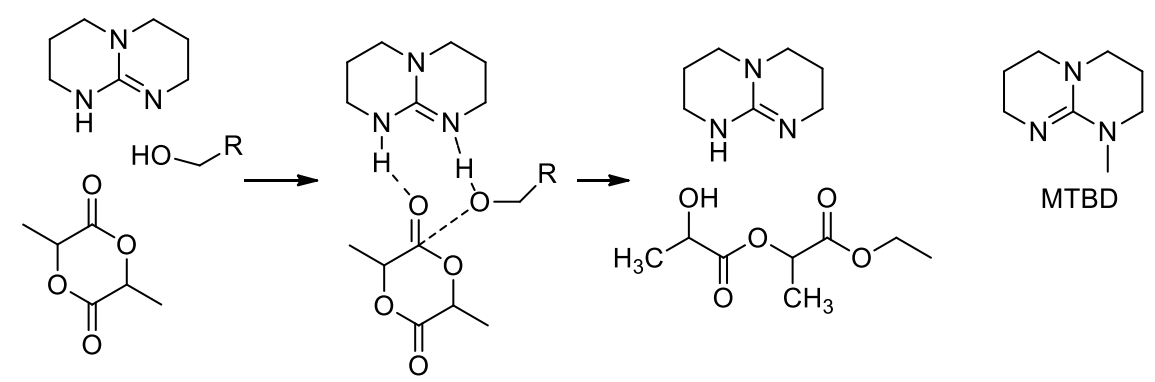

Scheme 4.3. TBD-catalysed ROP of LA by the H-bonding mechanism

A bifunctional catalyst system containing a thioruea and an amine functionality was reported in the literature. The thiourea is capable of hydrogen-bonding and acts as Hbond donor to activate the cyclic ester while the amine base can activates an alcohol present in the reaction. In the ROP of LA, the thiourea/amine bifunctional catalyst produced PLA of narrow PDI. It was also reported that combination of thiourea and amine molecules are equally active towards ring opening polymerization. ${ }^{10,12}$

There are different types of mechanism proposed for the polymerization of lactide:

(i) Nucleophilic Monomer Activation

Nucleophiles activate the monomer by direct attack on the monomer to give reactive zwitterionic alkoxide. Protonation of zwitterionic alkoxide by alcohol followed by acylation of the alkoxide lead to the formation of a ring opened alcohol that propagate by repeated attack on the activated monomer. Guanidines, ${ }^{13}$ amidines $^{14}$ and Nheterocyclic carbenes ${ }^{15}$ are postulated nucleophilic monomer activation mechanism for ring opening polymerization of cyclic esters. ${ }^{5}$ 


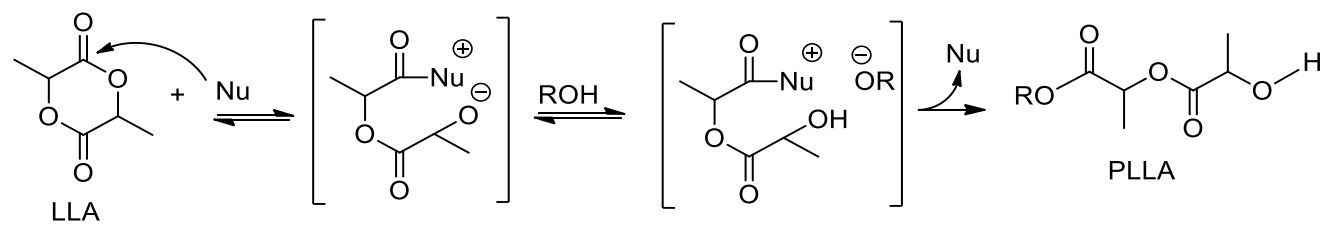

Scheme 4.4. Nucleophilic activation mechanism

(ii) Chain-End activation by a general base

The initiator or chain end is activated by deprotonation in the classical anionic polymerization to generate an alkoxide. The alkoxide is reactive enough to mediate ring opening polymerization. The alkoxide attacks at the carbonyl carbon of the monomer giving species having an ester end group and an active alcohol group due to acyl-oxygen bond cleavage. The species with an ester group and alcohol end group further reacts with the monomer for further propagation.

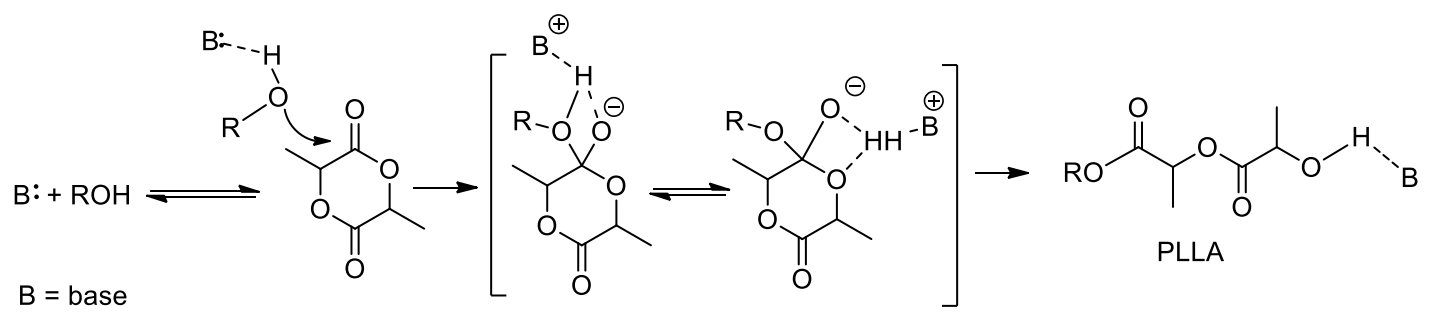

Scheme 4.5. Chain end activation mechanism

(iii) Bifunctional activation of monomer

Dual activation of both monomer and the chain end take place in the case of bifunctional activation mechanism (Scheme 4.6).

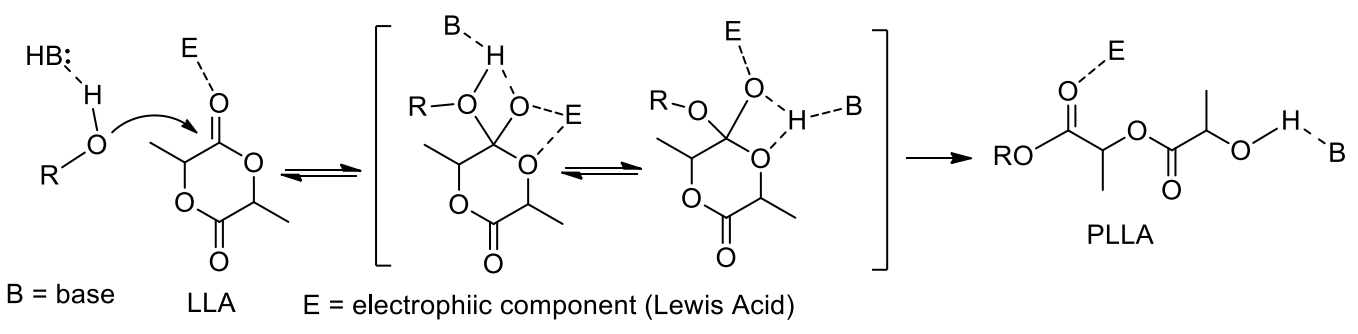

Scheme 4.6. Bifunctional activation using H-bonding 


\section{A. 2. Synthesis of Neutral phosphinimines bases}

There are few phosphinimine bases reported in the literature that are used as catalyst towards ROP of lactides. ${ }^{16}$ We synthesized simple phosphinimine with single step Staudinger reaction and its basicity was estimated with alcohol $\mathrm{OH}$ shift and corresponding relationship with the rate of ROP polymerization of lactide shown. These electron rich phosphinimines act as bronsted bases. Phosphinimines are stronger bases than phosphines due to delocalized PN double bond. The basicity of the phosphinimines is evaluated by the interactions with an alcohol using ${ }^{1} \mathrm{H}$ and ${ }^{31} \mathrm{P}$ NMR in the solution. Phosphine bases are used as bronsted base in the catalytic ring opening polymerization of cyclic esters such as lactide to yield biodegradable polymers. The modular nature of phosphinimine synthesis allows for the creation of a diverse ligand library where steric and electronic properties can be manipulated with ease. ${ }^{17}$

Neutral phosphinimines are believed to be stronger donor ligands than phosphines and amines due to potential delocalization about the $\mathrm{N}=\mathrm{P}$ double bond. The steric properties of phosphinimines are different than phosphines and amines since the steric bulk is slightly removed from the site of the lone pair electrons on the phosphinimine nitrogen. Hendrick and coworker have investigated that H-bonding pathway is preferable pathway for ring opening polymerization of L-lactide using a guanidine-based catalyst. ${ }^{9}$

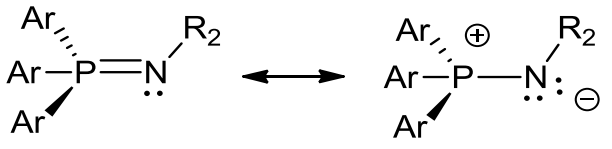

Figure 4.2. Mesomeric structure of phosphinimine ligands 


\section{B. Tolyl triaryl phosphinimines}

\section{B.1. Synthesis of Tolyl triaryl phosphinimines}

Electron rich phosphines 4.1-4.4 were synthesized in good yields by a two-step sequence (Scheme 4.7). Grignard reagent was generated in-situ by the reaction of 4bromo-N,N-dimethylaniline and $\mathrm{Mg}$ in THF under $\mathrm{N}_{2}$ atmosphere. The brown solution of the Grignard reagent was allowed to react with $\mathrm{Ph}_{2} \mathrm{PCl}$ or $\mathrm{PhPCl}_{2}$ at $0{ }^{\circ} \mathrm{C}$ for 1 hour and $25{ }^{\circ} \mathrm{C}$ for 12 hours to obtained the corresponding phosphines 4.1 and $\mathbf{4 . 2}$ respectively (Scheme 4.7). Phosphines 4.1 and 4.2 were isolated as a white solids in 85-86 \% yield on a 9 g scale. Phosphines $\mathbf{4 . 3}$ and $\mathbf{4 . 4}$ were synthesized by an analogous method (Scheme 4.7). Phosphine 4.3 was obtained as a light orange solid in $8.6 \mathrm{~g}$ scale, $76 \%$ yield. Phosphine 4.4 was obtained as yellow solid in $53 \%$ yield on a $5 \mathrm{~g}$ scale. Phosphines 4.14.4 were characterized by ${ }^{1} \mathrm{H},{ }^{13} \mathrm{C},{ }^{31} \mathrm{P}$ NMR. ${ }^{31} \mathrm{P}$ NMR of phosphines 4.1-4.4 show single peaks at $-7.3,-10.7,-11.3$ and $-10.1 \mathrm{ppm}$ respectively. These are consistent with values

reported in the literature. ${ }^{1}{ }^{31} \mathrm{P}$ chemical shifts are particularly useful in determining the purity of the product. The single peaks in the ${ }^{31} \mathrm{P}$ NMR spectra for these phosphines show they are pure.

Phosphinimines, $\mathrm{P}=\mathrm{N}$ double bond containing compounds can be prepared commonly by Kirsanov ${ }^{18}$ or Staudinger reaction. Both are two-step reactions. A typical Kirsanov reaction involves triphenylphosphine with bromine to give bromotriphenyl phosphonium bromide. The bromotriphenyl phosphonium bromide was treated in situ with an alkylamine to give a phosphinime. The Kirsanov reaction is used when the Staudinger reaction is not applicable, i.e. when the organic azide is not available to generate the phosphinimines. We utilized the Staudinger was treated in-situ with alkyl 
(a)

$\longrightarrow \mathrm{Br}+2 \mathrm{Mg} \stackrel{\mathrm{THF}}{\longrightarrow}$

4.1

(b)

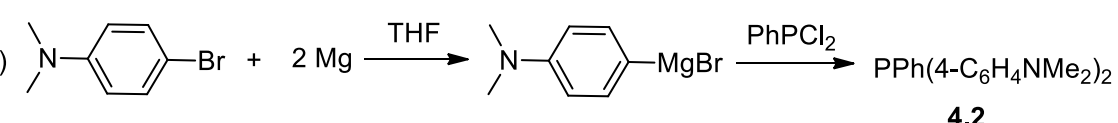

(c) $4 \mathrm{ArBr}+2 \mathrm{Mg} \stackrel{\mathrm{THF}}{\longrightarrow} 4 \mathrm{ArMgBr} \stackrel{\mathrm{PCl}_{3}}{\longrightarrow} \mathrm{PAr}_{3}$

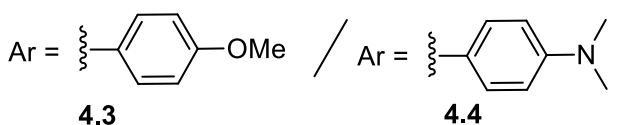

Scheme 4.7. Synthesis of electron rich phosphines

amines was treated in situ with alkylamines to give the phosphinimes. The Kirsanov reaction is used when the Staudinger reaction is not applicable, i.e. when the organic azide is not available to generate the phosphinimines. We utilized the Staudinger reaction for the synthesis of the phosphinimines due to ease of this reaction and the fact that the starting azides are readily available or easily synthesized. The Staudinger reaction is a very mild azide reduction. As there are varieties of methods for the preparing azides readily, the Staudinger reaction makes it possible to use an azide as an amine synthon. The complete Staudinger reaction is a two-step sequence in which an azide is converted to a phospinimine and the phosphinimine is converted to an amine by hydrolysis. For the

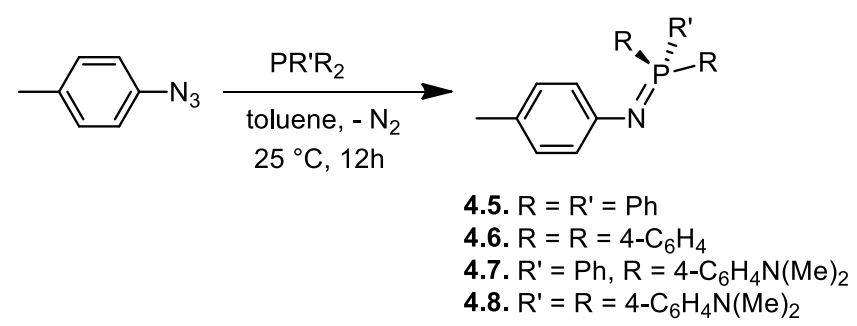

Scheme 4.8. Synthesis of tolyl phosphinimines 4.5-4.8 by the Staudinger reaction 
generation of phosphinimines for our study, the hydrolysis step is avoided. Phosphimines 4.5-4.8 were synthesized by the Staudinger reaction of tolyl azide and corresponding phosphine. The detail mechanism of the Staudinger reaction is illustrated in Chapter 2.
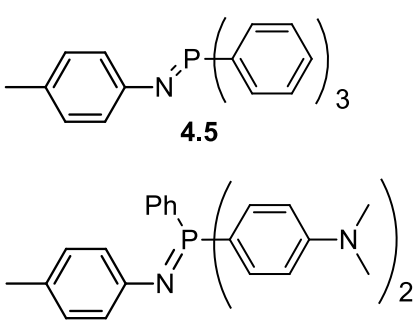

4.7
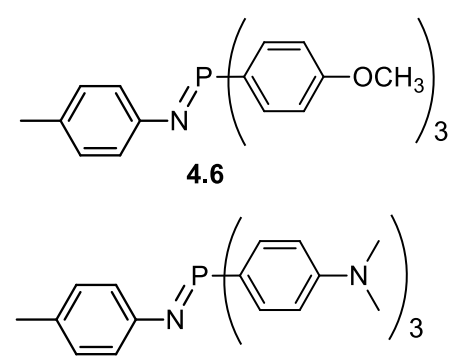

4.8

Figure 4.3. Series of tolyl phosphinimine bases

The Staudinger reaction between tolyl azide and triphenylphosphine $\left(\mathrm{PPh}_{3}\right)$, tris (4-methoxyphenyl)phosphine $\quad \operatorname{PPh}\left(4-\mathrm{C}_{6} \mathrm{H}_{4}-\mathrm{OMe}\right)_{3}, \quad$ phenyl(bisdimethylaminophenyl) phosphine $\left(\mathrm{PPh}\left(4-\mathrm{C}_{6} \mathrm{H}_{4}\left(4-\mathrm{NMe}_{2}\right)_{2}\right)\right.$, or (trisdimethylaminophenyl)phosphine $\mathrm{P}\left(\mathrm{C}_{6} \mathrm{H}_{4}(4-\right.$ $\left.\mathrm{NMe}_{2}\right)_{3}$, produce tolyl triphenylphosphine (4.5), tolyl-4-trimethoxyphenyl phosphinimine (4.6), Phenylethyl-bis-N,N-dimethylphenyl phosphinimine (4.7), tolyl-tris-N,Ndimethylphenyl phosphinimine (4.8) respectively. When the phosphine was added to a toluene solution of a tolyl azide rapid nitrogen evolution was observed at $25{ }^{\circ} \mathrm{C}$ and all reactions were complete in 16 hours at $25^{\circ} \mathrm{C}$.

Tolyl phosphinimines 4.5-4.6 were isolated as yellow solids and 4.7-4.8 as white solids. Phosphinimines 4.5-4.8 were characterized with ${ }^{1} \mathrm{H},{ }^{13} \mathrm{C},{ }^{31} \mathrm{P}$ NMR (Table 4.1). Phosphinimines 4.5-4.8 were synthesized in 1-2 gm scale and obtained in moderate to high yield. The ${ }^{31} \mathrm{P}$ NMR chemical shift for the isolated phosphinimines falls in the range of 1.52 to $-1.58 \mathrm{ppm}$ which is consistent with the values for the aryl phosphinimines reported in the literature. ${ }^{19}$ The single peaks in the ${ }^{31} \mathrm{P}$ NMR from $\delta 1.52$ to $-1.58 \mathrm{ppm}$ 
indicate a pure product in each case. Interpretation of ${ }^{1} \mathrm{H}$ NMR spectra clearly show the incorporation of the phosphine moiety in the phosphinimines. Phosphinimines 4.6-4.8 contain two sets of doublet of doublets in the aromatic region illustrating that the 2,6- and 3,5- proton signals are split by both the phenyl proton and the phosphorus nuclei.

\begin{tabular}{|c|c|c|c|}
\hline Compd. & gm & \% Y. & $\delta\left({ }^{31} \mathbf{P}\right) \mathbf{p p m}$ \\
\hline $\mathbf{4 . 5}$ & 1.0 & 90 & -1.58 \\
\hline $\mathbf{4 . 6}$ & 0.9 & 81 & -1.41 \\
\hline $\mathbf{4 . 7}$ & 1.7 & 64 & 0.98 \\
\hline $\mathbf{4 . 8}$ & 1.5 & 50 & 1.52 \\
\hline
\end{tabular}

Table 4.1. Yield, $\%$ Yield and ${ }^{31} \mathrm{P}$ shifts $\left(\mathrm{C}_{6} \mathrm{D}_{6}\right)$ of phosphinimines 4.5-4.8

\section{B. 2. Alcohol Activation by p-tolyl-phosphinimines}

The interaction of phosphinimines 4.5-4.8 with hydroxyl group is crucial for the success of the polymerization reaction. To investigate these interactions further, a series of ${ }^{1} \mathrm{H}$ NMR spectroscopy experiments was conducted in $\mathrm{C}_{6} \mathrm{D}_{6}$ at $25{ }^{\circ} \mathrm{C}$.

$$
\begin{aligned}
& \mathrm{B}:+\mathrm{HO}-\mathrm{R} \quad \underset{\mathrm{B}=\text { base }}{\stackrel{\mathrm{C}_{6} \mathrm{D}_{6}}{25^{\circ} \mathrm{C}}} \mathrm{B}:-\cdots-\mathrm{HO}-\mathrm{R} \\
&
\end{aligned}
$$

Figure 4.4. Activation of alcohol with base via hydrogen bonding

We have the $-\mathrm{OH}$ proton shift of the 2-(9-anthryl)ethanol for the reported organic catalyst such as DMAP, TBD and DBU (Table 4.2). These bases were mixed with 2-(9anthryl)ethanol in 1:1 ratio in $\mathrm{C}_{6} \mathrm{D}_{6}$ and ${ }^{1} \mathrm{H}$ NMR spectra were obtained. ${ }^{1} \mathrm{H}$ NMR spectra of these mixtures clearly show the $-\mathrm{OH}$ proton shifts downfiled in the presence of a 
nitrogen base. (Table 4.2). We utilized three different alcohols 2-(9-anthryl)ethanol, 9anthrylmthanol and 1-octadecanol for this initial study. The downfield shift of the alcohol $-\mathrm{OH}$ proton observed for the different alcohols in the presence o the same nitrogen base are similar in values. DMAP with 2-(9-anthryl)ethanol in 1:1 ratio in $\mathrm{C}_{6} \mathrm{D}_{6}$ shows a downfield shift of 1.4 ppm. DMAP with 2-(9-anthryl)ethanol or 1-octadecanol shows 1.90 and 1.97 ppm -OH proton shift respectively. TBD with 2-(9-anthryl)ethanol or 1octadecanol shows 1.24 and $1.26 \mathrm{ppm}-\mathrm{OH}$ proton shift respectively.

\begin{tabular}{|c|c|c|}
\hline $\begin{array}{c}\text { Mixture } \\
\text { Base + Alcohol }\end{array}$ & $\delta(\mathrm{OH})$ ppm & $\Delta \delta(\mathrm{OH}) \mathrm{ppm}$ \\
\hline $\mathrm{DMAP}+\mathrm{AnCH}_{2} \mathrm{CH}_{2} \mathrm{OH}$ & 2.17 & 1.40 \\
\hline $\mathrm{DMAP}+\mathrm{CH}_{3}\left(\mathrm{CH}_{2}\right)_{16} \mathrm{CH}_{2} \mathrm{OH}$ & 1.89 & 1.90 \\
\hline $\mathrm{DMAP}+\mathrm{AnCH}_{2} \mathrm{OH}$ & 2.94 & 1.97 \\
\hline $\mathrm{DBU}+\mathrm{AnCH}_{2} \mathrm{CH}_{2} \mathrm{OH}$ & 4.84 & 4.07 \\
\hline $\mathrm{TBD}+\mathrm{CH}_{3}\left(\mathrm{CH}_{2}\right)_{16} \mathrm{CH}_{2} \mathrm{OH}$ & 4.80 & 4.24 \\
\hline $\mathrm{TBD}+\mathrm{AnCH}_{2} \mathrm{CH}_{2} \mathrm{OH}$ & 5.03 & 4.26 \\
\hline
\end{tabular}

Table 4.2. Activation of alcohol with base via hydrogen bonding

Phosphinimines 4.5-4.8 were mixed with 2-(9-anthryl)ethanol $(\mathrm{AnOH})$ in 1:1 ratio in $\mathrm{C}_{6} \mathrm{D}_{6}$ and ${ }^{1} \mathrm{H}$ and ${ }^{31} \mathrm{P}$ NMR spectroscopy obtained (Scheme 4.9). The downfield shift of the hydroxyl resonance of the alcohol is the clear indication of the intermolecular hydrogen bonding between phosphinimines and 2-(9-anthryl)ethanol. ${ }^{31} \mathrm{P}$ NMR show single peak for clean reaction. 


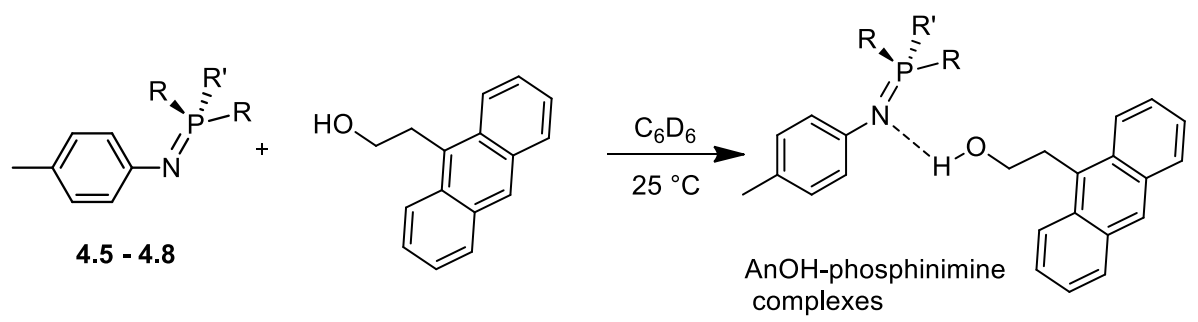

Scheme 4.9. Activation of 2-(9-anthryl)ethanol by phosphinimines

We postulate that observed that 9-anthrylmethanol has shown lower reactivity than 2-(9-anthryl)ethanol towards ROP of lactide. This may be due to the length of the alkyl chain between the alcohol and the aromatic ring. The anthrecene functional group is important because for the polymer end group analysis of the individual chains are observed by UV. Therefore, we chose 2-(9-anthryl)ethanol for our investigation of $-\mathrm{OH}$ activation by phosphinimines via hydrogen bonding. 2-(9-anthryl)ethanol is crystalline solid that allows for ease of handing in a glove box. The chemical shift of the $-\mathrm{OH}$ proton of free 2-(9-anthryl)ethanol is observed at $0.77 \mathrm{ppm}$ in $\mathrm{C}_{6} \mathrm{D}_{6}$ at $25^{\circ} \mathrm{C}$.

However side reaction can occur i.e.; alcohol can completely protonoate the phosphinimine to give protonated phosphinimine. The side reaction was verified by protonating tolyl phosphinimine $\mathbf{4 . 7}$ and $\mathbf{4 . 8}$ with pyridinium tetrafluroforate, [HPy][BF 4 in 1:1 in NMR scale reactions at ambient temperature. The protonated phosphine $\mathbf{4 . 1 5}$ and 4.16 shows single peak in the ${ }^{31} \mathrm{P}$ NMR at $32 \mathrm{ppm}$ and $31.7 \mathrm{ppm}$ in $\mathrm{CD}_{2} \mathrm{Cl}_{2}$ (Scheme 4.10).

The ${ }^{1} \mathrm{H}$ NMR of mixture DMAP and 2-(9-anthryl)ethanol (1:1) was established in $\mathrm{CD}_{6} \mathrm{Cl}_{6}$ at $25{ }^{\circ} \mathrm{C}$ under nitrogen. The $-\mathrm{OH}$ peak of free 2-(9-anthryl)ethanol in $\mathrm{C}_{6} \mathrm{D}_{6}$ appear at $0.77 \mathrm{ppm}$ in ${ }^{1} \mathrm{H}$ NMR spectroscopy. The addition of phosphinimine 4.5 to 2-(9anthryl)ethanol resulted -OH signal shift in the ${ }^{1} \mathrm{H}$ NMR spectroscopy, which indicates some degree of interaction. 
(a)

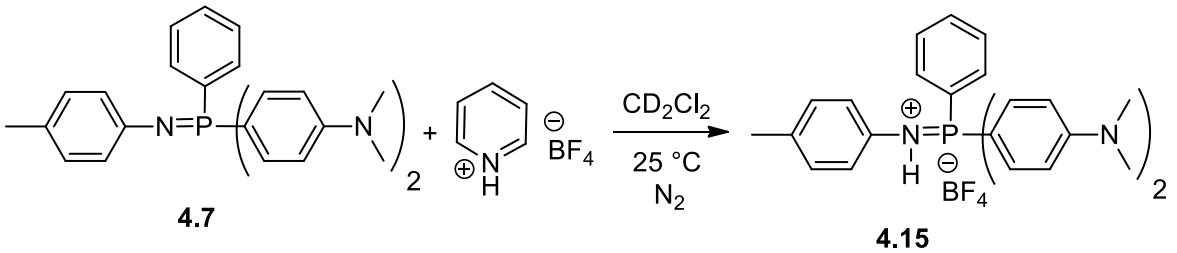

(b)

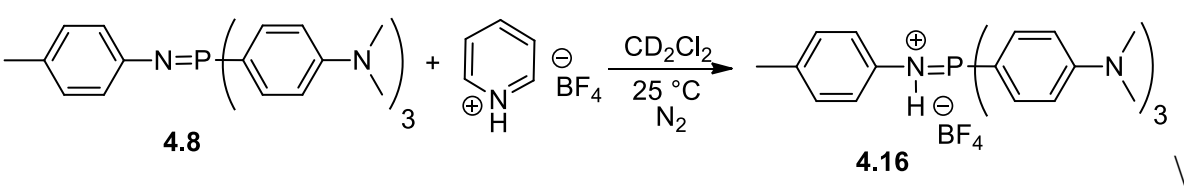

Scheme 4.10. Synthesis of protonated phosphinimine

The gradual increase of $-\mathrm{OH}$ shift in the ${ }^{1} \mathrm{H}$ NMR spectra, going from phosphinimine 4.5 and 4.6 to phosphinimine 4.7 was observed. Phosphinimine 4.7 resulted in the appearance of a single broad resonance at $\delta 3.07 \mathrm{ppm}$, which most likely represents significantly deshielded alcoholic protons (Table 4.3).

\begin{tabular}{|c|c|c|c|c|}
\hline Mixture & $\boldsymbol{\delta}(\mathbf{O H})$ & $\boldsymbol{\delta}\left({ }^{\mathbf{3 1}} \mathbf{P}\right) \mathbf{p p m}$ & $\Delta \boldsymbol{\delta}(\mathbf{O H})$ & $\boldsymbol{\Delta} \boldsymbol{\delta}\left({ }^{31} \mathbf{P}\right)$ \\
\hline $\mathbf{4 a s e}+$ Alcohol & $\mathbf{p p m}$ & & & \\
\hline $\mathbf{4 . 6}+\mathbf{A n O H}$ & 1.61 & 1.73 & 0.84 & 3.31 \\
\hline DMAP + AnOH & 2.00 & 2.79 & 1.23 & 4.20 \\
\hline $\mathbf{4 . 7}+\mathbf{A n O H}$ & 3.07 & 3.81 & 2.30 & -- \\
\hline $\mathbf{4 . 8}+\mathbf{A n O H}$ & 2.74 & 3.92 & 1.97 & 2.40 \\
\hline
\end{tabular}

Table 4.3. Alcohol H shift (in blue) by H-hydrogen bonding activation

In contrast, a broad signal is observed at $\delta 2 \mathrm{ppm}$ in the presence of phosphinimine 4.6. Most likely, this series of spectra show 2-(9-anthryl)ethanol-phosphinimine complexes in 
different stages of the deprotonation process: the stronger base 4.7 is able to abstract the proton of the alcohol to a higher degree than $\mathbf{4 . 5}$, the weaker base. The electron donating group dimethylamino (4-NMe $)$, at 4-postion of phosphine aryl ring was incorporated to increase the basicity of the phosphinimines. There is no great increase in the basicity observed going from two 4-NMe substituted to three 4-NMe $\mathrm{N}_{2}$ substituted product. The downfield shift of -OH of 2-(9-anthryl)ethanol 4.5-4.8 were $0.84,1.23,2.30$ and 1.97 ppm when 2-(9-anthryl)ethanol was reacted with phosphinimines respectively. The highest $-\mathrm{OH}$ shift of 2-(9-anthryl)ethanol was observed in the 4.7 i.e. $2.30 \mathrm{ppm}$. The higher number of 4-dimethylamino group in $4-\mathrm{CH}_{3} \mathrm{C}_{6} \mathrm{H}_{4} \mathrm{~N}=\mathrm{P}\left(4-\mathrm{C}_{6} \mathrm{H}_{4} \mathrm{~N}\left(\mathrm{CH}_{3}\right)_{2}\right)_{3} 4.8$ was anticipated to result larger $-\mathrm{OH}$ shift than $4-\mathrm{CH}_{3} \mathrm{C}_{6} \mathrm{H}_{4} \mathrm{~N}=\mathrm{P}\left(4-\mathrm{C}_{6} \mathrm{H}_{4} \mathrm{~N}_{(}\left(\mathrm{CH}_{3}\right)_{2}\right)_{2} \mathrm{Ph}$ 4.7. The OH shift of 4.8 was observed lower than 4.7. We consider that steric factor decreases the -OH shift in case of 4.8. ${ }^{1} \mathrm{H}$ NMR of known system like DBU and TBD was recorded in $\mathrm{C}_{6} \mathrm{D}_{6}$ at $25^{\circ} \mathrm{C}$. DBU or TBD was mixed with 2-(9-anthryl)ethanol (AnOH) in 1:1 ratio in $\mathrm{C}_{6} \mathrm{D}_{6}$ and ${ }^{1} \mathrm{H}$ NMR spectroscopy obtained. The DBU and TBD show the -OH shift of 3.30 and $4.00 \mathrm{ppm}$ shift in the ${ }^{1} \mathrm{H}$ NMR spectroscopy (Scheme 4.9).

\section{B. 3. Polymerization of lactide by tolyl-phosphinimines}

The catalytic behavior of tolyl phosphinimine 4.5-4.8 in the polymerization of lactide was studied in deuterated chloroform at $25{ }^{\circ} \mathrm{C}$ using 1-pyrene-4-butanol (PyOH) as the alcohol initiator with 1 equivalents of phosphinimine relative to initiation alcohol and 100 equivalent of L-lactide. Phosphinimine 4.5-4.8 do not show any catalytic activity towards ring opening polymerization of lactide when 1 equivalent phosphinimine, 1 equivalent of $\mathrm{PyOH}$ and 100 equivalent of L-lactide used for 24 hours at $25^{\circ} \mathrm{C}$ under $\mathrm{N}_{2}$. 
We tried ROP of lactide using PyOH and 9-anthrylethanol as alcohol initiator and benzyl bis(4-dimethylaminophenyl)phosphinimine as catalyst. With $\mathrm{PyOH}$ as alcohol initiator 95 \% conversion in 24 hours in $\mathrm{CD}_{2} \mathrm{Cl}_{2}$ of the L-lactide to poly-L-lactide was observed. Polymerization of L-lactide does not occur when $\mathrm{AnOH}$ was used in the similar condition with PyOH. We consider steric bulk of alcohol plays a role in the ROP of L-lactide. $\mathrm{PyOH}$ as well as 2-(9-anthryl)ethanol both alcohols are solid and easy to handle. We use 2-(9-anthryl)ethanol for most of our alcohol activation reactions. However, 2-(9anthryl)ethanol does not show any reactivity with lactide so we used $\mathrm{PyOH}$ for all lactide polymerization reaction. $\mathrm{PyOH}$ is expensive ( $\$ 90$ per gm) hence we use only in mg scale polymerization reactions.

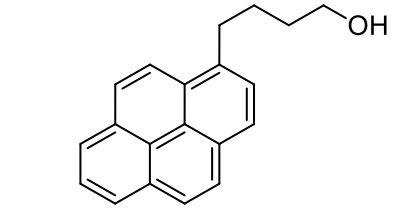

1-pyrene-4-butanol (PyOH)

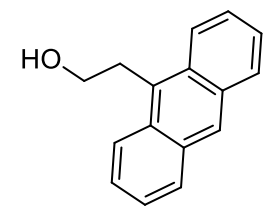

9-anthrylethanol (AnOH)

Figure 4.5. Alcohol initiators for ROP

Even using 4 equivalent of Phosphinimine 4.5-4.7 does not show any catalytic activity towards ROP of L-lactide for 24 hours at $25{ }^{\circ} \mathrm{C}$ under $\mathrm{N}_{2}$. tris(4dimethylaminophenyl)phosphinimine $\mathbf{4 . 8}$ shows catalytic acitivity towards the ROP of Llactide when 4: $1: 100$ (catalyst : $\mathrm{PyOH}: \mathrm{L}$-lactide) is used. The rate of ROP is $13 \%$ at 3 hours, $25 \%$ at 9 hours, and $41 \%$ at $24 \mathrm{hrs}$. The conversion of the lactide monomer to polylactide chain was measured by the ratio of the integrations of the ${ }^{1} \mathrm{H}$ NMR signal of the methine proton of the monomer compared to those of the polymers.

\section{C. Phenylethyl triarylphosphinimines}




\section{C.1. Synthesis of phenylethyl triarylphosphinimines}

Series of electron rich phenylethyl phosphimines 4.9-4.12 were synthesized by the Staudinger reaction of phenylethyl azide and corresponding phosphines respectively. When phosphines were added to the toluene solution or azides rapid nitrogen evolution was observed at $25{ }^{\circ} \mathrm{C}$ and all reactions were completed in 16 hours at ambient temperature phenylethyl phosphinimines 4.9-4.10 were isolated as a white solid and 4.114.12 yellow solid. Phosphinimines 4.9-4.12 were characterized with ${ }^{1} \mathrm{H},{ }^{13} \mathrm{C},{ }^{31} \mathrm{P}$ NMR (Table 4.1). The ${ }^{31} \mathrm{P}$ NMR chemical shift for the isolated phosphinimines falls in the range of 4.4-9 ppm which is consistent with the values for the aryl phosphinimines

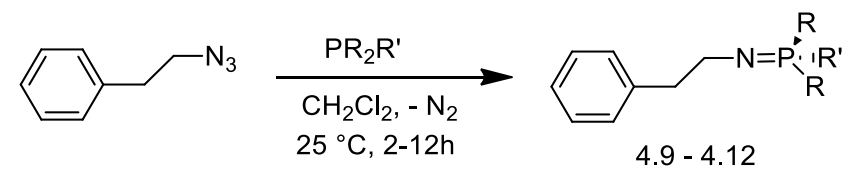

Scheme 4.11. Synthesis of phosphinimine by Staudinger reaction reported in the literature. ${ }^{2}$ Staudinger reaction between phenylethyl azide and triphenylphosphine $\left(\mathrm{PPh}_{3}\right)$ diphenyl(4-dimethylaminophenyl) phosphine; $\mathrm{PPh}_{2}(4-$ $\left.\mathrm{C}_{6} \mathrm{H}_{4} \mathrm{NMe}_{2}\right)_{2}$, or phenyl bis(4- dimethyl aminophenyl) phosphine; $\mathrm{PPh}\left(4-\mathrm{C}_{6} \mathrm{H}_{4} \mathrm{NMe}_{2}\right)_{2}$ or tris(4-diaminomethylphenyl)- phosphine; $\mathrm{P}\left(4-\mathrm{C}_{6} \mathrm{H}_{4} \mathrm{NMe}_{2}\right)_{3}$ produce phosphinimines 4.9-

\subsection{2.}
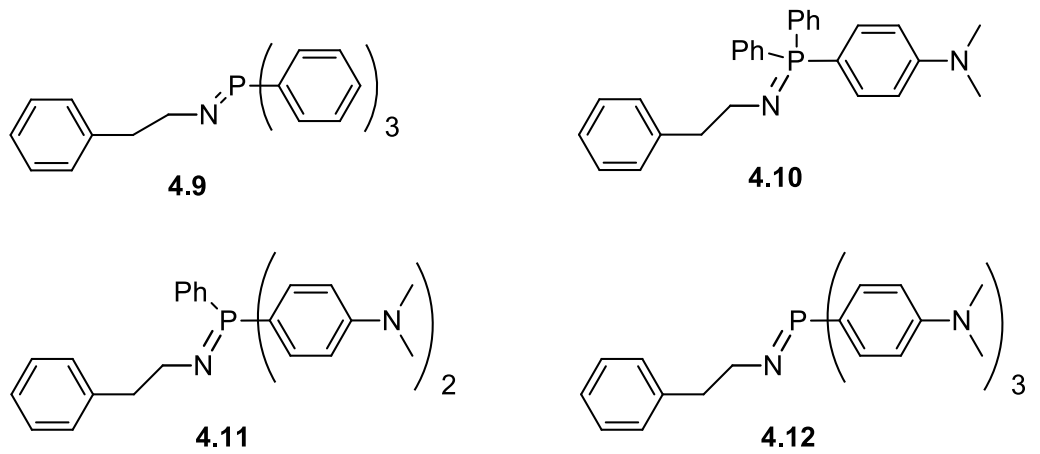

Figure 4.6. Phenylethyl Phosphinimine 4.8-4.11 
Phenylethyl phosphinimines 4.9-4.12 were synthesized in 1-2 gm scale and obtained from moderate to high yield. Thus obtained phosphinimines were characterized with ${ }^{1} \mathrm{H}$, ${ }^{13} \mathrm{C},{ }^{31} \mathrm{P}$ NMR (Table 4.3). The single peak of the ${ }^{31} \mathrm{P}$ NMR from $\delta 0.02 \mathrm{ppm}-7.25 \mathrm{ppm}$ suggest single component in the product obtained.

\begin{tabular}{|c|c|c|c|}
\hline Compd. & Yield(gm) & \% Yield & $\mathbf{\delta}\left({ }^{\mathbf{3}} \mathbf{P}\right) \mathbf{p p m}$ \\
\hline $\mathbf{4 . 1 1}$ & 0.8 & 50 & 4.4 \\
\hline $\mathbf{4 . 1 2}$ & 0.8 & 60 & 5.5 \\
\hline $\mathbf{4 . 1 3}$ & 1.2 & 60 & 6.3 \\
\hline $\mathbf{4 . 1 4}$ & 0.8 & 70 & 9 \\
\hline
\end{tabular}

Table 4.4. Yield, $\%$ Yield and ${ }^{31} \mathrm{P}$ shifts $\left(\mathrm{C}_{6} \mathrm{D}_{6}\right)$ of phosphinimines 4.11-4.14

\section{C.2. Alcohol activation by phenylethyl phosphinimines}

All phosphinimines 4.5-4.8 were mixed with 9-anthrylethanol in 1:1 ratio in deuterated benzene and ${ }^{1} \mathrm{H}$ and ${ }^{31} \mathrm{P}$ NMR spectroscopy obtained (Table 4.4). The addition of phosphinimine 4.5 to $\mathrm{AnOH}$ resulted -OH signal shift in the ${ }^{1} \mathrm{H}$ NMR spectroscopy, which indicates some degree of interaction.

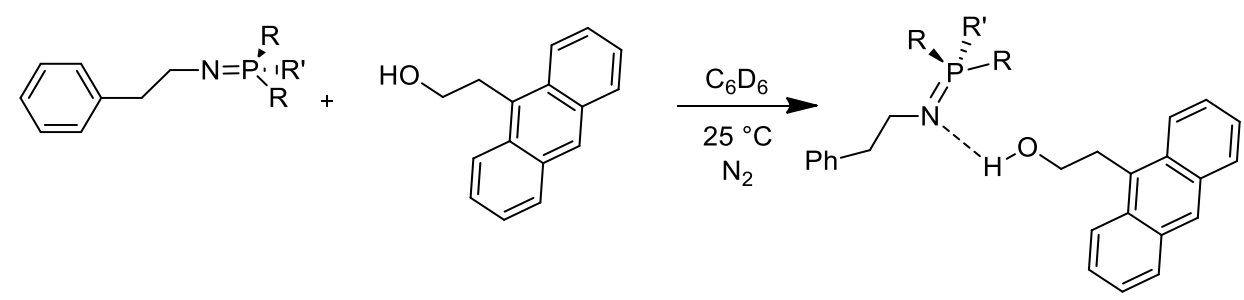

Scheme 4.12. Activation of phosphinimines with alcohol (AnOH)

The gradual increase of $-\mathrm{OH}$ shift in the ${ }^{1} \mathrm{H}$ NMR spectra, going from phosphinimine 4.9 and 4.10 to phosphinimine 4.11 was observed. Phosphinimine 4.9 resulted in the appearance of a single broad resonance at $\delta 2.17 \mathrm{ppm}$, which most likely 
represents significantly deshielded alcoholic protons (entry 4.9, Table 4.4). In contrast, a broad signal is observed at $\delta 3.53 \mathrm{ppm}$ in the presence of phosphinimine 4.11. Most

\begin{tabular}{|c|c|c|c|c|}
\hline Compd. & $\boldsymbol{\delta}(\mathbf{O H}) \mathbf{p p m}$ & $\begin{array}{c}\boldsymbol{\delta}\left({ }^{\mathbf{3}} \mathbf{P}\right) \\
\mathbf{p p m}\end{array}$ & $\boldsymbol{\Delta} \boldsymbol{\delta}(\mathbf{O H}) \mathbf{p p m}$ & $\begin{array}{c}\Delta \boldsymbol{\delta}\left({ }^{\mathbf{3}} \mathbf{P}\right) \\
\mathbf{p p m}\end{array}$ \\
\hline $\mathbf{4 . 1 1}$ & 2.17 & 4.38 & 1.40 & 0.02 \\
\hline $\mathbf{4 . 1 2}$ & 3.10 & 9.96 & 2.40 & 4.46 \\
\hline $\mathbf{4 . 1 3}$ & 4.30 & 11.60 & 3.53 & 5.3 \\
\hline $\mathbf{4 . 1 4}$ & 4.26 & 16.25 & 3.49 & 7.25 \\
\hline
\end{tabular}

Table 4.5. Alcohol H shift (in blue) by H-hydrogen bonding activation

likely, this series of spectra show AnOH-phosphinimine complexes in different stages of the deprotonation process: the stronger base $\mathbf{4 . 1 1}$ is able to abstract the proton of the alcohol to a higher degree than 4.10, the weaker base. The downfield shift of the hydroxyl resonance of the alcohol is the clear indication of the intermolecular hydrogen bonding between phosphinimines and anthrylethanol. Phenylethyl substituted phosphinimines enhances basicity vs tolyl substituted as observed in hydroxyl resonance of the alcohol shift. The least basic phosphinimine i.e; phenylethyltriphenyl 

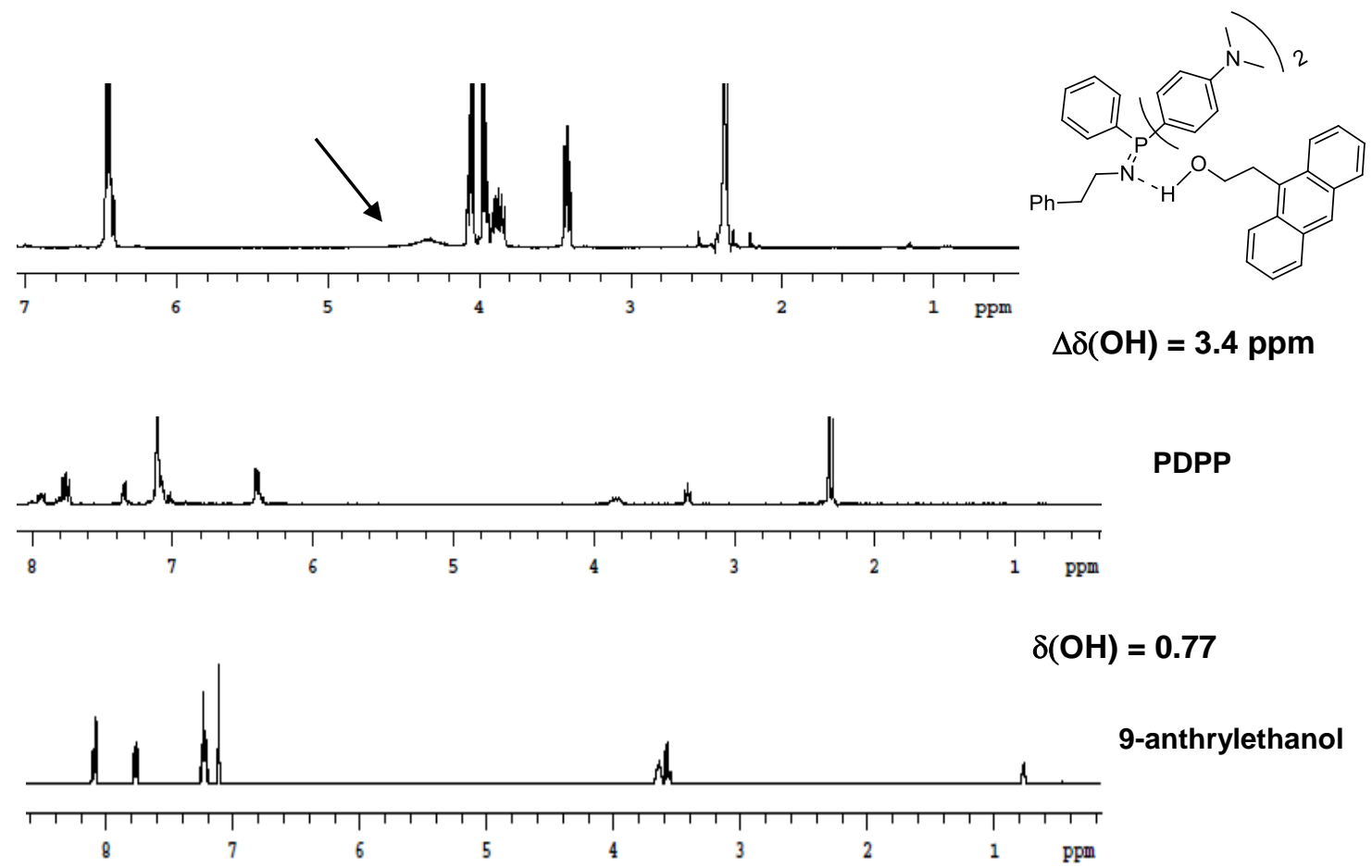

Figure 4.7. ${ }^{1} \mathrm{H}$ NMR of activation of phosphinimine with alcohol

phosphinimine 4.9 show $1.40 \mathrm{ppm}$ alcohols $-\mathrm{OH}$ shift that is comparative with the first organocatalyst DMAP for ROP of lactide studied by Hendrick et al.

\section{C.3. Polymerization of lactide by phenylethyl phosphinimines}

The catalytic behavior of phosphinimines towards the polymerization of lactide was studied in non-hydrogen bonding solvent, deuterated chloroform. 1 equivalent phosphinimines, 1 equivalent of pyrenebutanol (PyOH) and 100 equivalents of L-lactide were used, $\mathrm{t}=24$ hours at $25{ }^{\circ} \mathrm{C}$ under $\mathrm{N}_{2}$. Phosphinimine bases 4 equivalents enhance catalytic activity towards ROP of L-lactide as well as selectivity of the product compared to 1 equivalent.

The catalytic behavior of phenylethyl trisphenylphosphinimine (PTPP) in the polymerization of lactide was studied in deuterated chloroform at $25{ }^{\circ} \mathrm{C}$ using 
pyrenebutanol as the alcohol initiator with 1 and 4 equivalents of phosphinimine PTPP relative to initiator alcohol and 100 equivalent of L-lactide at $25{ }^{\circ} \mathrm{C}$ under $\mathrm{N}_{2}$ are shown

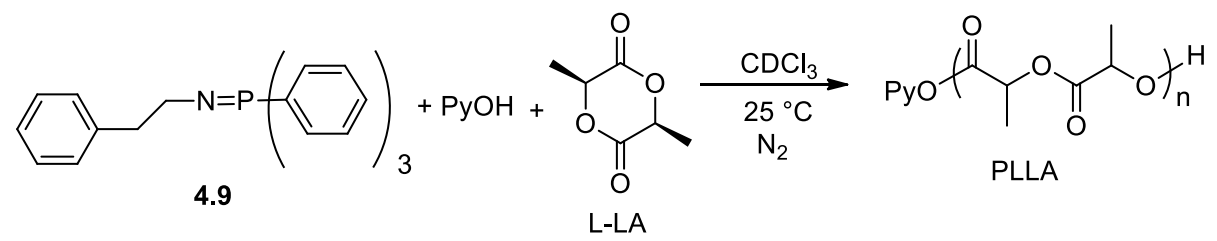

Scheme 4.13. phosphinimines 4.9 catalyzed ROP of lactide

in the Table 4.6. The catalytic activity of 1 equivalent PTTP show $10 \%$ PLA at 6 hours and $28 \%$ at 24 hours with 1 equivalent of $\mathrm{PyOH}$ and $[\mathrm{M}] /[\mathrm{I}]=100.4$ equivalents of PTTP show $60 \%$ PLA in 6 hours $92 \%$ at 24 hours (Figure 4.6).

The side product protonated phosphinimine was observed when 1 equivalent of phosphinimine was used while 4 equivalent of phosphinimine suppressed the formation

\begin{tabular}{|l|l|l|l|}
\hline S.N. & Cat.: init.: L-LA = 1:1:100 & S.N. & Cat.: init. : L-LA = 4:1:100 \\
\hline 1. & 6 hrs. $=10 \%$ (Protonated & 1. & 6 hrs. $=60 \%$ \\
\hline 2. & 24 hrs. $=28 \%$ & 2. & 24 hrs. $=92 \% \quad$ (NO \\
\hline
\end{tabular}

Table 4.6. Phosphinimine 4.9 activity toward ROP of lactide

of side product protonated phosphinimine. 4 equivalents of the phosphinimine base enhance the catalytic activity towards ROP of L-lactide as well as selectivity of the product compared to 1 equivalent. The catalytic behavior of phenylethyl (4dimethylaminophenyl) diphenyl phosphinimine (PDDP) in the polymerization of lactide was studied in deuterated chloroform at $25^{\circ} \mathrm{C}$ using pyrenebutanol as the alcohol initiator 
with 1 and 4 equivalents of phosphinimine PDDP relative to initiator alcohol and 100 equivalent of L-lactide at $25^{\circ} \mathrm{C}$ under $\mathrm{N}_{2}$.

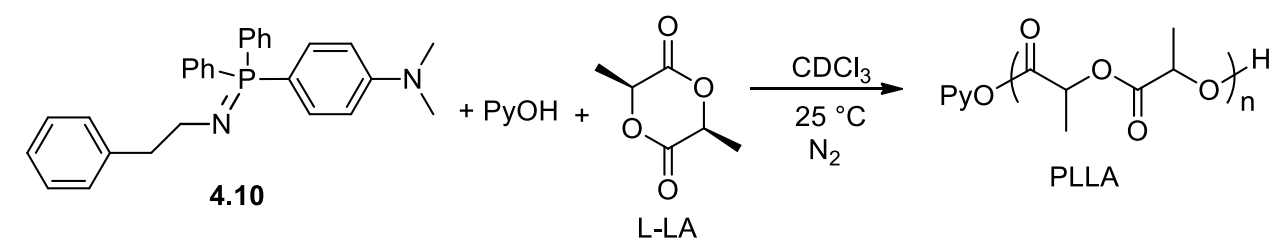

Scheme 4.14. Phosphinimines PDDP catalyzed ROP of lactide

The catalytic activity of 1 equivalent 4.9 show $4 \%$ PLA at 24 hours and $28 \%$ at 24 hours with 1 equivalent of $\mathrm{PyOH}$ and $[\mathrm{M}] /[\mathrm{I}]=100.4$ equivalent of PDDP show $59 \%$ PLA in 5 minutes $100 \%$ at 30 minutes (Figure 4.7).

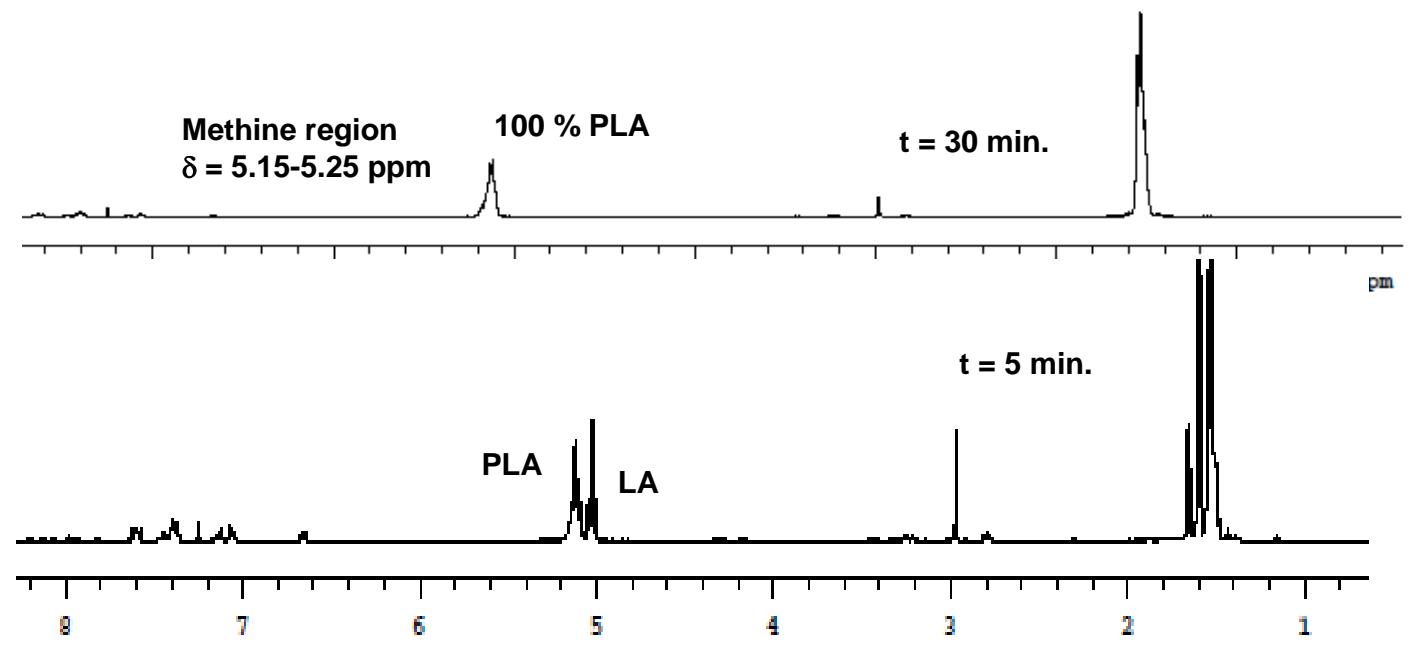

Figure 4.8. ${ }^{1} \mathrm{H}$ NMR showing polylactide (PLA) formation at $5 \mathrm{~min}$ and $25 \mathrm{~min}$.

The side product protonated phosphinimine was observed when 1 equivalent of phosphinimine was used while 4 equivalents of phosphinimine suppressed the formation DMAP, the first organic catalyst for the ROP of lactide reported that no polymerization occurred without addition of alcohol nucleophile. Phosphinimine 4.10 also catalyzes the 


\begin{tabular}{|l|l|l|l|}
\hline S.N. & Cat. : init. : L-LA = 1:1:100 & $\begin{array}{l}\text { Cat. : init. : L- } \\
\text { LA = 4:1:100 }\end{array}$ & $\begin{array}{l}\text { Cat. : init. : L-LA = 4:0:100 } \\
\text { (Absence of alcohol) }\end{array}$ \\
\hline 1. & phosphinimine observed) & PLA $\mathrm{hr}=4 \%$ PLA (protonated & 5 min. $=12 \%$ PLA \\
\hline 2. & & 30 min. $=100 \%$ & 3 hrs. $=100 \%$ \\
& & pho protonated & protonated \\
& & observed) & phosphinimine observed) \\
\hline
\end{tabular}

Table 4.7. Phosphinimine 4.10 (PDDP) activity toward ROP of lactide polymerization of LA in the absence of an initiating alcohol with 4 mol \% catalyst loading; LA is polymerized $12 \%$ conversion after 5 minutes and $100 \%$ conversion after 3 hours. This is slower than polymerization in the presence of alcohol (100\%, 30 minutes)

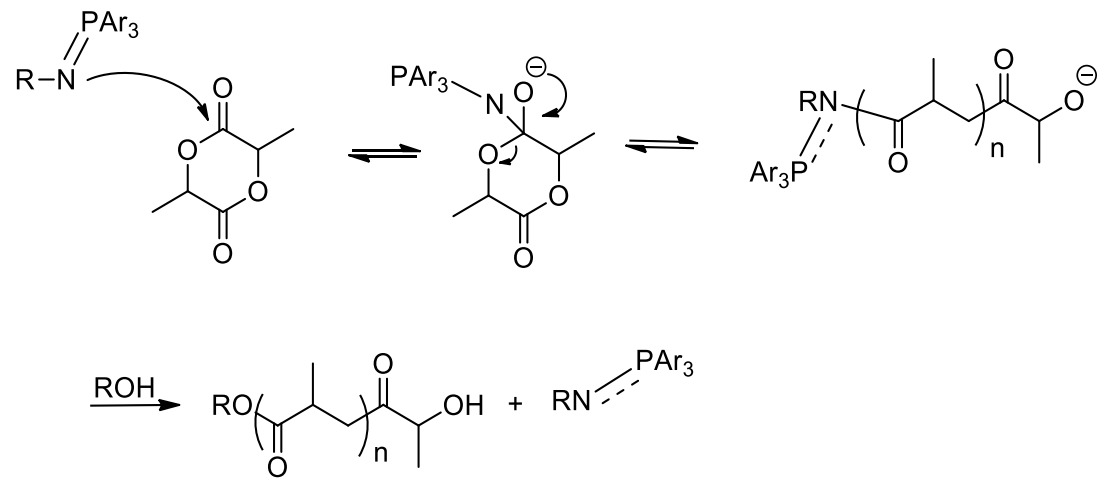

Scheme 4.15. Proposed Nucleophilic activation mechanism

using phosphinimine 4.10, in agreement with the proposed $\mathrm{H}$ bond activation mechanism is efficient. The mechanism of ROP of lactide was originally proposed via a nucleophilic 
monomer activation mechanism. ${ }^{4,20}$ The computational studies suggest an alcohol activation mechanism may be favorable. ${ }^{6}$

Our experiments with phosphinimine bases show that the ROP of lactide proceed with or without alcohol. However, addition of the alcohol initiator enhances the rate to the reaction ( 3 hours vs 30 minutes). Our experiment suggests that both pathways are accessible for ROP of lactide polymerization.

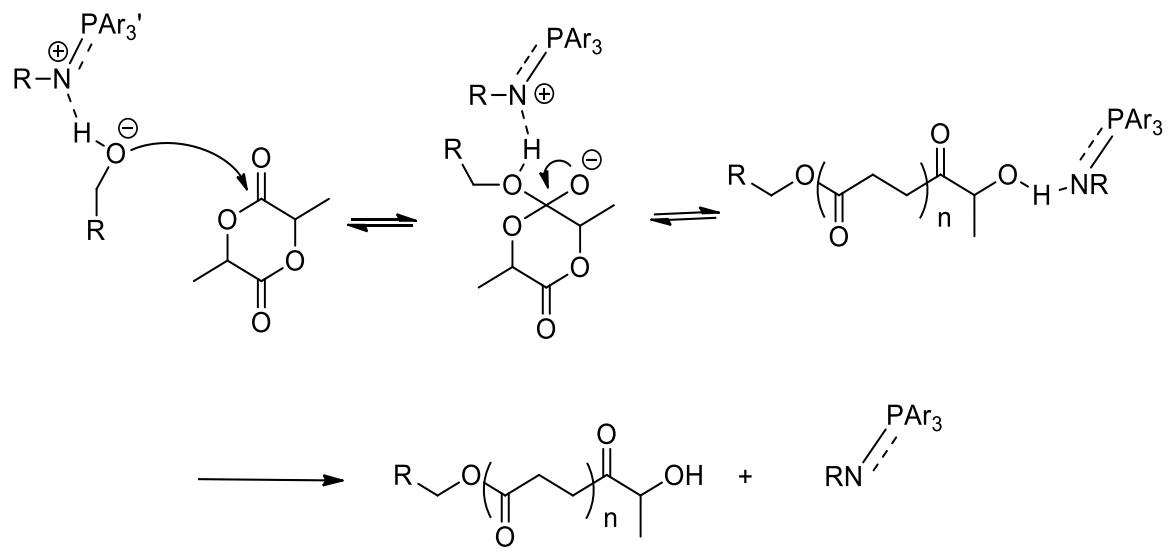

Scheme 4.16. Proposed H-bond activation mechanism

The catalytic behavior of phenylethyl-bis(4-N,N-dimethylaminophenyl) phenyl phosphinimine 4.11 (PDPP) in the polymerization of lactide was studied in deuterated chloroform at $25^{\circ} \mathrm{C}$ using pyrenebutanol as the alcohol initiator with 1 and 4 equivalents of phosphinimine 4.11 relative to initiator alcohol and 100 equivalent of L-lactide at 25 ${ }^{\circ} \mathrm{C}$ under $\mathrm{N}_{2}$ are shown in the Scheme 4.17.

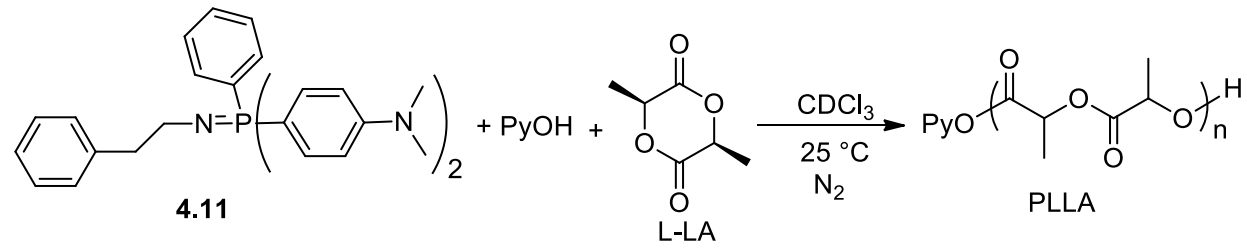

Scheme 4.17. Phosphinimines PDDP catalyzed ROP of lactide 
The catalytic activity of 1 equivalent phosphinimine 4.11 show $25 \%$ PLA at 5 minutes and $96 \%$ at 24 hours with 1 equivalent of $\mathrm{PyOH}$ and $[\mathrm{M}] /[\mathrm{I}]=100.4$ equivalent of PDDP show $96 \%$ PLA in 5 minutes Table 4.7.

The side product protonated phosphinimine was observed when 1 equivalent of phosphinimine was used while 4 equivalents of phosphinimine suppressed the formation of side product protonated phosphinimine. Phosphinimine Phenylethyl tris-N,N-

\begin{tabular}{|l|l|l|}
\hline S.N. & Cat. $:$ init. : L-LA = 1:1:100 & Cat. $:$ init. $:$ L-LA = 4:1:100 \\
\hline 1. & $\begin{array}{l}5 \text { min. }=25 \% \\
\text { (protonated phosphinimine observed) }\end{array}$ & $\begin{array}{l}\text { (NO protonated phosphinimine } \\
6 \text { hrs. }=96 \%\end{array}$ \\
\end{tabular}

Table 4.8. Phosphinimine 4.11 activity toward ROP of lactide dimethyaminolphenyl 4.12 (PTPP) catalyzes the polymerization of L-LA as well as rac-LA in the in presence of an initiating alcohol; pyrenebutanol with 4 mol \% catalyst loading LA in 5 minutes. Phosphinimine PTTP also catalyzes the polymerization of LLA in the presence anthrylethanol as an initiating alcohol.

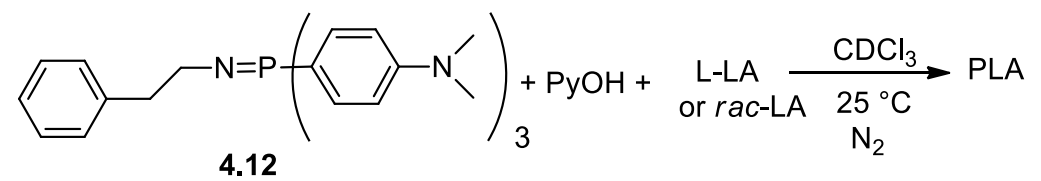

Scheme 4.18. Phosphinimines PTPP catalyzed ROP of lactide

However, the reaction rate is slower than that achieved with initiating anthrylethanol giving i.e. $28 \%$ conversion in 5 minutes. The slow initiation was probably due to the steric of anthrylalcohol in the closer proximity with the hydroxyl group. 
Commercially available phosphinimine bases 2-tert-butylimino-2-diethylamino1,3-dimethylperhydro-1,3,2-diazaphosphorine (BEMP) $\left(\mathrm{Pk}_{\mathrm{BH}+}(\mathrm{MeCN})=27.6\right)$ and $\mathrm{N}-$ tert-butyl-hexamethylphosphorimidic triamide $\left(\mathrm{P}^{1}-t-\mathrm{Bu}\right)$ have been used for ROP of lactide. The catalytic activity of BEMP was studied in dry toluene at room temperature for polymerization with $[\mathrm{M}] /[\mathrm{I}]=100$ using pyrenebutanol as the initiator. BEMP $(2 \mathrm{~mol}$ \%) polymerize L-lactide in 33 hours with $95 \%$ conversion with $[\mathrm{M}] /[\mathrm{I}]=100$ using pyrenebutanol as the initiator. The $\mathrm{P}^{1}-t-\mathrm{Bu}(1 \mathrm{~mol} \%)$ polymerize L-lactide in 70 hours

\begin{tabular}{|l|l|l|l|}
\hline S.N. & $\begin{array}{l}\text { Cat. : init. : L-LA }= \\
\text { 1:1:100 }\end{array}$ & Cat. : init. : L-LA /rac-LA & $\begin{array}{l}\text { Cat. } \\
\text { 9:1:100 } \\
\text { anthrylethanol: L-LA } \\
=4: 1: 100\end{array}$ \\
\hline 1. & $\begin{array}{l}\text { phosphinimine observed) } \\
24 \text { hrs. }=9 \%\end{array}$ & $\begin{array}{l}\text { min. }=7 \% \text { (protonated } \quad(\mathrm{NO} \text { protonated } \\
\text { phosphinimine observed) }\end{array}$ & $\begin{array}{l}5 \text { min. }=28 \% \text { (sterics) } \\
\text { phosphinimine } \\
\text { observed) }\end{array}$ \\
\hline
\end{tabular}

Table 4.9. Phosphinimine 4.12 activity toward ROP of lactide with $82 \%$ conversion with $[\mathrm{M}] /[\mathrm{I}]=100$ using pyrenebutanol as the initiator. ${ }^{16}$ The polymerization activity reported is based on the ${ }^{1} \mathrm{H}$ NMR spectroscopy. However, ${ }^{31} \mathrm{P}$ NMR of the phosphinimine was not reported in their study. It is not clear whether these phosphinimines are protonated or not, which is the common side reaction, we observed with 1 equivalent of phosphinimine in our study. 

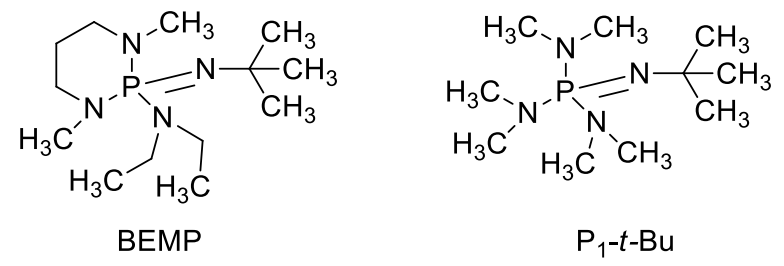

Figure 4.9. Chemical structure of phosphinimine bases

\section{C.4. Order of reactivity of phenethyl phosphinimines towards ROP of L-LA}

(Cat. : initiator : monomer $=4: 1: 100) / \mathrm{Ar}=\mathrm{PhCH}_{2} \mathrm{CH}_{2}$

\begin{tabular}{|c|c|c|c|}
\hline Tris & Bis & Mono-4-dimeamino & Triphenyl \\
\hline $\begin{array}{l}\mathrm{Ar}-\mathrm{N}=\mathrm{P}\left(\mathrm{N}_{3}^{\prime}\right)_{3} \\
\text { Most reactive, } \\
\delta(\mathrm{OH})=3.49\end{array}$ & $\begin{array}{l}\mathrm{Ar}-\mathrm{N}=\mathrm{Ph} \\
\delta(\mathrm{OH})=3.53\end{array}$ & & $\begin{array}{l}\mathrm{Ar}-\mathrm{N}=\mathrm{P} \\
\text { Least reactive } \\
\delta(\mathrm{OH})=1.4\end{array}$ \\
\hline $\begin{array}{l}\text { PTPP (4.12) } \\
t=5 \text { minutes } \\
\text { L-LA or DL-LA = } \\
100 \%\end{array}$ & $\begin{array}{l}\text { PDPP (4.11) } \\
t=5 \text { minutes } \\
\text { PLLA }=96 \%\end{array}$ & $\begin{array}{l}\text { PDDP }(\mathbf{4 . 1 0}) \\
\mathrm{t}=5 \text { minutes } \\
\text { PLLA }=59 \% \\
\mathrm{t}=30 \text { mins. } \\
\text { PLA }=100 \%\end{array}$ & $\begin{array}{l}\text { PTTP }(\text { 4.9) } \\
\mathrm{t}=5 \text { minutes } \\
\text { PLLA }=8 \% \\
\mathrm{t}=24 \mathrm{hrs}, \\
\text { PLA }=92 \%\end{array}$ \\
\hline
\end{tabular}

Table 4.10. Order of reactivity of various phosphinimines

A second method for the ROP of lactide is through bifunctional catalyst system that makes use of hydrogen bonding to the initiating alcohol as well as electrophilic 


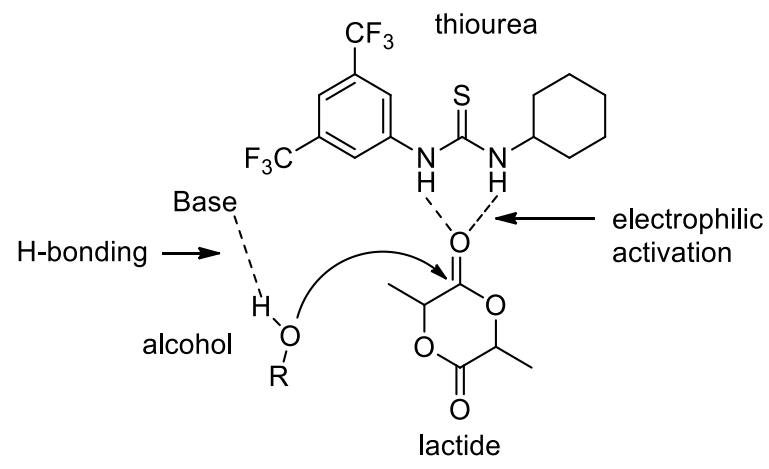

Scheme 4.19. Electrophilic activation by thiourea and H-bonding activation by base activation of the lactide to facilitate ROP (Scheme 4.20).

Having a cocatalyst that facilitates ester activation towards nucleophilic attack allows for the use of less basic compounds that cause minimal side reactions during ROP. The cocatalyst electrostatically interacts with the monomer carbonyl group providing electrophilic activation for subsequent addition of hydroxyl groups. 4.7 (4 equivalents) in presence of $\mathrm{PyOH}$ in $\mathrm{CDCl}_{3}$ does not show any catalytic activity toward $\mathrm{ROP}$ of lactide.

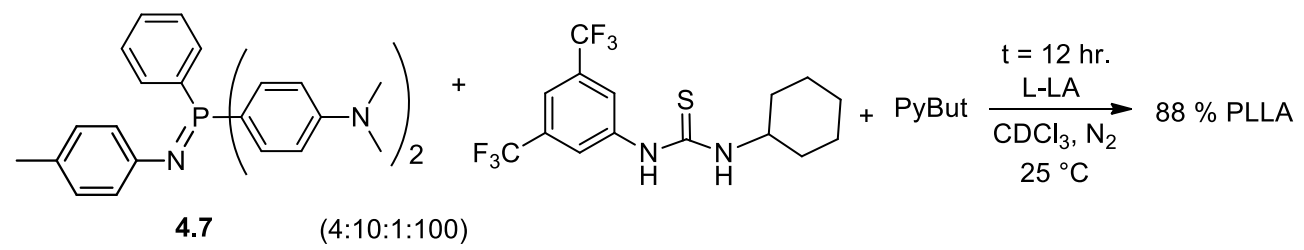

Scheme 4.20. Phosphinimines PTTP catalyzed ROP of lactide

The weakly basic tolyl phosphinimine in the presence of thiourea and alcohol showed catalytic activity. Phospinimine 4.6 alone does not show any catalytic activity but addition of thiourea, $\mathrm{H}$ donor catalyst enhances its activity for ROP of lactide (Scheme 4.21).

\section{D. Conclusion}

The series of tolyl/phenylethyl phosphinimines are synthesized by Staudinger reaction between azide and various phosphines 4.5-4.12 in 1-2 gm scale and obtained 
from moderate to high yield. These phosphinimines were characterized with ${ }^{1} \mathrm{H},{ }^{13} \mathrm{C},{ }^{31} \mathrm{P}$ NMR. The single peak in the ${ }^{31} \mathrm{P}$ NMR suggests a single component in the product obtained. In general, the substitution of the electron donating group in the phosphinimine aryl ring enhances the basicity of the phosphinimines. The correlation between the basicity of the phosphinimines and the downfield shift of the alcohol hydroxyl group when activated by phosphinimine was observed. The catalytic activity of these phosphinimines towards ring opening polymerization of lactide is evaluated by alcohol hydroxyl proton shift when interact with an alcohol (1:1) in non-hydrogen bonding solvent $\mathrm{CDCl}_{3}$ at $25{ }^{\circ} \mathrm{C}$ under $\mathrm{N}_{2}$ atmosphere. These phosphinimines were tested for ROP of lactides and their correlation with the basicity estimated with alcohol activation was shown. Phenylethyl phosphinimines 4.9-4.12 represent highly active catalysts for ROP under $\mathrm{N}_{2}$ at ambient temperature. Weakly basic tolyl phosphinimine 4.7 in the presence of thiourea and alcohol initiator showed catalytic activity. The bifunctioanl catalyst system makes use of both hydrogen bonding to the initiating alcohol and electrophilic activation of the cyclic ester to facilitate ROP (Figure 4.21). Having cocatalyst that facilitates ester activation towards nucleophilic attack allows for the use of less basic phosphinimines that causes minimal side reactions during ROP. The phosphinimine 4.8 reacts with lactide monomer even in absence of alcohol initiate with reasonable reaction rate. This experiment revealed that initiating alcohol is not required with phosphinimines to initiate the ROP of lactide. However, the addition of alcohol enhances the rate of the reaction. We anticipate that the ease of handling of these catalysts, combined with their high reactivity on the ROP of lactide will make them useful to the synthetic community. 


\section{REFERENCES}

1. Dove, A. P.; Gibson, V. C.; Marshall, E. L.; Rzepa, H. S.; White, A. J. P.; Williams, D. J., Journal of the American Chemical Society 2006, 128 (30), 98349843.

2. (a) Drumright, R. E.; Gruber, P. R.; Henton, D. E., Advanced Materials 2000, 12 (23), 1841-1846; (b) Gross, R. A.; Kalra, B., Science 2002, 297 (5582), 803-807.

3. Williams, C. K.; Hillmyer, M. A., Polymer Reviews 2008, 48 (1), 1-10.

4. Stanford, M. J.; Dove, A. P., Chemical Society Reviews 2010, 39 (2), 486-494.

5. Platel, R. H.; Hodgson, L. M.; Williams, C. K., Polymer Reviews 2008, 48 (1), $11-63$.

6. $\quad$ Petrus, R.; Sobota, P., Organometallics 2012, 31 (13), 4755-4762.

7. (a) Chen, H.-Y.; Peng, Y.-L.; Huang, T.-H.; Sutar, A. K.; Miller, S. A.; Lin, C.-C., Journal of Molecular Catalysis a-Chemical 2011, 339 (1-2), 61-71; (b) Chuang, H. J.; Weng, S. F.; Chang, C. C.; Lin, C. C.; Chen, H. Y., Dalton Transactions 2011, 40 (37), 9601-9607.

8. Sodergard, A.; Stolt, M., Progress in Polymer Science 2002, 27 (6), 1123-1163.

9. Carothers, W. H.; Dorough, G. L.; Natta, F. J. v., Journal of the American Chemical Society 1932, 54 (2), 761-772.

10. Kamber, N. E.; Jeong, W.; Waymouth, R. M.; Pratt, R. C.; Lohmeijer, B. G. G.; Hedrick, J. L., Chemical Reviews 2007, 107 (12), 5813-5840. 
11. Ragauskas, A. J.; Williams, C. K.; Davison, B. H.; Britovsek, G.; Cairney, J.; Eckert, C. A.; Frederick, W. J.; Hallett, J. P.; Leak, D. J.; Liotta, C. L.; Mielenz, J. R.; Murphy, R.; Templer, R.; Tschaplinski, T., Science 2006, 311 (5760), 484-489.

12. Hormnirun, P.; Sumrit, P., Abstr. Pap. Am. Chem. Soc. 2014, 248, 1.

13. Wheaton, C. A.; Hayes, P. G.; Ireland, B. J., Dalton Transactions 2009, (25), 48324846.

14. Dijkstra, P. J.; Du, H. Z.; Feijen, J., Polymer Chemistry 2011, 2 (3), 520-527.

15. Thomas, C. M., Chemical Society Reviews 2010, 39 (1), 165-173.

16. Cheng, M.; Attygalle, A. B.; Lobkovsky, E. B.; Coates, G. W., Journal of the American Chemical Society 1999, 121 (49), 11583-11584.

17. Chamberlain, B. M.; Cheng, M.; Moore, D. R.; Ovitt, T. M.; Lobkovsky, E. B.; Coates, G. W., Journal of the American Chemical Society 2001, 123 (14), 32293238.

18. (a) Chisholm, M. H.; Patmore, N. J.; Zhou, Z. P., Chem. Commun. 2005, (1), 127129; (b) Cai, C. X.; Amgoune, A.; Lehmann, C. W.; Carpentier, J. F., Chem. Commun. 2004, (3), 330-331.

19. (a) Ryner, M.; Stridsberg, K.; Albertsson, A. C.; von Schenck, H.; Svensson, M., Macromolecules 2001, 34 (12), 3877-3881; (b) Kricheldorf, H. R.; KreiserSaunders, I.; Stricker, A., Macromolecules 2000, 33 (3), 702-709.

20. Coates, G. W., Chemical Reviews 2000, 100 (4), 1223-1252.

21. (a) Labourdette, G.; Lee, D. J.; Patrick, B. O.; Ezhova, M. B.; Mehrkhodavandi, P., Organometallics 2009, 28 (5), 1309-1319; (b) Williams, C. K.; Breyfogle, L. E.; 
Choi, S. K.; Nam, W.; Young, V. G.; Hillmyer, M. A.; Tolman, W. B., Journal of the American Chemical Society 2003, 125 (37), 11350-11359.

22. (a) Darensbourg, D. J.; Choi, W.; Karroonnirun, O.; Bhuvanesh, N., Macromolecules 2008, 41 (10), 3493-3502; (b) Chisholm, M. H.; Gallucci, J. C.; Phomphrai, K., Inorganic Chemistry 2004, 43 (21), 6717-6725; (c) Ho, S. M.; Hsiao, C. S.; Datta, A.; Hung, C. H.; Chang, L. C.; Lee, T. Y.; Huang, J. H., Inorganic Chemistry 2009, 48 (16), 8004-8011; (d) Wanna, N.; Kraithong, T.; Khamnaen, T.; Phiriyawirut, P.; Charoenchaidet, S.; Tantirungrotechai, J., Catalysis Communications 2014, 45, 118-123; (e) Hsiao, M. W.; Wu, G. S.; Huang, B. H.; Lin, C. C., Inorganic Chemistry Communications 2013, 36, 90-95; (f) Hsiao, M. W.; Lin, C. C., Dalton Transactions 2013, 42 (6), 2041-2051; (g) Clark, L.; Deacon, G. B.; Forsyth, C. M.; Junk, P. C.; Mountford, P.; Townley, J. P.; Wang, J., Dalton Transactions 2013, 42 (25), 9294-9312.

23. Garces, A.; Sanchez-Barba, L. F.; Fernandez-Baeza, J.; Otero, A.; Honrado, M.; Lara-Sanchez, A.; Rodriguez, A. M., Inorganic Chemistry 2013, 52 (21), 1269112701.

24. Chapurina, Y.; Klitzke, J.; Casagrande, O.; Awada, M.; Dorcet, V.; Kirillov, E.; Carpentier, J. F., Dalton Transactions 2014, 43 (38), 14322-14333.

25. Klitzke, J. S.; Roisnel, T.; Kirillov, E.; Casagrande, O. D.; Carpentier, J. F., Organometallics 2014, 33 (1), 309-321.

26. (a) Zheng, X.-X.; Zhang, C.; Wang, Z.-X., Journal of Organometallic Chemistry 2015, 783, 105-115; (b) Gao, B.; Li, X.; Duan, R.; Duan, Q.; Li, Y.; Pang, X.; 
Zhuang, H.; Chen, X., RSC Advances 2015, 5 (37), 29412-29419; (c) Yi, W.; Ma, H. Y., Dalton Transactions 2014, 43 (13), 5200-5210.

7. Dove, A. P.; Gibson, V. C.; Marshall, E. L.; White, A. J. P.; Williams, D. J., Chem. Commun. 2001, (03), 283-284.

28. (a) Small, B. L.; Brookhart, M., Journal of the American Chemical Society 1998, 120 (28), 7143-7144; (b) Killian, C. M.; Tempel, D. J.; Johnson, L. K.; Brookhart, M., Journal of the American Chemical Society 1996, 118 (46), 11664-11665.

29. Darensbourg, D. J.; Karroonnirun, O., Inorganic Chemistry 2010, 49 (5), 23602371.

30. Zhang, C.; Sun, W. H.; Wang, Z. X., Eur. J. Inorg. Chem. 2006, (23), 4895-4902.

31. Hung, W. C.; Huang, Y.; Lin, C. C., J. Polym. Sci. Pol. Chem. 2008, 46 (19), 64666476.

32. (a) Jensen, T. R.; Breyfogle, L. E.; Hillmyer, M. A.; Tolman, W. B., Chem. Commun. 2004, (21), 2504-2505; (b) Jensen, T. R.; Schaller, C. P.; Hillmyer, M. A.; Tolman, W. B., Journal of Organometallic Chemistry 2005, 690 (24-25), 58815891.

33. Fliedel, C.; Vila-Vicosa, D.; Calhorda, M. J.; Dagorne, S.; Aviles, T., Chemcatchem 2014, 6 (5), 1357-1367.

34. Piedra-Arroni, E.; Brignou, P.; Amgoune, A.; Guillaume, S. M.; Carpentier, J. F.; Bourissou, D., Chem. Commun. 2011, 47 (35), 9828-9830.

35. Spassky, N.; Wisniewski, M.; Pluta, C.; LeBorgne, A., Macromolecular Chemistry and Physics 1996, 197 (9), 2627-2637. 
36. Nomura, N.; Ishii, R.; Yamamoto, Y.; Kondo, T., Chemistry-a European Journal 2007, 13 (16), 4433-4451.

37. Zhong, Z. Y.; Dijkstra, P. J.; Feijen, J., Angewandte Chemie-International Edition 2002, 41 (23), 4510-+.

38. Tang, Z. H.; Gibson, V. C., European Polymer Journal 2007, 43 (1), 150-155.

39. (a) Tang, Z.; Gibson, V. C., European Polymer Journal 2007, 43 (1), 150-155; (b) Hormnirun, P.; Marshall, E. L.; Gibson, V. C.; White, A. J. P.; Williams, D. J., Journal of the American Chemical Society 2004, 126 (9), 2688-2689.

40. Ovitt, T. M.; Coates, G. W., Journal of the American Chemical Society 2002, 124 (7), 1316-1326.

41. Ovitt, T. M.; Coates, G. W., J. Polym. Sci. Pol. Chem. 2000, 38, 4686-4692.

42. Ovitt, T. M.; Coates, G. W., Stereoselective ring-opening polymerization of mesolactide: Synthesis of syndiotactic poly(lactic acid). Journal of the American Chemical Society 1999, 121 (16), 4072-4073.

43. Bian, S.; Abbina, S.; Lu, Z. L.; Kolodka, E.; Du, G. D., Organometallics 2014, 33 (10), 2489-2495.

44. Garcia-Valle, F. M.; Estivill, R.; Gallegos, C.; Cuenca, T.; Mosquera, M. E. G.; Tabernero, V.; Cano, J., Organometallics 2015, 34 (2), 477-487.

45. Drent, E.; van Dijk, R.; van Ginkel, R.; van Oort, B.; Pugh, R. I., Chemical Communications 2002, (7), 744-745.

46. Burns, C. T.; Shang, S. S.; Thapa, R.; Mashuta, M. S., Tetrahedron Letters 2012, 53 (36), 4832-4835. 
47. Burns, C. T.; Shang, S. S.; Mashuta, M. S., Organometallics 2015, 34 (10), 18441854.

48. Wallis, C. J.; Kraft, I. L.; Patrick, B. O.; Mehrkhodavandi, P., Dalton Transactions 2010, 39 (2), 541-547.

49. Bassin, J. P.; Cremlyn, R. J.; Swinbourne, F. J., Phosphorus Sulfur and Silicon and the Related Elements 1991, 56 (1-4), 245-275.

50. Miller, S. C., Journal of Organic Chemistry 2010, 75 (13), 4632-4635.

51. Blackburn, C.; Achab, A.; Elder, A.; Ghosh, S.; Guo, J. P.; Harriman, G.; Jones, M., Journal of Organic Chemistry 2005, 70 (24), 10206-10209.

52. Braun, T. P.; Gutsch, P. A.; Zeitschrift Fur Naturforschung Section B-a Journal of Chemical Sciences 1999, 54 (7), 858-862.

53. Farrugia, L. J., J. Appl. Crystallogr. 1997, 30.

54. Taft, R. W.; Bordwell, F. G., Accounts of Chemical Research 1988, 21 (12), 463469.

55. (a) Xu, X.; Chen, Y. F.; Zou, G.; Ma, Z.; Li, G. Y., Journal of Organometallic Chemistry 2010, 695 (8), 1155-1162; (b) Tsai, Y. H.; Lin, C. H.; Lin, C. C.; Ko, B. T., J. Polym. Sci. Pol. Chem. 2009, 47 (19), 4927-4936.

56. (a) Abbina, S.; Du, G. D., Acs Macro Letters 2014, 3 (7), 689-692; (b) Yao, W.; Xue, Y. Z.; Liu, T. T.; Gao, A. H.; Wang, Y. F., Chemical Research in Chinese Universities 2014, 30 (1), 87-90.

57. Nederberg, F.; Connor, E. F.; Moller, M.; Glauser, T.; Hedrick, J. L., Angewandte Chemie-International Edition 2001, 40 (14), 2712-2715. 
58. Kiesewetter, M. K.; Shin, E. J.; Hedrick, J. L.; Macromolecules 2010, 43 (5), 20932107.

59. Bonduelle, C.; Martin-Vaca, B.; Cossio, F. P.; Bourissou, D., Chemistry-a European Journal 2008, 14 (17), 5304-5312.

60. Myers, M.; Connor, E. F.; Glauser, T.; Mock, A.; Nyce, G.; Hedrick, J. L., Journal of Polymer Science Part a-Polymer Chemistry 2002, 40 (7), 844-851.

61. Lohmeijer, B. G. G.; Pratt, R. C.; Leibfarth, F.; Logan, J. W.; Long, D. A.; Dove, A. P.; Nederberg, F.; Choi, J.; Wade, C.; Waymouth, R. M.; Hedrick, J. L., Macromolecules 2006, 39 (25), 8574-8583.

62. Chuma, A.; Horn, H. W.; Swope, W. C.; Pratt, R. C.; Zhang, L.; Lohmeijer, B. G. G.; Wade, C. G.; Waymouth, R. M.; Hedrick, J. L.; Rice, J. E., Journal of the American Chemical Society 2008, 130 (21), 6749-6754.

63. Kazakov, O. I.; Datta, P. P.; Isajani, M.; Kiesewetter, E. T.; Kiesewetter, M. K., Macromolecules 2014, 47 (21), 7463-7468.

64. Pratt, R. C.; Lohmeijer, B. G. G.; Long, D. A.; Waymouth, R. M.; Hedrick, J. L., Journal of the American Chemical Society 2006, 128 (14), 4556-4557.

65. Dove, A. P.; Pratt, R. C.; Lohmeijer, B. G. G.; Waymouth, R. M.; Hedrick, J. L., Journal of the American Chemical Society 2005, 127 (40), 13798-13799.

66. Brown Hayley, A.; De Crisci, A. G.; Hedrick, J. L.; Waymouth, R. M., ACS MACRO LETTERS 2012, 1 (9), 1113-1115.

67. Stukenbroeker, T. S.; Bandar, J. S.; Zhang, X.; Lambert, T. H.; Waymouth, R. M., ACS Macro Letters 2015, 853-856.

68. Kim, E.; Jang, J.; Chung, J. S., Macromolecular Research 2014, 22 (8), 864-869. 
69. Zhang, L.; Nederberg, F.; Pratt, R. C.; Waymouth, R. M.; Hedrick, J. L.; Wade, C. G., Macromolecules 2007, 40 (12), 4154-4158.

70. Stephan, D. W.; Stewart, J. C.; Guerin, F.; Courtenay, S.; Kickham, J.; Hollink, E.; Beddie, C.; Hoskin, A.; Graham, T.; Wei, P. R.; Spence, R. E. V.; Xu, W.; Koch, L.; Gao, X. L.; Harrison, D. G., Organometallics 2003, 22 (9), 1937-1947.

71. Kennedy, R. D., Chemical Communications 2010, 46 (26), 4782-4784.

72. du Boullay, O. T.; Marchal, E.; Martin-Vaca, B.; Cossio, F. P.; Bourissou, D., Journal of the American Chemical Society 2006, 128 (51), 16442-16443. 


\section{EXPERIMENTALS}

\section{Experimental Section 1: Ligand synthesis}

\section{(Chapter 2)}

\section{General Experimental}

All manipulations were performed under nitrogen or vacuum using Schlenk or high vacuum techniques or in a nitrogen-filled dry box. Nitrogen was purified by passage through columns containing activated molecular sieves and Q-5 oxygen scavenger. Pentane, hexanes, toluene, benzene, and dichloromethane were purified by passage through columns of activated $4 \AA$ molecular sieves. Diethyl ether and tetrahydrofuran were distilled from $\mathrm{Na}$ /benzophenone ketyl. $\mathrm{CDCl}_{3}$ and $\mathrm{CD}_{2} \mathrm{Cl}_{2}$ were dried over $\mathrm{CaH}_{2}$, degassed by freeze-pump-thaw cycles, and vacuum transferred to a storage vessel. N,N-dimethylethylenediamine, $\mathrm{PPh}_{3}, \mathrm{ZnEt}_{2}, \mathrm{ZnMe}_{2}(2.0 \mathrm{M}$ in toluene) were used as received from Aldrich. DL-Lactide (99\%) was used as received from Alfa Aesar and stored in a nitrogen filled dry box at $-35{ }^{\circ} \mathrm{C}$. 2-Amino-5methylbenzenesulfonyl chloride. ${ }^{46}$ (2.5) was prepared as described in the literature. All other reagents and solvents were purchased from Aldrich and used without further purification. ${ }^{1} \mathrm{H},{ }^{13} \mathrm{C},{ }^{31} \mathrm{P}$ NMR spectra were recorded in Teflon valve sealed tubes on Varian 400 and 500 spectrometers at ambient probe temperature unless otherwise indicated. $\quad{ }^{1} \mathrm{H}$ and ${ }^{13} \mathrm{C}$ chemical shifts are reported 
versus $\mathrm{SiMe}_{4}$ and were determined by reference to the residual ${ }^{1} \mathrm{H}$ and ${ }^{13} \mathrm{C}$ solvent peaks.

${ }^{31} \mathrm{P}$ chemical shifts were referenced to external $85 \%$ aqueous $\mathrm{H}_{3} \mathrm{PO}_{4}$.

\section{X-ray crystallography}

Crystals of $\mathbf{2 . 1 1}$ were grown by slow diffusion of hexanes into a solution of $\mathbf{4}$ dissolved in $\mathrm{CH}_{2} \mathrm{Cl}_{2}$. A colorless plate $0.39 \times 0.19 \times 0.08 \mathrm{~mm}^{3}$ crystal of 2.11 was mounted on a glass fiber for collection of x-ray data on an Agilent Gemini CCD diffractometer. software package (Version 1.171.36.32) was used to acquire a total of 249 thirty-second frame $\omega$-scan exposures of data at $100 \mathrm{~K}$ to a $2 \theta \max =55.56^{\circ}$ using monochromated MoK $\alpha$ radiation $(0.71073 \AA)$ from a sealed tube. Frame data were processed using CrysAlis PRO to determine final unit cell parameters: $\quad a=16.3456(3)$ $\AA, \mathrm{b}=17.2317(3) \AA, \mathrm{c}=18.5291(3) \AA, \alpha=\beta=\gamma=90^{\circ}, \mathrm{V}=5206.7(5) \AA^{3}, D_{\text {calc }}=1.321$ $\mathrm{Mg} / \mathrm{m}^{3}, \mathrm{Z}=8$ to produce raw hkl data that were then corrected for absorption (transmission min. $/ \max .=0.982 / 1.000 ; \mu=0.218 \mathrm{~mm}^{-1}$ ) using SCALE3 ABSPACK in CrysAlis PRO. The structure was solved by Patterson methods in the space group Pbca and refined by least squares methods on $\mathrm{F}^{2}$ using SHELXTL, All non-hydrogen atoms were refined with anisotropic atomic displacement parameters. The amine hydrogen atom was located by difference maps and refined isotropically, as were the methylene and phenyl hydrogen atoms. Methyl hydrogen atoms were calculated and allowed to ride on the attached $\mathrm{C}$ atom, and these atoms were assigned $\mathrm{U}(\mathrm{H})=1.5 \mathrm{x}$ Ueq. For all 6186 unique reflections (R(int) 0.042) the final anisotropic full matrix least-squares refinement on $\mathrm{F}^{2}$ for 420 variables converged at $\mathrm{R} 1=0.037$ and $\mathrm{wR} 2=0.088$ with a GOF of 1.04 . 
Crystals of 3.7 suitable for $\mathrm{x}$-ray analysis were grown by slow diffusion of anhydrous hexanes into a solution of $\mathbf{9}$ dissolved in anhydrous chlorobenzene. X-ray structural analysis for 9 was performed on a $0.38 \times 0.28 \times 0.18 \mathrm{~mm}^{3}$ colorless prism using a similar data acquisition strategy described above for $\mathbf{4}$ to acquire a total of 1,256 twenty-second frame $\omega$-scan exposures at $100 \mathrm{~K}$ to a $2 \theta_{\max }=56.32^{\circ} .9$ crystallizes in the monoclinic space group $\mathrm{I} / \mathrm{a}$ with unit cell parameters: $\mathrm{a}=17.73980(18) \quad \AA, \mathrm{b}=$ 16.25738(12) $\AA, c=23.6267(2) \AA, \beta=110.4401(11)^{\circ}, V=6384.98(10) \AA^{3}, Z=4$ and $D_{\text {calc }}=1.312 \mathrm{Mg} / \mathrm{m}^{3} . \quad 15,632$ raw independent data were corrected for absorption (transmission min. $/ \max .=0.802 / 1.000 ; \mu=0.942 \mathrm{~mm}^{-1}$ ) using SCALE3 ABSPACK. The structure contains two independent molecules of the complex 6 and one 0.60 occupancy chlorobenzene solvate molecule in the asymmetric unit. All non-hydrogen atoms were refined with anisotropic atomic displacement parameters. All hydrogen atoms were placed in their geometric equivalent positions and included as fixed contributions. For all 15,632 unique reflections (R(int) 0.035) the final anisotropic full matrix least-squares refinement on $\mathrm{F}^{2}$ for 726 variables converged at $\mathrm{R} 1=0.036$ and $\mathrm{wR} 2$ $=0.102$ with a GOF of 1.08 and an absolute structure (Flack) parameter of $-0.006(6)$.

Compounds 2.11 and 3.7, their precursors, and corresponding zinc complexes bear a sulfonated toluidine parent structure which has an atom-labeling scheme as follows:

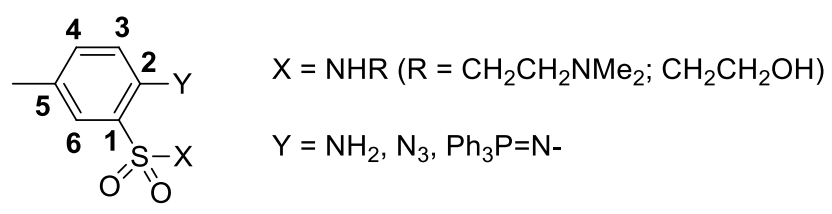




\section{Preparation of compounds}

2-NH $-5-C_{3} \mathbf{C}_{6} \mathbf{H}_{3} \mathbf{S O}_{2} \mathbf{N H}\left(\mathrm{CH}_{2}\right)_{2} \mathbf{N}\left(\mathrm{CH}_{3}\right)_{2}$ (2.9). To a solution of (2.02 mL, $18.43 \mathrm{mmol})$ in $\mathrm{CH}_{2} \mathrm{Cl}_{2}(112 \mathrm{~mL})$, 2-Amino-5-methylbenzenesulfonyl chloride (3.79 $\mathrm{g}, 18.43 \mathrm{mmol})$ was added in portions at $0{ }^{\circ} \mathrm{C}$. A brown solution was observed. After 30 minutes, the reaction mixture was warmed to $25{ }^{\circ} \mathrm{C}$ and stirred for 16 hours, affording a white suspension. The suspension was separated using a silica gel plug (25 g) and 9:1 solution of $\mathrm{CH}_{2} \mathrm{Cl}_{2} / \mathrm{MeOH}$. The fractions $(50 \mathrm{~mL})$ were analyzed by $\mathrm{UV}-\mathrm{Vis}$, and those that contained the product $\left(R_{f}=0.18\right)$ were combined and dried under vacuum yielding 2 as a dark yellow viscous oil $(4.31 \mathrm{~g}, 91 \%) .{ }^{1} \mathrm{H} \mathrm{NMR}\left(\mathrm{CDCl}_{3}\right): \delta 7.49(\mathrm{~s}, 1 \mathrm{H}$, $6-\mathrm{CH}$ of $\left.-\mathrm{C}_{6} \mathrm{H}_{3} \mathrm{SO}_{2}-\right), 7.10\left(\mathrm{dd}, J=7.2,1.2,1 \mathrm{H}, 4-\mathrm{CH}\right.$ of $\left.-\mathrm{C}_{6} \mathrm{H}_{3} \mathrm{SO}_{2}-\right), 6.64(\mathrm{~d}, J=8.4$, $1 \mathrm{H}, 3-\mathrm{CH}$ of $\left.-\mathrm{C}_{6} \mathrm{H}_{3} \mathrm{SO}_{2}-\right), 4.69$ (bs, $\left.2 \mathrm{H}, \mathrm{NH}_{2}\right), 2.88\left(\mathrm{~m}, 2 \mathrm{H},-\mathrm{NHCH}_{2} \mathrm{CH}_{2} \mathrm{~N}\left(\mathrm{CH}_{3}\right)_{2}\right), 2.28$ $\left(\mathrm{m}, 2 \mathrm{H},-\mathrm{NHCH}_{2} \mathrm{CH}_{2} \mathrm{~N}\left(\mathrm{CH}_{3}\right)_{2}\right), 2.24\left(\mathrm{~s}, 3 \mathrm{H}, 5-\mathrm{CH}_{3}\right.$ of $\left.-\mathrm{C}_{6} \mathrm{H}_{3} \mathrm{SO}_{2}-\right), 2.06(\mathrm{~s}, 6 \mathrm{H}$, $\mathrm{NHCH}_{2} \mathrm{CH}_{2} \mathrm{~N}\left(\mathrm{CH}_{3}\right)_{2} .{ }^{13} \mathrm{C} \mathrm{NMR}\left(\mathrm{CDCl}_{3}\right): \delta 142.8,134.9,129.5,127.1,121.1,117.6$, $56.7,44.6,40.1,20.1$.

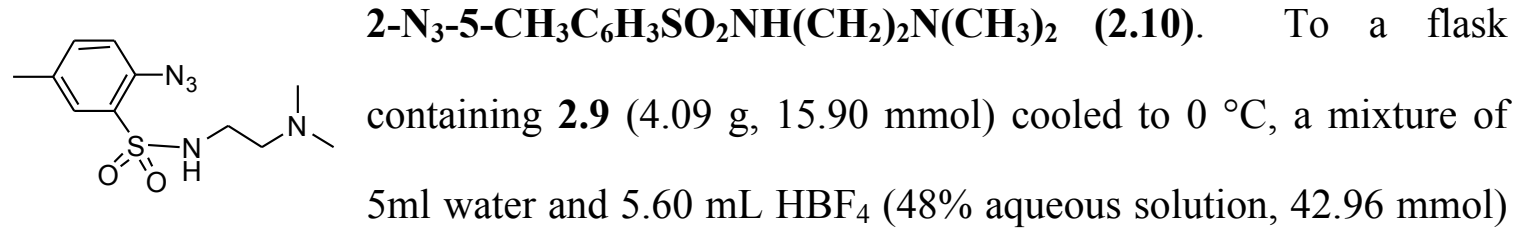
precooled to $0{ }^{\circ} \mathrm{C}$ was added (This and all other following manipulations in this reaction were performed in air). After 15 minutes, a solution of $\mathrm{NaNO}_{2}(1.2 \mathrm{~g}, 17.50 \mathrm{mmol})$ in water $(5 \mathrm{~mL})$ precooled to $0{ }^{\circ} \mathrm{C}$ was added dropwise with vigorous stirring. A red color solution was formed immediately. The mixture was stirred for 1 hour at $0{ }^{\circ} \mathrm{C}$. Urea 
$(0.18 \mathrm{~g}, 2.97 \mathrm{mmol})$ was added and stirred for 15 minutes at $0{ }^{\circ} \mathrm{C}$. Charcoal $(0.09 \mathrm{~g})$ was added and stirred for 10 minutes at $0{ }^{\circ} \mathrm{C}$. A red solution was obtained after a rapid filtration and kept at $0{ }^{\circ} \mathrm{C}$. With vigorous stirring, a $0{ }^{\circ} \mathrm{C}$ solution of $\mathrm{NaN}_{3}(1.76 \mathrm{~g}, 27.05$ mmol) dissolved in water $(5 \mathrm{~mL})$ was added dropwise to the red solution. The mixture was stirred for 1 hour at $0{ }^{\circ} \mathrm{C}$ and 12 hours at $25^{\circ} \mathrm{C}$. After stirring at $25{ }^{\circ} \mathrm{C}$ for 12 hours, a tan suspension was obtained. A tan solid was isolated by vacuum filtration and washed with $30 \mathrm{~mL} 10 \% \mathrm{~K}_{2} \mathrm{CO}_{3}$ solution at $25{ }^{\circ} \mathrm{C}$. The red solid was dissolved in $100 \mathrm{~mL}$ diethyl ether and dried with $\mathrm{Na}_{2} \mathrm{SO}_{4}$. The $\mathrm{Na}_{2} \mathrm{SO}_{4}$ was filtered off and the volatiles were removed under vacuum affording 3 as a tan solid (3.5 g, 64\%). ${ }^{1} \mathrm{H}$ NMR $\left(\mathrm{CDCl}_{3}\right): \delta 7.79$ (s, $1 \mathrm{H}, 6-\mathrm{CH}$ of $\left.-\mathrm{C}_{6} \mathrm{H}_{3} \mathrm{SO}_{2}-\right), 7.39$ (dd, $J=8.4,1.2,1 \mathrm{H}, 4-\mathrm{CH}$ of $\left.-\mathrm{C}_{6} \mathrm{H}_{3} \mathrm{SO}_{2}-\right), 7.18$ (d, $J=$ $8,1 \mathrm{H}, 3-\mathrm{CH}$ of $-\mathrm{C}_{6} \mathrm{H}_{3} \mathrm{SO}_{2}$ ) $, 5.56(\mathrm{bs}, 1 \mathrm{H}, \mathrm{NH}), 2.91(\mathrm{t}, 2 \mathrm{H}, J=5.6,2 \mathrm{H},-$ $\left.\mathrm{NHCH}_{2} \mathrm{CH}_{2} \mathrm{~N}\left(\mathrm{CH}_{3}\right)_{2}\right), 2.38\left(\mathrm{~s}, 3 \mathrm{H}, 5-\mathrm{CH}_{3}\right.$ of $\left.-\mathrm{C}_{6} \mathrm{H}_{3} \mathrm{SO}_{2}-\right), 2.32(\mathrm{t}, 2 \mathrm{H}, J=5.6$, $\left.\mathrm{NHCH}_{2} \mathrm{CH}_{2} \mathrm{~N}\left(\mathrm{CH}_{3}\right)_{2}\right), 2.12\left(\mathrm{~s}, 6 \mathrm{H},-\mathrm{NHCH}_{2} \mathrm{CH}_{2} \mathrm{~N}\left(\mathrm{CH}_{3}\right)_{2}\right) .{ }^{13} \mathrm{C} \mathrm{NMR}\left(\mathrm{CDCl}_{3}\right): \delta$ 135.0, 134.8, 134.4, 131.2, 129.2, 119.1, 56.9, 44.7, 40.5, 20.7.

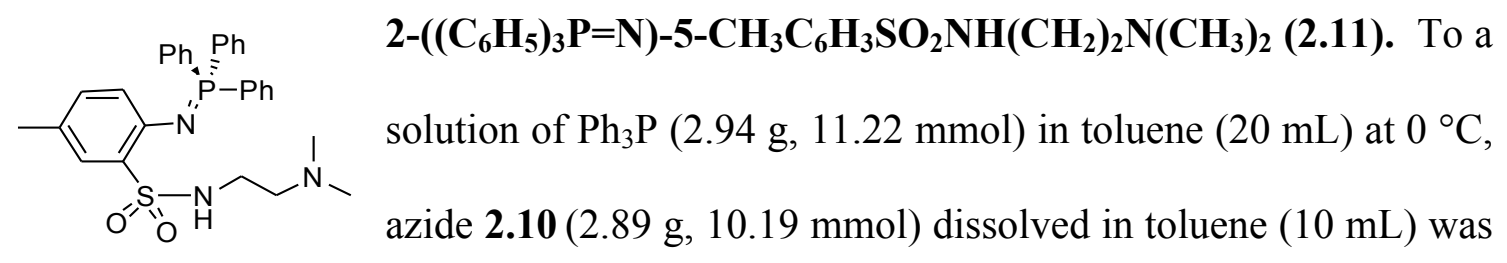

added via cannula. A clear yellow solution was observed immediately after addition was completed. After stirring for 10 minutes at $0{ }^{\circ} \mathrm{C}$ the ice bath was removed and the solution was allowed to warm to $25{ }^{\circ} \mathrm{C}$. A white suspension was observed after the reaction was stirred for 12 hours at $25{ }^{\circ} \mathrm{C}$. Compound 4 was obtained after vacuum filtration and $\mathrm{Et}_{2} \mathrm{O}$ washes $(3 \times 10 \mathrm{~mL})$ as a white solid $(4.6 \mathrm{~g}, 87 \%) .{ }^{1} \mathrm{H} \mathrm{NMR}\left(\mathrm{CD}_{2} \mathrm{Cl}_{2}\right)$ : $\delta 7.75\left(\mathrm{~m}, 6 \mathrm{H}, 2,6-\mathrm{CH}\right.$ of $\left.\left(\mathrm{C}_{6} \mathrm{H}_{5}\right)_{3} \mathrm{P}=\mathrm{N}-\right), 7.59\left(\mathrm{~m}, 4 \mathrm{H}, 4-\mathrm{CH}\right.$ of $\left(\mathrm{C}_{6} \mathrm{H}_{5}\right)_{3} \mathrm{P}=\mathrm{N}-$ and 6-CH of $\left.-\mathrm{C}_{6} \mathrm{H}_{3} \mathrm{SO}_{2}-\right), 7.49\left(\mathrm{~m}, 6 \mathrm{H}, 3,5-\mathrm{CH}\right.$ of $\left.\left(\mathrm{C}_{6} \mathrm{H}_{5}\right)_{3} \mathrm{P}=\mathrm{N}-\right), 6.96$ (bt, $\left.J=6,1 \mathrm{H},-\mathrm{SO}_{2} \mathrm{NHCH}_{2}-\right)$, 
$6.82\left(\mathrm{dd}, J=8.4,2,1 \mathrm{H}, 4-\mathrm{C} H\right.$ of $\left.-\mathrm{C}_{6} \mathrm{H}_{3} \mathrm{SO}_{2}-\right), 6.38\left(\mathrm{~d}, J=8.4,1 \mathrm{H}, 3-\mathrm{C} H\right.$ of $\left.-\mathrm{C}_{6} \mathrm{H}_{3} \mathrm{SO}_{2-}\right)$, $2.85\left(\mathrm{~m}, 2 \mathrm{H}, 2 \mathrm{H},-\mathrm{NHCH}_{2} \mathrm{CH}_{2} \mathrm{~N}\left(\mathrm{CH}_{3}\right)_{2}\right), 2.28\left(\mathrm{t}, J=6.4,2 \mathrm{H},-\mathrm{NHCH}_{2} \mathrm{CH}_{2} \mathrm{~N}_{(}\left(\mathrm{CH}_{3}\right)_{2}\right), 2.20$ (s, 3H, 5- $\mathrm{CH}_{3}$ of $\left.-\mathrm{C}_{6} \mathrm{H}_{3} \mathrm{SO}_{2}-\right), 1.91\left(\mathrm{~s}, 6 \mathrm{H},-\mathrm{NHCH}_{2} \mathrm{CH}_{2} \mathrm{~N}\left(\mathrm{CH}_{3}\right)_{2}\right) .{ }^{31} \mathrm{P} \mathrm{NMR}\left(\mathrm{CD}_{2} \mathrm{Cl}_{2}\right): \delta$ 8.8. ${ }^{13} \mathrm{C}$ NMR $\left(\mathrm{CD}_{2} \mathrm{Cl}_{2}\right): \delta 146.8,133.2,132.5\left(\mathrm{~d}, J_{\mathrm{PC}}=9.9\right), 132.1\left(\mathrm{~d}, J_{\mathrm{PC}}=2.3\right), 130.3$, $129.3,129.2,128.8\left(\mathrm{~d}, J_{\mathrm{PC}}=11.3\right), 125.8,122.1\left(\mathrm{~d}, J_{\mathrm{PC}}=10.7\right), 58.1,44.9,41.4,19.9$.

Crystal data and structure refinement for $\mathbf{2 . 1 1}$

Identification code

ctb131ta

Empirical formula C29 H32 N3 O2 P S

Formula weight 517.61

Temperature $100.05(10) \mathrm{K}$

Wavelength $0.71073 \AA$

Crystal system

Orthorhombic

Space group

Unit cell dimensions

$\mathrm{P} \mathrm{b} \mathrm{c} \mathrm{a}$

Unit cell dimensions

$a=16.3430(3) \AA \quad \alpha=90^{\circ}$.

$\mathrm{b}=17.2015(14) \AA \quad \beta=90^{\circ}$.

$\mathrm{c}=18.5209(4) \AA \quad \gamma=90^{\circ}$.

Volume

$5206.7(5) \AA^{3}$

Z

8

Density (calculated)

$1.321 \mathrm{Mg} / \mathrm{m}^{3}$

Absorption coefficient

$0.218 \mathrm{~mm}^{-1}$

$\mathrm{F}(000)$

2192

Crystal size

$0.39 \times 0.19 \times 0.08 \mathrm{~mm}^{3}$

Theta range for data collection

3.44 to $27.87^{\circ}$.

Index ranges

$-21<=\mathrm{h}<=21,-22<=\mathrm{k}<=22,-23<=1<=24$

Reflections collected 32739

Independent reflections

Completeness to theta $=27.87^{\circ}$

$6186[\mathrm{R}(\mathrm{int})=0.0420]$

$99.6 \%$

Absorption correction

Semi-empirical from equivalents

Max. and min. transmission

1.000 and 0.982

Refinement method

Full-matrix least-squares on $\mathrm{F}^{2}$

Data / restraints / parameters

$6186 / 0$ / 420

Goodness-of-fit on $\mathrm{F}^{2}$

1.044

Final R indices [I $>2 \operatorname{sigma}(\mathrm{I})]$

$\mathrm{R} 1=0.0371, \mathrm{wR} 2=0.0882$ 
$\mathrm{R}$ indices (all data)

Largest diff. peak and hole
$\mathrm{R} 1=0.0497, \mathrm{wR} 2=0.0962$

0.411 and -0.442 e. $\AA^{-}-3$

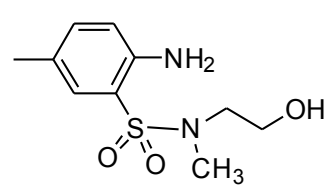

2- $\mathrm{NH}_{2}-5-\mathrm{CH}_{3} \mathrm{C}_{6} \mathrm{H}_{3} \mathrm{SO}_{2} \mathrm{NCH}_{3}\left(\mathrm{CH}_{2}\right)_{2} \mathrm{OH}$ (2.6). To a solution of 1,4Diazabicyclo[2.2.2] octane $\quad(2.9 \mathrm{~g}, \quad 25.04 \mathrm{mmol})$ and Nmethylaminoethanol $(2 \mathrm{~mL}, 21.9 \mathrm{mmol})$ in dichloromethane $(120$ $\mathrm{mL})$, 2-amino-5-methyl sulfonylchloride $(5.15 \mathrm{~g}, 25.04 \mathrm{mmol})$ added portionwise. A brown solution was observed. The brown reaction mixture stirred for 12 hours at $25{ }^{\circ} \mathrm{C}$. A brown suspension was observed after stirring 12 hours at $25^{\circ} \mathrm{C}$. The suspension was separated using a silica gel plug $(25 \mathrm{~g})$ with a $7: 3$ solution of $\mathrm{CH}_{2} \mathrm{Cl}_{2}$ :hexanes $(200 \mathrm{~mL})$ followed by a 7:3 solution of $\mathrm{CH}_{2} \mathrm{Cl}_{2}$ :EtOAc $(200 \mathrm{~mL})$. The $50 \mathrm{~mL}$ fractions were analyzed by UV-Vis, and those that contained the product were combined and dried under vacuum yielding 5 as yellow oil $(5.4 \mathrm{~g}, 88 \%)$. ${ }^{1} \mathrm{HNMR}\left(\mathrm{CDCl}_{3}\right)$ : $\delta 7.44(\mathrm{~s}, 1 \mathrm{H}, 6-$ $\mathrm{CH}), 7.13(\mathrm{~d}, J=8.4,1 \mathrm{H}, 4-\mathrm{CH}), 6.67$ (d, $J=8.8,1 \mathrm{H}, 3-\mathrm{CH}), 4.82\left(\mathrm{bs}, 2 \mathrm{H}, \mathrm{NH}_{2}\right), 3.70(\mathrm{t}$, $\left.J=5.6,2 \mathrm{H},-\mathrm{SO}_{2} \mathrm{~N}\left(\mathrm{CH}_{3}\right) \mathrm{CH}_{2}-\right), 3.29\left(\mathrm{t}, J=5.6,2 \mathrm{H},-\mathrm{SO}_{2} \mathrm{~N}\left(\mathrm{CH}_{3}\right) \mathrm{CH}_{2} \mathrm{CH}_{2}-\right), 2.83(\mathrm{~s}, 3 \mathrm{H}$, 5- $\left.\mathrm{CH}_{3} \mathrm{C}_{6} \mathrm{H}_{5}\right), 2.25$ (s, 3H, $\left.-\mathrm{SO}_{2} \mathrm{~N}\left(\mathrm{CH}_{3}\right) \mathrm{CH}_{2}-\right) .{ }^{13} \mathrm{C} \mathrm{NMR}\left(\mathrm{CDCl}_{3}\right): \delta 142.9,135.3,129.9$, 127.6, 119.8.1, 118.3, 59.6, 51.6, 44.6, 34.9, 20.6.

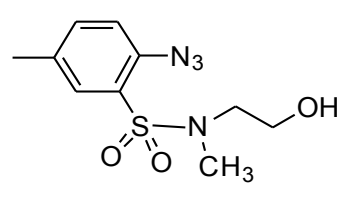

2- $\mathrm{N}_{3}-5-\mathrm{CH}_{3} \mathrm{C}_{6} \mathrm{H}_{3} \mathrm{SO}_{2} \mathrm{NCH}_{3}\left(\mathrm{CH}_{2}\right)_{2} \mathrm{OH}$ (2.7). To a flask containing $2.6(5.38 \mathrm{~g}, 22.02 \mathrm{mmol})$ cooled to $0{ }^{\circ} \mathrm{C}$, a mixture of $8 \mathrm{ml}$ water and $7.77 \mathrm{~mL} \mathrm{HBF}_{4}$ (48\% aqueous solution) precooled to $0{ }^{\circ} \mathrm{C}$ was added (all manipulations are performed in air). After 15 minutes, a solution of $\mathrm{NaNO}_{2}$ $(1.2 \mathrm{~g}, 17.5 \mathrm{mmol})$ in water $(5 \mathrm{~mL})$ precooled to $0{ }^{\circ} \mathrm{C}$ was added dropwise with vigorous stirring. A yellow color solution was formed immediately. The mixture was stirred for 1 hour at $0{ }^{\circ} \mathrm{C}$. Urea $(0.29 \mathrm{~g}, 4.8 \mathrm{mmol})$ added and stirred for 15 minutes. Charcoal added and stirred for 10 minutes. Clear yellow solution was obtained after quick filtration. With 
vigorous stirring, a cold solution of $\mathrm{NaN}_{3}(2.4 \mathrm{~g}, 37.4 \mathrm{mmol})$ in water $(8 \mathrm{~mL})$ was added dropwise to the yellow solution. The mixture stirred for 1 hour at $0{ }^{\circ} \mathrm{C}$ and 1 hour at 25 ${ }^{\circ} \mathrm{C}$. The reaction mixture was extracted with diethyl ether $(3 \mathrm{X} 30 \mathrm{~mL})$. The organic layers were combined and dried over $\mathrm{Na}_{2} \mathrm{SO}_{4}$ was filtered off and the volatiles were removed under vacuum affording compound 6 as a yellow viscous oil. (5.3 g, 88\%) ${ }^{1} \mathrm{HNMR}\left(\mathrm{CDCl}_{3}\right): \delta 7.76(\mathrm{~s}, 1 \mathrm{H}, 6-\mathrm{CH}), 7.36(\mathrm{dd}, J=8.4,1.2,1 \mathrm{H}, 4-\mathrm{CH}), 7.14(\mathrm{~d}, J=$ $8.4,1 \mathrm{H}, 3-\mathrm{CH}), 3.76\left(\mathrm{t}, J=5.2,2 \mathrm{H},-\mathrm{SO}_{2} \mathrm{~N}\left(\mathrm{CH}_{3}\right) \mathrm{CH}_{2}-\right), 3.38(\mathrm{t}, J=5.2,2 \mathrm{H},-$ $\left.\mathrm{SO}_{2} \mathrm{~N}\left(\mathrm{CH}_{3}\right) \mathrm{CH}_{2} \mathrm{CH}_{2}-\right), 2.91\left(\mathrm{~s}, 3 \mathrm{H},-\mathrm{SO}_{2} \mathrm{~N}\left(\mathrm{CH}_{3}\right) \mathrm{CH}_{2}-\right), 2.35$ (s, 3H, 5- $\left.\mathrm{CH}_{3} \mathrm{C}_{6} \mathrm{H}_{5}\right), 2.26$ ( bs, $1 \mathrm{H}, \mathrm{OH}) .{ }^{13} \mathrm{C} \mathrm{NMR}\left(\mathrm{CDCl}_{3}\right): \delta 135.2,134.9,134.6,132.1,128.8,119.8,60.4,52.3$, $35.7,20.7$.

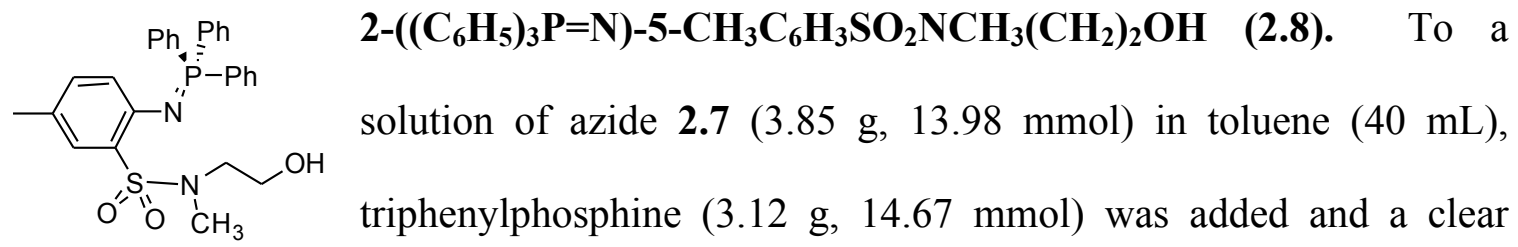
yellow solution was observed. The reaction mixture was stirred for 12 hours at $25^{\circ} \mathrm{C}$. A white suspension was observed after stirring 12 hours at $25^{\circ} \mathrm{C}$. A white solid was obtained by vacuum filtration and washed with $\mathrm{Et}_{2} \mathrm{O}(3 \times 20 \mathrm{ml})$ affording 7 (4.1 g, 60\%). ${ }^{1} \mathrm{HNMR}\left(\mathrm{CDCl}_{3}\right): \delta 7.77\left(\mathrm{~m}, 7 \mathrm{H}, 2,6-\mathrm{CH}\right.$ of $\left(\mathrm{C}_{6} \mathrm{H}_{5}\right){ }_{3} \mathrm{P}=\mathrm{N}-$ and $6-\mathrm{CH}$ of $\left.-\mathrm{C}_{6} \mathrm{H}_{3} \mathrm{SO}_{2-}\right), 7.54$ $\left(3 \mathrm{H}, 4-\mathrm{CH}\right.$ of $\left.\left(\mathrm{C}_{6} \mathrm{H}_{5}\right)_{3} \mathrm{P}=\mathrm{N}-\right), 7.45\left(\mathrm{~m}, 6 \mathrm{H}, 3,5-\mathrm{CH}\right.$ of $\left.\left(\mathrm{C}_{6} \mathrm{H}_{5}\right)_{3} \mathrm{P}=\mathrm{N}-\right), 6.79(\mathrm{dd}, J=10.4,2$, 4- $\mathrm{CH}$ of $\left.-\mathrm{C}_{6} \mathrm{H}_{3} \mathrm{SO}_{2}-\right), 6.38\left(\mathrm{dd}, J=9.2,0.8,3-\mathrm{CH}\right.$ of $\left.-\mathrm{C}_{6} \mathrm{H}_{3} \mathrm{SO}_{2}-\right), 4.41(\mathrm{~s}, \mathrm{OH}), 3.45(\mathrm{t}, J$ $\left.=10.4,5.2,2 \mathrm{H},-\mathrm{SO}_{2} \mathrm{~N}\left(\mathrm{CH}_{3}\right) \mathrm{CH}_{2^{-}}\right), 3.29\left(\mathrm{t}, J=10,5.2,2 \mathrm{H},-\mathrm{SO}_{2} \mathrm{~N}\left(\mathrm{CH}_{3}\right) \mathrm{CH}_{2} \mathrm{CH}_{2^{-}}\right)$, 2.81(s, 3H, $\left.-\mathrm{SO}_{2} \mathrm{~N}\left(\mathrm{CH}_{3}\right) \mathrm{CH}_{2}-\right), 2.17\left(\mathrm{~s}, 3 \mathrm{H}, 5-\mathrm{CH}_{3} \mathrm{C}_{6} \mathrm{H}_{5}\right) .{ }^{31} \mathrm{P} \mathrm{NMR}\left(\mathrm{CDCl}_{3}\right): \delta 8.5 .{ }^{13} \mathrm{C}$ $\operatorname{NMR}\left(\mathrm{CDCl}_{3}\right): \delta 148,134,132.7(\mathrm{~d}, J=36.4), 132.0(\mathrm{~d}, J=8.8), 130.2,129.7(\mathrm{~d}, J=$ 88.4), 129.2, 128. $8(\mathrm{~d}, J=48.8), 126.2,123.7(\mathrm{~d}, J=45.6), 58.6,51.0,32.9,20.2$ 
Experimental Section 2: Zinc complexes synthesis (Chapter 3)

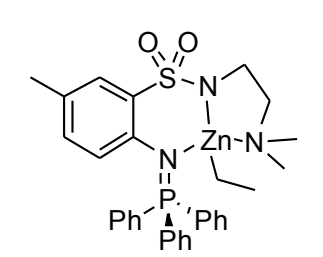

$\left[\kappa^{3}-2-\left(\left(\mathrm{C}_{6} \mathrm{H}_{5}\right)_{3} \mathrm{P}=\mathrm{N}\right)-5-\mathrm{CH}_{3} \mathrm{C}_{6} \mathrm{H}_{3} \mathrm{SO}_{2} \mathrm{~N}\left(\mathrm{CH}_{2}\right)_{2} \mathrm{~N}\left(\mathrm{CH}_{3}\right)_{2}\right] \mathrm{ZnEt}$

(3.7).

A milky suspension of $2.11(1.00 \mathrm{~g}, 1.93 \mathrm{mmol})$ in toluene $(50 \mathrm{~mL})$ was frozen at $-196^{\circ} \mathrm{C}$ using liquid nitrogen. To the frozen suspension

was added $2.9 \mathrm{~mL}$ of a $\mathrm{Et}_{2} \mathrm{Zn}$ solution $(1 \mathrm{M}$ in toluene, $2.89 \mathrm{mmol})$. After the $\mathrm{Et}_{2} \mathrm{Zn}$ addition, the liquid nitrogen bath was removed and the reaction mixture was allowed to warm slowly to $25{ }^{\circ} \mathrm{C}$. After 30 minutes the reaction mixture had warmed to $25{ }^{\circ} \mathrm{C}$ and was a white suspension. The reaction mixture was allowed to stir at $25{ }^{\circ} \mathrm{C}$ for 12 hours. After 12 hours at $25^{\circ} \mathrm{C}$, the solvent was removed in vacuum leaving a white solid. The white solid was washed with dry hexanes $(2 \times 20 \mathrm{~mL})$ and the wash solutions were removed by syringe. The residual solvent was removed under vacuum to yield $\mathbf{8}$ as a white solid (1.1 g, 92\%). ${ }^{1} \mathrm{HNMR}\left(\mathrm{CD}_{2} \mathrm{Cl}_{2}\right): \delta 7.99\left(\mathrm{~m}, 6 \mathrm{H}\right.$, ortho $-\mathrm{CH}$ of $\left.\left(\mathrm{C}_{6} \mathrm{H}_{5}\right)_{3} \mathrm{P}=\mathrm{N}-\right)$, $7.65\left(\mathrm{~s}, 1 \mathrm{H}, 6-\mathrm{CH}\right.$ of $\left.-\mathrm{C}_{6} \mathrm{H}_{3} \mathrm{SO}_{2}-\right), 7.60\left(\mathrm{~m}, 3 \mathrm{H}\right.$, para $-\mathrm{CH}$ of $\left.\left(\mathrm{C}_{6} \mathrm{H}_{5}\right){ }_{3} \mathrm{P}=\mathrm{N}-\right), 7.52(\mathrm{~m}, 6 \mathrm{H}$, meta $-\mathrm{CH}$ of $\left.\left(\mathrm{C}_{6} \mathrm{H}_{5}\right)_{3} \mathrm{P}=\mathrm{N}-\right), 6.69\left(\mathrm{~d}, J=7.6,1 \mathrm{H}, 4-\mathrm{CH}\right.$ of $\left.-\mathrm{C}_{6} \mathrm{H}_{3} \mathrm{SO}_{2}-\right), 6.46(\mathrm{~d}, J=8.4$, $1 \mathrm{H}, 3-\mathrm{CH}$ of $-\mathrm{C}_{6} \mathrm{H}_{3} \mathrm{SO}_{2}-$ ), 3.11 (bs, $\left.2 \mathrm{H},-\mathrm{NHCH}_{2} \mathrm{CH}_{2} \mathrm{~N}\left(\mathrm{CH}_{3}\right)_{2}\right), 2.18$ (s, 3H, 5- $\mathrm{CH}_{3}$ of $\left.\mathrm{C}_{6} \mathrm{H}_{3} \mathrm{SO}_{2}-\right), 1.96$ (bs, 8H, $-\mathrm{NHCH}_{2} \mathrm{CH}_{2} \mathrm{~N}\left(\mathrm{CH}_{3}\right)_{2}$ and $\left.-\mathrm{NHCH}_{2} \mathrm{CH}_{2} \mathrm{~N}\left(\mathrm{CH}_{3}\right)_{2}\right), 0.67$ (t, $J=8$,

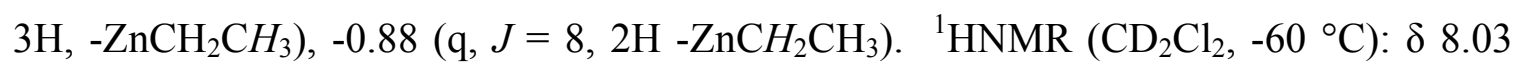
(m, 6H, ortho $-\mathrm{CH}$ of $\left.\left(\mathrm{C}_{6} \mathrm{H}_{5}\right)_{3} \mathrm{P}=\mathrm{N}-\right), 7.63\left(\mathrm{~m}, 3 \mathrm{H}\right.$, para $-\mathrm{CH}$ of $\left.\left(\mathrm{C}_{6} \mathrm{H}_{5}\right)_{3} \mathrm{P}=\mathrm{N}-\right), 7.60(\mathrm{~s}, 1 \mathrm{H}$, 6- $\mathrm{CH}$ of $\left.-\mathrm{C}_{6} \mathrm{H}_{3} \mathrm{SO}_{2}-\right), 7.55\left(\mathrm{~m}, 6 \mathrm{H}\right.$, meta $-\mathrm{CH}$ of $\left.\left(\mathrm{C}_{6} \mathrm{H}_{5}\right)_{3} \mathrm{P}=\mathrm{N}-\right), 6.70(\mathrm{~d}, J=8,1 \mathrm{H}, 4-\mathrm{CH}$ of $\left.-\mathrm{C}_{6} \mathrm{H}_{3} \mathrm{SO}_{2}-\right), 6.49\left(\mathrm{~d}, J=8,1 \mathrm{H}, \quad 3-\mathrm{CH}\right.$ of $\left.-\mathrm{C}_{6} \mathrm{H}_{3} \mathrm{SO}_{2}-\right), 3.19(\mathrm{~m}, 1 \mathrm{H}, \quad-$ $\left.\mathrm{NHCH}_{2} \mathrm{CH}_{2} \mathrm{~N}\left(\mathrm{CH}_{3}\right)_{2}\right), 3.03\left(\mathrm{~m}, 1 \mathrm{H},-\mathrm{NHCH}_{2} \mathrm{CH}_{2} \mathrm{~N}\left(\mathrm{CH}_{3}\right)_{2}\right), 2.16$ (s, 6H, 5- $\mathrm{CH}_{3}$ of $\mathrm{C}_{6} \mathrm{H}_{3} \mathrm{SO}_{2}$ - and $-\mathrm{NCH}_{3}$ of $\left.-\mathrm{NHCH}_{2} \mathrm{CH}_{2} \mathrm{~N}\left(\mathrm{CH}_{3}\right)_{2}\right), 1.96\left(\mathrm{~m}, 1 \mathrm{H},-\mathrm{NHCH}_{2} \mathrm{CH}_{2} \mathrm{~N}\left(\mathrm{CH}_{3}\right)_{2}\right)$, 
$1.81\left(\mathrm{~s}, 3 \mathrm{H},-\mathrm{NCH}_{3}\right.$ of $\left.-\mathrm{NHCH}_{2} \mathrm{CH}_{2} \mathrm{~N}\left(\mathrm{CH}_{3}\right)_{2}\right), 1.62\left(\mathrm{~m}, 1 \mathrm{H},-\mathrm{NHCH}_{2} \mathrm{CH}_{2} \mathrm{~N}\left(\mathrm{CH}_{3}\right)_{2}\right), 0.57$ (t, $\left.J=8.5,3 \mathrm{H},-\mathrm{ZnCH}_{2} \mathrm{CH}_{3}\right),-0.91\left(\mathrm{~m}, 1 \mathrm{H}-\mathrm{ZnCH}_{2} \mathrm{CH}_{3}\right),-1.20\left(\mathrm{~m}, 1 \mathrm{H}-\mathrm{ZnCH}_{2} \mathrm{CH}_{3}\right)$. ${ }^{1} \mathrm{HNMR}\left(\mathrm{CD}_{2} \mathrm{Cl}_{2}, 45{ }^{\circ} \mathrm{C}\right): \delta 8.00\left(\mathrm{~m}, 6 \mathrm{H}\right.$, ortho $-\mathrm{CH}$ of $\left.\left(\mathrm{C}_{6} \mathrm{H}_{5}\right)_{3} \mathrm{P}=\mathrm{N}-\right), 7.68(\mathrm{~s}, 1 \mathrm{H}, 6-\mathrm{CH}$ of $\left.-\mathrm{C}_{6} \mathrm{H}_{3} \mathrm{SO}_{2}-\right), 7.62\left(\mathrm{~m}, 3 \mathrm{H}\right.$, para $-\mathrm{CH}$ of $\left.\left(\mathrm{C}_{6} \mathrm{H}_{5}\right)_{3} \mathrm{P}=\mathrm{N}-\right), 7.53(\mathrm{~m}, 6 \mathrm{H}$, meta $-\mathrm{CH}$ of $\left.\left(\mathrm{C}_{6} \mathrm{H}_{5}\right)_{3} \mathrm{P}=\mathrm{N}-\right), 6.70\left(\mathrm{dd}, J=8.4,2,1 \mathrm{H}, 4-\mathrm{CH}\right.$ of $\left.-\mathrm{C}_{6} \mathrm{H}_{3} \mathrm{SO}_{2}-\right), 6.47$ (dd, $J=8.4,2,1 \mathrm{H}, 3-$ $\mathrm{CH}$ of $\left.-\mathrm{C}_{6} \mathrm{H}_{3} \mathrm{SO}_{2}-\right), 3.13\left(\mathrm{t}, J=5.6,2 \mathrm{H},-\mathrm{NHCH}_{2} \mathrm{CH}_{2} \mathrm{~N}\left(\mathrm{CH}_{3}\right)_{2}\right), 2.20$ (s, 3H, 5- $\mathrm{CH}_{3}$ of $\left.\mathrm{C}_{6} \mathrm{H}_{3} \mathrm{SO}_{2}-\right), 1.98$ (bs, 6H, - $\left.\mathrm{NHCH}_{2} \mathrm{CH}_{2} \mathrm{~N}\left(\mathrm{CH}_{3}\right)_{2}\right), 1.86$ (bs, $2 \mathrm{H},-\mathrm{NHCH}_{2} \mathrm{CH}_{2} \mathrm{~N}\left(\mathrm{CH}_{3}\right)_{2}$ ), $0.70\left(\mathrm{t}, J=8.4,3 \mathrm{H},-\mathrm{ZnCH}_{2} \mathrm{CH}_{3}\right),-0.86$ (q, $\left.J=8.4,2 \mathrm{H}-\mathrm{ZnCH}_{2} \mathrm{CH}_{3}\right) .{ }^{31} \mathrm{P}$ NMR $\left(\mathrm{CD}_{2} \mathrm{Cl}_{2}\right): \delta 26.4 .{ }^{31} \mathrm{P}$ NMR $\left(\mathrm{CD}_{2} \mathrm{Cl}_{2},-60{ }^{\circ} \mathrm{C}\right): \delta 26.4 .{ }^{31} \mathrm{P}$ NMR $\left(\mathrm{CD}_{2} \mathrm{Cl}_{2}, 45{ }^{\circ} \mathrm{C}\right): \delta$ 26.4. ${ }^{13} \mathrm{C} \mathrm{NMR}\left(\mathrm{CD}_{2} \mathrm{Cl}_{2}\right): \delta 143.0\left(\mathrm{~d}, J_{\mathrm{PC}}=3.8\right), 139.5\left(\mathrm{~d}, J_{\mathrm{PC}}=12.9\right), 133.7(\mathrm{~d}, J=9.9)$, $132.6\left(\mathrm{~d}, J_{\mathrm{PC}}=2.3\right), 130.5,130.3,128.7(\mathrm{~d}, J=12.2), 127.6,126.7,126.2(\mathrm{~d}, J=7.6)$, 59.6, 45.8, 43.8, 20.2, $13.0\left(\mathrm{ZnCH}_{2} \mathrm{CH}_{3}\right),-0.57\left(\mathrm{ZnCH}_{2} \mathrm{CH}_{3}\right) .{ }^{13} \mathrm{C}^{\mathrm{NMR}}\left(\mathrm{CD}_{2} \mathrm{Cl}_{2},-60\right.$ $\left.{ }^{\circ} \mathrm{C}\right): \delta 142.8,133.8\left(\mathrm{~d}, J_{\mathrm{PC}}=9.1\right), 133.0,130.8,130.7,129.0\left(\mathrm{~d}, J_{\mathrm{PC}}=12.1\right), 128.6,128.3$, $126.3\left(\mathrm{~d}, J_{\mathrm{PC}}=8.4\right), 126.2\left(\mathrm{~d}, J_{\mathrm{PC}}=110.2\right), 125.4,78.0,59.4,43.9,20.5,13.7$ $\left(\mathrm{ZnCH}_{2} \mathrm{CH}_{3}\right),-0.90\left(\mathrm{ZnCH}_{2} \mathrm{CH}_{3}\right)$.

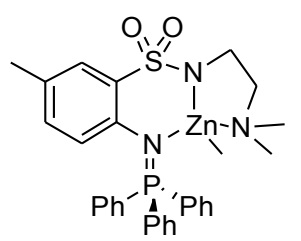

$\left[\kappa^{3}-2-\left(\left(\mathrm{C}_{6} \mathrm{H}_{5}\right)_{3} \mathrm{P}=\mathrm{N}\right)-5-\mathrm{CH}_{3} \mathrm{C}_{6} \mathrm{H}_{3} \mathrm{SO}_{2} \mathrm{NH}\left(\mathrm{CH}_{2}\right)_{2} \mathrm{~N}\left(\mathrm{CH}_{3}\right)_{2}\right] \mathrm{ZnMe}$

(3.13). A milky suspension of $2.11(0.50 \mathrm{~g}, 0.97 \mathrm{mmol})$ in toluene (30 $\mathrm{mL}$ ) was frozen at $-196{ }^{\circ} \mathrm{C}$ using liquid nitrogen. To the frozen suspension was added $0.94 \mathrm{~mL}$ of a $\mathrm{Me}_{2} \mathrm{Zn}$ solution ( $2 \mathrm{M}$ in toluene, $1.87 \mathrm{mmol}$ ). After the $\mathrm{Me}_{2} \mathrm{Zn}$ addition, the liquid nitrogen bath was removed and the reaction mixture was allowed to warm slowly to $25^{\circ} \mathrm{C}$. After 30 minutes the reaction had warmed to $25{ }^{\circ} \mathrm{C}$ and the solution was clear and colorless. The reaction mixture was allowed to stir at 25 ${ }^{\circ} \mathrm{C}$ for 12 hours. The solvent was removed in vacuum leaving a white solid. The white 
solid was washed with dry hexanes $(2 \times 20 \mathrm{~mL})$ and the wash solutions were removed by syringe. The residual solvent was removed under vacuum to yield $\mathbf{9}$ as a white solid $(0.45$ g, $78 \%$ ). ${ }^{1} \mathrm{HNMR}\left(\mathrm{CD}_{2} \mathrm{Cl}_{2}\right): \delta 7.97\left(\mathrm{~m}, 6 \mathrm{H}\right.$, ortho $-\mathrm{CH}$ of $\left.\left(\mathrm{C}_{6} \mathrm{H}_{5}\right)_{3} \mathrm{P}=\mathrm{N}-\right), 7.67$ (bs, $1 \mathrm{H}, 6-$ $\mathrm{CH}$ of $\left.-\mathrm{C}_{6} \mathrm{H}_{3} \mathrm{SO}_{2}-\right), 7.60\left(\mathrm{~m}, 3 \mathrm{H}\right.$, para $-\mathrm{CH}$ of $\left.\left(\mathrm{C}_{6} \mathrm{H}_{5}\right)_{3} \mathrm{P}=\mathrm{N}-\right), 7.52(\mathrm{~m}, 6 \mathrm{H}$, meta $-\mathrm{CH}$ of $\left.\left(\mathrm{C}_{6} \mathrm{H}_{5}\right)_{3} \mathrm{P}=\mathrm{N}-\right), 6.70\left(\mathrm{dd}, J=8.4,2,1 \mathrm{H}, 4-\mathrm{CH}\right.$ of $\left.-\mathrm{C}_{6} \mathrm{H}_{3} \mathrm{SO}_{2}-\right), 6.46(\mathrm{dd}, J=8.4,2,1 \mathrm{H}, 3-$ $\mathrm{CH}$ of $\left.-\mathrm{C}_{6} \mathrm{H}_{3} \mathrm{SO}_{2}-\right), 3.11$ (bs, 2H, $\left.-\mathrm{NHCH}_{2} \mathrm{CH}_{2} \mathrm{~N}\left(\mathrm{CH}_{3}\right)_{2}\right), 2.19$ (s, 3H, 5- $\mathrm{CH}_{3}$ of $-\mathrm{C}_{6} \mathrm{H}_{3} \mathrm{SO}_{2}-$ ), 1.90 (bs, $8 \mathrm{H},-\mathrm{NHCH}_{2} \mathrm{CH}_{2} \mathrm{~N}\left(\mathrm{CH}_{3}\right)_{2}$ and $\left.-\mathrm{NHCH}_{2} \mathrm{CH}_{2} \mathrm{~N}\left(\mathrm{CH}_{3}\right)_{2}\right)$, -1.76 (s, $3 \mathrm{H}, \mathrm{ZnCH}_{3}$ ). ${ }^{1} \mathrm{HNMR}\left(\mathrm{CD}_{2} \mathrm{Cl}_{2},-40{ }^{\circ} \mathrm{C}\right): \delta 8.00\left(\mathrm{~m}, 6 \mathrm{H}\right.$, ortho $-\mathrm{CH}$ of $\left.\left(\mathrm{C}_{6} \mathrm{H}_{5}\right)_{3} \mathrm{P}=\mathrm{N}-\right)$, $7.63(\mathrm{~m}, 4 \mathrm{H}$, para $-\mathrm{CH}$ of $\left(\mathrm{C}_{6} \mathrm{H}_{5}\right)_{3} \mathrm{P}=\mathrm{N}$ - and 6- $\mathrm{CH}$ of $\left.-\mathrm{C}_{6} \mathrm{H}_{3} \mathrm{SO}_{2}-\right), 7.55\left(\mathrm{~m}, 6 \mathrm{H}\right.$, meta $-\mathrm{CH}$ of $\left.\left(\mathrm{C}_{6} \mathrm{H}_{5}\right)_{3} \mathrm{P}=\mathrm{N}-\right)$, $6.72\left(\mathrm{~d}, J=8,1 \mathrm{H}, 4-\mathrm{CH}\right.$ of $\left.-\mathrm{C}_{6} \mathrm{H}_{3} \mathrm{SO}_{2}-\right), 6.49\left(\mathrm{~d}, J=8,1 \mathrm{H}, 3-\mathrm{CH}\right.$ of $\left.-\mathrm{C}_{6} \mathrm{H}_{3} \mathrm{SO}_{2}-\right), 3.15$ (bm, 1H, - $\left.\mathrm{NHCH}_{2} \mathrm{CH}_{2} \mathrm{~N}\left(\mathrm{CH}_{3}\right)_{2}\right), 3.04$ (bm, 1H, - $\left.\mathrm{NHCH}_{2} \mathrm{CH}_{2} \mathrm{~N}\left(\mathrm{CH}_{3}\right)_{2}\right), 2.18$ (s, 6H, 5$\mathrm{CH}_{3}$ of $\left.-\mathrm{C}_{6} \mathrm{H}_{3} \mathrm{SO}_{2}-\right), \quad 2.05$ (bs, $4 \mathrm{H}, \quad-\mathrm{NCH}_{3}$ of $-\mathrm{NHCH}_{2} \mathrm{CH}_{2} \mathrm{~N}\left(\mathrm{CH}_{3}\right)_{2}$ and $\left.\mathrm{NHCH}_{2} \mathrm{CH}_{2} \mathrm{~N}\left(\mathrm{CH}_{3}\right)_{2}\right), 1.70$ (s, 3H, $-\mathrm{NCH}_{3}$ of $\left.-\mathrm{NHCH}_{2} \mathrm{CH}_{2} \mathrm{~N}\left(\mathrm{CH}_{3}\right)_{2}\right), 1.63$ (bm, $1 \mathrm{H}$, $\left.\mathrm{NHCH}_{2} \mathrm{CH}_{2} \mathrm{~N}\left(\mathrm{CH}_{3}\right)_{2}\right),-1.86\left(\mathrm{~s}, 3 \mathrm{H}, \mathrm{ZnCH}_{3}\right) .{ }^{1} \mathrm{HNMR}\left(\mathrm{C}_{6} \mathrm{D}_{6}\right): \delta 8.26$ (s, $1 \mathrm{H}, 6-\mathrm{CH}$ of $\left.\mathrm{C}_{6} \mathrm{H}_{3} \mathrm{SO}_{2}-\right), 8.02\left(\mathrm{~m}, 6 \mathrm{H}\right.$, ortho $-\mathrm{CH}$ of $\left.\left(\mathrm{C}_{6} \mathrm{H}_{5}\right)_{3} \mathrm{P}=\mathrm{N}-\right), 6.96(\mathrm{~m}, 9 \mathrm{H}, 3 \mathrm{H}$, para $-\mathrm{CH}$ and $6 \mathrm{H}$, meta $-\mathrm{CH}$ of $\left.\left(\mathrm{C}_{6} \mathrm{H}_{5}\right)_{3} \mathrm{P}=\mathrm{N}-\right), 6.48\left(\mathrm{~m}, 2 \mathrm{H}, 3-\mathrm{CH}\right.$ and 4-CH of $\left.-\mathrm{C}_{6} \mathrm{H}_{3} \mathrm{SO}_{2}-\right), 3.62(\mathrm{bs}$, $\left.1 \mathrm{H},-\mathrm{NHCH}_{2} \mathrm{CH}_{2} \mathrm{~N}\left(\mathrm{CH}_{3}\right)_{2}\right), 3.19$ (bs, $\left.1 \mathrm{H},-\mathrm{NHCH}_{2} \mathrm{CH}_{2} \mathrm{~N}\left(\mathrm{CH}_{3}\right)_{2}\right), 1.86$ (s, 3H, 5- $\mathrm{CH}_{3}$ of $\mathrm{C}_{6} \mathrm{H}_{3} \mathrm{SO}_{2}$ ) $) 1.61$ (bs, 8H, - $\mathrm{NHCH}_{2} \mathrm{CH}_{2} \mathrm{~N}\left(\mathrm{CH}_{3}\right)_{2}$ and $\left.-\mathrm{NHCH}_{2} \mathrm{CH}_{2} \mathrm{~N}\left(\mathrm{CH}_{3}\right)_{2}\right),-1.19$ (s, 3H, $\left.\mathrm{ZnCH}_{3}\right) .{ }^{31} \mathrm{P}$ NMR $\left(\mathrm{CD}_{2} \mathrm{Cl}_{2}\right): \delta 26.0 .{ }^{31} \mathrm{P}$ NMR $\left(\mathrm{C}_{6} \mathrm{D}_{6}\right): \delta 25.2 .{ }^{13} \mathrm{C}$ NMR $\left(\mathrm{C}_{6} \mathrm{D}_{6}\right): \delta 143.4$ $\left(\mathrm{d}, J_{\mathrm{CP}}=3.2\right), 141.6\left(\mathrm{~d}, J_{\mathrm{CP}}=11.3\right), 133.7\left(\mathrm{~d}, J_{\mathrm{CP}}=9.7\right), 132.6\left(\mathrm{~d}, J_{\mathrm{CP}}=9.7\right), 132.2(\mathrm{~d}$, $\left.J_{\mathrm{CP}}=2.5\right), 130.3,129.6(\mathrm{~d}, J=12.1), 128.9,128.5(\mathrm{~d}, J=12.1), 125.6(\mathrm{~d}, J=8), 59.3$, 45.3, 43.3, 20.1, -14.7 $\left(\mathrm{ZnCH}_{3}\right)$.

Crystal data and structure refinement for $\mathbf{3 . 1 3}$ Identification code ctb14ltc 
Empirical formula

Formula weight

Temperature

Wavelength

Crystal system

Space group

Unit cell dimensions

Volume

Z

Density (calculated)

Absorption coefficient

$\mathrm{F}(000)$

Crystal size

Theta range for data collection

Index ranges

Reflections collected

Independent reflections

Completeness to theta $=28.16^{\circ}$

Absorption correction

Max. and min. transmission

Refinement method

Data / restraints / parameters

Goodness-of-fit on $\mathrm{F}^{2}$

Final $\mathrm{R}$ indices [I $>2 \operatorname{sigma}(\mathrm{I})]$

$\mathrm{R}$ indices (all data)

Absolute structure parameter

Largest diff. peak and hole
C63.60 H71 C10.60 N6 O4 P2 S2 Zn2

1261.53

$100.05(10) \mathrm{K}$

$0.71073 \AA$

Monoclinic

I a

$a=17.73980(18) \AA \quad \alpha=90^{\circ}$.

$\mathrm{b}=16.25738(12) \AA \quad \beta=110.4401(11)^{\circ}$.

$\mathrm{c}=23.6267(2) \AA \quad \gamma=90^{\circ}$.

6384.98(10) $\AA^{3}$

4

$1.312 \mathrm{Mg} / \mathrm{m}^{3}$

$0.942 \mathrm{~mm}^{-1}$

2635.2

$0.38 \times 0.28 \times 0.18 \mathrm{~mm}^{3}$

3.24 to $28.16^{\circ}$.

$-23<=\mathrm{h}<=23,-21<=\mathrm{k}<=21,-31<=1<=31$

112102

$15632[\mathrm{R}(\mathrm{int})=0.0353]$

$99.8 \%$

Semi-empirical from equivalents

1.00000 and 0.80181

Full-matrix least-squares on $\mathrm{F}^{2}$

$15632 / 2 / 726$

1.085

$\mathrm{R} 1=0.0352, \mathrm{wR} 2=0.1004$

$\mathrm{R} 1=0.0365, \mathrm{wR} 2=0.1018$

$-0.006(6)$

0.764 and -0.558 e. $\AA^{-3}$

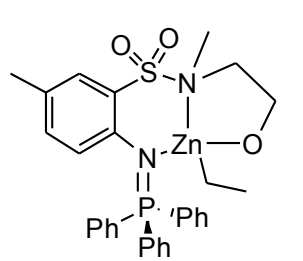

$\left[\kappa^{3}-2-\left(\left(\mathrm{C}_{6} \mathrm{H}_{5}\right)_{3} \mathrm{P}=\mathrm{N}\right)-5-\mathrm{CH}_{3} \mathrm{C}_{6} \mathrm{H}_{3} \mathrm{SO}_{2} \mathrm{NCH}_{3}\left(\mathrm{CH}_{2}\right)_{2} \mathrm{O}\right] \mathrm{ZnEt} \quad(3.5) . \quad \mathrm{A}$ solution of phosphinimine ligand $\mathbf{2 . 8}(0.4 \mathrm{~g}, 0.79 \mathrm{mmol})$ in toluene (20 $\mathrm{mL}$ ) was cooled to $-35{ }^{\circ} \mathrm{C}$ and $0.95 \mathrm{~mL} \mathrm{Et} 2 \mathrm{Zn}$ (1M in toluene, 0.95 
mmol) was added under nitrogen. The reaction mixture was allowed to warm to room temperature and stirred 12 hours. After 12 hours of stirring, the solvent volume was reduced under vacuum to $5 \mathrm{~mL}$. This resulted in a white suspension in the flask. The white solid was washed with dry hexanes $(2 \times 10 \mathrm{~mL})$ and the wash solutions were removed by syringe. The remaining solvent was removed under vacuum to yield compound $\mathbf{1 0}$ as a white solid $(0.4 \mathrm{~g}, 80 \%) .{ }^{1} \mathrm{HNMR}\left(\mathrm{CDCl}_{3}\right): \delta 7.81(\mathrm{~m}, 6 \mathrm{H}$, ortho $-\mathrm{CH}$ of $\left.\left(\mathrm{C}_{6} \mathrm{H}_{5}\right)_{3} \mathrm{P}=\mathrm{N}-\right) 7.60\left(\mathrm{~s}, 1 \mathrm{H}, 6-\mathrm{CH}\right.$ of $\left.-\mathrm{C}_{6} \mathrm{H}_{3} \mathrm{SO}_{2}-\right), 7.44(9 \mathrm{H}$, para and meta $-\mathrm{CH}$ of $\left.\left(\mathrm{C}_{6} \mathrm{H}_{5}\right)_{3} \mathrm{P}=\mathrm{N}-\right), 6.71\left(\mathrm{dd}, J=10,1.6,4-\mathrm{CH}\right.$ of $\left.-\mathrm{C}_{6} \mathrm{H}_{3} \mathrm{SO}_{2}-\right), 6.34$ (d, $J=8.8,3-\mathrm{CH}$ of $\left.\mathrm{C}_{6} \mathrm{H}_{3} \mathrm{SO}_{2-}\right), 3.78\left(\mathrm{t}, J=6.8,2 \mathrm{H},-\mathrm{SO}_{2} \mathrm{~N}\left(\mathrm{CH}_{3}\right) \mathrm{CH}_{2^{-}}\right), 3.29(\mathrm{t}, J=6.4,2 \mathrm{H},-$ $\mathrm{SO}_{2} \mathrm{~N}\left(\mathrm{CH}_{3}\right) \mathrm{CH}_{2} \mathrm{CH}_{2^{-}}$), 2.82 (s, 3H, - $\left.\mathrm{SO}_{2} \mathrm{~N}\left(\mathrm{CH}_{3}\right) \mathrm{CH}_{2}-\right), 2.09$ (s, 3H, 5- $\left.\mathrm{CH}_{3} \mathrm{C}_{6} \mathrm{H}_{5}\right), 1.10$ (t, $J=8,2 \mathrm{H}$ of $\mathrm{ZnCH}_{2}$ ), 0.25 (quartet, $J=8,3 \mathrm{H}$ of $\left.\mathrm{ZnCH}_{2} \mathrm{CH}_{3}\right) .{ }^{31} \mathrm{P}$ NMR $\left(\mathrm{CDCl}_{3}\right): \delta 3.1$. ${ }^{13} \mathrm{C} \mathrm{NMR}\left(\mathrm{CDCl}_{3}\right): \delta 148.2,133.4,132.6(\mathrm{~d}, J=39.2), 131.7,130.9,129.9,128.6(\mathrm{~d}, J=$ 48.8), 125.2, 124.9, 122.8 (d, $J=48.8), 63.5,53.26,37.0,20.1,12.4,-1.4$.

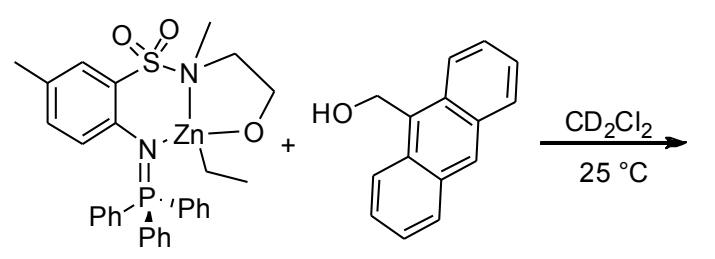

Reaction of 10 with 9-anthrylmethanol. A $\mathrm{mg}, 23.9 \mu \mathrm{mol}) . \mathrm{CD}_{2} \mathrm{Cl}_{2}(0.75 \mathrm{~mL})$ was added via vacuum transfer at $-196{ }^{\circ} \mathrm{C}$. After the NMR tube was flushed with $\mathrm{N}_{2}$, the valved NMR tube was sealed, warmed to $25^{\circ} \mathrm{C}$ and shaken until the solids dissolved. ${ }^{1} \mathrm{H}$ and ${ }^{31} \mathrm{P}\left\{{ }^{1} \mathrm{H}\right\}$ NMR spectra were obtained after 10 minutes. ${ }^{1} \mathrm{H}$ and ${ }^{31} \mathrm{P}\left\{{ }^{1} \mathrm{H}\right\}$ NMR spectra established that $2.11(24 \%)$ and $2.8(76 \%)$ were present in solution. The solution was allowed to sit at $25{ }^{\circ} \mathrm{C}$ for 24 hours. ${ }^{1} \mathrm{H}$ and ${ }^{31} \mathrm{P}\left\{{ }^{1} \mathrm{H}\right\}$ NMR spectra were obtained. ${ }^{1} \mathrm{H}$ and ${ }^{31} \mathrm{P}\left\{{ }^{1} \mathrm{H}\right\}$ NMR spectra established that 
complex $\mathbf{1 0}$ had reacted with 9-anthrylmethanol to form ligand 2.8. The identity of the zinc specie(s) present in solution after the formation of $\mathbf{2 . 1 1}$ was not determined.
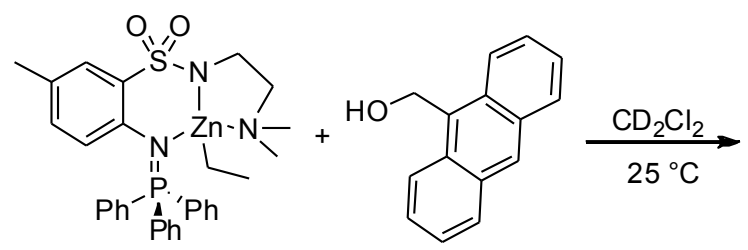

Reaction of 8 with 9-anthrylmethanol.

anthrylmethanol $(5.0 \mathrm{mg}, 24.5 \mu \mathrm{mol}) . \mathrm{CD}_{2} \mathrm{Cl}_{2}(0.75 \mathrm{~mL})$ was added via vacuum transfer at $-196{ }^{\circ} \mathrm{C}$. After the NMR tube was flushed with $\mathrm{N}_{2}$, the valved NMR tube was sealed, warmed to $25{ }^{\circ} \mathrm{C}$ and shaken until the solids dissolved. ${ }^{1} \mathrm{H}$ and ${ }^{31} \mathrm{P}\left\{{ }^{1} \mathrm{H}\right\}$ NMR spectra established that 3.7 and 9-anthrylmethanol were the only species present in solution. The solution was allowed to sit at $25{ }^{\circ} \mathrm{C}$ for 24 hours. ${ }^{1} \mathrm{H}$ and ${ }^{31} \mathrm{P}\left\{{ }^{1} \mathrm{H}\right\}$ NMR spectra were obtained. ${ }^{1} \mathrm{H}$ and ${ }^{31} \mathrm{P}\left\{{ }^{1} \mathrm{H}\right\}$ NMR spectra established that no reaction had occurred between 8 and 9-anthrylmethanol after 24 hours at $25^{\circ} \mathrm{C}$ in $\mathrm{CD}_{2} \mathrm{Cl}_{2}$.
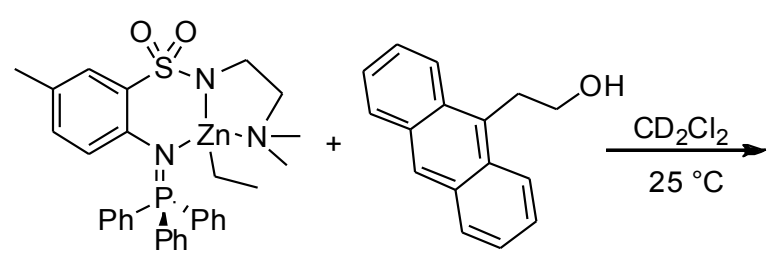

Reaction of 8 with $\quad 2-(9-$ anthryl)ethanol. A valved NMR tube was loaded with $3.7(20.0 \mathrm{mg}, 32.7$ $\mu \mathrm{mol})$ and 2-(9-anthryl)ethanol $(7.0 \mathrm{mg}, 32.7 \mu \mathrm{mol}) . \mathrm{CD}_{2} \mathrm{Cl}_{2}(0.75 \mathrm{~mL})$ was added via vacuum transfer at $-196^{\circ} \mathrm{C}$. After the NMR tube was flushed with $\mathrm{N}_{2}$, the valved NMR tube was sealed, warmed to $25{ }^{\circ} \mathrm{C}$ and shaken until the solids dissolved. ${ }^{1} \mathrm{H}$ and ${ }^{31} \mathrm{P}\left\{{ }^{1} \mathrm{H}\right\}$ NMR spectra established that $\mathbf{8}$ and 2-(9-anthryl)ethanol were the only species present in solution. The solution was allowed to sit at $25{ }^{\circ} \mathrm{C}$ for 24 hours. ${ }^{1} \mathrm{H}$ and ${ }^{31} \mathrm{P}\left\{{ }^{1} \mathrm{H}\right\}$ NMR spectra were obtained. ${ }^{1} \mathrm{H}$ and ${ }^{31} \mathrm{P}\left\{{ }^{1} \mathrm{H}\right\}$ NMR spectra established that $3.7(92 \%)$ and ligand $2.11(8 \%)$ were present in solution after 24 hours at $25^{\circ} \mathrm{C}$ in $\mathrm{CD}_{2} \mathrm{Cl}_{2}$. 


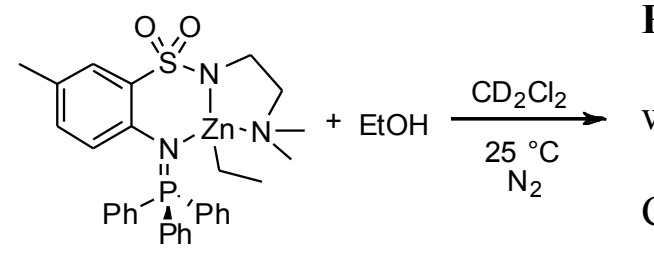

Reaction of 8 with ethanol. A valved NMR tube

at $-196{ }^{\circ} \mathrm{C}$. After the NMR tube was flushed with $\mathrm{N}_{2}$, the valved NMR tube was sealed, warmed to $25^{\circ} \mathrm{C}$ and shaken until the solids dissolved. Via a microsyringe, ethanol (3.6 $\mu \mathrm{L}, 61.4 \mu \mathrm{mol})$ was added quickly after opening the valve of the sealed tube. The NMR tube was resealed immediately and subjected to a freeze-pump-thaw cycle. The tube was flushed with $\mathrm{N}_{2}$ and warmed to $25{ }^{\circ} \mathrm{C}$ to produce a clear colorless solution. ${ }^{1} \mathrm{H}$ and ${ }^{31} \mathrm{P}\left\{{ }^{1} \mathrm{H}\right\}$ NMR spectra established that $\mathbf{8}$ and ethanol were the only species present in solution. The solution was allowed to sit at $25{ }^{\circ} \mathrm{C}$ for 24 hours. ${ }^{1} \mathrm{H}$ and ${ }^{31} \mathrm{P}\left\{{ }^{1} \mathrm{H}\right\}$ NMR spectra were obtained. ${ }^{1} \mathrm{H}$ and ${ }^{31} \mathrm{P}\left\{{ }^{1} \mathrm{H}\right\}$ NMR spectra established that $3.7(87 \%)$ and ligand $2.11(13 \%)$ were present in solution after 24 hours at $25^{\circ} \mathrm{C}$ in $\mathrm{CD}_{2} \mathrm{Cl}_{2}$.

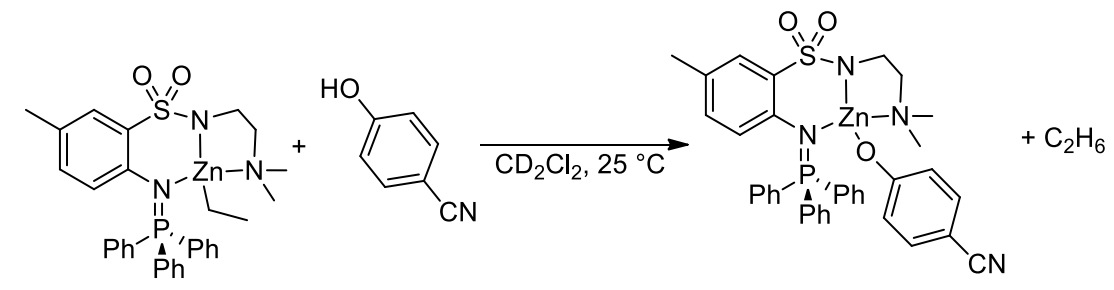

Generation of $\quad\left[\kappa^{3}-2-\left(\left(\mathrm{C}_{6} \mathrm{H}_{5}\right)_{3} \mathrm{P}=\mathrm{N}\right)-5-\mathrm{CH}_{3} \mathrm{C}_{6} \mathrm{H}_{3} \mathrm{SO}_{2} \mathrm{NH}\left(\mathrm{CH}_{2}\right)_{2} \mathrm{~N}\left(\mathrm{CH}_{3}\right)_{2}\right] \mathrm{Zn}(4-$ $\left.\mathbf{O C}_{6} \mathbf{H}_{4} \mathbf{C N}\right)$ (3.10). A valved NMR tube was charged with 3.7 (10 mg, $\left.16.3 \mathrm{mmol}\right)$, 4cyanophenol (2 $\mathrm{mg}, 16.3 \mathrm{mmol})$, and $\mathrm{CD}_{2} \mathrm{Cl}_{2}(0.5 \mathrm{~mL})$ was added via vacuum transfer at $196^{\circ} \mathrm{C}$. After the NMR tube was flushed with $\mathrm{N}_{2}$, the tube was sealed, warmed to $25^{\circ} \mathrm{C}$, and shaken until the solids dissolved. ${ }^{1} \mathrm{H}$ and ${ }^{31} \mathrm{P}\left\{{ }^{1} \mathrm{H}\right\}$ NMR spectra established, after 10 min at $25{ }^{\circ} \mathrm{C}$, that 3.10 was the only species present in solution along with ethane. ${ }^{1} \mathrm{HNMR}\left(\mathrm{CD}_{2} \mathrm{Cl}_{2}\right): \delta 7.94\left(\mathrm{~m}, 6 \mathrm{H}\right.$, ortho $\mathrm{CH}$ of $\left.\left(\mathrm{C}_{6} \mathrm{H}_{5}\right)_{3} \mathrm{P}=\mathrm{N}-\right)$, $7.76(\mathrm{~s}, 1 \mathrm{H}, 6-\mathrm{CH}$ of $\left.\mathrm{C}_{6} \mathrm{H}_{3} \mathrm{SO}_{2}-\right), 7.45\left(\mathrm{~m}, 9 \mathrm{H}\right.$, meta and para $\mathrm{CH}$ of $\left.\left(\mathrm{C}_{6} \mathrm{H}_{5}\right)_{3} \mathrm{P}=\mathrm{N}-\right), 7.14(\mathrm{~m}, 2 \mathrm{H}$, ortho $\mathrm{CH}$ of 
$\left.\mathrm{ZnOC}_{6} \mathrm{H}_{4} \mathrm{CN}\right), 6.81\left(\mathrm{~d}, J=8,4-\mathrm{CH}\right.$ of $\left.-\mathrm{C}_{6} \mathrm{H}_{3} \mathrm{SO}_{2-}\right), 6.65\left(\mathrm{~d}, J=8,3-\mathrm{CH}\right.$ of $\left.-\mathrm{C}_{6} \mathrm{H}_{3} \mathrm{SO}_{2-}\right)$, $6.30\left(\mathrm{~m}, 1 \mathrm{H}\right.$, meta $\mathrm{CH}$ of $\left.\mathrm{ZnOC}_{6} \mathrm{H}_{4} \mathrm{CN}\right), 3.17\left(t, 2 \mathrm{H},-\mathrm{NHCH}_{2} \mathrm{CH}_{2} \mathrm{~N}\left(\mathrm{CH}_{3}\right)_{2}\right), 2.24(\mathrm{~s}, 3 \mathrm{H}$, 5- $\mathrm{CH}_{3}$ of $\left.-\mathrm{C}_{6} \mathrm{H}_{3} \mathrm{SO}_{2}-\right), 2.00$ (bs, $2 \mathrm{H},-\mathrm{NHCH}_{2} \mathrm{CH}_{2} \mathrm{~N}\left(\mathrm{CH}_{3}\right)_{2}$ and $\left.6 \mathrm{H},-\mathrm{NHCH}_{2} \mathrm{CH}_{2} \mathrm{~N}\left(\mathrm{CH}_{3}\right)_{2}\right)$, $0.85\left(\mathrm{C}_{2} \mathrm{H}_{6}\right) .{ }^{31} \mathrm{P} \mathrm{NMR}\left(\mathrm{CD}_{2} \mathrm{Cl}_{2}\right): \delta 28.7$.

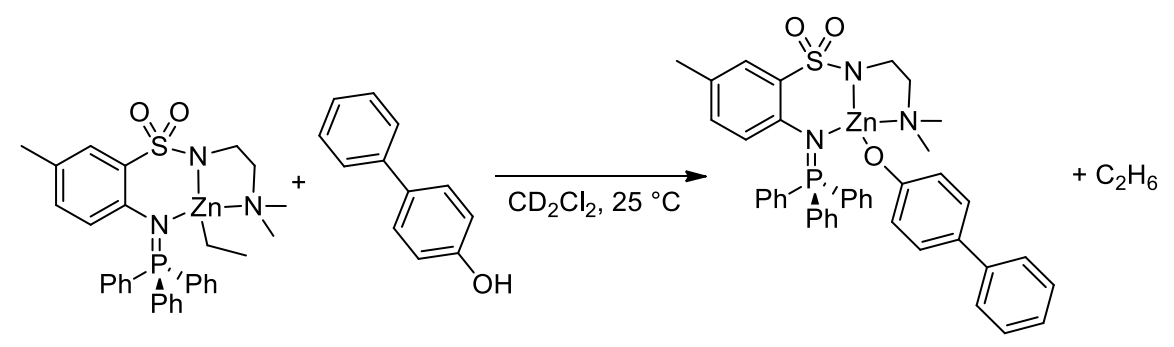

Generation of $\quad\left[\kappa^{3}-2-\left(\left(\mathrm{C}_{6} \mathrm{H}_{5}\right)_{3} \mathrm{P}=\mathrm{N}\right)-5-\mathrm{CH}_{3} \mathrm{C}_{6} \mathrm{H}_{3} \mathrm{SO}_{2} \mathrm{NH}\left(\mathrm{CH}_{2}\right)_{2} \mathrm{~N}\left(\mathrm{CH}_{3}\right)_{2}\right] \mathrm{Zn}(4-$ $\left.\mathbf{O C}_{6} \mathbf{H}_{4} \mathbf{C}_{6} \mathbf{H}_{5}\right)$ (3.11). A valved NMR tube was loaded with $\mathbf{8}(10 \mathrm{mg}, 16.3 \mathrm{mmol})$, 4phenylphenol (2.8 $\mathrm{mg}, 16.3 \mathrm{mmol})$, and $\mathrm{CD}_{2} \mathrm{Cl}_{2}(0.5 \mathrm{~mL})$ was added via vacuum transfer at $-196{ }^{\circ} \mathrm{C}$. After the NMR tube was flushed with $\mathrm{N}_{2}$, the tube was sealed, warmed to 25 ${ }^{\circ} \mathrm{C}$, and shaken until the solids dissolved. After $10 \mathrm{~min}$ at $25^{\circ} \mathrm{C}$, integration of the ${ }^{31} \mathrm{P}\left\{{ }^{1} \mathrm{H}\right\}$ NMR spectra established that $78 \%$ of 3.11 was present in solution along with 22 \% of 3.7. After $50 \mathrm{~min}$ at $25{ }^{\circ} \mathrm{C},{ }^{1} \mathrm{H}$ and ${ }^{31} \mathrm{P}\left\{{ }^{1} \mathrm{H}\right\}$ NMR spectra established that 3.11 was the only species present in solution along with ethane. ${ }^{1} \mathrm{HNMR}\left(\mathrm{CD}_{2} \mathrm{Cl}_{2}\right): \delta 7.98(\mathrm{~m}, 6 \mathrm{H}$, ortho $\mathrm{CH}$ of $\left.\left(\mathrm{C}_{6} \mathrm{H}_{5}\right)_{3} \mathrm{P}=\mathrm{N}-\right), 7.50\left(\mathrm{~s}, 1 \mathrm{H}, 6-\mathrm{CH}\right.$ of $\left.-\mathrm{C}_{6} \mathrm{H}_{3} \mathrm{SO}_{2^{-}}\right) 7.48(\mathrm{~m}, 11 \mathrm{H}$, meta, para $\mathrm{CH}$ of $\left.\left(\mathrm{C}_{6} \mathrm{H}_{5}\right)_{3} \mathrm{P}=\mathrm{N}-\right)$ and ortho $\mathrm{CH}$ of $\left.\mathrm{Zn}-\mathrm{OC}_{6} H_{4} \mathrm{C}_{6} \mathrm{H}_{5}\right), 7.35(\mathrm{t}, J=7.6,2 \mathrm{H}$, meta $\mathrm{CH}$ of $\left.\mathrm{Zn}-\mathrm{OC}_{6} \mathrm{H}_{4} \mathrm{C}_{6} H_{5}\right), 7.14\left(\mathrm{~m}, 3 \mathrm{H}\right.$, para $\mathrm{CH}$ of $\mathrm{Zn}-\mathrm{OC}_{6} \mathrm{H}_{4} \mathrm{C}_{6} \mathrm{H}_{5}$ and meta $\mathrm{CH}$ of $\mathrm{Zn}-$ $\left.\mathrm{OC}_{6} H_{4} \mathrm{C}_{6} \mathrm{H}_{5}\right), 6.82\left(\mathrm{~d}, J=7.6,3-\mathrm{CH}\right.$ of $\left.-\mathrm{C}_{6} \mathrm{H}_{3} \mathrm{SO}_{2}-\right), 6.65(\mathrm{~d}, J=8.4,1 \mathrm{H}, 4-\mathrm{CH}$ of $\left.\mathrm{C}_{6} \mathrm{H}_{3} \mathrm{SO}_{2-}\right), \quad 6.33$ (bs, $2 \mathrm{H}$, ortho $\mathrm{CH}$ of $\left.\mathrm{Zn}_{-}-\mathrm{OC}_{6} \mathrm{H}_{4} \mathrm{C}_{6} H_{5}\right), \quad 3.20 \quad(\mathrm{~s}, \quad 2 \mathrm{H}$, $\left.\mathrm{NHCH}_{2} \mathrm{CH}_{2} \mathrm{~N}\left(\mathrm{CH}_{3}\right)_{2}\right), \quad 2.24 \quad\left(\mathrm{~s}, \quad 3 \mathrm{H}, \quad 5-\mathrm{CH}_{3}\right.$ of $\left.-\mathrm{C}_{6} \mathrm{H}_{3} \mathrm{SO}_{2^{-}}\right), \quad 2.02 \quad(\mathrm{bs}, \quad 8 \mathrm{H}$, - 
$\left.\mathrm{NHCH}_{2} \mathrm{CH}_{2} \mathrm{~N}\left(\mathrm{CH}_{3}\right)_{2}\right)$, and $\left.-\mathrm{NHCH}_{2} \mathrm{CH}_{2} \mathrm{~N}\left(\mathrm{CH}_{3}\right)_{2}\right), 0.85\left(\mathrm{C}_{2} \mathrm{H}_{6}\right) .{ }^{31} \mathrm{P} \mathrm{NMR}\left(\mathrm{CD}_{2} \mathrm{Cl}_{2}\right): \delta$ 28.5.

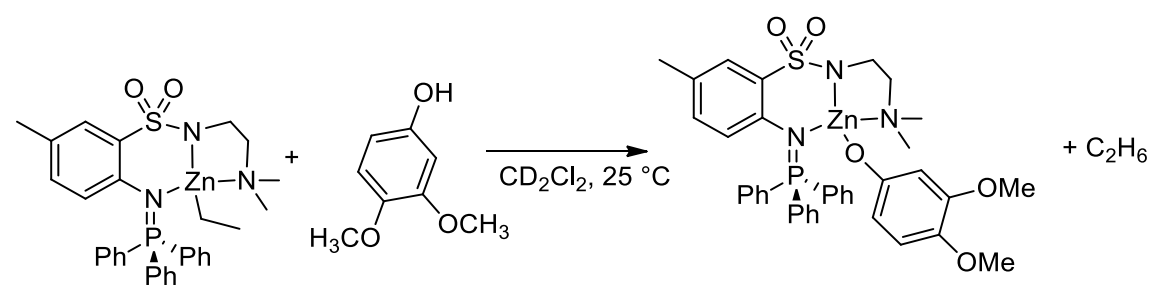

Generation of $\quad\left[\kappa^{3}-2-\left(\left(\mathrm{C}_{6} \mathrm{H}_{5}\right)_{3} \mathrm{P}=\mathrm{N}\right)-5-\mathrm{CH}_{3} \mathrm{C}_{6} \mathrm{H}_{3} \mathrm{SO}_{2} \mathrm{NH}\left(\mathrm{CH}_{2}\right)_{2} \mathrm{~N}\left(\mathrm{CH}_{3}\right)_{2}\right] \mathrm{Zn}(3,4-$ $\left.\mathbf{O C}_{6} \mathbf{H}_{3}(\mathbf{O M e})_{2}\right)$ (3.12). A valved NMR tube was loaded with $\mathbf{8}$ (10 mg, $\left.16.3 \mathrm{mmol}\right), 3$, 4-dimethoxyphenol $(2.5 \mathrm{mg}, 16.3 \mathrm{mmol})$ and $\mathrm{CD}_{2} \mathrm{Cl}_{2}(0.5 \mathrm{~mL})$ was added via vacuum transfer at $-196{ }^{\circ} \mathrm{C}$. After the NMR tube was flushed with $\mathrm{N}_{2}$, the tube was sealed, warmed to $25^{\circ} \mathrm{C}$, and shaken until the solids dissolved. After $10 \mathrm{~min}$ at $25^{\circ} \mathrm{C}$, integration of the ${ }^{31} \mathrm{P}\left\{{ }^{1} \mathrm{H}\right\}$ NMR spectra established that $33 \%$ of 3.12 was present in solution along with $67 \%$ of 3.7 . After $5 \mathrm{~h}$ at $25{ }^{\circ} \mathrm{C}$, integration of the ${ }^{31} \mathrm{P}\left\{{ }^{1} \mathrm{H}\right\}$ NMR spectra established that $93 \%$ of 3.12 was present in solution along with $7 \%$ of 3.7 . After $12 \mathrm{~h}$ at $25{ }^{\circ} \mathrm{C},{ }^{1} \mathrm{H}$ and ${ }^{31} \mathrm{P}\left\{{ }^{1} \mathrm{H}\right\}$ NMR spectra established that 3.12 was the only species present in solution along with ethane. ${ }^{1} \mathrm{HNMR}\left(\mathrm{CD}_{2} \mathrm{Cl}_{2}\right): \delta 7.96\left(\mathrm{~m}, 6 \mathrm{H}\right.$, ortho $\mathrm{CH}$ of $\left.\left(\mathrm{C}_{6} \mathrm{H}_{5}\right)_{3} \mathrm{P}=\mathrm{N}-\right), 7.75(\mathrm{~s}$, $1 \mathrm{H}, 6-\mathrm{CH}$ of $\left.-\mathrm{C}_{6} \mathrm{H}_{3} \mathrm{SO}_{2}-\right), 7.52\left(\mathrm{~m}, 3 \mathrm{H}\right.$, para $-\mathrm{CH}$ of $\left.\left(\mathrm{C}_{6} \mathrm{H}_{5}\right)_{3} \mathrm{P}=\mathrm{N}-\right), 7.44(\mathrm{~m}, 6 \mathrm{H}$, meta $\mathrm{CH}$ of $\left.\left(\mathrm{C}_{6} \mathrm{H}_{5}\right)_{3} \mathrm{P}=\mathrm{N}-\right), 6.77\left(\mathrm{~d}, J=8,1 \mathrm{H}, 4-\mathrm{CH}\right.$ of $\left.-\mathrm{C}_{6} \mathrm{H}_{3} \mathrm{SO}_{2}-\right), 6.62(\mathrm{~d}, J=8.4,1 \mathrm{H}, 3-\mathrm{CH}$ of $\left.-\mathrm{C}_{6} \mathrm{H}_{3} \mathrm{SO}_{2}-\right), 6.42\left(\mathrm{~d}, J=6.8,1 \mathrm{H}\right.$, ortho $-\mathrm{CH}$ of $-\mathrm{OC}_{6} \mathrm{H}_{3}\left(\mathrm{OCH}_{3}\right)_{2}, 5.87(\mathrm{~m}, 2 \mathrm{H}$, meta and ortho $-\mathrm{CH}$ of $-\mathrm{OC}_{6} \mathrm{H}_{3}\left(\mathrm{OCH}_{3}\right)_{2}, 3.67\left(\mathrm{~s}, 6 \mathrm{H},-\mathrm{OC}_{6} \mathrm{H}_{3}\left(\mathrm{OCH}_{3}\right)_{2}, 3.16(\mathrm{t}, J=5.6,2 \mathrm{H}\right.$, $\left.\mathrm{NHCH}_{2} \mathrm{CH}_{2} \mathrm{~N}\left(\mathrm{CH}_{3}\right)_{2}\right), \quad 2.23 \quad\left(\mathrm{~s}, \quad 3 \mathrm{H}, \quad 5-\mathrm{CH}_{3} \quad\right.$ of $\left.\quad-\mathrm{C}_{6} \mathrm{H}_{3} \mathrm{SO}_{2^{-}}\right), \quad 2.00 \quad(\mathrm{bs}, \quad 8 \mathrm{H},-$ $\left.\mathrm{NHCH}_{2} \mathrm{CH}_{2} \mathrm{~N}\left(\mathrm{CH}_{3}\right)_{2}\right)$ and $\left.-\mathrm{NHCH}_{2} \mathrm{CH}_{2} \mathrm{~N}\left(\mathrm{CH}_{3}\right)_{2}\right), 0.85\left(\mathrm{C}_{2} \mathrm{H}_{6}\right) .{ }^{31} \mathrm{P} \mathrm{NMR}\left(\mathrm{CD}_{2} \mathrm{Cl}_{2}\right): \delta$ 28.5 . 


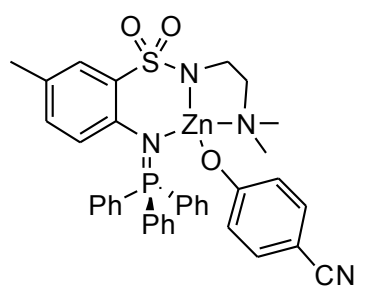

$\left[\kappa^{3}-2-\left(\left(\mathrm{C}_{6} \mathrm{H}_{5}\right)_{3} \mathrm{P}=\mathrm{N}\right)-5-\mathrm{CH}_{3} \mathrm{C}_{6} \mathrm{H}_{3} \mathrm{SO}_{2} \mathrm{NH}\left(\mathrm{CH}_{2}\right)_{2} \mathrm{~N}\left(\mathrm{CH}_{3}\right)_{2}\right] \mathrm{Zn}(4-$ $\left.\mathbf{O C}_{6} \mathbf{H}_{4} \mathbf{C N}\right)$ (3.10). A flask containing $3.7(300.0 \mathrm{mg}, 0.49 \mathrm{mmol})$ and 4-cyanophenol $(58.5 \mathrm{mg}, 0.49 \mathrm{mmol})$ was charged with $\mathrm{CH}_{2} \mathrm{Cl}_{2}(20 \mathrm{~mL})$ and stirred for 1 hour under nitrogen. The solvent

was removed under vacuum leaving $\mathbf{3 . 1 0}$ as a white solid. (250 mg, $73 \%$ ). ${ }^{1} \mathrm{HNMR}$ $\left(\mathrm{CD}_{2} \mathrm{Cl}_{2}\right): \delta 7.95\left(\mathrm{~m}, 6 \mathrm{H}\right.$, ortho $\mathrm{CH}$ of $\left.\left(\mathrm{C}_{6} \mathrm{H}_{5}\right)_{3} \mathrm{P}=\mathrm{N}-\right), 7.76\left(\mathrm{~s}, 1 \mathrm{H}, 6-\mathrm{CH}\right.$ of $\left.-\mathrm{C}_{6} \mathrm{H}_{3} \mathrm{SO}_{2}-\right)$, $7.45\left(\mathrm{~m}, 9 \mathrm{H}\right.$, meta and para $\mathrm{CH}$ of $\left.\left(\mathrm{C}_{6} \mathrm{H}_{5}\right)_{3} \mathrm{P}=\mathrm{N}-\right), 7.13(\mathrm{~d}, J=8.8,2 \mathrm{H}$, ortho $\mathrm{CH}$ of $\mathrm{ZnOC}_{6} \mathrm{H}_{4} \mathrm{CN}$ ), $6.81\left(\mathrm{~d}, J=8,4-\mathrm{CH}\right.$ of $\left.-\mathrm{C}_{6} \mathrm{H}_{3} \mathrm{SO}_{2}-\right), 6.63$ (d, $J=8,3-\mathrm{CH}$ of $-\mathrm{C}_{6} \mathrm{H}_{3} \mathrm{SO}_{2-}$ ), $6.28\left(\mathrm{~d}, J=8.8,1 \mathrm{H}\right.$, meta $\mathrm{CH}$ of $\left.\mathrm{ZnOC}_{6} \mathrm{H}_{4} \mathrm{CN}\right), 3.17\left(t, 2 \mathrm{H},-\mathrm{NHCH}_{2} \mathrm{CH}_{2} \mathrm{~N}_{(}\left(\mathrm{CH}_{3}\right)_{2}\right), 2.24$

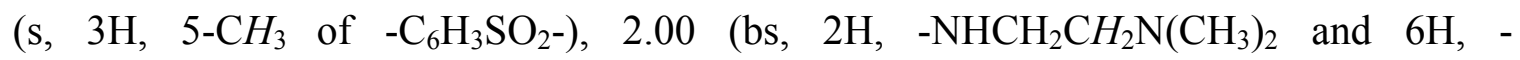
$\left.\mathrm{NHCH}_{2} \mathrm{CH}_{2} \mathrm{~N}\left(\mathrm{CH}_{3}\right)_{2}\right) .{ }^{31} \mathrm{P}$ NMR $\left(\mathrm{CD}_{2} \mathrm{Cl}_{2}\right): \delta 28.6 .{ }^{13} \mathrm{C} \mathrm{NMR}\left(\mathrm{CD}_{2} \mathrm{Cl}_{2}\right): \delta 170.4,141.8$, $138.6(\mathrm{~d}, J=48.4), 133.3,133.2(\mathrm{~d}, J=39.9), 132.8(\mathrm{~d}, J=12), 131.2,129.8,129.1(\mathrm{~d}, J$ $=48.4), 126.6,125.8(\mathrm{~d}, J=30.4), 125.7,121.3,119.3,95.3,60.3,45.5,43.2,20.2$.

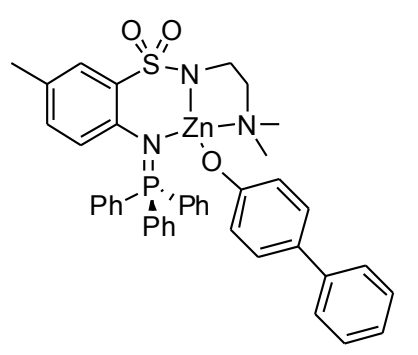

$\left[\kappa^{3}-2-\left(\left(\mathrm{C}_{6} \mathrm{H}_{5}\right)_{3} \mathrm{P}=\mathrm{N}\right)-5-\mathrm{CH}_{3} \mathrm{C}_{6} \mathrm{H}_{3} \mathrm{SO}_{2} \mathrm{NH}\left(\mathrm{CH}_{2}\right)_{2} \mathrm{~N}\left(\mathrm{CH}_{3}\right)_{2}\right] \mathrm{Zn}(4-$ $\left.\mathbf{O C}_{6} \mathbf{H}_{4} \mathbf{C}_{6} \mathbf{H}_{5}\right)$ (3.11). A flask containing $3.7(300.0 \mathrm{mg}, 0.49$ mmol) and 4-hydroxybiphenyl (83.5 $\mathrm{mg}, 0.49 \mathrm{mmol})$ was charged with $\mathrm{CH}_{2} \mathrm{Cl}_{2}(20 \mathrm{~mL})$ and stirred for 12 hours under nitrogen. The solvent was removed under vacuum leaving $\mathbf{3 . 1 1}$ as a white solid. (200 mg, $55 \%) .{ }^{1} \mathrm{HNMR}\left(\mathrm{CD}_{2} \mathrm{Cl}_{2}\right): \delta 7.98\left(\mathrm{~m}, 6 \mathrm{H}\right.$, ortho $-\mathrm{CH}$ of $\left.\left(\mathrm{C}_{6} \mathrm{H}_{5}\right)_{3} \mathrm{P}=\mathrm{N}-\right), 7.76(\mathrm{~s}, 1 \mathrm{H}, 6-\mathrm{CH}$ of $\left.-\mathrm{C}_{6} \mathrm{H}_{3} \mathrm{SO}_{2}-\right) 7.48\left(\mathrm{~m}, 11 \mathrm{H}\right.$, meta and para $-\mathrm{CH}$ of $\left.\left(\mathrm{C}_{6} \mathrm{H}_{5}\right)_{3} \mathrm{P}=\mathrm{N}-\right)$ and ortho $-\mathrm{CH}$ of $\mathrm{Zn}-$ $\left.\mathrm{OC}_{6} H_{4} \mathrm{C}_{6} \mathrm{H}_{5}\right), 7.35\left(\mathrm{t}, J=7.6,2 \mathrm{H}\right.$, meta $-\mathrm{CH}$ of $\left.\mathrm{Zn}-\mathrm{OC}_{6} \mathrm{H}_{4} \mathrm{C}_{6} H_{5}\right), 7.13(\mathrm{~m}, 3 \mathrm{H}$, para $-\mathrm{CH}$ of $\mathrm{Zn}-\mathrm{OC}_{6} \mathrm{H}_{4} \mathrm{C}_{6} H_{5}$ and meta $-\mathrm{CH}$ of $\left.\mathrm{Zn}-\mathrm{OC}_{6} H_{4} \mathrm{C}_{6} \mathrm{H}_{5}\right), 6.18$ (dd, $J=2,8,3-\mathrm{CH}$ of - 
$\mathrm{C}_{6} \mathrm{H}_{3} \mathrm{SO}_{2-}$ ), 6.65 (dd, $J=4,8.4,1 \mathrm{H}, 4-\mathrm{CH}$ of $-\mathrm{C}_{6} \mathrm{H}_{3} \mathrm{SO}_{2-}$ ), 6.31 (d, $J=7.2,2 \mathrm{H}$, ortho $\mathrm{CH}$ of $\left.\mathrm{Zn}-\mathrm{OC}_{6} \mathrm{H}_{4} \mathrm{C}_{6} \mathrm{H}_{5}\right), 3.19$ (t, $\left.J=5.6,2 \mathrm{H},-\mathrm{NHCH}_{2} \mathrm{CH}_{2} \mathrm{~N}\left(\mathrm{CH}_{3}\right)_{2}\right), 2.24$ (s, $1 \mathrm{H}, 5-\mathrm{CH}_{3}$ of $\left.-\mathrm{C}_{6} \mathrm{H}_{3} \mathrm{SO}_{2}-\right), 2.02$ (bs, 8H, of $\left.-\mathrm{NHCH}_{2} \mathrm{CH}_{2} \mathrm{~N}\left(\mathrm{CH}_{3}\right)_{2}\right)$ and $\left.-\mathrm{NHCH}_{2} \mathrm{CH}_{2} \mathrm{~N}\left(\mathrm{CH}_{3}\right)_{2}\right) .{ }^{31} \mathrm{P} \mathrm{NMR}$ $\left(\mathrm{CD}_{2} \mathrm{Cl}_{2}\right): \delta 28.6 .{ }^{13} \mathrm{C} \mathrm{NMR}\left(\mathrm{CD}_{2} \mathrm{Cl}_{2}\right): \delta 133.3(\mathrm{~d}, J=39.6), 132.7,132.6,132.4,132.0$, $131.0,129.7,129.0,128.9,128.8,128.4,127.2,126.8,126.0,125.9,125.7,125.0,118.8$ $60.2,45.6,43.3,20.2$.

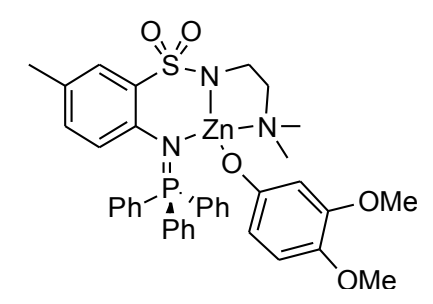

\section{$\left[\kappa^{3}-2-\left(\left(\mathrm{C}_{6} \mathrm{H}_{5}\right)_{3} \mathrm{P}=\mathrm{N}\right)-5-\right.$ \\ $\left.\mathrm{CH}_{3} \mathrm{C}_{6} \mathrm{H}_{3} \mathrm{SO}_{2} \mathrm{NH}\left(\mathrm{CH}_{2}\right)_{2} \mathrm{~N}\left(\mathrm{CH}_{3}\right)_{2}\right] \mathrm{Zn}\left(3,4-\mathrm{OC}_{6} \mathrm{H}_{3}(\mathrm{OMe})_{2}\right)$}

(3.12). A flask containing $3.7(250.0 \mathrm{mg}, 0.4 \mathrm{mmol})$ and 3,4dimethoxyphenol $(63.0 \mathrm{mg}, 0.4 \mathrm{mmol})$ was charged with $\mathrm{CH}_{2} \mathrm{Cl}_{2}(20 \mathrm{~mL})$ and stirred for 16 hours under nitrogen. The solvent was removed under vacuum leaving 3.12 as a white solid. (100 mg, $33 \%)$. ${ }^{1} \mathrm{HNMR}\left(\mathrm{CD}_{2} \mathrm{Cl}_{2}\right): \delta 7.96(\mathrm{~m}, 6 \mathrm{H}$, ortho $-\mathrm{CH}$ of $\left.\left(\mathrm{C}_{6} \mathrm{H}_{5}\right)_{3} \mathrm{P}=\mathrm{N}-\right), 7.92\left(\mathrm{~s}, 1 \mathrm{H}, 6-\mathrm{CH}\right.$ of $\left.-\mathrm{C}_{6} \mathrm{H}_{3} \mathrm{SO}_{2}-\right), 7.52(\mathrm{~m}, 3 \mathrm{H}$, para $-\mathrm{CH}$ of $\left.\left(\mathrm{C}_{6} \mathrm{H}_{5}\right)_{3} \mathrm{P}=\mathrm{N}-\right), 7.44\left(\mathrm{~m}, 6 \mathrm{H}\right.$, meta $-\mathrm{CH}$ of $\left.\left(\mathrm{C}_{6} \mathrm{H}_{5}\right)_{3} \mathrm{P}=\mathrm{N}-\right), 6.79(\mathrm{dd}, J=8.4,2.4,1 \mathrm{H}, 4-\mathrm{CH}$ of $-\mathrm{C}_{6} \mathrm{H}_{3} \mathrm{SO}_{2}$ ) $), 6.62\left(\mathrm{dd}, J=8,1.6,1 \mathrm{H}, 3-\mathrm{CH}\right.$ of $\left.-\mathrm{C}_{6} \mathrm{H}_{3} \mathrm{SO}_{2}-\right), 6.42(\mathrm{~d}, J=8.4,1 \mathrm{H}$, ortho $\mathrm{CH}$ of $\mathrm{Zn}-\mathrm{OC}_{6} \mathrm{H}_{3}\left(\mathrm{OCH}_{3}\right)_{2}, 5.87$ (m, 2H, meta and ortho $-\mathrm{CH}$ of $\mathrm{Zn}-\mathrm{OC}_{6} \mathrm{H}_{3}\left(\mathrm{OCH}_{3}\right)_{2}, 3.67$ (2s, 6H, Zn- $-\mathrm{OC}_{6} \mathrm{H}_{3}\left(\mathrm{OCH}_{3}\right)_{2}, 3.16\left(\mathrm{t}, J=5.6,2 \mathrm{H},-\mathrm{NHCH}_{2} \mathrm{CH}_{2} \mathrm{~N}\left(\mathrm{CH}_{3}\right)_{2}\right), 2.23(\mathrm{~s}, 3 \mathrm{H}, 5-$ $\mathrm{CH}_{3}$ of $\left.-\mathrm{C}_{6} \mathrm{H}_{3} \mathrm{SO}_{2}-\right), 1.99$ (bs, 8H,- $\left.\mathrm{NHCH}_{2} \mathrm{CH}_{2} \mathrm{~N}\left(\mathrm{CH}_{3}\right)_{2}\right)$ and $\left.-\mathrm{NHCH}_{2} \mathrm{CH}_{2} \mathrm{~N}\left(\mathrm{CH}_{3}\right)_{2}\right) .{ }^{31} \mathrm{P}$ NMR $\left(\mathrm{CD}_{2} \mathrm{Cl}_{2}\right): \delta 28.5 .{ }^{13} \mathrm{C}$ NMR $\left(\mathrm{CD}_{2} \mathrm{Cl}_{2}\right): \delta 133.3(\mathrm{~d}, J=42.4), 132.7,132.6,131.0$, $129.6,129.0,128.8,126.9,125.8,103.5,60.2,55.2,45.6,43.3,20.2$.

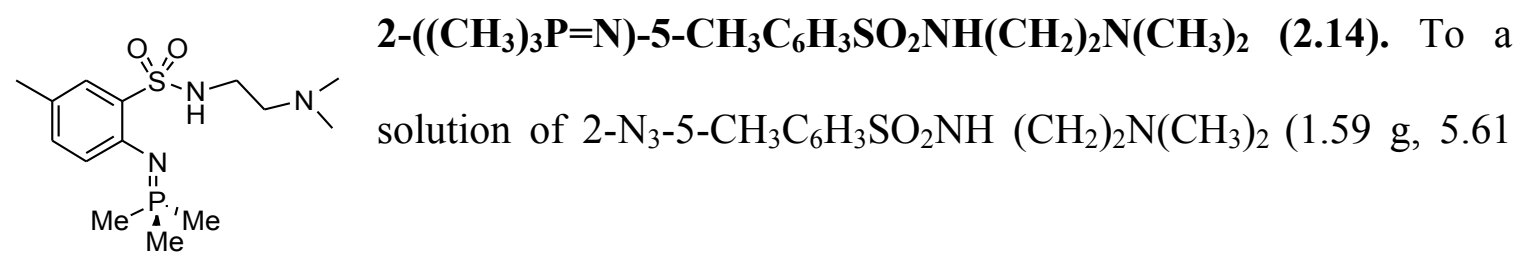


$\mathrm{mmol})$ in toluene $(10 \mathrm{~mL}), 6.2 \mathrm{~mL}$ of $\mathrm{Me}_{3} \mathrm{P}(1 \mathrm{M}$ solution in tolutene, $6.17 \mathrm{mmol})$ was added under nitrogen. Red solution and suspension was observed immediately. Suspension dissolved to give clear brown solution after stirring for 12 hours at $25{ }^{\circ} \mathrm{C}$. The solvent was removed under vacuum leaving brown solid. The brown solid was washed with $3 \times 10 \mathrm{~mL}$ dry pentane and trace of the solvent was removed under vacuum yield off white solid (1.6 g, 86 \%). $\quad{ }^{1} \mathrm{HNMR}\left(\mathrm{CD}_{2} \mathrm{Cl}_{2}\right): \delta 7.53$ (s, 1H, 6-CH), 7.10 (bs, $1 \mathrm{H}$ of $\left.\mathrm{SO}_{2} \mathrm{NH}\right), 7.08(\mathrm{dd}, J=8.0,5.6,1 \mathrm{H}, 4-\mathrm{C} H), 6.53(\mathrm{dd}, J=7.6,1.2,1 \mathrm{H}, 3-\mathrm{CH}), 2.77$ (m, 2H, -N-CH $\left.H_{2}\right), 2.36\left(\mathrm{~m}, 2 \mathrm{H}, \mathrm{NHCH}_{2} \mathrm{CH}_{2}\right), 2.24$ (s, 3H, 5- $\left.\mathrm{CH}_{3}\right), 2.13$ (s, 6H, -N $\left(\mathrm{CH}_{3}\right)_{2}$, $1.67\left(\mathrm{~d}, J=13.2,9 \mathrm{H},-\mathrm{N}=\mathrm{P}\left(\mathrm{CH}_{3}\right)_{3} \cdot{ }^{31} \mathrm{P}\right.$ NMR $\left(\mathrm{CD}_{2} \mathrm{Cl}_{2}\right): \delta 12.3 .{ }^{13} \mathrm{C} \mathrm{NMR}\left(\mathrm{CD}_{2} \mathrm{Cl}_{2}\right): \delta$ $149.2,135.4,131.8,130.9,127.2,122.8(\mathrm{~d}, J=48.4), 60.2,47.1 .0,42.9,21.8,17.6(\mathrm{~d}, J$ $=273)$.

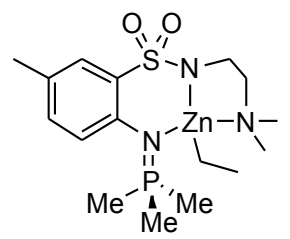

\section{$2-\left(\left(\mathrm{CH}_{3}\right)_{3} \mathrm{P}=\mathrm{N}\right)-5-\mathrm{CH}_{3} \mathrm{C}_{6} \mathrm{H}_{3} \mathrm{SO}_{2} \mathrm{NH}\left(\mathrm{CH}_{2}\right)_{2} \mathrm{~N}\left(\mathrm{CH}_{3}\right)_{2} \mathrm{ZnEt}$}

To a solution of phosphinimine ligand $(1 \mathrm{~g}, 3.01 \mathrm{mmol})$ in toluene (40 $\mathrm{mL}), 4.5 \mathrm{~mL}$ of $\mathrm{Et}_{2} \mathrm{Zn}(1 \mathrm{M}$ in toluene, $4.52 \mathrm{mmol})$ solution was added at $-35^{\circ} \mathrm{C}$ under nitrogen. The reaction mixture was allowed to warm to room temperature stirred 12 hours. The solvent was removed in vacuum leaving yellowish gluey material. $10 \mathrm{~mL}$ toluene was added and stirred for 2 hours. Yellow suspension in the solution was observed. The yellow suspension was washed with $3 \times 10 \mathrm{~mL}$ dry hexane and the solvent was removed under vacuum to yield yellowish white solid (1.14 g, 90\%). ${ }^{1} \mathrm{HNMR}$ $\left(\mathrm{CD}_{2} \mathrm{Cl}_{2}\right): \delta 7.69(\mathrm{~s}, 1 \mathrm{H}, 6-\mathrm{CH}), 7.07(\mathrm{dd}, J=8.0,2.4,1 \mathrm{H}, 4-\mathrm{CH}), 6.68(\mathrm{dd}, J=8.0$, 2.8,1H, 3-CH), $2.98\left(\mathrm{t}, J=11.6,6.0,2 \mathrm{H},-\mathrm{N}-\mathrm{CH}_{2}\right), 2.31$ (s, 3H, 5- $\left.\mathrm{CH}_{3}\right), 2.20-1.90$ (bs, $2 \mathrm{H}, \mathrm{NHCH}_{2} \mathrm{CH}_{2}$ and $\left.6 \mathrm{H},-\mathrm{N}\left(\mathrm{CH}_{3}\right)_{2}\right), 1.68\left(\mathrm{~d}, J=12.8,9 \mathrm{H},-\mathrm{N}=\mathrm{P}\left(\mathrm{CH}_{3}\right)_{3}\right), 1.28(\mathrm{t}, J=16$, $8,3 \mathrm{H}$ of $-\mathrm{ZnCH}_{2} \mathrm{CH}_{3},-0.89\left(\mathrm{q}, J=16,8,2 \mathrm{H}\right.$ of $\left.-\mathrm{ZnCH}_{2}\right) .{ }^{31} \mathrm{P} \mathrm{NMR}\left(\mathrm{CD}_{2} \mathrm{Cl}_{2}\right): \delta 35.4$. 
${ }^{13} \mathrm{C}$ NMR $\left(\mathrm{CD}_{2} \mathrm{Cl}_{2}\right): \quad \delta 143.4,140.7,131.4131 .1,129.2,127.7,59.4,45.4,43.2,20.3$, $15.8,13.0,(\mathrm{~d}, J=273), 0.13$. 


\section{Experimental Section 3: phosphinimine synthesis}

\section{(Chapter 4)}

$\mathbf{P P h}_{2}\left(4-\mathbf{C}_{6} \mathbf{H}_{4} \mathbf{N}\left(\mathrm{CH}_{3}\right)_{2}\right)_{2}$ (4.1). Under nitrogen, a $500 \mathrm{~mL} 3$ neck round bottom flask was charged with magnesium powder $(1.43 \mathrm{~g}, 58.95 \mathrm{mmol})$. The $\mathrm{Mg}$ powder was suspended in THF $(100 \mathrm{~mL})$ and stirred under nitrogen. A water condenser and a $250 \mathrm{~mL}$ pressure equalizing addition funnel were attached to the necks of the $500 \mathrm{~mL}$ RBF under nitrogen. The starting material, 4-bromo-N,N-dimethylaniline $(11.80 \mathrm{~g}, 58.95 \mathrm{mmol})$ in a separate $250 \mathrm{~mL} \mathrm{RBF}$, was dissolved in $100 \mathrm{~mL}$ of THF and transferred to the pressure equalizing addition funnel via cannula. The $250 \mathrm{~mL}$ RBF was rinsed with THF $(2 \times 10 \mathrm{~mL})$ and both washes were transferred to the addition funnel via cannula. The 4-bromo-N,Ndimethylaniline/THF solution was added to the Mg/THF suspension dropwise over 25 minutes to maintain a gentle reflux and then refluxed further for 1 hour after the addition was complete. After 1 of reflux, the brown solution was cooled to $25^{\circ} \mathrm{C}$ and the addition funnel was charged with $20 \mathrm{~mL} \mathrm{THF,} \mathrm{Ph}_{2} \mathrm{PCl}(5.3 \mathrm{~mL}, 29.48 \mathrm{mmol})$, and $20 \mathrm{~mL}$ THF. The grey-brown reaction suspension was cooled to $0{ }^{\circ} \mathrm{C}$ and the $\mathrm{Ph}_{2} \mathrm{PCl} / \mathrm{THF}$ solution was added dropwise over 20 minutes. After the addition was complete the funnel was rinsed with $20 \mathrm{~mL}$ THF into the reaction mixture and the reaction mixture was refluxed for 1 hour. After 1 hour of reflux, the reaction was cooled to $25{ }^{\circ} \mathrm{C}$ and allowed to stir overnight under nitrogen. The next morning the reaction mixture was cooled to $0{ }^{\circ} \mathrm{C}$ and a $10 \%$ aqueous solution of $\mathrm{NH}_{4} \mathrm{Cl}(140 \mathrm{~mL})$ was added dropwise over 10 minutes. After the $\mathrm{NH}_{4} \mathrm{Cl}$ addition was completed the reaction mixture was stirred for a further 25 minutes at $25^{\circ} \mathrm{C}$. Toluene $(200 \mathrm{~mL})$ was used to transfer the biphasic reaction mixture to a $1 \mathrm{~L}$ sept. funnel. The aqueous layer was extracted with the toluene and then collected in a $1 \mathrm{~L}$ Erlenmeyer flask. The aqueous layer was extracted twice more with toluene $(2 \mathrm{x}$ 
$200 \mathrm{~mL}$ ), combined with the first layer, and dried over $\mathrm{MgSO}_{4}$. The $\mathrm{MgSO}_{4}$ was filtered off and the volatiles were removed under vacuum affording a white solid and a small amount of yellow oil. The mixture was suspended in hexanes $(50 \mathrm{~mL})$, filtered and rinsed with $50 \mathrm{~mL}$ hexanes yielding 4.1 as a white solid (7.69 g, $85 \%)$. ${ }^{1} \mathrm{H}$ NMR $\left(\mathrm{CDCl}_{3}\right): \delta 7.31\left(\mathrm{~m}, 10 \mathrm{H}, \mathrm{C}_{6} \mathrm{H}_{5} \mathrm{Ar}-H\right), 7.26\left(\mathrm{~m}, 2 \mathrm{H}, 2-\mathrm{CH}\right.$ of $\left.\mathrm{P}\left(4-\mathrm{C}_{6} \mathrm{H}_{4} \mathrm{~N}\left(\mathrm{CH}_{3}\right)_{2}\right)\right), 6.71$ $\left(\mathrm{d}, 2 \mathrm{H}, J=8,3-\mathrm{CH}\right.$ of $\left.\mathrm{P}\left(4-\mathrm{C}_{6} \mathrm{H}_{4} \mathrm{~N}\left(\mathrm{CH}_{3}\right)_{2}\right)\right), 2.98\left(\mathrm{~s}, 6 \mathrm{H},-\mathrm{N}\left(\mathrm{CH}_{3}\right)_{2}\right) .{ }^{13} \mathrm{C} \mathrm{NMR}\left(\mathrm{CDCl}_{3}\right): \delta$ ${ }^{13} \mathrm{C}$ NMR $\left(\mathrm{CDCl}_{3}\right): \delta 152.0,150.4,134.5\left(\mathrm{~d}, J_{\mathrm{PC}}=19.8\right), 133.4\left(\mathrm{~d}, J_{\mathrm{PC}}=10.7\right), 128.3$, $124.4,120.1,118.9,112.3\left(\mathrm{~d}, J_{\mathrm{PC}}=7.5\right), 111.1\left(\mathrm{~d}, J_{\mathrm{PC}}=12.2\right), 40.3,40.0 .{ }^{31} \mathrm{P}$ NMR $\left(\mathrm{CDCl}_{3}\right):-7.3$.

$\operatorname{PPh}\left(4-\mathrm{C}_{6} \mathbf{H}_{4} \mathbf{N}\left(\mathrm{CH}_{3}\right)_{2}\right)_{2}$ (4.2). Under nitrogen, a $500 \mathrm{~mL} 3$ neck round bottom flask was charged with magnesium powder $(2.08 \mathrm{~g}, 85.74 \mathrm{mmol})$. The Mg powder was suspended in THF $(80 \mathrm{~mL})$ and stirred under nitrogen. A water condenser and a $250 \mathrm{~mL}$ pressure equalizing addition funnel were attached to the necks of the $500 \mathrm{~mL}$ RBF under nitrogen. The starting material, 4-bromo-N,N-dimethylaniline $(17.15 \mathrm{~g}, 85.74 \mathrm{mmol})$ in a separate $250 \mathrm{~mL} \mathrm{RBF}$, was dissolved in $60 \mathrm{~mL}$ of THF and transferred to the pressure equalizing addition funnel via cannula. The $250 \mathrm{~mL}$ RBF was rinsed with THF $(2 \times 10 \mathrm{~mL})$ and both washes were transferred to the addition funnel via cannula. The 4-bromo-N,Ndimethylaniline/THF solution was added to the $\mathrm{Mg}$ /THF suspension dropwise over 25 minutes to maintain a gentle reflux and then refluxed further for 1.5 hours after the addition was complete. After 1.5 hours of reflux, the grey-brown suspension was cooled to $25{ }^{\circ} \mathrm{C}$ and the addition funnel was charged with $20 \mathrm{~mL}$ THF, $\mathrm{PhPCl}_{2}(4.0 \mathrm{~mL}, 29.48$ $\mathrm{mmol}$ ), and $20 \mathrm{~mL}$ THF. The grey-brown reaction suspension was cooled to $0{ }^{\circ} \mathrm{C}$ and the $\mathrm{PhPCl}_{2} / \mathrm{THF}$ solution was added dropwise over 20 minutes. After the addition was 
complete the funnel was rinsed with $20 \mathrm{~mL}$ THF into the reaction mixture and the reaction mixture was refluxed for 1 hour. After 1 hour of reflux, the reaction was cooled to $25{ }^{\circ} \mathrm{C}$ and allowed to stir overnight under nitrogen. The next morning the reaction mixture was cooled to $0{ }^{\circ} \mathrm{C}$ and a $10 \%$ aqueous solution of $\mathrm{NH}_{4} \mathrm{Cl}(140 \mathrm{~mL})$ was added dropwise over 10 minutes. After the $\mathrm{NH}_{4} \mathrm{Cl}$ addition was completed the reaction mixture was stirred for a further 25 minutes at $25^{\circ} \mathrm{C}$. Toluene $(200 \mathrm{~mL})$ was used to transfer the biphasic reaction mixture to a $1 \mathrm{~L}$ sept. funnel. The aqueous layer was extracted with the toluene and then collected in a $1 \mathrm{~L}$ Erlenmeyer flask. The aqueous layer was extracted twice more with toluene $(2 \times 200 \mathrm{~mL})$, combined with the first layer, and dried over $\mathrm{MgSO}_{4}$. The $\mathrm{MgSO}_{4}$ was filtered off and the volatiles were removed under vacuum affording a white solid and a small amount of yellow oil. The mixture was suspended in hexanes $(50 \mathrm{~mL})$, filtered and rinsed with $50 \mathrm{~mL}$ hexanes yielding 4.2 as a white solid (8.54 g, 86\%). ${ }^{1} \mathrm{H}$ NMR (DMSO- $\left.d_{6}\right): \delta 7.30\left(\mathrm{~m}, 3 \mathrm{H}, \mathrm{C}_{6} \mathrm{H}_{5} \mathrm{Ar}-H\right), 7.13\left(\mathrm{~m}, 2 \mathrm{H}, \mathrm{C}_{6} \mathrm{H}_{5} \mathrm{Ar}-\right.$ $H)$, 7.11-7.08 (m, 5H, Ar-H), 6.74-6.69 (m. 4H, Ar-H), 7.08 (m, 4H, 2-CH of $\mathrm{P}(4-$ $\left.\left.\mathrm{C}_{6} \mathrm{H}_{4} \mathrm{~N}\left(\mathrm{CH}_{3}\right)_{2}\right)\right), 6.70\left(\mathrm{~d}, 4 \mathrm{H}, J=8,3-\mathrm{CH}\right.$ of $\left.\mathrm{P}\left(4-\mathrm{C}_{6} \mathrm{H}_{4} \mathrm{~N}\left(\mathrm{CH}_{3}\right)_{2}\right)\right), 2.89(\mathrm{~d}, 12 \mathrm{H},-$ $\left.\mathrm{N}\left(\mathrm{CH}_{3}\right)_{2}\right) .{ }^{13} \mathrm{C}$ NMR $\left(\mathrm{DMSO}-d_{6}\right): \delta 150.5,140.0\left(\mathrm{~d}, J_{\mathrm{PC}}=11.5\right), 134.5\left(\mathrm{~d}, J_{\mathrm{PC}}=21.4\right)$, $132.1\left(\mathrm{~d}, J_{\mathrm{PC}}=18.3\right), 128.2\left(\mathrm{~d}, J_{\mathrm{PC}}=6.12\right), 127.7,121.8\left(\mathrm{~d}, J_{\mathrm{PC}}=5.32\right), 112.3\left(\mathrm{~d}, J_{\mathrm{PC}}=\right.$ 7.6), 39.7, 39.5. ${ }^{31} \mathrm{P}$ NMR (DMSO- $\left.d_{6}\right):-10.7$.

$\mathbf{P}\left(4-\mathrm{C}_{6} \mathbf{H}_{4} \mathbf{N}\left(\mathrm{CH}_{3}\right)_{2}\right)_{3}$ (4.3). Under nitrogen, a $1 \mathrm{~L} 2$ neck round bottom flask was charged with magnesium powder $(2.81 \mathrm{~g}, 115.61 \mathrm{mmol})$. The Mg powder was suspended in THF $(110 \mathrm{~mL})$ and stirred under nitrogen. A water condenser and a $250 \mathrm{~mL}$ pressure equalizing addition funnel were attached to the 2 necks of the $1 \mathrm{~L}$ RBF under nitrogen. The starting material, 4-bromo-N,N-dimethylaniline $(23.07 \mathrm{~g}, 115.30 \mathrm{mmol})$ in a separate 
$250 \mathrm{~mL}$ RBF, was dissolved in $60 \mathrm{~mL}$ of THF and transferred to the pressure equalizing addition funnel via cannula. The $250 \mathrm{~mL}$ RBF was rinsed with THF $(2 \times 10 \mathrm{~mL})$ and both washes were transferred to the addition funnel via cannula. The 4-bromo-N,Ndimethylaniline/THF solution was added to the $\mathrm{Mg}$ /THF suspension dropwise over 25 minutes to maintain a gentle reflux and then refluxed further for 1 hour after the addition was complete. After 1 hour of reflux, the grey-brown suspension was cooled to $25{ }^{\circ} \mathrm{C}$ and the addition funnel was charged with $20 \mathrm{~mL}$ THF, $\mathrm{PCl}_{3}(2.5 \mathrm{~mL}, 28.65 \mathrm{mmol})$, and $20 \mathrm{~mL}$ THF. The grey-brown reaction suspension was cooled to $0{ }^{\circ} \mathrm{C}$ and the $\mathrm{PCl}_{3} / \mathrm{THF}$ solution was added dropwise over 20 minutes. After the addition was complete the funnel was rinsed with $20 \mathrm{~mL}$ THF into the reaction mixture. The reaction was allowed to stir at $25{ }^{\circ} \mathrm{C}$ overnight under nitrogen. The next morning the reaction mixture, now containing a light yellow precipitate, was cooled to $0{ }^{\circ} \mathrm{C}$ and a $10 \%$ aqueous solution of $\mathrm{NH}_{4} \mathrm{Cl}(140$ $\mathrm{mL}$ ) was added dropwise over 10 minutes. During the $\mathrm{NH}_{4} \mathrm{Cl}$ addition the yellow solid changed in color to a white solid and bubbling was observed from the solution. After the $\mathrm{NH}_{4} \mathrm{Cl}$ addition was completed the reaction mixture was stirred for a further 25 minutes at $0{ }^{\circ} \mathrm{C}$. Dichloromethane $(200 \mathrm{~mL})$ was used to transfer the biphasic reaction mixture to a $1 \mathrm{~L}$ sept. funnel. The aqueous layer was extracted with the $\mathrm{CH}_{2} \mathrm{Cl}_{2}$ and then collected in a $1 \mathrm{~L}$ Erlenmeyer flask. The aqueous layer was extracted twice more with $\mathrm{CH}_{2} \mathrm{Cl}_{2}(2 \mathrm{x}$ $200 \mathrm{~mL}$ ), combined with the first layer, and dried over $\mathrm{MgSO}_{4}$. The $\mathrm{MgSO}_{4}$ was filtered off and the volatiles were removed under vacuum affording a light orange solid. The orange solid was suspended in toluene $(20 \mathrm{~mL})$, filtered and rinsed with $50 \mathrm{~mL}$ hexanes yielding 4.3 as a light orange solid $(8.61 \mathrm{~g}, 76 \%) .{ }^{1} \mathrm{H} \mathrm{NMR}\left(\mathrm{CDCl}_{3}\right): \delta 7.20(\mathrm{~m}, 6 \mathrm{H}, 2-$ $\mathrm{CH}$ of $\left.\mathrm{P}\left(4-\mathrm{C}_{6} \mathrm{H}_{4} \mathrm{~N}\left(\mathrm{CH}_{3}\right)_{2}\right)\right), 6.68\left(\mathrm{~d}, 6 \mathrm{H}, J=8,3-\mathrm{CH}\right.$ of $\left.\mathrm{P}\left(4-\mathrm{C}_{6} \mathrm{H}_{4} \mathrm{~N}\left(\mathrm{CH}_{3}\right)_{2}\right)\right), 2.94(\mathrm{~s}, 18 \mathrm{H}$, 
$\left.-\mathrm{N}\left(\mathrm{CH}_{3}\right)_{2}\right) .{ }^{13} \mathrm{C}$ NMR $\left(\mathrm{CDCl}_{3}\right): \delta 152.0,150.4,134.5\left(\mathrm{~d}, J_{\mathrm{PC}}=19.8\right), 133.4\left(\mathrm{~d}, J_{\mathrm{PC}}=\right.$ $10.7), 128.3,124.4,120.1,118.9,112.3\left(\mathrm{~d}, J_{\mathrm{PC}}=7.5\right), 111.1\left(\mathrm{~d}, J_{\mathrm{PC}}=12.2\right), 40.3,40.0$. ${ }^{31} \mathrm{P} \mathrm{NMR}\left(\mathrm{CDCl}_{3}\right) \delta-11.3$.

$\mathbf{P}\left(4-\mathbf{C}_{6} \mathbf{H}_{4} \mathbf{O C H}_{3}\right)_{3}$ (4.4). Under nitrogen, a $1 \mathrm{~L} 2$ neck round bottom flask was charged with magnesium powder $(2.43 \mathrm{~g}, 100 \mathrm{mmol})$. The $\mathrm{Mg}$ powder was suspended in THF $(110 \mathrm{~mL})$ and stirred under nitrogen. A water condenser and a $250 \mathrm{~mL}$ pressure equalizing addition funnel were attached to the 2 necks of the $1 \mathrm{~L}$ RBF under nitrogen. The starting material, Bromoanisole $(15.57 \mathrm{~g}, 83.24 \mathrm{mmol})$ in a separate $250 \mathrm{~mL} R B F$, was dissolved in $70 \mathrm{~mL}$ of THF and transferred to the pressure equalizing addition funnel via cannula. The $250 \mathrm{~mL}$ RBF was rinsed with THF $(2 \times 10 \mathrm{~mL})$ and both washes were transferred to the addition funnel via cannula. The bromoanisole/THF solution was added to the $\mathrm{Mg} / \mathrm{THF}$ suspension dropwise over 25 minutes to maintain a gentle reflux and then refluxed further for 1 hour after the addition was complete. After 1 hour of reflux, the grey-brown suspension was cooled to $25^{\circ} \mathrm{C}$ and the addition funnel was charged with 20 $\mathrm{mL}$ THF, $\mathrm{PCl}_{3}(2.40 \mathrm{~mL}, 27.30 \mathrm{mmol})$, and $20 \mathrm{~mL}$ THF. The grey brown suspension was cooled to $0{ }^{\circ} \mathrm{C}$ and the $\mathrm{PCl}_{3} / \mathrm{THF}$ solution was added dropwise over 20 minutes. After the addition was complete the funnel was rinsed with $20 \mathrm{~mL}$ THF into the reaction mixture. After reflux for 1 hour, the reaction mixture was filtered through celite in the air and a red solution was obtained. Ice $(10 \mathrm{~g})$ and $10 \% \mathrm{HCl}(200 \mathrm{~mL})$ ware added to obtain a yellow solution. The yellow solution was extracted with diethyl ether $(3 \times 100 \mathrm{~mL})$ and the combined ether washes were reduced under vacuum to give $\mathbf{4 . 4}$ as a yellow solid. Yellow crude solid was recrystallized from ethanol $(80 \mathrm{~mL})$ to obtained a yellow solid $(5.00 \mathrm{~g}$, 53\%). ${ }^{1} \mathrm{H}$ NMR $\left(\mathrm{CDCl}_{3}\right): \delta 7.20\left(\mathrm{t}, J=7.6,6 \mathrm{H}, 2,6-\mathrm{CH}\right.$ of $\left.\mathrm{P}\left(4-\mathrm{C}_{6} \mathrm{H}_{4} \mathrm{OCH}_{3}\right)_{3}\right), 6.88(\mathrm{~d}, J=$ 
8, 6H, 3,5-CH of $\left.\mathrm{P}\left(4-\mathrm{C}_{6} \mathrm{H}_{4} \mathrm{OCH}\right)_{3}\right), 3.79\left(\mathrm{~s}, 9 \mathrm{H},-\mathrm{OCH}_{3}\right),{ }^{13} \mathrm{C} \mathrm{NMR}\left(\mathrm{CDCl}_{3}\right): \delta 160,135$ $\left(\mathrm{d}, J_{\mathrm{PC}}=19.8\right), 128\left(\mathrm{~d}, J_{\mathrm{PC}}=10.7\right), 112.3\left(\mathrm{~d}, J_{\mathrm{PC}}=7.5\right), 114\left(\mathrm{~d}, J_{\mathrm{PC}}=12.2\right), 55.1(-$ $\left.\mathrm{OCH}_{3}\right) .{ }^{31} \mathrm{P} \mathrm{NMR}\left(\mathrm{CDCl}_{3}\right): \delta-10.1$.

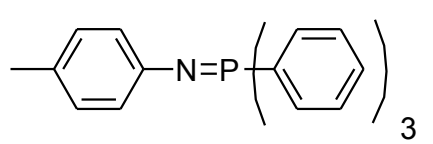

4- $\mathrm{CH}_{3} \mathbf{C}_{6} \mathbf{H}_{4} \mathbf{N}=\mathbf{P P h}_{3}$ (4.5). The compound was synthesized 4- $\mathrm{H}_{3} \mathrm{CC}_{6} \mathrm{H}_{4} \mathrm{~N}_{3}(1.00 \mathrm{~g}, 3.00 \mathrm{mmol})$ in toluene $(10 \mathrm{~mL})$, a solution of triphenylphosphine $(2.16 \mathrm{~g}, 3.30 \mathrm{mmol})$ in toluene $(10 \mathrm{~mL})$ was added dropwise at $0{ }^{\circ} \mathrm{C}$. After 30 minutes, the reaction mixture was warmed to $25{ }^{\circ} \mathrm{C}$ and stirred for 16 hours. Toluene was removed under vacuum, resulting in a yellow solid. The yellow solid was treated with 1:3 toluenehexanes $(40 \mathrm{~mL})$ affording a precipitate which was stirred under $\mathrm{N}_{2}$. The stirring was stopped and the yellow solid allowed to settle. The 1:3 toluene/hexanes was removed using syringe. Hexanes $(10 \mathrm{~mL})$ was added to the solid. The solid was collected by filtration and rinsed with hexanes $(10 \mathrm{~mL})$ to yield 4.5 as a yellow solid $(1.00 \mathrm{~g}, 90 \%) .{ }^{1} \mathrm{H}$ NMR $\left(\mathrm{CDCl}_{3}\right): \quad \delta 7.78\left(\mathrm{~m}, 6 \mathrm{H}\right.$ of $3,5-\mathrm{CH}$ of $\left.-\mathrm{N}=\mathrm{P}\left(\mathrm{C}_{6} \mathrm{H}_{5}\right)_{3}\right), 7.52(\mathrm{~m}, 3 \mathrm{H}, 4-\mathrm{CH}$ of $\left.\mathrm{N}=\mathrm{P}\left(\mathrm{C}_{6} \mathrm{H}_{5}\right)_{3}\right), 7.44\left(\mathrm{~m}, 6 \mathrm{H}\right.$ of 3,5-CH of $\left.-\mathrm{N}=\mathrm{P}\left(\mathrm{C}_{6} \mathrm{H}_{5}\right)_{3}\right), 6.84(\mathrm{~d}, J=7.6,2 \mathrm{H}, 2,6-\mathrm{CH}$ of $\left.\mathrm{P}=\mathrm{N}\left(4-\mathrm{C}_{6} \mathrm{H}_{4} \mathrm{CH}_{3}\right)\right), 6.72\left(\mathrm{~d}, J=7.6,2 \mathrm{H}, 3,5-\mathrm{CH}\right.$ of $\left.-\mathrm{P}=\mathrm{N}\left(4-\mathrm{C}_{6} \mathrm{H}_{4} \mathrm{CH}_{3}\right)\right), 2.19(\mathrm{~s}, 3 \mathrm{H}, 4-$ $\left.\mathrm{CH}_{3}\right) .{ }^{1} \mathrm{H}$ NMR $\left(\mathrm{C}_{6} \mathrm{D}_{6}\right): \delta 7.79\left(\mathrm{~m}, 6 \mathrm{H}\right.$ of $2,6-\mathrm{CH}$ of $\left.-\mathrm{N}=\mathrm{P}\left(\mathrm{C}_{6} \mathrm{H}_{5}\right)_{3}\right), 7.14(\mathrm{~d}, J=8,2 \mathrm{H}$, 2,6- $\mathrm{CH}$ of $\left.-\mathrm{P}=\mathrm{N}\left(\mathrm{C}_{6} \mathrm{H}_{4} \mathrm{CH}_{3}\right)\right)$, 6.99-6.91 (m, $11 \mathrm{H}, 3,5-\mathrm{CH}$ of $-\mathrm{N}=\mathrm{P}\left(\mathrm{C}_{6} \mathrm{H}_{5}\right)_{3}, 4-\mathrm{CH}$ of $\mathrm{N}=\mathrm{P}\left(\mathrm{C}_{6} \mathrm{H}_{5}\right)_{3}$ and 3,5- $\mathrm{CH}$ of $\left.-\mathrm{P}=\mathrm{N}\left(\mathrm{C}_{6} \mathrm{H}_{4} \mathrm{CH}_{3}\right)\right), 2.14\left(\mathrm{~s}, 3 \mathrm{H},-\mathrm{CH}_{3}\right) .{ }^{31} \mathrm{P}$ NMR $\left(\mathrm{CDCl}_{3}\right): \delta$ 2.82. ${ }^{31} \mathrm{P}$ NMR $\left(\mathrm{C}_{6} \mathrm{D}_{6}\right): \delta-1.58 .{ }^{13} \mathrm{C}$ NMR $\left(\mathrm{CDCl}_{3}\right): \delta 148.2,132.7,131.6,130.6,129$, $128.6,126.3,123\left(\mathrm{~d}, J_{\mathrm{PC}}=17.5\right), 20.5$.

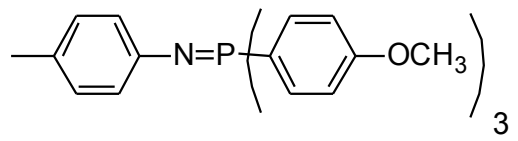

4- $\mathrm{CH}_{3} \mathrm{C}_{6} \mathrm{H}_{4} \mathrm{~N}=\mathrm{P}\left(4-\mathrm{C}_{6} \mathrm{H}_{5} \mathrm{OCH}_{3}\right)_{3}$ (4.6). To a solution of 
4- $\mathrm{H}_{3} \mathrm{CC}_{6} \mathrm{H}_{4} \mathrm{~N}_{3}(0.40 \mathrm{~g}, 3.00 \mathrm{mmol})$ in toluene $(10 \mathrm{~mL})$, a solution of 4- tris(4methoxyphenyl)phosphine $(1.20 \mathrm{~g}, 3.30 \mathrm{mmol})$ in toluene $(10 \mathrm{~mL})$, was added dropwise at $0{ }^{\circ} \mathrm{C}$. A clear colorless solution was observed. After 30 minutes, the reaction mixture was warmed to $25{ }^{\circ} \mathrm{C}$ and stirred for 16 hours. The solvent was removed under vacuum resulting in a (evaporated to) yellow viscous solid. Diethyl ether $(20 \mathrm{~mL})$ was added to the solid and the suspension stirred for 30 minutes. The solid was collected by filteration and rinsed with diethyl ether $(3 \times 20 \mathrm{~mL})$ to yield 4.6 as a white $(0.90 \mathrm{~g}, 81 \%) .{ }^{1} \mathrm{H}$ NMR $\left(\mathrm{C}_{6} \mathrm{D}_{6}\right): \delta 7.80\left(\mathrm{dd}, J=11.2,8.8,6 \mathrm{H}\right.$ of $2,6-\mathrm{C} H$ of $\left.-\mathrm{N}=\mathrm{P}\left(4-\mathrm{C}_{6} \mathrm{H}_{5} \mathrm{OCH}_{3}\right)_{3}\right), 7.27(\mathrm{~d}, J=8.4$, $2 \mathrm{H}, 2,6-\mathrm{CH}$ of $\left.-\mathrm{P}=\mathrm{N}\left(4-\mathrm{C}_{6} \mathrm{H}_{4} \mathrm{CH}_{3}\right)\right), 7.04\left(\mathrm{~d}, J=7.8,2 \mathrm{H}, 3,5-\mathrm{CH}\right.$ of $-\mathrm{N}=\mathrm{P}\left(\mathrm{C}_{6} \mathrm{H}_{5}\right)_{3}, 6.61$ $\left(\mathrm{m}, 6 \mathrm{H}, 4-\mathrm{CH}\right.$ of $\left.-\mathrm{N}=\mathrm{P}\left(\mathrm{C}_{6} \mathrm{H}_{5}\right)_{3}\right), 3.11\left(\mathrm{~s}, 9 \mathrm{H},-\mathrm{OCH}_{3}\right), 2.19$ (s, 4-CH, $\left.-\mathrm{CH}_{3}\right) .{ }^{31} \mathrm{P}$ NMR $\left(\mathrm{C}_{6} \mathrm{D}_{6}\right): \delta-1.41$.

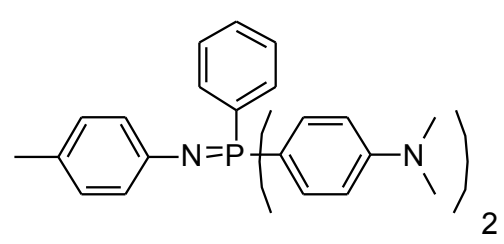

4- $\mathrm{CH}_{3} \mathrm{C}_{6} \mathrm{H}_{4} \mathrm{~N}=\mathrm{P}\left(4-\mathrm{C}_{6} \mathrm{H}_{4} \mathrm{NCH}_{3}\right)_{2} \mathrm{Ph}(4.7)$. To a solution of bis(4-dimethyl aminophenyl)phenyl phosphine azide $(0.76 \mathrm{~g}, 5.79 \mathrm{mmol})$ in toluene, a solution of 4$\mathrm{H}_{3} \mathrm{CC}_{6} \mathrm{H}_{4} \mathrm{~N}_{3}(2.22 \mathrm{~g}, 6.37 \mathrm{mmol})$ in toluene $(20 \mathrm{~mL})$, was added dropwise at $0{ }^{\circ} \mathrm{C}$. A clear colorless solution was observed. After 30 minutes, the reaction mixture was warmed to $25{ }^{\circ} \mathrm{C}$ and stirred for 16 hours. The solvent was removed under vacuum resulting in a yellow solid. Diethyl ether $(20 \mathrm{~mL})$ was added to the solid and the suspension stirred for 30 minutes. The solid was collected by filtration and rinsed with diethyl ether $(3 \times 20 \mathrm{~mL})$ to yield 4.9 as a yellow solid. Toluene was removed under vacuum, resulting viscous yellow residue. The yellow solid residue was treated with 1:4 toluene-hexanes $(40 \mathrm{~mL})$ affording a white precipitate which was stirred under $\mathrm{N}_{2}$. The stirring was stopped and the yellow solid allowed to settle. The 1:4 toluene/hexanes was removed using syringe. 
Hexanes $(20 \mathrm{~mL})$ was added to the solid. The solid was collected by filtration and rinsed with hexanes $(2 \times 10 \mathrm{~mL})$ to yield 4.7 as a white solid $(1.69 \mathrm{~g}, 64 \%) .{ }^{1} \mathrm{H}$ NMR $\left(\mathrm{CDCl}_{3}\right): \delta$ $7.80\left(\mathrm{~m}, 2 \mathrm{H}\right.$ of $2,6-\mathrm{C} H$ of $\left.\left(\mathrm{C}_{6} \mathrm{H}_{5}\right) \mathrm{P}=\mathrm{N}-\right), 7.57(\mathrm{dd}, J=11.6,9.2,4 \mathrm{H}, 3,5-\mathrm{CH}$ of $-\mathrm{N}=\mathrm{P}(4-$ $\mathrm{C}_{6} \mathrm{H}_{4} \mathrm{~N}\left(\mathrm{CH}_{3}\right)_{2}, 7.39\left(\mathrm{~m}, 3 \mathrm{H}, 2,6-\mathrm{CH}\right.$ and 4-CH of $\left.-\mathrm{N}=\mathrm{P}\left(\mathrm{C}_{6} \mathrm{H}_{5}\right)\right), 6.81(\mathrm{~d}, J=8,2 \mathrm{H}, 2,6-$ $\mathrm{CH}$ of $-\mathrm{P}=\mathrm{N}\left(4-\mathrm{C}_{6} \mathrm{H}_{4} \mathrm{CH}_{3}\right), 6.74\left(\mathrm{~d}, J=8.4,2 \mathrm{H}, 3,5-\mathrm{CH}\right.$ of $\left.-\mathrm{P}=\mathrm{N}\left(4-\mathrm{C}_{6} \mathrm{H}_{4} \mathrm{CH}_{3}\right)\right), 6.67(\mathrm{dd}, J$ $=8.8,2,4 \mathrm{H}, 3,5-\mathrm{CH}$ of $\left.-\mathrm{N}=\mathrm{P}\left(4-\mathrm{C}_{6} \mathrm{H}_{4} \mathrm{~N}\left(\mathrm{CH}_{3}\right)_{2}\right)_{2}\right), 2.99\left(\mathrm{~s}, 12 \mathrm{H},-\mathrm{NCH}_{3}\right), 2.17(\mathrm{~s}, 4-\mathrm{CH}$, $\left.\mathrm{CH}_{3}\right) .{ }^{1} \mathrm{H}$ NMR $\left(\mathrm{C}_{6} \mathrm{D}_{6}\right): \delta 8.12\left(\mathrm{dd}, J=11.2,8.8,2 \mathrm{H}\right.$ of 2,6-CH of $\left(\mathrm{C}_{6} \mathrm{H}_{5}\right) \mathrm{P}=\mathrm{N}-, 7.87$ (m, $4 \mathrm{H}, 3,5-\mathrm{CH}$ of $\left.-\mathrm{N}=\mathrm{P}\left(4-\mathrm{C}_{6} \mathrm{H}_{4} \mathrm{~N}\left(\mathrm{CH}_{3}\right)_{2}\right)\right), 7.38\left(\mathrm{~d}, J=8,2 \mathrm{H}, 2,6-\mathrm{CH}\right.$ of $\left.-\mathrm{P}=\mathrm{N}\left(\mathrm{C}_{6} \mathrm{H}_{5}\right)\right), 7.07$ (m, $5 \mathrm{H}, 3,5-\mathrm{CH}$ of $-\mathrm{P}=\mathrm{N}\left(4-\mathrm{C}_{6} \mathrm{H}_{4} \mathrm{CH}_{3}\right), 3,5-\mathrm{CH}$ of $-\mathrm{N}=\mathrm{P}\left(\mathrm{C}_{6} \mathrm{H}_{5}\right)$ and $4-\mathrm{C} H$ of $\left.-\mathrm{N}=\mathrm{P}\left(\mathrm{C}_{6} \mathrm{H}_{5}\right)\right)$, $6.35\left(\mathrm{dd}, J=9.2,2,4 \mathrm{H}, 3,5-\mathrm{CH}\right.$ of $\left.-\mathrm{N}=\mathrm{P}\left(4-\mathrm{C}_{6} \mathrm{H}_{4} \mathrm{~N}\left(\mathrm{CH}_{3}\right)_{2}\right)_{2}\right), 2.32\left(\mathrm{~s}, 12 \mathrm{H},-\mathrm{NCH}_{3}\right), 2.22$ (s, 4-CH, $\left.-\mathrm{CH}_{3}\right) .{ }^{31} \mathrm{P}$ NMR $\left(\mathrm{CDCl}_{3}\right): \delta 2.16 .{ }^{31} \mathrm{P} \mathrm{NMR}\left(\mathrm{C}_{6} \mathrm{D}_{6}\right): \delta 0.98 .{ }^{13} \mathrm{C} \mathrm{NMR}(\mathrm{CDCl})_{3}$ : $\delta 152,149.5,134.3,132.7,131,129.2,128,125,123,115.7,111.5,40.2,20.7$.

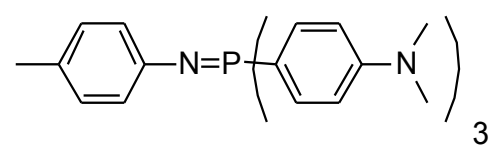

4- $\mathrm{CH}_{3} \mathrm{C}_{6} \mathrm{H}_{4} \mathrm{~N}=\mathbf{P}\left(4-\mathrm{C}_{6} \mathrm{H}_{4} \mathrm{~N}\left(\mathrm{CH}_{3}\right)_{2}\right)_{3}$ (4.8). To a solution of tris(4-dimethyl aminophenyl) phosphine $(2.70 \mathrm{~g}, 6.90$ $\mathrm{mmol})$ in toluene $(20 \mathrm{~mL})$, a solution of $4-\mathrm{H}_{3} \mathrm{CC}_{6} \mathrm{H}_{4} \mathrm{~N}_{3}(0.80 \mathrm{~g}, 6.10 \mathrm{mmol})$ in toluene (20 $\mathrm{mL}$ ), was added dropwise at $0{ }^{\circ} \mathrm{C}$. A clear colorless solution was observed. After 30 minutes, the reaction mixture was warmed to $25^{\circ} \mathrm{C}$ and stirred for 16 hours. The solvent was removed under vacuum resulting in a yellow viscous solid. Diethyl ether $(20 \mathrm{~mL})$ was added to the solid and the suspension stirred for 30 minutes. The solid was collected by filtration and rinsed with diethyl ether $(2 \times 10 \mathrm{~mL})$ to yield 4.8 as a white solid $(2.26 \mathrm{~g}$, $75 \%) .{ }^{1} \mathrm{H}$ NMR $\left(\mathrm{CDCl}_{3}\right): \delta 7.57(\mathrm{dd}, J=11.2,8.8,6 \mathrm{H}, 2,6-\mathrm{CH}$ of $-\mathrm{N}=\mathrm{P}(4-$ $\left.\left.\mathrm{C}_{6} \mathrm{H}_{4} \mathrm{~N}\left(\mathrm{CH}_{3}\right)_{2}\right)_{3}\right), 6.67\left(\mathrm{~m}, 4 \mathrm{H}, 2,6-\mathrm{CH}\right.$ and 3,5-CH of $\left.-\mathrm{P}=\mathrm{N}\left(4-\mathrm{C}_{6} \mathrm{H}_{5} \mathrm{CH}_{3}\right)\right), 6.65(\mathrm{~m}, 6 \mathrm{H}$, 3,5-CH of $\left.\left.-\mathrm{N}=\mathrm{P}\left(4-\mathrm{C}_{6} \mathrm{H}_{4} \mathrm{~N}\left(\mathrm{CH}_{3}\right)_{2}\right)_{3}\right), 2.36\left(\mathrm{~s}, 18 \mathrm{H},-\mathrm{N}\left(\mathrm{CH}_{3}\right)_{2}\right)_{3}\right), 2.25\left(\mathrm{~s}, 4-\mathrm{CH}_{3}\right) .{ }^{1} \mathrm{H} \mathrm{NMR}$ 
$\left(\mathrm{C}_{6} \mathrm{D}_{6}\right): \delta 8.01\left(\mathrm{dd}, J=10.8,8.4,6 \mathrm{H}, 2,6-\mathrm{CH}\right.$ of $-\mathrm{N}=\mathrm{P}\left(4-\mathrm{C}_{6} \mathrm{H}_{4} \mathrm{~N}\left(\mathrm{CH}_{3}\right)_{2}\right)_{3}, 7.47(\mathrm{~d}, J=8$, $2 \mathrm{H}, 2,6-\mathrm{CH}$ of $\left.-\mathrm{P}=\mathrm{N}\left(\mathrm{C}_{6} \mathrm{H}_{5}\right)\right), 7.11\left(\mathrm{~d}, J=8,2 \mathrm{H}, 3,5-\mathrm{CH}\right.$ of $\left.-\mathrm{P}=\mathrm{N}\left(\mathrm{C}_{6} \mathrm{H}_{5}\right)\right), 6.44(\mathrm{~m}, 6 \mathrm{H}$, 3,5-CH of $\left.\left.-\mathrm{N}=\mathrm{P}\left(4-\mathrm{C}_{6} \mathrm{H}_{4} \mathrm{~N}\left(\mathrm{CH}_{3}\right)_{2}\right)_{3}\right), 2.36\left(\mathrm{~s}, 18 \mathrm{H},-\mathrm{N}\left(\mathrm{CH}_{3}\right)_{2}\right)_{3}\right), 2.25\left(\mathrm{~s}, 4-\mathrm{CH}, \mathrm{CH}_{3}\right) .{ }^{31} \mathrm{P}$ $\operatorname{NMR}\left(\mathrm{CDCl}_{3}\right): \delta 6.5 .{ }^{31} \mathrm{P} \mathrm{NMR}\left(\mathrm{C}_{6} \mathrm{D}_{6}\right): \delta 1.5 .{ }^{13} \mathrm{C} \mathrm{NMR}\left(\mathrm{CDCl}_{3}\right): \delta 152,149,134,129$, $125,123\left(\mathrm{~d}, J_{\mathrm{PC}}=18.2\right), 117\left(\mathrm{~d}, J_{\mathrm{PC}}=7.8\right), 111,40.2,20.7$.

$\mathrm{C}_{6} \mathrm{H}_{5} \mathrm{CH}_{2} \mathrm{~N}=\mathrm{PPh}_{3}$ (4.9). The compound was synthesized

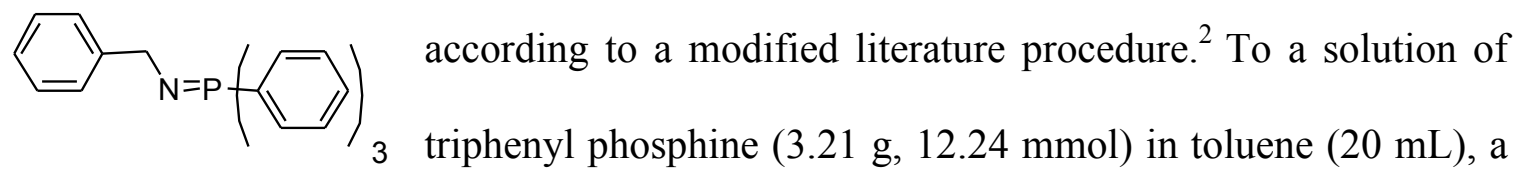
solution of $\mathrm{PhCH}_{2} \mathrm{~N}_{3}(1.50 \mathrm{~g}, 11.10 \mathrm{mmol})$ in toluene $(20 \mathrm{~mL})$, was added dropwise at 0 ${ }^{\circ} \mathrm{C}$. A clear colorless solution was observed. After 30 minutes, the reaction mixture was warmed to $25{ }^{\circ} \mathrm{C}$ and stirred for 16 hours. The solvent was removed under vacuum resulting in a (evaporated to) yellow viscous solid. Diethyl ether $(20 \mathrm{~mL})$ was added to the (viscous) solid and the suspension stirred for 30 minutes. The solid was collected by filtration and rinsed with diethyl ether $(3 \times 20 \mathrm{~mL})$ to yield 4.9 as a yellow solid $(0.48 \mathrm{~g}$, $12 \%) .{ }^{1} \mathrm{H}$ NMR $\left(\mathrm{CDCl}_{3}\right): \delta 7.70\left(\mathrm{~m}, 6 \mathrm{H}, 2,6-\mathrm{CH}\right.$ of $-\mathrm{N}=\mathrm{P}\left(\mathrm{C}_{6} \mathrm{H}_{5}\right)_{3}, 7.41-7.52(\mathrm{~m}, 11 \mathrm{H}$ of 3,5-CH and 4- $\mathrm{CH}$ of $-\mathrm{N}=\mathrm{P}\left(\mathrm{C}_{6} \mathrm{H}_{5}\right)_{3}$, and 2,6-CH of $-\mathrm{CH}_{2}\left(\mathrm{C}_{6} \mathrm{H}_{5}\right), 7.24$ (m, 2H, 3,5-CH of $\left.\mathrm{CH}_{2}\left(\mathrm{C}_{6} \mathrm{H}_{5}\right)\right), 7.13\left(\mathrm{~m}, 1 \mathrm{H}, 4-\mathrm{CH}\right.$ of $\left.\mathrm{CH}_{2}\left(\mathrm{C}_{6} \mathrm{H}_{5}\right)\right), 4.40\left(\mathrm{~d}, J=18,-\mathrm{CH}_{2}\right) .{ }^{1} \mathrm{H}$ NMR $\left(\mathrm{C}_{6} \mathrm{D}_{6}\right)$ :

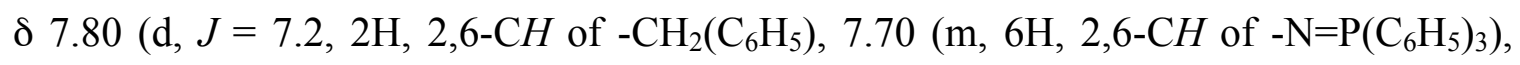
$7.29\left(\mathrm{t}, J=7.6,2 \mathrm{H}\right.$ of $3,5-\mathrm{CH}$ of $\left.-\mathrm{CH}_{2}\left(\mathrm{C}_{6} \mathrm{H}_{5}\right)\right), 7.12\left(\mathrm{~m}, 1 \mathrm{H}\right.$ of $4-\mathrm{CH}$ of $\left.-\mathrm{CH}_{2}\left(\mathrm{C}_{6} \mathrm{H}_{5}\right)\right)$, 6.95-7.01 (m, 9H, 3,5-CH and 4-CH of $-\mathrm{N}=\mathrm{P}\left(\mathrm{C}_{6} \mathrm{H}_{5}\right)_{3}, 4.68\left(\mathrm{~d}, J=15.2,2 \mathrm{H}\right.$, of $\left.-\mathrm{CH}_{2}\right) .{ }^{31} \mathrm{P}$ $\operatorname{NMR}\left(\mathrm{CDCl}_{3}\right): \delta 11.3 .{ }^{31} \mathrm{P} \mathrm{NMR}\left(\mathrm{C}_{6} \mathrm{D}_{6}\right): \delta 5.9$.

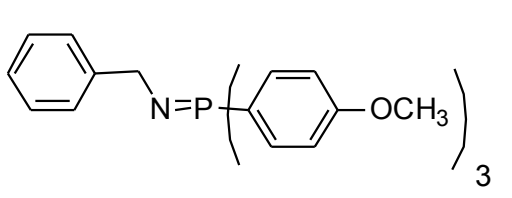

$\mathrm{C}_{6} \mathrm{H}_{5} \mathrm{CH}_{2} \mathrm{~N}=\mathrm{P}\left(4-\mathrm{C}_{6} \mathrm{H}_{4} \mathrm{OCH}_{3}\right)_{3}$ (4.10). To a solution of tris(4-methoxyphenyl)phosphine (1.20 g, $3.40 \mathrm{mmol})$ in 
toluene $(10 \mathrm{~mL})$, a solution of $\mathrm{PhCH}_{2} \mathrm{~N}_{3}(0.40 \mathrm{~g}, 3.00 \mathrm{mmol})$ in toluene $(10 \mathrm{~mL})$, was added dropwise at $0{ }^{\circ} \mathrm{C}$. A clear colorless solution was observed. After 30 minutes, the reaction mixture was warmed to $25^{\circ} \mathrm{C}$ and stirred for 16 hours. The solvent was removed under vacuum resulting in a yellow viscous solid. Diethyl ether $(20 \mathrm{~mL})$ was added to the solid and the suspension stirred for 30 minutes. The solid was collected by filtration and rinsed with diethyl ether $(3 \times 20 \mathrm{~mL})$ to yield 4.10 as a white solid $(0.90 \mathrm{~g}, 81 \%) .{ }^{1} \mathrm{H}$ $\operatorname{NMR}\left(\mathrm{CDCl}_{3}\right): \delta 7.59\left(\mathrm{dd}, J=9.2,1.6,6 \mathrm{H}, 2,6-\mathrm{CH}\right.$ of $\left.-\mathrm{N}=\mathrm{P}\left(4-\mathrm{C}_{6} \mathrm{H}_{5} \mathrm{OCH}_{3}\right)_{3}\right), 7.44(\mathrm{~d}, J$ $=7.2,2 \mathrm{H}$ of $2,6-\mathrm{CH}$ of $\left.-\mathrm{CH}_{2}\left(\mathrm{C}_{6} \mathrm{H}_{5}\right)\right), 7.21\left(\mathrm{t}, J=8,2 \mathrm{H}\right.$ of $3,5-\mathrm{CH}$ of $\left.-\mathrm{CH}_{2}\left(\mathrm{C}_{6} \mathrm{H}_{5}\right)\right), 7.12(\mathrm{t}$, $J=7.6,1 \mathrm{H}, 4-\mathrm{CH}$ of $\left.-\mathrm{CH}_{2}\left(\mathrm{C}_{6} \mathrm{H}_{5}\right)\right), 6.91(\mathrm{dd}, J=6.4,1.6,6 \mathrm{H}, 2,6-\mathrm{CH}$ of $-\mathrm{N}=\mathrm{P}(4-$ $\left.\left.\mathrm{C}_{6} \mathrm{H}_{5} \mathrm{OCH}_{3}\right)_{3}\right), \quad 4.33\left(\mathrm{~d}, J=18,2 \mathrm{H}, 3,5-\mathrm{CH}\right.$ of $\left.-\mathrm{CH}_{2}\right), 3.82$ (s, 9H, 4-OCH$\left.H_{3}\right) .{ }^{1} \mathrm{H}$ NMR $\left(\mathrm{C}_{6} \mathrm{D}_{6}\right): \delta 7.98\left(\mathrm{~d}, J=7.6,2 \mathrm{H}\right.$ of $2,6-\mathrm{CH}$ of $-\mathrm{CH}_{2}\left(\mathrm{C}_{6} \mathrm{H}_{5}\right), 7.78(\mathrm{~m}, 6 \mathrm{H}, 2,6-\mathrm{CH}$ of $-\mathrm{N}=\mathrm{P}(4-$ $\left.\left.\mathrm{C}_{6} \mathrm{H}_{5} \mathrm{OCH}_{3}\right)_{3}\right), 7.39\left(\mathrm{t}, J=7.6,2 \mathrm{H}\right.$ of $3,5-\mathrm{CH}$ of $\left.-\mathrm{CH}_{2}\left(\mathrm{C}_{6} \mathrm{H}_{5}\right)\right), 7.20(\mathrm{~m}, 1 \mathrm{H}$ of $4-\mathrm{CH}$ of $\left.\mathrm{CH}_{2}\left(\mathrm{C}_{6} \mathrm{H}_{5}\right)\right), 6.71\left(\mathrm{~m}, 6 \mathrm{H}, 3,5-\mathrm{CH}\right.$ of $\left.-\mathrm{N}=\mathrm{P}\left(4-\mathrm{C}_{6} \mathrm{H}_{5} \mathrm{OCH}_{3}\right)_{3}\right), 4.8(\mathrm{~d}, J=15.6,2 \mathrm{H}, 3,5-\mathrm{CH}$ of $\left.-\mathrm{CH}_{2}\right), 3.19$ (s, 9H, 4-OCH$\left.)_{3}\right) .{ }^{31} \mathrm{P}$ NMR $\left(\mathrm{CDCl}_{3}\right): \delta 11.4 .{ }^{31} \mathrm{P}$ NMR $\left(\mathrm{C}_{6} \mathrm{D}_{6}\right): \delta 6 .{ }^{13} \mathrm{C}$ $\operatorname{NMR}\left(\mathrm{CDCl}_{3}\right): \delta 161.8,146.2,134.2\left(\mathrm{~d}, J_{\mathrm{pc}}=10.6\right), 133.8\left(\mathrm{~d}, J_{\mathrm{PC}}=11.4\right), 127.7\left(\mathrm{~d}, J_{\mathrm{PC}}\right.$ $=53.2), 125.3,123.5\left(\mathrm{~d}, J_{\mathrm{PC}}=98.7\right), 113.8\left(\mathrm{~d}, J_{\mathrm{PC}}=12.9\right), 55.2,48.9$.

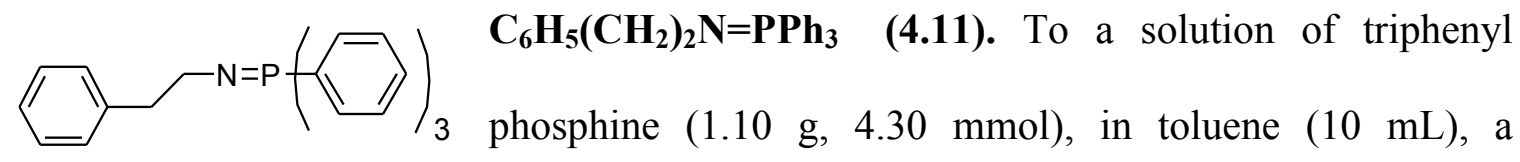
solution of $\mathrm{PhCH}_{2} \mathrm{CH}_{2} \mathrm{~N}_{3}(0.63 \mathrm{~g}, 4.30 \mathrm{mmol})$ in toluene $(10 \mathrm{~mL})$ was added dropwise at $0{ }^{\circ} \mathrm{C}$. A clear colorless solution was observed. After 30 minutes, the reaction mixture was warmed to $25{ }^{\circ} \mathrm{C}$ and stirred for 2 hours. The solvent was removed under vacuum resulting in a yellow viscous solid. Hexanes $(20 \mathrm{~mL})$ was added to the solid and the suspension stirred for 30 minutes. The stirring was stopped and the yellow solid allowed 
to settle. The hexanes was removed using syringe. Hexanes $(10 \mathrm{~mL})$ was added to the solid. The solid was collected by filtration and rinsed with hexanes $(3 \times 10 \mathrm{~mL})$ to yield 4.11 as a white solid $(0.80 \mathrm{~g}, 50 \%) .{ }^{1} \mathrm{H}$ NMR $\left(\mathrm{CDCl}_{3}\right): \delta 7.62(\mathrm{~m}, 6 \mathrm{H}$ of $2,6-\mathrm{CH}$ of $\left.\mathrm{N}=\mathrm{P}\left(\mathrm{C}_{6} \mathrm{H}_{5}\right)_{3}\right), 7.49\left(\mathrm{~m}, 3 \mathrm{H}\right.$, of $4-\mathrm{CH}$ of $\left.-\mathrm{N}=\mathrm{P}\left(\mathrm{C}_{6} \mathrm{H}_{5}\right)_{3}\right), 7.42(\mathrm{~m}, 6 \mathrm{H}, 3,5-\mathrm{CH}$ of $\left.\mathrm{N}=\mathrm{P}\left(\mathrm{C}_{6} \mathrm{H}_{5}\right)_{3}\right), 7.18\left(\mathrm{~m}, 2 \mathrm{H}\right.$, of 2,6- $\mathrm{CH}$ of $\left.-\mathrm{CH}_{2} \mathrm{CH}_{2}\left(\mathrm{C}_{6} \mathrm{H}_{5}\right)\right), 7.10(\mathrm{~m}, 2 \mathrm{H}$, of 3,5-CH and $1 \mathrm{H}, 4-\mathrm{CH}$ of $\left.\mathrm{CH}_{2} \mathrm{CH}_{2}\left(\mathrm{C}_{6} \mathrm{H}_{5}\right)_{2}\right), 3.32\left(\mathrm{~m}, 2 \mathrm{H},-\mathrm{CH}\right.$ of $\left.\mathrm{CH}_{2} \mathrm{CH}_{2}\left(\mathrm{C}_{6} \mathrm{H}_{5}\right)\right), 2.85(\mathrm{~m}, 2 \mathrm{H},-\mathrm{CH}$ of $\left.-\mathrm{CH}_{2} \mathrm{CH}_{2}\left(\mathrm{C}_{6} \mathrm{H}_{5}\right)\right) .{ }^{1} \mathrm{H}$ NMR $\left(\mathrm{C}_{6} \mathrm{D}_{6}\right): \delta 7.62\left(\mathrm{~m}, 6 \mathrm{H} \text { of 2,6-CH of }-\mathrm{N}=\mathrm{P}_{(}\left(\mathrm{C}_{6} \mathrm{H}_{5}\right)\right)_{3}, 7.66(\mathrm{~m}$, $3 \mathrm{H}$, of 4-CH of - $\left.\mathrm{N}=\mathrm{P}\left(\mathrm{C}_{6} \mathrm{H}_{5}\right)_{3}\right), 7.25\left(\mathrm{~d}, J=7.6,2 \mathrm{H}\right.$, of 2,6- $\mathrm{CH}$ of $\left.-\mathrm{CH}_{2} \mathrm{CH}_{2}\left(\mathrm{C}_{6} \mathrm{H}_{5}\right)\right), 7.11$ (m, 2H, 3,5-CH of $\left.\mathrm{CH}_{2} \mathrm{CH}_{2}\left(\mathrm{C}_{6} \mathrm{H}_{5}\right)\right), 6.96\left(\mathrm{~m}, 10 \mathrm{H}\right.$, of 3,5-CH of -N=P( $\left.\left(\mathrm{C}_{6} \mathrm{H}_{5}\right)_{3}\right), 4-\mathrm{CH}$ of $\left.\mathrm{N}=\mathrm{P}\left(\mathrm{C}_{6} \mathrm{H}_{5}\right)_{3}\right)$, and 4-CH of $\left.\mathrm{CH}_{2} \mathrm{CH}_{2}\left(\mathrm{C}_{6} \mathrm{H}_{5}\right)_{2}\right), 3.65\left(\mathrm{~m}, 2 \mathrm{H},-\mathrm{CH}\right.$ of $\left.\mathrm{CH}_{2} \mathrm{CH}_{2}\left(\mathrm{C}_{6} \mathrm{H}_{5}\right)\right), 3.15$ $\left(\mathrm{t}, J=7.6,2 \mathrm{H},-\mathrm{CH}\right.$ of $\left.-\mathrm{CH}_{2} \mathrm{CH}_{2}\left(\mathrm{C}_{6} \mathrm{H}_{5}\right)\right) \cdot{ }^{31} \mathrm{P}$ NMR $\left(\mathrm{CDCl}_{3}\right): \delta 11.3 \cdot{ }^{31} \mathrm{P} \mathrm{NMR}\left(\mathrm{C}_{6} \mathrm{D}_{6}\right): \delta$ 4.4. ${ }^{13} \mathrm{C} \mathrm{NMR}\left(\mathrm{CDCl}_{3}\right): \delta 141.6,132.5,132,131.2,128.9,128.4(J=11.4), 127.9,125.4$, $48.2,42.5\left(\mathrm{~d}, J_{\mathrm{PC}}=17.5\right)$.

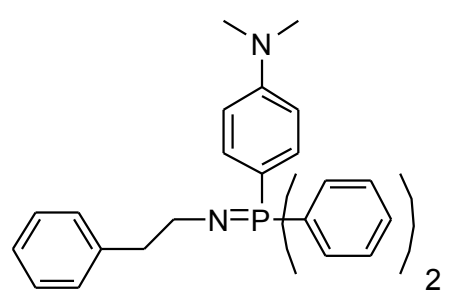

$\mathrm{C}_{6} \mathrm{H}_{5}\left(\mathrm{CH}_{2}\right)_{2} \mathrm{~N}=\mathbf{P}\left(4-\mathrm{C}_{6} \mathrm{H}_{4} \mathrm{~N}\left(\mathrm{CH}_{3}\right)_{2}\right)_{2} \mathrm{Ph}_{2}$ (4.12). To a solution of 4-dimethyl aminophenyldiphenyl phosphine (1.00 g, 3.40 mmol) in methylene chloride $(10 \mathrm{~mL})$, a solution of $\mathrm{PhCH}_{2} \mathrm{CH}_{2} \mathrm{~N}_{3}(0.50 \mathrm{~g}, 3.40 \mathrm{mmol})$ in methylene chloride (10 $\mathrm{mL}$ ) was added dropwise at $0{ }^{\circ} \mathrm{C}$. A clear yellow solution was observed. After 30 minutes, the reaction mixture was warmed to $25{ }^{\circ} \mathrm{C}$ and stirred for 3 hour. The solvent was removed under vacuum resulting in a yellow spongy solid. Diethyl ether $(20 \mathrm{~mL})$ was added to the solid and the suspension stirred for 30 minutes. The solid was collected by filtration and rinsed with diethyl ether $(3 \times 20 \mathrm{~mL})$ to yield $\mathbf{4 . 1 2}$ as a yellow solid (1.20 g, $60 \%) .{ }^{1} \mathrm{H}$ NMR $\left(\mathrm{CDCl}_{3}\right): \delta 7.63\left(\mathrm{~m}, 4 \mathrm{H}\right.$ of 2,6-CH of $\left.-\mathrm{N}=\mathrm{P}\left(\mathrm{C}_{6} \mathrm{H}_{5}\right)\right), 7.41-7.49(\mathrm{~m}, 6 \mathrm{H}$, 
3,5-CH and 4-CH of $\left(\mathrm{C}_{6} \mathrm{H}_{5}\right) \mathrm{P}=\mathrm{N}-$ and $2 \mathrm{H}, 2,6-\mathrm{CH}$ of $\left.-\mathrm{N}=\mathrm{PC}_{6} \mathrm{H}_{4} \mathrm{~N}_{(}\left(\mathrm{CH}_{3}\right)_{2}\right), 7.17(\mathrm{~m}, 2 \mathrm{H}$, 3,5-CH of $\left.-\mathrm{N}=\mathrm{PC}_{6} \mathrm{H}_{4} \mathrm{~N}\left(\mathrm{CH}_{3}\right)_{2}\right), 7.11\left(\mathrm{~m}, 3 \mathrm{H}, 2,6-\mathrm{CH}\right.$ and $4-\mathrm{CH}$ of $\left.-\mathrm{CH}_{2} \mathrm{CH}_{2}\left(\mathrm{C}_{6} \mathrm{H}_{5}\right)\right), 6.68$ (m, $2 \mathrm{H}, 3,5-\mathrm{CH}$ of $\left.-\mathrm{CH}_{2} \mathrm{CH}_{2}\left(\mathrm{C}_{6} \mathrm{H}_{5}\right)\right), 3.29\left(\mathrm{~m}, 2 \mathrm{H},-\mathrm{CH}\right.$ of $\left.-\mathrm{CH}_{2} \mathrm{CH}_{2}\left(\mathrm{C}_{6} \mathrm{H}_{5}\right)\right), 3.00$ (s, $6 \mathrm{H}$, $\left.\mathrm{N}\left(\mathrm{CH}_{3}\right)_{2}\right), 2.85\left(\mathrm{~m}, 2 \mathrm{H},-\mathrm{CH}\right.$ of $-\mathrm{CH}_{2} \mathrm{CH}_{2}\left(\mathrm{C}_{6} \mathrm{H}_{5}\right) .{ }^{1} \mathrm{H}$ NMR $\left(\mathrm{C}_{6} \mathrm{D}_{6}\right): \delta 7.80$ (m, 4H of 2,6$\mathrm{CH}$ of $\left.-\mathrm{N}=\mathrm{P}\left(\mathrm{C}_{6} H_{5}\right)\right), 7.62\left(\mathrm{~m}, 2 \mathrm{H}, \quad\right.$ of $\left.-\mathrm{N}=\mathrm{PC}_{6} H_{4} \mathrm{~N}\left(\mathrm{CH}_{3}\right)_{2},\right) 7.28(\mathrm{~d}, J=7.6,2 \mathrm{H}$, of $\left.\mathrm{N}=\mathrm{PC}_{6} \mathrm{H}_{4} \mathrm{~N}\left(\mathrm{CH}_{3}\right)_{2},\right) 7.03\left(\mathrm{~m}, 7 \mathrm{H}, 3,5-\mathrm{CH}\right.$ and $4-\mathrm{CH}$ of $\left(\mathrm{C}_{6} \mathrm{H}_{5}\right) \mathrm{P}=\mathrm{N}-$ and $4-\mathrm{CH}$ of $\left.\mathrm{CH}_{2} \mathrm{CH}_{2}\left(\mathrm{C}_{6} \mathrm{H}_{5}\right)\right), 6.34\left(\mathrm{~m}, 2 \mathrm{H}, 3,5-\mathrm{CH}\right.$ of $\left.-\mathrm{CH}_{2} \mathrm{CH}_{2}\left(\mathrm{C}_{6} \mathrm{H}_{5}\right)\right), 3.74(\mathrm{~m}, 2 \mathrm{H}, \mathrm{CH}$ of $\mathrm{CH}_{2} \mathrm{CH}_{2}\left(\mathrm{C}_{6} \mathrm{H}_{5}\right), 3.24$ (s, 6H, 2,6- $\mathrm{CH}$ of $\left.-\mathrm{N}=\mathrm{PC}_{6} \mathrm{H}_{4} \mathrm{~N}\left(\mathrm{CH}_{3}\right)_{2}\right), 2.30$ (m, 6H, $\left.-\mathrm{NCH}_{3}\right) .{ }^{31} \mathrm{P}$ NMR $\left(\mathrm{CDCl}_{3}\right): \delta 13 .{ }^{31} \mathrm{P}$ NMR $\left(\mathrm{C}_{6} \mathrm{D}_{6}\right): \delta 5.49 .{ }^{13} \mathrm{C}$ NMR $\left(\mathrm{CDCl}_{3}\right): \delta 152.1,141.8,133.9$, $132.5,132,130.8,128.9,128.1,128.3127 .9,125.3,111.3\left(\mathrm{~d}, J_{\mathrm{PC}}=12.2\right), 48.5,42.6$, 39.9 .

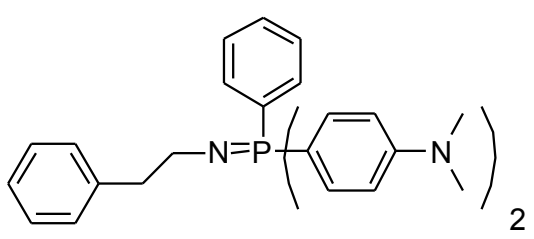

$\mathrm{C}_{6} \mathrm{H}_{5}\left(\mathrm{CH}_{2}\right)_{2} \mathrm{~N}=\mathrm{P}\left(4-\mathrm{C}_{6} \mathrm{H}_{4} \mathrm{~N}\left(\mathrm{CH}_{3}\right)_{2}\right)_{2} \mathrm{Ph}$ (4.13). To a solution of bis(4-dimethylaminophenyl)phenyl 2 phosphine $(0.90 \mathrm{~g}, 2.60 \mathrm{mmol})$ in methylene chloride (10 mL), a solution of $\mathrm{PhCH}_{2} \mathrm{CH}_{2} \mathrm{~N}_{3}(0.38 \mathrm{~g}, 2.60 \mathrm{mmol})$ in methylene chloride $(10 \mathrm{~mL})$ was added dropwise at $0{ }^{\circ} \mathrm{C}$. A clear yellow solution was observed. After 30 minutes, the reaction mixture was warmed to $25{ }^{\circ} \mathrm{C}$ and stirred for 1 hour. The solvent was removed under vacuum resulting in a yellow solid. Diethyl ether $(20 \mathrm{~mL})$ was added to the solid and the suspension stirred for 30 minutes. The solid was collected by filteration and rinsed with diethyl ether $(3 \times 20 \mathrm{~mL})$ to yield 4.13 as a white solid $(1.20 \mathrm{~g}, 60) .{ }^{1} \mathrm{HNMR}$ $\left(\mathrm{CDCl}_{3}\right): \delta 7.65\left(\mathrm{~m}, 2 \mathrm{H}\right.$ of $2,6-\mathrm{CH}$ of $-\mathrm{N}=\mathrm{P}\left(\mathrm{C}_{6} \mathrm{H}_{5}\right), 7.46(\mathrm{~m}, 4 \mathrm{H}, 2,6-\mathrm{CH}$ of $-\mathrm{N}=\mathrm{P}(4-$ $\left.\mathrm{C}_{6} \mathrm{H}_{4} \mathrm{~N}\left(\mathrm{CH}_{3}\right)_{2}\right)_{2}, 7.36-7.42\left(\mathrm{~m}, 3 \mathrm{H}, 3,5-\mathrm{CH}\right.$ and $4-\mathrm{CH}$ of $\left.-\mathrm{P}=\mathrm{N}\left(\mathrm{C}_{6} \mathrm{H}_{5}\right)\right), 7.17(\mathrm{~m}, 2 \mathrm{H}, 2,6-$ $\mathrm{CH}$ of $\left.-\mathrm{CH}_{2}\left(\mathrm{C}_{6} \mathrm{H}_{5}\right)\right), 7.11\left(\mathrm{~m}, 2 \mathrm{H}, 3,5-\mathrm{CH}\right.$ and $4-\mathrm{CH}$ of $\left.-\mathrm{CH}_{2}\left(\mathrm{C}_{6} \mathrm{H}_{5}\right)\right), 6.68$ (dd, $J=8.4$, 
1.6, 4H, 3,5-CH of -N=P(4- $\left.\left.\mathrm{C}_{6} H_{4} \mathrm{~N}\left(\mathrm{CH}_{3}\right)_{2}\right)_{2}\right), 3.29\left(\mathrm{~m}, 2 \mathrm{H},-\mathrm{CH}\right.$ of $\left.-\mathrm{CH}_{2} \mathrm{CH}_{2}\left(\mathrm{C}_{6} \mathrm{H}_{5}\right)\right), 2.98$ (s, $\left.\left.12 \mathrm{H},-\mathrm{N}\left(\mathrm{CH}_{3}\right)_{2}\right)_{2}\right), 2.85\left(\mathrm{~m}, 2 \mathrm{H},-\mathrm{CH}\right.$ of $\left.-\mathrm{CH}_{2} \mathrm{CH}_{2}\left(\mathrm{C}_{6} \mathrm{H}_{5}\right)\right) .{ }^{1} \mathrm{H} \mathrm{NMR}\left(\mathrm{C}_{6} \mathrm{D}_{6}\right): \delta 7.95(\mathrm{~m}$, $2 \mathrm{H}$ of 2,6- $\mathrm{CH}$ of $-\mathrm{N}=\mathrm{P}\left(\mathrm{C}_{6} \mathrm{H}_{5}\right), 7.46\left(\mathrm{~m}, 5 \mathrm{H}, 2,6-\mathrm{CH}\right.$ of $-\mathrm{N}=\mathrm{P}\left(4-\mathrm{C}_{6} \mathrm{H}_{4} \mathrm{~N}\left(\mathrm{CH}_{3}\right)_{2}\right)_{2}$ and of 4$C H$ of $\left.-\mathrm{N}=\mathrm{P}\left(\mathrm{C}_{6} \mathrm{H}_{5}\right)\right), 7.34\left(\mathrm{~d}, J=7.6,4 \mathrm{H}, 3,5-\mathrm{CH}\right.$ of $-\mathrm{N}=\mathrm{P}\left(4-\mathrm{C}_{6} \mathrm{H}_{4} \mathrm{~N}\left(\mathrm{CH}_{3}\right)_{2}\right)_{2}, 3.86(\mathrm{~m}$, $2 \mathrm{H},-\mathrm{CH}$ of $\left.-\mathrm{CH}_{2} \mathrm{CH}_{2}\left(\mathrm{C}_{6} \mathrm{H}_{5}\right)\right), 3.33\left(\mathrm{~m}, 2 \mathrm{H},-\mathrm{CH}\right.$ of $\left.-\mathrm{CH}_{2} \mathrm{CH}_{2}\left(\mathrm{C}_{6} \mathrm{H}_{5}\right)\right), 2.32(\mathrm{~s}, 12 \mathrm{H},-$ $\left.\left.\mathrm{N}\left(\mathrm{CH}_{3}\right)_{2}\right)_{2}\right) .{ }^{31} \mathrm{P}$ NMR $\left(\mathrm{CDCl}_{3}\right): \delta$ 14.5. ${ }^{31} \mathrm{P}$ NMR $\left(\mathrm{C}_{6} \mathrm{D}_{6}\right): \delta 6.29 .{ }^{13} \mathrm{C} \mathrm{NMR}\left(\mathrm{CDCl}_{3}\right): \delta$ $134.1,133.5,132.5,132,130.9,129,128.3,128,127.9,125.3,117.7,111,47.9,41.9$, 39.9.

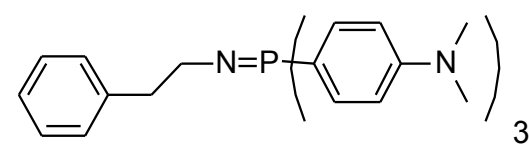

$\mathrm{C}_{6} \mathrm{H}_{5}\left(\mathrm{CH}_{2}\right)_{2} \mathrm{~N}=\mathrm{P}\left(4-\mathrm{C}_{6} \mathrm{H}_{4} \mathrm{~N}\left(\mathrm{CH}_{3}\right)_{3}\right) \quad$ (4.14). To a solution of tris(4-dimethyl aminophenyl) phosphine (2.70 g, $6.90 \mathrm{mmol})$ in methylene chloride $(10 \mathrm{~mL})$, a solution of $\mathrm{PhCH}_{2} \mathrm{CH}_{2} \mathrm{~N}_{3}(1.20 \mathrm{~g}$, $3.30 \mathrm{mmol})$ in methylene chloride $(10 \mathrm{~mL})$ was added dropwise at $0{ }^{\circ} \mathrm{C}$. A clear yellowish solution was observed. After 30 minutes, the reaction mixture was warmed to $25{ }^{\circ} \mathrm{C}$ and stirred for 1 hour. Solvent was evaporated to yellow viscous solid. Diethyl ether $(20 \mathrm{~mL})$ was added to the solid and the suspension stirred for 30 minutes. The solid was collected by filtration and rinsed with diethyl ether $(3 \times 20 \mathrm{~mL})$ to yield 4.14 as a yellow solid (1.20 g, $70 \%) .{ }^{1} \mathrm{H}$ NMR $\left(\mathrm{CDCl}_{3}\right)$ : $\delta 7.48(\mathrm{~m}, 6 \mathrm{H}, 2,6-\mathrm{CH}$ of $-\mathrm{N}=\mathrm{P}(4-$ $\left.\mathrm{C}_{6} \mathrm{H}_{4} \mathrm{~N}\left(\mathrm{CH}_{3}\right)_{2}\right)_{3}, 7.18-7.08\left(\mathrm{~m}, 4 \mathrm{H}, 2,6-\mathrm{CH}, 3,5-\mathrm{CH}\right.$ and 4-CH of $\left(\mathrm{C}_{6} \mathrm{H}_{5}\right) \mathrm{CH}_{2} \mathrm{CH}_{2^{-}}, 6.66$ (m, $6 \mathrm{H}, 3,5-\mathrm{CH}$ of $-\mathrm{N}=\mathrm{P}\left(4-\mathrm{C}_{6} \mathrm{H}_{4} \mathrm{~N}\left(\mathrm{CH}_{3}\right)_{2}\right)_{3}, 3.23\left(\mathrm{~m}, 2 \mathrm{H},-\mathrm{CH}\right.$ of $\left.-\mathrm{CH}_{2} \mathrm{CH}_{2}\left(\mathrm{C}_{6} \mathrm{H}_{5}\right)\right), 2.89$ $\left(\mathrm{m}, 2 \mathrm{H},-\mathrm{CH}\right.$ of $\left.-\mathrm{CH}_{2} \mathrm{CH}_{2}\left(\mathrm{C}_{6} \mathrm{H}_{5}\right)\right), 2.98\left(\mathrm{~s}, \quad 18 \mathrm{H},-\mathrm{N}=\mathrm{P}\left(4-\mathrm{C}_{6} \mathrm{H}_{4} \mathrm{~N}\left(\mathrm{CH}_{3}\right)_{2}\right)_{3}\right) .{ }^{1} \mathrm{H} \quad \mathrm{NMR}$ $\left(\mathrm{C}_{6} \mathrm{D}_{6}\right): \delta 7.98\left(\mathrm{~m}, 6 \mathrm{H}, 2,6-\mathrm{CH}\right.$ of $-\mathrm{N}=\mathrm{P}\left(4-\mathrm{C}_{6} \mathrm{H}_{4} \mathrm{~N}\left(\mathrm{CH}_{3}\right)_{2}\right)_{3}, 7.35(\mathrm{~d}, J=7.6,2 \mathrm{H}, 2,6-C H$ of $\left.-\mathrm{CH}_{2}\left(\mathrm{C}_{6} \mathrm{H}_{5}\right)\right), 6.98\left(\mathrm{t}, J=7.2,2 \mathrm{H}, 3,5-\mathrm{CH}-\mathrm{CH}_{2}\left(\mathrm{C}_{6} \mathrm{H}_{5}\right)\right), 6.43(\mathrm{~m}, 7 \mathrm{H}, 2,6-\mathrm{CH}$ and 4$\mathrm{CH}$ of $-\mathrm{N}=\mathrm{P}\left(4-\mathrm{C}_{6} \mathrm{H}_{4} \mathrm{~N}\left(\mathrm{CH}_{3}\right)_{2}\right)_{3}, 3.84\left(\mathrm{~m}, 2 \mathrm{H},-\mathrm{CH}\right.$ of $\left.-\mathrm{CH}_{2} \mathrm{CH}_{2}\left(\mathrm{C}_{6} \mathrm{H}_{5}\right)\right), 3.40(\mathrm{t}, J=7.6$, 
$2 \mathrm{H},-\mathrm{CH}$ of $\left.-\mathrm{CH}_{2} \mathrm{CH}_{2}\left(\mathrm{C}_{6} \mathrm{H}_{5}\right)\right), 2.33$ (s, 18H, $\left.-\mathrm{N}=\mathrm{P}\left(4-\mathrm{C}_{6} \mathrm{H}_{4} \mathrm{~N}\left(\mathrm{CH}_{3}\right)_{2}\right)_{3}\right) .{ }^{31} \mathrm{P} \mathrm{NMR}\left(\mathrm{CDCl}_{3}\right)$ : $\delta 22 .{ }^{31} \mathrm{P}$ NMR $\left(\mathrm{C}_{6} \mathrm{D}_{6}\right): \delta 9 .{ }^{13} \mathrm{C}\left(\mathrm{CDCl}_{3}\right): \delta 152,134.6\left(\mathrm{~d}, J_{\mathrm{PC}}=11.4\right), 133.3\left(\mathrm{~d}, J_{\mathrm{PC}}=\right.$ $10.7), 129\left(\mathrm{~d}, J_{\mathrm{PC}}=120.7\right), 128,127.7,111.6\left(\mathrm{~d}, J_{\mathrm{PC}}=12.9\right), 111\left(\mathrm{~d}, J_{\mathrm{PC}}=12.9\right), 40(\mathrm{~d}$, $\left.J_{\mathrm{PC}}=10.6\right)$.

Generation of $\left[4-\mathrm{CH}_{3} \mathrm{C}_{6} \mathrm{H}_{4} \mathrm{HN}=\mathrm{P}\left(4-\mathrm{C}_{6} \mathrm{H}_{4} \mathrm{NCH}_{3}\right)_{2} \mathrm{Ph}\right]\left[\mathrm{BF}_{4}\right]$ (4.15) by the protonation of 4-4- $\mathrm{CH}_{3} \mathrm{C}_{6} \mathrm{H}_{4} \mathrm{~N}=\mathrm{P}\left(4-\mathrm{C}_{6} \mathrm{H}_{4} \mathrm{NCH}_{3}\right)_{2} \mathrm{Ph}$ (4.7) with $[\mathrm{PyH}]\left[\mathrm{BF}_{4}\right]$

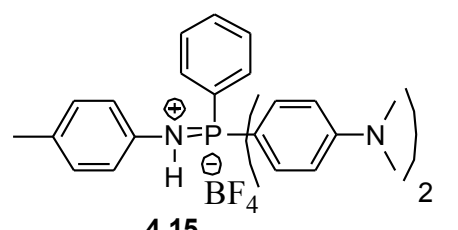

4.15

A valved NMR tube was loaded with $4.7(31.7 \mathrm{mg}, 70 \mu \mathrm{mol})$, $\mathrm{HPyBF}_{4}(11.7 \mathrm{mg}, 70 \mu \mathrm{mol})$ and $\mathrm{CD}_{2} \mathrm{Cl}_{2}(1 \mathrm{~mL})$ was added via vacuum transfer at $-196{ }^{\circ} \mathrm{C}$. After the NMR tube was flushed with $\mathrm{N}_{2}$, the tube was sealed, warmed to $25{ }^{\circ} \mathrm{C}$, and shaken until the solids dissolved. After 30 minutes, ${ }^{1} \mathrm{H},{ }^{31} \mathrm{P},{ }^{11} \mathrm{~B}$, and ${ }^{19} \mathrm{~F}$ spectra were recorded. ${ }^{1} \mathrm{H}$ and ${ }^{31} \mathrm{P}$ NMR spectra showed that $4-\mathrm{CH}_{3} \mathrm{C}_{6} \mathrm{H}_{4} \mathrm{~N}=\mathrm{P}\left(4-\mathrm{C}_{6} \mathrm{H}_{4} \mathrm{NCH}_{3}\right)_{2} \mathrm{Ph}$ was completely protonated to generate $\left[4-\mathrm{CH}_{3} \mathrm{C}_{6} \mathrm{H}_{4} \mathrm{HN}=\mathrm{P}-\left(4-\mathrm{C}_{6} \mathrm{H}_{4} \mathrm{NCH}_{3}\right)_{2} \mathrm{Ph}\right]\left[\mathrm{BF}_{4}\right]$ and release free pyridine. ${ }^{1} \mathrm{H}$ NMR $\left(\mathrm{CD}_{2} \mathrm{Cl}_{2}\right): \delta 8.54\left(\mathrm{~d}, 2 \mathrm{H},, 2,6-\mathrm{CH}\right.$ of $\left.\mathrm{C}_{5} \mathrm{H}_{5} \mathrm{~N}\right), 7.75\left(\mathrm{~m}, 1 \mathrm{H}, 4-\mathrm{CH}\right.$ of $\mathrm{C}_{5} \mathrm{H}_{5} \mathrm{~N}$ and 3,5-CH and 4- $\mathrm{CH}$ of $\left.\left(\mathrm{C}_{6} \mathrm{H}_{5}\right) \mathrm{P}=\mathrm{N}-\right), 7.61\left(\mathrm{~m}, 2 \mathrm{H}\right.$ of 2,6- $\mathrm{CH}$ of $\left.\left(\mathrm{C}_{6} \mathrm{H}_{5}\right) \mathrm{P}=\mathrm{N}-\right), 7.48(\mathrm{dd}, J=12,8.8$, $4 \mathrm{H}, 2,6-\mathrm{CH}$ of $-\mathrm{N}=\mathrm{P}\left(4-\mathrm{C}_{6} \mathrm{H}_{4} \mathrm{~N}\left(\mathrm{CH}_{3}\right)_{2}, 7.33\left(\mathrm{t}, J=6,2 \mathrm{H}, 3,5-\mathrm{CH}\right.\right.$ of $\left.-\mathrm{N}=\mathrm{P}\left(\mathrm{C}_{6} \mathrm{H}_{5}\right)\right), 6.96(\mathrm{~d}$, $J=8,2 \mathrm{H}, 2,6-\mathrm{CH}$ of $-\mathrm{P}=\mathrm{N}\left(4-\mathrm{C}_{6} \mathrm{H}_{4} \mathrm{CH}_{3}\right), 6.83-6.77\left(\mathrm{~m}, 7 \mathrm{H}, 3,5-\mathrm{CH}\right.$ of $-\mathrm{P}=\mathrm{N}\left(4-\mathrm{C}_{6} \mathrm{H}_{4} \mathrm{CH}_{3}\right.$, 3,5-CH of $\left.-\mathrm{N}=\mathrm{P}\left(4-\mathrm{C}_{6} \mathrm{H}_{4} \mathrm{~N}\left(\mathrm{CH}_{3}\right)_{2}\right)_{2}\right)$, and $\left.-\mathrm{NH}\right), 3.06\left(\mathrm{~s}, 12 \mathrm{H},-\mathrm{NCH}_{3}\right), 2.22(\mathrm{~s}, 4-\mathrm{CH}$, $\left.\mathrm{CH}_{3}\right) .{ }^{31} \mathrm{P}$ NMR $\left(\mathrm{CD}_{2} \mathrm{Cl}_{2}\right): \delta 32 .{ }^{19} \mathrm{~F}$ NMR $\left(\mathrm{CD}_{2} \mathrm{Cl}_{2}\right): \delta-151.7 .{ }^{11} \mathrm{~B}$ NMR $\left(\mathrm{CD}_{2} \mathrm{Cl}_{2}\right): \delta-$ 1.12. ${ }^{13} \mathrm{C}$ NMR $\left(\mathrm{CD}_{2} \mathrm{Cl}_{2}\right): \delta 154.6,149.6,137.2,136.3,135.4,134.7,134.1,133.5,130.2$, $130,124.5,121.7,112.4,103\left(\mathrm{~d}, J_{\mathrm{PC}}=116.9\right), 40.2,20.9$. 
Generation of $\left[4-\mathrm{CH} 3 \mathrm{C}_{6} \mathrm{H}_{4} \mathrm{HN}=\mathrm{P}\left(4-\mathrm{C}_{6} \mathrm{H}_{4} \mathrm{~N}\left(\mathrm{CH}_{3}\right)_{2}\right)_{3}\right]\left[\mathrm{BF}_{4}\right]$ by the protonation of 4$\mathrm{CH}_{3} \mathrm{C}_{6} \mathrm{H}_{4} \mathrm{~N}=\mathrm{P}\left(4-\mathrm{C}_{6} \mathrm{H}_{4} \mathrm{~N}\left(\mathrm{CH}_{3}\right)_{2}\right)_{3}(4.16)$ with $[\mathrm{PyH}]\left[\mathrm{BF}_{4}\right]$

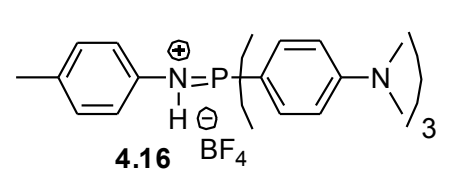

A valved NMR tube was loaded with 4.8 (29.7 $\mathrm{mg}, 59.9$ $\mu \mathrm{mol}), \mathrm{HPyBF}_{4}(10 \mathrm{mg}, 59.9 \mu \mathrm{mol})$ and $\mathrm{CD}_{2} \mathrm{Cl}_{2}(1 \mathrm{~mL})$ was added via vacuum transfer at $-196{ }^{\circ} \mathrm{C}$. After the NMR tube was flushed with $\mathrm{N}_{2}$, the tube was sealed, warmed to $25{ }^{\circ} \mathrm{C}$, and shaken until the solids dissolved. After 30 minutes, ${ }^{1} \mathrm{H}$, ${ }^{31} \mathrm{P},{ }^{11} \mathrm{~B}$, and ${ }^{19} \mathrm{~F}$ spectra were recorded. ${ }^{1} \mathrm{H}$ and ${ }^{31} \mathrm{P}$ NMR spectra showed that 4$\mathrm{CH}_{3} \mathrm{C}_{6} \mathrm{H}_{4} \mathrm{~N}=\mathrm{P}\left(4-\mathrm{C}_{6} \mathrm{H}_{4} \mathrm{~N}\left(\mathrm{CH}_{3}\right)_{2}\right)_{3} \quad$ was completely protonated to generate [4$\left.\mathrm{CH} 3 \mathrm{C}_{6} \mathrm{H}_{4} \mathrm{HN}=\mathrm{P}\left(4-\mathrm{C}_{6} \mathrm{H}_{4} \mathrm{~N}\left(\mathrm{CH}_{3}\right)_{2}\right)_{3}\right]\left[\mathrm{BF}_{4}\right]$ and release free pyridine. ${ }^{1} \mathrm{H} \mathrm{NMR}\left(\mathrm{CD}_{2} \mathrm{Cl}_{2}\right): \delta$ $8.54\left(\mathrm{~d}, J=4.4,2 \mathrm{H}\right.$, , 2,6-C $\mathrm{C}$ of $\left.\mathrm{C}_{5} \mathrm{H}_{5} \mathrm{~N}\right), 7.72\left(\mathrm{t}, J=8,1 \mathrm{H}, 4-\mathrm{C} H\right.$ of $\left.\mathrm{C}_{5} \mathrm{H}_{5} \mathrm{~N}\right), 1 \mathrm{H}, 4-\mathrm{CH}$ of $\left.\mathrm{C}_{5} \mathrm{H}_{5} \mathrm{~N}\right), 7.47\left(\mathrm{dd}, J=12,8.8,6 \mathrm{H}, 2,6-\mathrm{CH}\right.$ of $\left.-\mathrm{N}=\mathrm{P}\left(4-\mathrm{C}_{6} \mathrm{H}_{4} \mathrm{~N}\left(\mathrm{CH}_{3}\right)_{2}\right)_{3}\right), 7.31((\mathrm{dd}, J=$ 7.6, 2, 2H, 4-CH of $\left.\mathrm{C}_{5} \mathrm{H}_{5} \mathrm{~N}\right), 2 \mathrm{H}, 3,5-\mathrm{CH}$ of $\left.\mathrm{C}_{5} \mathrm{H}_{5} \mathrm{~N}\right), 6.96(\mathrm{~m}, 2 \mathrm{H}, 2,6-\mathrm{CH}$ of $-\mathrm{P}=\mathrm{N}(4-$

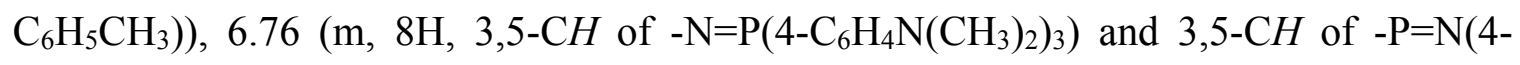
$\left.\left.\mathrm{C}_{6} \mathrm{H}_{5} \mathrm{CH}_{3}\right)\right), 6.31\left(\mathrm{~d},(\mathrm{t}, J=8,-\mathrm{P}=\mathrm{NH}), \quad 3.05\left(\mathrm{~s}, 18 \mathrm{H},-\mathrm{N}\left(\mathrm{CH}_{3}\right)_{2}\right)_{3}\right), 2.22\left(\mathrm{~s}, 4-\mathrm{CH}_{3}\right) .{ }^{31} \mathrm{P}$ NMR $\left(\mathrm{CD}_{2} \mathrm{Cl}_{2}\right): \delta 31.7 .{ }^{19} \mathrm{~F}$ NMR $\left(\mathrm{CD}_{2} \mathrm{Cl}_{2}\right): \delta-152.2 .{ }^{11} \mathrm{~B}$ NMR $\left(\mathrm{CD}_{2} \mathrm{Cl}_{2}\right): \delta-1.13 .{ }^{13} \mathrm{C}$ $\operatorname{NMR}\left(\mathrm{CD}_{2} \mathrm{Cl}_{2}\right): \delta 154.3,149.6,137.1,136.7,135,133,130.3,124.5,121.3,112.2,104$ $\left(\mathrm{d}, J_{\mathrm{PC}}=116.9\right), 40.2,20.8$.

Generation of $\left[\mathrm{C}_{6} \mathrm{H}_{5} \mathrm{CH}_{2} \mathrm{NH}=\mathrm{P}\left(4-\mathrm{C}_{6} \mathrm{H}_{4} \mathrm{OCH}_{3}\right)_{3}\right]\left[\mathrm{C}_{6} \mathrm{H}_{5} \mathrm{COO}\right]$ by the protonation of 4$\mathrm{CH}_{3} \mathrm{C}_{6} \mathrm{H}_{4} \mathrm{~N}=\mathrm{P}\left(4-\mathrm{C}_{6} \mathrm{H}_{4} \mathrm{~N}\left(\mathrm{CH}_{3}\right)_{2}\right)_{3}(4.10)$ with $\left[\mathrm{C}_{6} \mathrm{H}_{5} \mathrm{COOH}\right]$

A valved NMR tube was loaded with 4.17 (11 mg, $24 \mu \mathrm{mol}), \mathrm{C}_{6} \mathrm{H}_{5} \mathrm{COOH}(40 \mathrm{mg}, 24$ $\mu \mathrm{mol})$ and $\mathrm{CD}_{2} \mathrm{Cl}_{2}(1 \mathrm{~mL})$ was added via vacuum transfer at $-196{ }^{\circ} \mathrm{C}$. After the NMR tube was flushed with $\mathrm{N}_{2}$, the tube was sealed, warmed to $25^{\circ} \mathrm{C}$, and shaken until the solids dissolved. After 30 minutes, ${ }^{1} \mathrm{H},{ }^{31} \mathrm{P}$, spectra were recorded. ${ }^{1} \mathrm{H}$ and ${ }^{31} \mathrm{P}$ NMR spectra 


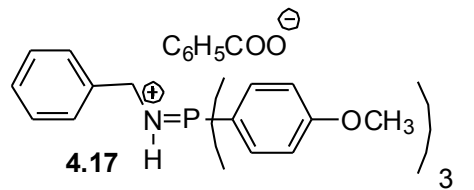

showed that $4-\mathrm{CH}_{3} \mathrm{C}_{6} \mathrm{H}_{4} \mathrm{~N}=\mathrm{P}-\left(4-\mathrm{C}_{6} \mathrm{H}_{4} \mathrm{~N}\left(\mathrm{CH}_{3}\right)_{2}\right)_{3}$ (4.10) was completely protonated to generate $\left[\mathrm{C}_{6} \mathrm{H}_{5} \mathrm{CH}_{2}-\mathrm{NH}=\mathrm{P}(4-\right.$ $\left.\left.\mathrm{C}_{6} \mathrm{H}_{4} \mathrm{OCH}_{3}\right)_{3}\right]\left[\mathrm{C}_{6} \mathrm{H}_{5} \mathrm{COO}\right] . \quad{ }^{1} \mathrm{H} \quad \mathrm{NMR} \quad\left(\mathrm{CD}_{2} \mathrm{Cl}_{2}\right):{ }^{1} \mathrm{H} \quad \mathrm{NMR}$

$\left(\mathrm{CDCl}_{3}\right): \delta 11.55(\mathrm{bs},-\mathrm{N} H), 7.98(\mathrm{~d}, J=6,2 \mathrm{H}), 7.68(\mathrm{~m}, 5 \mathrm{H}), 7.55(\mathrm{bs}), 7.25(\mathrm{~m}, 6 \mathrm{H})$, $7.10(\mathrm{~d}, J=7.2,3 \mathrm{H}), 6.96(\mathrm{~d}, J=8.4,6 \mathrm{H}), 4.31(\mathrm{~d}, J=16,2 \mathrm{H}), 3.8(\mathrm{~s}, 9 \mathrm{H}) .{ }^{31} \mathrm{P}\left(\mathrm{CDCl}_{3}\right)$ :

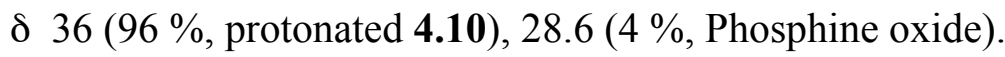

\section{${ }^{1}$ H NMR $\left(\mathrm{C}_{6} \underline{\mathrm{D}_{6}}\right)$ of alcohols}

${ }^{1} \mathrm{H}$ NMR of alcohols were taken in non-hydrogen bonding solvent, $\mathrm{C}_{6} \mathrm{D}_{6}$. The ${ }^{1} \mathrm{H}$ NMR resonance peaks were assigned. The -OH proton peak is observed in these free alcohols in ${ }^{1} \mathrm{H}$ NMR $\left(\mathrm{C}_{6} \mathrm{D}_{6}\right)$.

(a) 9-Anthracenethanol

A valved NMR tube was loaded with 9-Anthracenethanol (10.0 mg, $44.98 \mathrm{mmol})$ and $\mathrm{C}_{6} \mathrm{D}_{6}(0.75 \mathrm{~mL})$ was added via vacuum transfer at $-196{ }^{\circ} \mathrm{C}$. After the NMR tube was flushed with $\mathrm{N}_{2}$, the valved NMR tube was sealed, warmed to $25^{\circ} \mathrm{C}$ and shaken until the solids dissolved. After 10 minutes, ${ }^{1} \mathrm{H}$ spectra was recorded.

${ }^{1} \mathrm{H}$ NMR $\left(\mathrm{C}_{6} \mathrm{D}_{6}\right): \delta 8.107(\mathrm{~s}, 1 \mathrm{H}, 9-\mathrm{CH}), 8.10(\mathrm{~d}, 2 \mathrm{H}, J=8.8,8-\mathrm{CH}), 7.77(\mathrm{~m}, 2 \mathrm{H}$, 4, 6-CH), 7.11-7.26 (m, 4H, 2,3,7,8-CH ), $3.64\left(\mathrm{~m}, 2 \mathrm{H},-\mathrm{CH}_{2} \mathrm{OH}\right), 3.55(\mathrm{~m}, 2 \mathrm{H},-$ $\left.\mathrm{CH}_{2} \mathrm{CH}_{2} \mathrm{OH}\right), 0.77(\mathrm{~s},-\mathrm{OH}) .{ }^{13} \mathrm{C}$ NMR $\left(\mathrm{C}_{6} \mathrm{D}_{6}\right): \delta 131.7,130.8,130.5,129.1$, $126.3,125.4,124.7,124.5,62.8,31.1$.

(b) 9-Anthracenmethanol 
A valved NMR tube was loaded with 9-Anthracenmethanol (5.0 mg, $24.00 \mathrm{mmol})$ and $\mathrm{C}_{6} \mathrm{D}_{6}(0.75 \mathrm{~mL})$ was added via vacuum transfer at $-196{ }^{\circ} \mathrm{C}$. After the NMR tube was flushed with $\mathrm{N}_{2}$, the valved NMR tube was sealed, warmed to $25^{\circ} \mathrm{C}$ and shaken until the solids dissolved. After 10 minutes, ${ }^{1} \mathrm{H}$ spectra was recorded. ${ }^{1} \mathrm{H}$ NMR: 8.19 (d, $J=8.8,2 \mathrm{H}, 8-\mathrm{CH}), 8.10(\mathrm{~s}, 1 \mathrm{H}, 9-\mathrm{CH}), 7.757$ (d, $J=8.4,2 \mathrm{H}, 4,6-$ $\mathrm{CH}), 7.21(\mathrm{~m}, 4 \mathrm{H}, 2,3,7,8-\mathrm{CH}), 5.2\left(\mathrm{~s}, 2 \mathrm{H},-\mathrm{CH}_{2} \mathrm{OH}\right), 0.97(\mathrm{~s},-\mathrm{OH})$.

(c) 1-octadecanol

A valved NMR tube was loaded with 1-octadecanol (10.0 mg, $36.96 \mathrm{mmol})$ and $\mathrm{C}_{6} \mathrm{D}_{6}(0.75 \mathrm{~mL})$ was added via vacuum transfer at $-196^{\circ} \mathrm{C}$. After the NMR tube was flushed with $\mathrm{N}_{2}$, the valved NMR tube was sealed, warmed to $25{ }^{\circ} \mathrm{C}$ and shaken until the solids dissolved. After 10 minutes, ${ }^{1} \mathrm{H}$ spectra was recorded. ${ }^{1} \mathrm{H}$ $\operatorname{NMR}\left(\mathrm{C}_{6} \mathrm{D}_{6}\right): \delta 3.3\left(\mathrm{t}, J=6,2 \mathrm{H},-\mathrm{CH}_{2} \mathrm{OH}\right), 1.36-1.21\left(\mathrm{~m}, 32 \mathrm{H},-\mathrm{CH}_{2}\right), 0.871(\mathrm{~m},-$ $\left.\mathrm{CH}_{3}\right), 0.56(\mathrm{~s},-\mathrm{OH}) .{ }^{13} \mathrm{C} \mathrm{NMR}\left(\mathrm{C}_{6} \mathrm{D}_{6}\right): \delta 62,32.8,31.9,29.8,29.7$ 29.52, 29.43, $25.8,22.7$.

${ }^{1} \mathrm{HNMR}\left(\mathrm{C}_{6} \underline{\mathrm{D}_{6}}\right)$ of Nitrogen bases of the known system

(a) 4-Dimethylaminopyridine (DMAP)

A valved NMR tube was loaded with DMAP $(10.0 \mathrm{mg}, 81.85 \mathrm{mmol})$ and $\mathrm{C}_{6} \mathrm{D}_{6}$ $(0.75 \mathrm{~mL})$ was added via vacuum transfer at $-196{ }^{\circ} \mathrm{C}$. After the NMR tube was flushed with $\mathrm{N}_{2}$, the valved NMR tube was sealed, warmed to $25{ }^{\circ} \mathrm{C}$ and shaken until the solids dissolved. After 10 minutes, ${ }^{1} \mathrm{H}$ spectra was recorded. ${ }^{1} \mathrm{H}$ NMR $\left(\mathrm{C}_{6} \mathrm{D}_{6}\right): \delta 8.42\left(\mathrm{~d}, J=6,2 \mathrm{H}, 2,6-\mathrm{CH}\right.$ of $\left.-\mathrm{NC}_{5} \mathrm{H}_{4} \mathrm{~N}\left(\mathrm{CH}_{3}\right)_{2}\right), 6.07$ (q, $J=1.6,3,5-\mathrm{CH}$ of $\left.-\mathrm{NC}_{5} \mathrm{H}_{4} \mathrm{~N}\left(\mathrm{CH}_{3}\right)_{2}\right), 2.19\left(\mathrm{~s},-\mathrm{CH}_{3}\right),{ }^{13} \mathrm{C} \mathrm{NMR}\left(\mathrm{C}_{6} \mathrm{D}_{6}\right): \delta 150,106.5,37.9$.

(b) Triazabicyclodecene (TBD) 
A valved NMR tube was loaded with TBD (5.0 mg, $35.91 \mathrm{mmol})$ and $\mathrm{C}_{6} \mathrm{D}_{6}(0.75$ $\mathrm{mL}$ ) was added via vacuum transfer at $-196{ }^{\circ} \mathrm{C}$. After the NMR tube was flushed with $\mathrm{N}_{2}$, the valved NMR tube was sealed, warmed to $25^{\circ} \mathrm{C}$ and shaken until the solids dissolved. After 10 minutes, ${ }^{1} \mathrm{H}$ spectra was recorded. ${ }^{1} \mathrm{H}$ NMR $\left(\mathrm{C}_{6} \mathrm{D}_{6}\right)$ :

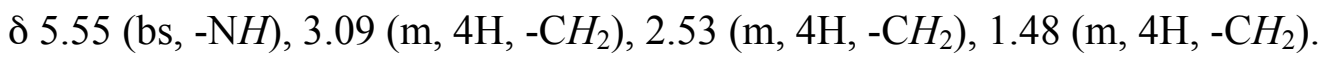

(c) 1,8-Diazabicyclo[5.4.0]undec-7-ene (DBU) A valved NMR tube was loaded with DBU (5.0 mg, $32.84 \mathrm{mmol})$ and $\mathrm{C}_{6} \mathrm{D}_{6}(0.75$ $\mathrm{mL}$ ) was added via vacuum transfer at $-196{ }^{\circ} \mathrm{C}$. After the NMR tube was flushed with $\mathrm{N}_{2}$, the valved NMR tube was sealed, warmed to $25^{\circ} \mathrm{C}$ and shaken until the solids dissolved. After 10 minutes, ${ }^{1} \mathrm{H}$ spectra was recorded. ${ }^{1} \mathrm{H}$ NMR $\left(\mathrm{C}_{6} \mathrm{D}_{6}\right)$ : $\delta 3.34\left(\mathrm{t}, J=5.6,2 \mathrm{H},-\mathrm{CH}_{2}\right), 2.73\left(\mathrm{t}, J=6.4,2 \mathrm{H},-\mathrm{CH}_{2}\right), 2.65(\mathrm{t}, J=4.8,2 \mathrm{H},-$ $\left.\mathrm{CH}_{2}\right), 1.47\left(\mathrm{~m}, 4 \mathrm{H},-\mathrm{CH}_{2}\right), 1.26\left(\mathrm{~m}, 2 \mathrm{H},-\mathrm{CH}_{2}\right), 1.15\left(\mathrm{~m}, 2 \mathrm{H},-\mathrm{CH}_{2}\right)$.

Alcohol activation of literature reported systems.

(a) DMAP+ 9-Anthrylethanol

A valved NMR tube was loaded with DMAP $(5.0 \mathrm{mg}, 40.92 \mathrm{mmol})$ and 9Anthrylethanol $(9.0 \mathrm{mg}, 40.92 \mathrm{mmol}) . \quad \mathrm{C}_{6} \mathrm{D}_{6}(0.75 \mathrm{~mL})$ was added via vacuum transfer at $-196^{\circ} \mathrm{C}$. After the NMR tube was flushed with $\mathrm{N}_{2}$, the valved NMR tube was sealed, warmed to $25^{\circ} \mathrm{C}$ and shaken until the solids dissolved. After 10 minutes, ${ }^{1} \mathrm{H}$ spectra was recorded. ${ }^{1} \mathrm{H}$ NMR $\left(\mathrm{C}_{6} \mathrm{D}_{6}\right): \delta 8.33(\mathrm{dd}, J=4.8,1.6,2 \mathrm{H})$, $8.15(\mathrm{~m}, 1 \mathrm{H}), 8.08(\mathrm{~s}, 1 \mathrm{H}), 7.23(\mathrm{~m}, 4 \mathrm{H}), 6.01(\mathrm{dd}, J=4.8,1.2,2 \mathrm{H}), 3.79(\mathrm{~m}, 2 \mathrm{H})$, $3.68(\mathrm{~m}, 2 \mathrm{H}), 2.17(\mathrm{~s},-\mathrm{OH}), 2.15\left(\mathrm{~s}, 6 \mathrm{H},-\mathrm{CH} \mathrm{H}_{3}\right) .-\mathrm{OH}$ proton shift in ${ }^{1} \mathrm{H}$ NMR $\Delta \delta(\mathrm{OH}):(2.17-0.77) \mathrm{ppm}=\delta 1.4 \mathrm{ppm}$.

(b) DMAP+ 9-Anthrylmethanol 
A valved NMR tube was loaded with DMAP (4.0 mg, $32.74 \mathrm{mmol}$ ) and 9Anthrylmethanol (6.8 mg, $32.74 \mathrm{mmol}) . \mathrm{C}_{6} \mathrm{D}_{6}(0.75 \mathrm{~mL})$ was added via vacuum transfer at $-196{ }^{\circ} \mathrm{C}$. After the NMR tube was flushed with $\mathrm{N}_{2}$, the valved NMR tube was sealed, warmed to $25^{\circ} \mathrm{C}$ and shaken until the solids dissolved. After 10 minutes, ${ }^{1} \mathrm{H}$ spectra was recorded. ${ }^{1} \mathrm{H}$ NMR $\left(\mathrm{C}_{6} \mathrm{D}_{6}\right): \delta 8.35(\mathrm{~d}, J=8.4,2 \mathrm{H}), 8.26$ $(\mathrm{d}, J=5.2,2 \mathrm{H}), 8.11(\mathrm{~s}), 7.76(\mathrm{~d}, J=8,2 \mathrm{H}), 7.22(\mathrm{~m}, 3 \mathrm{H}), 7.106(\mathrm{~s}), 5.96(\mathrm{~d} J=$ 5.6, 2H, $\left.-\mathrm{CH}_{2}\right), 5.39\left(\mathrm{~s}, 2 \mathrm{H},-\mathrm{CH}_{2}\right), 2.94(\mathrm{~s},-\mathrm{OH}), 2.11\left(\mathrm{~s}, 6 \mathrm{H},-\mathrm{CH}_{3}\right), 1.94$ (s). $\mathrm{OH}$ proton shift in ${ }^{1} \mathrm{H}$ NMR $\Delta \delta(\mathrm{OH}):(2.94-0.97) \mathrm{ppm}=\delta 1.97 \mathrm{ppm}$.

(c) DMAP+ 1-octadecanol

A valved NMR tube was loaded with DMAP (5.0 mg, $40.92 \mathrm{mmol}$ ) and 1octadecanol (11.0 mg, $40.92 \mathrm{mmol}) . \quad \mathrm{C}_{6} \mathrm{D}_{6}(0.75 \mathrm{~mL})$ was added via vacuum transfer at $-196{ }^{\circ} \mathrm{C}$. After the NMR tube was flushed with $\mathrm{N}_{2}$, the valved NMR tube was sealed, warmed to $25^{\circ} \mathrm{C}$ and shaken until the solids dissolved. After 10 minutes, ${ }^{1} \mathrm{H}$ spectra was recorded. ${ }^{1} \mathrm{H}$ NMR $\left(\mathrm{C}_{6} \mathrm{D}_{6}\right): \delta 8.38(\mathrm{~m}, 2 \mathrm{H}), 7.113(\mathrm{~s})$, $6.03(\mathrm{~m}, 2 \mathrm{H}), 3.47(\mathrm{t}, J=6.4,2 \mathrm{H}), 2.17\left(\mathrm{~s}, 6 \mathrm{H},-\mathrm{CH}_{3}\right), 1.88(\mathrm{~s},-\mathrm{OH}), 1.47(\mathrm{~m}$, 2H), 1.29-1.25 (m, 27H, $\left.-\mathrm{CH}_{2}\right), 0.86(\mathrm{t}, J=6.8,3 \mathrm{H})$. $-\mathrm{OH}$ proton shift in ${ }^{1} \mathrm{H}$ NMR $\Delta \delta(\mathrm{OH}):(1.88-0.56) \mathrm{ppm}=\delta 1.33 \mathrm{ppm}$.

(d) TBD+9-Anthrylethanol

A valved NMR tube was loaded with TBD (5.0 mg, $35.91 \mathrm{mmol})$ and 9Anthrylethanol $(8.0 \mathrm{mg}, 35.91 \mathrm{mmol}) . \mathrm{C}_{6} \mathrm{D}_{6}(0.75 \mathrm{~mL})$ was added via vacuum transfer at $-196{ }^{\circ} \mathrm{C}$. After the NMR tube was flushed with $\mathrm{N}_{2}$, the valved NMR tube was sealed, warmed to $25^{\circ} \mathrm{C}$ and shaken until the solids dissolved. After 10 
minutes, ${ }^{1} \mathrm{H}$ spectra was recorded. ${ }^{1} \mathrm{H}$ NMR $\left(\mathrm{C}_{6} \mathrm{D}_{6}\right): \delta 8.32(\mathrm{~d}, J=8.8,2 \mathrm{H}), 8.09$ (s, $1 \mathrm{H}), 7.78(\mathrm{~d}, J=8.4,2 \mathrm{H}), 7.21\left(\mathrm{~m}, 4 \mathrm{H},-\mathrm{CH}_{2}\right), 5.03(\mathrm{~s}, 2 \mathrm{H},-\mathrm{OH}), 4.03(\mathrm{~m}, 2 \mathrm{H}-$ $\left.\mathrm{CH}_{2}\right), 3.90\left(\mathrm{~m}, 2 \mathrm{H}-\mathrm{CH}_{2}\right), 2.79(\mathrm{~m}, 3 \mathrm{H}), 2.43(\mathrm{~m}, 3 \mathrm{H}), 1.29(\mathrm{~m}, 3 \mathrm{H})$. - $\mathrm{OH}$ proton shift in ${ }^{1} \mathrm{H}$ NMR $\Delta \delta(\mathrm{OH}):(5.03-0.77) \mathrm{ppm}=4.26 \mathrm{ppm}$.

(e) TBD+1-octadecanol

A valved NMR tube was loaded with TBD $(5.0 \mathrm{mg}, 35.91 \mathrm{mmol})$ and 1Octadecanol $(9.7 \mathrm{mg}, 35.91 \mathrm{mmol}) . \quad \mathrm{C}_{6} \mathrm{D}_{6}(0.75 \mathrm{~mL})$ was added via vacuum transfer at $-196{ }^{\circ} \mathrm{C}$. After the NMR tube was flushed with $\mathrm{N}_{2}$, the valved NMR tube was sealed, warmed to $25^{\circ} \mathrm{C}$ and shaken until the solids dissolved. After 10 minutes, ${ }^{1} \mathrm{H}$ spectra was recorded. ${ }^{1} \mathrm{H}$ NMR $\left(\mathrm{C}_{6} \mathrm{D}_{6}\right): \delta 4.8(\mathrm{~s},-\mathrm{OH}), 3.66(\mathrm{t}, J=$ 6.8, 2H), 2.97 (t, $\left.J=5.6,4 \mathrm{H},-\mathrm{CH}_{2}\right), 2.45\left(\mathrm{t}, J=6.4,4 \mathrm{H},-\mathrm{CH}_{2}\right), 1.61(\mathrm{~m}, 2 \mathrm{H})$, $1.43(\mathrm{~m}, 7 \mathrm{H}), 1.28\left(\mathrm{~m}, 32 \mathrm{H},-\mathrm{CH}_{2}\right), 0.85\left(\mathrm{~m}, 4 \mathrm{H},-\mathrm{CH}_{2}\right) .-\mathrm{OH}$ proton shift in ${ }^{1} \mathrm{H}$ $\mathrm{NMR} \Delta \delta(\mathrm{OH}):(4.80-0.56) \mathrm{ppm}=4.24 \mathrm{ppm}$.

(f) DBU + 9-Anthrylethanol

A valved NMR tube was loaded with DBU (3.47 $\mathrm{mg}, 22.79 \mathrm{mmol}$ ) and 9Anthrylethanol $(5.0 \mathrm{mg}, 22.79 \mathrm{mmol}) . \quad \mathrm{C}_{6} \mathrm{D}_{6}(0.75 \mathrm{~mL})$ was added via vacuum transfer at $-196{ }^{\circ} \mathrm{C}$. After the NMR tube was flushed with $\mathrm{N}_{2}$, the valved NMR tube was sealed, warmed to $25^{\circ} \mathrm{C}$ and shaken until the solids dissolved. After 1S0 minutes, ${ }^{1} \mathrm{H}$ spectra was recorded. ${ }^{1} \mathrm{H}$ NMR $\left(\mathrm{C}_{6} \mathrm{D}_{6}\right): \delta 8.33(\mathrm{~d}, \quad J=6$, $2 \mathrm{H}), 8.10,7.78(\mathrm{dd}, J=8.8,1.6,2 \mathrm{H}), 7.26(\mathrm{~m}, 4 \mathrm{H}), 4.07(\mathrm{bs},-\mathrm{OH}), 4.02(\mathrm{t}, J=8$, 2H), 3.89 (t, $\left.J=8,2 \mathrm{H},-\mathrm{CH}_{2}\right), 2.58\left(\mathrm{t}, J=6.4,2 \mathrm{H},-\mathrm{CH}_{2}\right), 2.51(\mathrm{t}, J=5.2,2 \mathrm{H},-$ 
$\left.\mathrm{CH}_{2}\right), 2.28\left(\mathrm{t}, J=5.2,2 \mathrm{H},-\mathrm{CH}_{2}\right), 1.40(\mathrm{~m}, 4 \mathrm{H}), 1.17\left(\mathrm{~m}, 2 \mathrm{H},-\mathrm{CH}_{2}\right), 1.04(\mathrm{~m}, 2 \mathrm{H},-$ $\left.\mathrm{CH}_{2}\right)$. $-\mathrm{OH}$ proton shift in ${ }^{1} \mathrm{H}$ NMR $\Delta \delta(\mathrm{OH}):(4.07-0.77) \mathrm{ppm}=3.30 \mathrm{ppm}$. 


\section{Experimental Section 4: Activation of 9-anthrylethanol}

(Chapter 4)

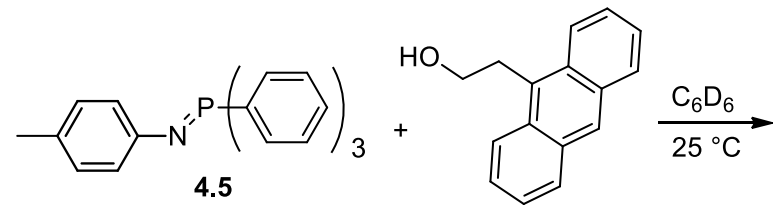

A valved NMR tube was loaded with 4.5 (16.5 mg, $45.0 \mathrm{mmol})$, 9-anthrylethanol (10 mg, $45.0 \mathrm{mmol})$ and $\mathrm{C}_{6} \mathrm{D}_{6}(0.5 \mathrm{~mL})$ was added via vacuum transfer at $-196{ }^{\circ} \mathrm{C}$. After the NMR tube was flushed with $\mathrm{N}_{2}$, the tube was sealed, warmed to $25^{\circ} \mathrm{C}$, and shaken until the solids dissolved. After $10 \mathrm{~min}$ at $25^{\circ} \mathrm{C}$, the proton of $-\mathrm{OH}$ group shift was noted compared to that of 9-anthrylethanol. ${ }^{1} \mathrm{H}$ NMR: $\delta 8.12$ (t, $J=10.8,3 \mathrm{H} 4-\mathrm{CH}$ of $\left.\left.\mathrm{N}=\mathrm{P}\left(\mathrm{C}_{6} \mathrm{H}_{5}\right)_{3}\right)\right), 7.78\left(\mathrm{~m}, 8 \mathrm{H}, 3,5-\mathrm{CH}\right.$ of $\left.\left.-\mathrm{N}=\mathrm{P}\left(\mathrm{C}_{6} \mathrm{H}_{5}\right)_{3}\right)\right), 7.24(\mathrm{~m}, 4 \mathrm{H}), 7.19(\mathrm{~d}, J=6.4$, 2H), $6.97(\mathrm{~m}, 11 \mathrm{H}), 3.74\left(\mathrm{~m}, 4 \mathrm{H},-\mathrm{CH}_{2}\right), 2.17(\mathrm{~s}, 3 \mathrm{H}), 1.61(\mathrm{~s},-\mathrm{OH}) .{ }^{31} \mathrm{P}$ NMR: 1.73 (single peak). - $\mathrm{OH}$ proton shift in ${ }^{1} \mathrm{H}$ NMR $\Delta \delta(\mathrm{OH}):(1.61-0.77)=0.84 \mathrm{ppm}$

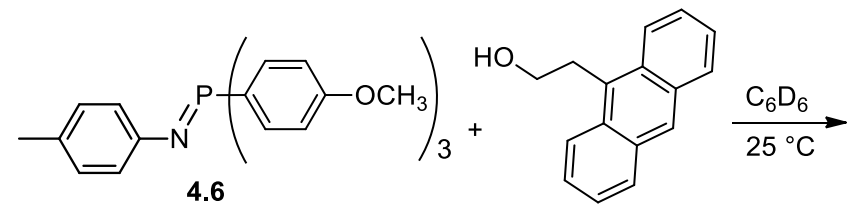

A valved NMR tube was loaded with 4.6 (7.7 mg, $18.0 \mathrm{mmol})$, 9-anthrylethanol (4 mg, $18.0 \mathrm{mmol})$ and $\mathrm{C}_{6} \mathrm{D}_{6}(0.5 \mathrm{~mL})$ was added via vacuum transfer at $-196{ }^{\circ} \mathrm{C}$. After the NMR tube was flushed with $\mathrm{N}_{2}$, the tube was sealed, warmed to $25^{\circ} \mathrm{C}$, and shaken until the solids dissolved. After $10 \mathrm{~min}$ at $25^{\circ} \mathrm{C}$, the proton of $-\mathrm{OH}$ group shift was noted compared to that of 9-anthrylethanol. ${ }^{1} \mathrm{H}$ NMR $\left(\mathrm{C}_{6} \mathrm{D}_{6}\right): \delta 8.25(\mathrm{~d}, J=6.4,2 \mathrm{H}), 8.20$ (s, $1 \mathrm{H}), 7.91\left(\mathrm{~m}, 8 \mathrm{H}, 2,6-\mathrm{CH}\right.$ of $\left.-\mathrm{N}=\mathrm{P}\left(4-\mathrm{C}_{6} \mathrm{H}_{5} \mathrm{OCH}_{3}\right)_{3}\right), 7.38(\mathrm{~m}, 8 \mathrm{H}), 7.16(\mathrm{~d}, J=6.4,2 \mathrm{H})$, $6.73\left(\mathrm{~m}, 6 \mathrm{H}, 4-\mathrm{CH}\right.$ of $\left.-\mathrm{N}=\mathrm{P}\left(\mathrm{C}_{6} \mathrm{H}_{5}\right)_{3}\right), 3.87\left(\mathrm{~m}, 2 \mathrm{H},-\mathrm{CH}_{2}\right), 3.79\left(\mathrm{~m}, 3 \mathrm{H},-\mathrm{CH}_{2}\right), 3.23(\mathrm{~s}$, 
$\left.9 \mathrm{H},-\mathrm{OCH} \mathrm{H}_{3}\right), 2.31(\mathrm{~s}, 3 \mathrm{H}), 2.00(\mathrm{bs},-\mathrm{OH}) .{ }^{31} \mathrm{P}$ NMR $\left(\mathrm{C}_{6} \mathrm{D}_{6}\right): \delta 2.78$ (single peak). -OH proton shift in ${ }^{1} \mathrm{H}$ NMR $\Delta \delta(\mathrm{OH}):(2.00-0.77)=1.23 \mathrm{ppm}$.

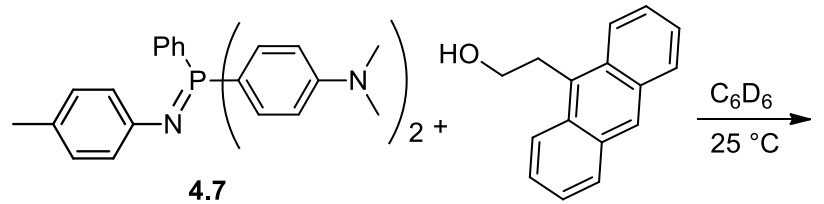

A valved NMR tube was loaded with 4.7 (10.3 mg, $22.5 \mathrm{mmol})$, 9-anthrylethanol (5 mg, $22.5 \mathrm{mmol})$ and $\mathrm{C}_{6} \mathrm{D}_{6}(0.5 \mathrm{~mL})$ was added via vacuum transfer at $-196{ }^{\circ} \mathrm{C}$. After the NMR tube was flushed with $\mathrm{N}_{2}$, the tube was sealed, warmed to $25^{\circ} \mathrm{C}$, and shaken until the solids dissolved. After $10 \mathrm{~min}$ at $25^{\circ} \mathrm{C}$, the proton of $-\mathrm{OH}$ group shift was noted compared to that of 9-anthrylethanol. ${ }^{1} \mathrm{H}$ NMR $\left(\mathrm{C}_{6} \mathrm{D}_{6}\right): \delta 8.19(\mathrm{~d}, J=1.96,2 \mathrm{H}, 2,6-\mathrm{CH}$ of $\left.\left(\mathrm{C}_{6} \mathrm{H}_{5}\right) \mathrm{P}=\mathrm{N}-\right), 8.17(\mathrm{~s}, 2 \mathrm{H}), 8.09(\mathrm{~m}, 6 \mathrm{H}), 7.80(\mathrm{~m}, 6 \mathrm{H}), 7.37(\mathrm{~d}, J=8.4,2 \mathrm{H}), 7.24(\mathrm{~m}$, 4H), $7.05(\mathrm{~s}, 8 \mathrm{H}), 6.30(\mathrm{~m}, 4 \mathrm{H}), 3.78\left(\mathrm{~m}, 4 \mathrm{H},-\mathrm{CH}_{2}\right), 3.07(\mathrm{bs},-\mathrm{OH}), 2.28(\mathrm{~s}, 12 \mathrm{H}$, $\left.\mathrm{NCH}_{3}\right), 2.19\left(\mathrm{~s}, 3 \mathrm{H},-\mathrm{CH}_{3}\right) .{ }^{31} \mathrm{P}$ NMR $\left(\mathrm{C}_{6} \mathrm{D}_{6}\right): \delta 3.81$ (single peak). -OH proton shift in ${ }^{1} \mathrm{H}$ NMR $\Delta \delta(\mathrm{OH}):(3.07-0.77)=2.30 \mathrm{ppm}$.

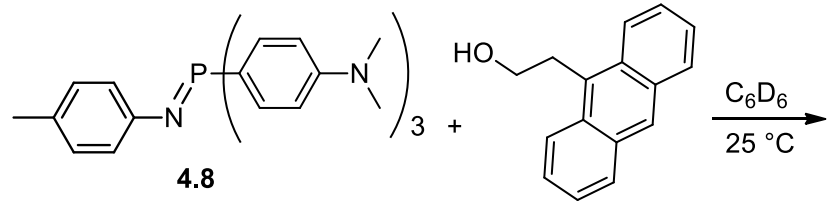

A valved NMR tube was loaded with 4.8 (11.17 mg, $22.5 \mathrm{mmol})$, 9-anthrylethanol (5 mg, $22.5 \mathrm{mmol})$ and $\mathrm{C}_{6} \mathrm{D}_{6}(0.5 \mathrm{~mL})$ was added via vacuum transfer at $-196{ }^{\circ} \mathrm{C}$. After the NMR tube was flushed with $\mathrm{N}_{2}$, the tube was sealed, warmed to $25{ }^{\circ} \mathrm{C}$, and shaken until the solids dissolved. After $10 \mathrm{~min}$ at $25{ }^{\circ} \mathrm{C}$, the proton of $-\mathrm{OH}$ group shift was noted compared to that of 9-anthrylethanol. ${ }^{1} \mathrm{HNMR}: 8.236(\mathrm{~d}, J=8.4,2 \mathrm{H}), 8.12(\mathrm{~s}, 1 \mathrm{H},-\mathrm{CH})$, $7.99\left(\mathrm{~m}, 6 \mathrm{H}, 2,6-\mathrm{CH}\right.$ of $\left.\left.-\mathrm{N}=\mathrm{P}\left(4-\mathrm{C}_{6} \mathrm{H}_{4} \mathrm{~N}\left(\mathrm{CH}_{3}\right)_{2}\right)_{3}\right),\right), 7.81(\mathrm{~m}, 2 \mathrm{H}), 7.5(\mathrm{~d}, J=8.4,2 \mathrm{H})$, $7.27(\mathrm{~m}, 4 \mathrm{H}), 7.11(\mathrm{~d}, J=7.6,2 \mathrm{H}), 6.43\left(\mathrm{~m}, 6 \mathrm{H}, 3,5-\mathrm{CH}\right.$ of $\left.-\mathrm{N}=\mathrm{P}\left(4-\mathrm{C}_{6} \mathrm{H}_{4} \mathrm{~N}\left(\mathrm{CH}_{3}\right)_{2}\right)_{3}\right), 3.84$ 
(m, 4H, $\left.-\mathrm{CH}_{2}\right), 2.74$ (bs, $\left.-\mathrm{OH}\right), 2.34\left(\mathrm{~s}, 18 \mathrm{H},-\mathrm{NCH}_{3}\right), 2.24\left(\mathrm{~s}, 3 \mathrm{H},-\mathrm{CH}_{3}\right) .{ }^{31} \mathrm{P}$ NMR: 3.92 $(98 \%), 11.32 .-\mathrm{OH}$ proton shift in ${ }^{1} \mathrm{H} \mathrm{NMR} \Delta \delta(\mathrm{OH}):(2.74-0.77)=1.97 \mathrm{ppm}$

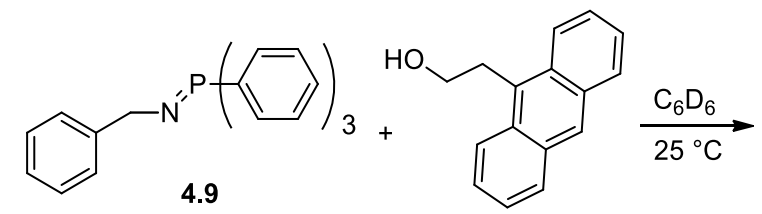

A valved NMR tube was loaded with 4.9 (8.2 mg, $22.5 \mathrm{mmol})$, 9-anthrylethanol (5 mg, $22.5 \mathrm{mmol})$ and $\mathrm{C}_{6} \mathrm{D}_{6}(0.5 \mathrm{~mL})$ was added via vacuum transfer at $-196{ }^{\circ} \mathrm{C}$. After the NMR tube was flushed with $\mathrm{N}_{2}$, the tube was sealed, warmed to $25^{\circ} \mathrm{C}$, and shaken until the solids dissolved. After $10 \mathrm{~min}$ at $25^{\circ} \mathrm{C}$, the proton of $-\mathrm{OH}$ group shift was noted compared to that of 9-anthrylethanol. ${ }^{1} \mathrm{H}$ NMR $\left(\mathrm{C}_{6} \mathrm{D}_{6}\right): \delta 8.14(\mathrm{~m}, 2 \mathrm{H},-\mathrm{CH}), 8.07$ (s, $\mathrm{CH}), 7.78-7.66\left(\mathrm{~m}, 10 \mathrm{H}, 2,6-\mathrm{CH}\right.$ of $\left.-\mathrm{N}=\mathrm{P}\left(\mathrm{C}_{6} \mathrm{H}_{5}\right)_{3}\right), 7.28-7.21(\mathrm{~m}, 6 \mathrm{H}, 3,5-\mathrm{CH}$ of $\left.\mathrm{CH}_{2}\left(\mathrm{C}_{6} \mathrm{H}_{5}\right)\right), 7.11(\mathrm{~s}, 5 \mathrm{H}), 7.0-6.95(\mathrm{~m}, 9 \mathrm{H}), 4.65\left(\mathrm{~d}, J=16.4,2 \mathrm{H},-\mathrm{C}_{6} \mathrm{H}_{5} \mathrm{CH}_{2}\right), 3.76-3.64$ (m, 4H, $\left.-\mathrm{CH}_{2}\right), 2.537$ (bs, -OH). ${ }^{31} \mathrm{P}$ NMR: 8.536 (98\%). -OH proton shift in ${ }^{1} \mathrm{H}$ NMR $\Delta \delta(\mathrm{OH}):(2.54-0.77)=1.77 \mathrm{ppm}$

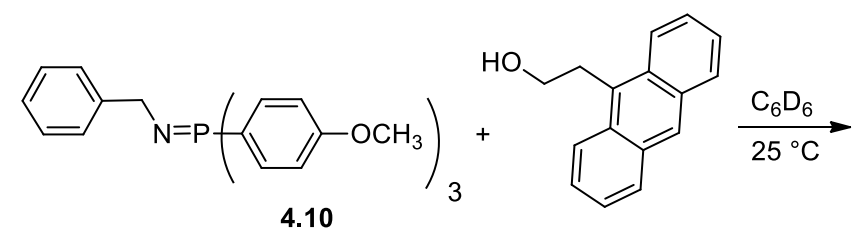

A valved NMR tube was loaded with 4.10 (5.5 mg, $22.5 \mathrm{mmol})$, 9-anthrylethanol (5 mg, $22.5 \mathrm{mmol})$ and $\mathrm{C}_{6} \mathrm{D}_{6}(0.5 \mathrm{~mL})$ was added via vacuum transfer at $-196{ }^{\circ} \mathrm{C}$. After the NMR tube was flushed with $\mathrm{N}_{2}$, the tube was sealed, warmed to $25^{\circ} \mathrm{C}$, and shaken until the solids dissolved. After $10 \mathrm{~min}$ at $25^{\circ} \mathrm{C}$, the proton of $-\mathrm{OH}$ group shift was noted compared to that of 9-anthrylethanol. 
${ }^{1} \mathrm{H}$ NMR $\left(\mathrm{C}_{6} \mathrm{D}_{6}\right): \delta 8.18(\mathrm{~d}, 2 \mathrm{H}, J=8.8,2 \mathrm{H}-\mathrm{C} H), 8.06(\mathrm{~s}, 2 \mathrm{H}-\mathrm{CH}), 7.87(\mathrm{~d}, J=7.6,2 \mathrm{H}$, $\mathrm{H},-\mathrm{CH}), 7.71\left(\mathrm{~m}, 6 \mathrm{H}, 2,6-\mathrm{CH}\right.$ of $\left.-\mathrm{N}=\mathrm{P}\left(\mathrm{C}_{6} \mathrm{H}_{5}\right)_{3}\right), 7.31(\mathrm{t}, J=7.6,2 \mathrm{H}-\mathrm{CH}), 7.22(\mathrm{~m}, 3 \mathrm{H}$, -CH), $6.65\left(\mathrm{dd}, J=8.6,1.6,6 \mathrm{H}, 3,5-\mathrm{CH}\right.$ of $\left.\mathrm{CH}_{2}\left(\mathrm{C}_{6} \mathrm{H}_{5}\right)\right), 4.72\left(\mathrm{~d}, J=17,2 \mathrm{H}-\mathrm{CH}_{2}\right), 3.76-$ 3.80 (m, 2H, - $\left.\mathrm{CH}_{2}\right), 3.73\left(\mathrm{~m}, 2 \mathrm{H},-\mathrm{CH}_{2}\right), 3.15$ (bs, - $\left.\mathrm{OH}\right) .{ }^{31} \mathrm{P}$ NMR: 8.86 (93 \%). - $\mathrm{OH}$ proton shift in ${ }^{1} \mathrm{H}$ NMR $\Delta \delta(\mathrm{OH}):(3.15-0.77)=2.38 \mathrm{ppm}$.

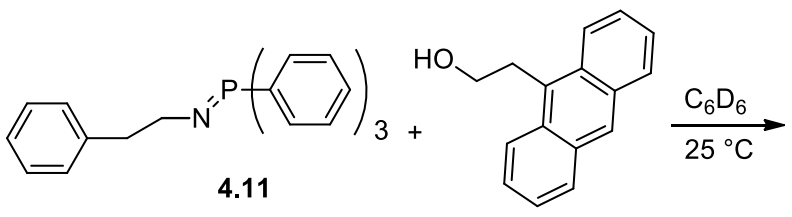

A valved NMR tube was loaded with 4.11 (8.6 mg, $22.5 \mathrm{mmol})$, 9-anthrylethanol (5 mg, $22.5 \mathrm{mmol})$ and $\mathrm{C}_{6} \mathrm{D}_{6}(0.5 \mathrm{~mL})$ was added via vacuum transfer at $-196{ }^{\circ} \mathrm{C}$. After the NMR tube was flushed with $\mathrm{N}_{2}$, the tube was sealed, warmed to $25^{\circ} \mathrm{C}$, and shaken until the solids dissolved. After $10 \mathrm{~min}$ at $25^{\circ} \mathrm{C}$, the proton of $-\mathrm{OH}$ group shift was noted compared to that of 9-anthrylethanol. ${ }^{1} \mathrm{H}$ NMR $\left(\mathrm{C}_{6} \mathrm{D}_{6}\right): \delta{ }^{1} \mathrm{H}$ NMR: $8.14(\mathrm{~m}, 2 \mathrm{H},-\mathrm{CH})$, $8.14(\mathrm{~s},-\mathrm{CH}), 7.78\left(\mathrm{~m}, 7 \mathrm{H}, 2,6-\mathrm{CH}\right.$ of $\left.\left.-\mathrm{N}=\mathrm{PPh}_{3}\right)\right), 7.38(\mathrm{~m}, 2 \mathrm{H}, 2,6-\mathrm{CH}$ of $\mathrm{CH}_{2} \mathrm{CH}_{2}\left(\mathrm{C}_{6} \mathrm{H}_{5}\right), 7.30(\mathrm{~m}, 5 \mathrm{H}), 7.16\left(\mathrm{~m}, 6 \mathrm{H}, 3,5-\mathrm{CH}\right.$ of $\left.-\mathrm{N}=\mathrm{PPh}_{3}\right), 6.46(\mathrm{~m}, 4 \mathrm{H}), 4.22$ (bs, $-\mathrm{OH}), 3.78\left(\mathrm{~m}, 2 \mathrm{H},-\mathrm{CH}_{2}\right), 3.69\left(\mathrm{~m}, 2 \mathrm{H},-\mathrm{CH}_{2}\right), 3.56\left(\mathrm{~m}, 2 \mathrm{H},-\mathrm{C}_{6} \mathrm{H}_{5} \mathrm{CH}_{2}\right), 3.14(\mathrm{~m}, 2 \mathrm{H},-$ $\left.\mathrm{C}_{6} \mathrm{H}_{5} \mathrm{CH}_{2} \mathrm{CH}_{2}\right), 2.16$ (bs, -OH). ${ }^{31} \mathrm{P}$ NMR $\left(\mathrm{C}_{6} \mathrm{D}_{6}\right): \delta 6.35$ (98\%), 25.64 (2 \%, Phosphine oxide). $-\mathrm{OH}$ proton shift in ${ }^{1} \mathrm{H}$ NMR $\Delta \delta(\mathrm{OH}):(2.16-0.77)=1.40 \mathrm{ppm}$.

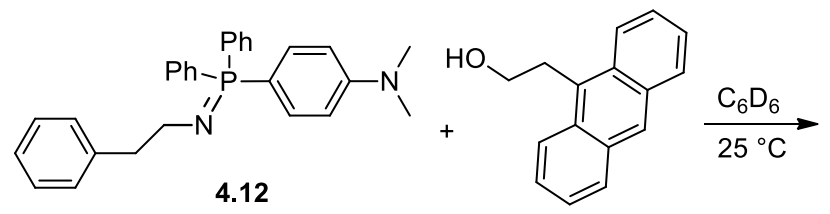

A valved NMR tube was loaded with 4.12 (7.7 mg, $18.0 \mathrm{mmol})$, 9-anthrylethanol (4 mg, $18.0 \mathrm{mmol})$ and $\mathrm{C}_{6} \mathrm{D}_{6}(0.5 \mathrm{~mL})$ was added via vacuum transfer at $-196{ }^{\circ} \mathrm{C}$. After the NMR tube was flushed with $\mathrm{N}_{2}$, the tube was sealed, warmed to $25^{\circ} \mathrm{C}$, and shaken until 
the solids dissolved. After $10 \mathrm{~min}$ at $25^{\circ} \mathrm{C}$, the proton of $-\mathrm{OH}$ group shift was noted compared to that of 9-anthrylethanol. ${ }^{1} \mathrm{H}$ NMR: $\delta 8.21(\mathrm{~m}, 2 \mathrm{H},-\mathrm{CH}), 8.08(\mathrm{~s},-\mathrm{CH}), 7.76$ $\left(\mathrm{m}, 5 \mathrm{H}, 2,6-\mathrm{CH}\right.$ of $\left.-\mathrm{N}=\mathrm{P}\left(\mathrm{C}_{6} \mathrm{H}_{5}\right)\right), 7.60(\mathrm{~m}, 2 \mathrm{H}), 7.22(\mathrm{~m}, 6 \mathrm{H}, 3,5-\mathrm{CH}$ and $4-\mathrm{CH}$ of $\left.\left(\mathrm{C}_{6} \mathrm{H}_{5}\right) \mathrm{P}=\mathrm{N}-\right), 7.1(\mathrm{~m}, 7 \mathrm{H}), 7.02(\mathrm{~m}, 6 \mathrm{H}), 6.31(\mathrm{~m}, 2 \mathrm{H}), 4.22(\mathrm{~s}), 3.85(\mathrm{~m}, 2 \mathrm{H}), 3.72(\mathrm{~m}$, $\left.4 \mathrm{H},-\mathrm{C}_{6} \mathrm{H}_{5} \mathrm{CH}_{2}\right), 3.22\left(\mathrm{~m}, 2 \mathrm{H},-\mathrm{C}_{6} \mathrm{H}_{5} \mathrm{CH}_{2} \mathrm{CH}_{2}\right), 3.1$ (bs, $\left.-\mathrm{OH}\right), 2.28\left(\mathrm{~s}, 6 \mathrm{H},-\mathrm{N}\left(\mathrm{CH}_{3}\right)_{2},{ }^{31} \mathrm{P}\right.$ NMR: $\delta 9.95$ (96\%), 26.83 (5\%, Phosphine oxide). -OH proton shift in ${ }^{1} \mathrm{H}$ NMR $\Delta \delta(\mathrm{OH}):(3.1-0.77)=2.4 \mathrm{ppm}$.

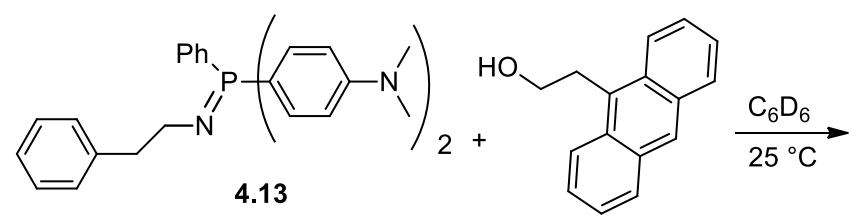

A valved NMR tube was loaded with 4.13 (9.6 mg, $18 \mathrm{mmol})$, 9-anthrylethanol (4 mg, 18 mmol) and $\mathrm{C}_{6} \mathrm{D}_{6}(0.5 \mathrm{~mL})$ was added via vacuum transfer at $-196^{\circ} \mathrm{C}$. After the NMR tube was flushed with $\mathrm{N}_{2}$, the tube was sealed, warmed to $25^{\circ} \mathrm{C}$, and shaken until the solids dissolved. After $10 \mathrm{~min}$ at $25{ }^{\circ} \mathrm{C}$, the proton of -OH group shift was noted compared to that of 9-anthrylethanol. ${ }^{1} \mathrm{H}$ NMR: $8.36\left(\mathrm{~m}, 2 \mathrm{H}\right.$, of 2,6- $\mathrm{CH}$ of $-\mathrm{N}=\mathrm{P}\left(\mathrm{C}_{6} \mathrm{H}_{5}\right), 8.16(\mathrm{~s}), 7.82$ (m, 7H), $7.38(\mathrm{~m}, 2 \mathrm{H}), 7.30(\mathrm{~m}, 5 \mathrm{H}), 7.16(\mathrm{~m}, 6 \mathrm{H}), 6.46(\mathrm{~m}, 4 \mathrm{H}), 4.22(\mathrm{bs},-\mathrm{OH}),$, (m, 2H, - $\mathrm{CH}_{2}$ ), $3.87\left(\mathrm{~m}, 3 \mathrm{H},-\mathrm{CH}_{2}\right), 3.78\left(\mathrm{~m}, 2 \mathrm{H}, \mathrm{CH}_{2}\right), 3.33(\mathrm{t}, J=7.2,2 \mathrm{H}), 2.29(\mathrm{~s}, 12 \mathrm{H}$, $\left.-\mathrm{C}_{6} \mathrm{H}_{5} \mathrm{CH}_{3}\right) .{ }^{31} \mathrm{P}$ NMR: $11.61(82 \%), 27.25$ (Phosphine oxide). -OH proton shift in ${ }^{1} \mathrm{H}$ $\operatorname{NMR} \Delta \delta(\mathrm{OH}):(4.22-0.77)=3.43 \mathrm{ppm}$

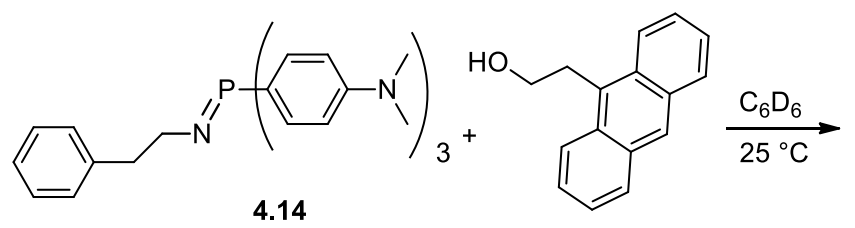

A valved NMR tube was loaded with 4.14 (11.4 mg, $18 \mathrm{mmol})$, 9-anthrylethanol (4 mg, $18 \mathrm{mmol})$ and $\mathrm{C}_{6} \mathrm{D}_{6}(0.5 \mathrm{~mL})$ was added via vacuum transfer at $-196{ }^{\circ} \mathrm{C}$. After the NMR 
tube was flushed with $\mathrm{N}_{2}$, the tube was sealed, warmed to $25^{\circ} \mathrm{C}$, and shaken until the solids dissolved. After $10 \mathrm{~min}$ at $25{ }^{\circ} \mathrm{C}$, the proton of $-\mathrm{OH}$ group shift was noted compared to that of 9-anthrylethanol. ${ }^{1} \mathrm{H}$ NMR $\left(\mathrm{C}_{6} \mathrm{D}_{6}\right): \delta 8.32(\mathrm{~d}, J=8.8), 8.07(\mathrm{~s}), 7.78$ (m), $6.38(\mathrm{~d}, J=8.0), 4.17(\mathrm{bs},-\mathrm{OH}), 3.99\left(\mathrm{~m}, 8 \mathrm{H},-\mathrm{CH}_{2}\right), 3.90\left(\mathrm{~m}, 2 \mathrm{H},-\mathrm{CH}_{2}\right), 3.77(\mathrm{~m}$, $\left.2 \mathrm{H}, \mathrm{CH}_{2}\right), 3.4\left(\mathrm{~m}, 2 \mathrm{H}, \mathrm{CH}_{2}\right), 2.3\left(\mathrm{~m}, 2 \mathrm{H},-\mathrm{CH}_{3}\right) .{ }^{31} \mathrm{P}$ NMR $\left(\mathrm{C}_{6} \mathrm{D}_{6}\right): \delta 16(54 \%), 27.82$ (Phosphine oxide). - $\mathrm{OH}$ proton shift in ${ }^{1} \mathrm{H}$ NMR $\Delta \delta(\mathrm{OH}):(4.17-0.77)=3.46 \mathrm{ppm}$.

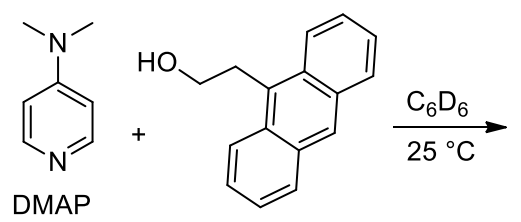

A valved NMR tube was loaded with 4-dimethylaminopyridine (DMAP) (5 mg, 40.9 mmol), 9-anthrylethanol $(9.1 \mathrm{mg}, 40.9 \mathrm{mmol})$ and $\mathrm{C}_{6} \mathrm{D}_{6}(0.5 \mathrm{~mL})$ was added via vacuum transfer at $-196{ }^{\circ} \mathrm{C}$. After the NMR tube was flushed with $\mathrm{N}_{2}$, the tube was sealed, warmed to $25^{\circ} \mathrm{C}$, and shaken until the solids dissolved. After $10 \mathrm{~min}$ at $25^{\circ} \mathrm{C}$, the proton of -OH group shift was noted compared to that of 9-anthrylethanol. ${ }^{1} \mathrm{H}$ NMR $\left(\mathrm{C}_{6} \mathrm{D}_{6}\right)$ : $\delta 8.33(\mathrm{dd}, J=4.8,1.6,2 \mathrm{H}), 8.15(\mathrm{~m}, 1 \mathrm{H}), 8.08(\mathrm{~s}, 1 \mathrm{H}), 7.23(\mathrm{~m}, 4 \mathrm{H}), 6.01(\mathrm{dd}, J=4.8$, 1.2, 2H), $3.79(\mathrm{~m}, 2 \mathrm{H}), 3.68(\mathrm{~m}, 2 \mathrm{H}), 2.17(\mathrm{~s},-\mathrm{OH}), 2.15(\mathrm{~s}, 6 \mathrm{H},-\mathrm{CH}) .-\mathrm{OH}$ proton shift in ${ }^{1} \mathrm{H}$ NMR $\Delta \delta(\mathrm{OH}):(2.17-0.77) \mathrm{ppm}=1.4 \mathrm{ppm}$.

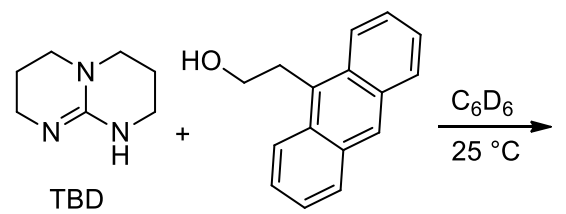

A valved NMR tube was loaded with triazabicyclodecene (TBD) (5 mg, 40.9 mmol), 9anthrylethanol (8 mg, $40.9 \mathrm{mmol})$ and $\mathrm{C}_{6} \mathrm{D}_{6}(0.5 \mathrm{~mL})$ was added via vacuum transfer at $196{ }^{\circ} \mathrm{C}$. After the NMR tube was flushed with $\mathrm{N}_{2}$, the tube was sealed, warmed to $25^{\circ} \mathrm{C}$, and shaken until the solids dissolved. After $10 \mathrm{~min}$ at $25^{\circ} \mathrm{C}$, the proton of $-\mathrm{OH}$ group 
shift was noted compared to that of 9-anthrylethanol. ${ }^{1} \mathrm{H}$ NMR $\left(\mathrm{C}_{6} \mathrm{D}_{6}\right): \delta 8.32(\mathrm{~d}, J=8.8$, 2H), $8.09(\mathrm{~s}, 1 \mathrm{H}), 7.78(\mathrm{~d}, J=8.4,2 \mathrm{H}), 7.21(\mathrm{~m}, 4 \mathrm{H}), 5.03(\mathrm{~s}, 2 \mathrm{H}), 4.03\left(\mathrm{~m}, 2 \mathrm{H},-\mathrm{CH}_{2}\right)$, $3.90(\mathrm{~m}, 2 \mathrm{H}), 2.79(\mathrm{~m}, 3 \mathrm{H}), 2.43\left(\mathrm{~m}, 3 \mathrm{H},-\mathrm{CH}_{2}\right), 1.29\left(\mathrm{~m}, 3 \mathrm{H},-\mathrm{CH}_{2}\right)$. $-\mathrm{OH}$ proton shift in ${ }^{1} \mathrm{H}$ NMR $\Delta \delta(\mathrm{OH}):(5.03-0.77) \mathrm{ppm}=4.26 \mathrm{ppm}$.

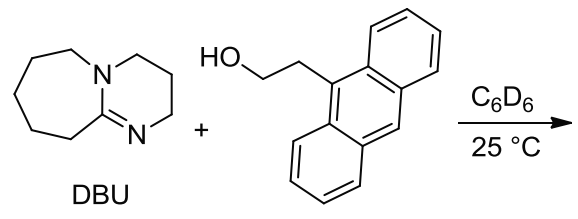

A valved NMR tube was loaded with 1,8-Diazabicyloundec-7-ene (DBU) $(3.47 \mathrm{mg}, 22.5$ mmol), 9-anthrylethanol (5 mg, $22.5 \mathrm{mmol})$ and $\mathrm{C}_{6} \mathrm{D}_{6}(0.5 \mathrm{~mL})$ was added via vacuum transfer at $-196{ }^{\circ} \mathrm{C}$. After the NMR tube was flushed with $\mathrm{N}_{2}$, the tube was sealed, warmed to $25^{\circ} \mathrm{C}$, and shaken until the solids dissolved. After 10 min at $25{ }^{\circ} \mathrm{C}$, the proton of $-\mathrm{OH}$ group shift was noted compared to that of 9-anthrylethanol. ${ }^{1} \mathrm{H}$ NMR $\left(\mathrm{C}_{6} \mathrm{D}_{6}\right)$ : $\delta 8.33(\mathrm{~d}, J=6,2 \mathrm{H}), 8.10,7.78(\mathrm{dd}, J=8.8,1.6,2 \mathrm{H}), 7.26(\mathrm{~m}, 4 \mathrm{H}), 4.07(\mathrm{bs},-\mathrm{OH}), 4.02$ (t, $J=8,2 \mathrm{H}), 3.89(\mathrm{t}, J=8,2 \mathrm{H}), 2.58(\mathrm{t}, J=6.4,2 \mathrm{H}), 2.51(\mathrm{t}, J=5.2,2 \mathrm{H}), 2.28(\mathrm{t}, J=$ 5.2, $2 \mathrm{H}), 1.40(\mathrm{~m}, 4 \mathrm{H}), 1.17(\mathrm{~m}, 2 \mathrm{H}), 1.04(\mathrm{~m}, 2 \mathrm{H}) .-\mathrm{OH}$ proton shift in ${ }^{1} \mathrm{H}$ NMR $\Delta \delta(\mathrm{OH}):(4.87-0.77) \mathrm{ppm}=4.07 \mathrm{ppm}$. 


\section{Experimental Section 5: Ring opening polymerization of L-lactide}

\section{(Chapter 4)}

\section{General Experimental}

The percent conversion of polymerization of the lactide is calculated by integration of the methane protons of the both polymer and the monomer and comparison of their relative integration values. The methane peak of the monomer is observed at $\sim 5.04 \mathrm{ppm}$ while the methane peaks of the polymer are observed at 5.13-5.25 ppm the \% conversion of the monomer is determined using the following formula below,

$\%$ conversion of $\mathrm{LA}=$ (integration of PLA $\mathrm{CH}$ resonance/integration of PLA CH resonance + integration of unreacted $\mathrm{LA} \mathrm{CH}$ resonance) $)^{*} 100$

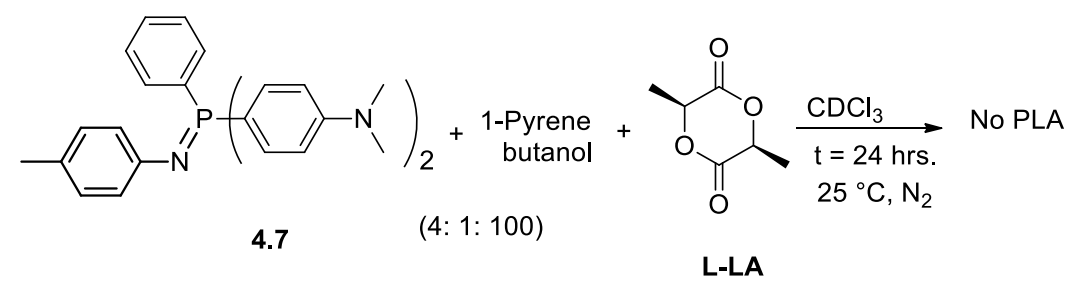

A valved NMR tube was loaded with $4.5(0.77 \mathrm{mg}, 3.64 \mathrm{mmol})$, pyrenebutanol (1 mg, $3.64 \mathrm{mmol})$, and L-Lactide $(100 \mathrm{mg}, 0.7 \mathrm{~mol}) . \mathrm{CDCl}_{3}(0.5 \mathrm{~mL})$ was added via vacuum transfer at $-196{ }^{\circ} \mathrm{C}$. After the NMR tube was flushed with $\mathrm{N}_{2}$, the valved NMR tube was sealed, warmed to $25{ }^{\circ} \mathrm{C}$ and shaken until the solids dissolved. ${ }^{1} \mathrm{H}$ NMR spectra established at 24 hours show no polymer formation. ${ }^{31} \mathrm{P}\left\{{ }^{1} \mathrm{H}\right\}$ spectra established that there is formation of protonated phosphinimine. ${ }^{1} \mathrm{H}$ NMR $\left(\mathrm{CDCl}_{3}\right): \delta$ 5.01-5.06 (L-LA monomer, -CH), 5.13-5.25 (L-LA monomer, -CH). 


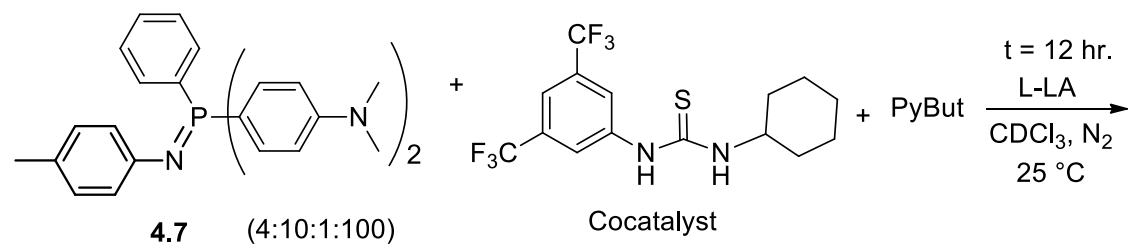

A valved NMR tube was loaded with 4.7 (4.84 mg, $14.56 \mathrm{mmol})$, thiourea (13.5 mg, 36.4 mmol pyrenebutanol (1 mg, $3.64 \mathrm{mmol})$, and l-lactide (100 mg, $0.7 \mathrm{~mol}) . \mathrm{CDCl}_{3}(0.5 \mathrm{~mL})$ was added via vacuum transfer at $-196{ }^{\circ} \mathrm{C}$. After the NMR tube was flushed with $\mathrm{N}_{2}$, the valved NMR tube was sealed, warmed to $25^{\circ} \mathrm{C}$ and shaken until the solids dissolved. ${ }^{1} \mathrm{H}$ NMR spectra established at $12 \mathrm{~h}$ hours show that $88 \%$ L-LA monomer respectively. ${ }^{31} \mathrm{P}\left\{{ }^{1} \mathrm{H}\right\}$ spectra established that there is no formation of protonated phosphinimine. ${ }^{1} \mathrm{H}$ $\operatorname{NMR}\left(\mathrm{CDCl}_{3}\right): \delta$ 5.01-5.06 (L-LA, -CH), 5.13-5.25 (88\%, PLLA, -CH).

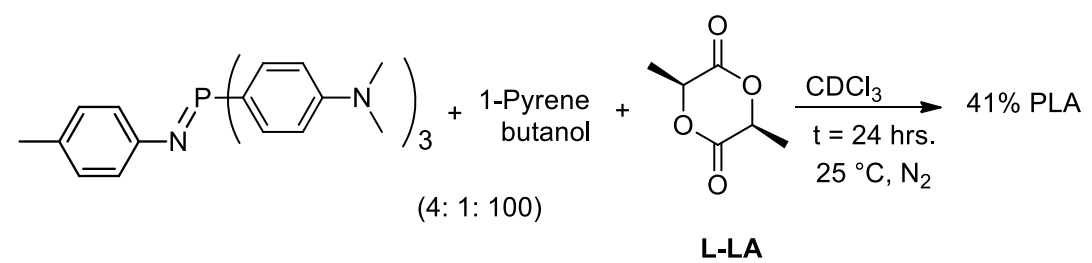

A valved NMR tube was loaded with $4.8(3.72 \mathrm{mg}, 14.56 \mathrm{mmol})$, pyrenebutanol (1 mg, $3.64 \mathrm{mmol})$, and l-lactide $(100 \mathrm{mg}, 0.7 \mathrm{~mol}) . \mathrm{CDCl}_{3}(0.5 \mathrm{~mL})$ was added via vacuum transfer at $-196{ }^{\circ} \mathrm{C}$. After the NMR tube was flushed with $\mathrm{N}_{2}$, the valved NMR tube was sealed, warmed to $25{ }^{\circ} \mathrm{C}$ and shaken until the solids dissolved. ${ }^{1} \mathrm{H}$ NMR spectra established at $12 \mathrm{~h}$ hours show that $41 \%$ L-LA monomer respectively. ${ }^{31} \mathrm{P}\left\{{ }^{1} \mathrm{H}\right\}$ spectra established that there is no formation of protonated phosphinimine. ${ }^{1} \mathrm{H}$ NMR $\left(\mathrm{CDCl}_{3}\right): \delta$ 5.01-5.06 (L-LA, -CH), 5.13-5.25 (41 \%, PLLA, -CH). 


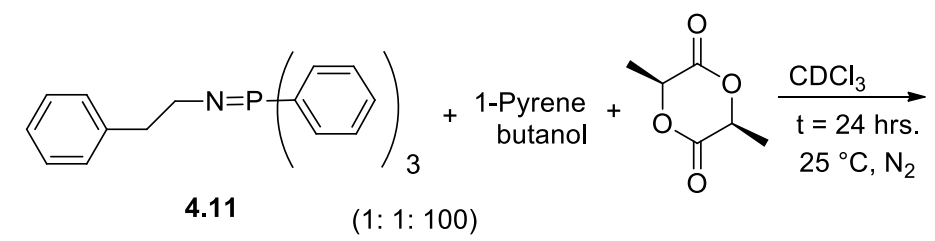

A valved NMR tube was loaded with 4.11 (10.82 mg, $3.64 \mathrm{mmol})$, pyrenebutanol (1 mg, $3.64 \mathrm{mmol})$, and l-lactide $(100 \mathrm{mg}, 0.7 \mathrm{~mol}) . \mathrm{CDCl}_{3}(0.5 \mathrm{~mL})$ was added via vacuum transfer at $-196^{\circ} \mathrm{C}$. After the NMR tube was flushed with $\mathrm{N}_{2}$, the valved NMR tube was sealed, warmed to $25{ }^{\circ} \mathrm{C}$ and shaken until the solids dissolved. ${ }^{1} \mathrm{H}$ NMR spectra established at $12 \mathrm{~h}$ hours show that $28 \%$ L-LA monomer respectively. ${ }^{31} \mathrm{P}\left\{{ }^{1} \mathrm{H}\right\}$ spectra established that there is formation of protonated phosphinimine. ${ }^{1} \mathrm{H}$ NMR $\left(\mathrm{CDCl}_{3}\right): \delta$ 5.01-5.06 (L-LA, -CH), 5.13-5.25 (28 \%, PLLA, -CH).

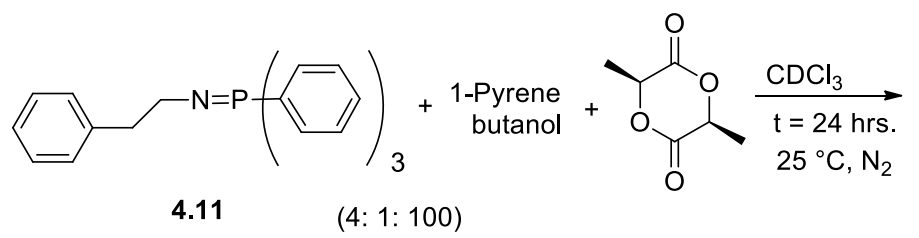

A valved NMR tube was loaded with 4.11 (43.28 mg, $14.56 \mathrm{mmol})$, pyrenebutanol (1 mg, $3.64 \mathrm{mmol})$, and l-lactide $(100 \mathrm{mg}, 0.7 \mathrm{~mol}) . \mathrm{CDCl}_{3}(0.5 \mathrm{~mL})$ was added via vacuum transfer at $-196^{\circ} \mathrm{C}$. After the NMR tube was flushed with $\mathrm{N}_{2}$, the valved NMR tube was sealed, warmed to $25{ }^{\circ} \mathrm{C}$ and shaken until the solids dissolved. ${ }^{1} \mathrm{H}$ NMR spectra established at $24 \mathrm{~h}$ hours show that $92 \%$ L-LA monomer respectively. ${ }^{31} \mathrm{P}\left\{{ }^{1} \mathrm{H}\right\}$ spectra established that there is no formation of protonated phosphinimine. ${ }^{1} \mathrm{H} \mathrm{NMR}\left(\mathrm{CDCl}_{3}\right): \delta$ 5.01-5.06 (L-LA, -CH), 5.13-5.25 (92\%, PLLA, -CH). 


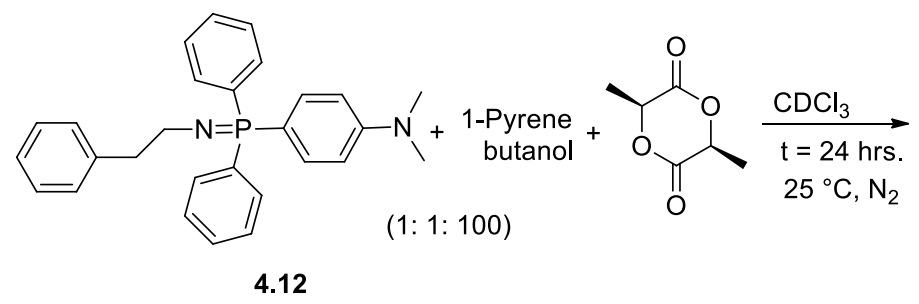

A valved NMR tube was loaded with $4.12(1.54 \mathrm{mg}, 3.64 \mathrm{mmol})$, pyrenebutanol (1 mg, $3.64 \mathrm{mmol})$, and l-lactide $(100 \mathrm{mg}, 0.7 \mathrm{~mol}) . \mathrm{CDCl}_{3}(0.5 \mathrm{~mL})$ was added via vacuum transfer at $-196^{\circ} \mathrm{C}$. After the NMR tube was flushed with $\mathrm{N}_{2}$, the valved NMR tube was sealed, warmed to $25{ }^{\circ} \mathrm{C}$ and shaken until the solids dissolved. . ${ }^{1} \mathrm{H}$ NMR spectra established at 24 h hours show that $4 \%$ L-LA monomer respectively. ${ }^{31} \mathrm{P}\left\{{ }^{1} \mathrm{H}\right\}$ spectra established that there is no formation of protonated phosphinimine. ${ }^{1} \mathrm{H}$ NMR $\left(\mathrm{CDCl}_{3}\right): \delta$ 5.01-5.06 (L-LA, -CH), 5.13-5.25 (4 \%, PLLA, -CH).

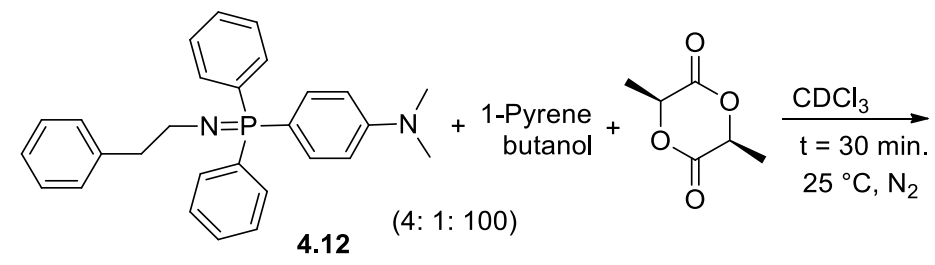

A valved NMR tube was loaded with $4.12(6.16 \mathrm{mg}, 14.56 \mathrm{mmol})$, pyrenebutanol (1 mg, $3.64 \mathrm{mmol})$, and l-lactide $(100 \mathrm{mg}, 0.7 \mathrm{~mol}) . \mathrm{CDCl}_{3}(0.5 \mathrm{~mL})$ was added via vacuum transfer at $-196^{\circ} \mathrm{C}$. After the NMR tube was flushed with $\mathrm{N}_{2}$, the valved NMR tube was sealed, warmed to $25{ }^{\circ} \mathrm{C}$ and shaken until the solids dissolved. ${ }^{1} \mathrm{H}$ NMR spectra established at 30 minutes show $100 \%$ PLLA formation. ${ }^{31} \mathrm{P}\left\{{ }^{1} \mathrm{H}\right\}$ spectra established that there is no formation of protonated phosphinimine. ${ }^{1} \mathrm{H}$ NMR $\left(\mathrm{CDCl}_{3}\right): \delta 5.01-5.06$ (LLA, -CH), 5.13-5.25 (100\%, PLLA, -CH). 


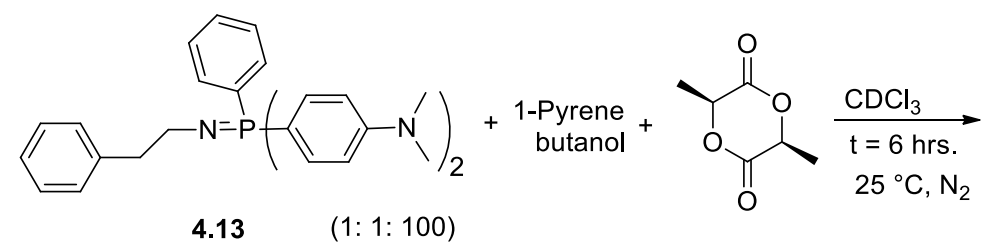

A valved NMR tube was loaded with 4.13 (1.26 mg, $3.64 \mathrm{mmol})$, pyrenebutanol (1 mg, $3.64 \mathrm{mmol})$, and l-lactide $(100 \mathrm{mg}, 0.7 \mathrm{~mol}) . \mathrm{CDCl}_{3}(0.5 \mathrm{~mL})$ was added via vacuum transfer at $-196^{\circ} \mathrm{C}$. After the NMR tube was flushed with $\mathrm{N}_{2}$, the valved NMR tube was sealed, warmed to $25{ }^{\circ} \mathrm{C}$ and shaken until the solids dissolved. ${ }^{1} \mathrm{H}$ NMR spectra established at 6 hours show $96 \%$ PLLA formation. ${ }^{31} \mathrm{P}\left\{{ }^{1} \mathrm{H}\right\}$ spectra established that there is a formation of protonated phosphinimine. ${ }^{1} \mathrm{H}$ NMR $\left(\mathrm{CDCl}_{3}\right)$ : $\delta$ 5.01-5.06 (L-LA, -CH), 5.13-5.25 (100\%, PLLA, -CH).

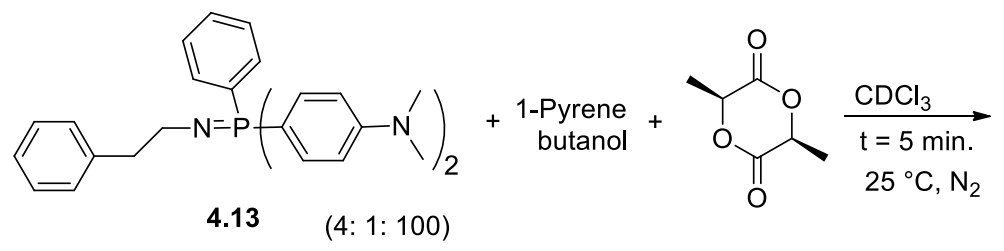

A valved NMR tube was loaded with 4.13 (5.04 mg, $14.56 \mathrm{mmol})$, pyrenebutanol (1 mg, $3.64 \mathrm{mmol})$, and l-lactide $(100 \mathrm{mg}, 0.7 \mathrm{~mol}) . \mathrm{CDCl}_{3}(0.5 \mathrm{~mL})$ was added via vacuum transfer at $-196{ }^{\circ} \mathrm{C}$. After the NMR tube was flushed with $\mathrm{N}_{2}$, the valved NMR tube was sealed, warmed to $25{ }^{\circ} \mathrm{C}$ and shaken until the solids dissolved. ${ }^{1} \mathrm{H}$ NMR spectra established at 5 minutes show $96 \%$ PLLA formation. ${ }^{31} \mathrm{P}\left\{{ }^{1} \mathrm{H}\right\}$ spectra established that there is no formation of protonated phosphinimine. ${ }^{1} \mathrm{H}$ NMR $\left(\mathrm{CDCl}_{3}\right): \delta 5.01-5.06(\mathrm{~L}-$ LA, -CH), 5.13-5.25 (96\%, PLLA, -CH). 


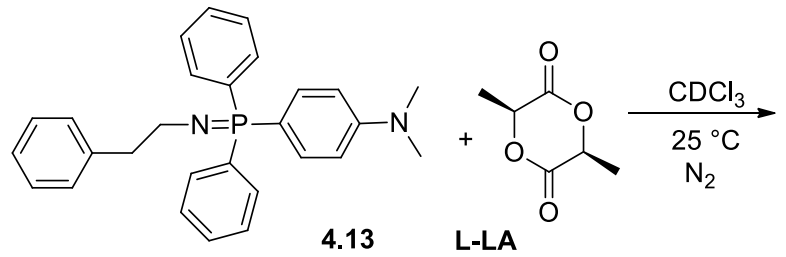

A valved NMR tube was loaded with 4.13 (5.04 mg, $14.56 \mathrm{mmol})$, pyrenebutanol (1 mg, $3.64 \mathrm{mmol})$, and l-lactide $(100 \mathrm{mg}, 0.7 \mathrm{~mol}) . \mathrm{CDCl}_{3}(0.5 \mathrm{~mL})$ was added via vacuum transfer at $-196{ }^{\circ} \mathrm{C}$. After the NMR tube was flushed with $\mathrm{N}_{2}$, the valved NMR tube was sealed, warmed to $25{ }^{\circ} \mathrm{C}$ and shaken until the solids dissolved. ${ }^{1} \mathrm{H}$ NMR spectra established at 3 hours show $100 \%$ PLLA formation. ${ }^{31} \mathrm{P}\left\{{ }^{1} \mathrm{H}\right\}$ spectra established that there is no formation of protonated phosphinimine. ${ }^{1} \mathrm{H}$ NMR $\left(\mathrm{CDCl}_{3}\right): \delta$ 5.01-5.06 (LLA, -CH), 5.13-5.25 (100\%, PLLA, -CH).

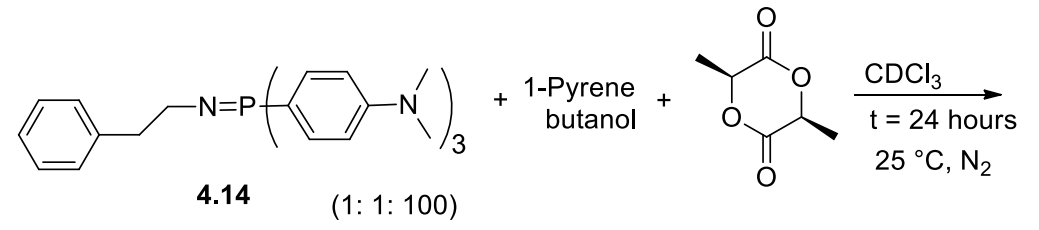

A valved NMR tube was loaded with 4.14 (0.98 mg, $3.64 \mathrm{mmol})$, pyrenebutanol (1 mg, $3.64 \mathrm{mmol})$, and l-lactide $(100 \mathrm{mg}, 0.7 \mathrm{~mol}) . \mathrm{CDCl}_{3}(0.5 \mathrm{~mL})$ was added via vacuum transfer at $-196^{\circ} \mathrm{C}$. After the NMR tube was flushed with $\mathrm{N}_{2}$, the valved NMR tube was sealed, warmed to $25{ }^{\circ} \mathrm{C}$ and shaken until the solids dissolved. ${ }^{1} \mathrm{H}$ NMR spectra established at 24 hours show $9 \%$ PLLA formation. ${ }^{31} \mathrm{P}\left\{{ }^{1} \mathrm{H}\right\}$ spectra established that there is a formation of protonated phosphinimine. ${ }^{1} \mathrm{H} \mathrm{NMR}\left(\mathrm{CDCl}_{3}\right): \delta$ 5.01-5.06 (L-LA, $\left.-\mathrm{CH}\right)$, 5.13-5.25 (9\%, PLLA, $-\mathrm{CH})$. 


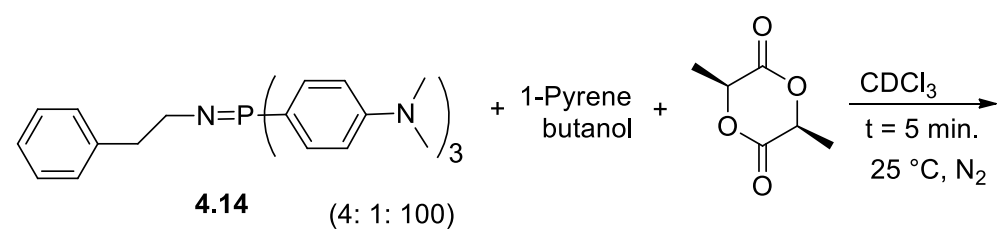

A valved NMR tube was loaded with 4.14 (3.92 mg, $14.56 \mathrm{mmol})$, pyrenebutanol (1 mg, $3.64 \mathrm{mmol})$, and l-lactide $(100 \mathrm{mg}, 0.7 \mathrm{~mol}) . \mathrm{CDCl}_{3}(0.5 \mathrm{~mL})$ was added via vacuum transfer at $-196{ }^{\circ} \mathrm{C}$. After the NMR tube was flushed with $\mathrm{N}_{2}$, the valved NMR tube was sealed, warmed to $25{ }^{\circ} \mathrm{C}$ and shaken until the solids dissolved. ${ }^{1} \mathrm{H}$ NMR spectra established at 5 minutes show $100 \%$ PLLA formation. ${ }^{31} \mathrm{P}\left\{{ }^{1} \mathrm{H}\right\}$ spectra established that there is no formation of protonated phosphinimine. ${ }^{1} \mathrm{H}$ NMR $\left(\mathrm{CDCl}_{3}\right): \delta 5.01-5.06(\mathrm{~L}-$ LA, -CH), 5.13-5.25 (96\%, PLLA, -CH). 


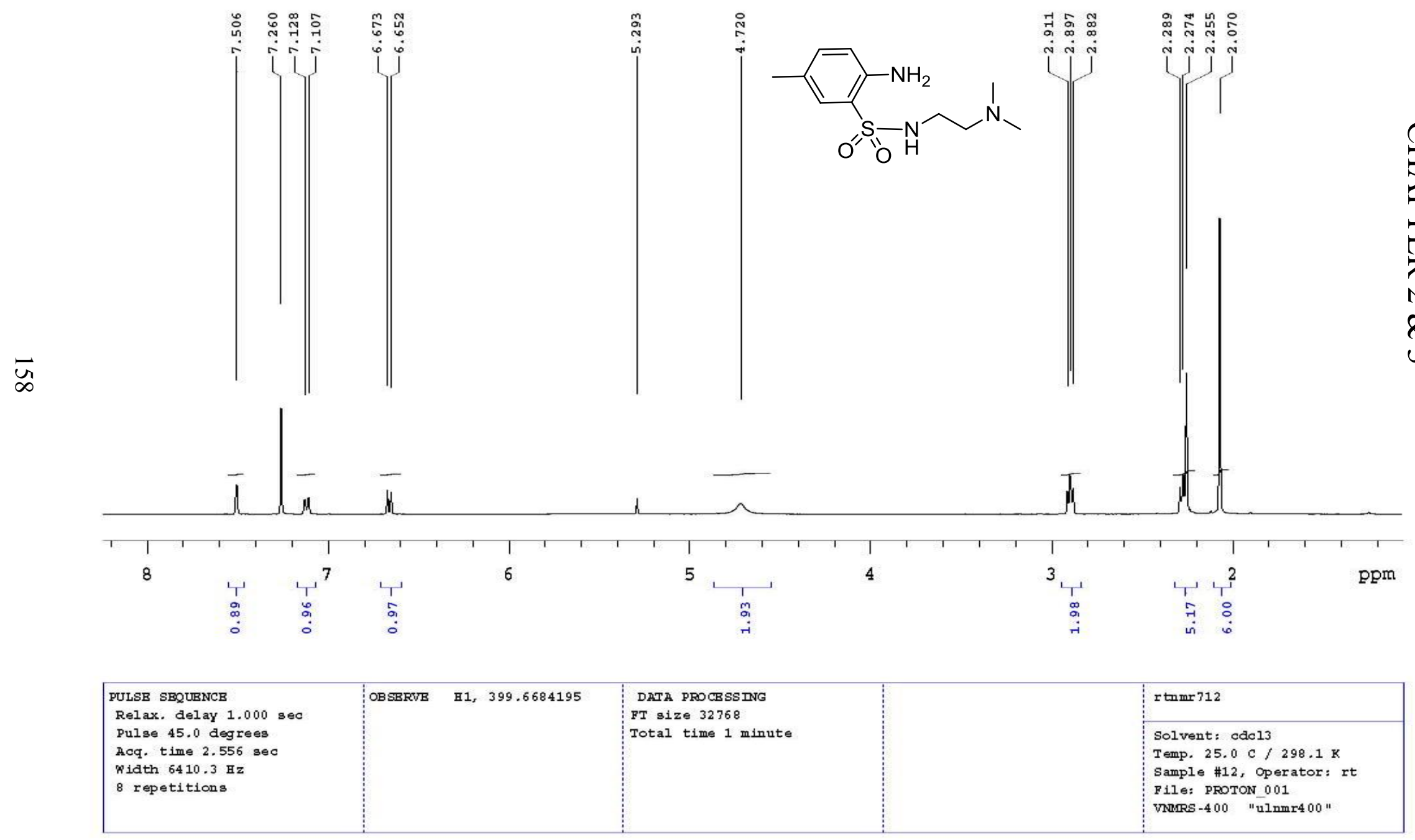




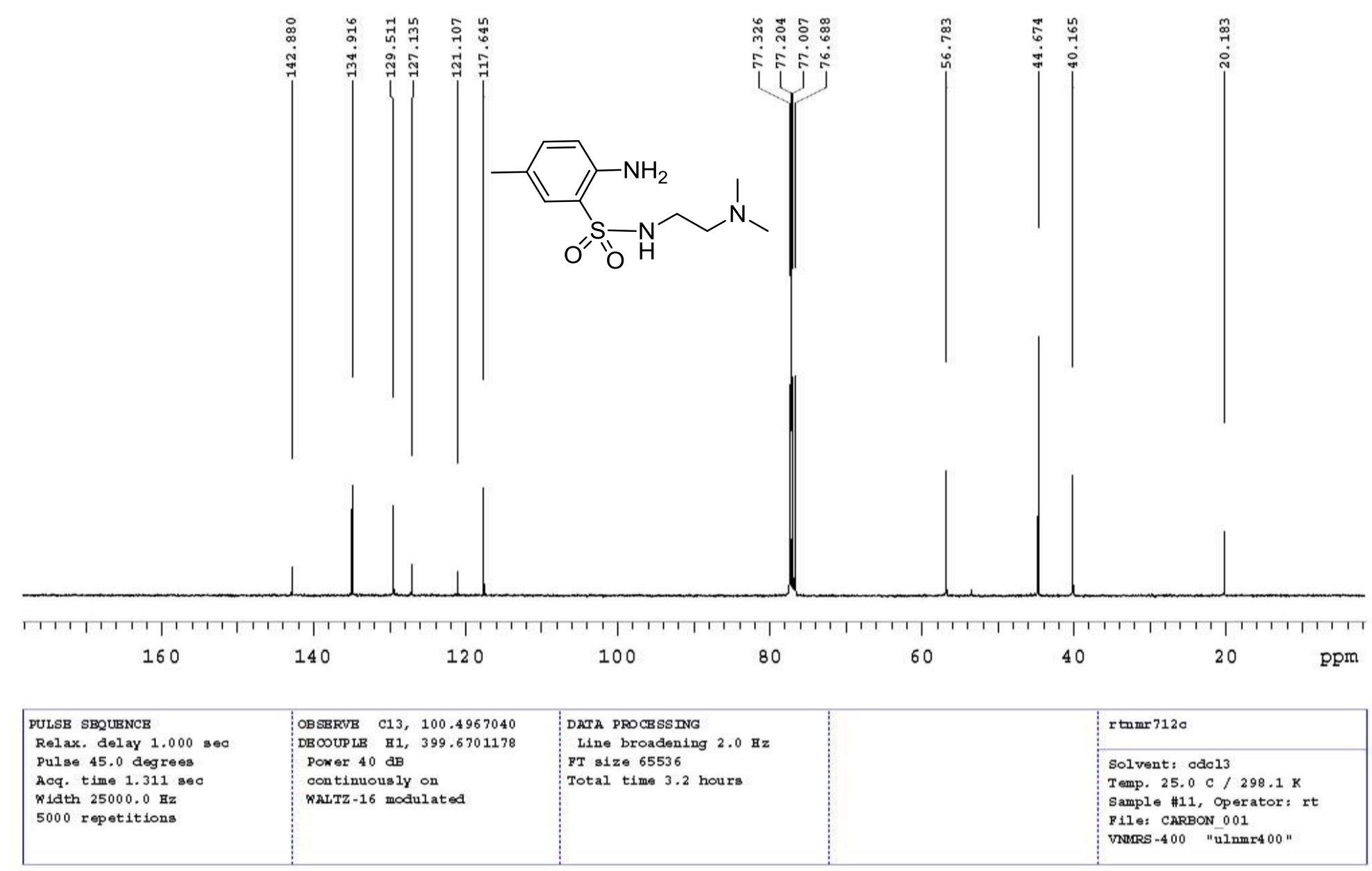




\section{rtnmr524}

Sample Name rtnmr524

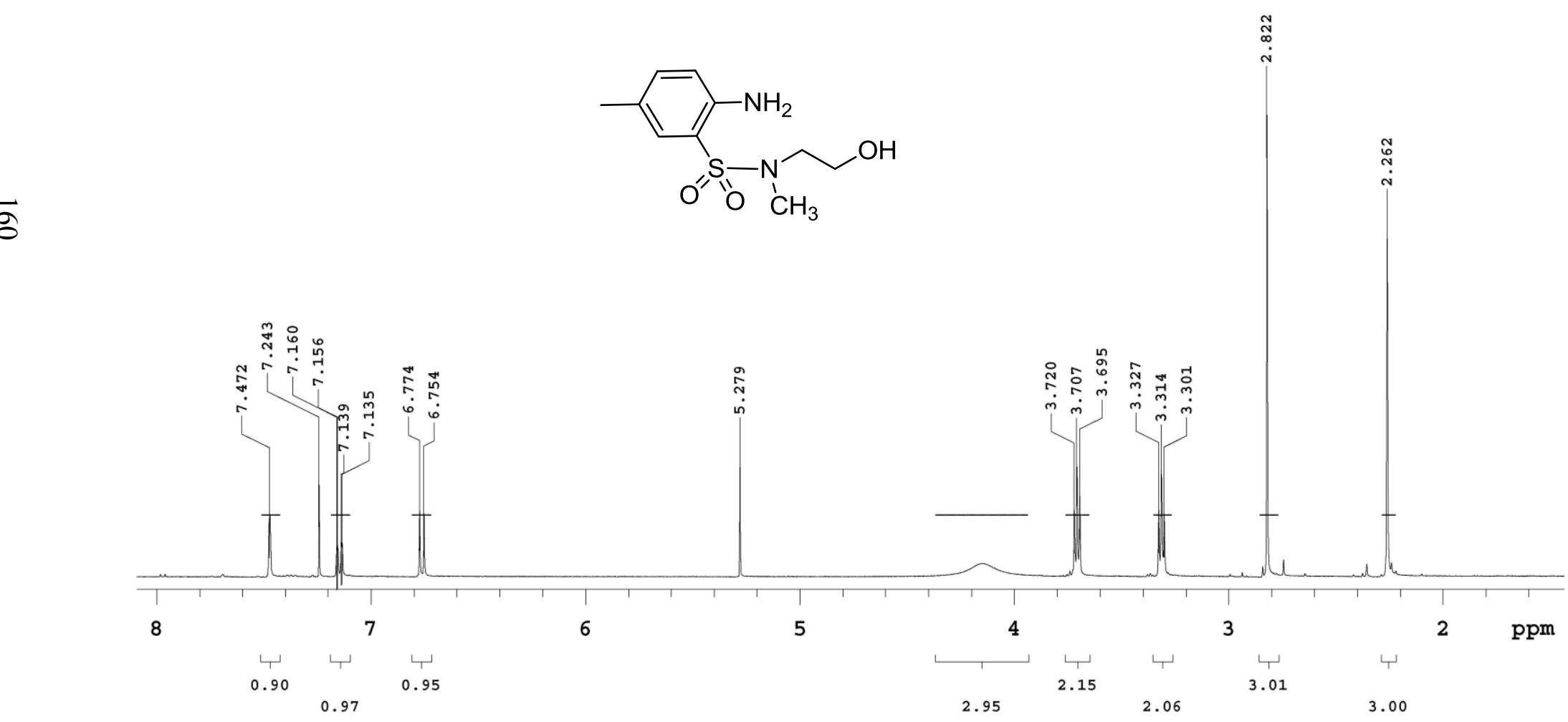


Study owner $n$

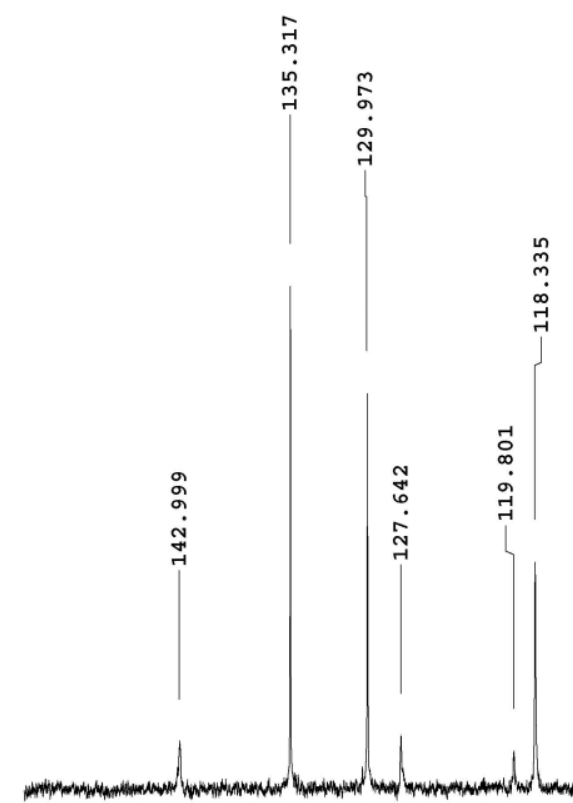

1.
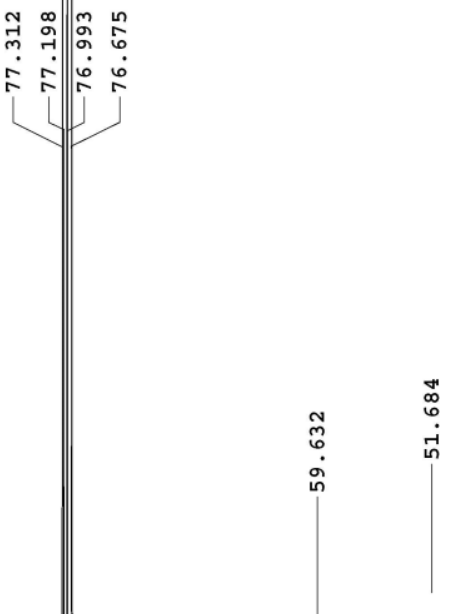


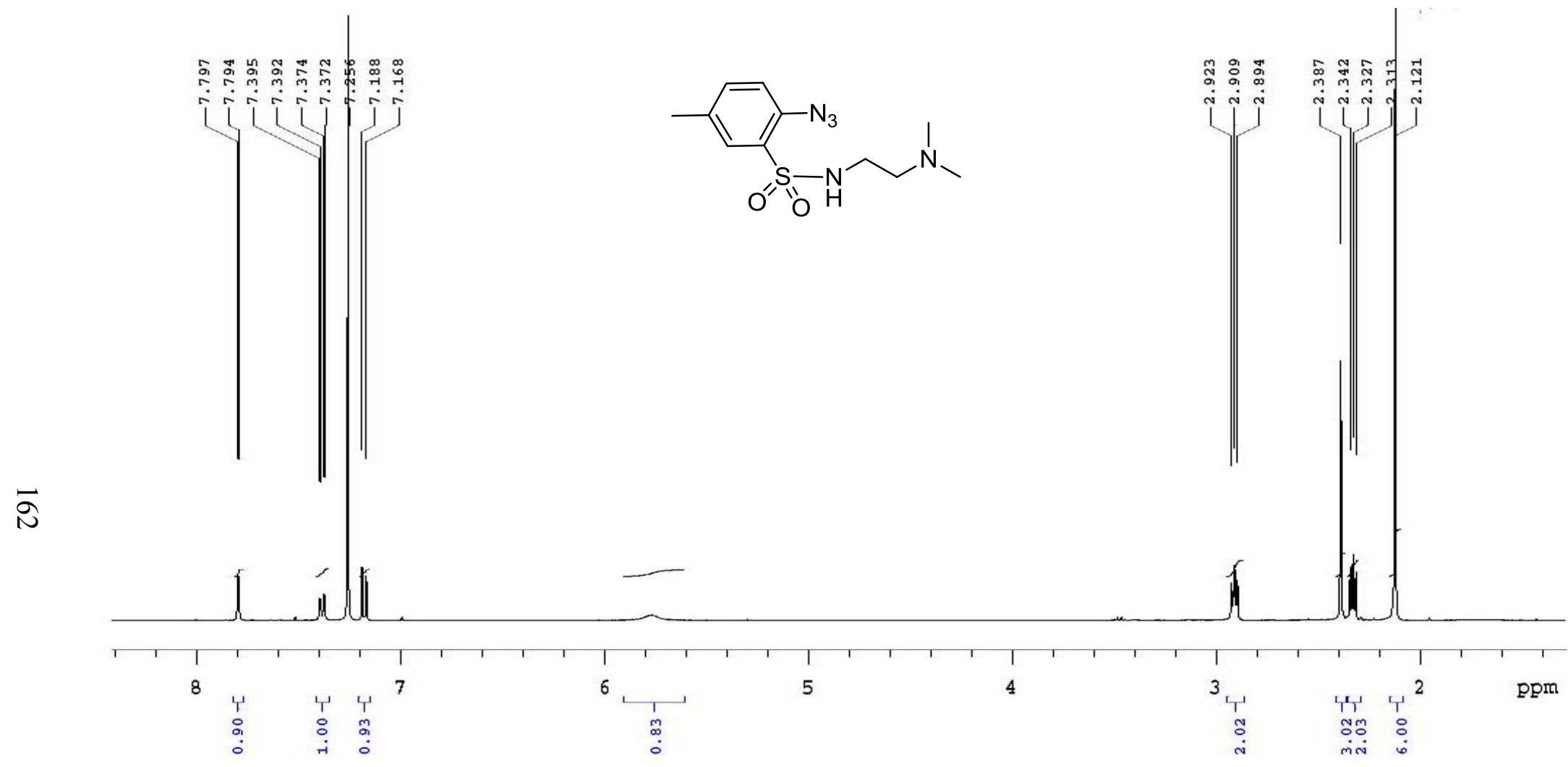

\begin{tabular}{|c|c|c|c|}
\hline $\begin{array}{l}\text { PULSB SEQUBNCB } \\
\text { Relax. delay } 1.000 \mathrm{sec} \\
\text { pulse } 45.0 \text { deg rees } \\
\text { Acq. time } 2.556 \mathrm{seC} \\
\text { Nidth } 6410.3 \mathrm{~Hz} \\
8 \text { repetitions }\end{array}$ & OBSBRVB H $1,399.6684195$ & $\begin{array}{l}\text { DATA PROCBSSING } \\
\text { FT size } 32768 \\
\text { Total time } 1 \text { minute }\end{array}$ & $\begin{array}{l}\text { rtamr } 313 \\
\text { Solvent: cdcl3 } \\
\text { Temp. } 25.0 \mathrm{c} / 298.1 \mathrm{~K} \\
\text { Operator: rt } \\
\text { File: PROTON } 001 \\
\text { VNMRS }-400 \text { "ulnmr } 400 \text { " }\end{array}$ \\
\hline
\end{tabular}



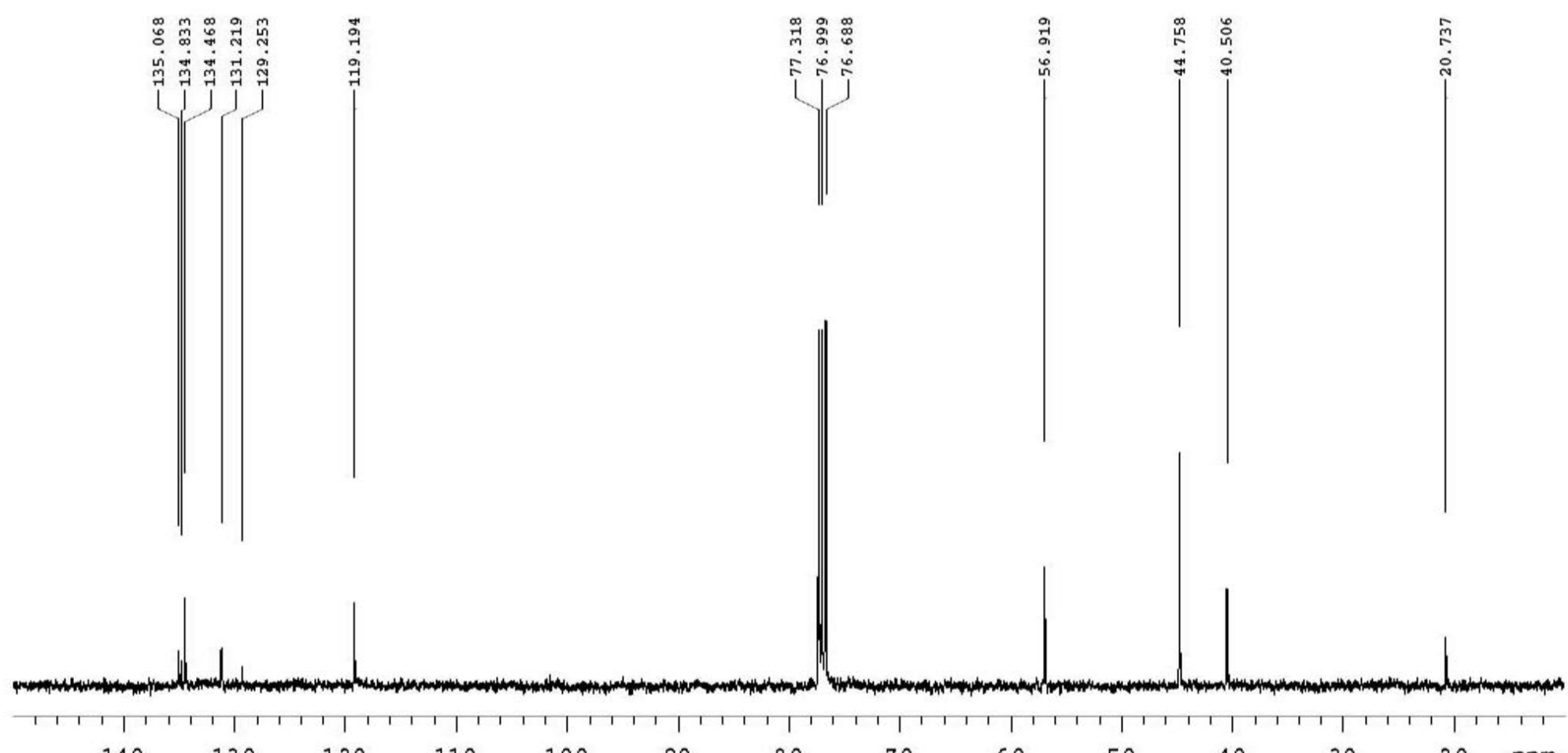

110

100

90

80

70

60

50

40

30

20 ppm

PULSB SEQUBNCB

Relax. delay $1.000 \mathrm{se}$

OBSBRVB $\quad$ C13, 100.4967040

DATA PEOCBSSING

Pulse 45.0 degrees

DECOUP LB H1, 399.6701178

Line broadening $2.0 \mathrm{~Hz}$

Acq. time $1.311 \mathrm{sec}$

Power 40 dB

512 repetitions

continuously on

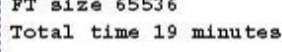

$r \tan 7130$

Solvent: ode13

Temp. $25.0 \mathrm{C} / 298.1 \mathrm{~K}$

Sample \#11, Operator: rt

File: CARBON 001

vNare -400 "ulnmr 400 " 


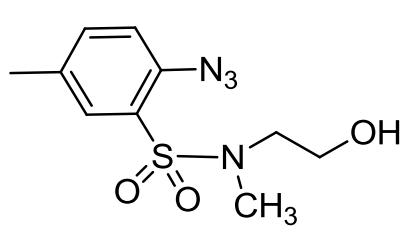

$\stackrel{\vec{\perp}}{+}$

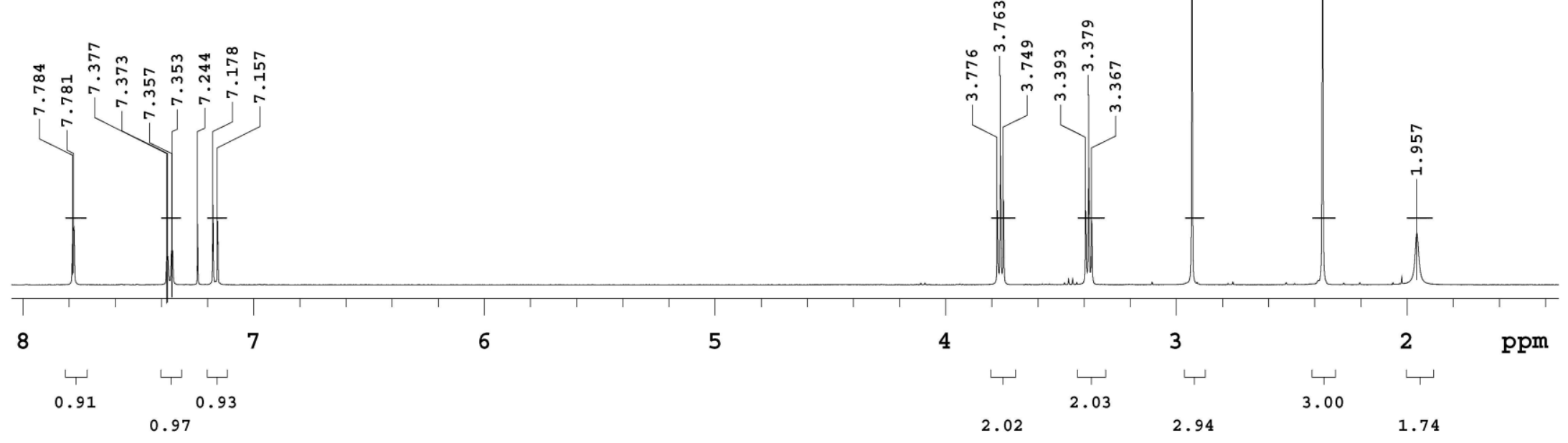


rtnmr534c

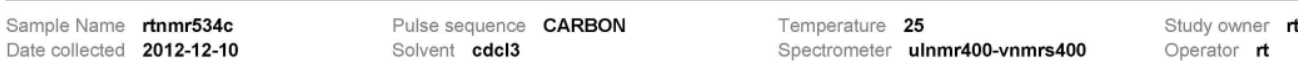

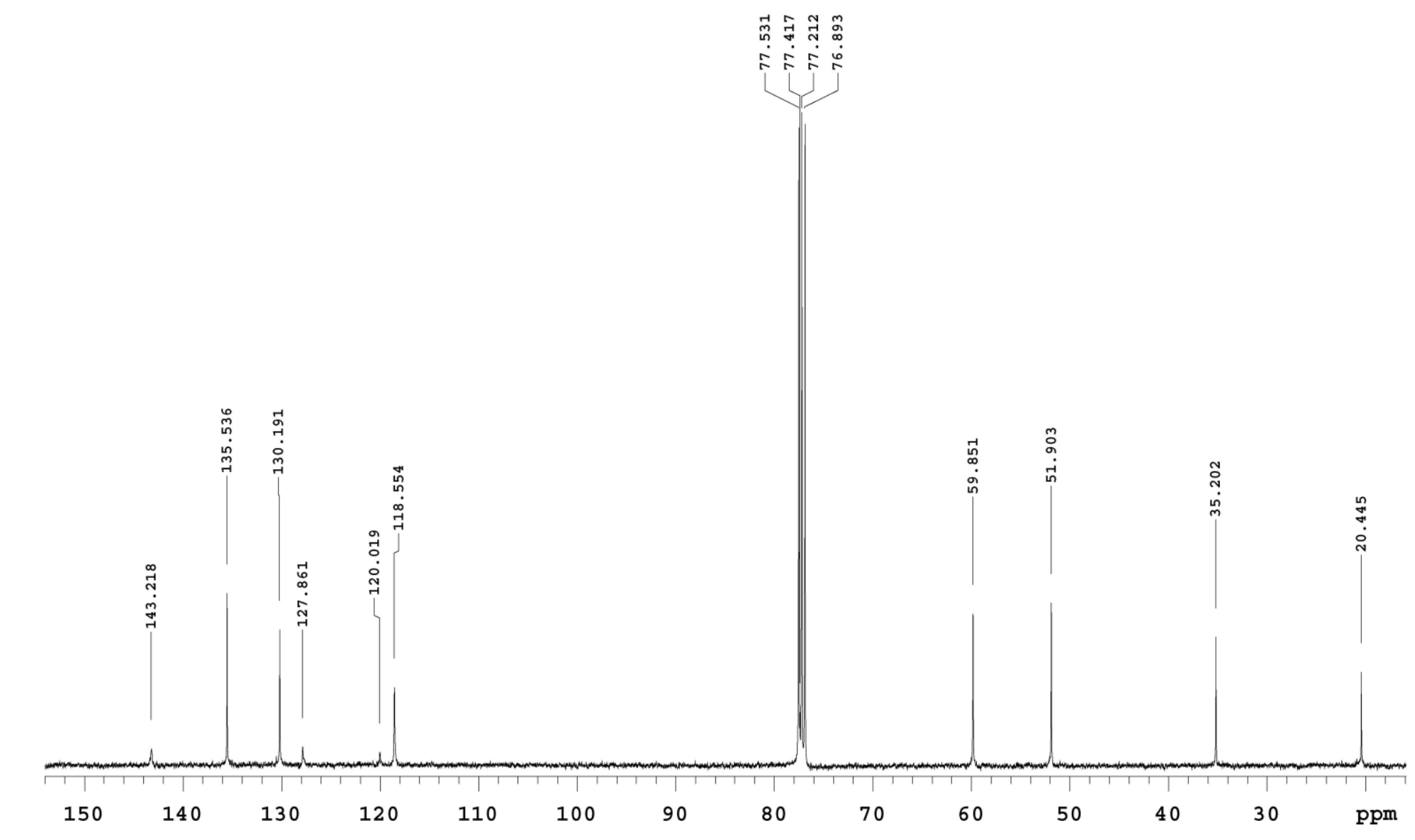




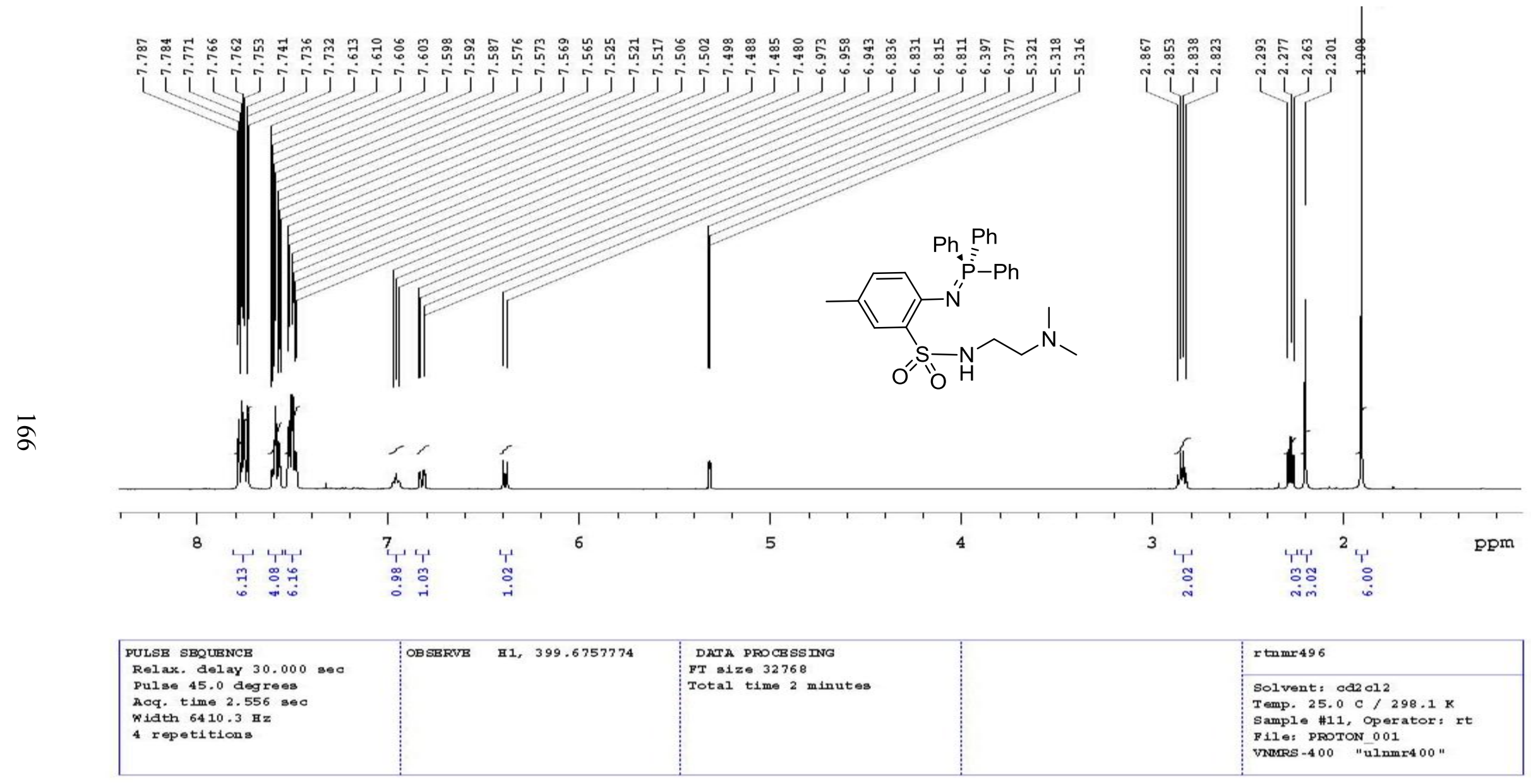




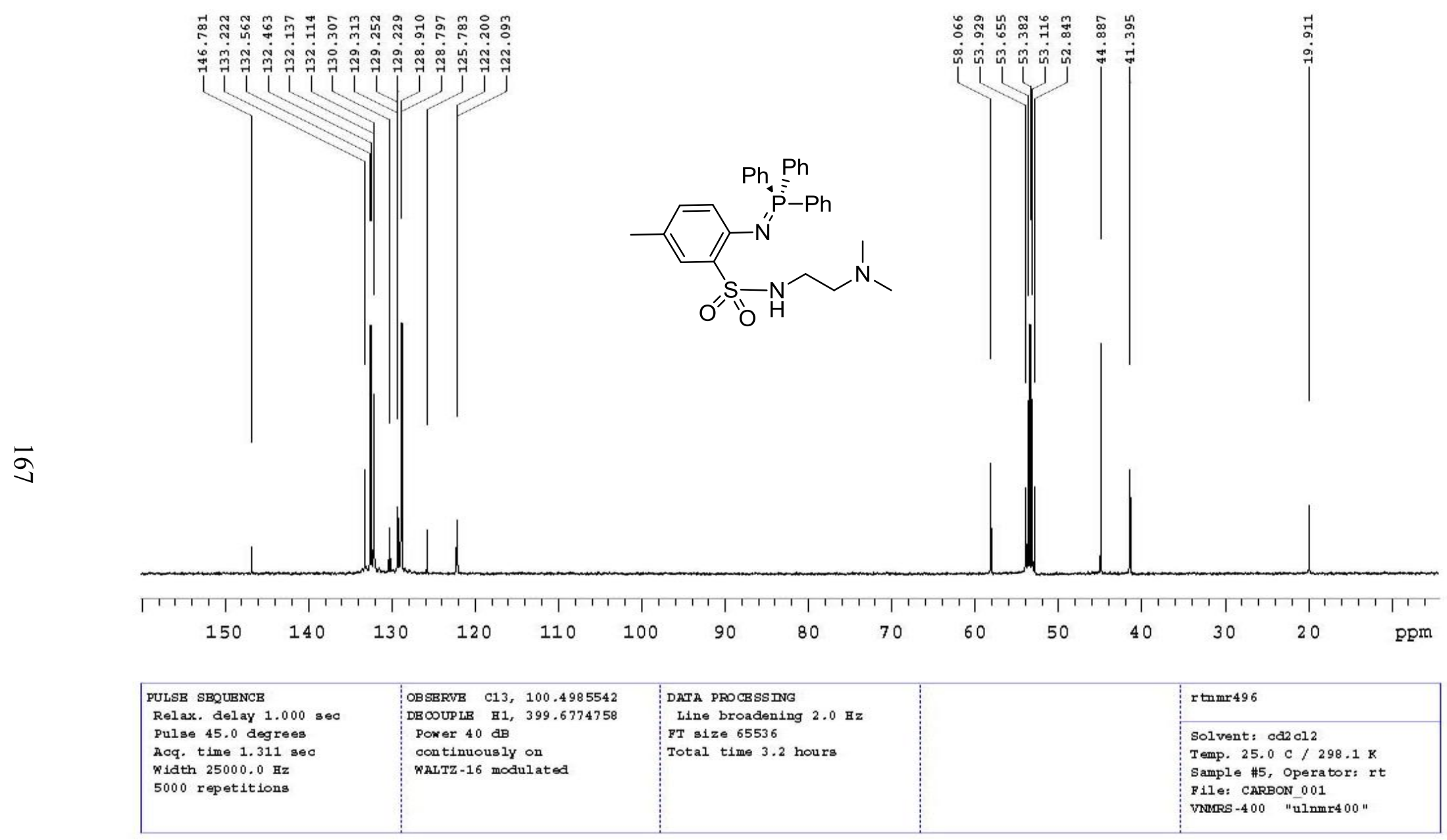



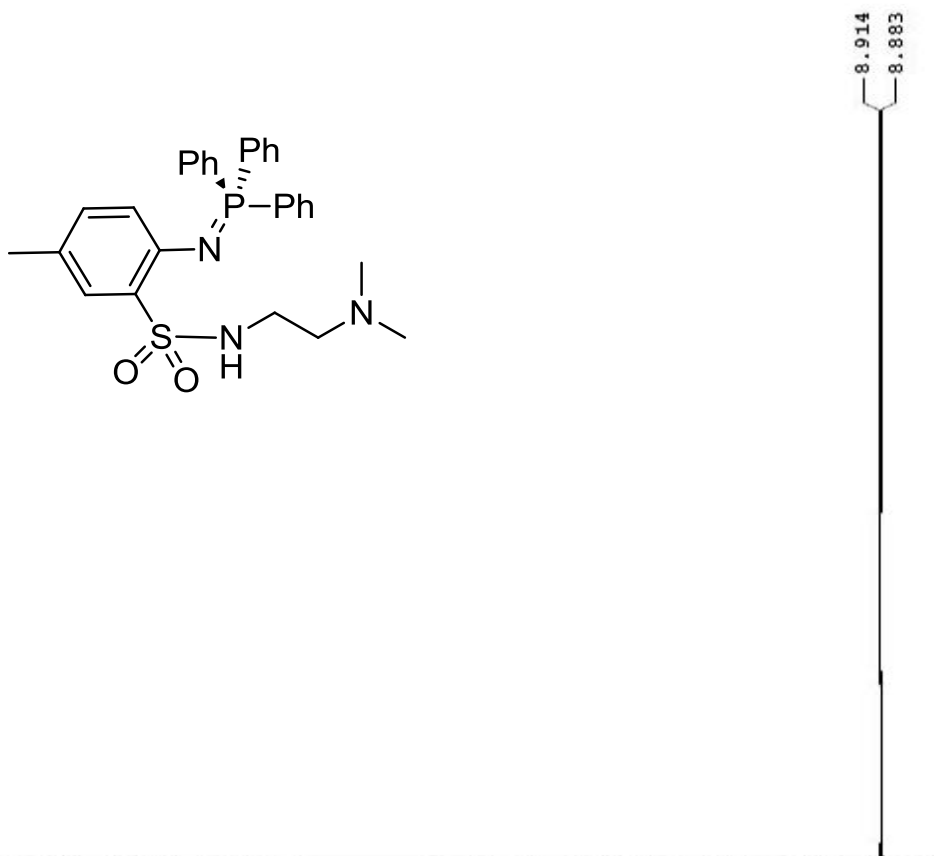

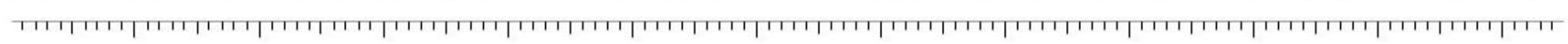
160 140

120

100

80

60

40

20

0

$-20$

ppm

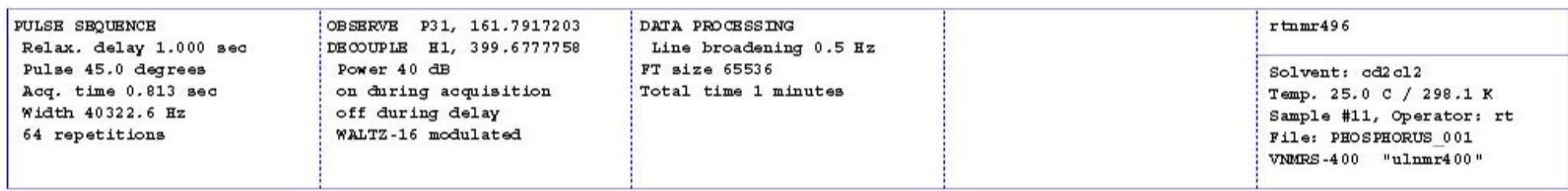




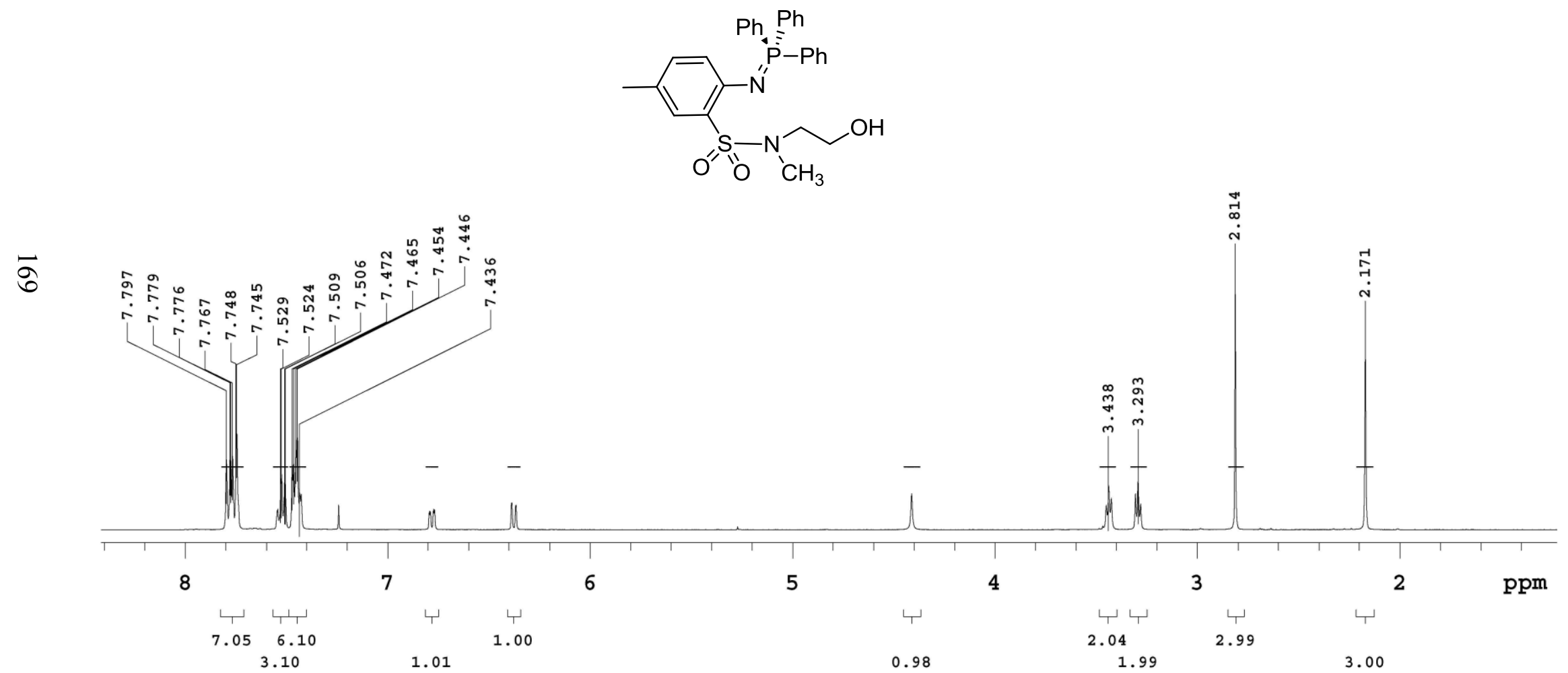


rtnmr516dry

Sample Name rtnmr516dry Pulse sequence CARBON Solvent $\mathbf{c d c | 3}$

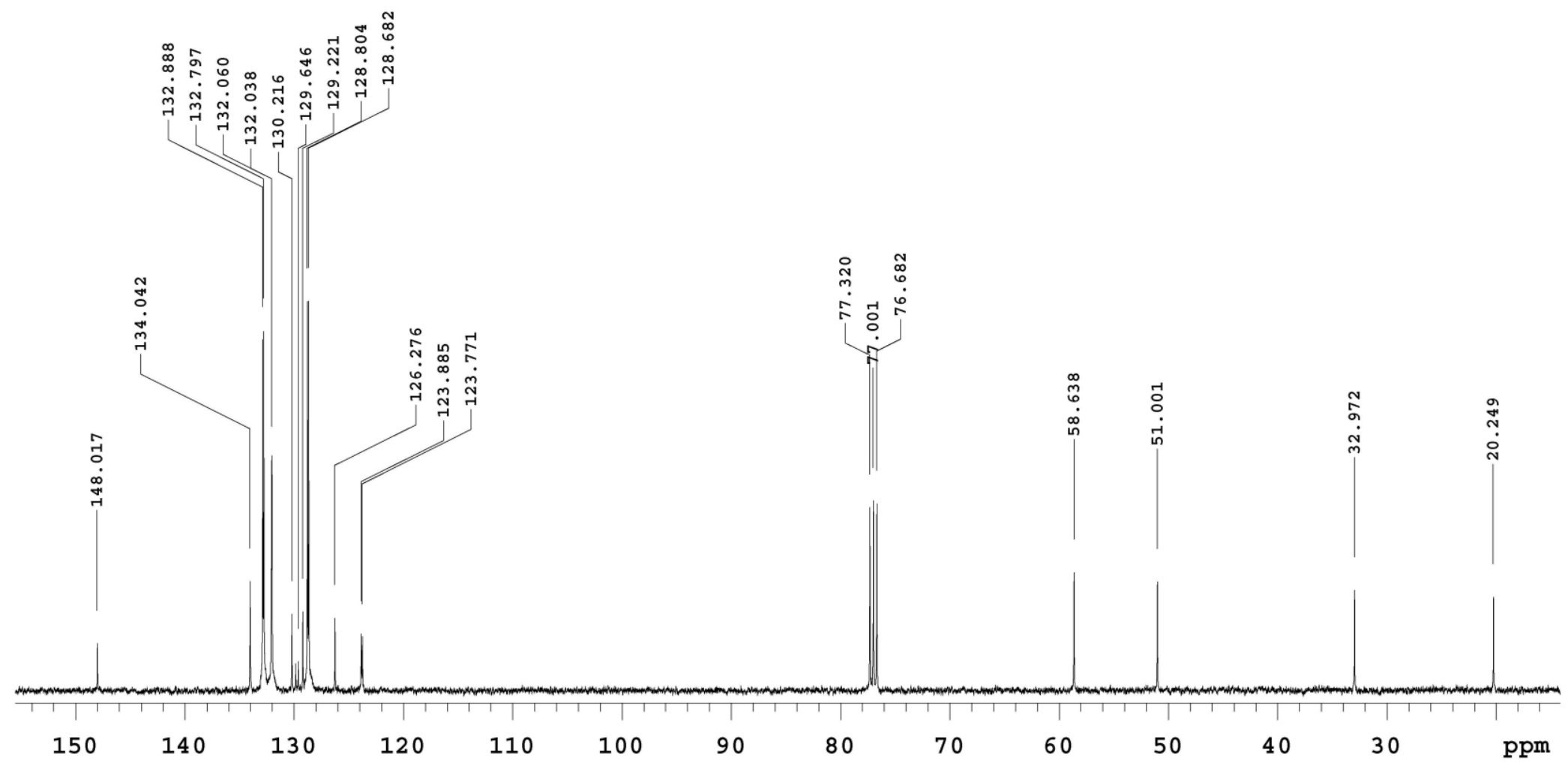




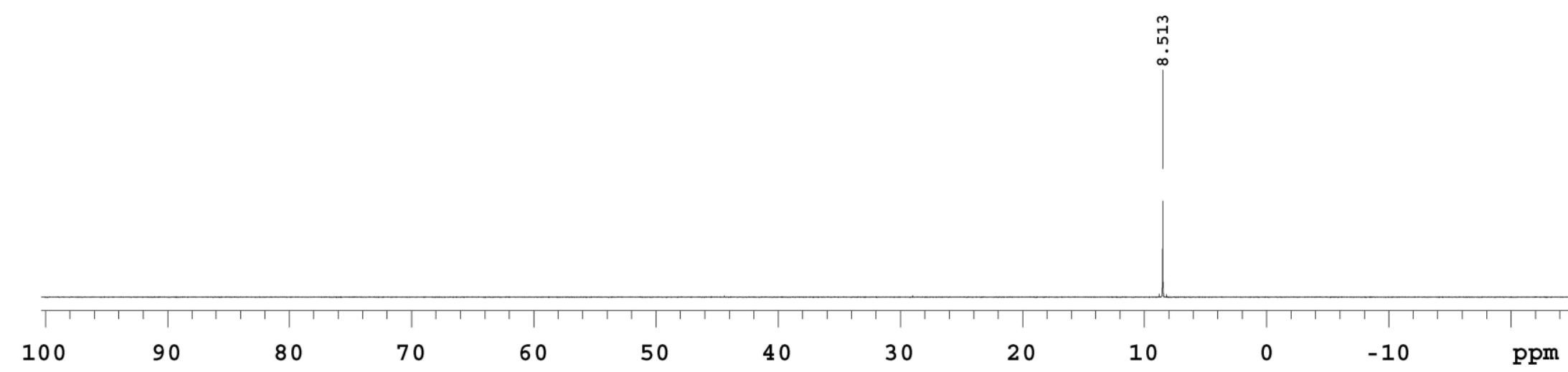




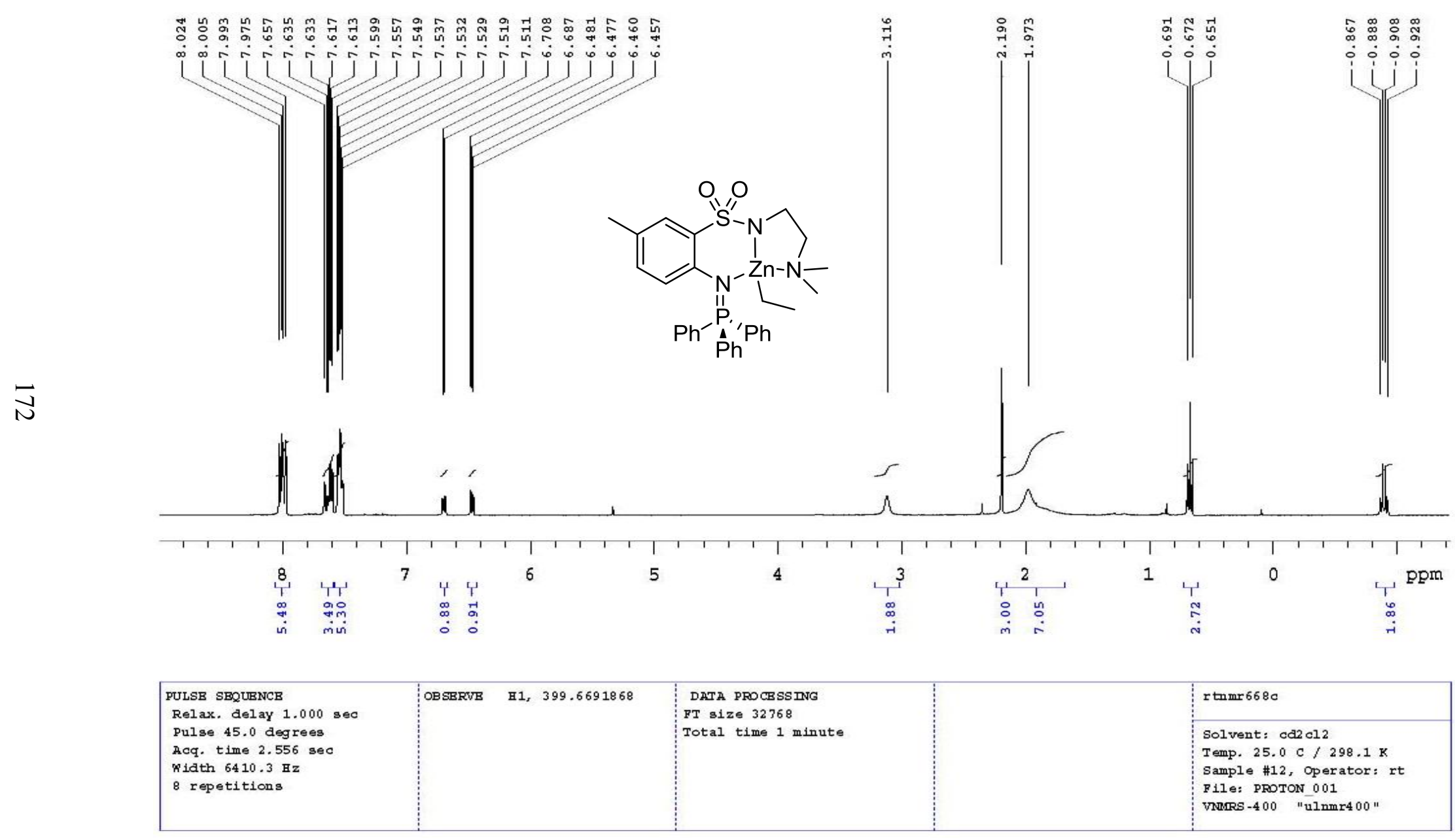




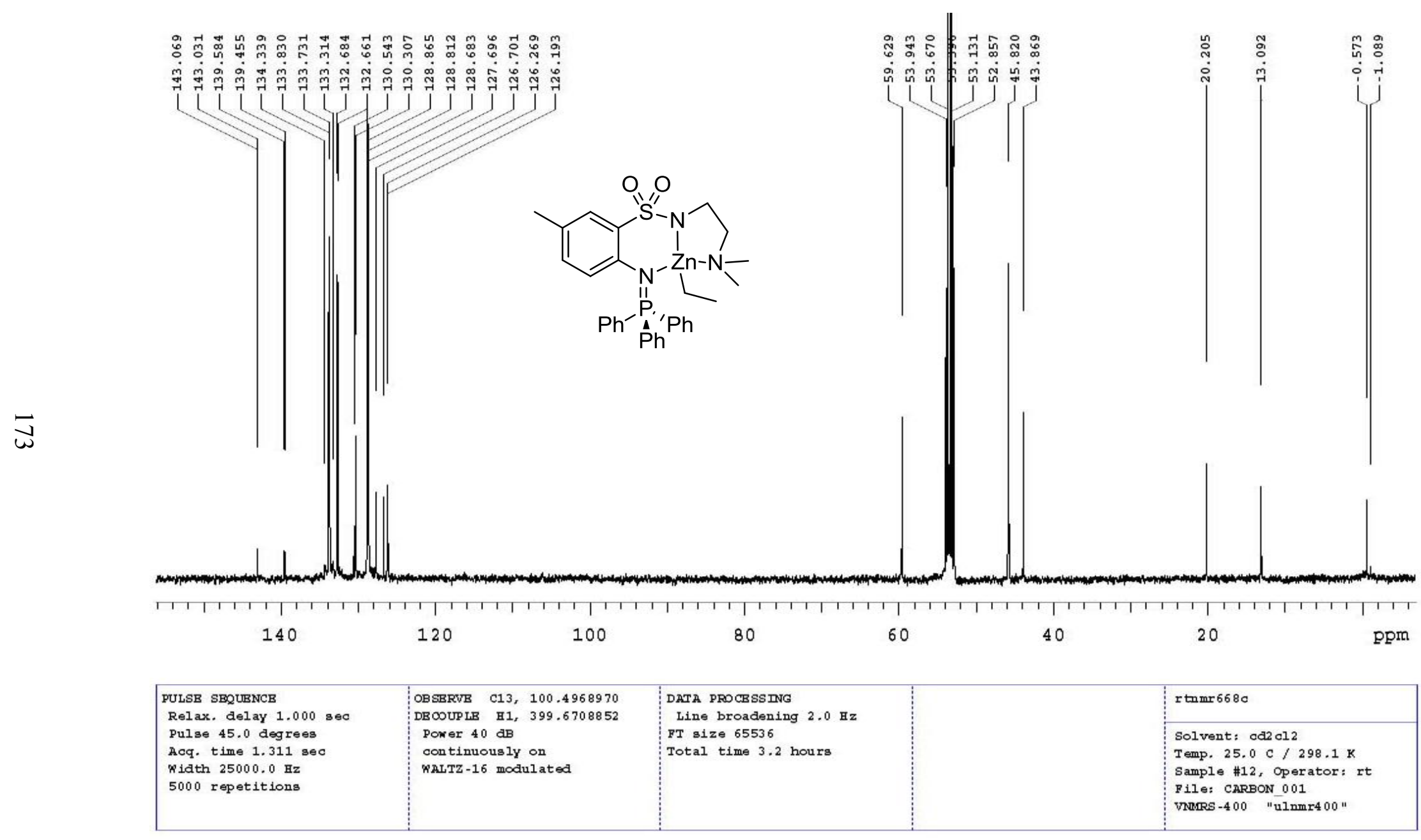



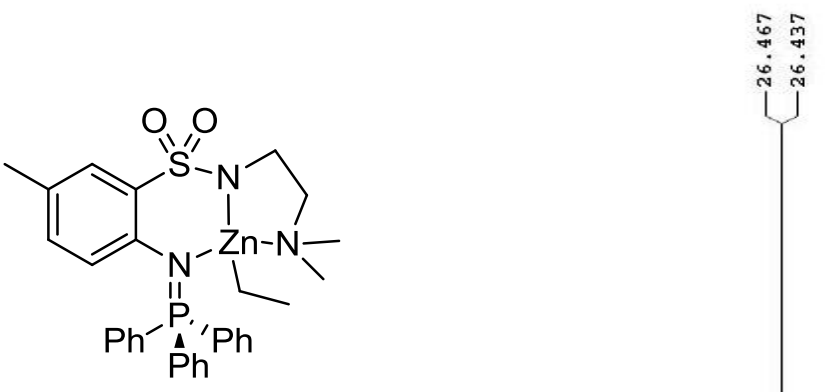

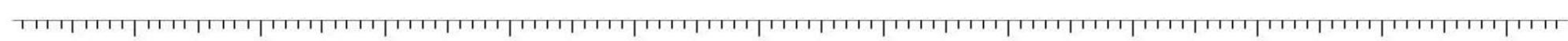
180 160 140 120 100 80 60 40 20

\begin{tabular}{|l|} 
PULSB SBQUBNCB \\
Relax. delay $1.000 \mathrm{sec}$ \\
Pulse 45.0 degrees \\
Acq. time $0.813 \mathrm{sec}$ \\
Nidth $40322.6 \mathrm{~Hz}$ \\
64 repetitions \\
\end{tabular}

OBSBRVB P31, 161.3890524
DBOOUPLB H1, 399.6711852
PONer 40 dB
on during acquisition
off during delay
NALTZ-16 modulated

DATA PROCBSSING
Line broadening $0.5 \mathrm{~Hz}$
FT size 65536
Total time 1 minutes

Solvent: od2c12

Temp. $25.0 \mathrm{C} / 298.1 \mathrm{~K}$

Sample \#5, Operator: r

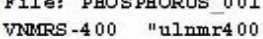




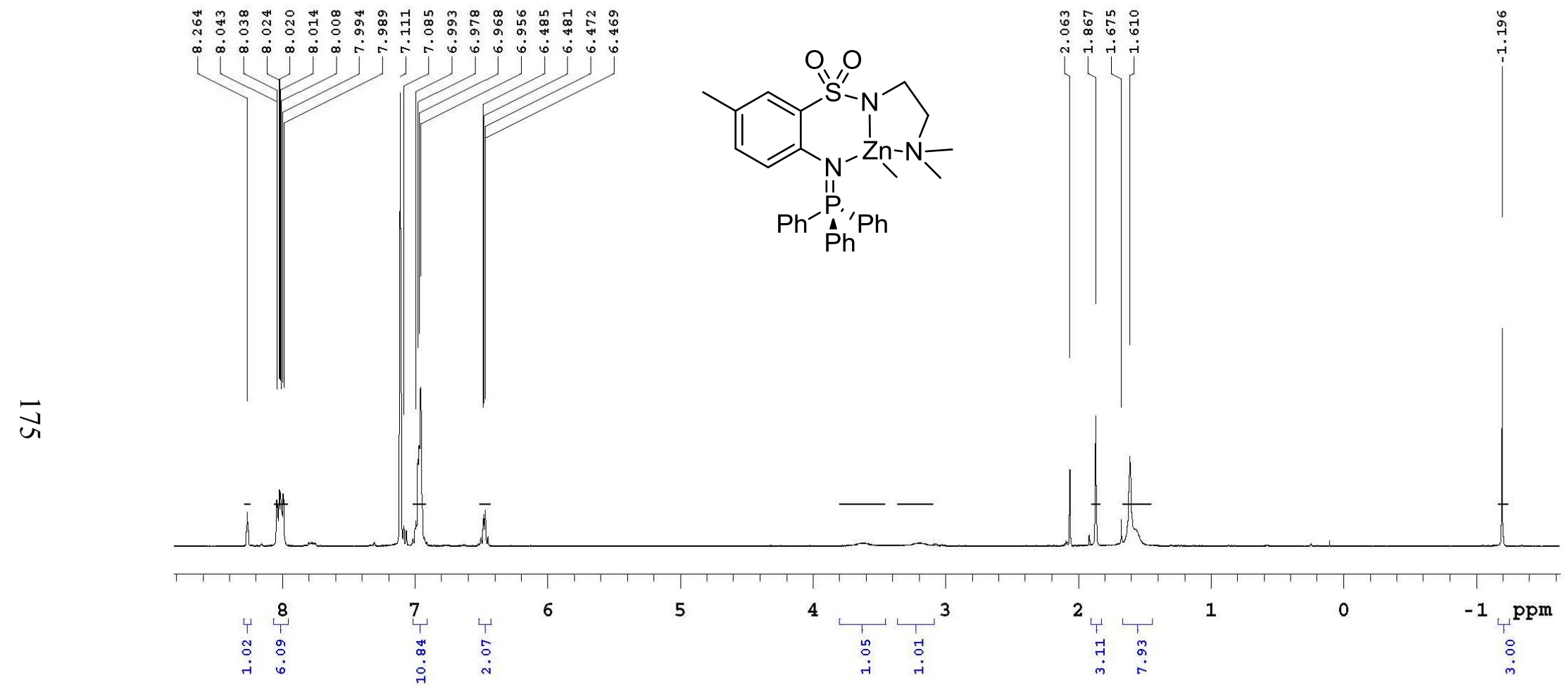

\begin{tabular}{|c|c|c|c|}
\hline $\begin{array}{l}\text { PULSE SEQUENCE } \\
\text { Relax. delay } 30.000 \mathrm{sec} \\
\text { Pulse } 45.0 \text { degrees }\end{array}$ & OBSERVE $\quad$ H1, 399.6295263 & $\begin{array}{l}\text { DATA PROCESSING } \\
\text { FT size } 32768 \\
\text { Total time } 2 \text { minutes }\end{array}$ & rtnmr1124 \\
\hline $\begin{array}{l}\text { Acq. time } 2.556 \mathrm{sec} \\
\text { Width } 6410.3 \mathrm{~Hz} \\
4 \text { repetitions }\end{array}$ & & & $\begin{array}{l}\text { Solvent: c6d6 } \\
\text { Temp. } 25.0 \mathrm{C} / 298.1 \mathrm{~K} \\
\text { Sample \#7, Operator: } \mathrm{rt} \\
\text { File: PROTON_001 } \\
\text { VNMRS-400 "ulnmr } 400 "\end{array}$ \\
\hline
\end{tabular}




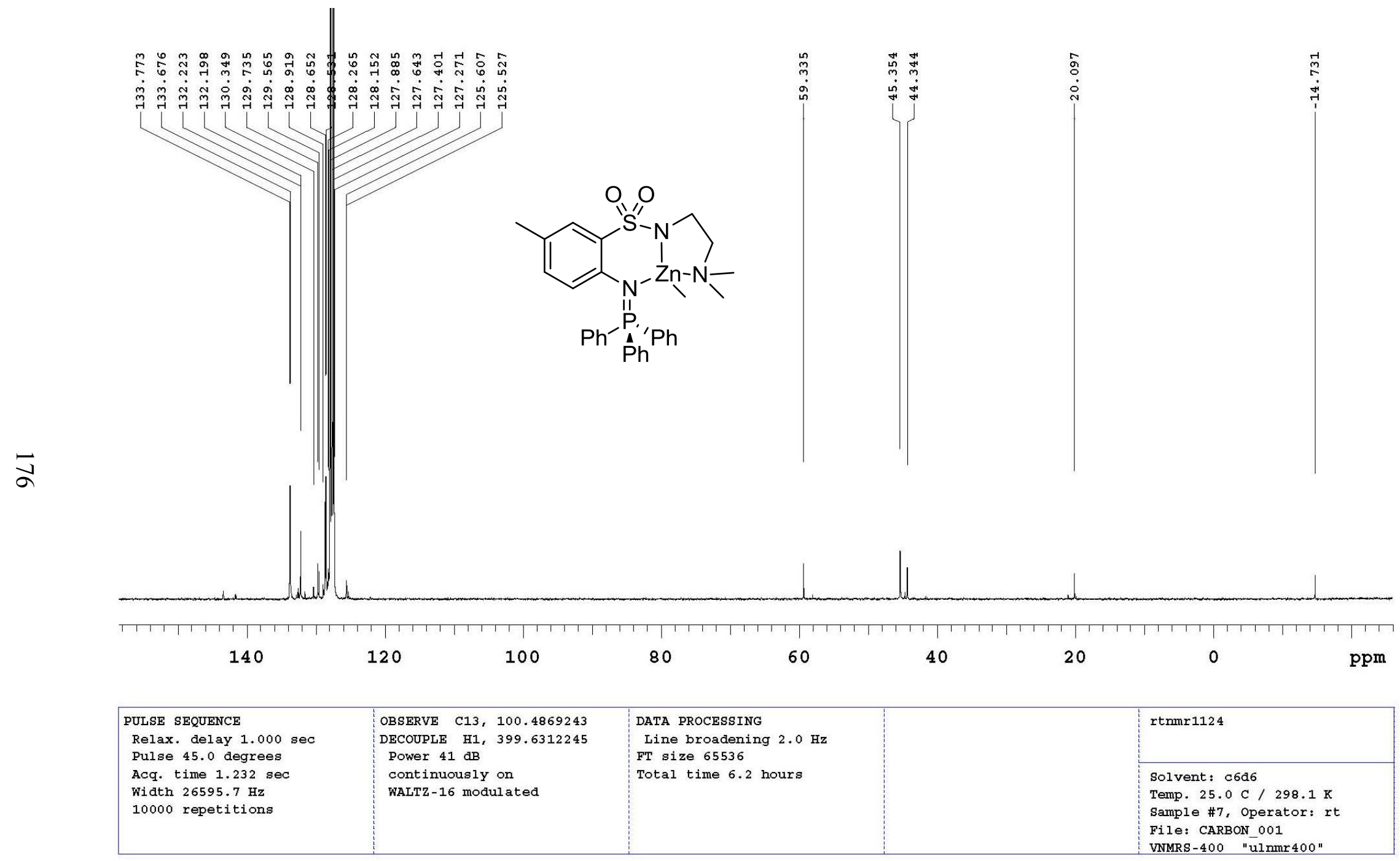



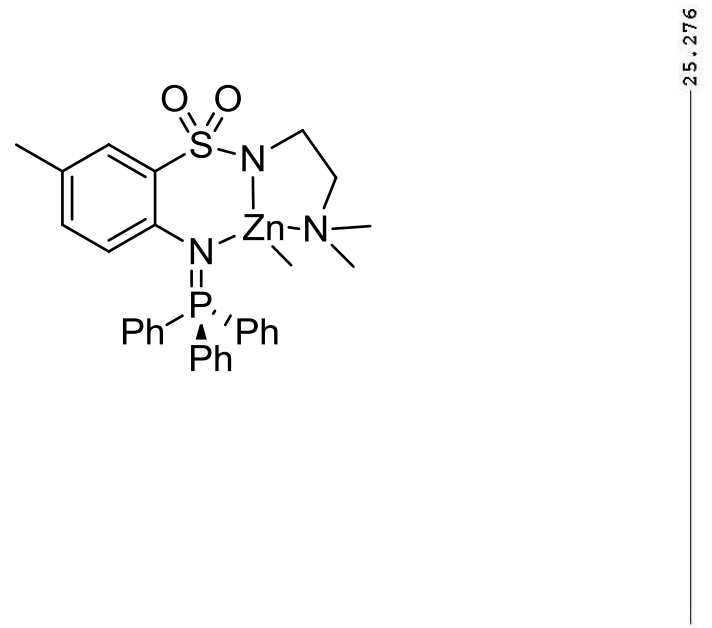

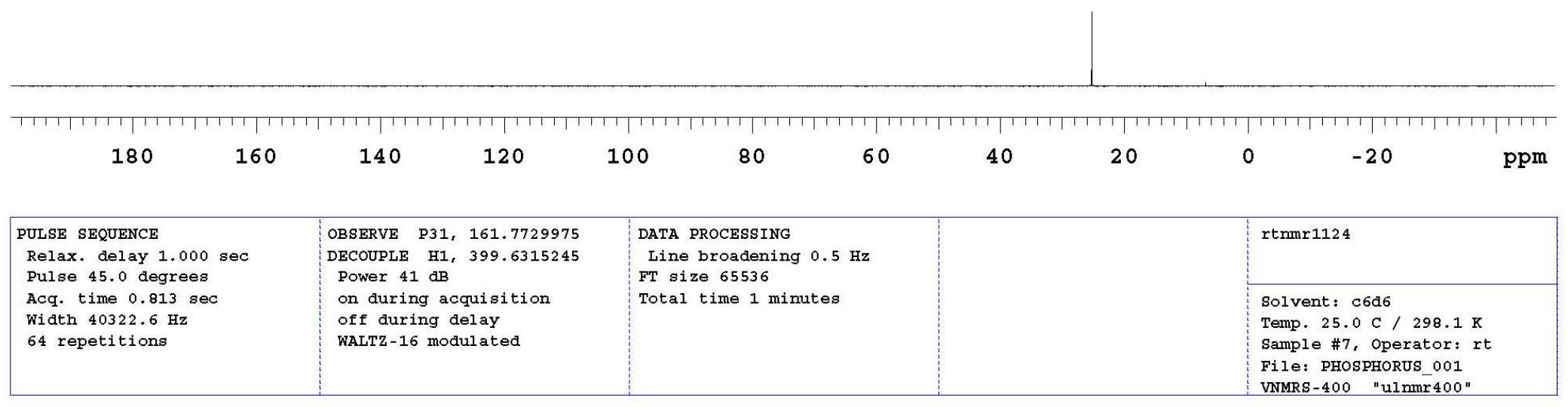



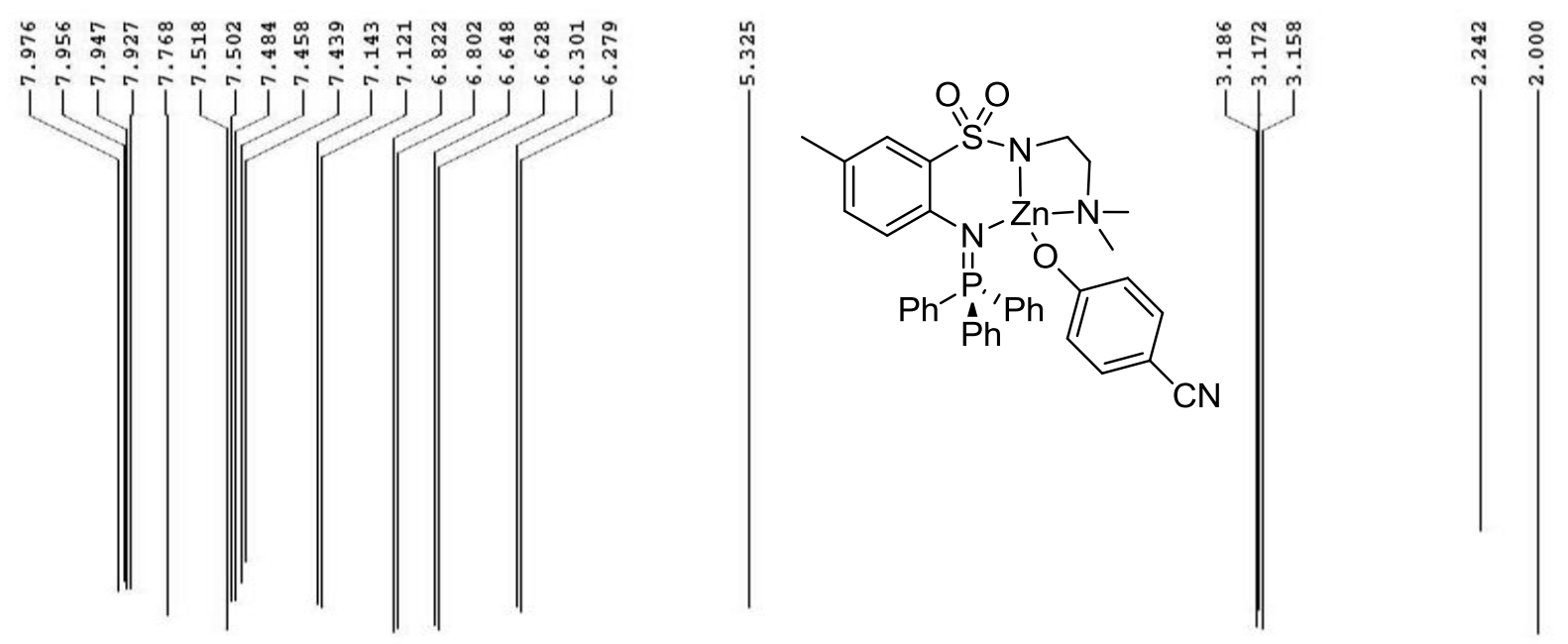

స

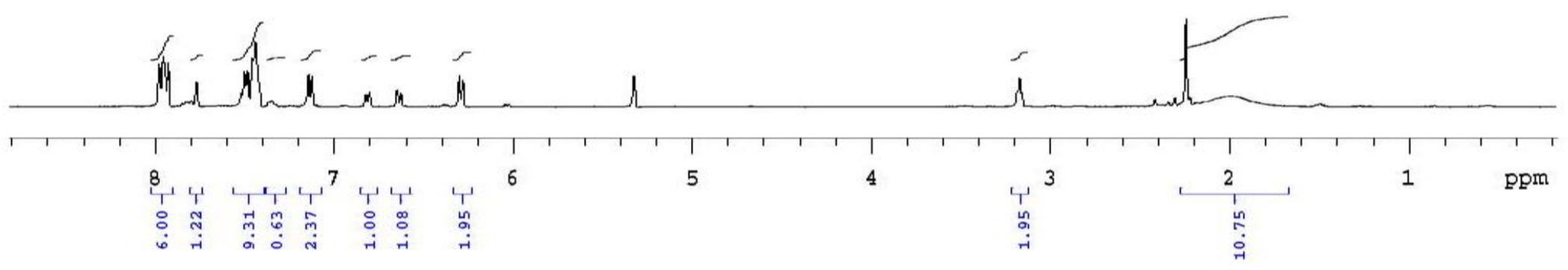

\begin{tabular}{|c|c|c|c|}
\hline $\begin{array}{l}\text { PULSB SEQUBNCB } \\
\text { Relax. delay } 30.000 \mathrm{sec} \\
\text { pulse } 45.0 \text { degrees } \\
\text { Acq. time } 2.556 \mathrm{sec} \\
\text { Pidth } 6410.3 \mathrm{~Hz} \\
4 \text { repetitions }\end{array}$ & OBSBRVB $\quad$ H1，399.6619266 & $\begin{array}{l}\text { DATA PROCBSSING } \\
\text { FT size } 32768 \\
\text { Total time } 2 \text { minutes }\end{array}$ & $\begin{array}{l}\text { rtamr } 358 \\
\text { Solvent: od } 2 \text { c12 } \\
\text { Temp. 25.0 C/298.1 K } \\
\text { Sample \#91, Operator: rt } \\
\text { Pile: PROTON_001 } \\
\text { VNARS -400 "ulnmr400" }\end{array}$ \\
\hline
\end{tabular}




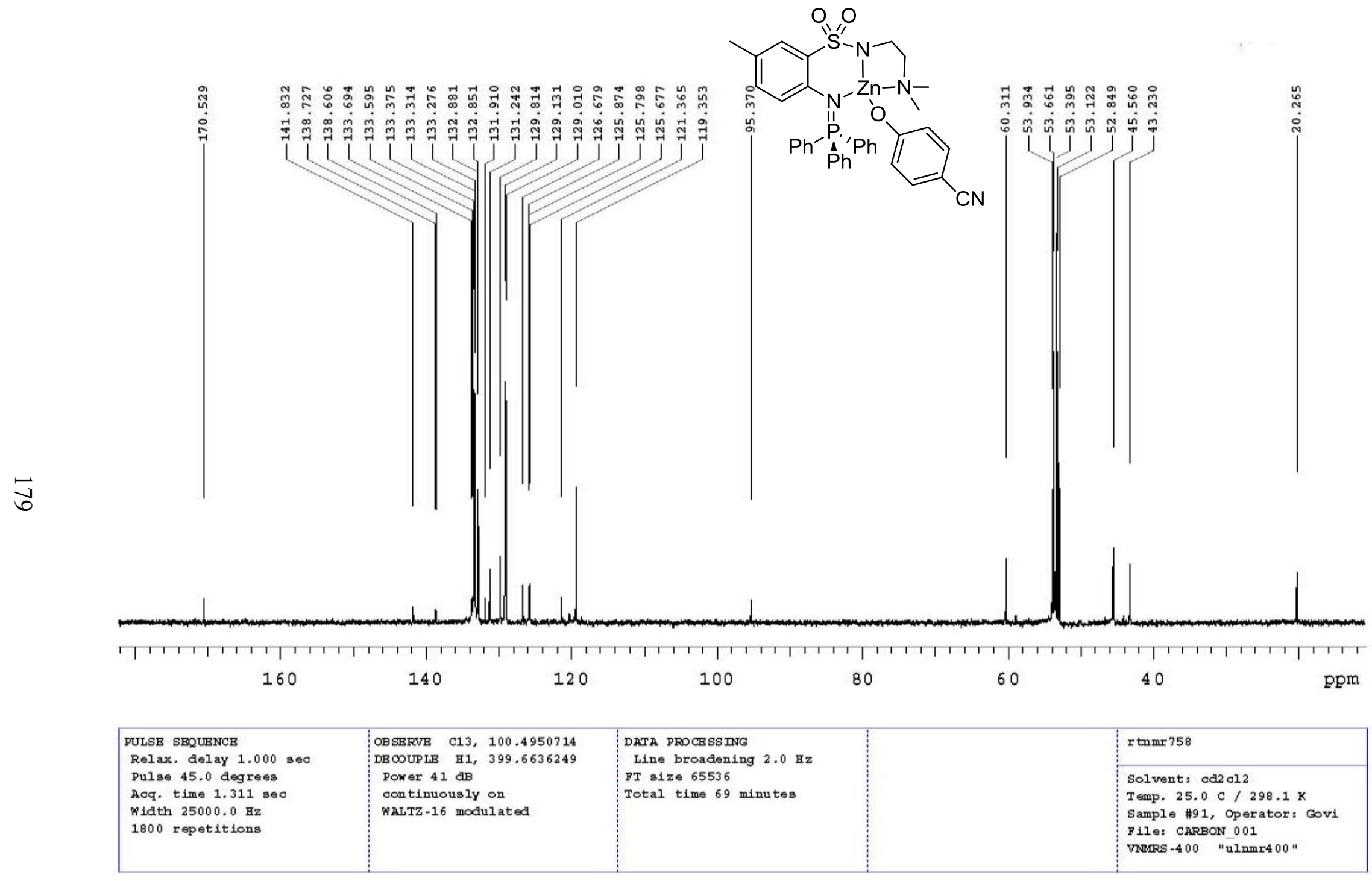



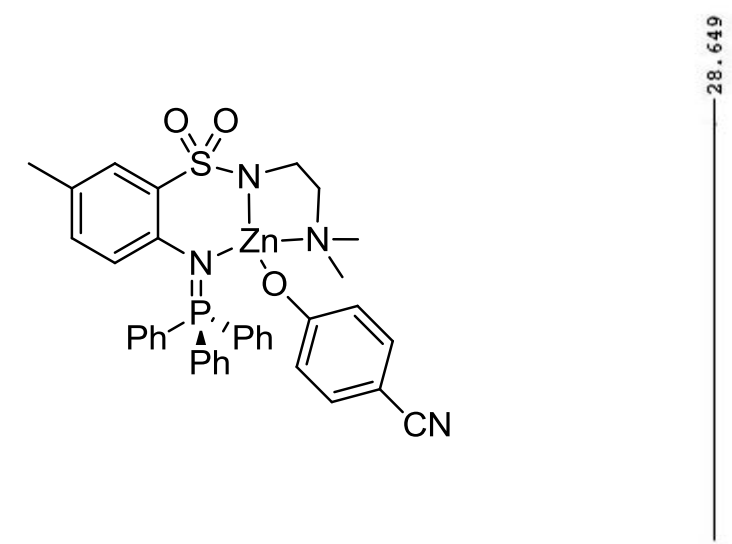

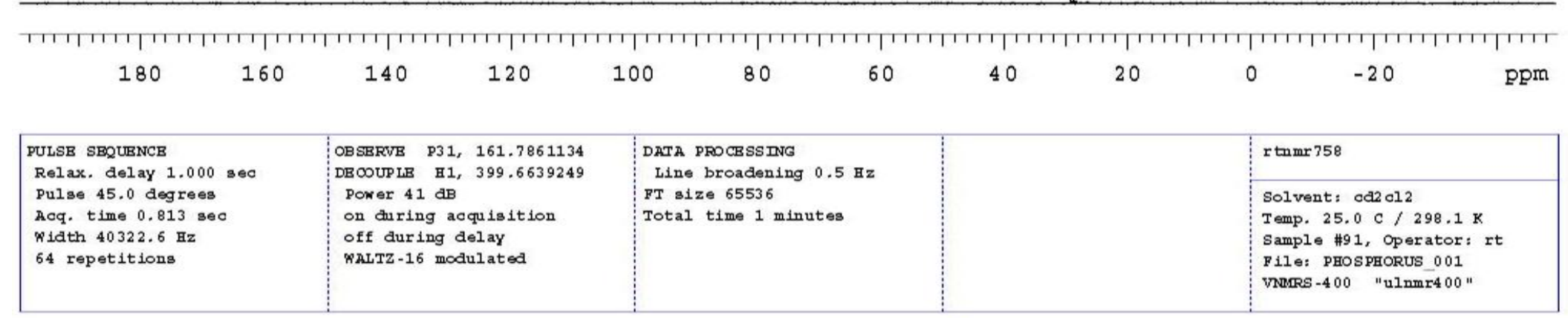




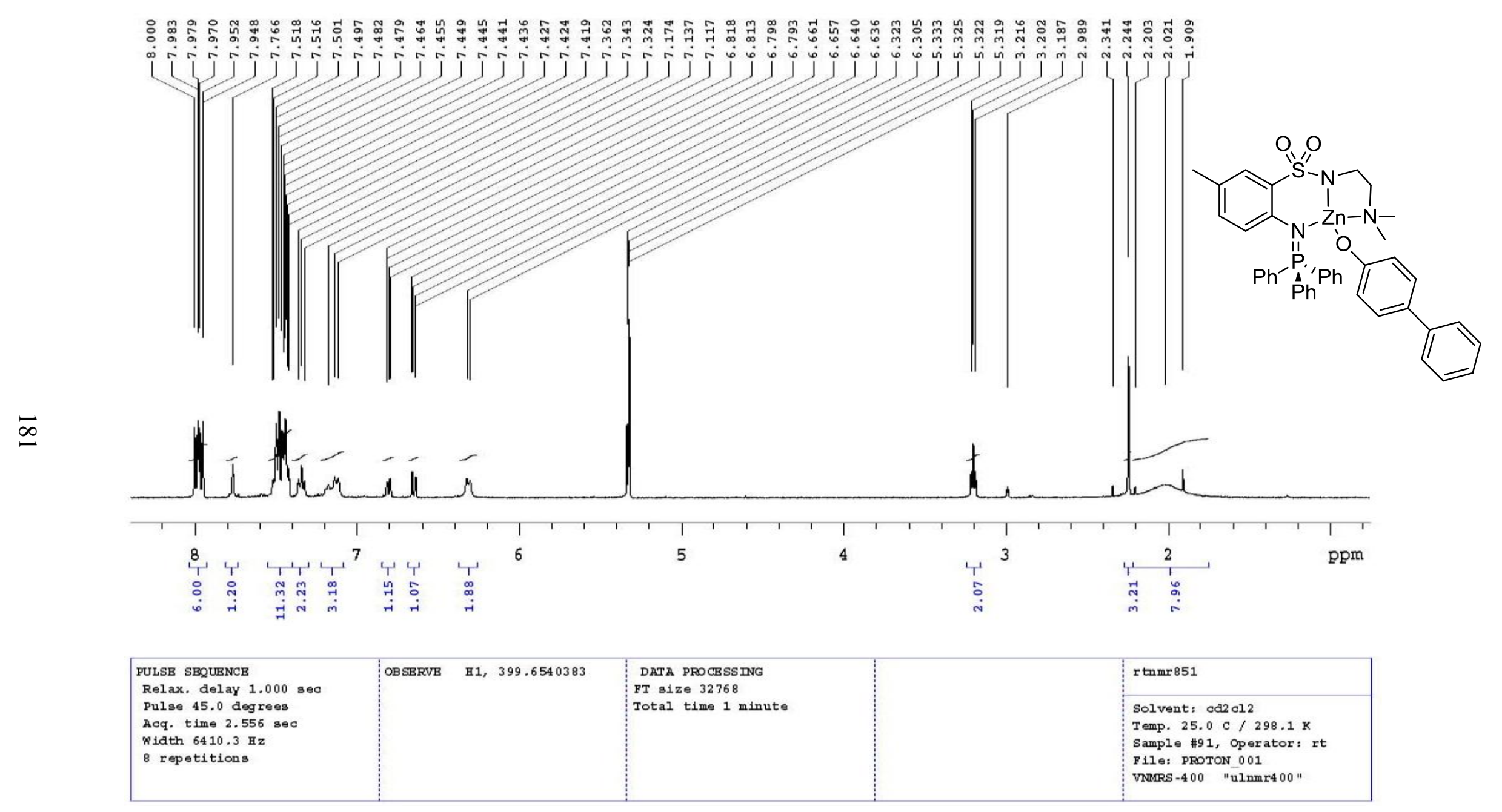




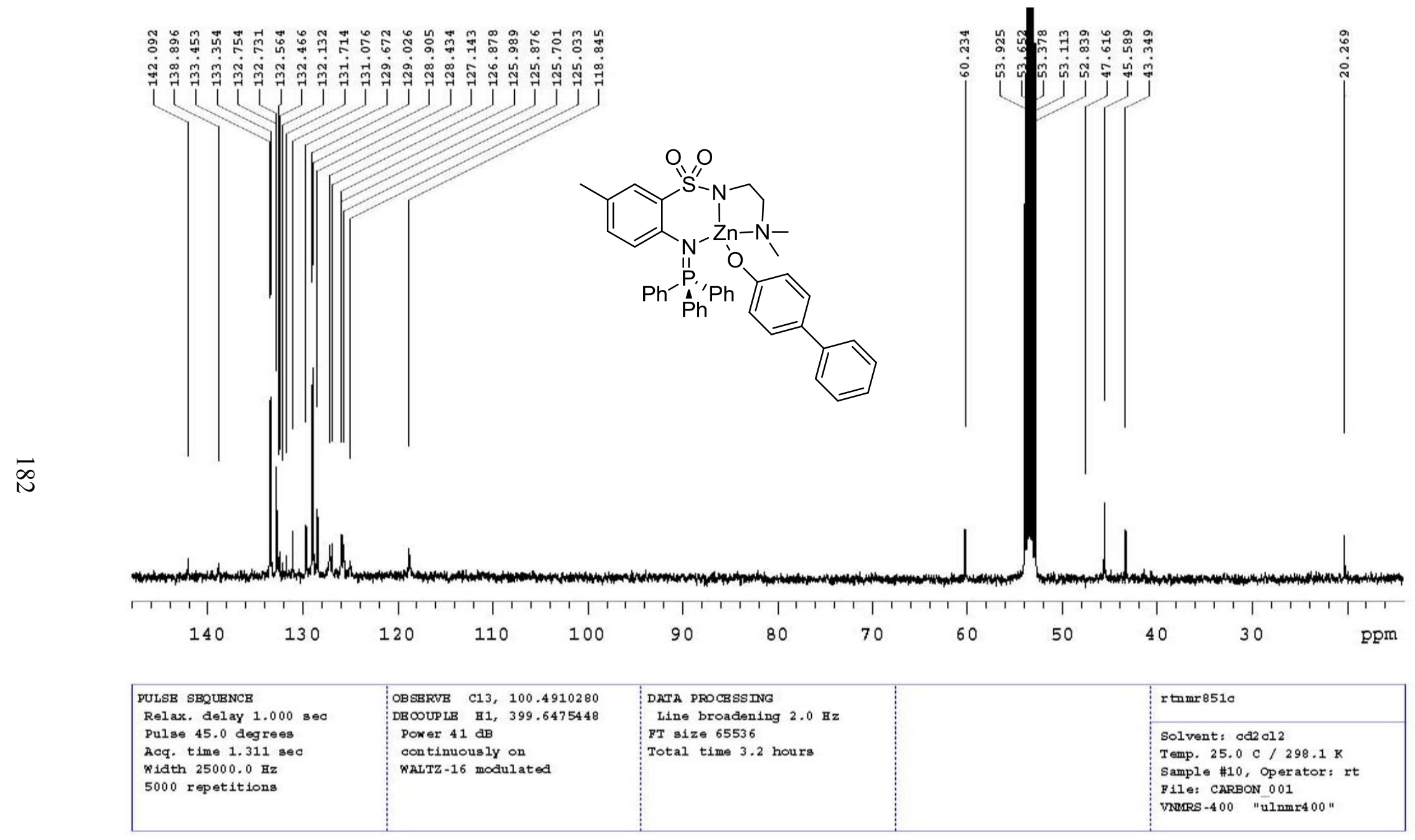




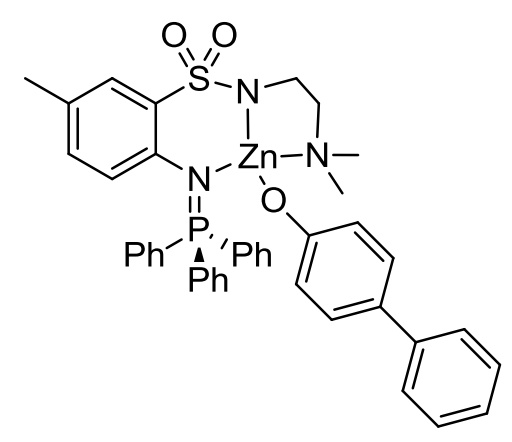

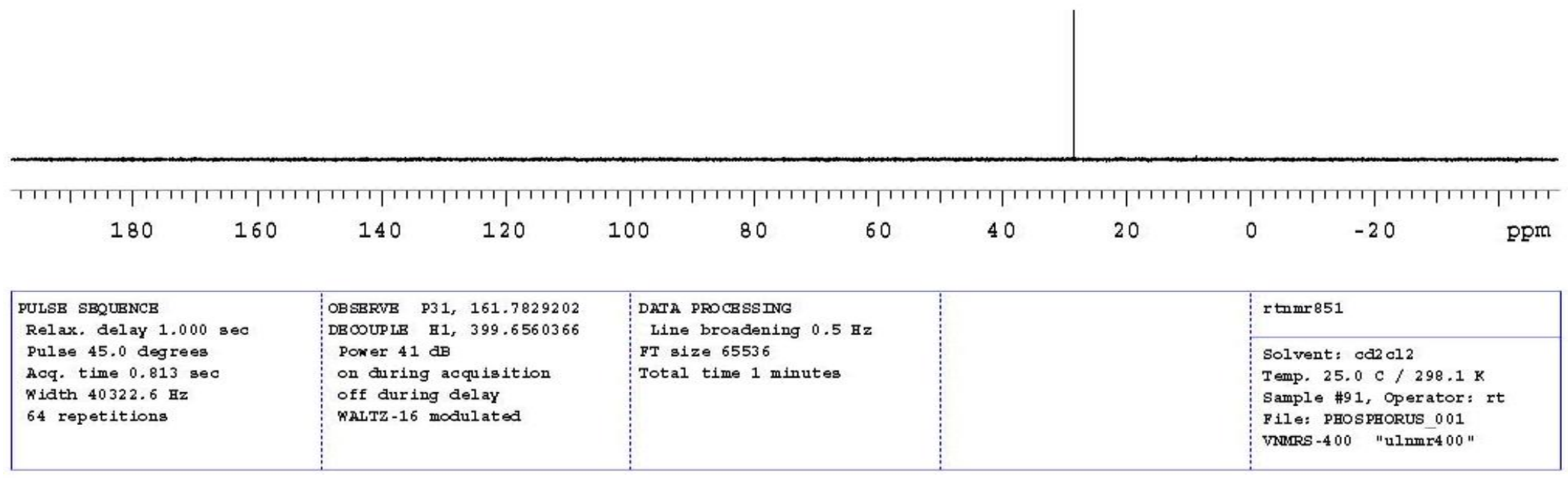




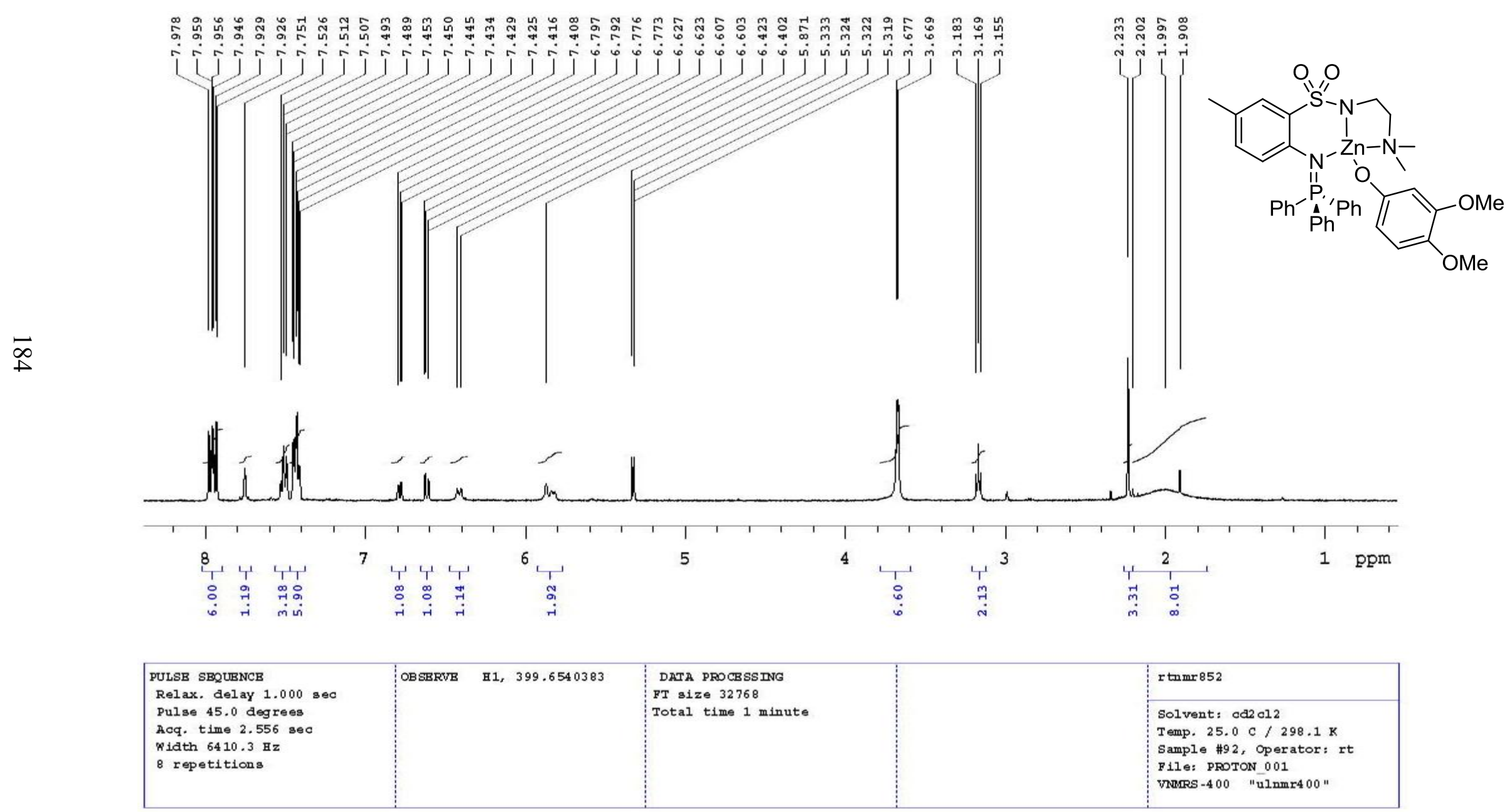




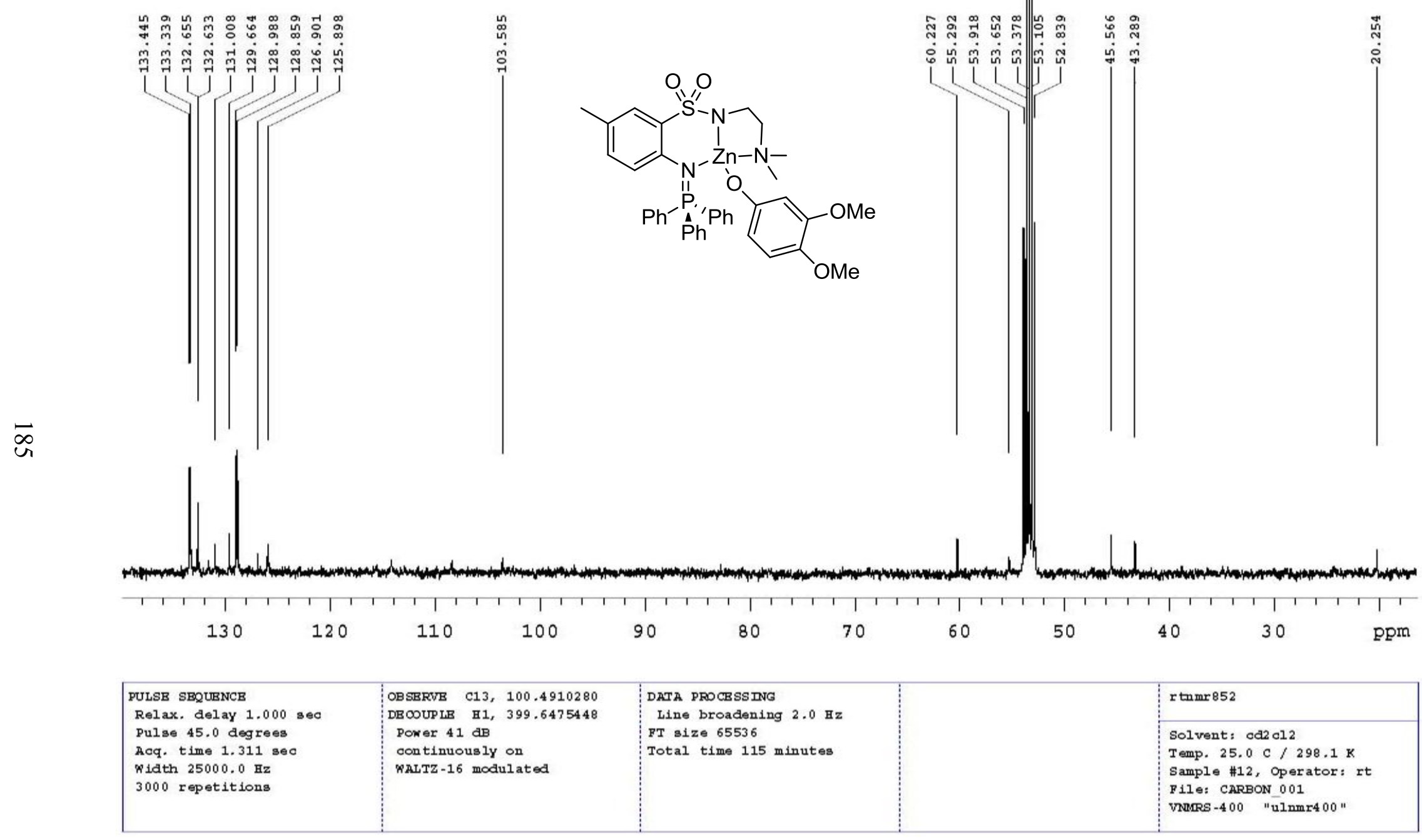




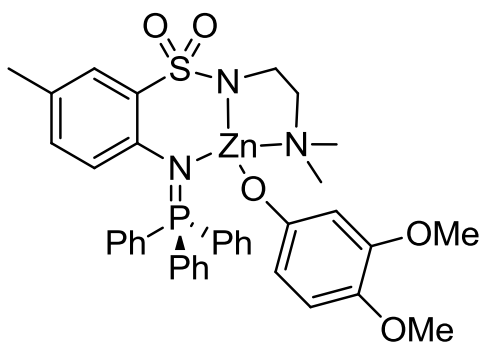

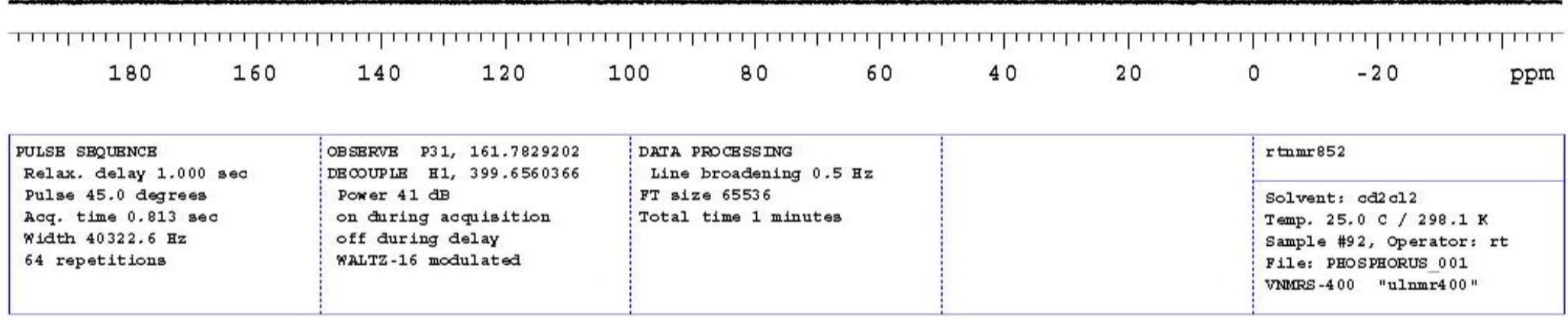


rtnmr1181

$\begin{array}{llll}\text { Sample Name } & \text { rnmr1181 } & \text { Pulse sequence } & \text { PROTON } \\ \text { Date collected } & \mathbf{2 0 1 5 - 0 7 - 0 7} & \text { Solvent } \text { cdcl3 } & \end{array}$

Temperature 25

Study owner rt

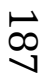
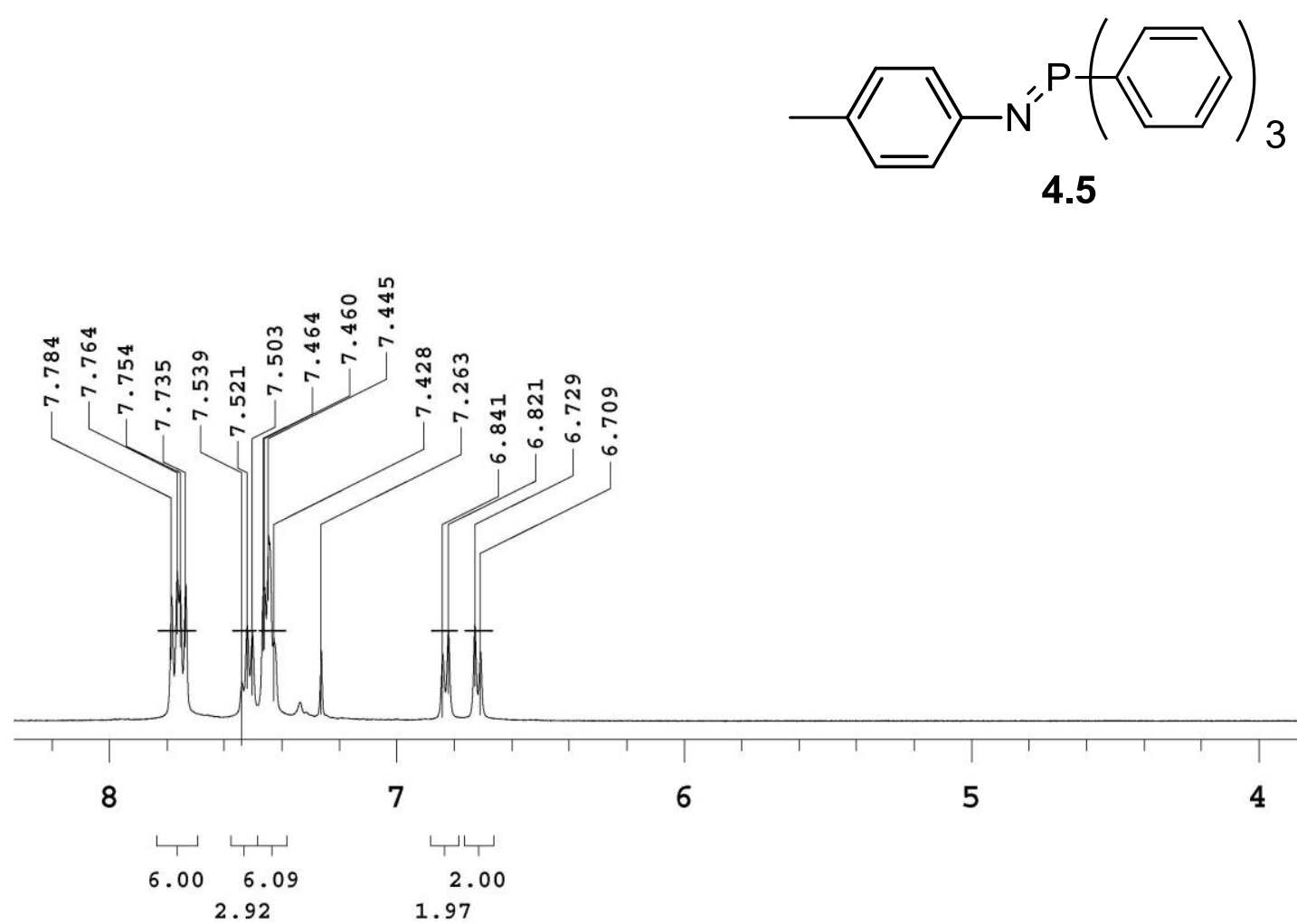

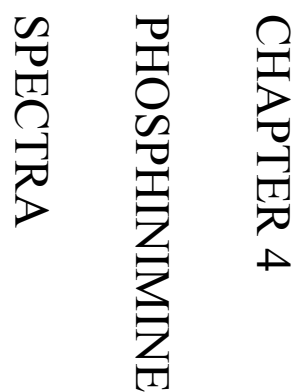

足

$$
2.92 \quad 1.97
$$


rtnmr1181

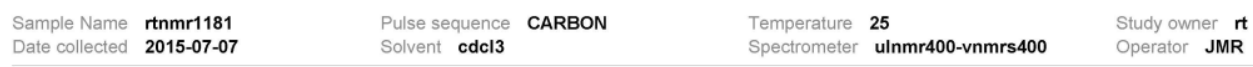

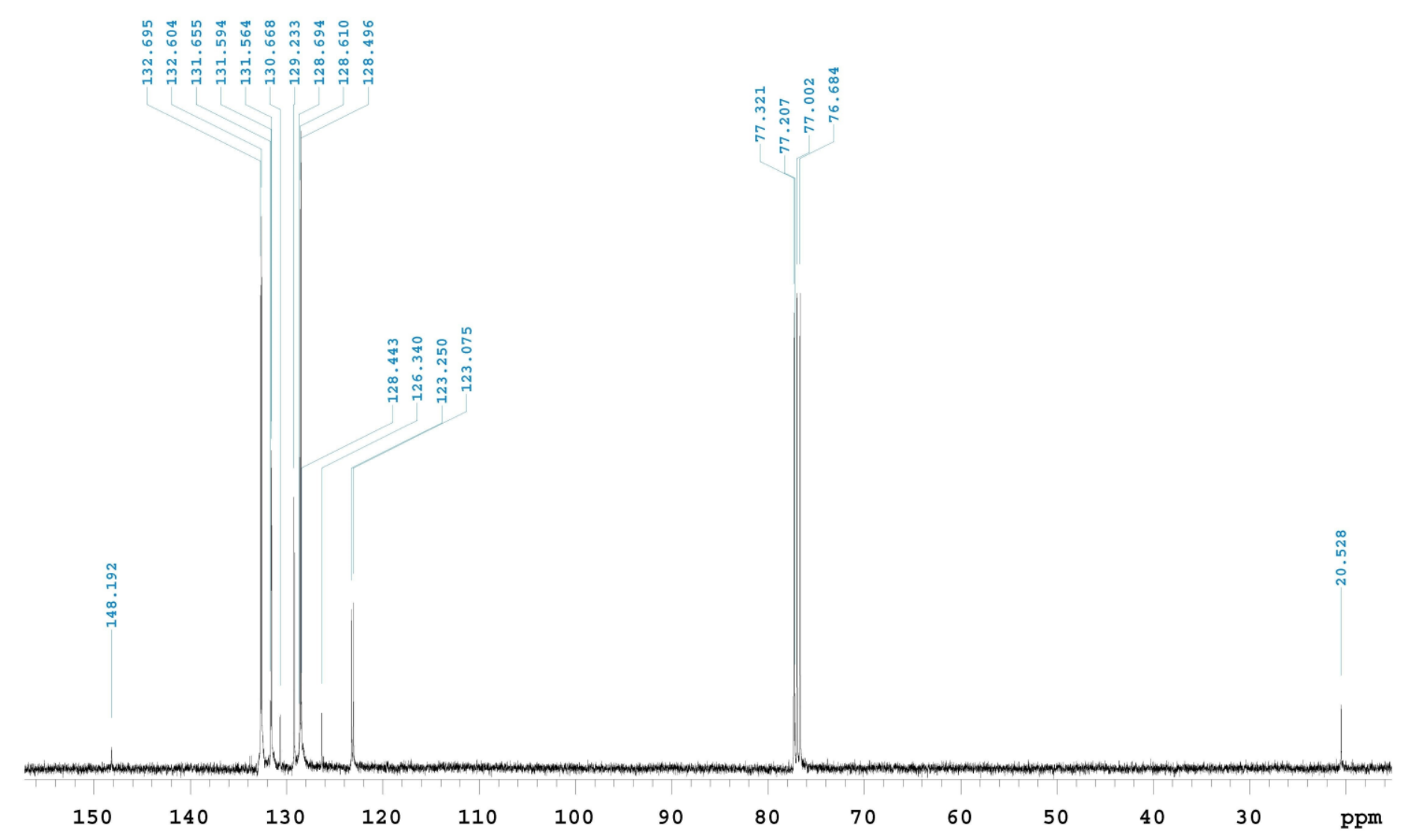




\section{rtnmr1181}

Sample Name rtnmr1181 Pulse sequence PHOSPHORUS Temperature 25

Date collected 2015-07-07 Spectrometer ulnmr400-vnmrs400

Study owner rt

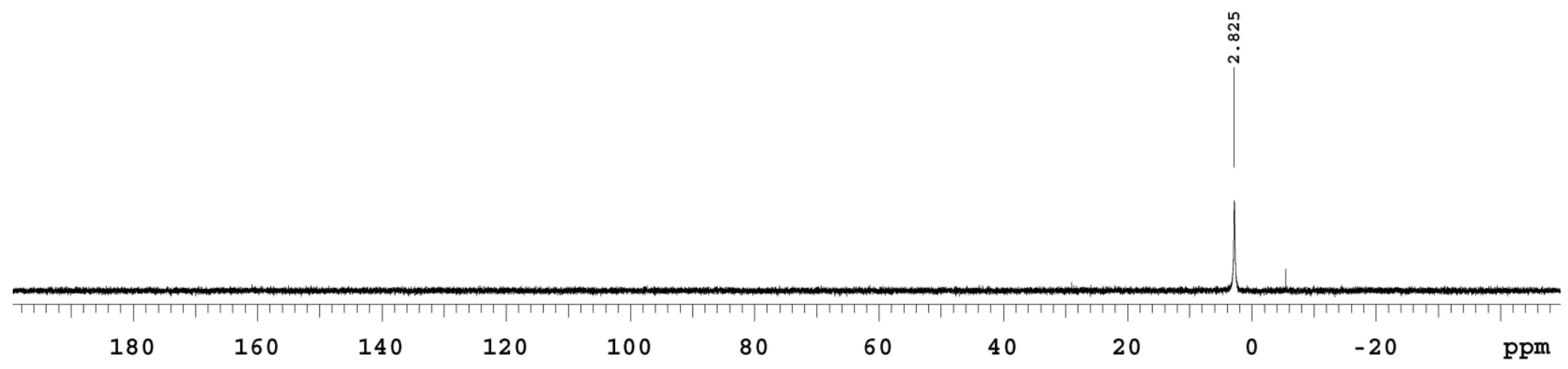


rtnmr900

Sample Name rinmroo0
Date collected
2014-06-04 Pulse sequence PRoToN
Solvent c6d6

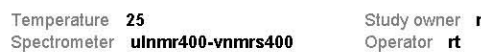

$\vec{\circ}$

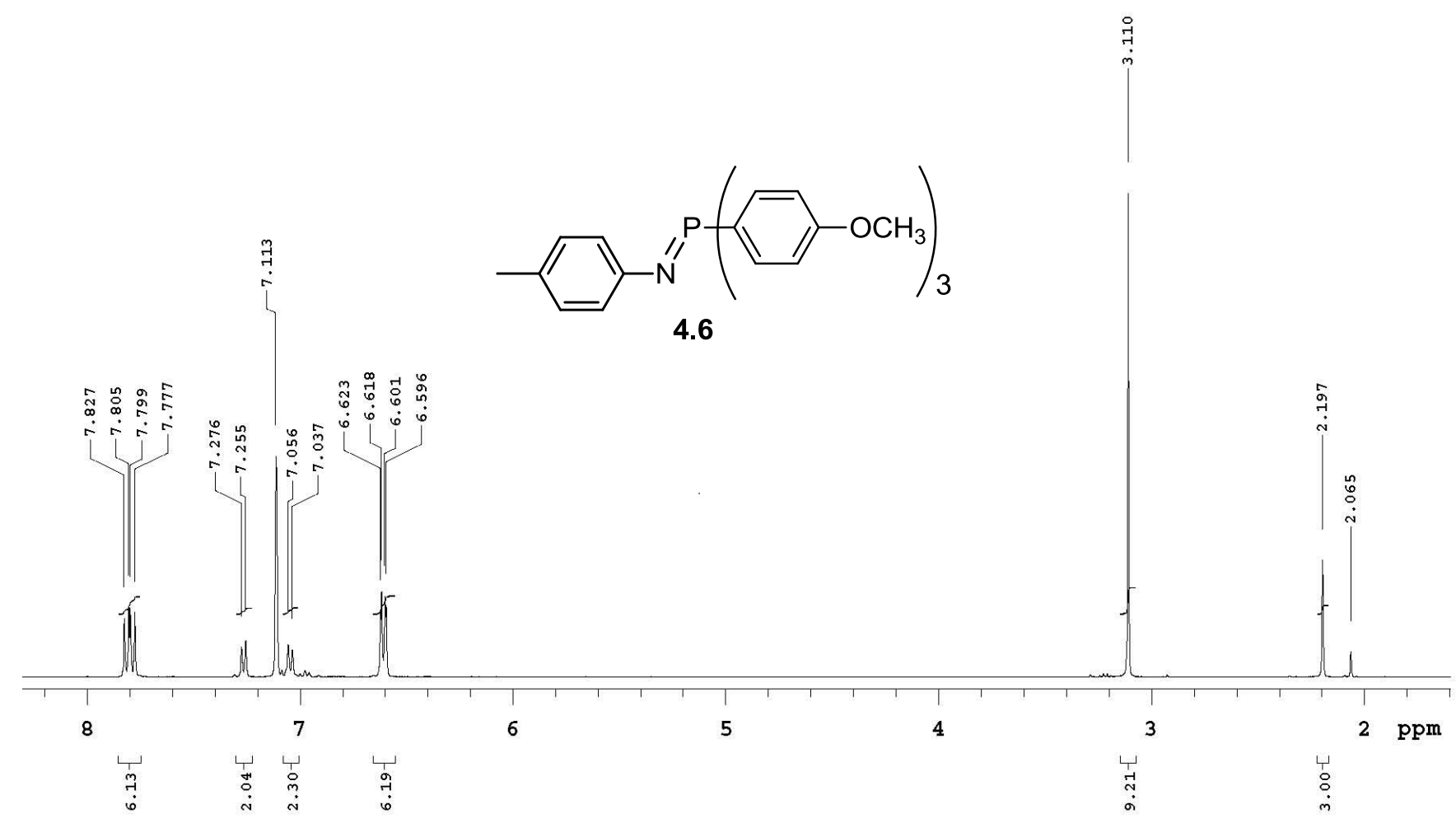


rnmr1182

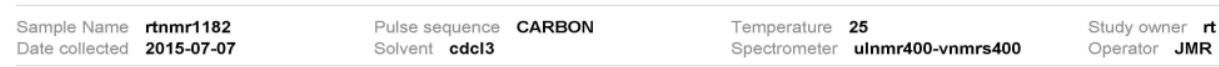

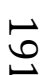

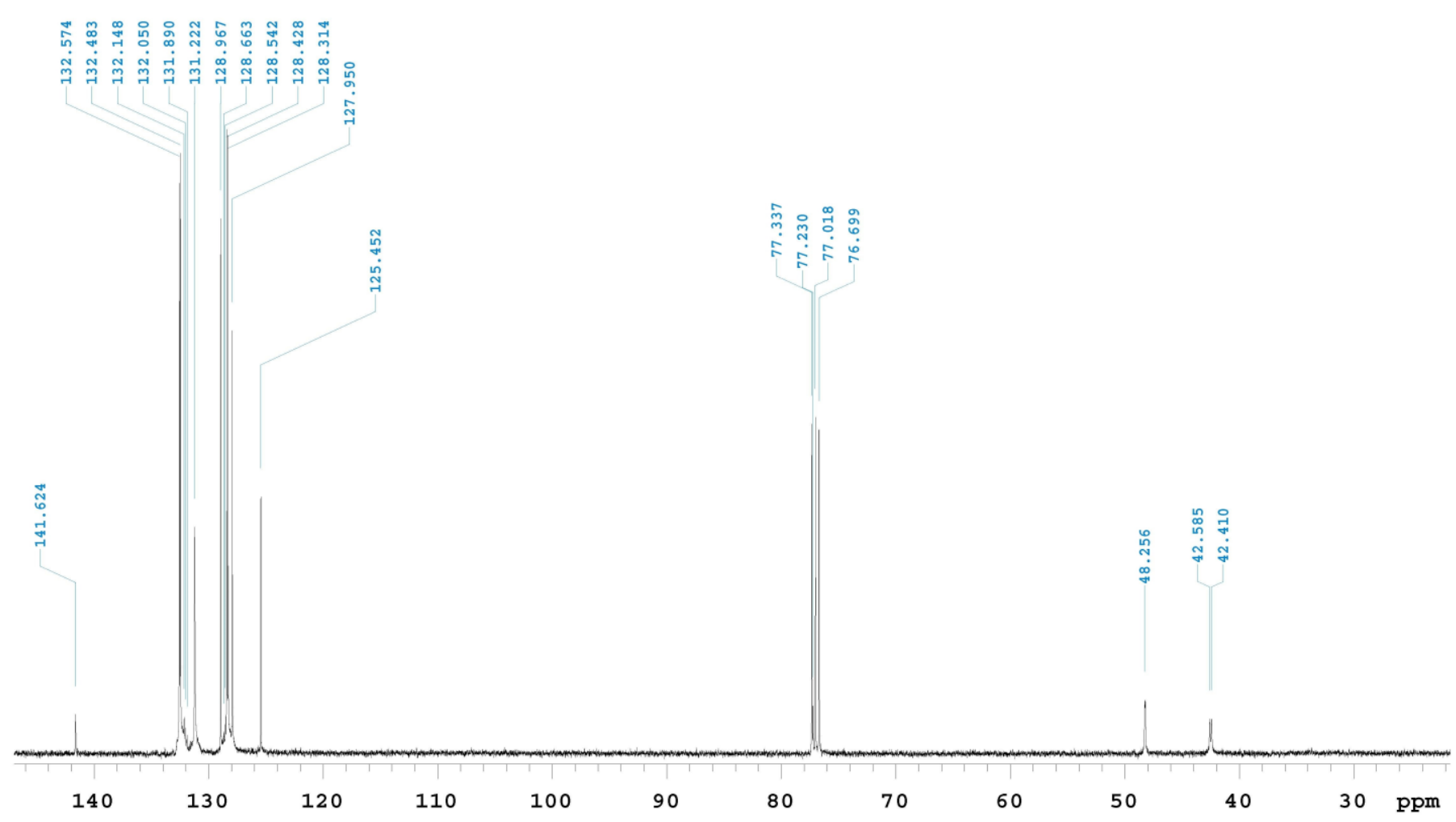


PULSE SEQUENCE

Relax. delay $1.000 \mathrm{sec}$

Pulse 45.0 degree

Acq. time $0.813 \mathrm{sec}$

32 repetitions

OBSERVE P31，161.7793080 DECOUPLE H1, 399.6471134

oring

of during acquisition

WALTZ-16 modul at
DATA PROCESSING

Line broadening $0.5 \mathrm{~Hz}$

Total time 1 minute rtnmr900

Solvent: c6d6

Temp. $25.0 \mathrm{C} / 298.1 \mathrm{~K}$

Sample t91, Operator:

VNMRS - 400 "ulnmr400" 
EMD-NMR-027
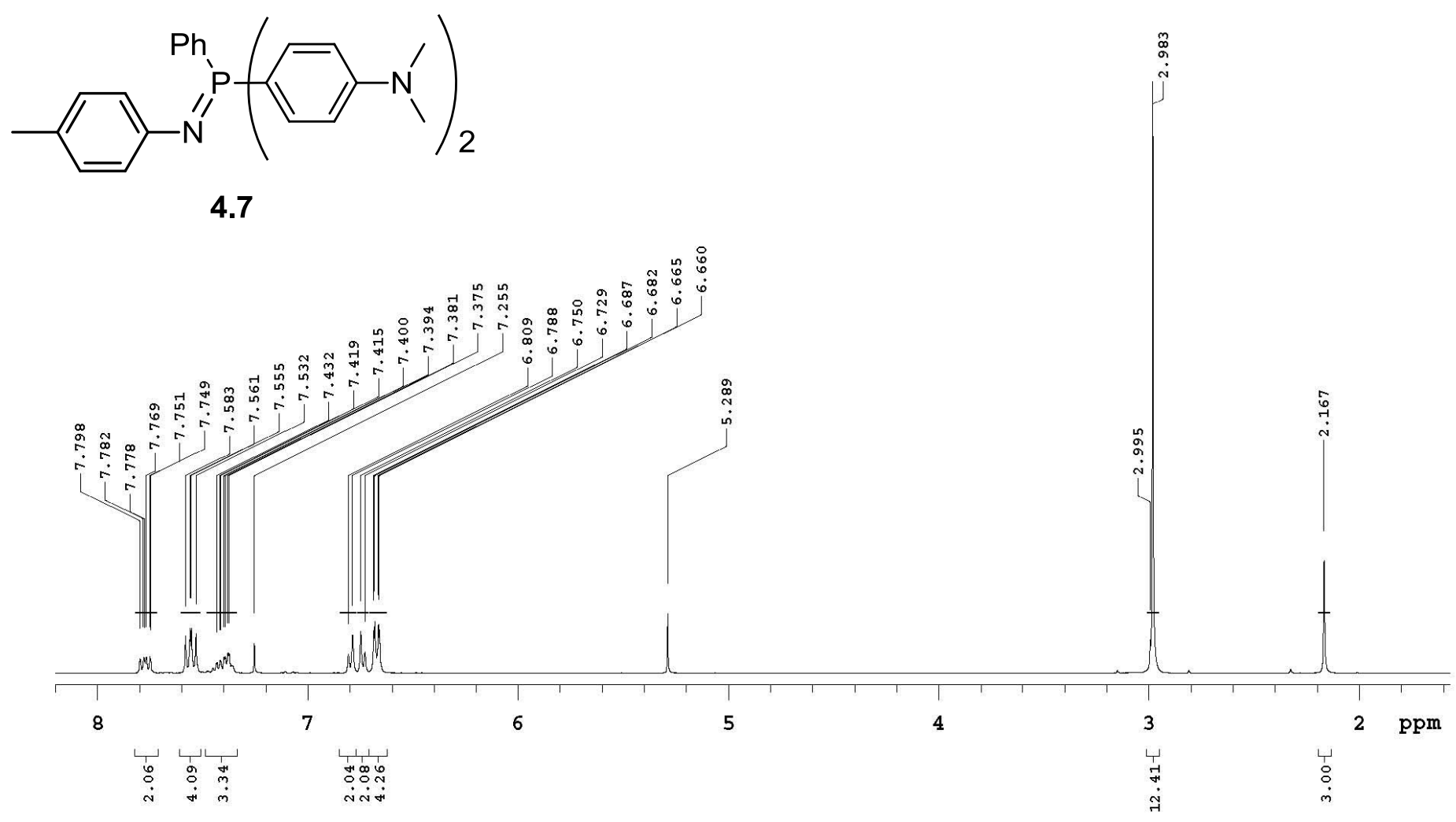
EMD-NMR-029

Sample Name EMD-NMR-029
Date collected 2014-07-05

Pulse sequence CARBoN
Solvent cdcl3

$\begin{array}{ll}\text { Temperature } 25 & \begin{array}{l}\text { Study owner burnsUG } \\ \text { Operator it }\end{array} \\ \text { Spectrometer ulnmr400-vnmrs400 } & \end{array}$

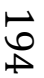

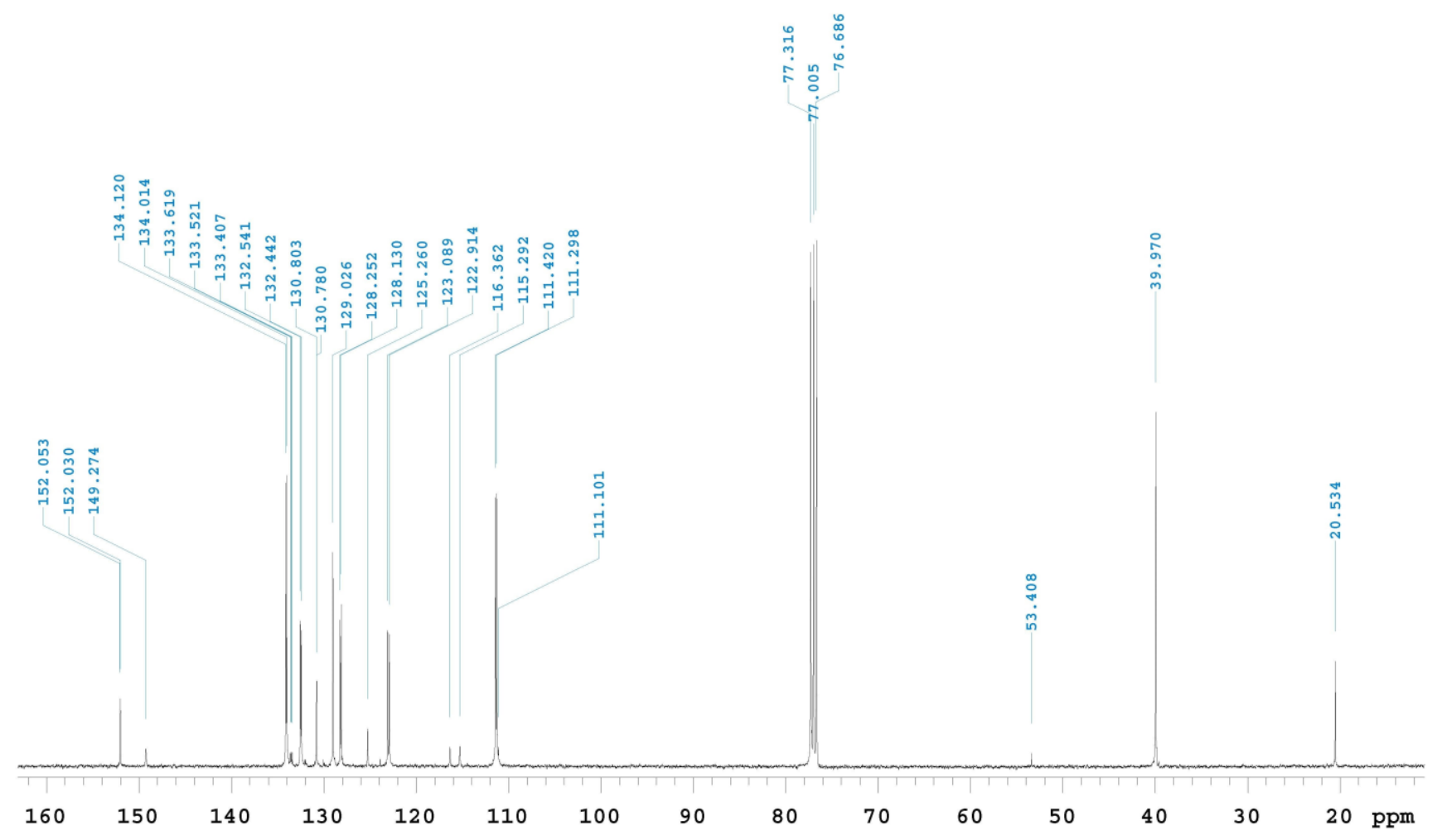


EMD-NMR-027

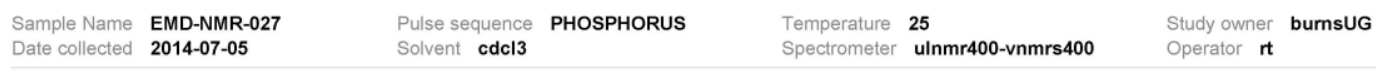

$\vec{\bullet}$

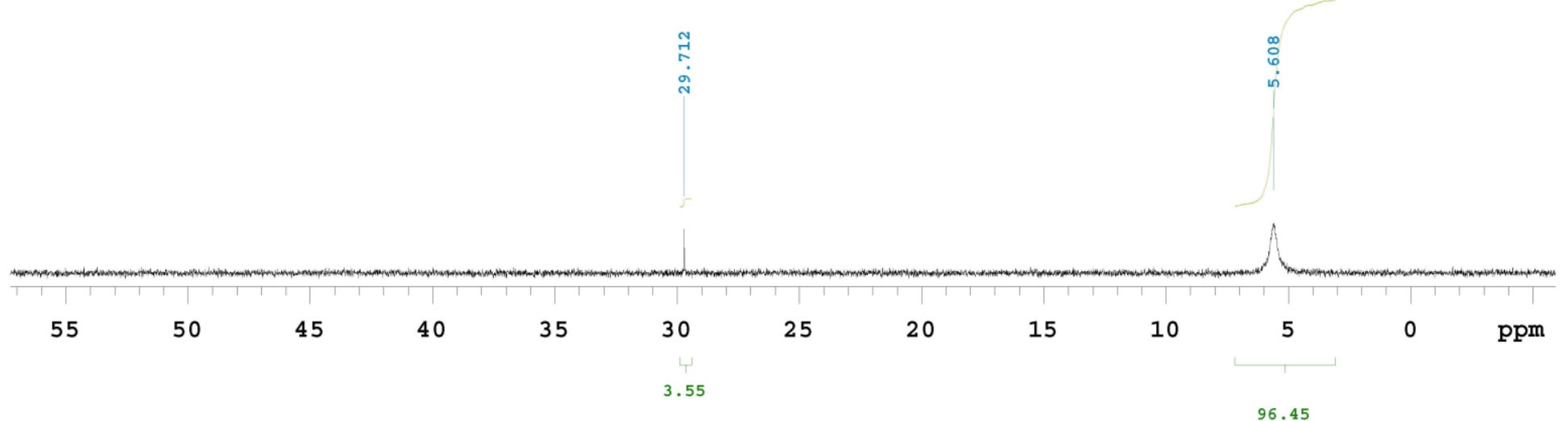


EMD-NMR.051

\begin{tabular}{llll}
$\begin{array}{l}\text { Sample Name EMD-NMR-051 } \\
\text { Date collecled 2014-07-17 }\end{array}$ & $\begin{array}{l}\text { Pulse sequence PROTON } \\
\text { Solvent cdcl3 }\end{array}$ & $\begin{array}{l}\text { Temperature } 25 \\
\text { Spectrometer ulnmr400-vnnmrs400 }\end{array}$ & $\begin{array}{l}\text { Study owner burnsug } \\
\text { Operator burnsUG }\end{array}$ \\
\hline
\end{tabular}

ळ

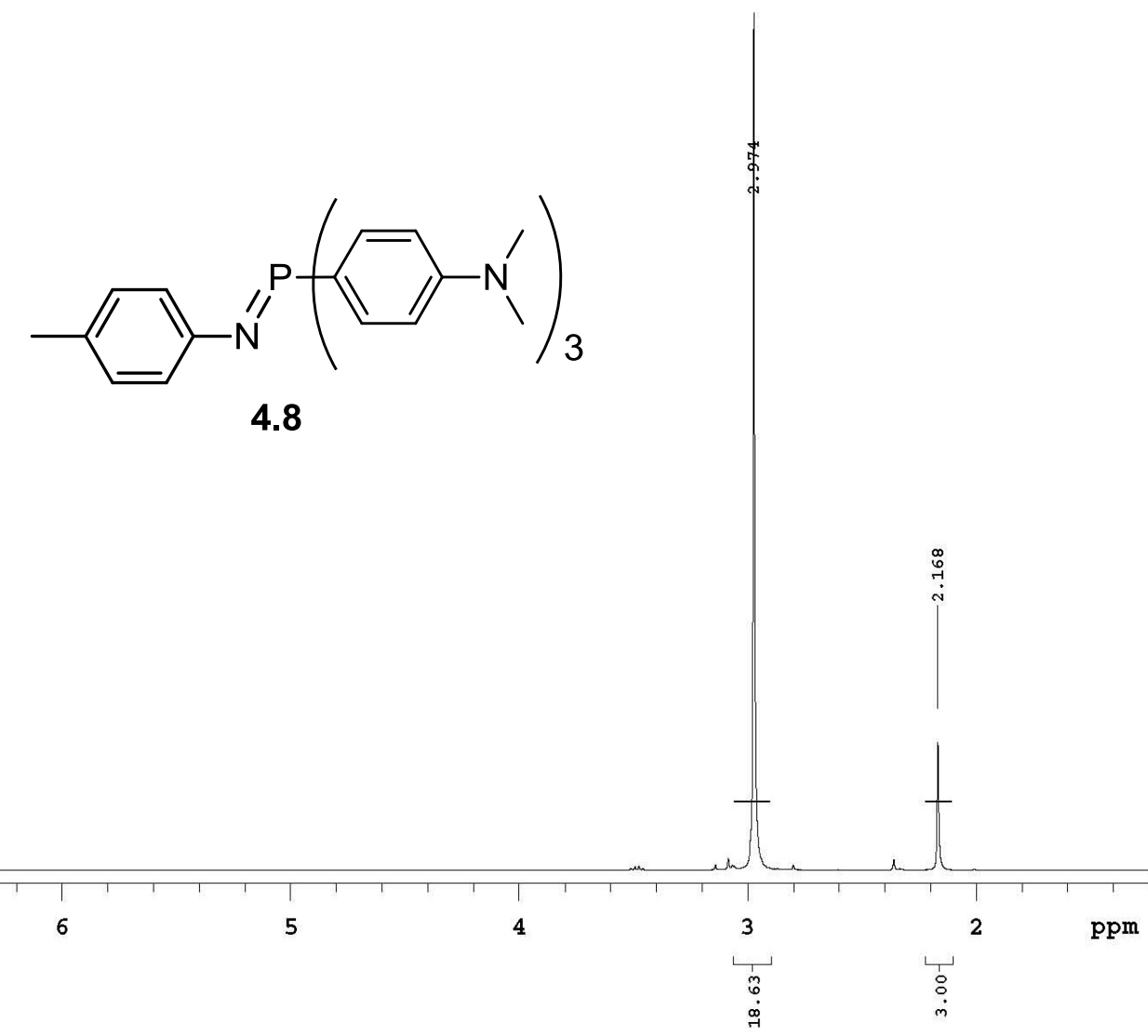




\section{EMD-NMR-030}

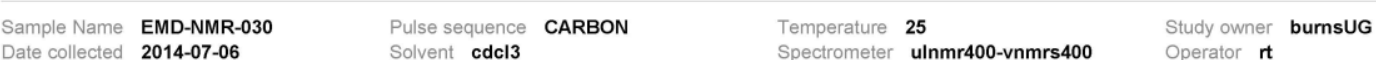

$\underset{v}{ }$

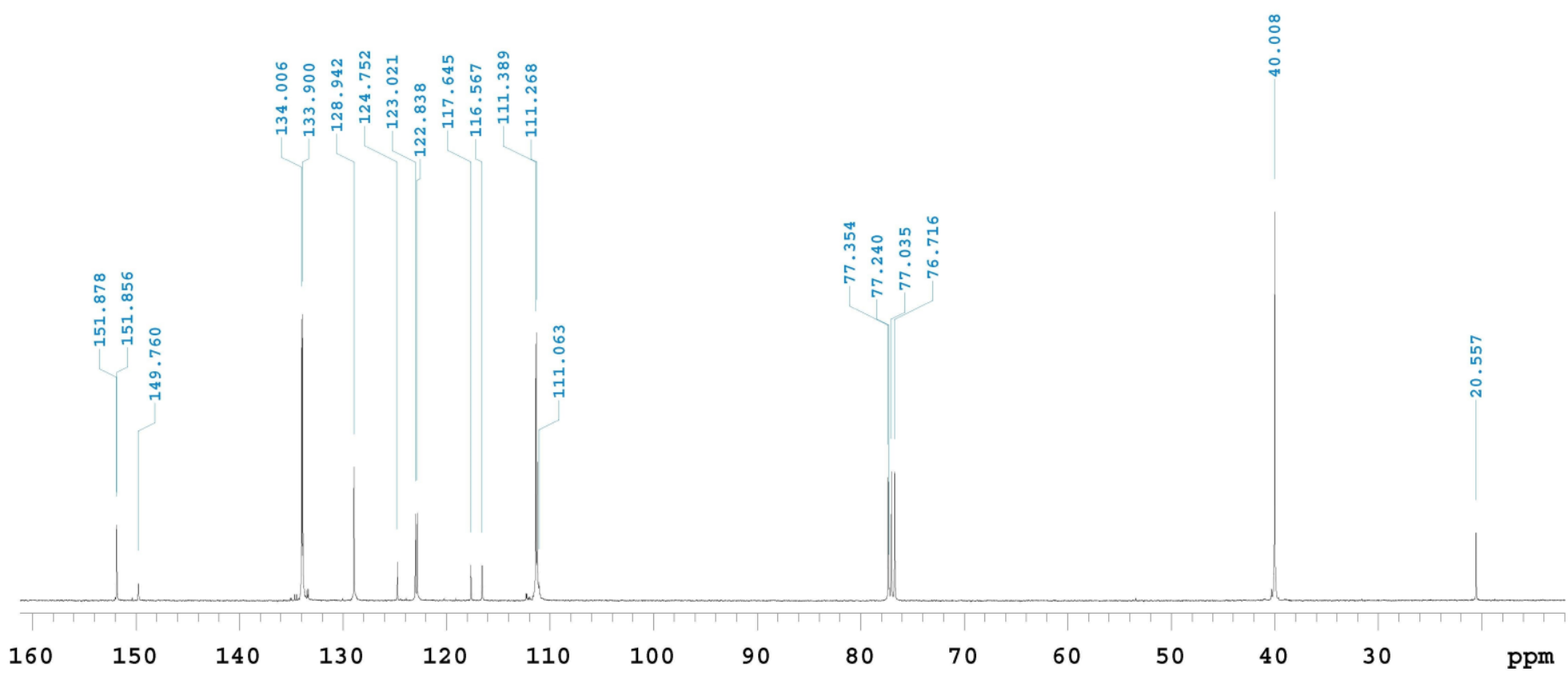


EMD-NMR-051

$\begin{array}{ll}\text { Sample Name EMD-NMR-051 } & \text { EMT- } \\ \text { Date collected } & \text { 2014-07-17 }\end{array}$

Pulse sequence PHOSPHORUS Solvent cdc13

Temperature 25

Spectrometer ulnmr400-vnmrs400

Study owner burnsUG

PHOSPHORUS

Sper

Operator $\mathbf{r t}$

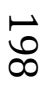

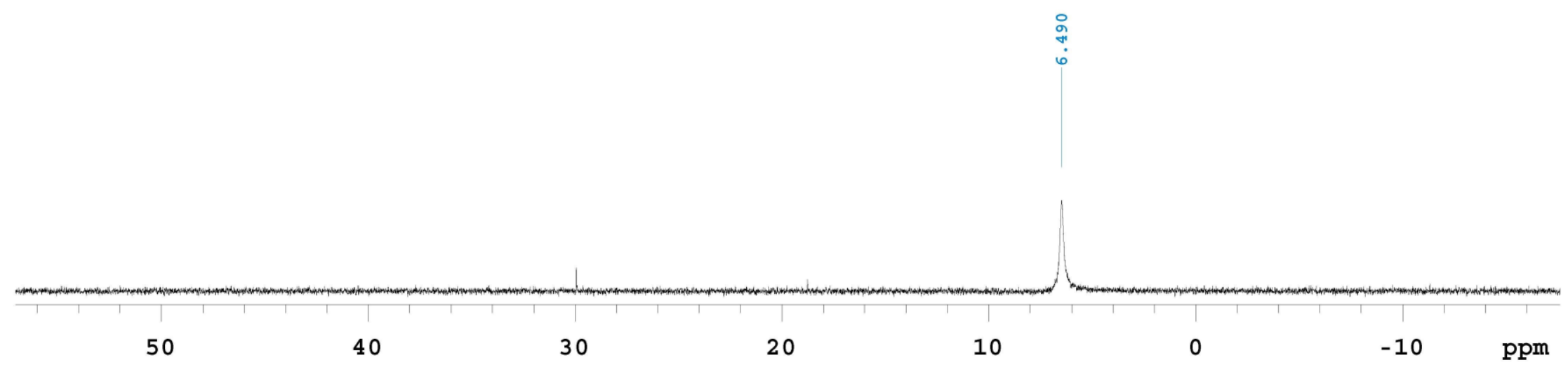




\section{EMD-NMR-038}

Sample Name EMD-NMR-038 Pulse sequence PROTON

PROTON Temperature $\mathbf{2 5}$

25

Study owner burnsuG

ate collected 2014-07-07

$\overrightarrow{8}$
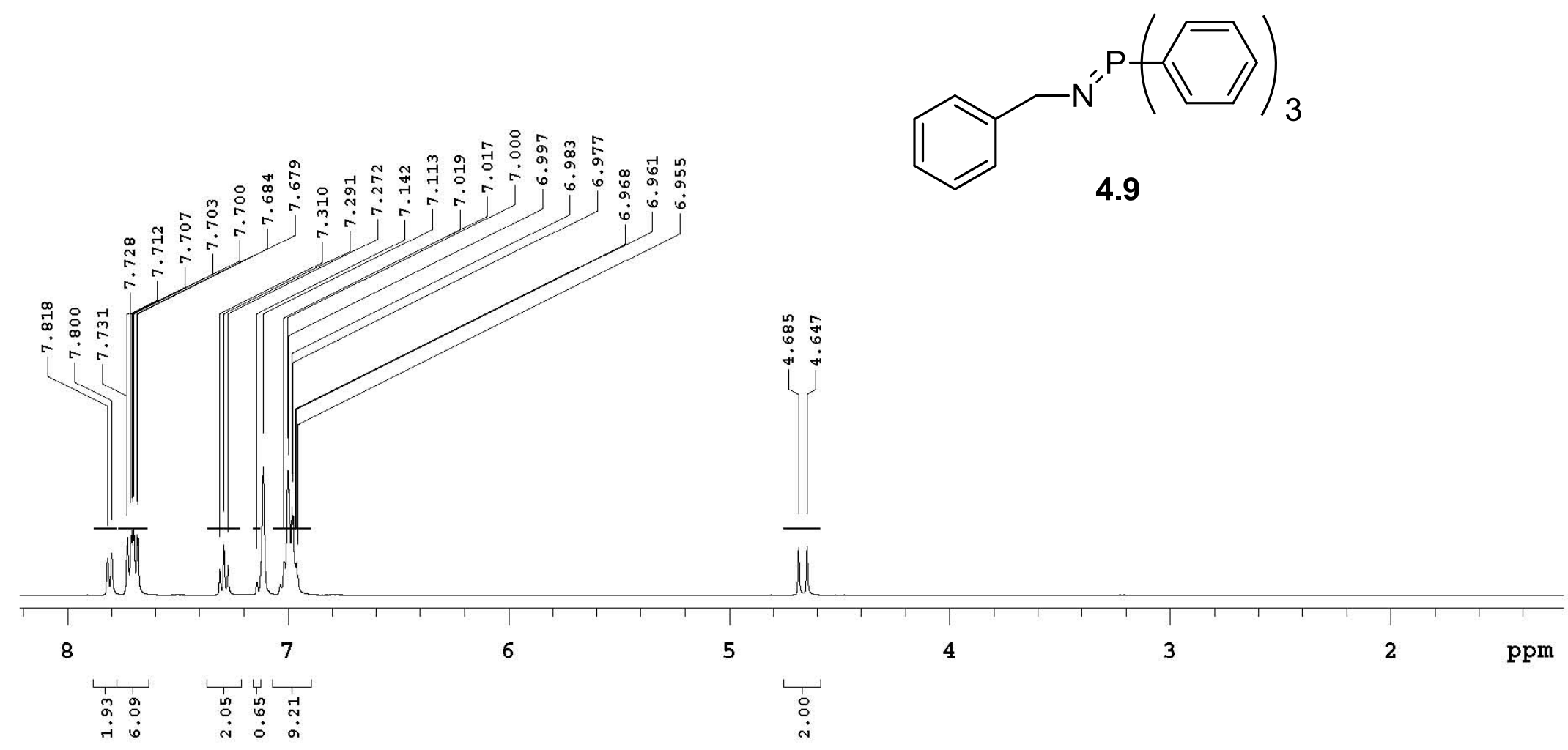
EMD-NMR-038

Sample Name EMD-NMR-038 Pulse sequence PHOSPHORUS Date collected 2014-07-07 Solvent c6d6

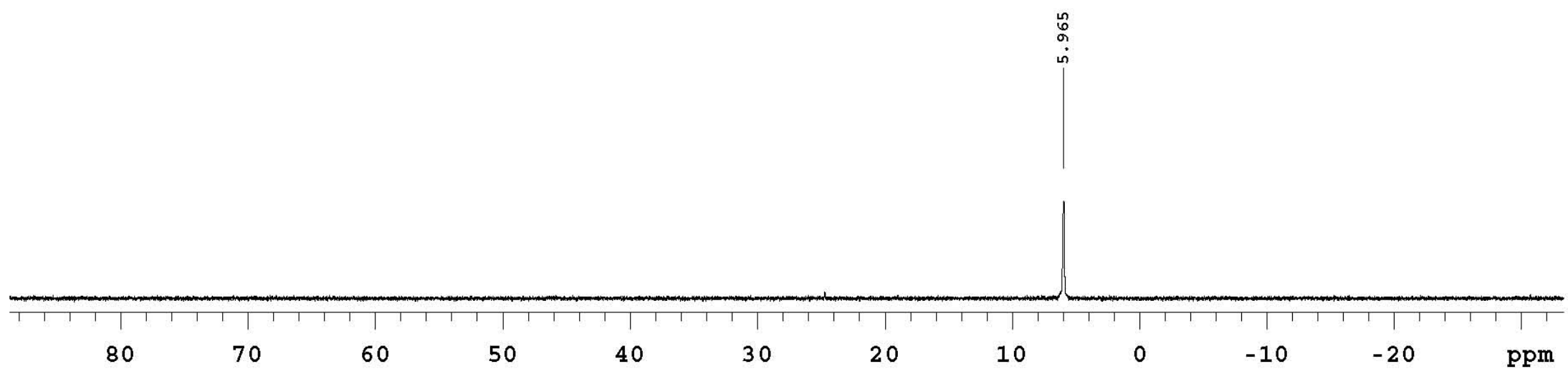


rtnmr957

$\begin{array}{ll}\text { Sample Name } & \text { rtnmr957 } \\ \text { Date collected } & \text { 2014-07-28 }\end{array}$ Pulse sequence PROTON

Temperature $\mathbf{2 5}$
Spectrometer ulnmr400-vnmms400 Study owner $\mathbf{r t}$
Operator $\mathbf{~} \mathbf{t t}$

N
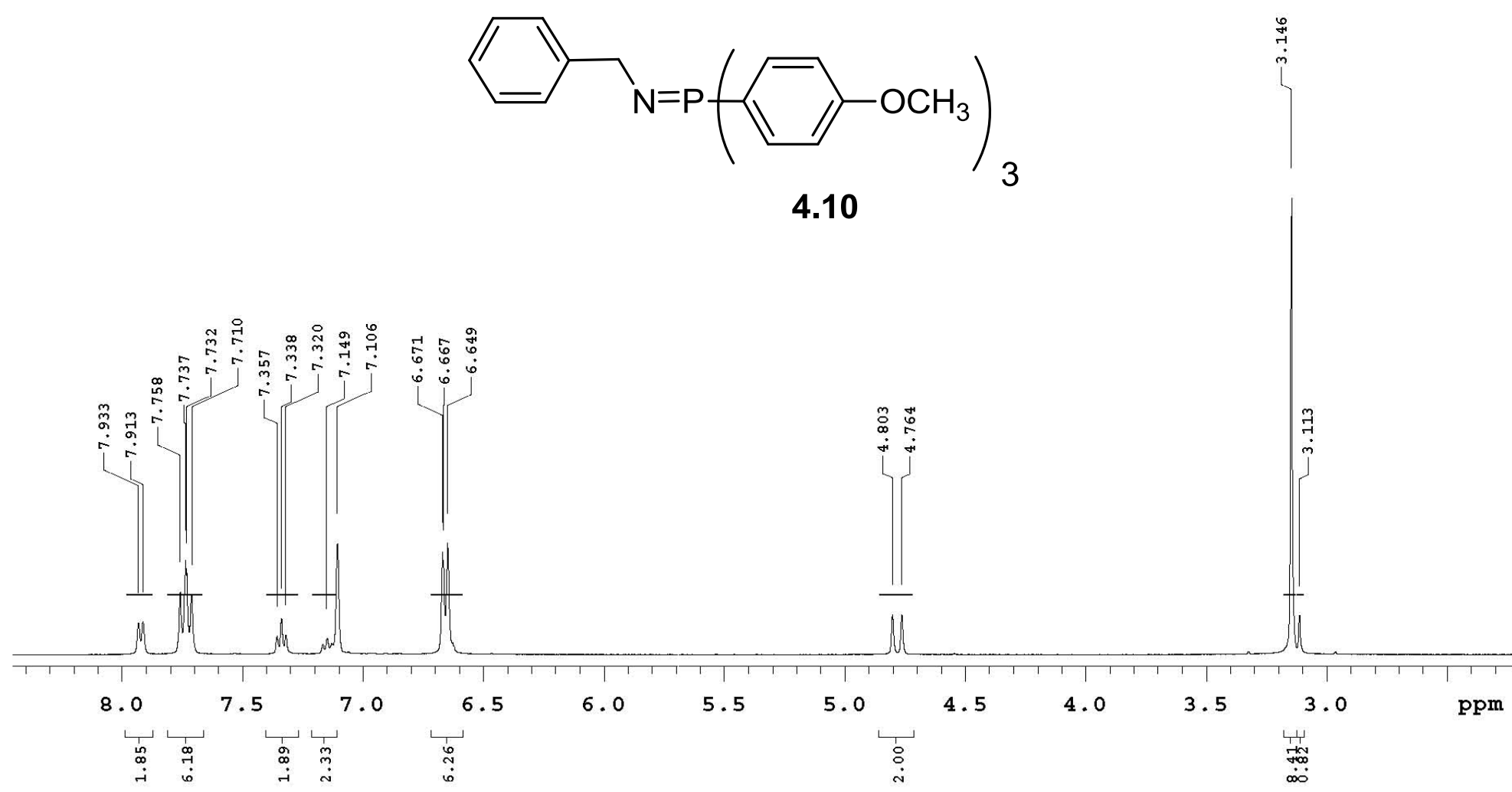


\section{rtnmr1186}

Sample Name rtrmir1186 Pulse sequence CARBoN Temperature 25 Study owner $\mathbf{n}$
Operator $\mathbf{r t}$

莫

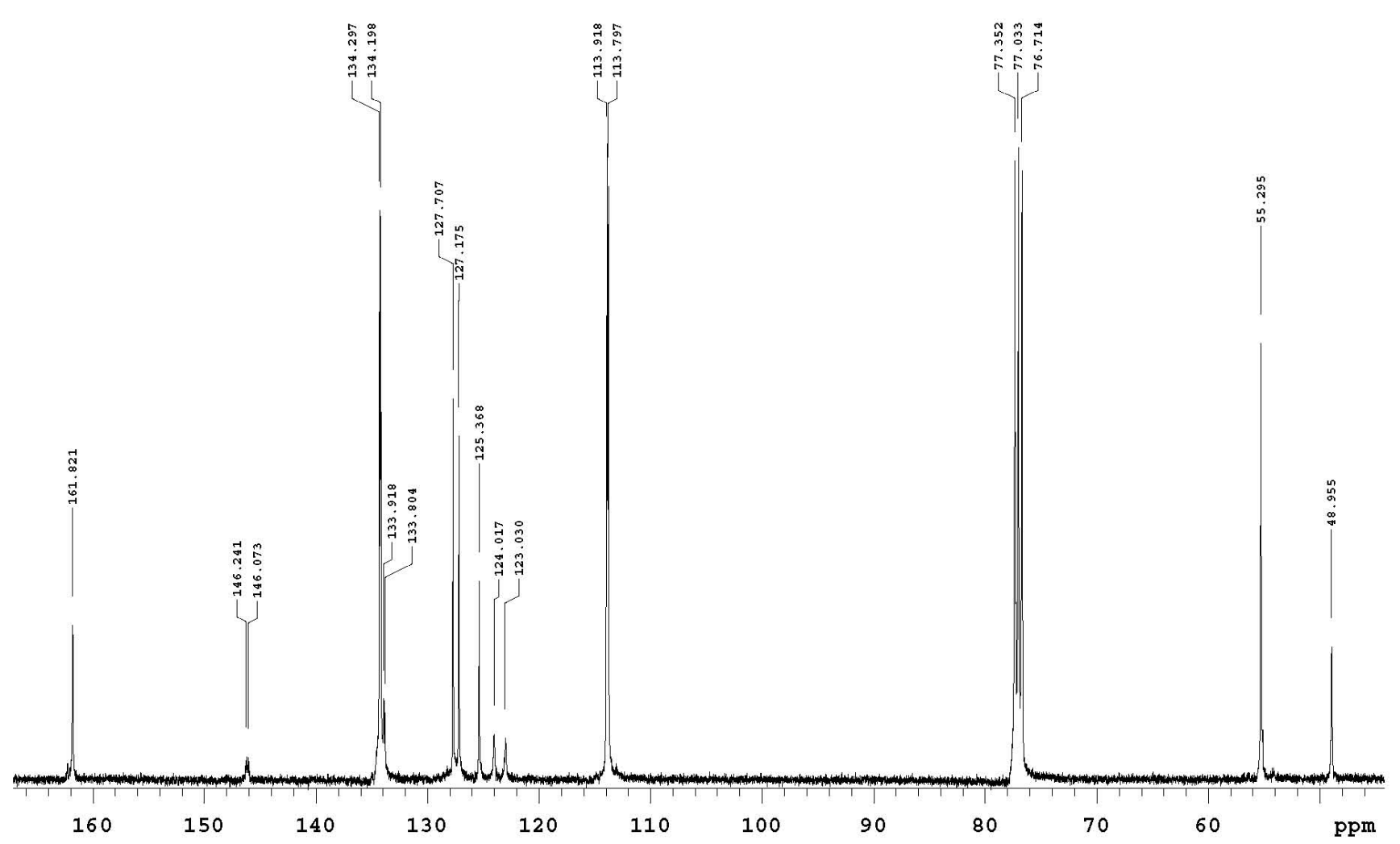


rtnmr957

$\begin{array}{ll}\text { Sample Name rtnmr957 } \\ \text { Date collected } & \mathbf{2 0 1 4 - 0 7 - 2 0}\end{array}$

Pulse sequence PHOSPHORUS

Temperature 25
Spectrometer
ulnmr400-vnmrs400

Study owner $\mathbf{r t}$
Operator $\mathbf{r t}$

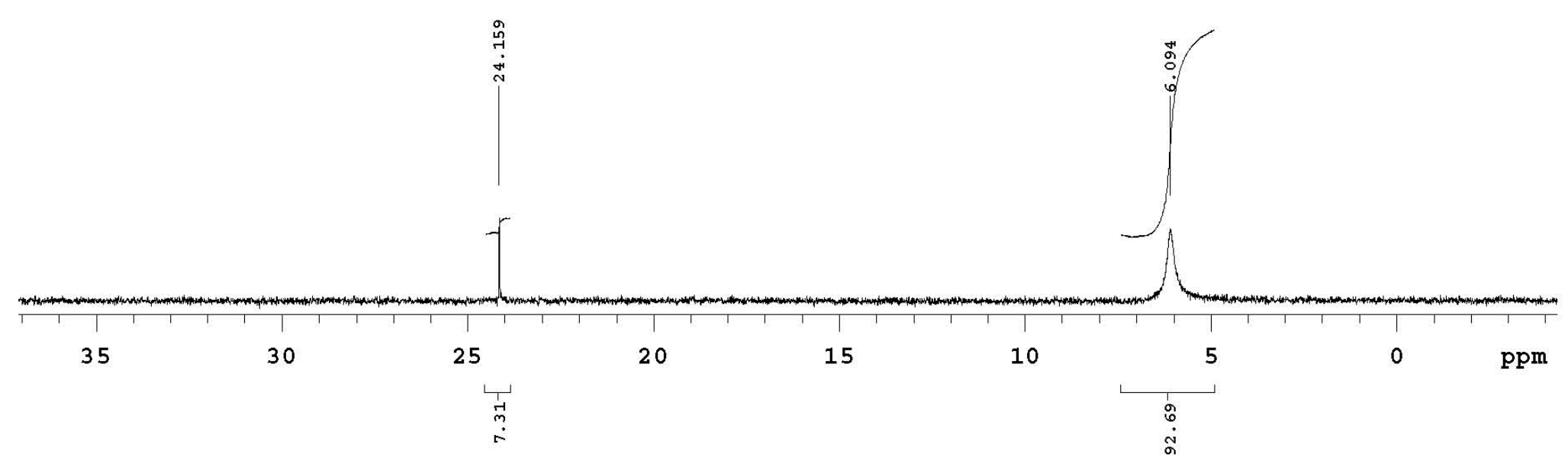




\section{rtnmr1182}

Sample Name rtnmr1182

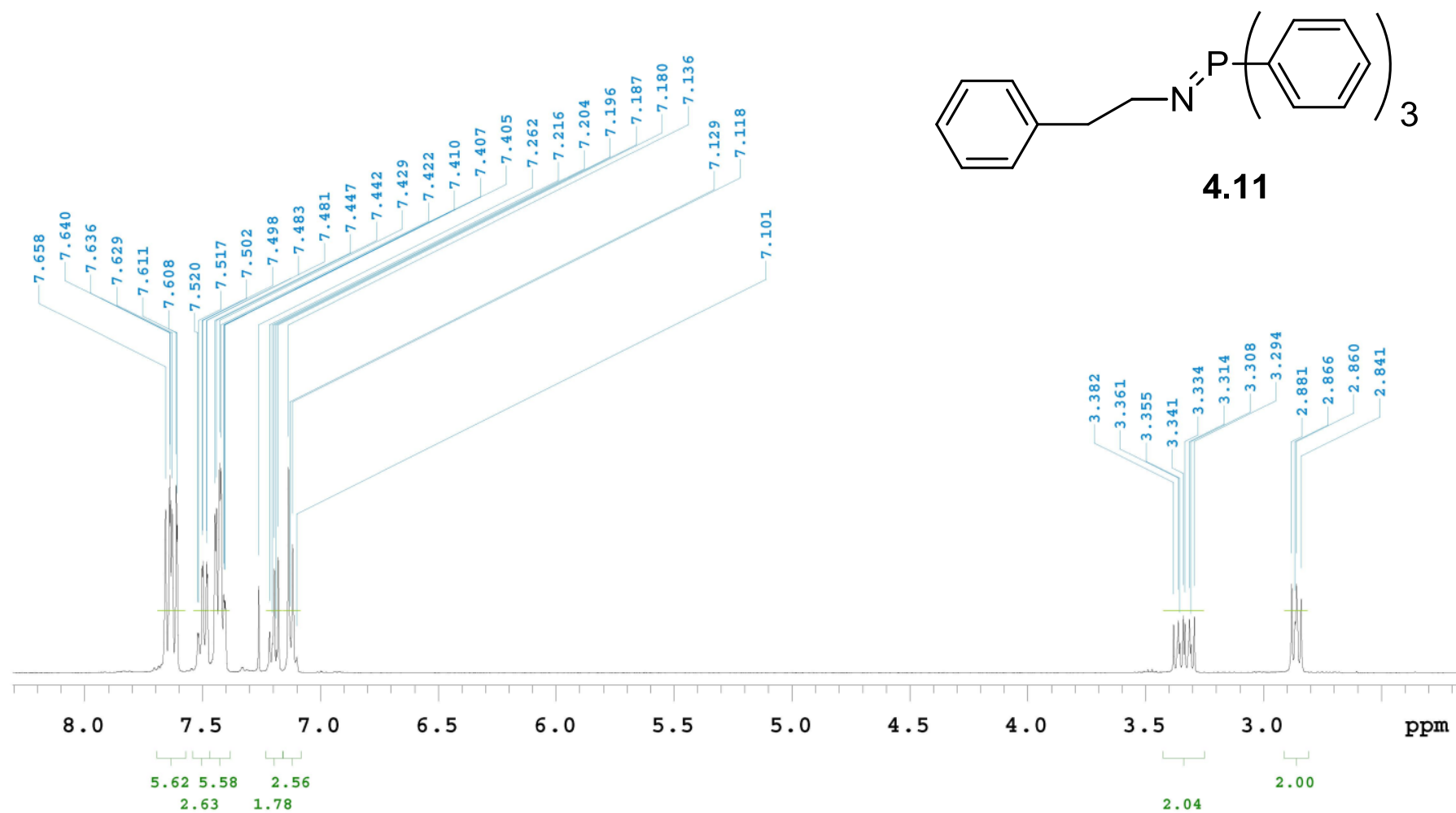


rtnmr1182

Sample Name rtnmr1182 Pulse sequence CARBON
Solvent cdcl3

Temperature 25
Spectrometer
ulnmr400-vnmrs400

Study owner rt
Operator JMR

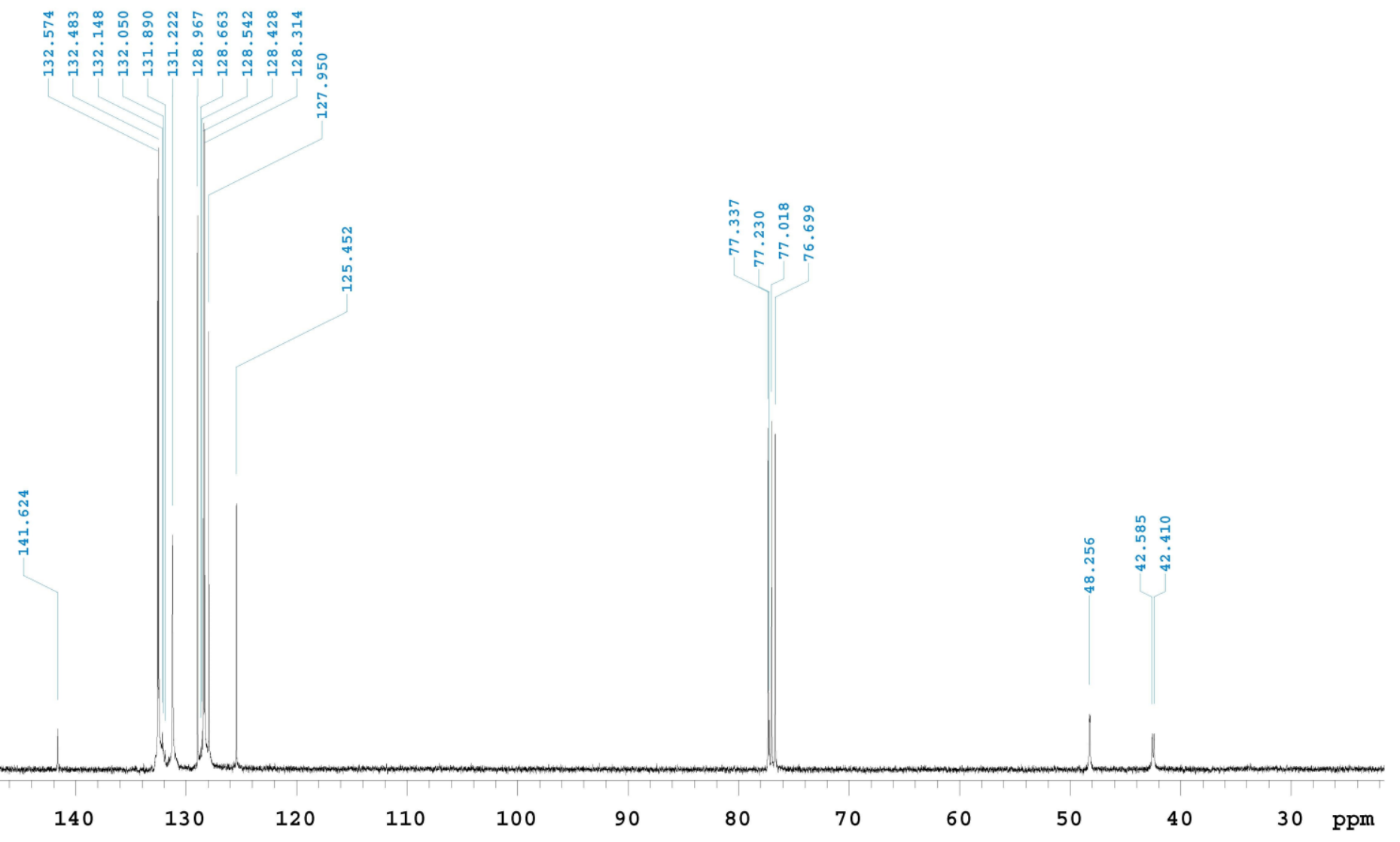




\section{rtnmr1182}

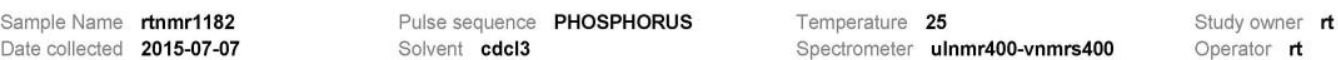

ㅇํㅇ

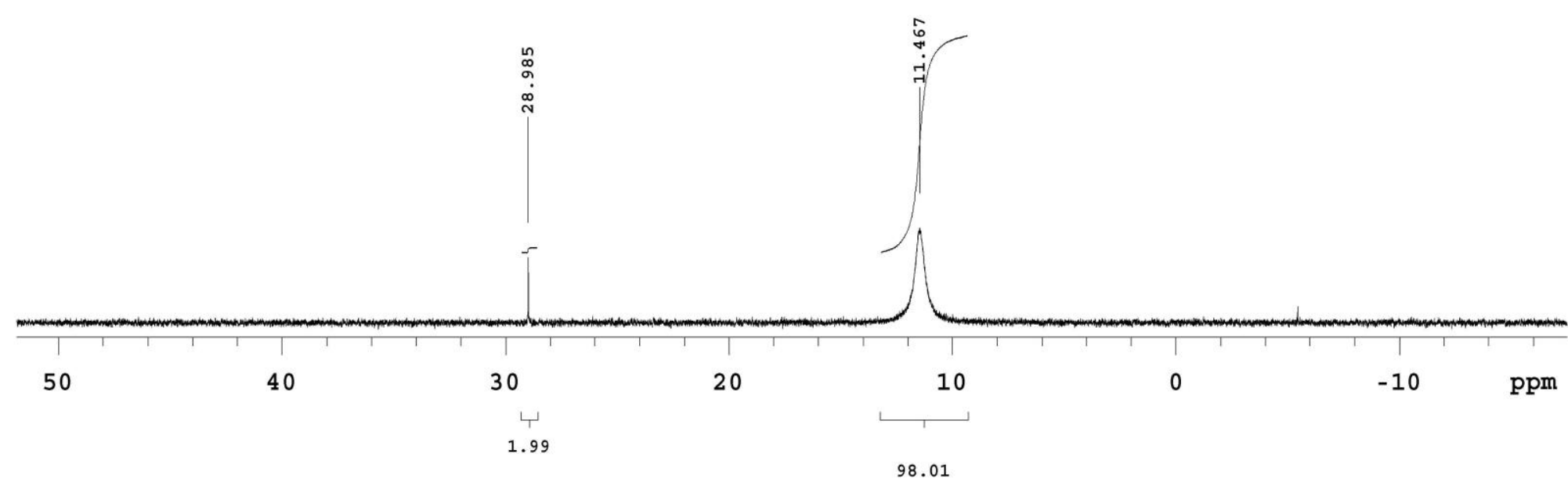




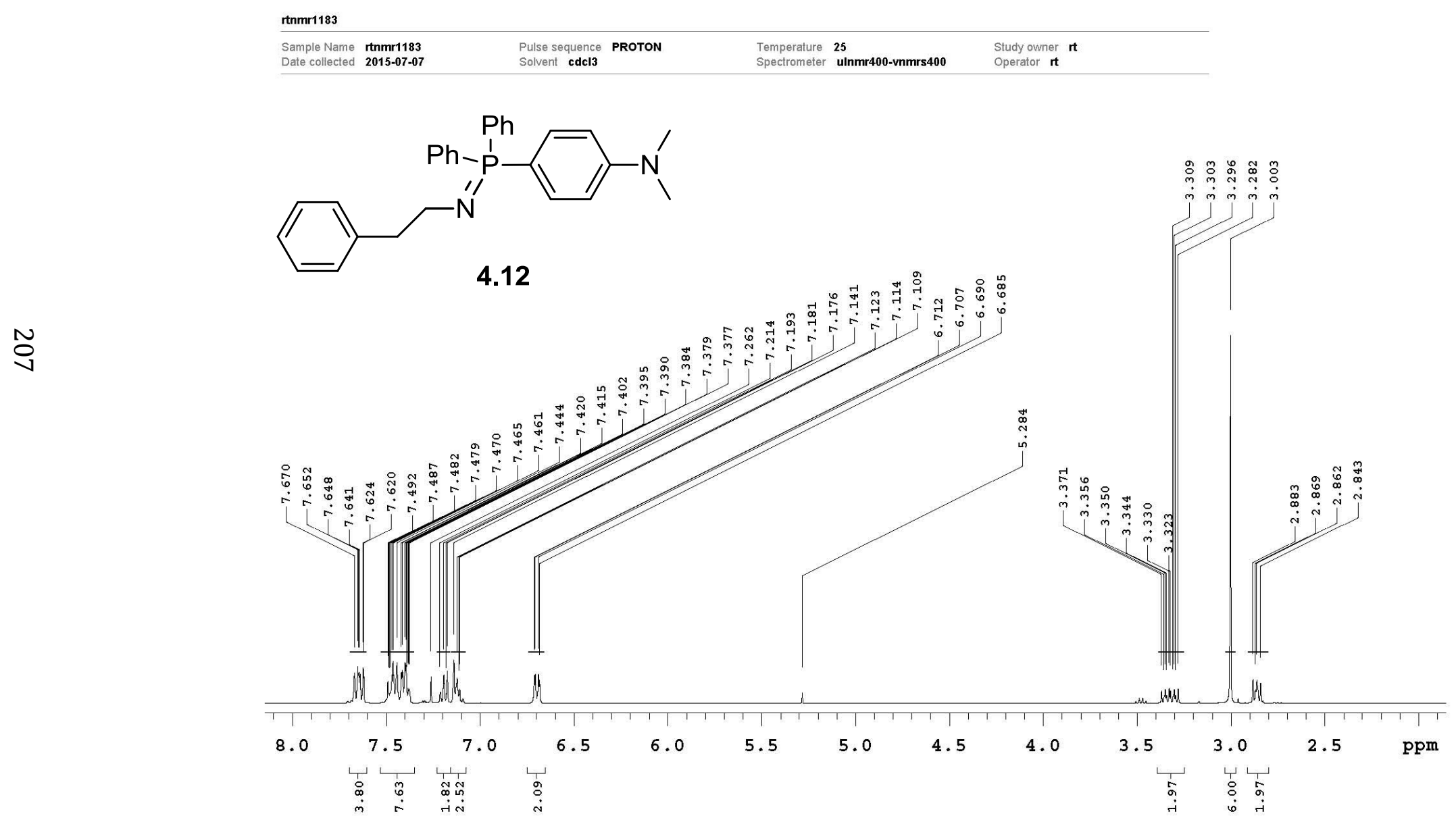




\section{rtnmr1183}

$\begin{array}{lll}\text { Sample Name rtnmr1183 } & \text { Pulse sequence } & \text { CARBON } \\ \text { Date collected } & \text { 2015-07-07 } & \text { Solvent } \text { cdcl3 }\end{array}$

Temperature 25
Spectrometer ulnmr400-vnmms400

Study owner $n$

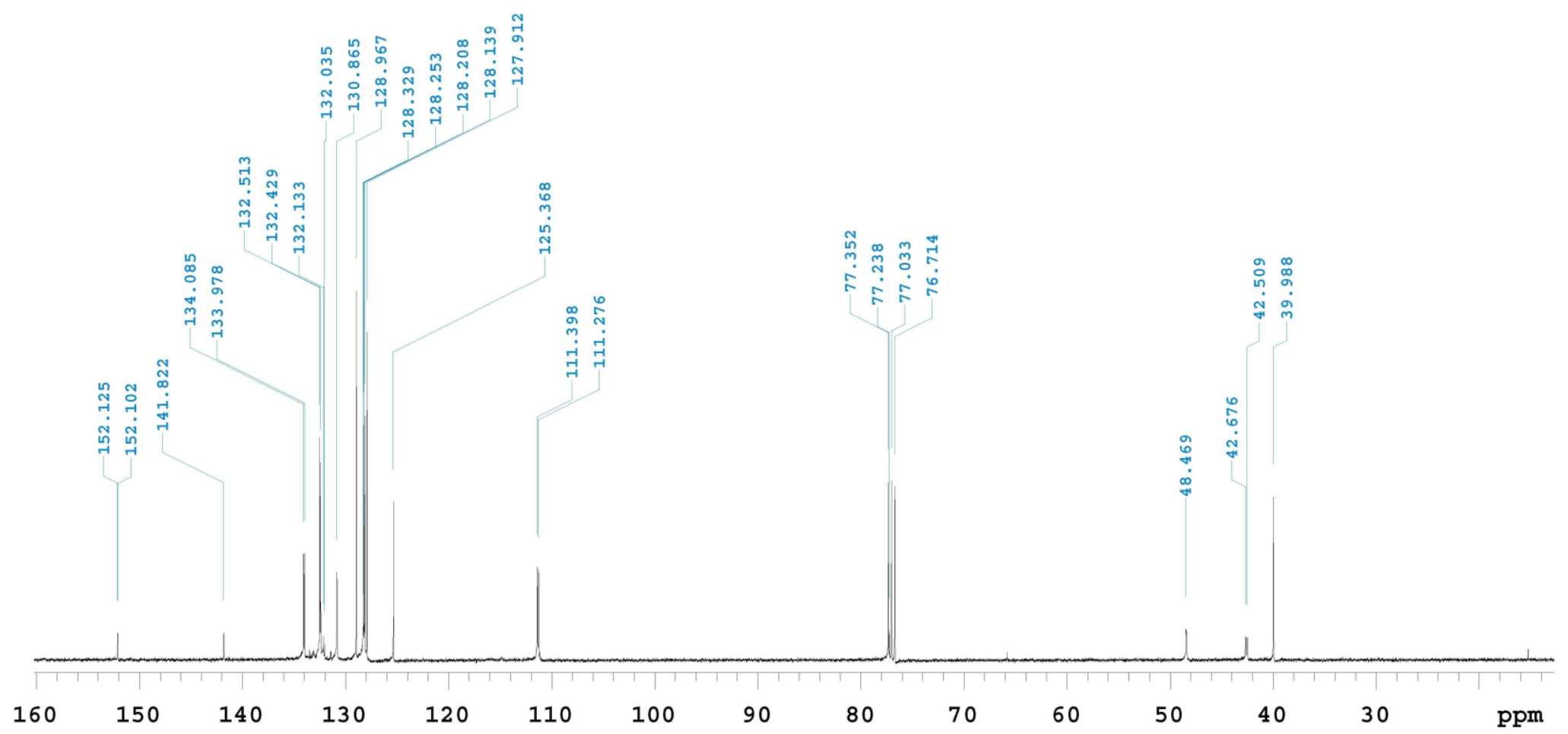


rtnmr1183

Sample Name rnmr1183

Date collected 2015-07-07 Pulse sequence PHOSPHORUS Solvent cdc13 Temperature 25 Spectrometer ulnmr400-vnmrs400 Study owner $\mathbf{r t}$

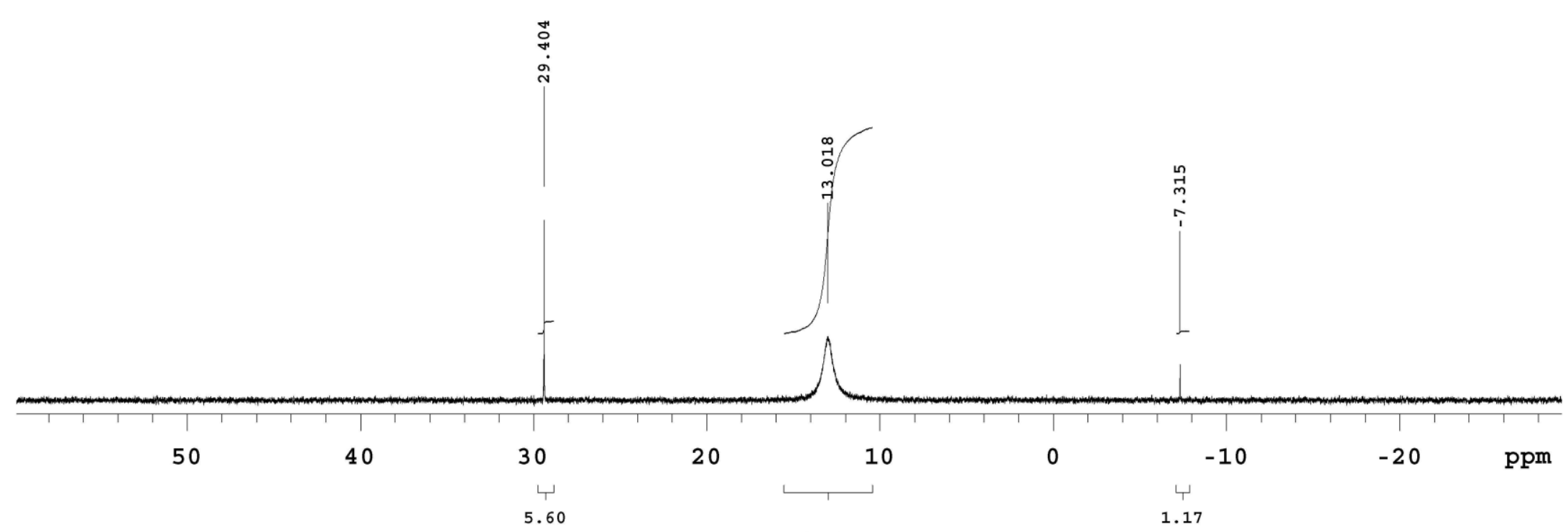

93.23 


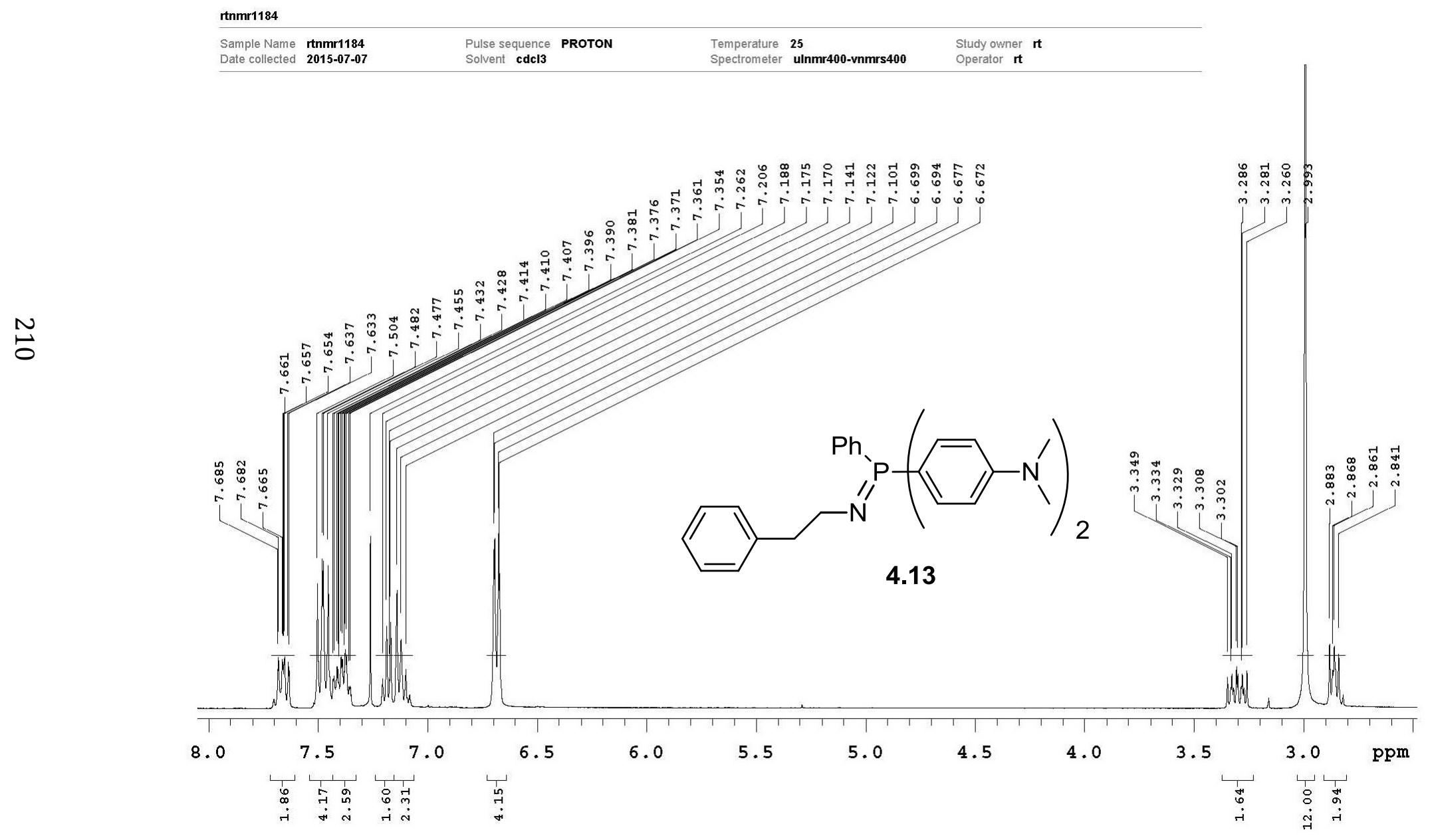




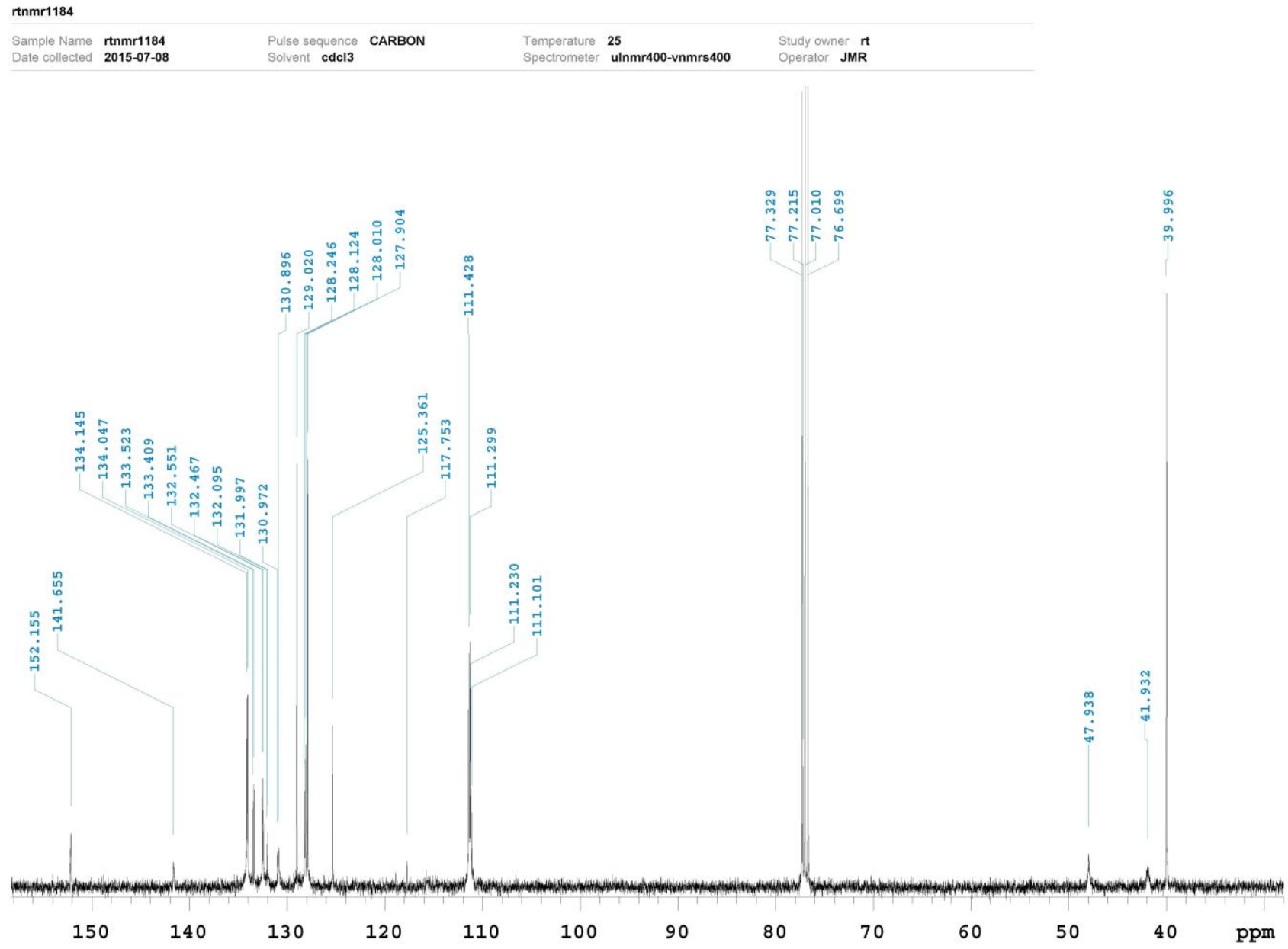


rtnmr118

Sample Name rnmr1184 Pulse sequence PHOSPHORUS
Solvent cdcl3 Temperature 25
Spectrometer ulnmr400-vnmrs400 Study owner $\mathbf{r t}$
Operator $\mathbf{~ r t}$

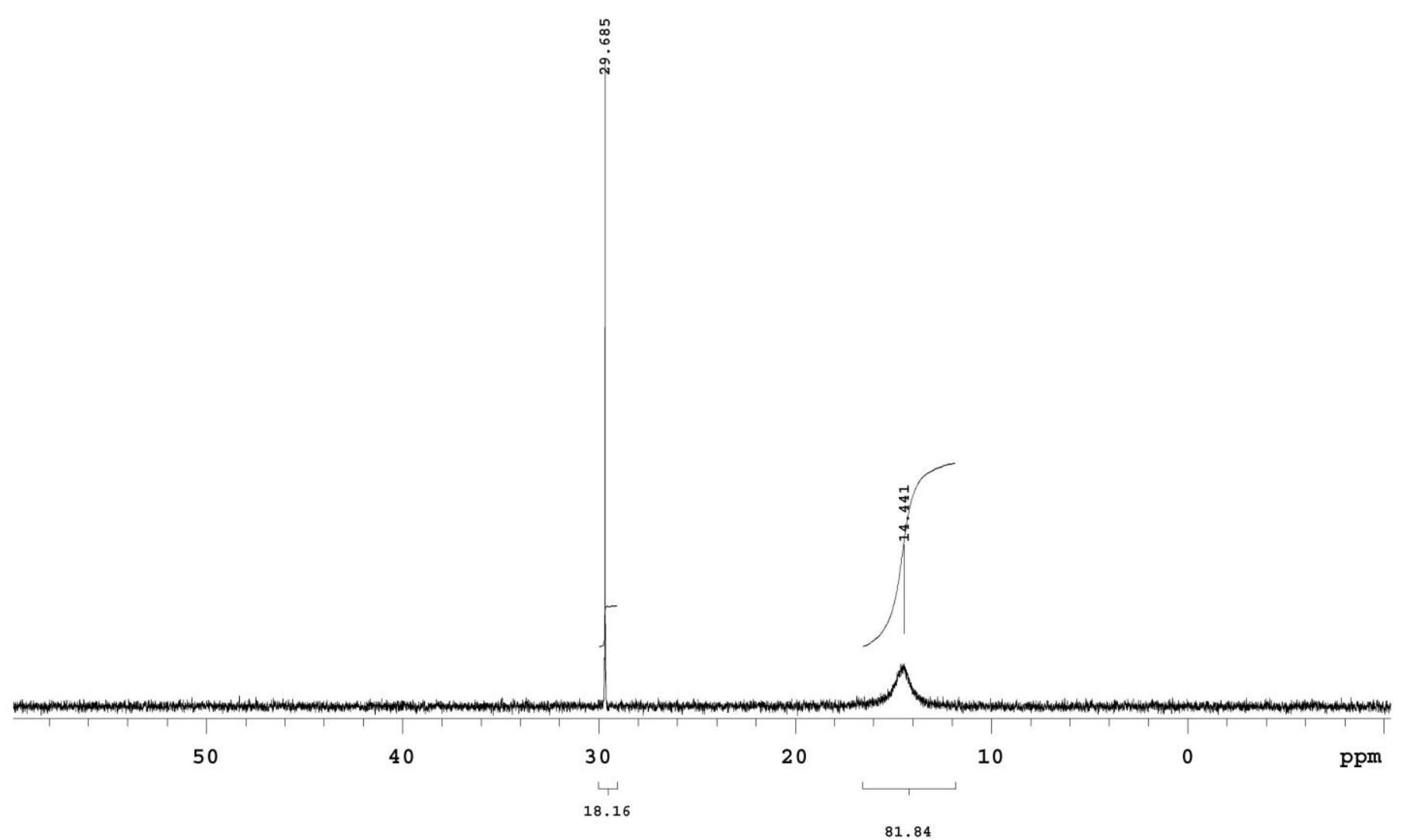




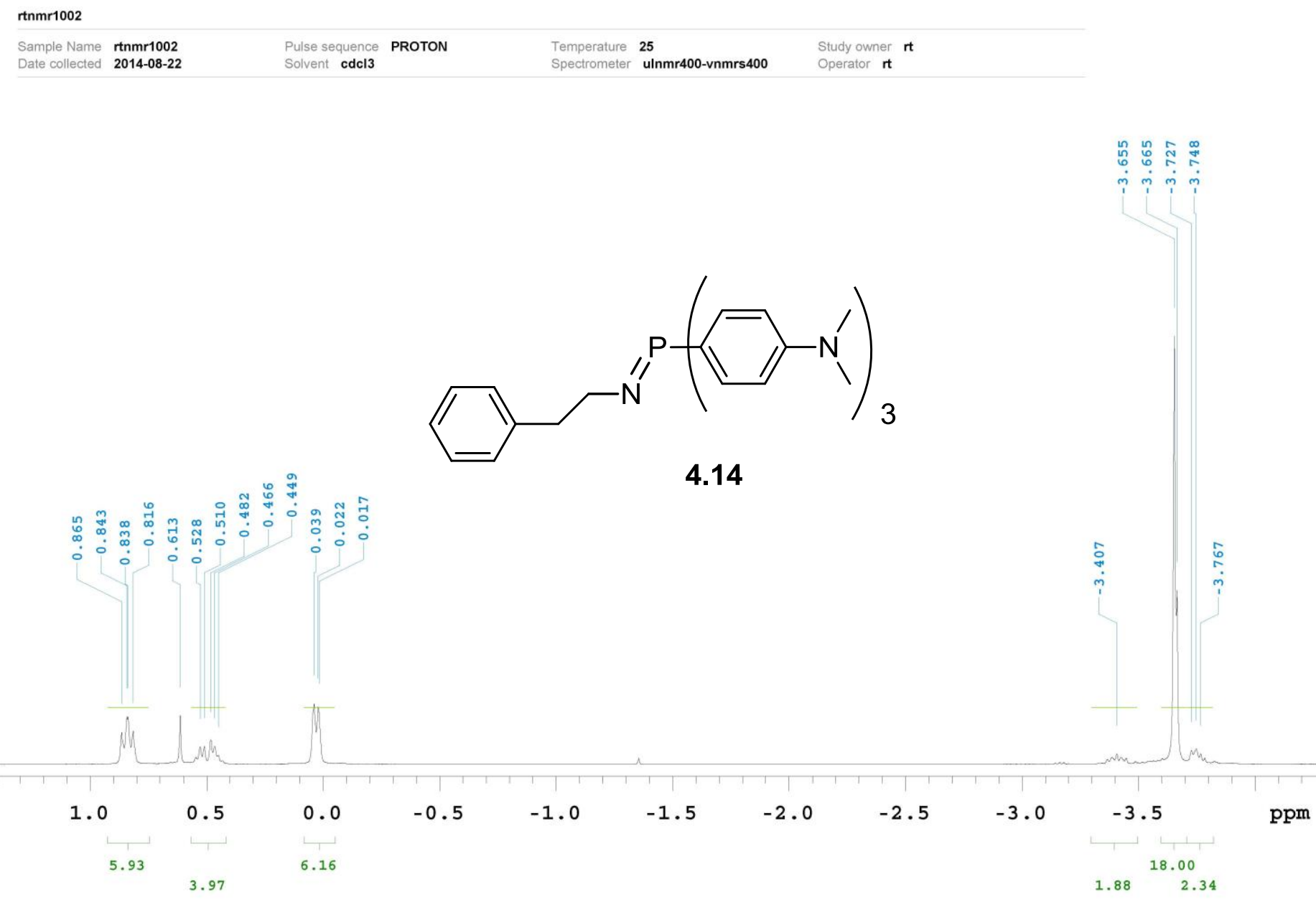




\begin{tabular}{|c|c|c|c|}
\hline $\begin{array}{l}\text { PULSE SEQUENCE } \\
\text { Relax. delay } 1.000 \text { sec } \\
\text { Pulse } 45.0 \text { degrees } \\
\text { Acq. time } 1.311 \mathrm{sec} \\
\text { Width } 25000.0 \mathrm{~Hz} \\
5000 \text { repetitions }\end{array}$ & $\begin{array}{l}\text { OBSERVE C13, } 100.4888450 \\
\text { DECOUPLE H1, } 399.6388631 \\
\text { POwer } 41 \mathrm{~dB} \\
\text { Continuously on } \\
\text { WALTI-16 modulated }\end{array}$ & $\begin{array}{l}\text { DATA PROCESSING } \\
\text { Line broadening } 2.0 \mathrm{~Hz} \\
\text { FT size } 65556 \\
\text { Total time } 3.2 \text { hours }\end{array}$ & $\begin{array}{l}\text { rtnmr1002 } \\
\text { aug 22, } 14 \\
\text { Solvent: cdc13 } \\
\text { Ambient temperature } \\
\text { Sample \#9, operator: rt } \\
\text { File: CARBon-001 } \\
\text { UWMRS-400 "ulnmr400" }\end{array}$ \\
\hline
\end{tabular}

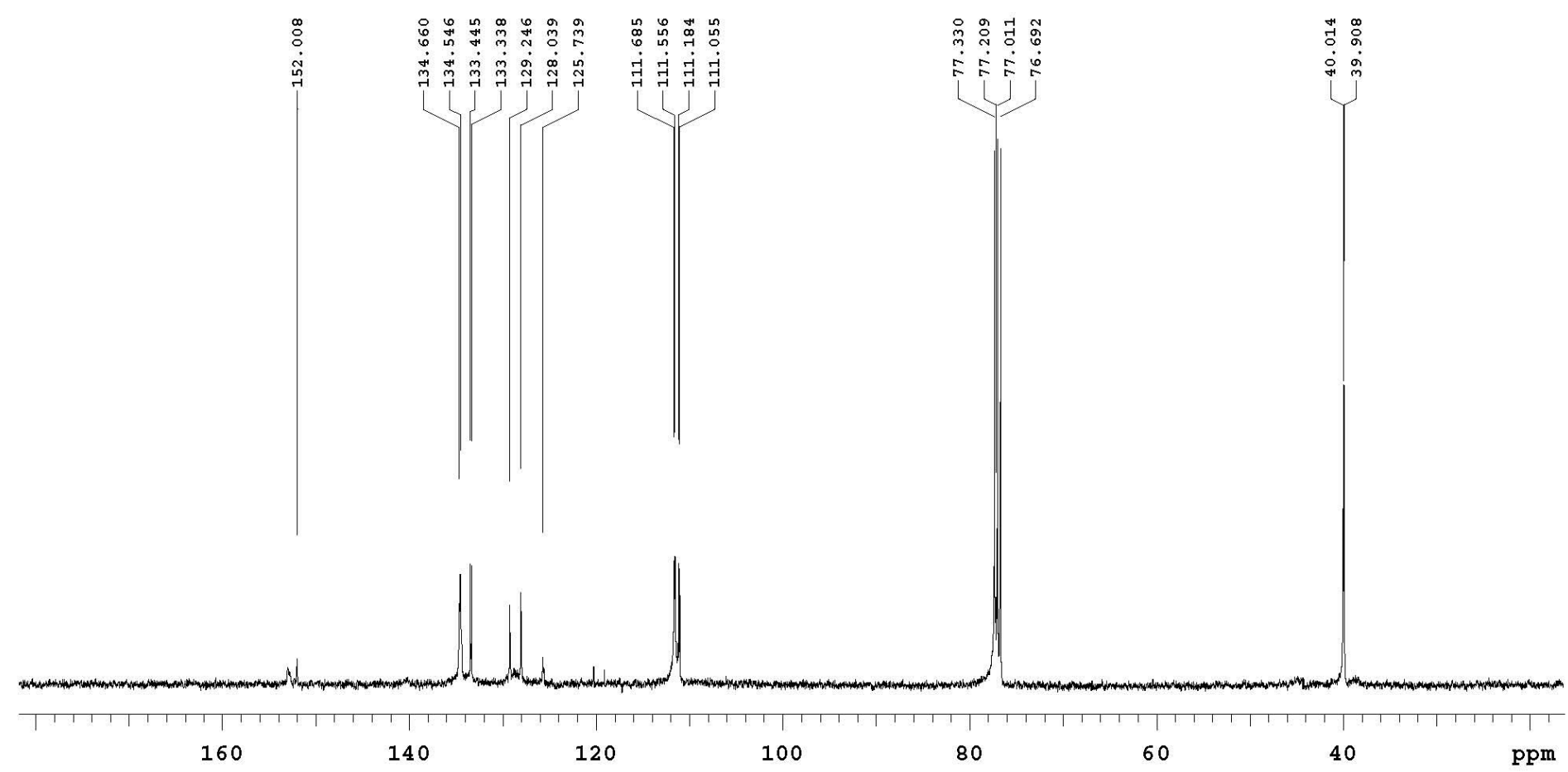




\section{rtnmr1002}

$\begin{array}{ll}\text { Sample Name } & \text { rtnmr1002 } \\ \text { Date collected } & \text { 2014-08-22 }\end{array}$ Pulse sequence
Solvent cdc13

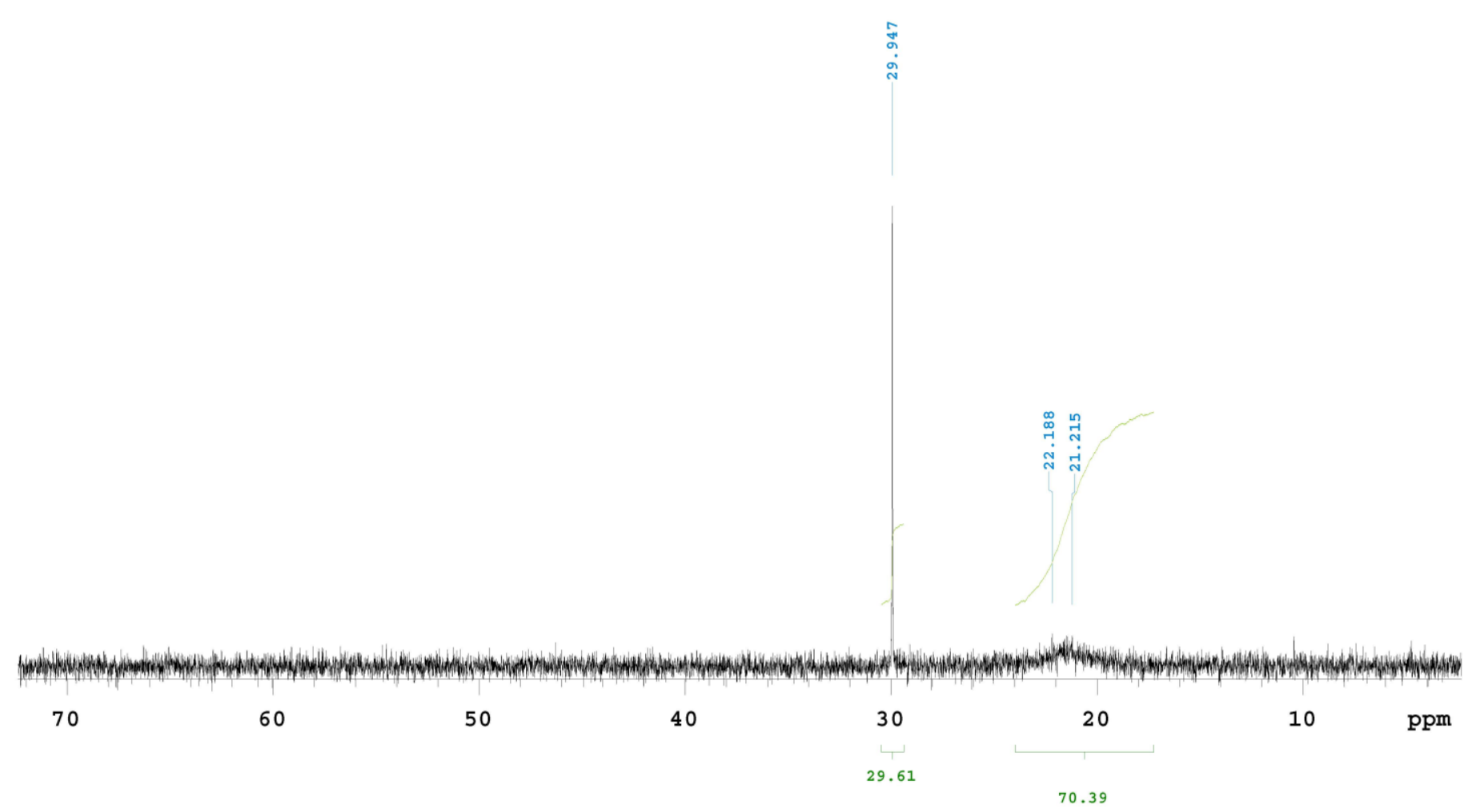


EMD-NMR-031

Sample Name EMD-NMR-031
Date collected 2014-07-06

Pulse sequence PROTON

$\begin{array}{ll}\text { Temperature } 25 & \begin{array}{l}\text { Study owner burnsUG } \\ \text { Operator burnsUG }\end{array}\end{array}$

$\stackrel{\sim}{\sigma}$
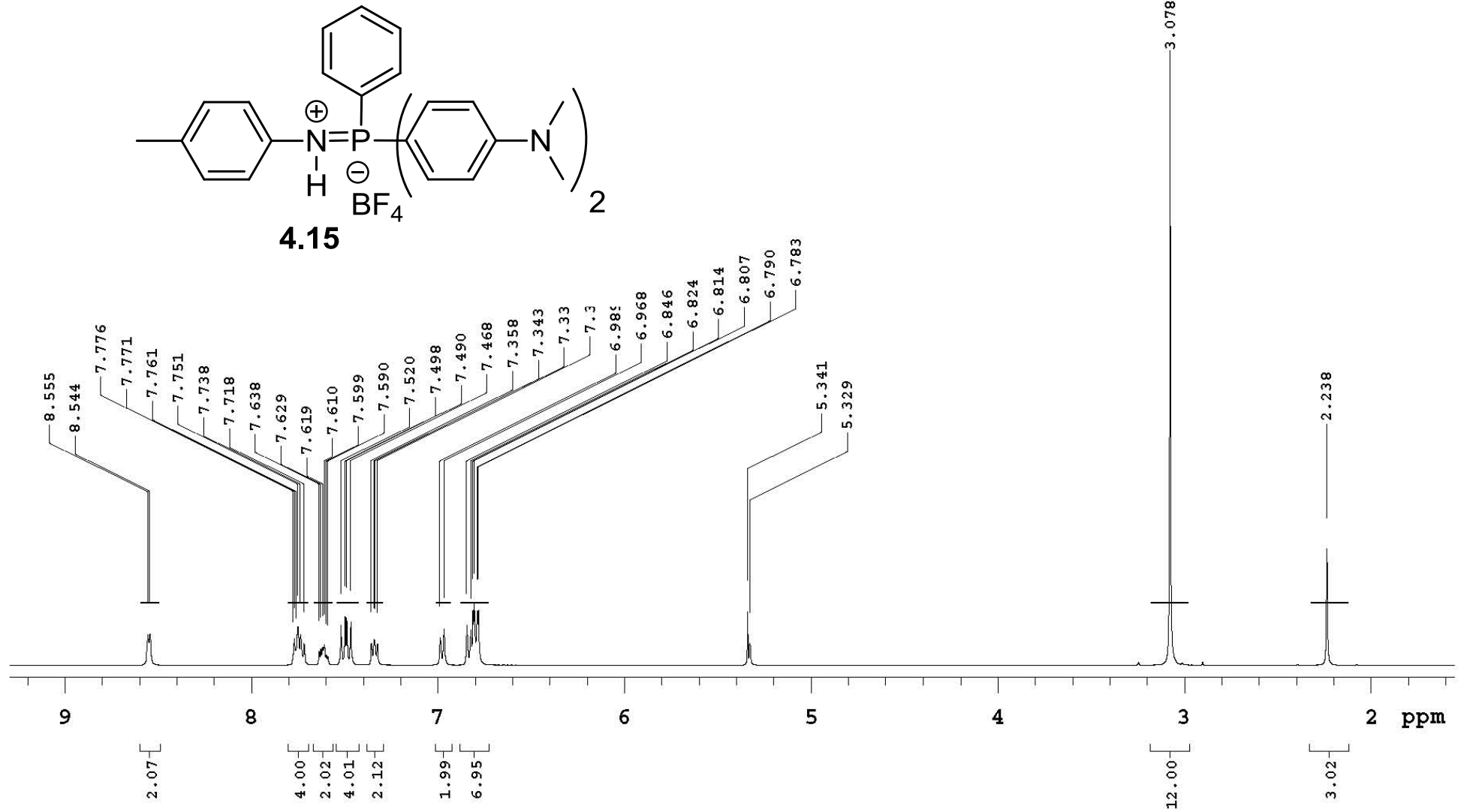


\section{EMD-NMR-031}

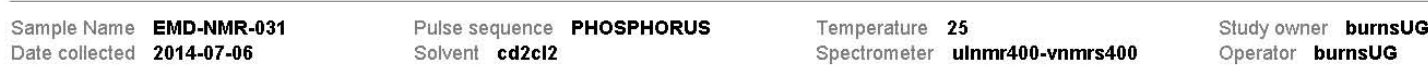

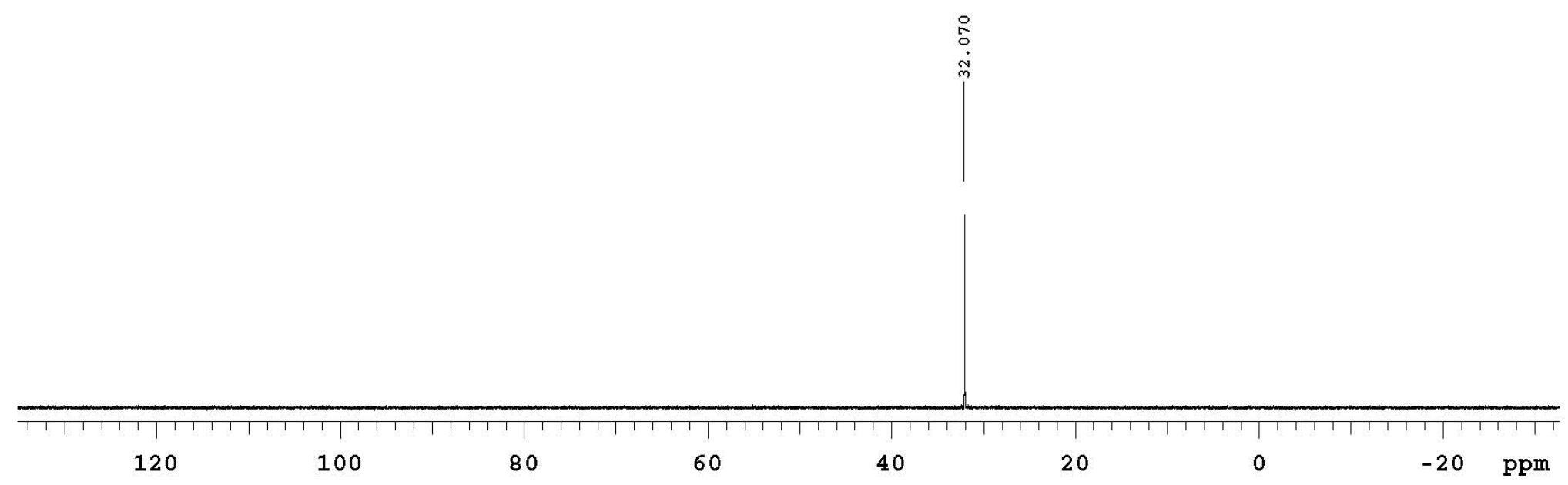


Sample Name EMD-NMR-031 $\quad$ Pulse sequence BORON $\quad$ Temperature $25 \quad$ Study owner burnsUG

Date collected 2014-07-06 $\quad$ Solvent $\mathbf{c d 2 c 1 2}$ Spectrometer ulnmr400-vnmrs400 Operator burnsUG

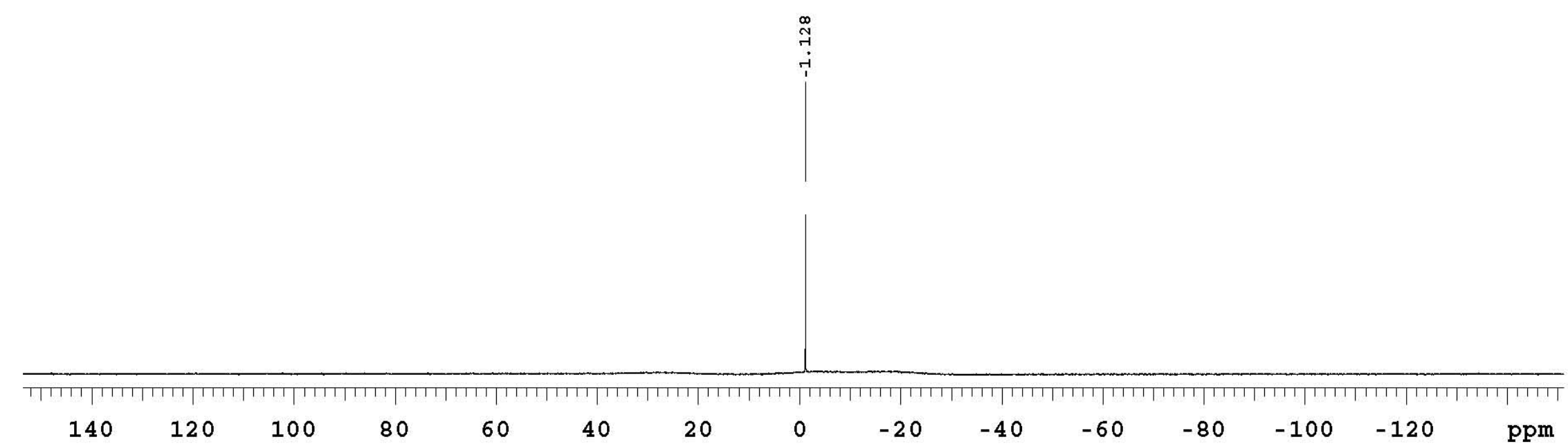


EMD-NMR-031

Sample Name EMD-NMR-031 Pulse sequence FLUORINE

Date collected 2014-07-06

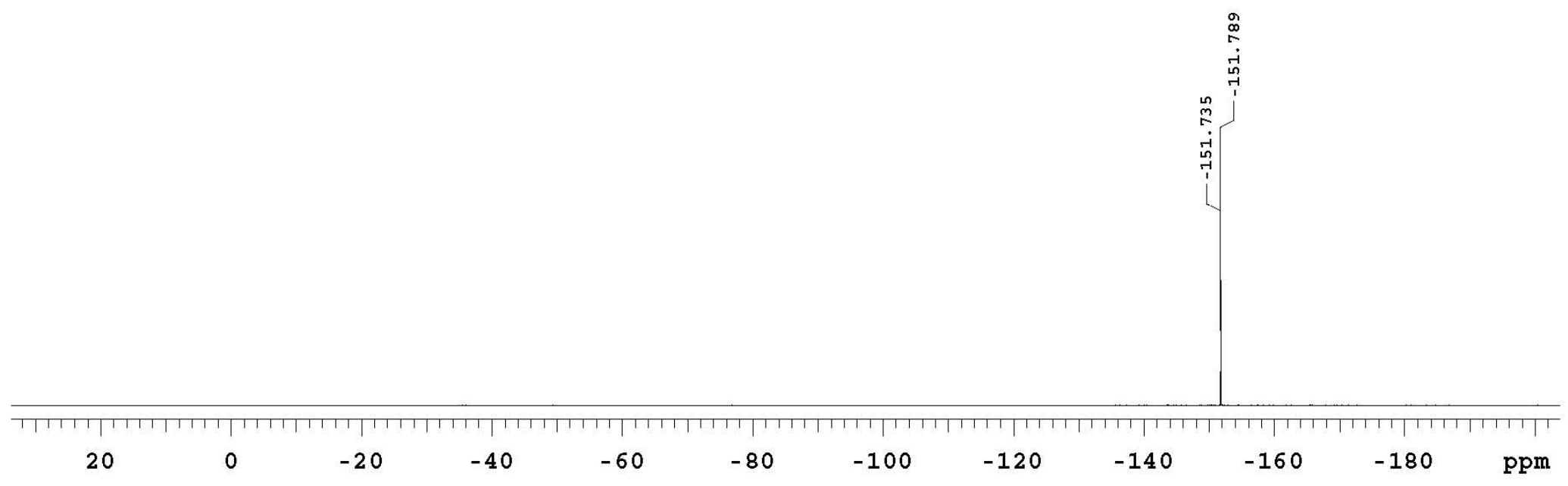


EMD-NMR-032

Sample Name EMD-NMR-032 Pulse sequence PROTON Temperature 25
Spectrometer
ulnmr400-vnmrs400

Study owner burnsug Solvent cd2c12

$$
\text { PROTON }
$$
Spectrometer ulnmr400-vnmrs400

Operator burnsug
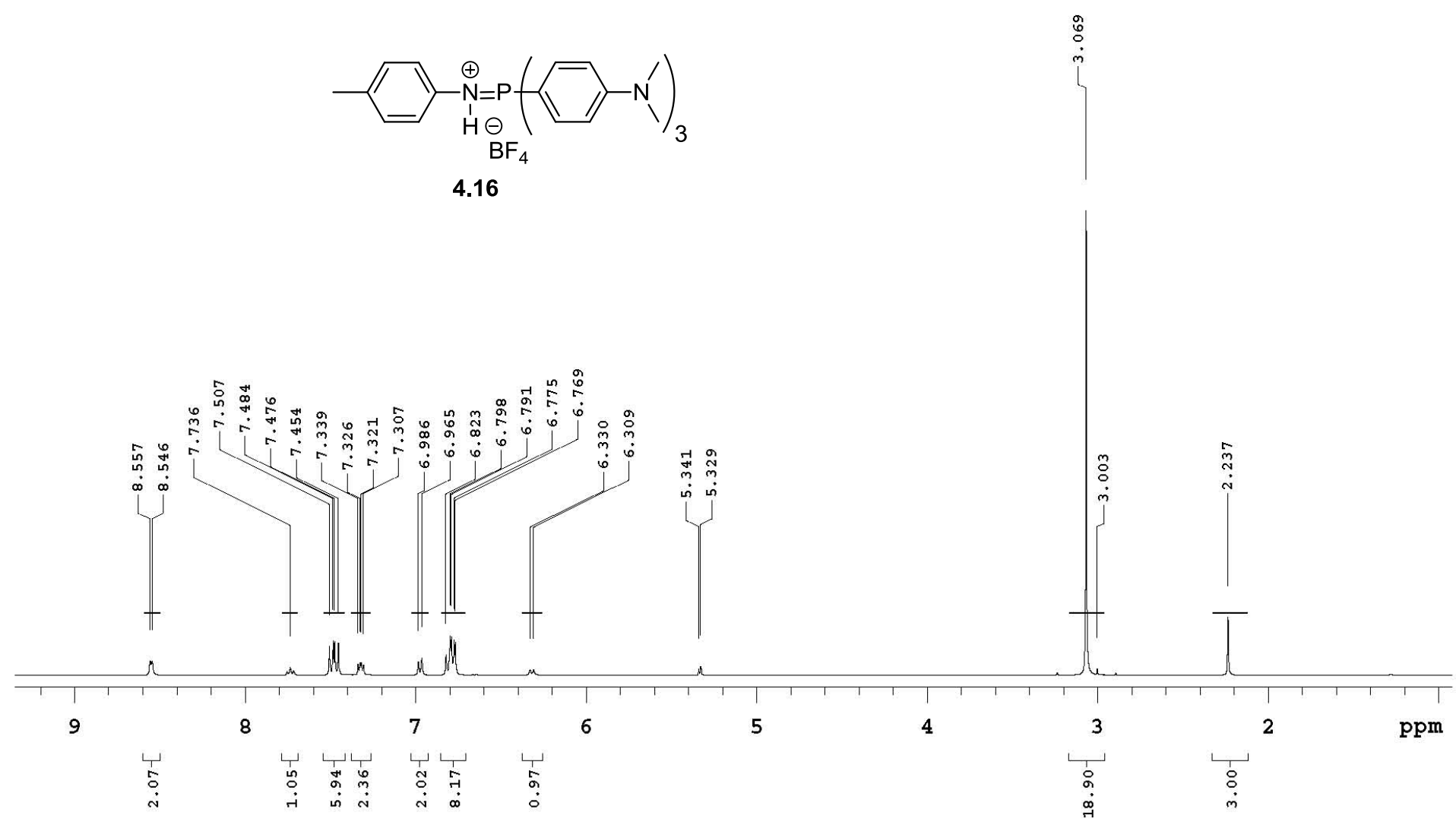


\section{EMD-NMR-032}

Sample Name EMD NMR-032

Date collected 2014-07-06

Pulse sequence PHOSPHORUS

Temperature 25

Spectrometer ulnmr400-vnmrs400

Study owner burnsuG

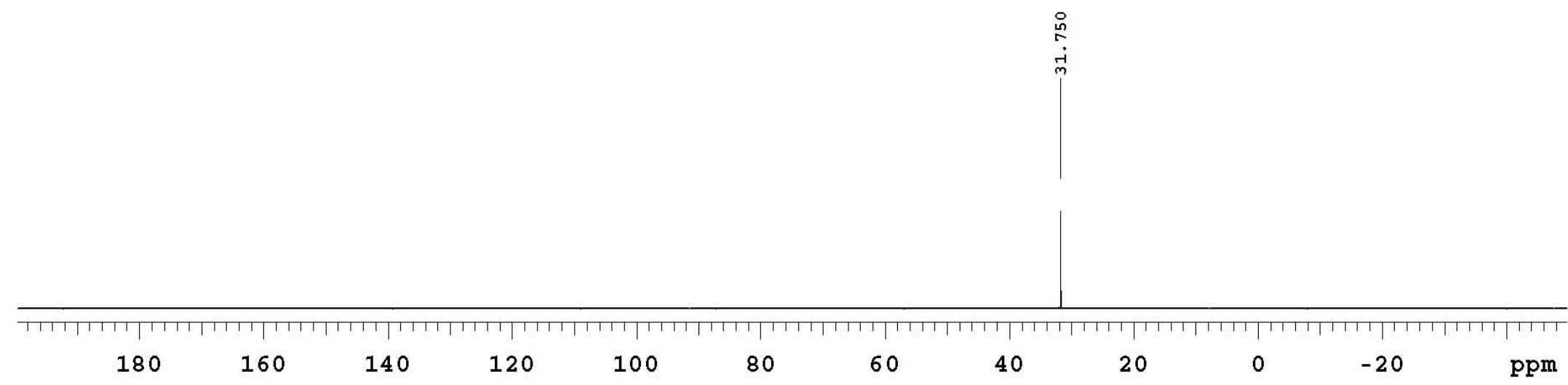




\section{EMD-NMR-032}

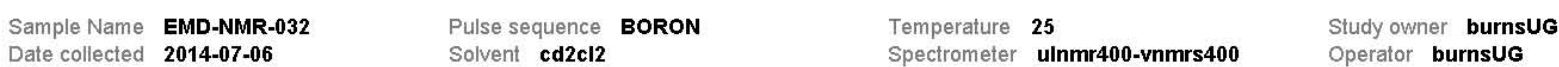

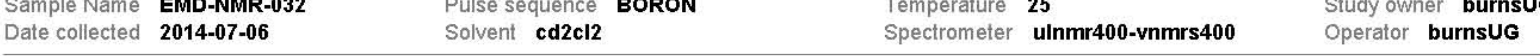

N

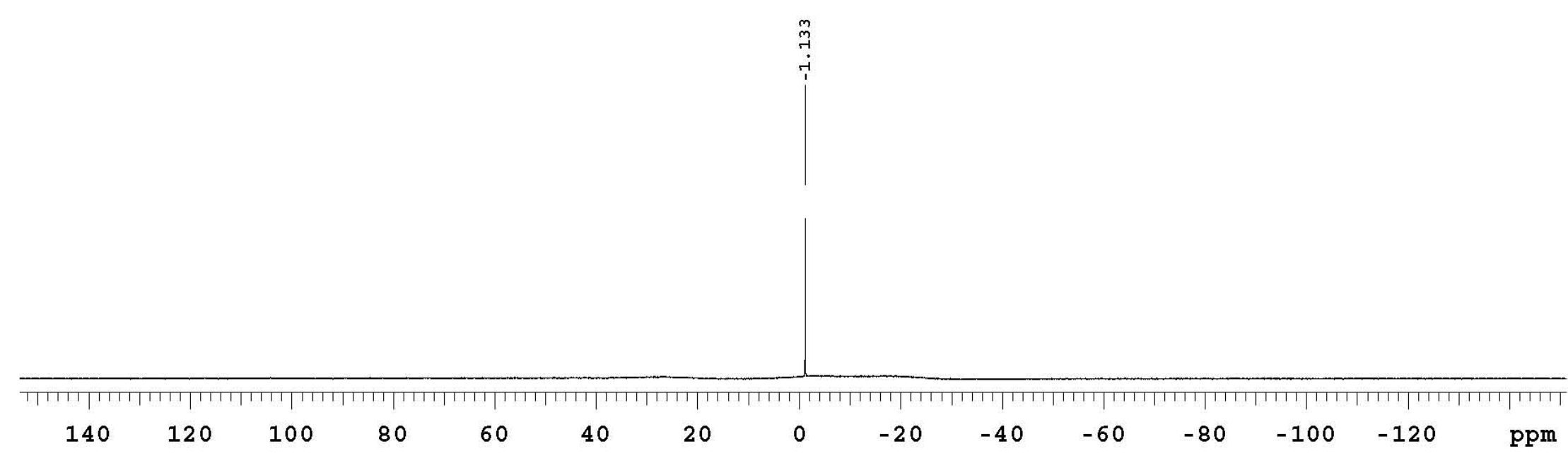




\section{EMD-NMR-032}

Sample Name EMD-NMR-032 Pulse sequence FLUORINE

Date collected 2014-07-06

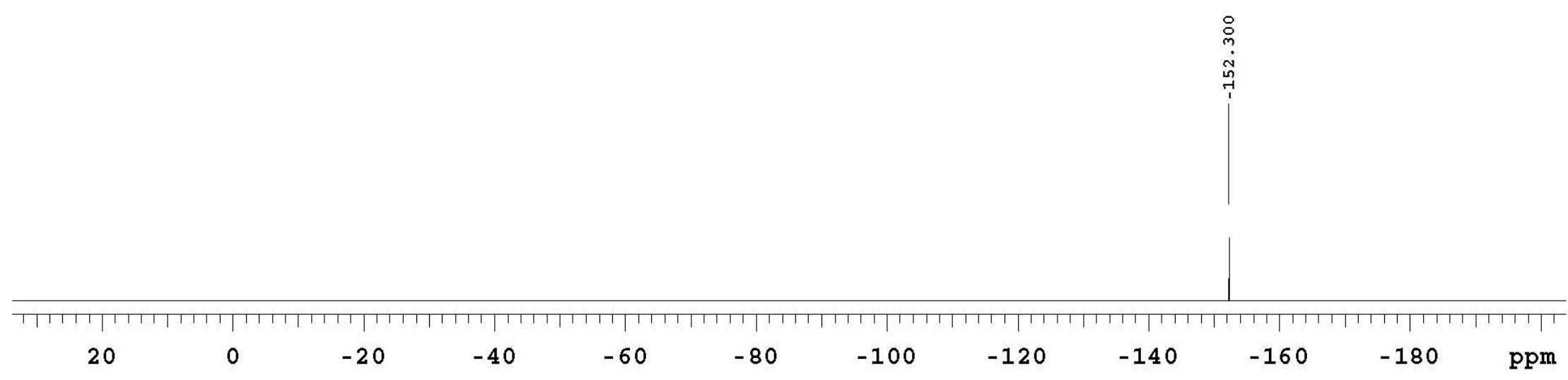


9-Anthracenethanol in $\mathrm{C}_{6} \mathrm{D}_{6}$

rnmm865

$\begin{array}{ll}\text { Sample Name rtnmr865 } \\ \text { Date collected } & \text { 2014-05-05 }\end{array}$

Pulse sequence PROTON

Temperature 25

Study owner $\mathbf{n}$

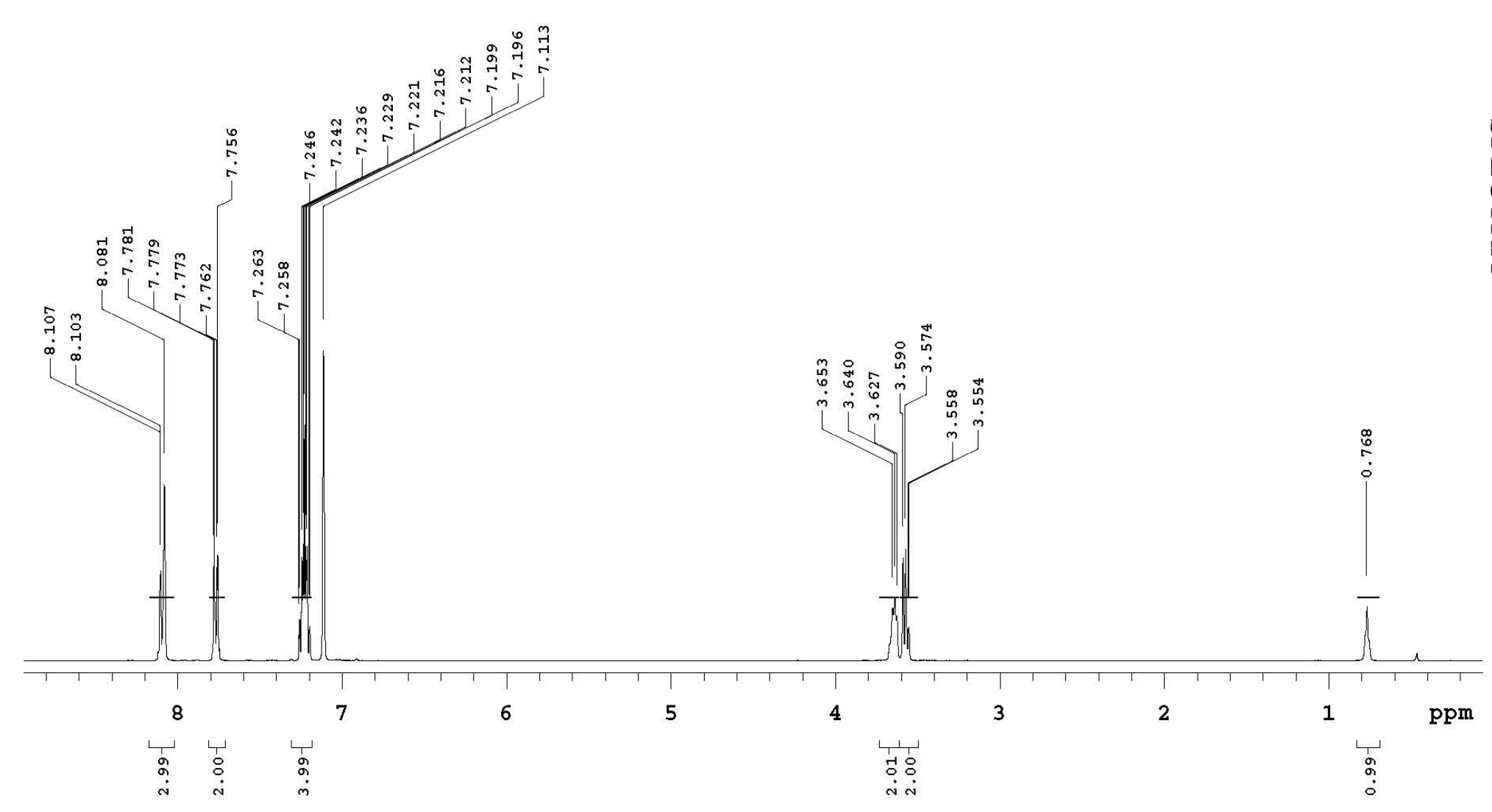

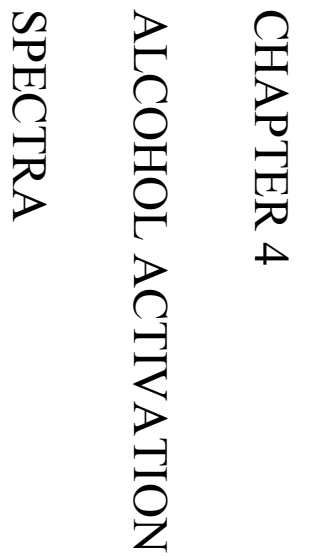

$\stackrel{N}{\perp}$

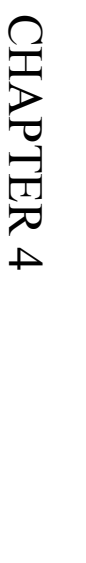


rtnmr1058

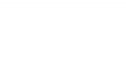

9-Anthracenmethanol in $\mathrm{C}_{6} \mathrm{D}_{6}$

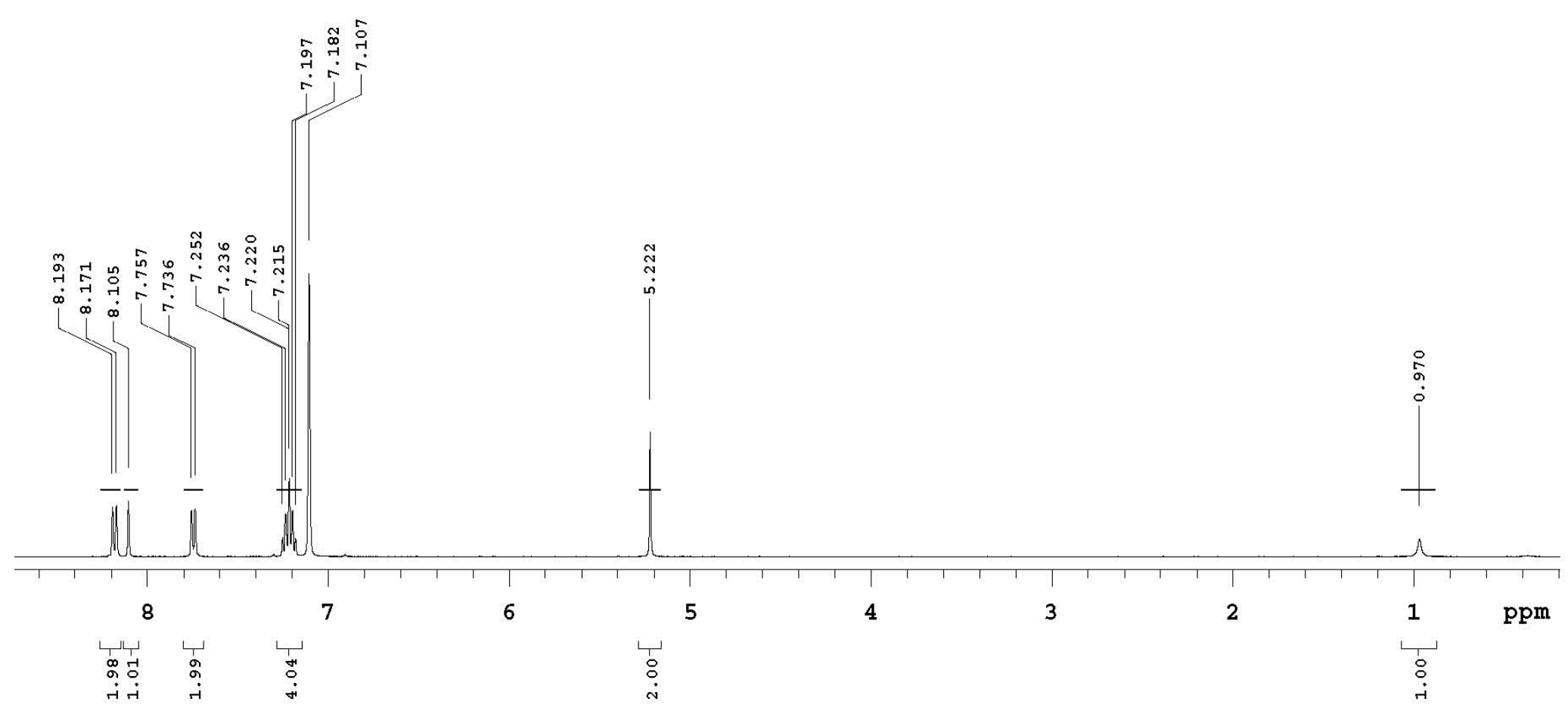




\section{rtnmr866}

Sample Name rtnmr866 rtnmr866
2014-05-05

Solvent c6d6

1-Octadecanol in $\mathrm{C}_{6} \mathrm{D}_{6}$

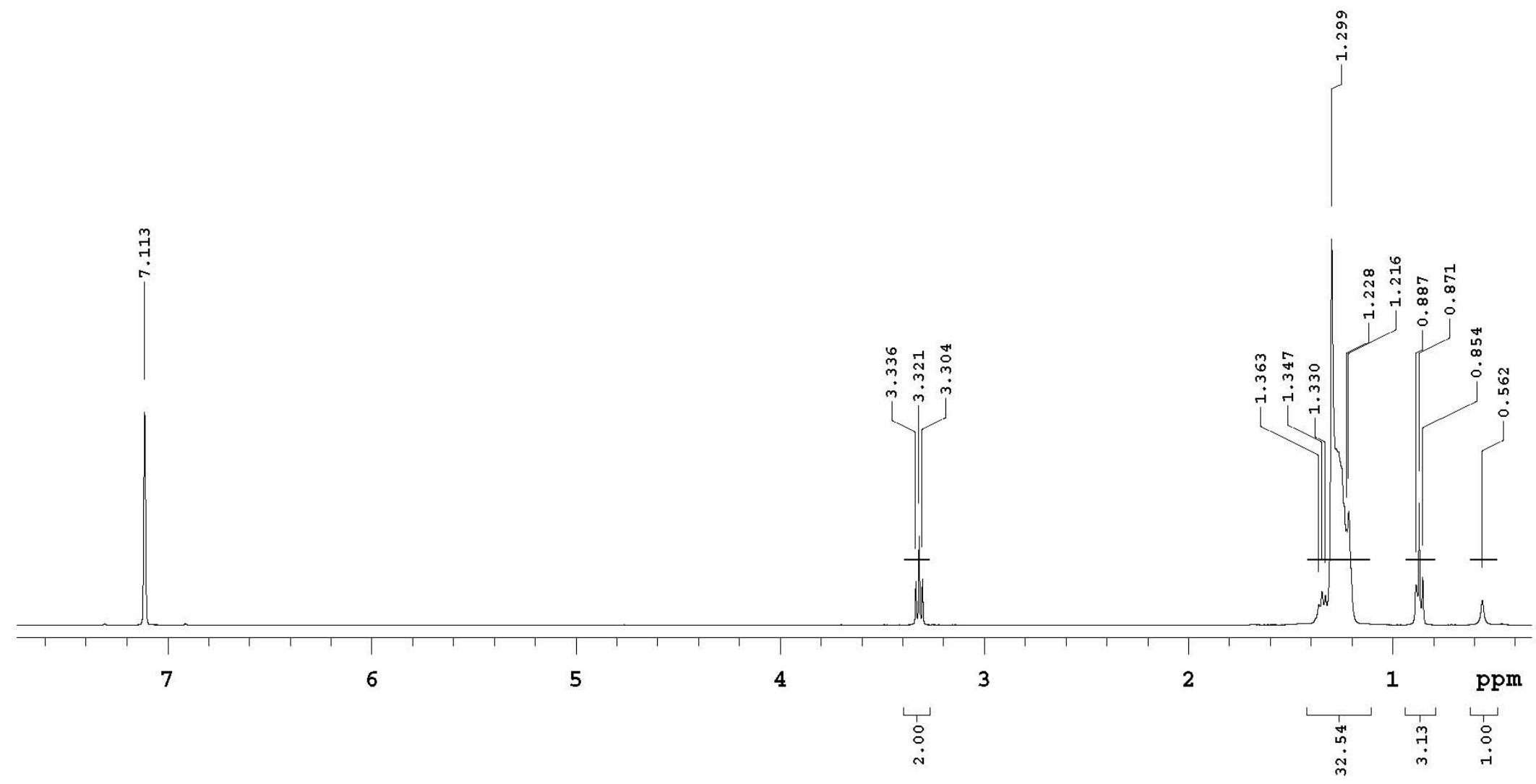


rtnmr870_dmap

Sample Name rnmmr870_dm Date collected 2014-05-07

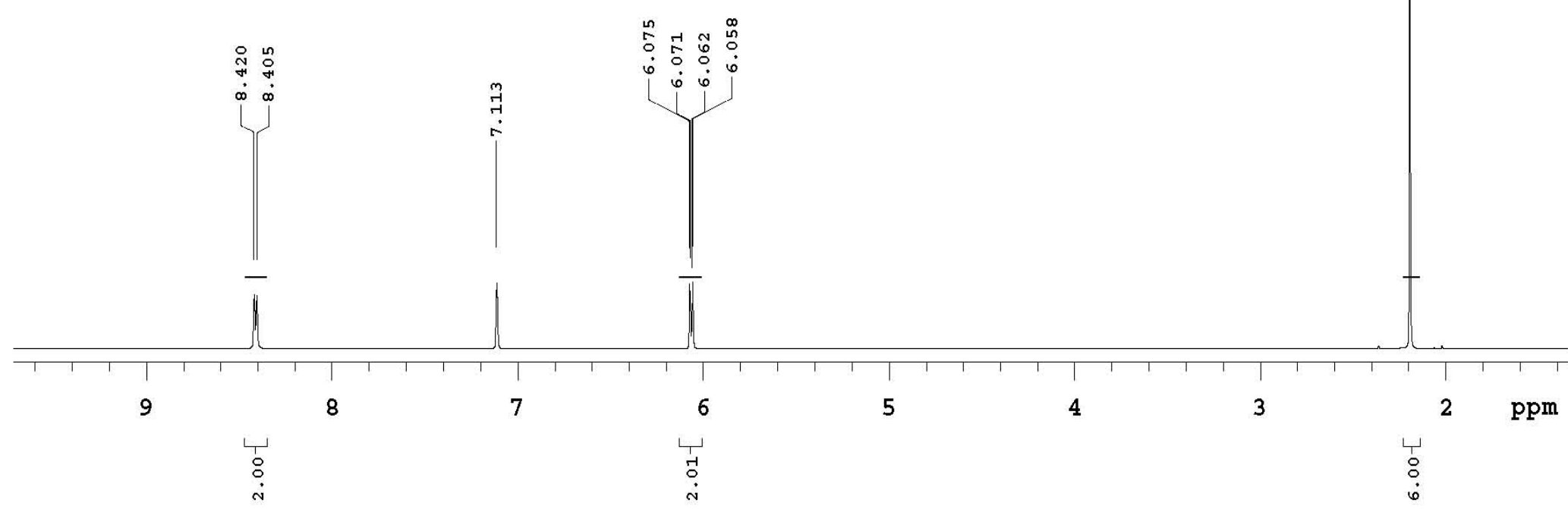


Triazabicyclodecene (TBD) in $\mathrm{C}_{6} \mathrm{D}_{6}$

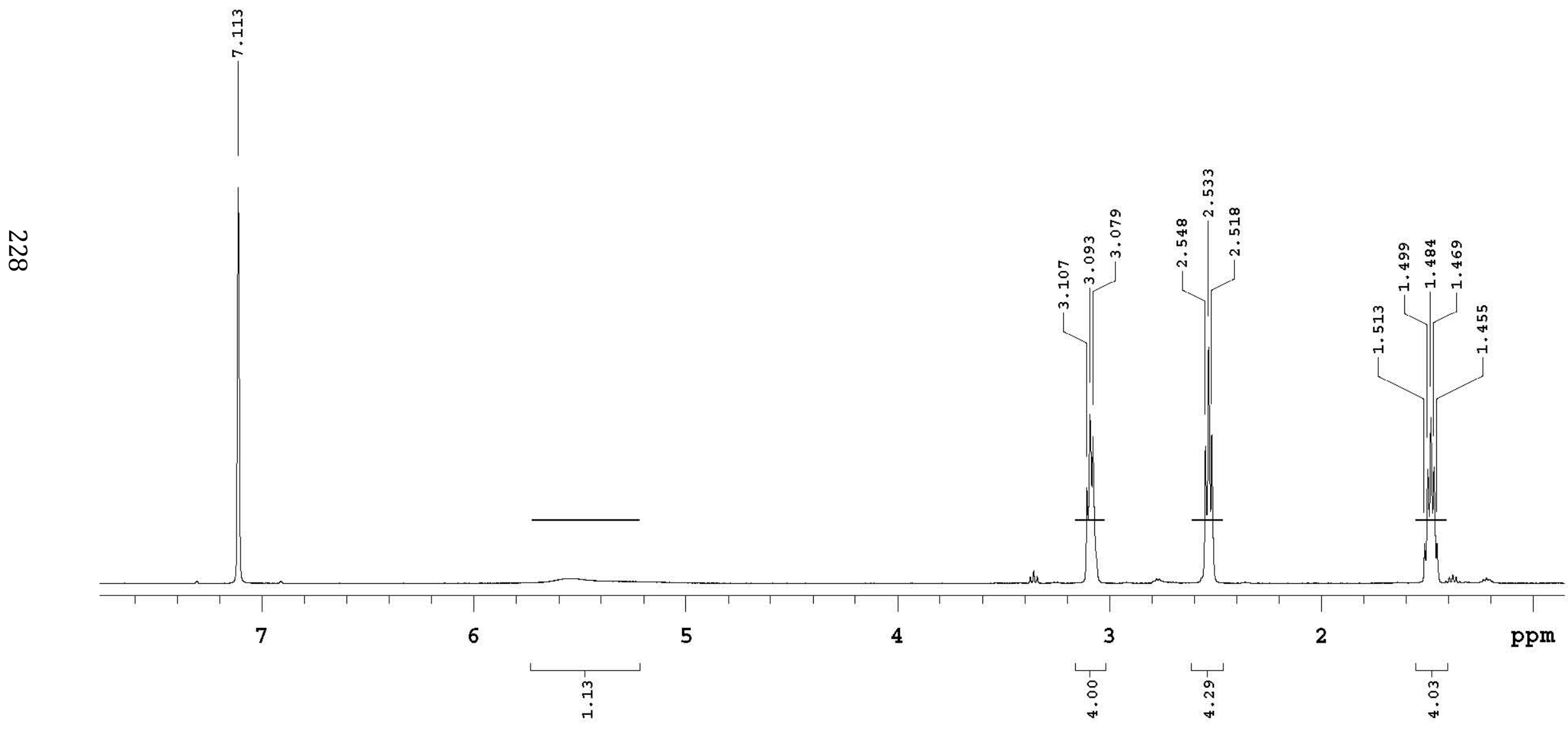


DBU in $\mathrm{C}_{6} \mathrm{D}_{6}$

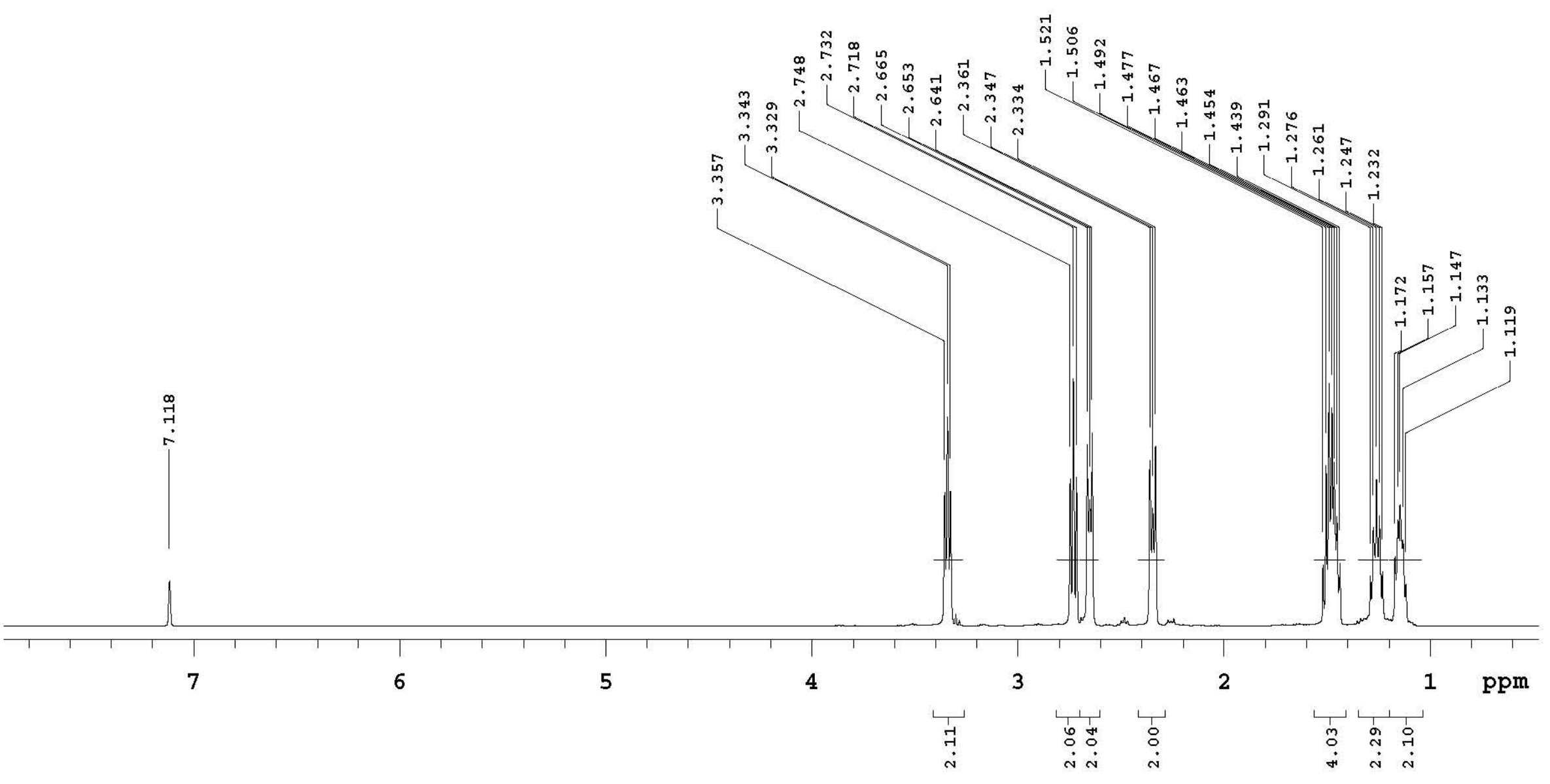




\section{rtnmr868}

Sample Name rtnmr868

rtnmr868
2014-05-07

Pulse sequence PROTON
Solvent c6d6

Temperature 25

ectrometer ulnmr400-vnmrs400

Study owner

DMAP+ 9-Anthrylethanol

$\underset{\tilde{O}}{\sim}$
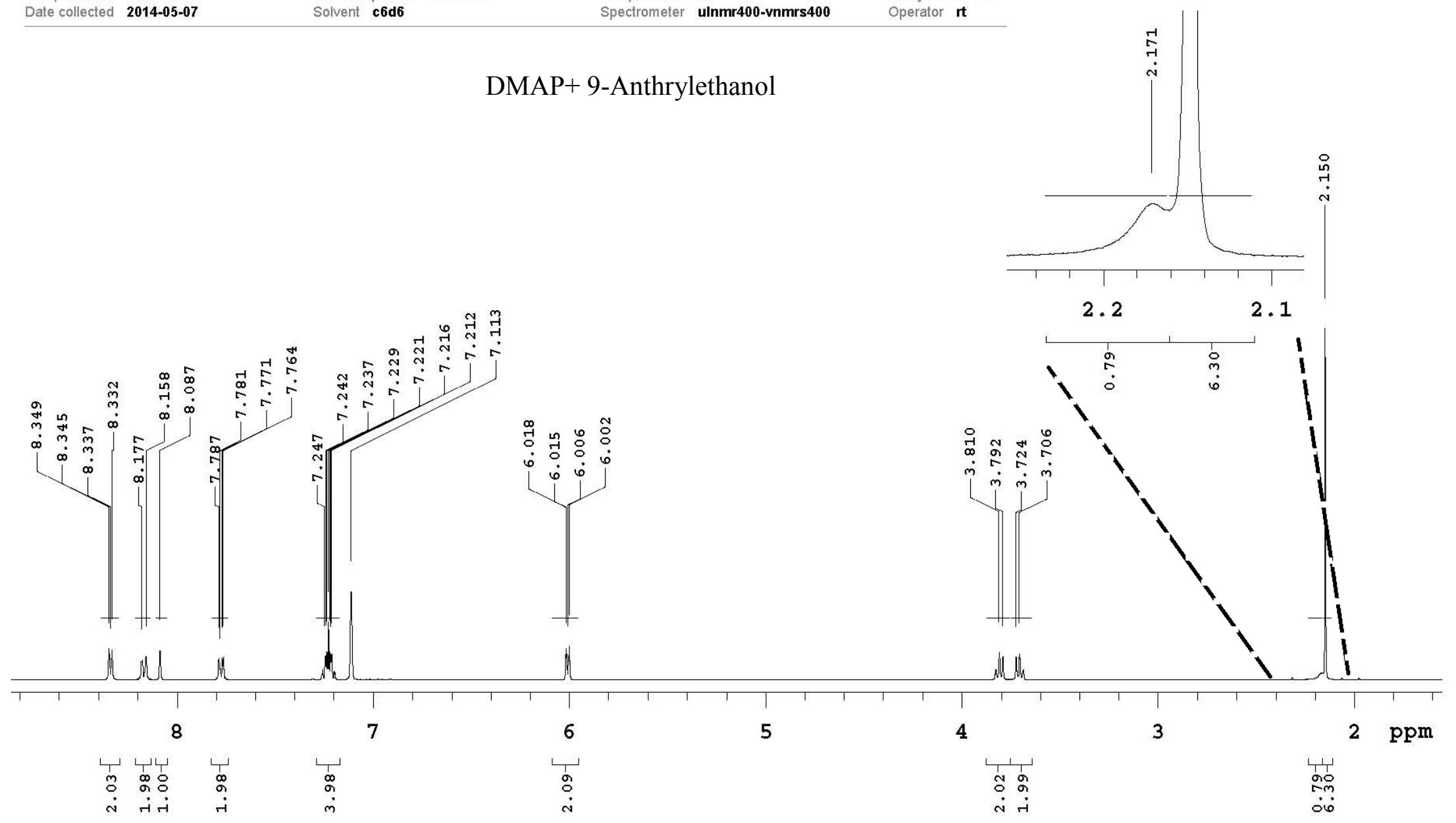
DMAP+9-Anthrylmethanol

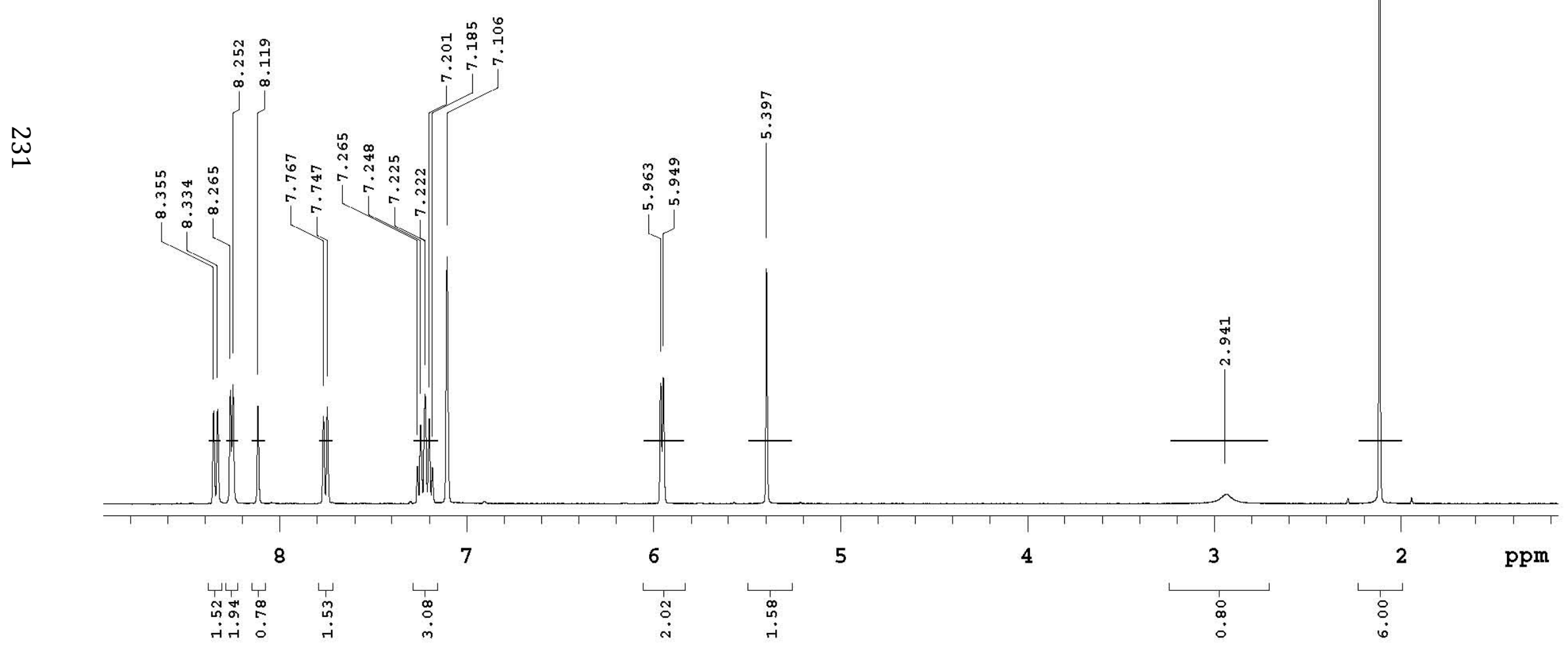




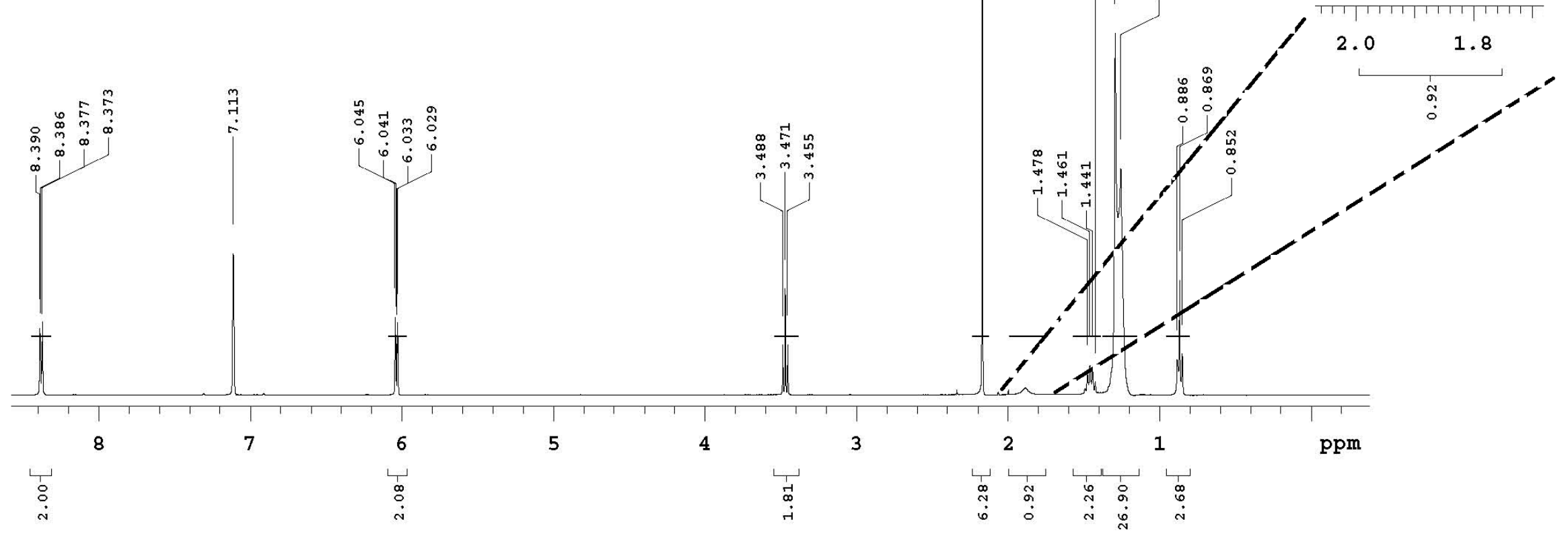


TBD+ 9-Anthrylethanol

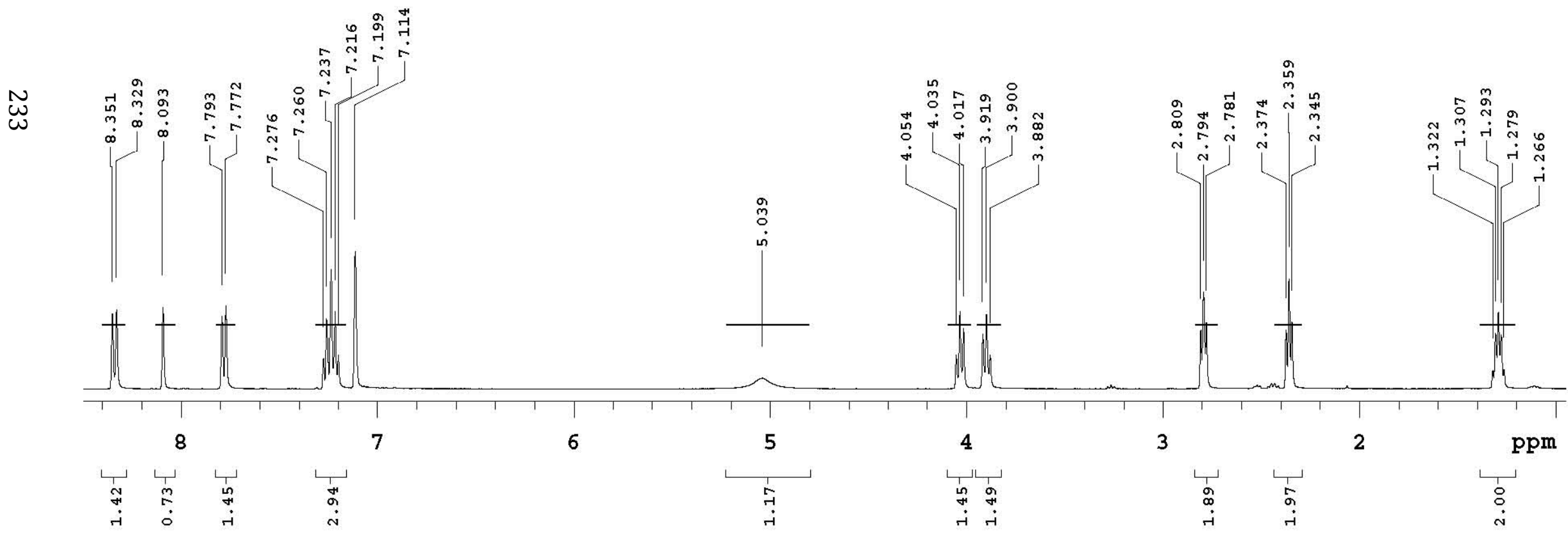


rtnmr873

Sample Name rtnmr873 Date collected 2014-05-07 Pulse sequence PROTON Solvent $\mathbf{c 6 d} 6$ unmr400-vnmrs400 Sludy owner

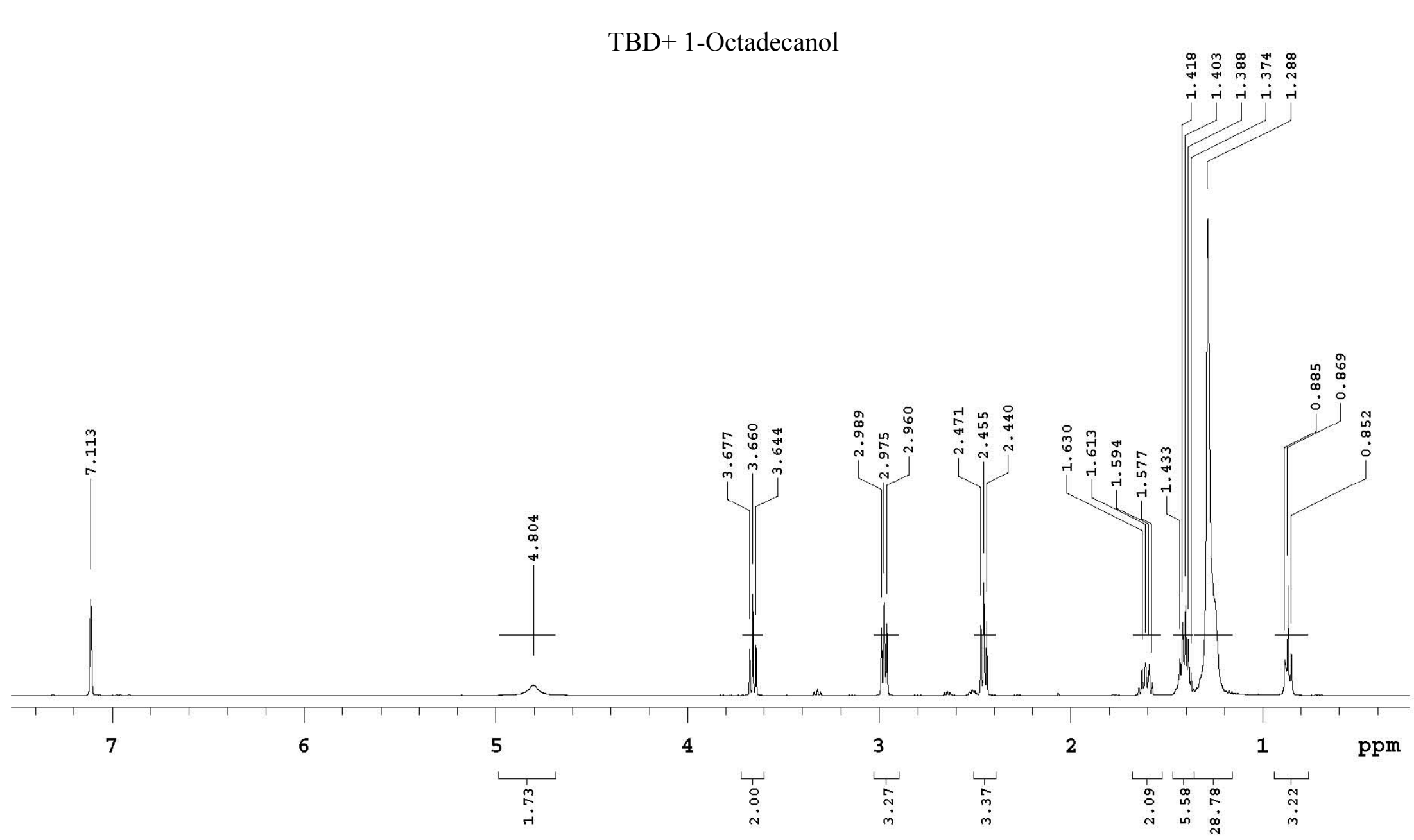


DBU+9-Anthrylethanol

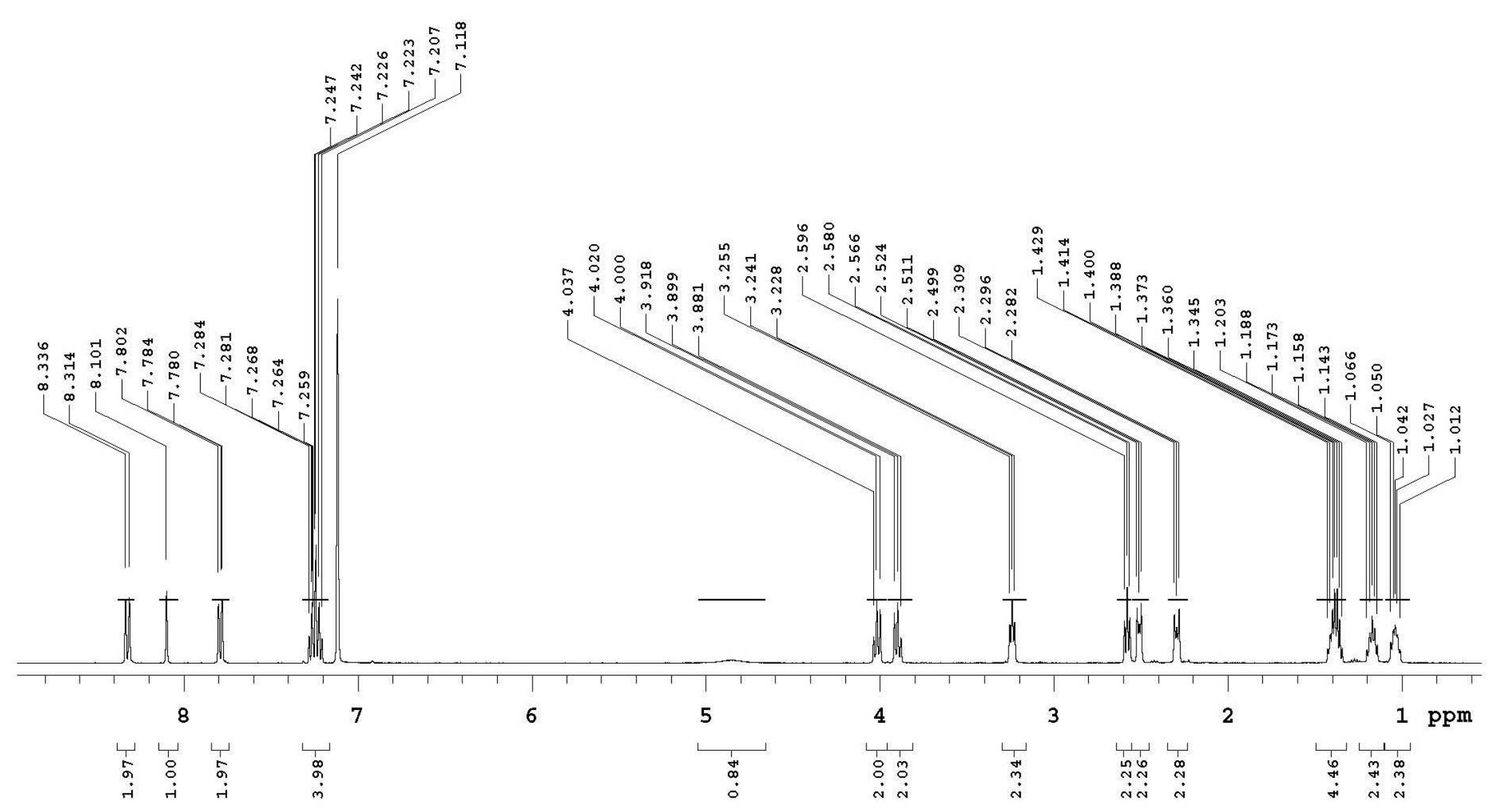




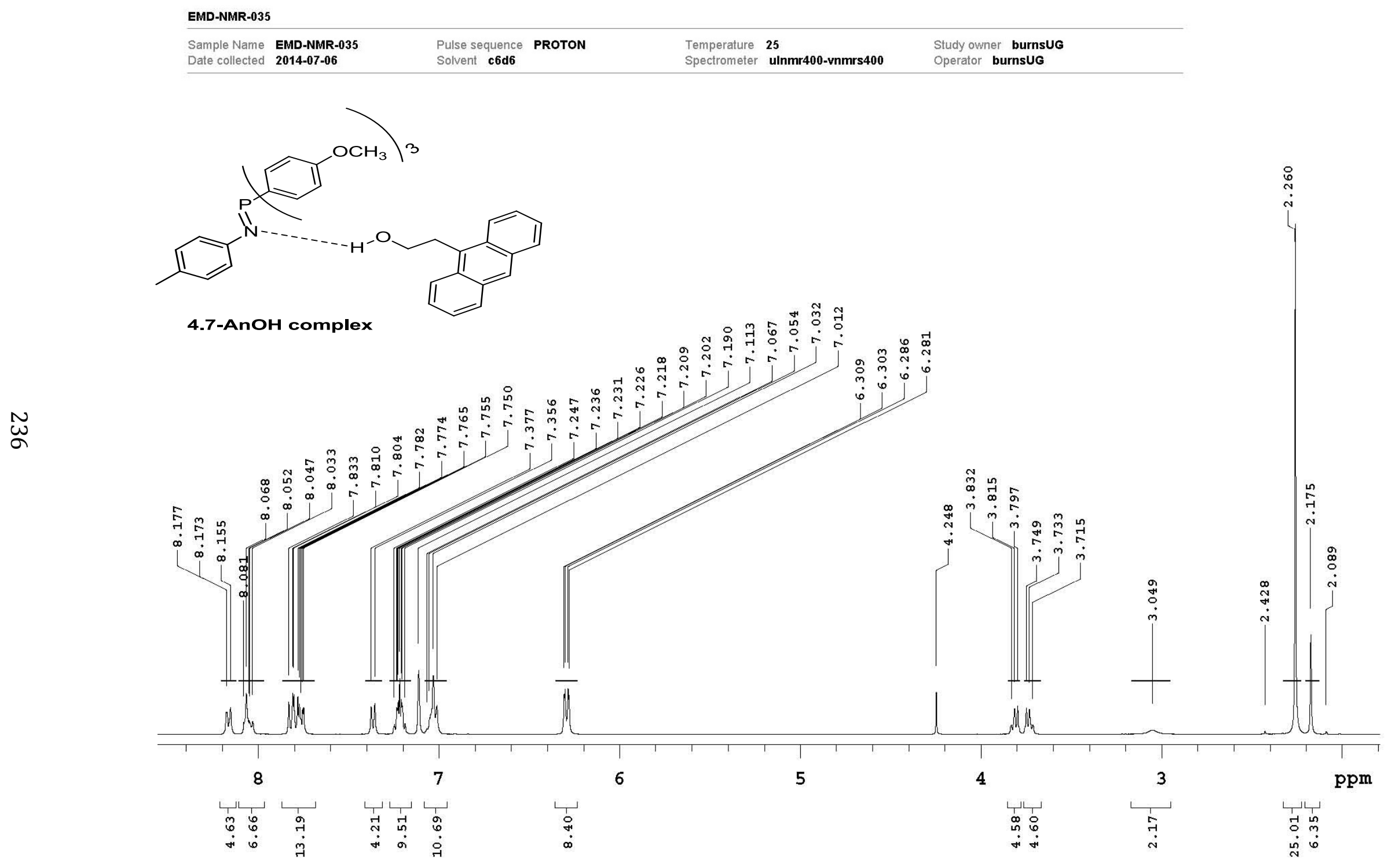


EMD-NMR-035

Sample Name EMD-NMR-035 Pulse sequence PHOSPHORUS

Date collecied

Pulse sequence
Solvent $\mathbf{c 6 d 6}$

Temperature 25

Spectrometer ulnmr400-vnmrs400

Study owner burnsUG

collected 2014-07-06

(2)

$\underset{\text { U }}{\sim}$

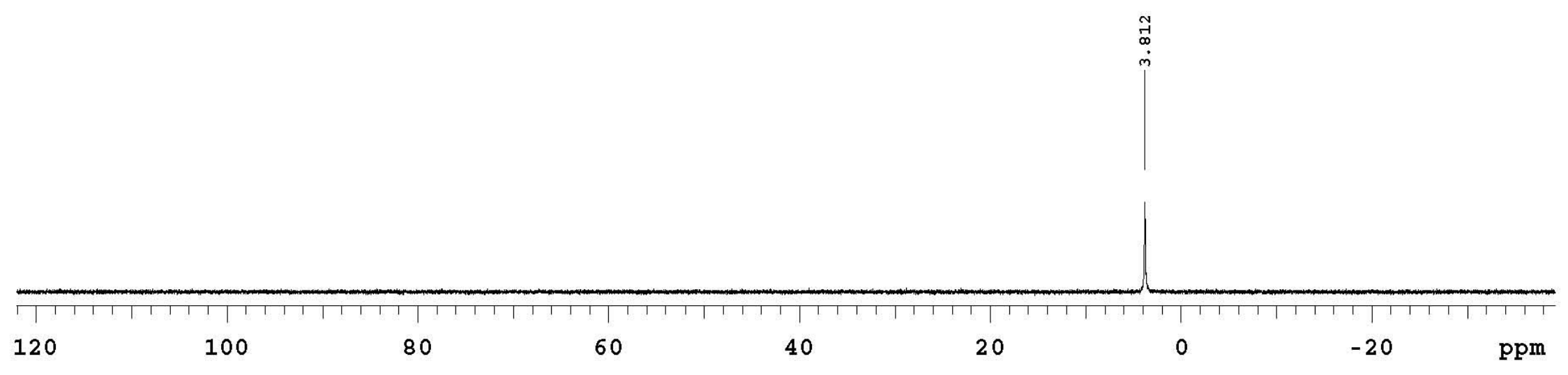




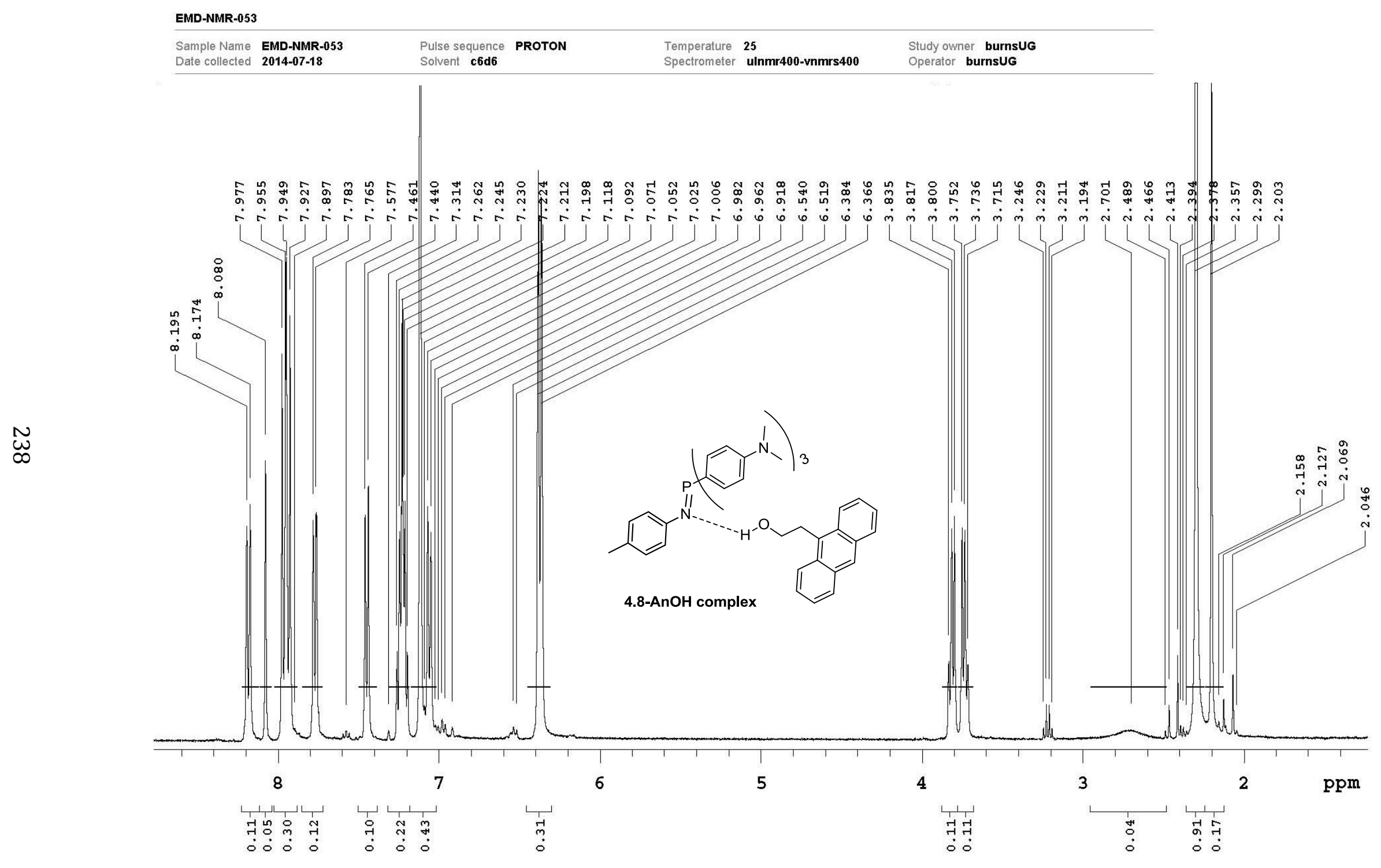




\section{EMD-NMR-053}

Sample Name EMD-NMR-053

Pulse sequence PHOSPHORUS

Date collected

Solvent c6d6

Spectrometer ulnmr400-vnmrs400

Study owner burnsUG

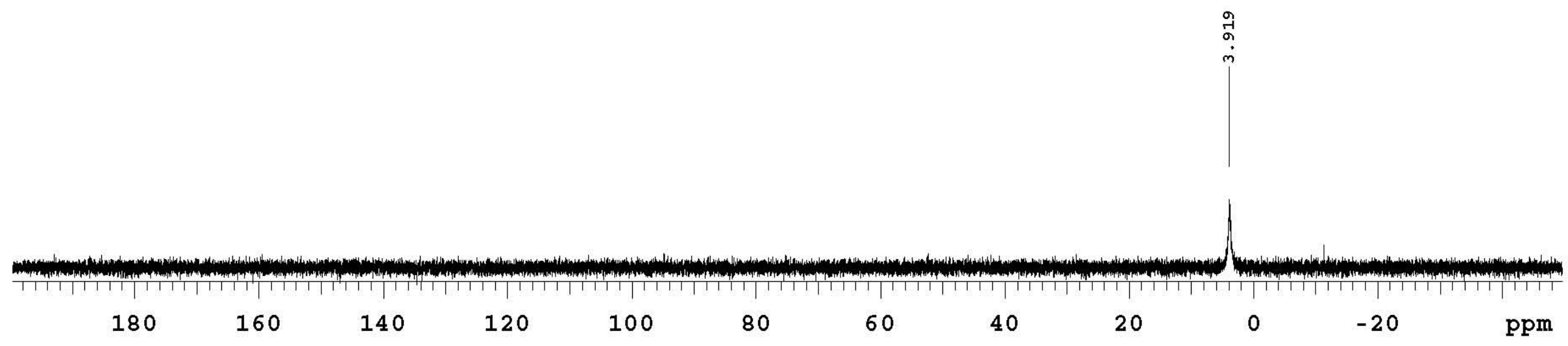




\section{EMD-NMR-033}

\section{Sample Name EMD-NMR-033}

Pulse sequence PROTON

Temperature $\mathbf{2 5}$

tudy owner burnsuG

Solvent c6d6

Spectrometer ulnmr400-vnmrs400

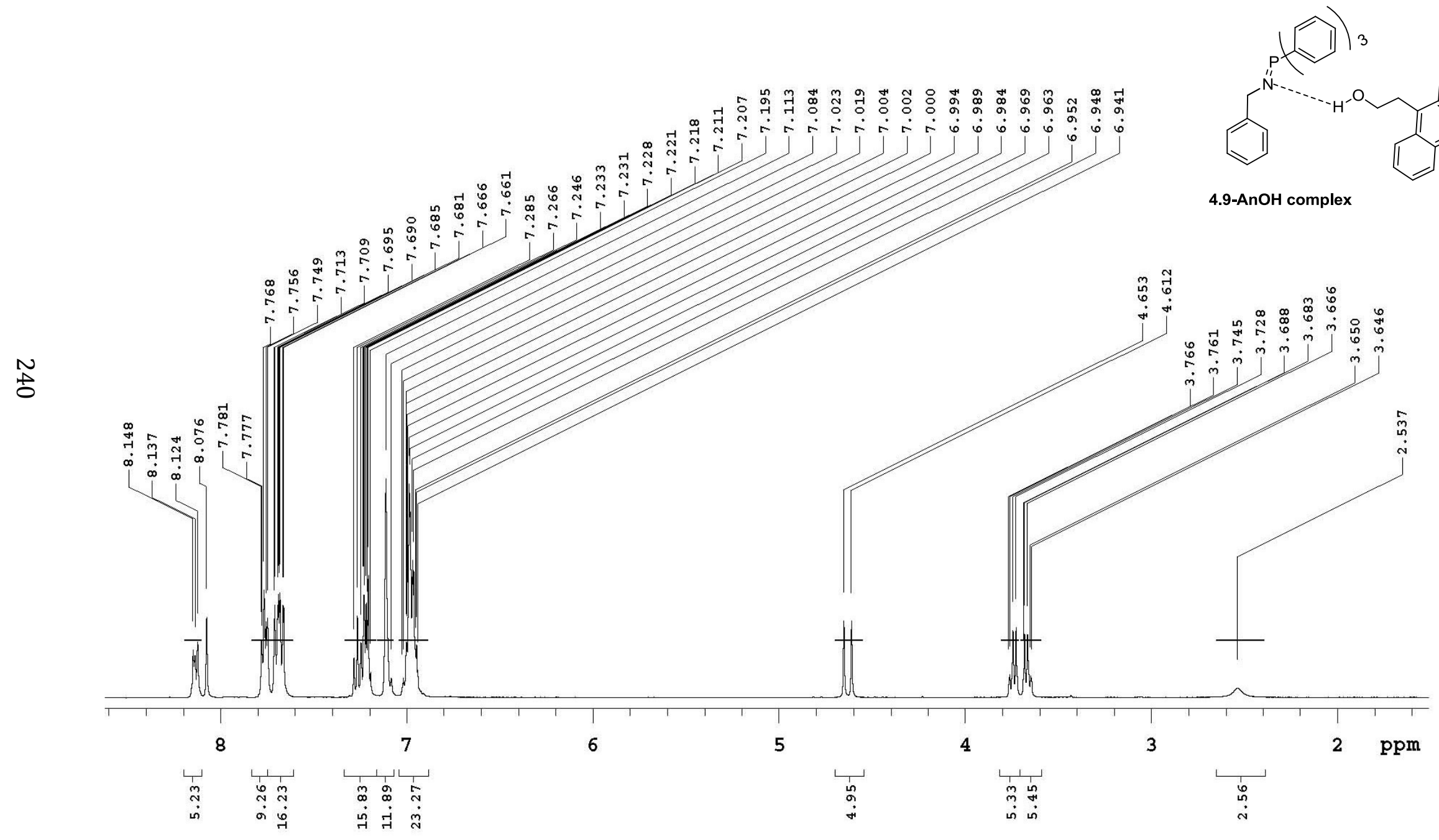




\section{EMD-NMR-033}

Sample Name EMD-NMR-033

Date collected 2014-07-06

Pulse sequence PHOSPHORUS Solvent c6d6

$\begin{array}{ll}\text { Temperature } & \mathbf{2 5} \\ \text { Spectrometer } & \text { ulnmr400-vnmrs400 }\end{array}$

Study owner burnsUG Operator burnsug

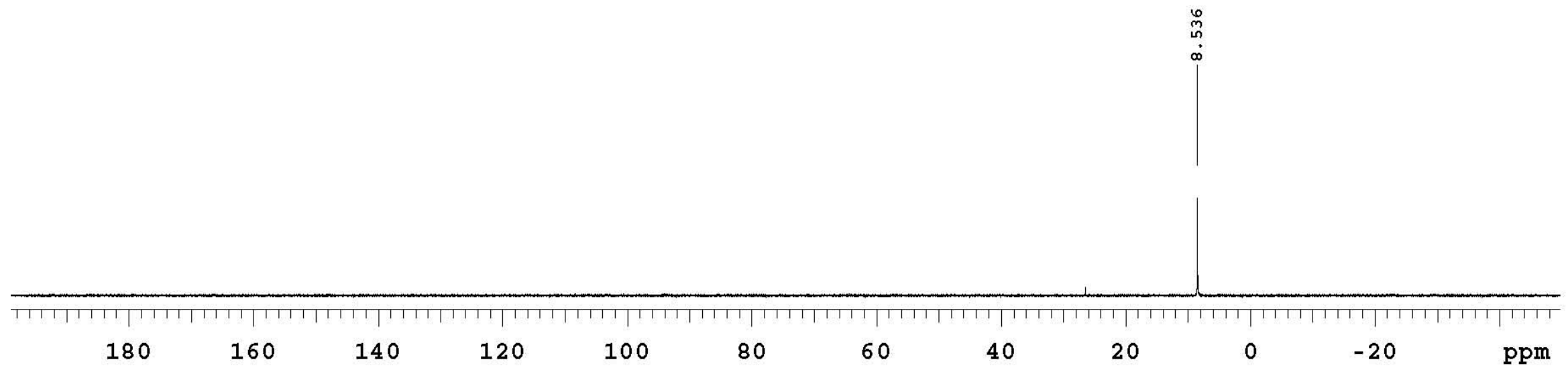




\section{rtnmr958}

Sample Name rtnmr958

Study owner $\mathbf{n}$

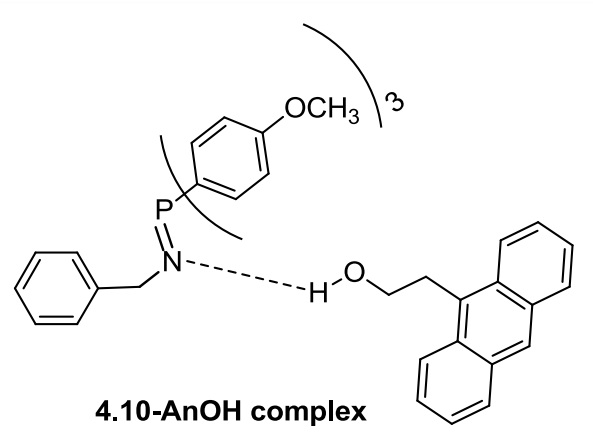

$\stackrel{\text { N }}{1}$

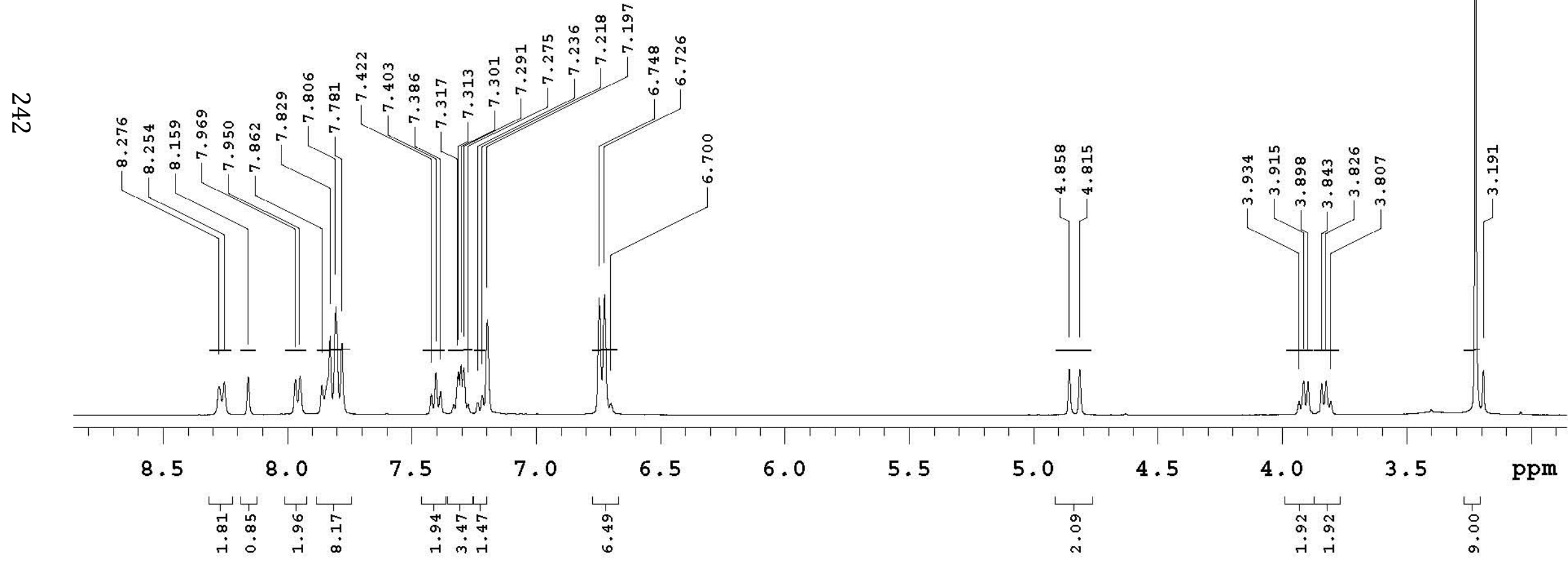


rtnmr958

Sample Name rtnmr958

Pulse sequence PHOSPHORUS

Temperature $\mathbf{2 5}$

$\begin{array}{lll}\text { Temperature } & \mathbf{2 5} & \text { Study owner } \\ \text { Spectrometer } & \text { ulnmr400-vnmrs400 } & \text { Operator } \text { it }\end{array}$

Date collected 2014-07-28

Solvent c6d6

$\stackrel{N}{\omega}$

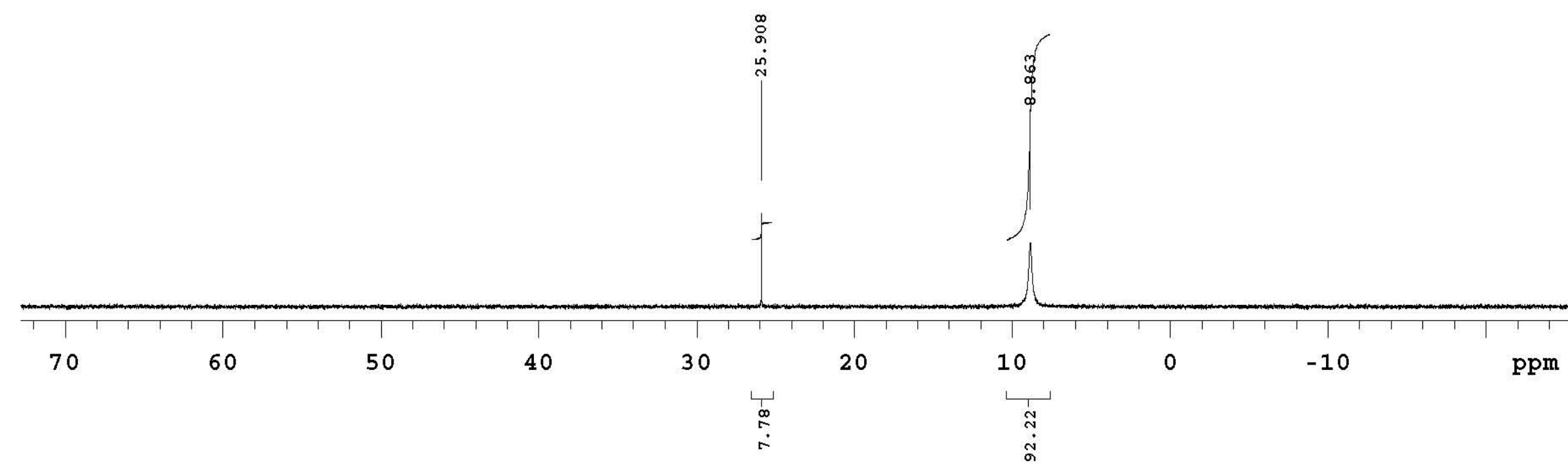




\section{rtnmr997}

Sample Name rtnmr997

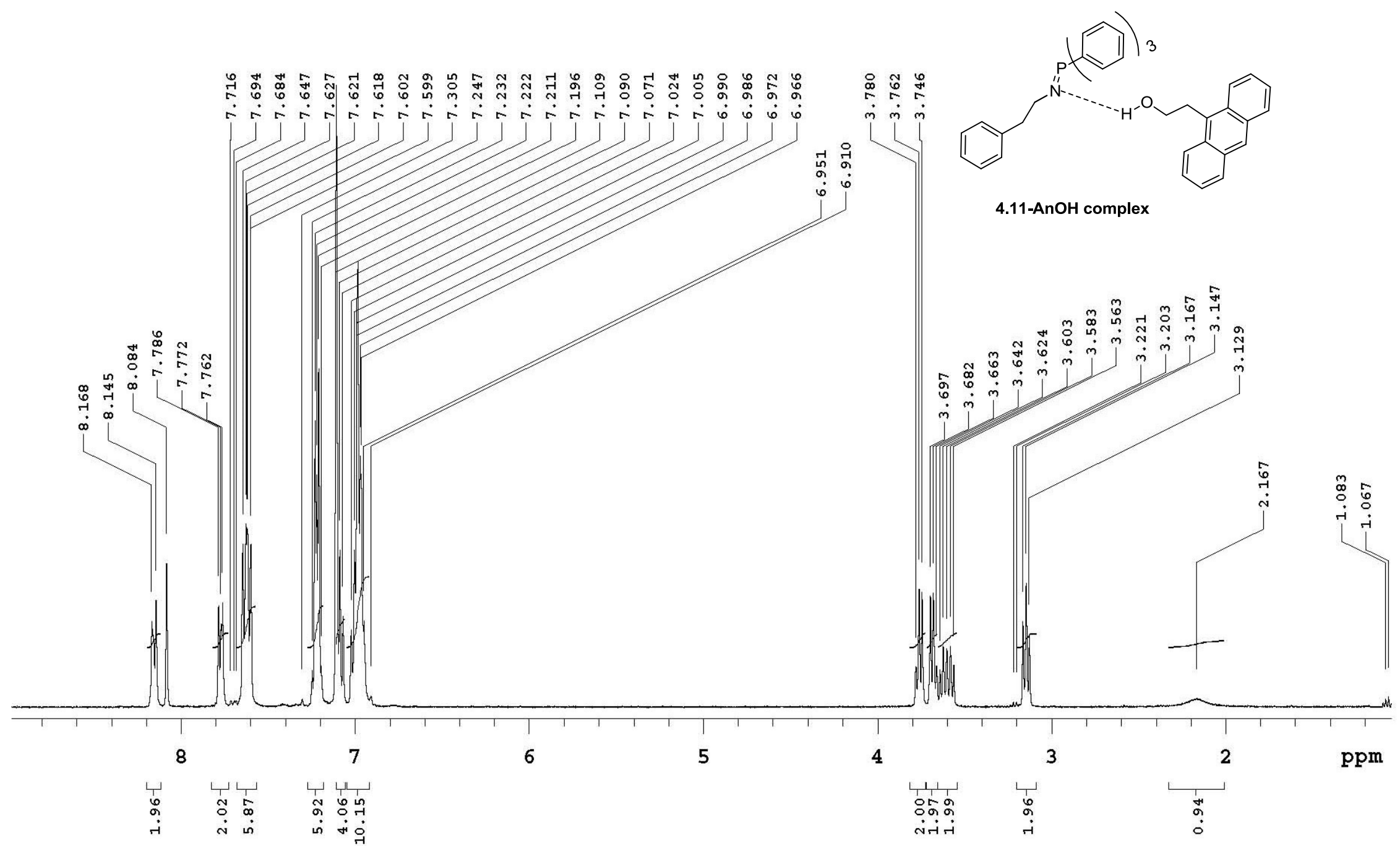

$\stackrel{N}{+}$ 
rtnmr997

Sample Name rtnmr997

Pulse sequence PHOSPHORUS

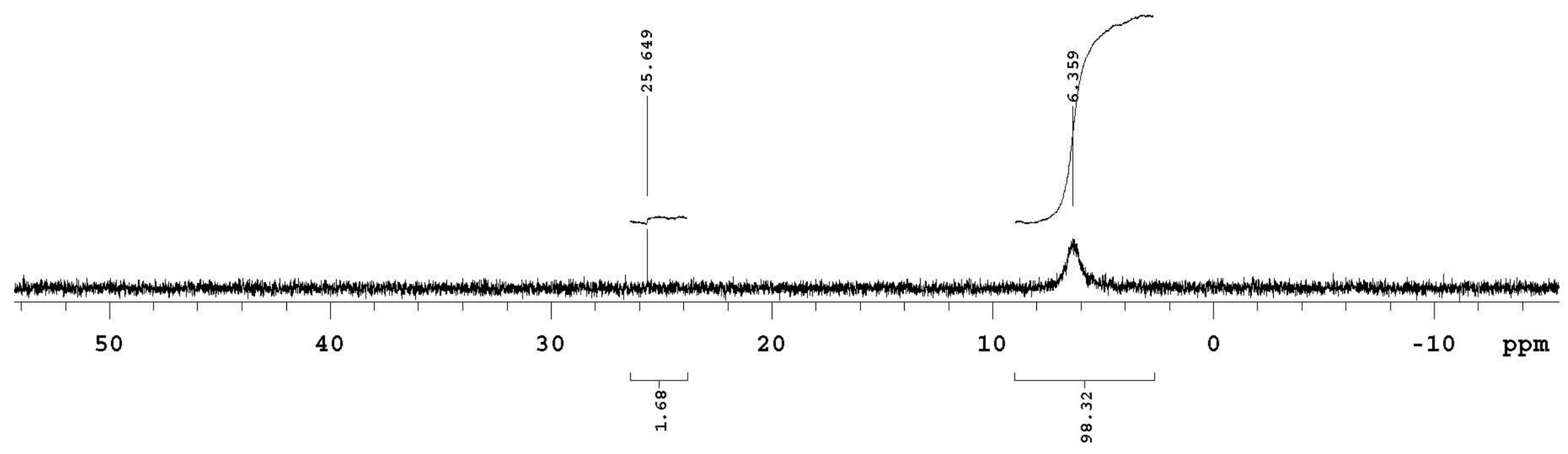




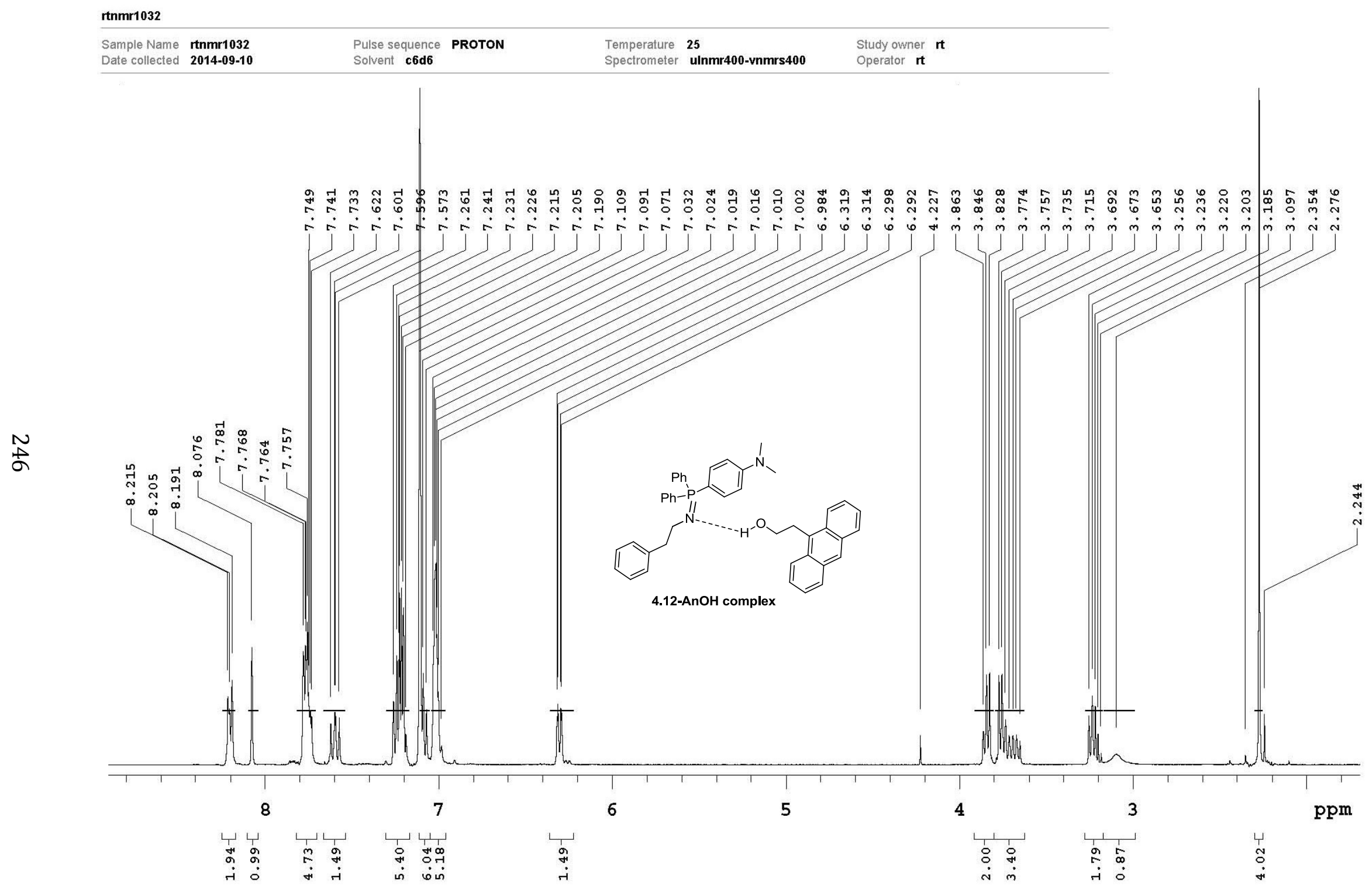


rtnmr1032

Sample Name rtnmr1032

Pulse sequence PHOSPHORUS Solvent $\mathbf{c 6 d 6}$

Temperature $\mathbf{2 5}$
Spectrometer ulnmr400-vnmrs400

Study owner

Date collected 2014-09-10

$\stackrel{\text { ก }}{\stackrel{n}{n}}$

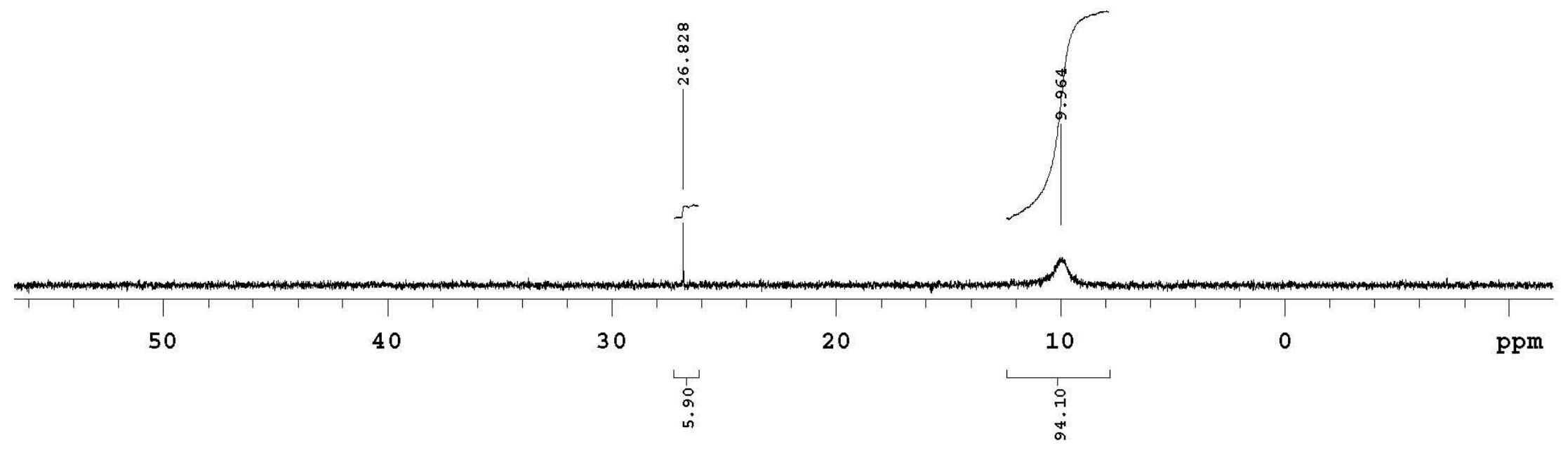




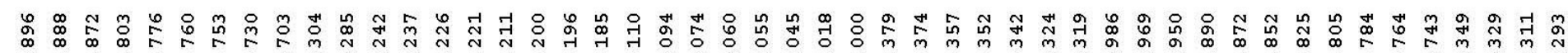

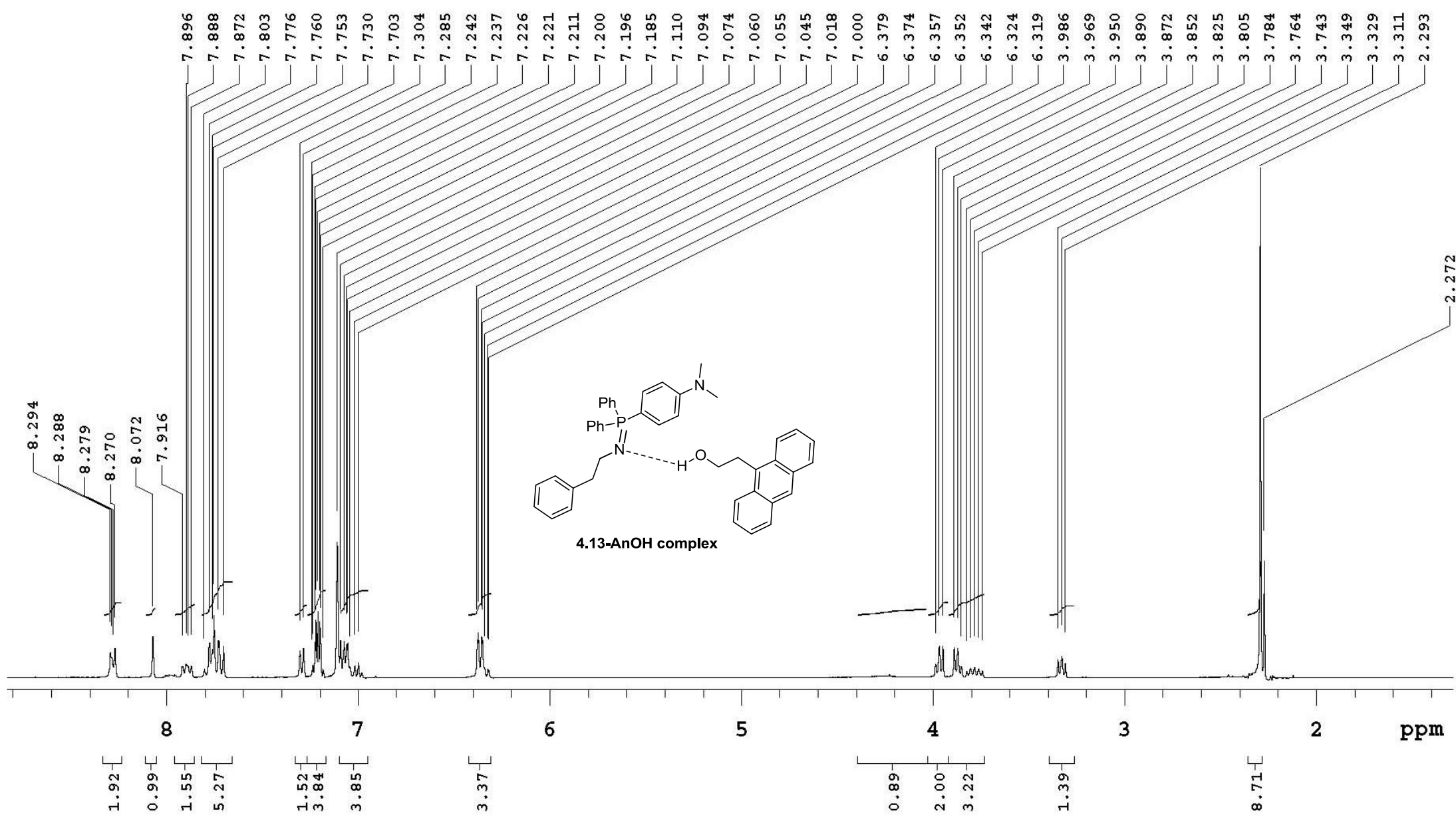


rtnmr1028

$\begin{array}{ll}\text { Sample Name } & \text { rtnmr1028 } \\ \text { Date collected } & \text { 2014-09-08 }\end{array}$

Pulse sequence PHOSPHORUS

Temperature 25

Spectrometer ulnmr400-vnmrs400

Study owner

Solvent c6d6

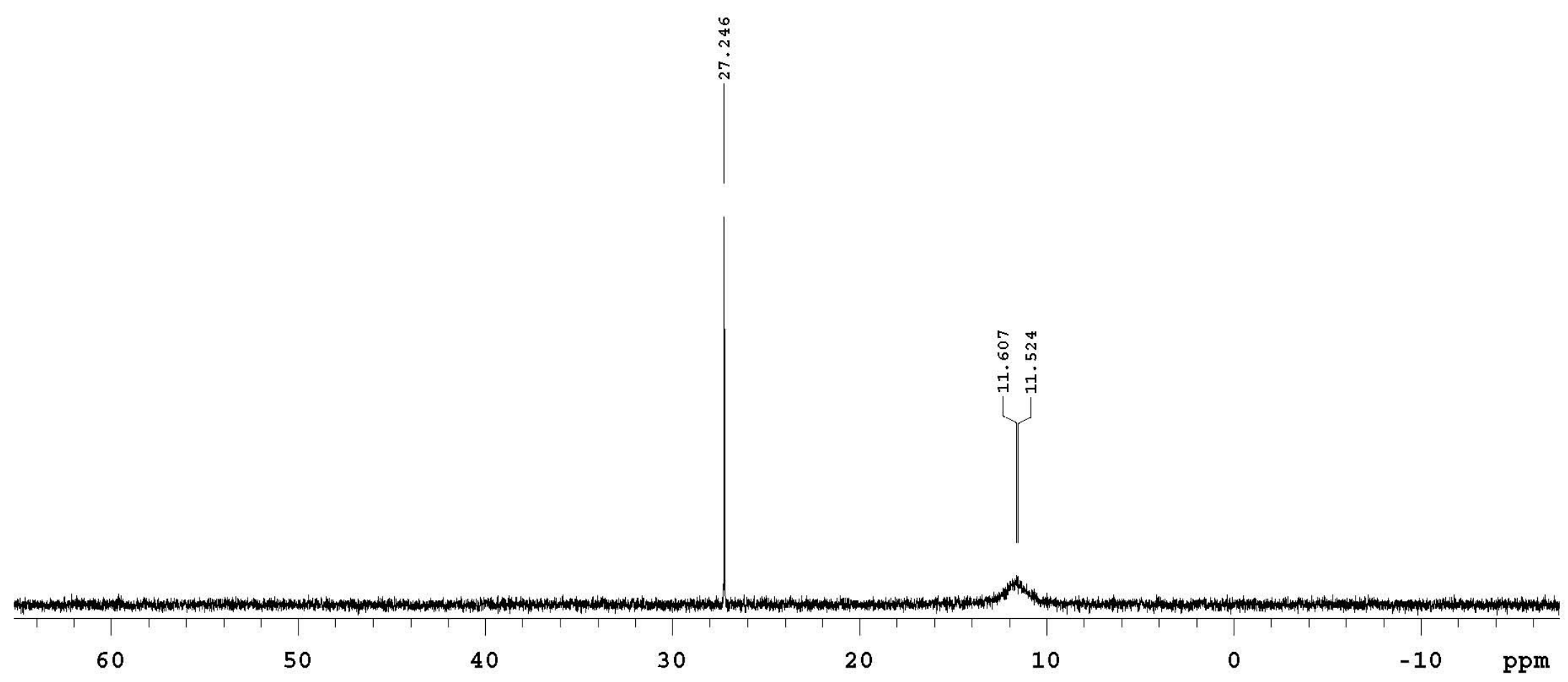




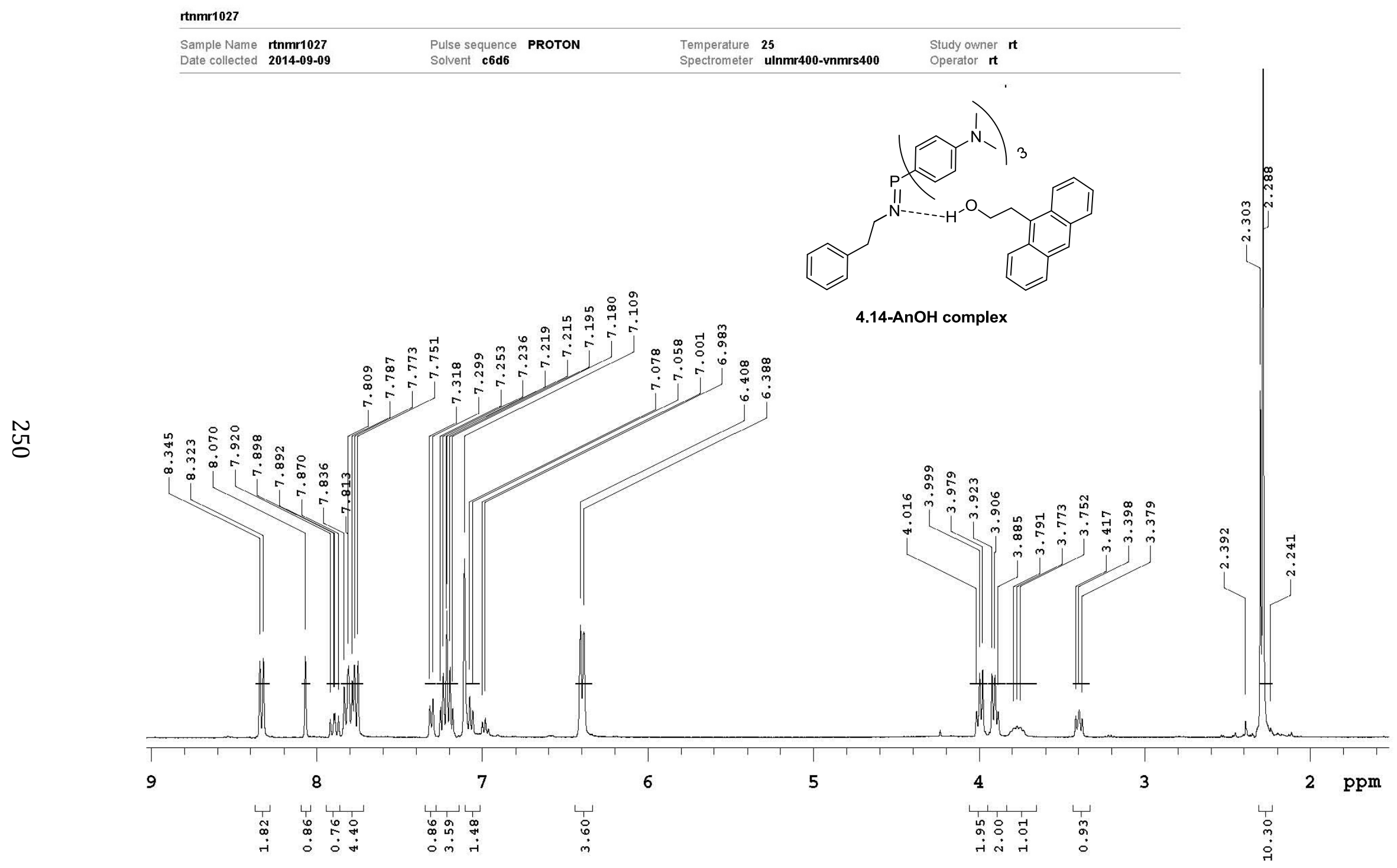


rnmr1027

Sample Name rtnmr1027 Pulse sequence PHOSPHORUS Solvent c6d6

Temperature $\mathbf{2 5}$

Spectrometer ulnmr400-vnmrs400

Study owner $\mathbf{n}$

Date collected 2014-09-09

(2)

$\stackrel{N}{v}$

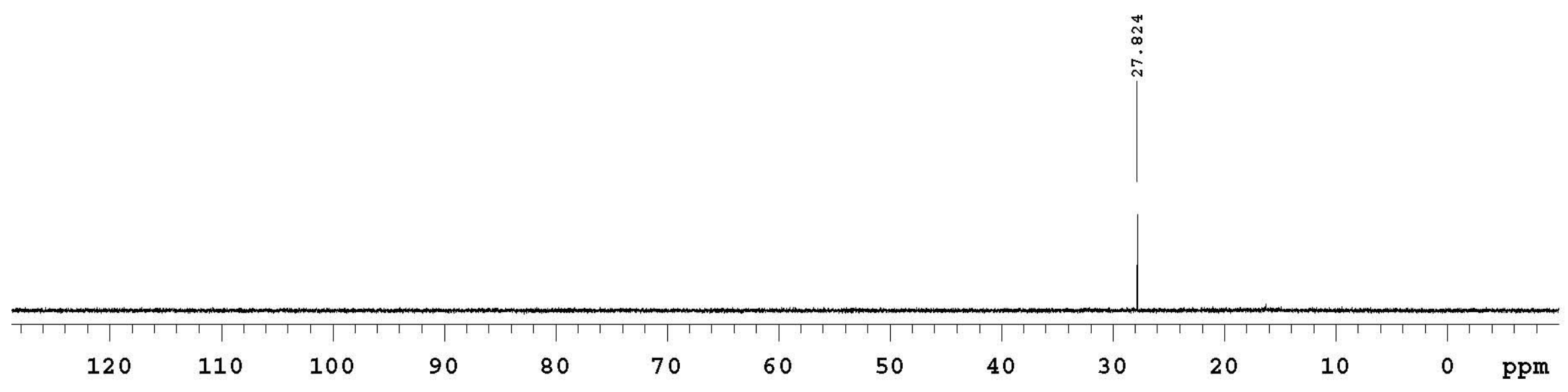




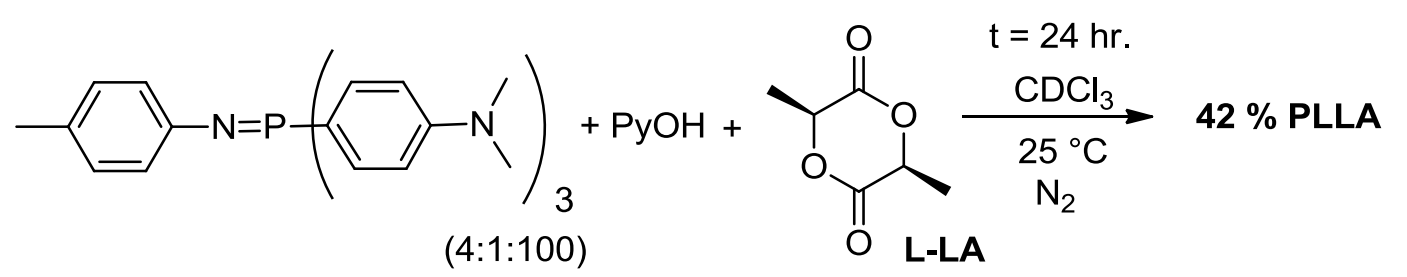

覙

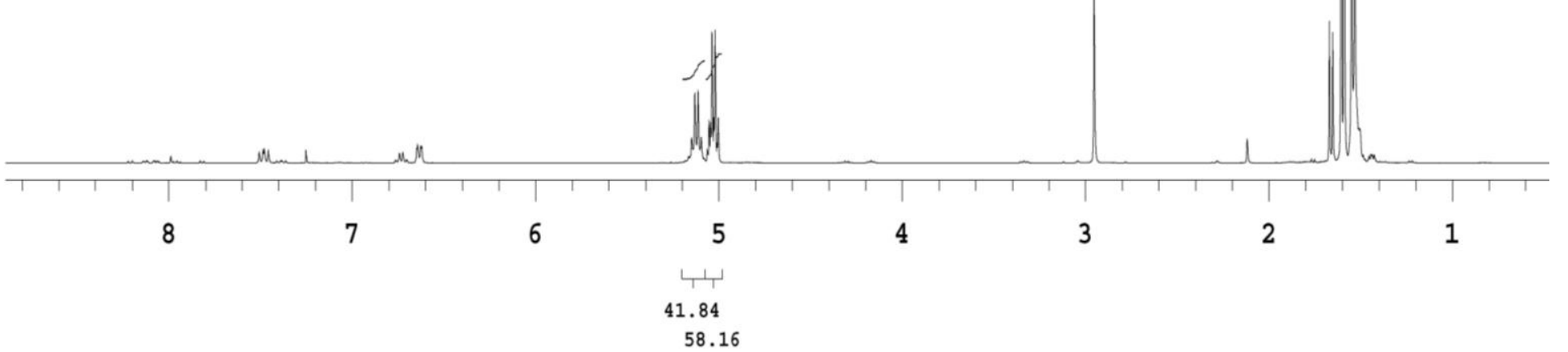

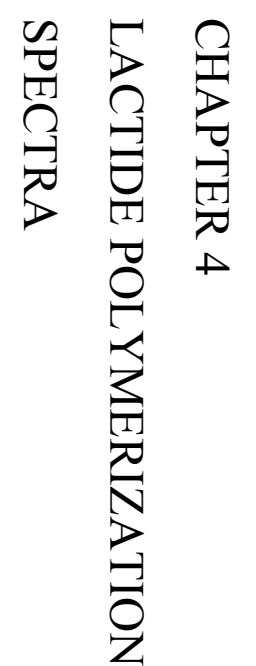

ppm 


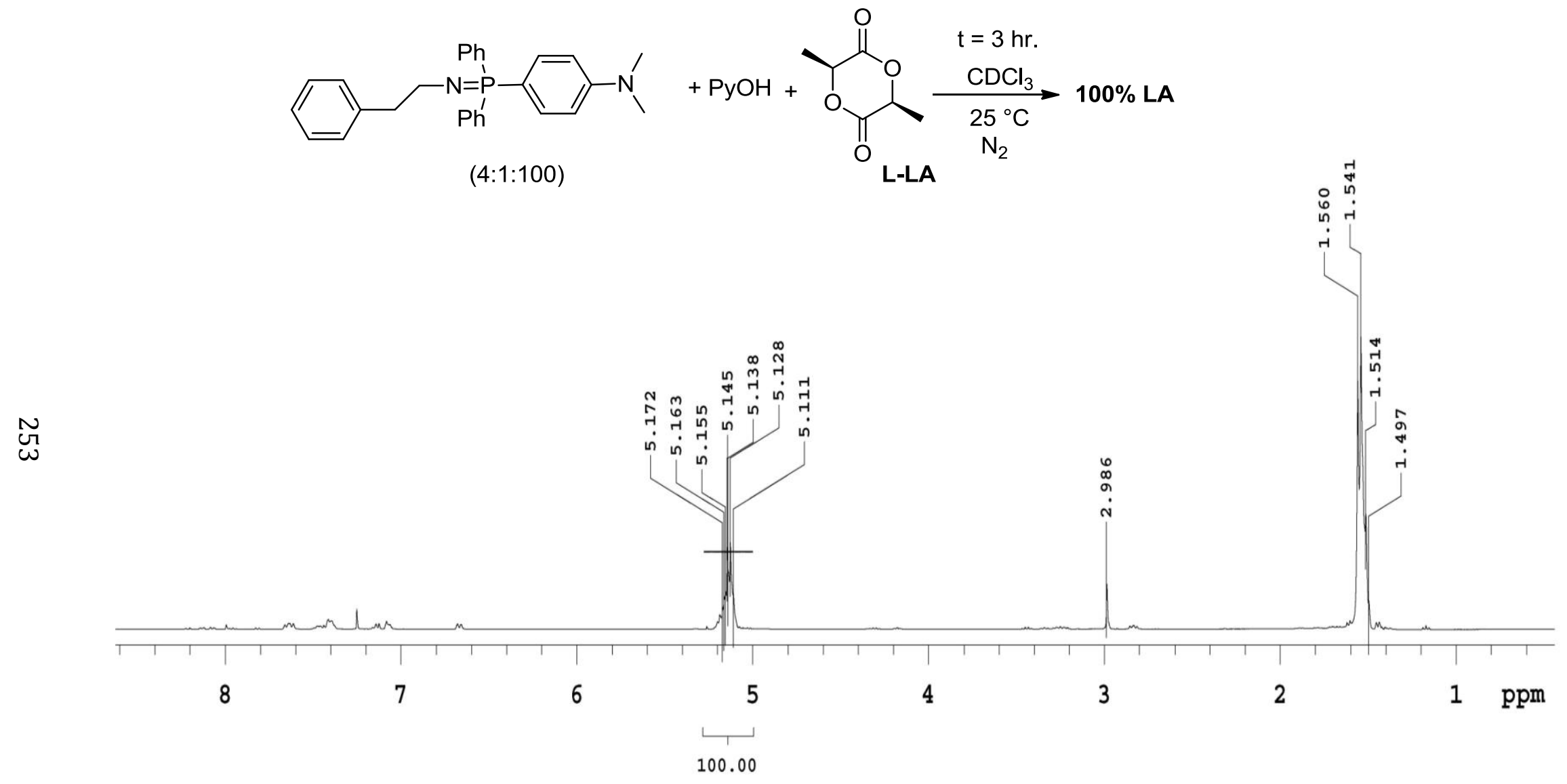




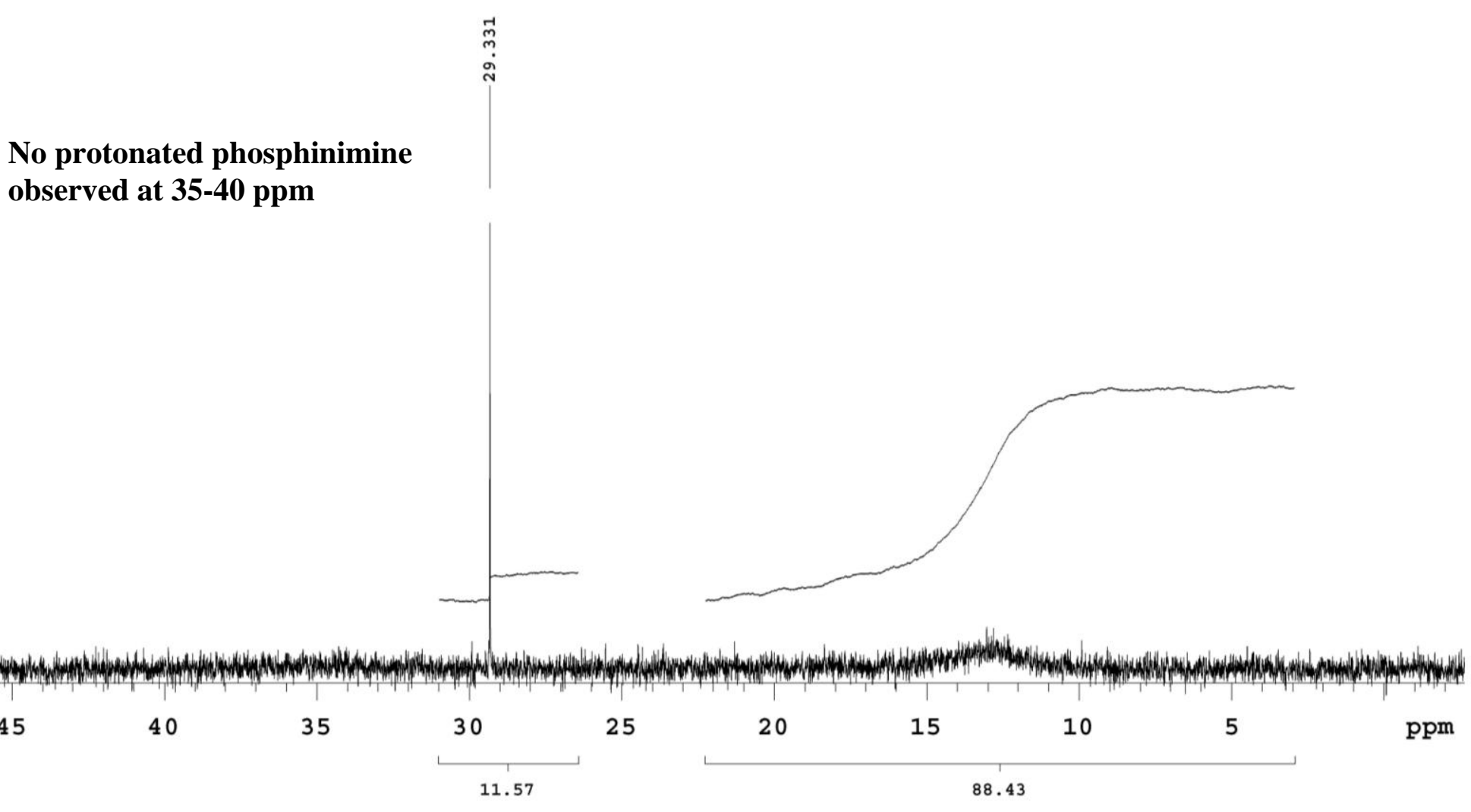



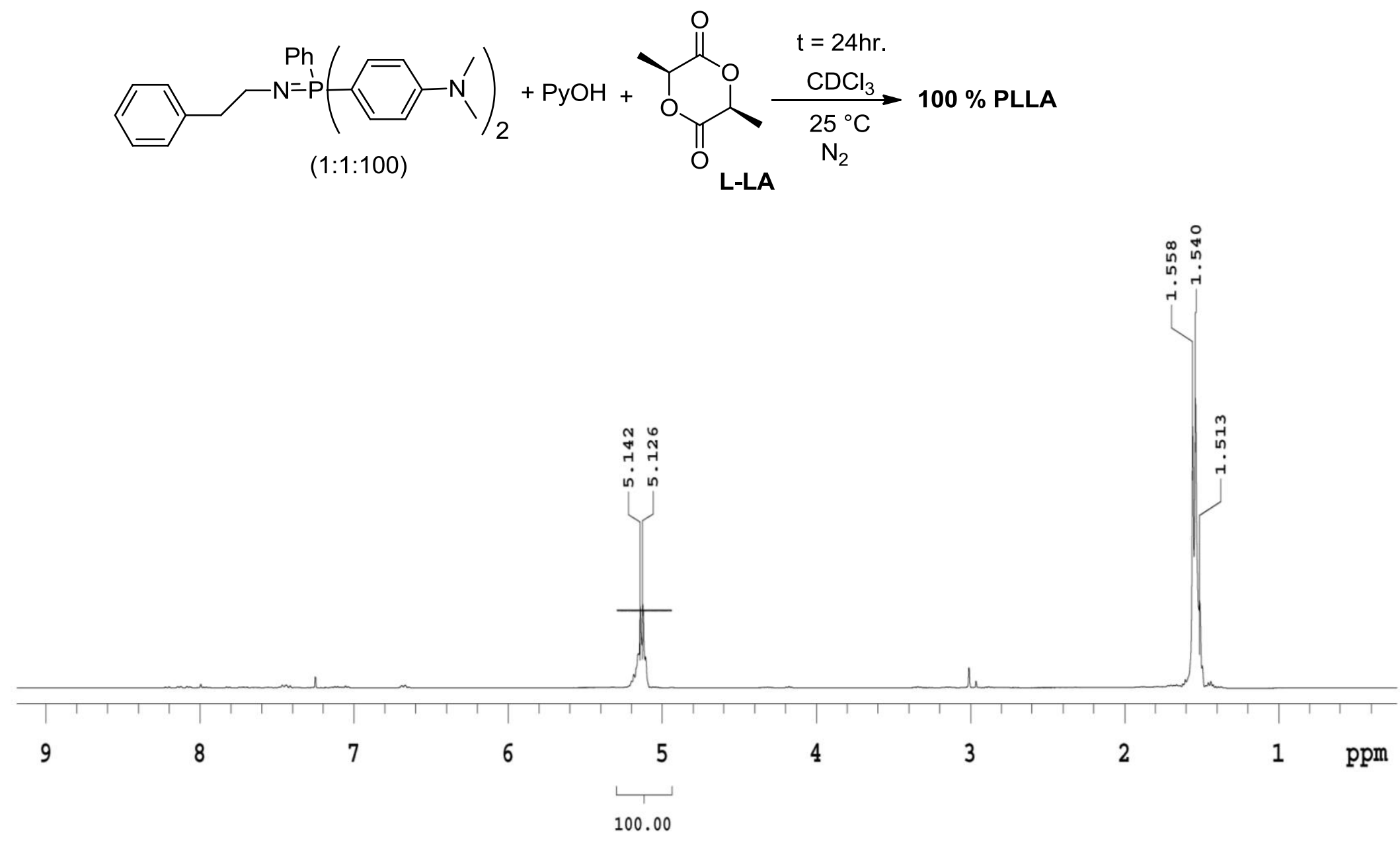


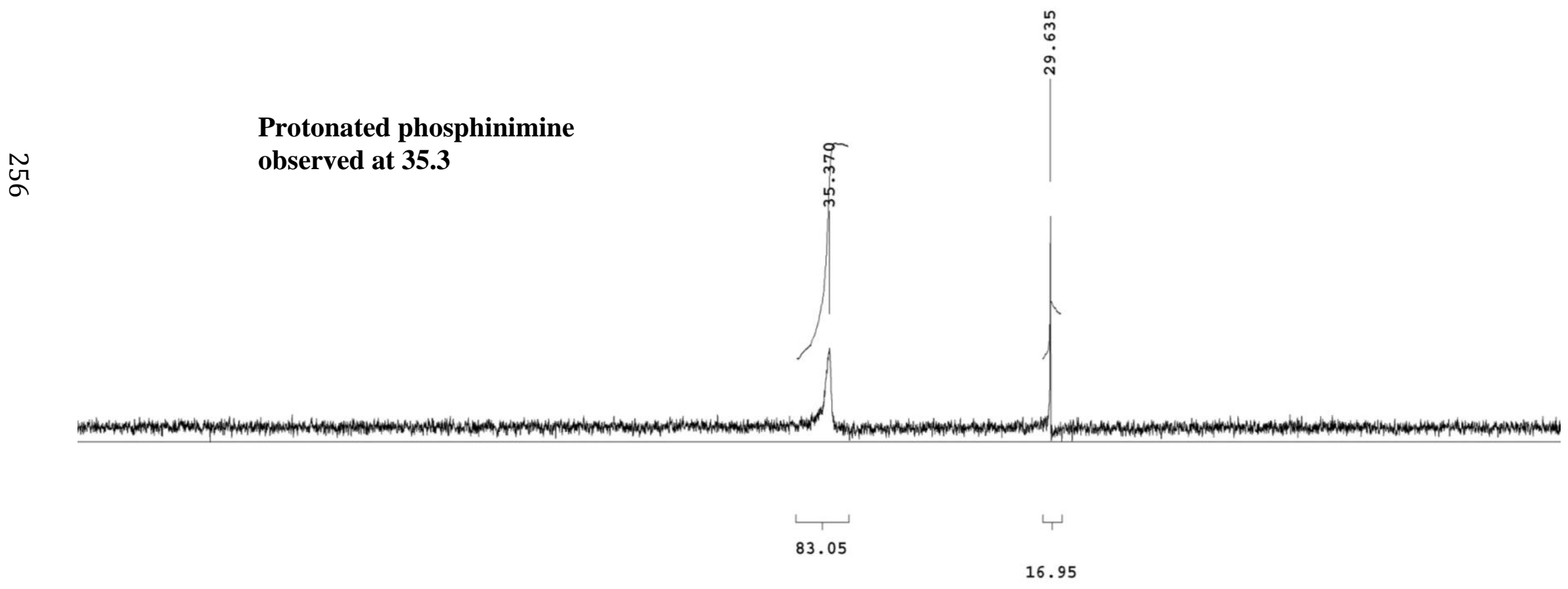




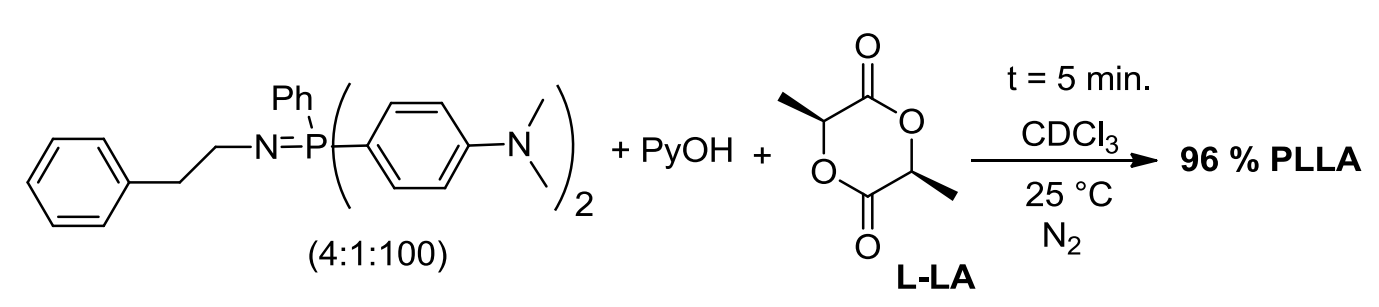

N

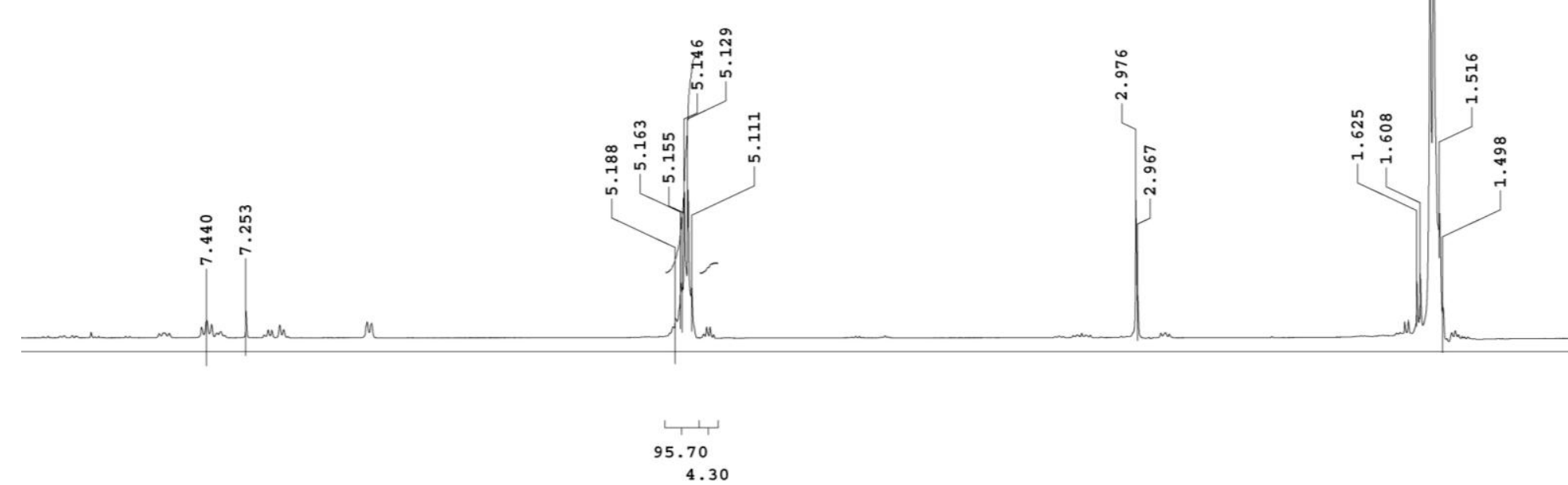


No protonated phosphinimine observed at 35-40 ppm

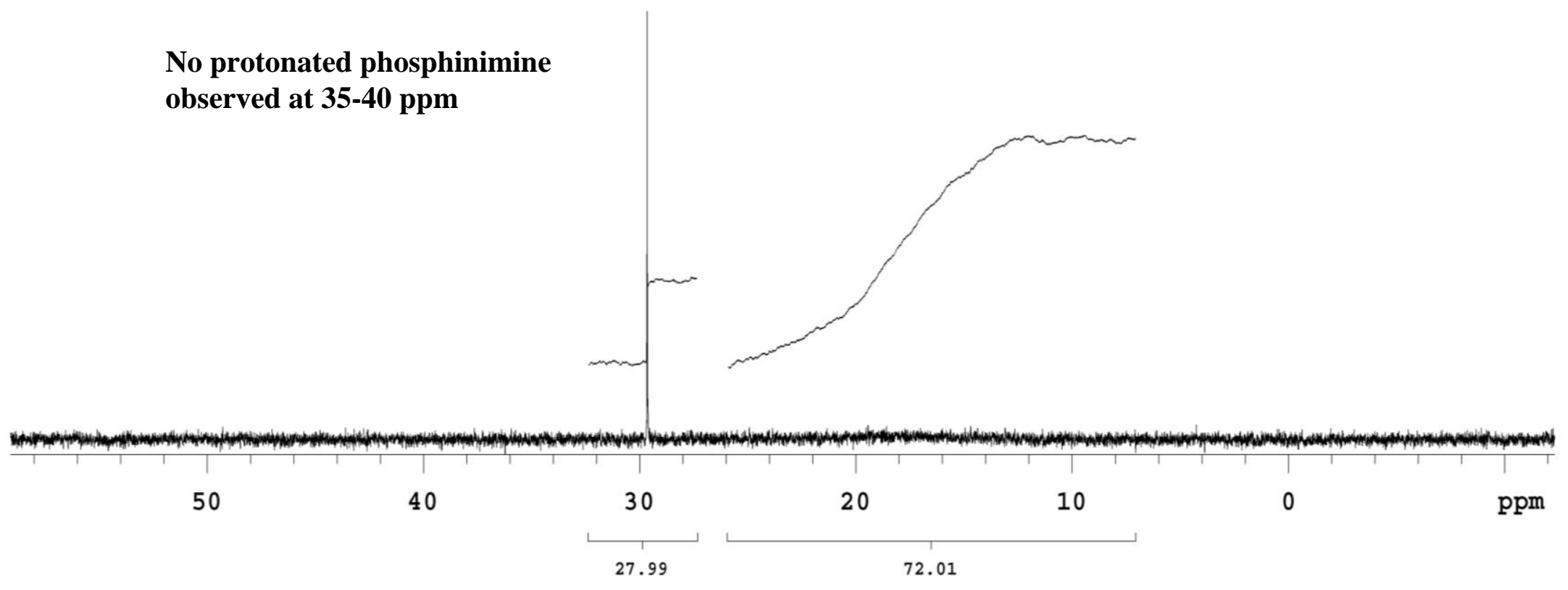




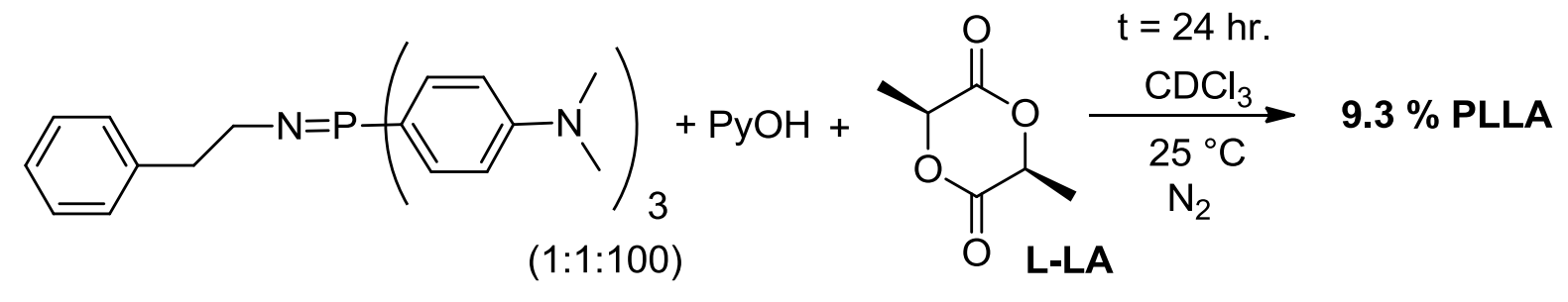

ज్

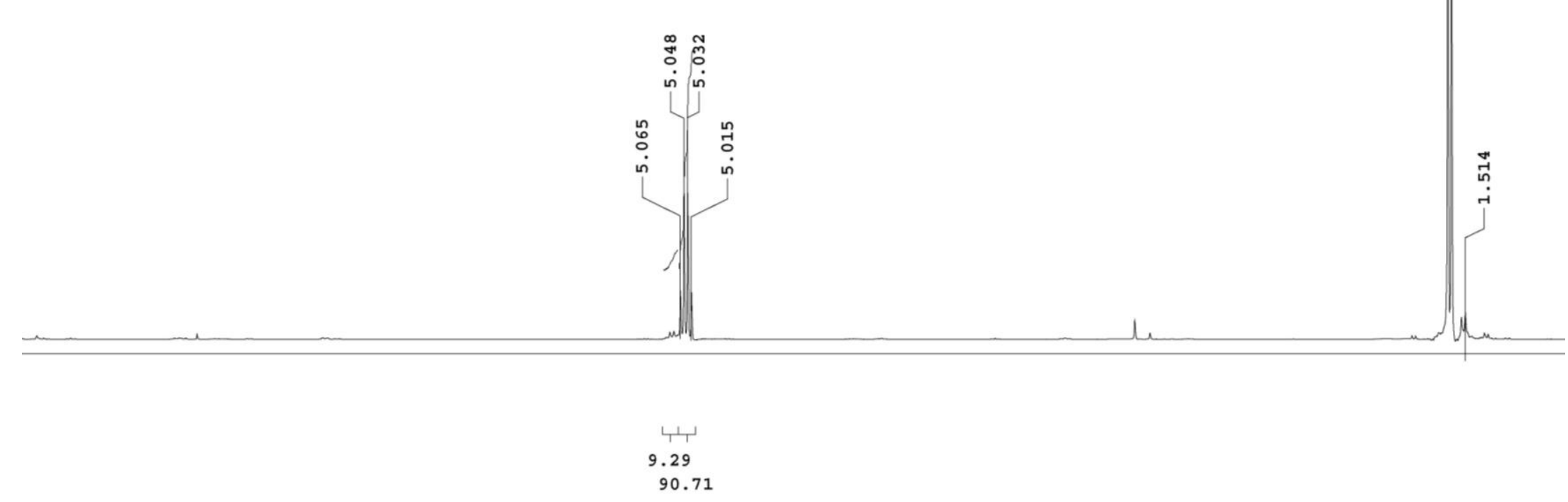




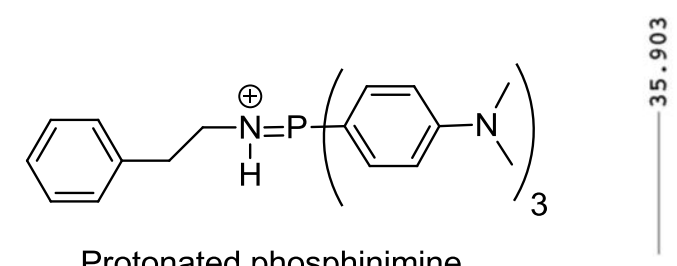

Protonated phosphinimine

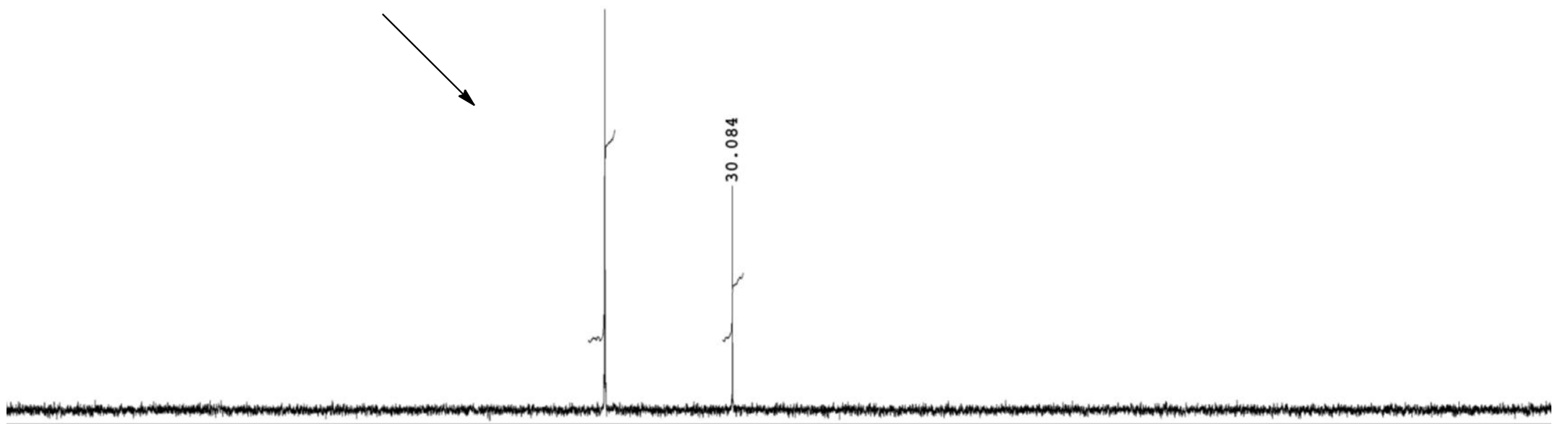

75.81 


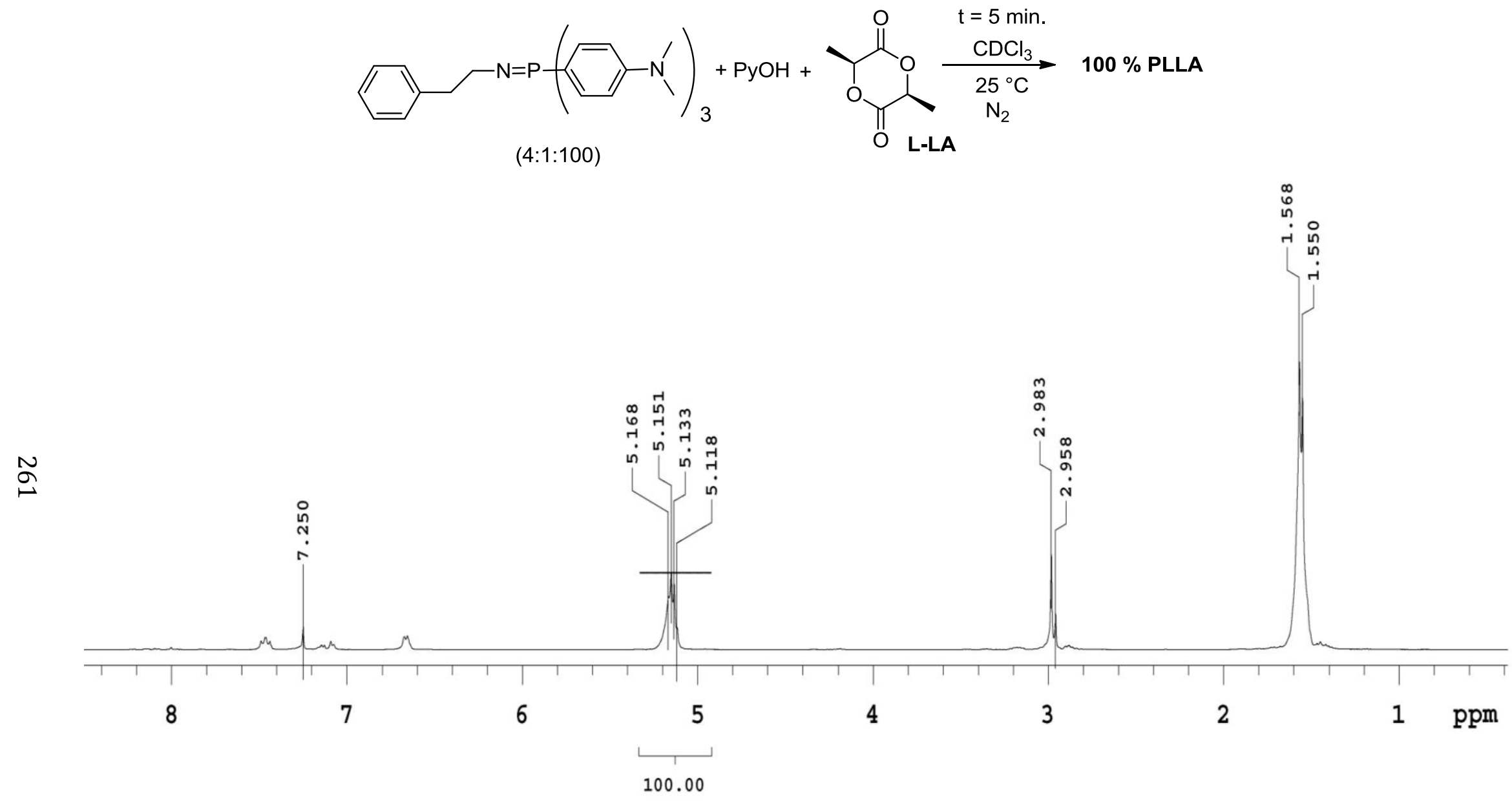




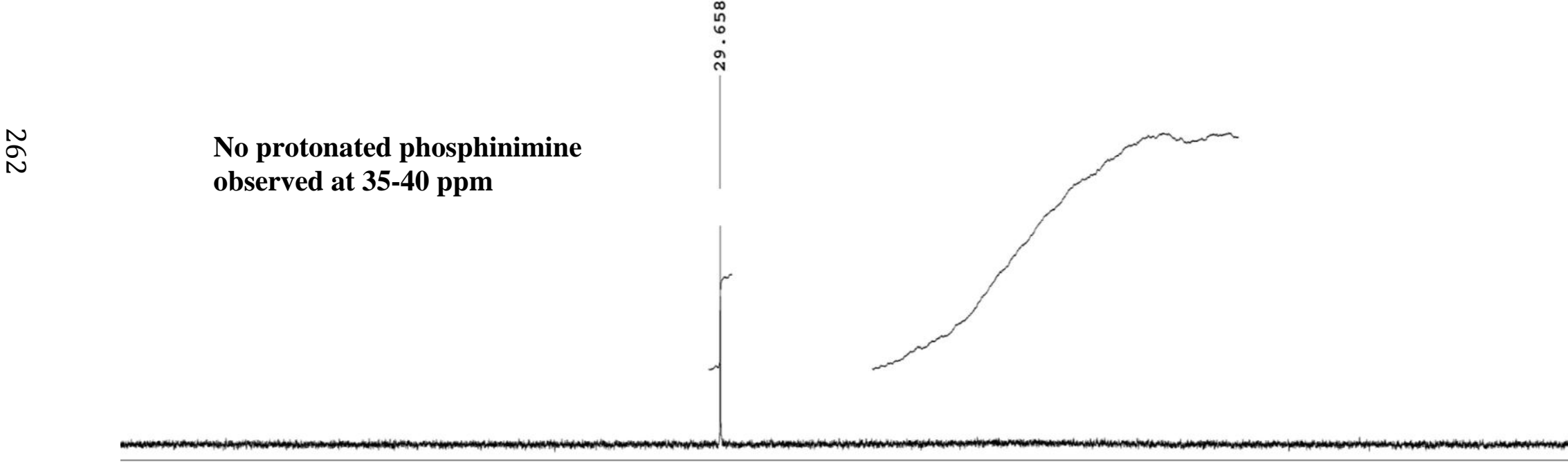




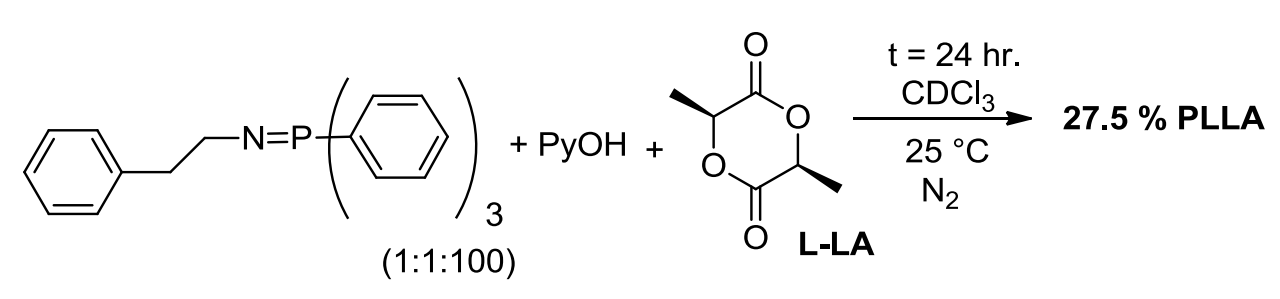

స్
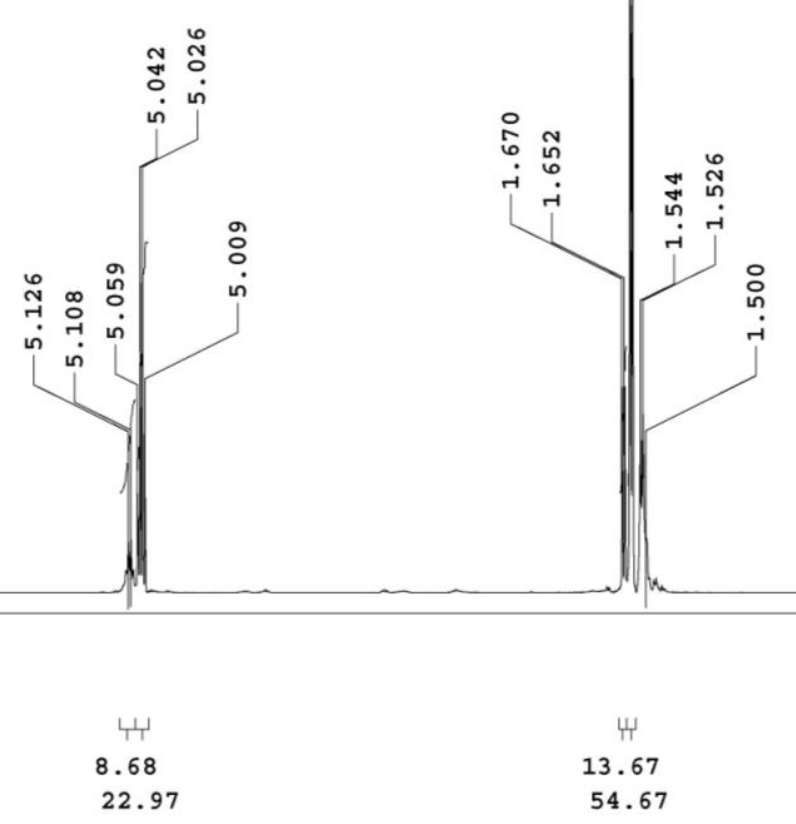
Protonated phosphinimine

observed at 35-40 ppm
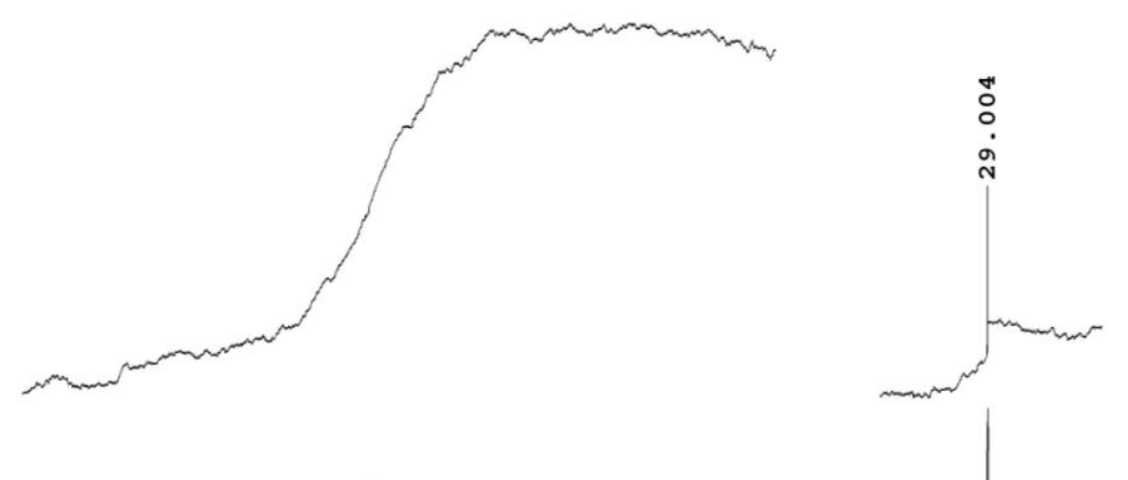

Now

83.72

16.28 


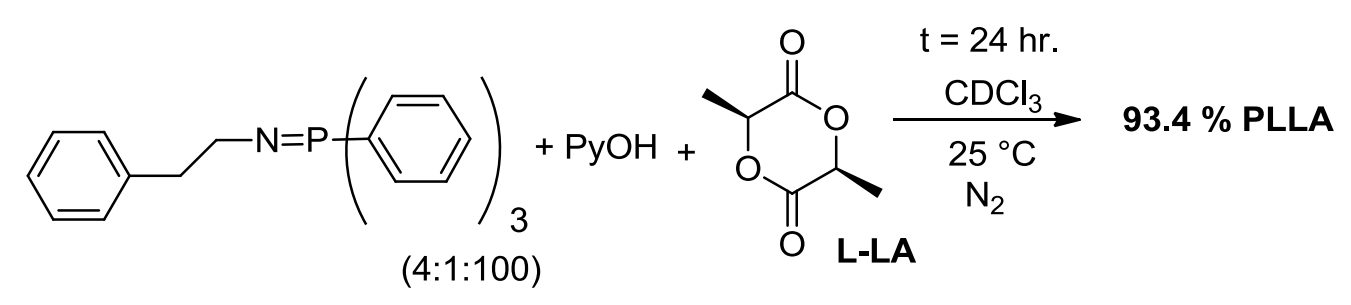

్

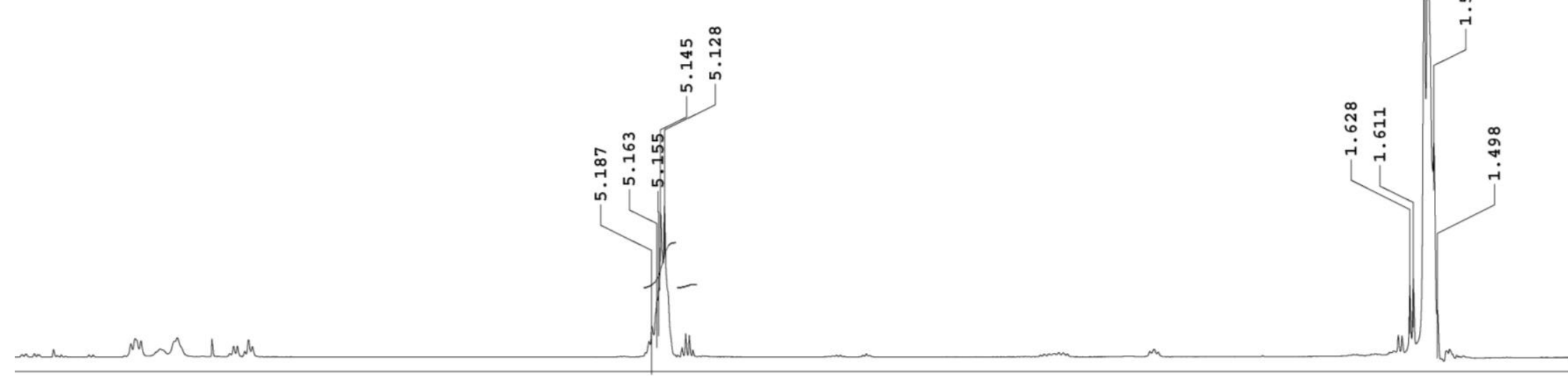

$$
\begin{gathered}
L_{1} \\
93.38 \\
6.62
\end{gathered}
$$


No protonated phosphinimine observed at 35-40 ppm

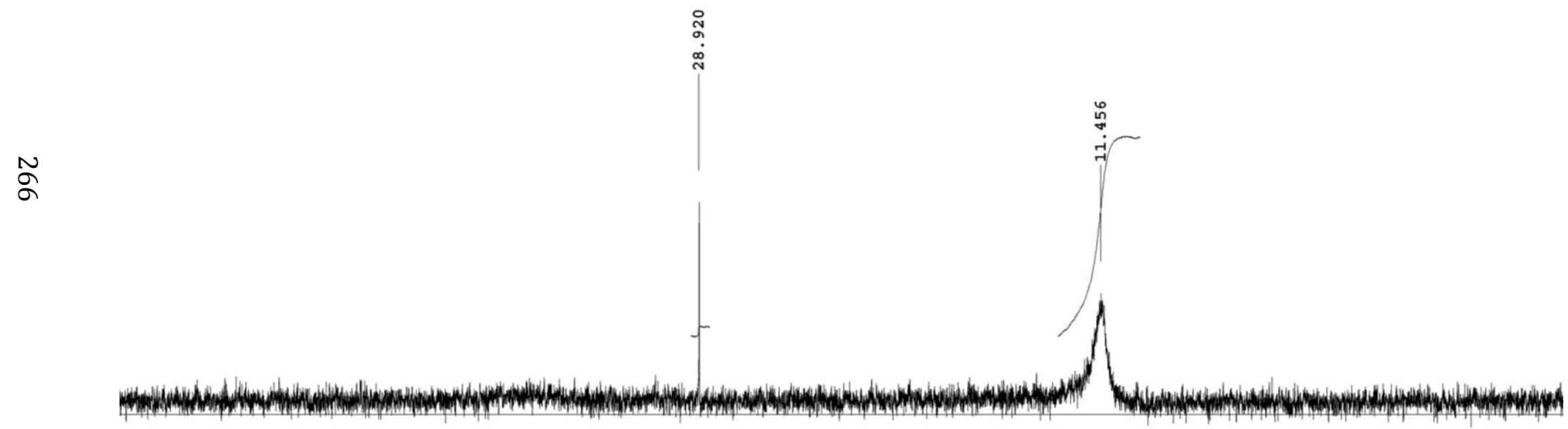

ᄂ.

95.79 


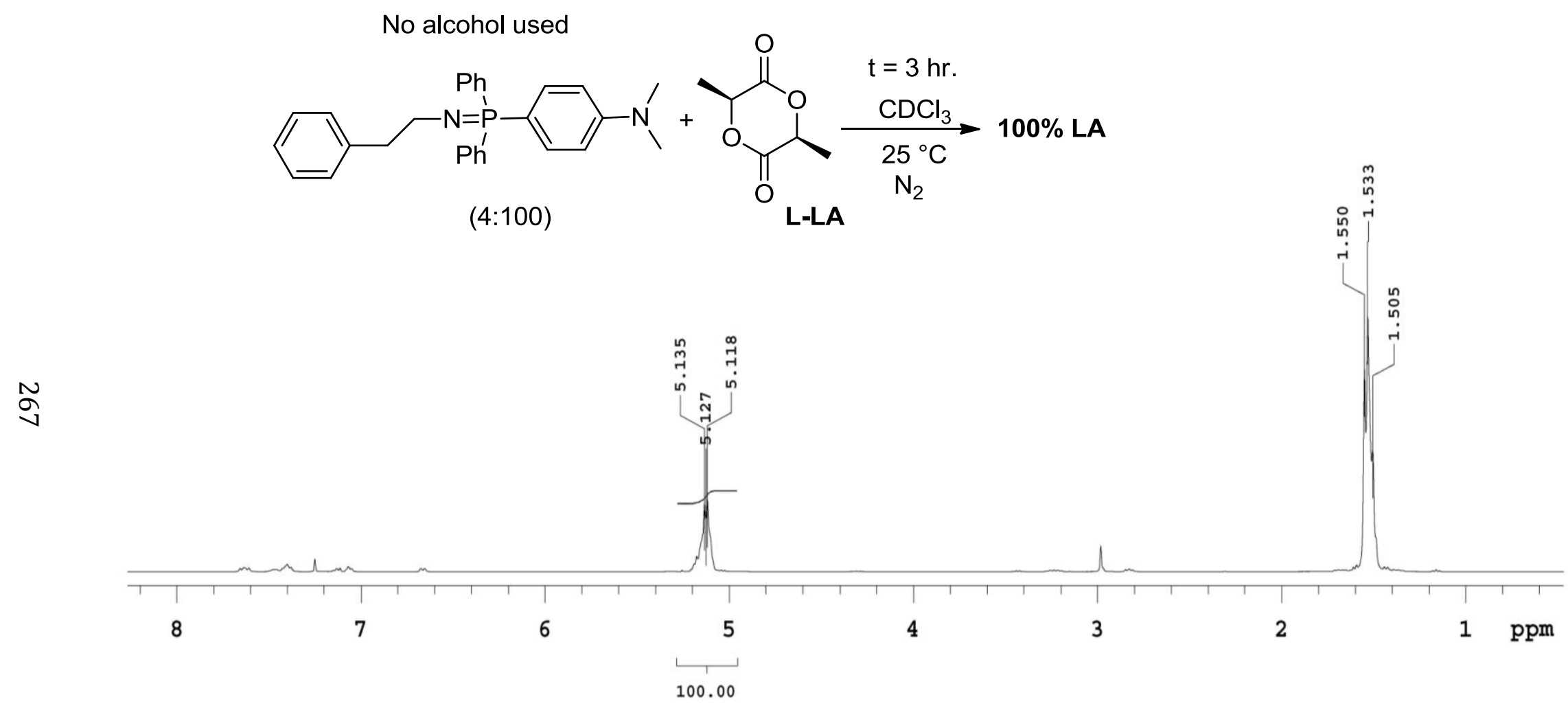




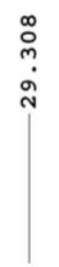

No protonated phosphinimine observed at 35-40 ppm

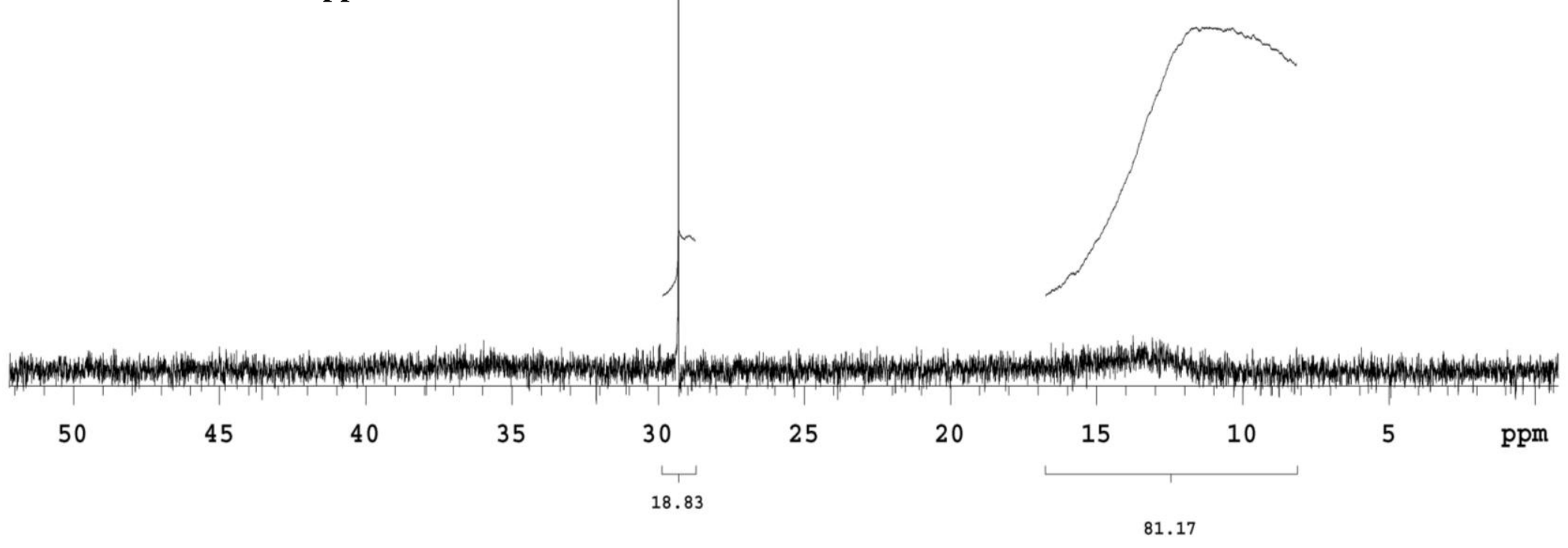




\section{CURRICULUM VITAE}

Department of Chemistry

University of Louisville

2320 South Brook Street

Louisville, KY 40292
776 David Fairleigh ct. \# 2

Louisville, KY 40217

rajeshthapa@hotmail.com

Phone: 502-291-8651

Objective: To utilize my skills and knowledge as a synthetic organic chemist in designing and synthesizing novel compounds for catalysis. I would like to develop my synthetic chemistry skill to explore and develop new material technologies for the benefit of mankind.

\section{Pertinent Skills:}

- Design, Synthesis of organic compounds and metal complexes for catalysis

- Development of new methodologies for application of organic synthesis

- Synthesis and manipulation of air and moisture sensitive organic compounds and metal complexes using nitrogen filled glove box, high vacuum and schlenk line technique

- Organic compound identification, isolation and characterization by using NMR, IR, UV-Vis, GC/MS, HPLC, column chromatography etc.

- Scientific paper writing and presentation

- Strong written and verbal communication skills necessary to convey technical details

\section{Education}

2010 - 2015 PhD in Organometallic Chemistry

Advisor: Christopher T. Burns

University of Louisville, Louisville, KY

Dissertation Title: Neutral phosphinimines and zinc phosphinimine catalyst towards ring opening polymerization of cyclic esters.

2007-2009 MS in Organic Chemistry

Advisor: Richard T. Taylor,

Miami University, Oxford, $\mathrm{OH}$

Thesis Title: Regioselectivity in free radical bromination by NBS towards unsymmetrical dimethyl pyridine. 
1995-1997 B.S. in Organic Chemistry

Tribhuvan University, Kirtipur, Kathmandu, Nepal

\section{Experience}

2011-2015 Graduate Teaching Assistant

University of Louisville, Louisville, KY

Summer2010 CHEM 209 (chemical analysis III)

January 2010-May 2010 CHEM 343 (Organic I)

2012- Present CHEM 344 (Organic II)

2007-2008 Graduate Teaching Assistant

Department of Chemistry

Miami University, Oxford, OH

Organic Chemistry Course CHM 244

CHM 245, CHM 245H

01/2009- Graduate Research Assistant

05/2009 Miami University, Oxford, OH

Funding Celsus Laboratory

Cincinnati, Ohio

2000-2006 Chemistry Instructor

Capital College and Research Center

Kathmandu, Nepal

\section{Awards}

- Chemistry Departmental Fellowship

University of Louisville, Louisville, KY (2010-2011)

- The Follett's Miami Co-op Book Store Award for English as a Second Language-Honorable Mention - Miami University

Department to English (2009)

\section{Publications}

1. "Phosphinimine Zinc Complexes for Ring Opening Polymerization of Cyclic Esters" Burns, Christopher T.; Thapa, Rajesh (manuscript ready for submission)

2. "Electron rich phosphinimines: organocatalysts for Polymerization for Cyclic esters" Burns, Christopher T.; Thapa, Rajesh (writing manuscript)

3. "Regioselectivity in free radical bromination of unsymmetrical dimethylated pyridines" Thapa, Rajesh; Brown, Jordan; Balestri, Thomas; Taylor, Richard T. Tetrahedron Letters (2014), 55(49), 6743-6746 
4. "Synthesis of air-stable zwitterionic 2-phosphiniminium-arenesulfonates" Burns, Christopher T.; Shang, Suisheng; Thapa, Rajesh; Mashuta, Mark S. Tetrahedron Letters (2012), 53(36), 4832-4835

5. "Synthesis of mesoporous birnessite- $\mathrm{MnO}_{2}$ composite as a cathode electrode for lithium battery"

Thapa, Arjun Kumar; Pandit, Bill; Thapa, Rajesh; Luitel, Tulashi; Paudel, Hem Sharma; Sumanasekera, Gamini; Sunkara, Mahendra K.; Gunawardhana, Nanda; Ishihara, Tatsumi; Yoshio, Masaki, Electrochimica Acta (2014), 116, 188-193

6. "Polythiophene Mesoporous Birnessite- $\mathrm{MnO}_{2} / \mathrm{Pd}$ Cathode Air Electrode for Rechargeable Li-Air Battery"

By Thapa, Arjun Kumar; Pandit, Bill; Paudel, Hem Sharma; Thapa, Rajesh; Ida, Shintaro; Jasinski, Jacek B.; Sumanasekera, Gamini U.; Ishihara, Tatsumi, Electrochimica Acta (2014), 127, 410-415

7. Rajesh Thapa; "Regioselectivity in free radical bromination of unsymmetrical dimethylated pyridines" MS Dissertation, 2009, Miami University, Oxford, OH

\section{Presentation}

- Poster presentation on "Synthesis of air-stable zwitterionic 2phosphiniminium-arenesulfonates" at Ohio Inorganic Week, University of Cincinnati, Cincinnati, OH

- Poster presentation on "Regioselectivity in free radical bromination of unsymmetrical dimethylated pyridines" at 2008 REEL (Research Experiences to Enhance Learning) Student Symposium and University of Cincinnati, ACS meeting 2008.

\section{References}

\section{Professor Michael H. Nantz}

(Department Chair and Professor)

Department of Chemistry

University of Louisville

Louisville, KY 40208

(502)-852-8149

michael.nantz@louisville.edu

\section{Dr. Christopher T. Burns}

Department of Chemistry

University of Louisville

Louisville, KY 40208

(502)-852-5977

Christopher.burns@louisville.edu

\author{
Professor Richard T. Taylor \\ Department of Chemistry and \\ Biochemistry \\ Miami University, \\ Oxford, OH 45056 \\ (513)-529-2816 \\ taylorrt@muohio.edu
}

\section{Professor Mark Noble}

Department of Chemistry

University of Louisville

Louisville, KY 40208

(502)-852-7296

menoble@louisville.edu 